
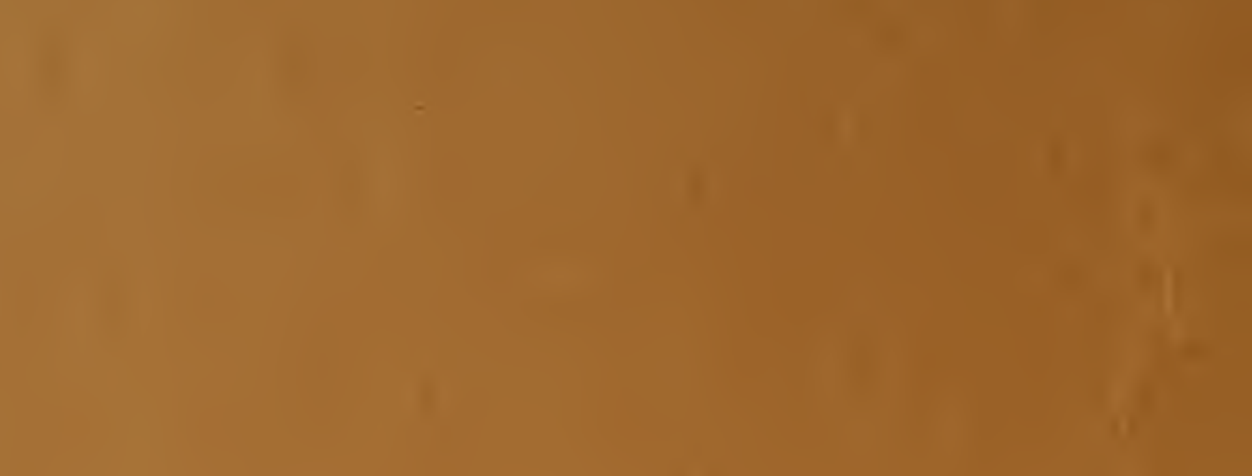

\section{if}

in

(1)

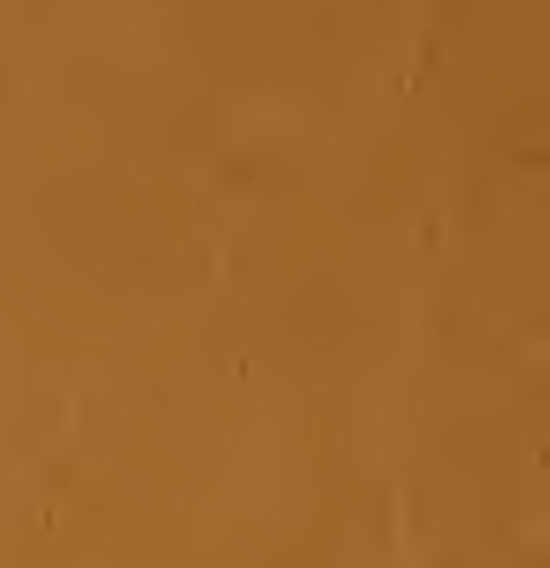

11

(1)

tit

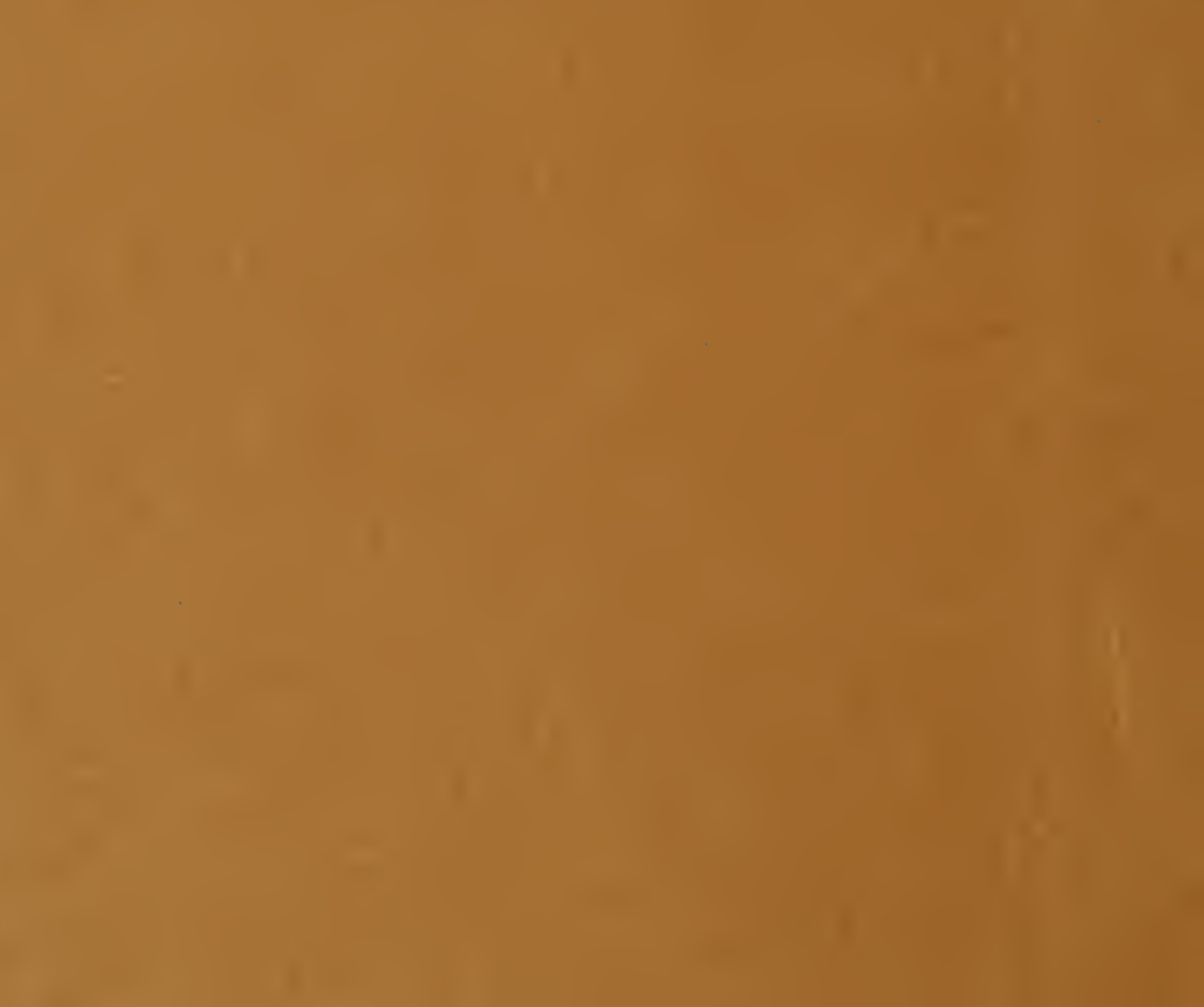




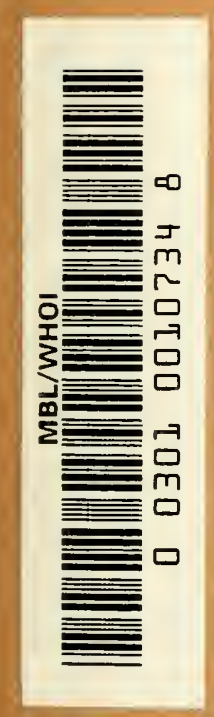




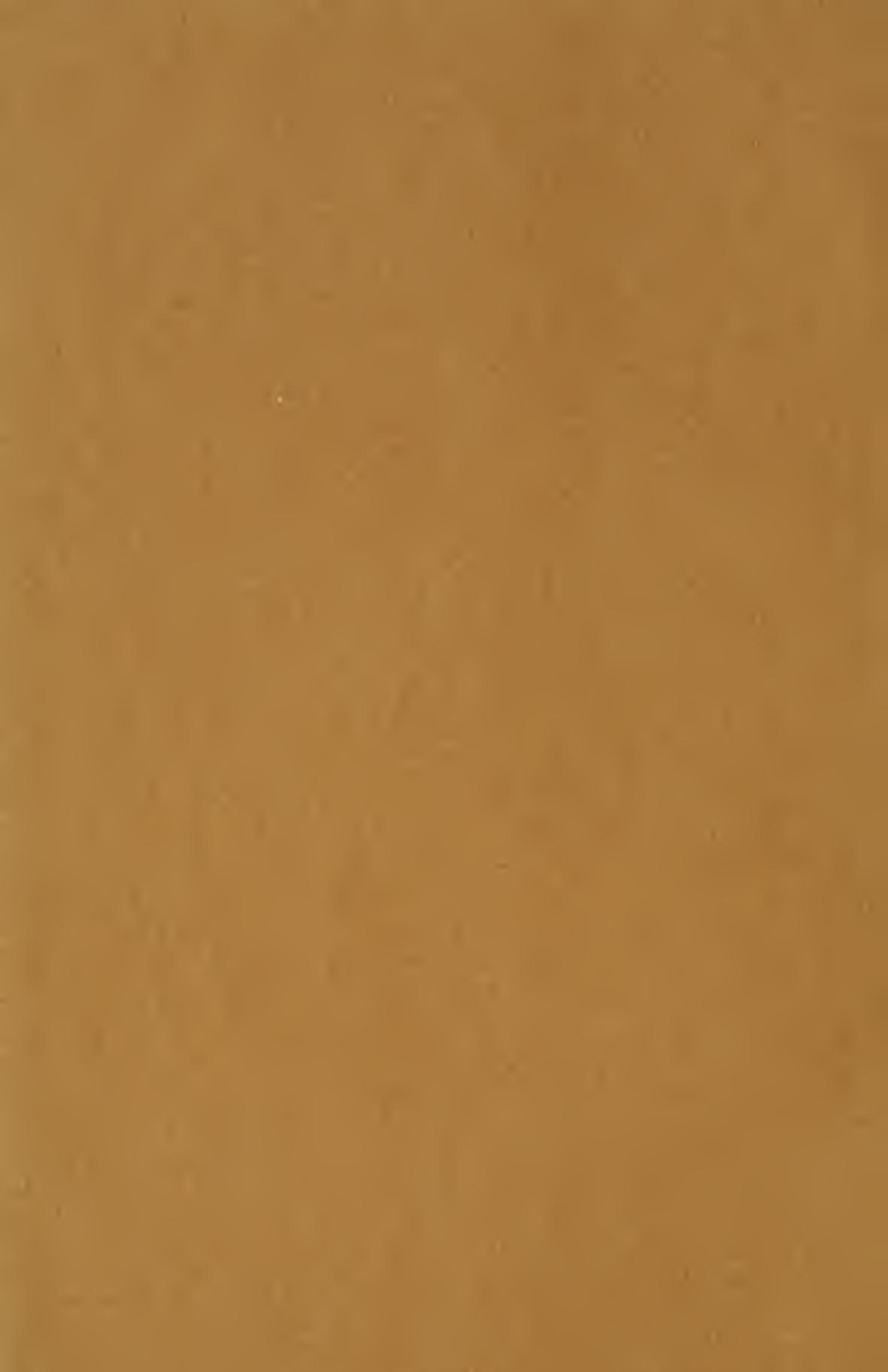






E S S A Y I N B I O L O G Y 




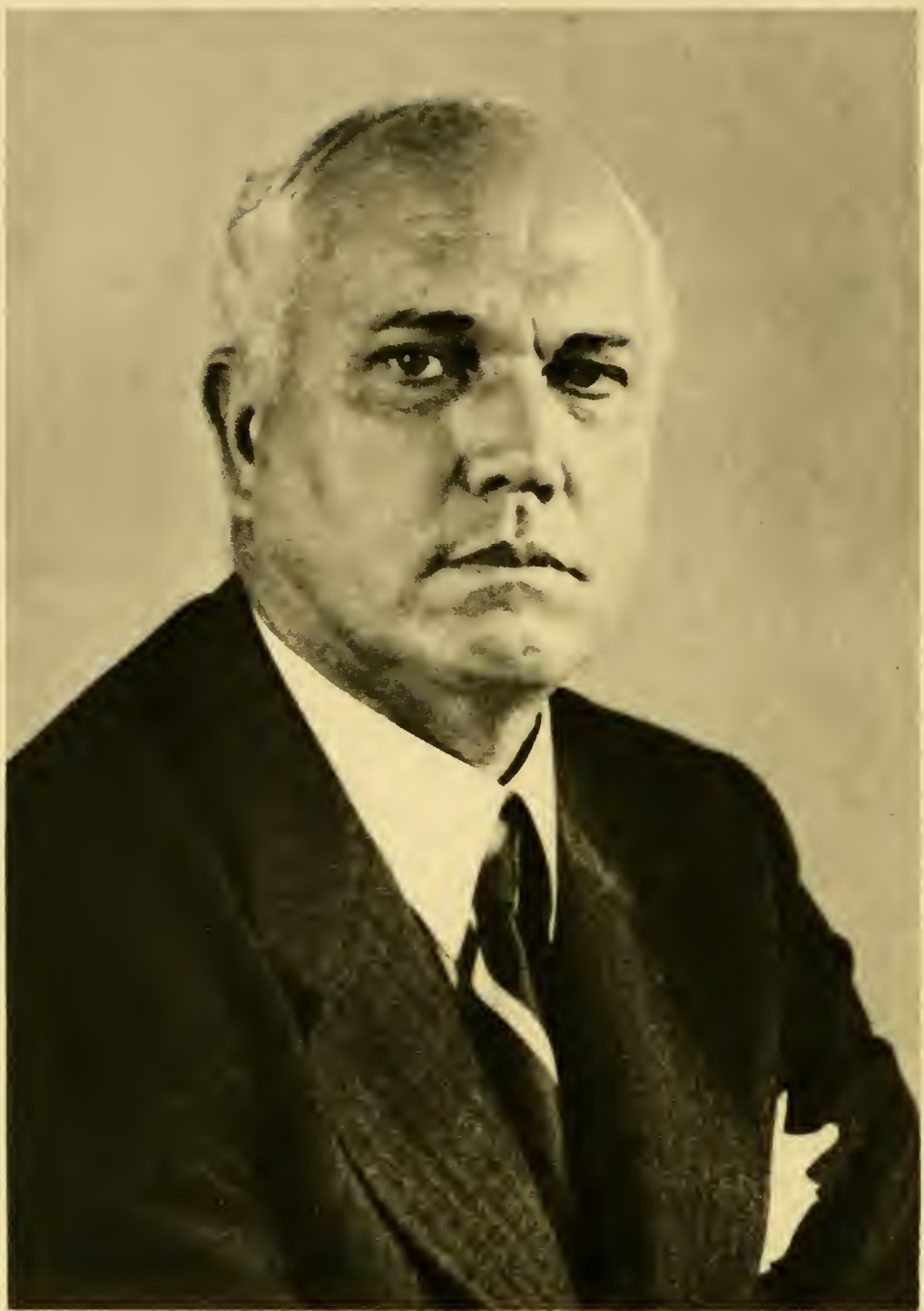

HERBERT M. EVANS 


\title{
Essays in Biology
}

\author{
In Honor of
}

H E R B ERT M. E V A N S

WRITTEN BY H I F R I N D S

University of California Press BERKELEY ANd LOS ANGELES ' 1943 


\section{UNIVERSITY OF CALIFORNIA PRES \\ BERKELEY AND LOS ANGELES \\ CALIFORNIA \\ CA M BRIDGE UNIVERSITY PRESS \\ LONDON, ENGLAND}

COPYRIGHT, I943, BY

THE REGENTS OF THE UNIVERSTY OF CALIFORNIA 


\section{TO HERBERT MALEAN EVANS ON HIS SIXTIETH BIRTHDAY}

Oour colleagues, students and other friends dedi-
cate this volume to the celebration of your anniver-
sary with the confident hope that the truth you have so zealously sought these forty years nay not be prostituted or strangled in the black and desolate years that loom ahead.

Your pursuit of truth and natural law has brought a fuller knowledge and understanding of fundamental problems in embryology, histology, and physiology. Wisdom, the brightest jewel in the crown of scholarship, has joined originality, insight, and energy in your labors. We look forward to watching your keen and effective pursuit of truth for many years to come.

Your understanding and enthusiasm have inspired all who have worked with you and spurred them on to their utmost efforts. Your example continues to guide and stimulate them. We look upon you as one

Of those who conquered, inch by difficult inch, The freedom of this realm of law for man;

Dreamers of dreams, the builders of nur hope. 



\section{A NOTE FROM THE PUBLICATION COMMITTEE}

Group of FRIENDS, associates, and students of Professor Herbert
McLean Evans has prepared this volume on the occasion of his
sixtieth birthday as a tribute to him in a form appropriate to his example and suggestive of his own enthusiastic endeavors. It was intended that the volume should include papers representative of the range of interests which have characterized the last forty years of Dr. Evans's scientific career, namely Anatomy, Embryology, Physiology of Reproduction, Endocrinology, Nutrition, the History of Medicine, and the History of Science. Of the many scientific friends and colleagues in various parts of the world who responded to our invitation with promises of manuscripts, some, to our regret, were prevented by the present unsettled conditions. To those friends of Professor Evans who were able to join with us in preparing this Sixtieth Birthday greeting, we are deeply grateful. All of us who have come in contact with Dr. Evans's genius share a common joy in suggesting to him through this book something of the appreciation we feel for his leadership, cultural ideals, and scholarly achievements.

We are especially grateful to George $\mathbf{W}$. Bartelmez and George $W^{\prime}$. Corner for advice during the preparation of this volume.

Publication of the book was made possible through the generous financial coöperation of the following:

Dr. Elmer Belt, Dr. Harold Brumn, Dr. Frederick C. Cordes, Dr. I. A. Emge, Dr. Frank Hinman, Hoftman-La Roche, Inc., Dr. William J. Kerr, Dr. Chauncey D. Leake, Dr. Herbert C. Moffitt, Mr. James K. Moffitt, Schering Corporation, Dr. Francis S. Smyth, The U'pjohn Company, Winthrop Chemical Company.

SAMUEI. T. FARQLHAR,

Chaunchy I). LeAke,

WIIIAM R. LYONS.

Murham E. Sumpson, Chaiman 



\title{
HERBERT M. EVANS
}

\author{
Biographical Data
}

$\mathrm{B}$ RN, MODESTo, CALIFORnLA, September 29, 1882, son of I)r. C. W'. and Bessic (McLean) Evans. B.S., University of California, 190.1; M.D., Johns Hop. kins University, 1908; M.D. (honoris causa), Albert Ludwigs-Universität Freiburg i.Br., 1930, and Universidad Católica de Chile, 19f1; Sc.D. (h.r.), Universidad Mayor de San Marcos de Lima, 19.1.

Assistant, Instructor, Associate, and Associate Professor of Anatomy, Jolns Hopkins University, 1908-1915; Research Associate, Carnegic Institution of Washington, 1913-1915: Professor of Anatomy, University of California, 1915-; Research Associate in Agriculuture, 1923-25; Reseanch Asorciate in Lixperimental Biology, College of Agriculture, 1925-: Hertsstein Professor of Biology and Director of the Institute of Experinental Biology, University of California, 1930-; Honorary Member, Facultad de Biología y Ciencias Médicas, Universidad de Chile, 19ł1; Honorary Prolessor, Facultad de Ciencias Médicas, Universidad Central del Ecuador, 1941. Ararded John Scott Medal. 1928.

Editor: University of California Publications in Anatomy, 1921-; American Anatomical Memoirs, 1918-1939: Journal of Nutrition, 1928-1933. Fellow: American Academy of Arts and Sciences; Nember, National Academy of Sciences; Member, Kaiserliche Leopoldinisch-Carolinische Deutsche Akadenic der Naturforscher; Member, Societas Regia Medicorum Budapestincusis; Honorary Foreign Member, Academia Nacionai de Medicina de Buenos Aires: Corresponding and Honoras y Member, Sociedad Argentina de Biología; Honorary Member, Sociedad Médica de Chile. Honorary Member, Sociedad de Biología de Santiago de Chile. Member, American Assor iation of Anatomists (president, 1930-1932); Member, American Medical Association: Member. American Physiological Society; Member, Society for Experimental Biology and Medicine; Fellow, American Association for the Adrancenent of Srience (president Pacific Division, 1936-1937): Member, Association for the Sundy of Internal Secretions: Honorary Member, Harwey Society of New York: Honorary Member, Society for Biological Research, University of Pittsburgh. Member, Phi Beta Kappa; Sigma Xi; Alpha Delta Phi: Alpha Onega Alpha; Nu Sigma Nu. Member, History ol Science Society. University ol California. Conresponding Nember, Sociedad Argentina de Historia de la Nedicina. Delegate, Third International Conference on Standindization of Hormones. Genera, 1938; Delegate, Second Pan American Congress of Enclocrinologr. Montevideo, 1941.

Faculty Research Lecturer, University of California, 1925; Bacon Lecturer. University of Illinois, 1931; Iertzstein Lecturer, Stanlord University and Lni. versity of California, 1934; Beaumont Lecumes, Wayne Comnty Medical Society, Detroit, 1937; Jackson Lecturer, University of Minnesota, 1937; Willinm 
Henry Welch Lecturer, Mount Sinai Hospital, New York, 1939; Jones Lecturer, University of Oregon, 1940; Messenger Lecturer, Cornell University, 1942; Mellon Lecturer, University of Pittsburgh, 1942; National Sigma Xi Lecturer, 1942; Guiteras Lecturer, American Urological Association, New York, 1942. 


\section{BIBLIOGRAPHY \\ $\mathrm{OF}$}

HERBERT MCLEAN EVANS

$1904^{-1} 94^{2}$

称

Compiled by

THOMAS COWLES 



\section{BIBLIOGRAPHY OF HERBERT MCLEAN EVANS}

$$
1904-1942
$$

1904

A new cestraciont spine from the lower Triassic of Idaho. Iniv. California l'uhlus. Bull. Depmt. Geol. 3(18):397-ן02. May, 190.1 .

\section{7}

The blood-supply of lymphatic vessels in man. Amer. Jl. Anat. $7: 195^{-208 . ~ A n g . ~} 1$, 1907 .

The parathyoid glandules. Their blood supply, and their preservation in operation upon the thyroid gland. (With William S. Halsted.) Ann. Surg. 46:489-506. Oct., 1907.

Notes on the resection of large portions of the small intestine. (With 1. G. Brenizer.) Johns Hopkins Hosp. Bull. 18:477-480. Dec., $190 \%$.

$$
1908
$$

Book review of "The Liser in Antiquity and the Beginnings of Inatomy," by Prof.

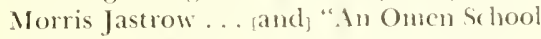
Text"; . . Anat. Recrd. 2:123-127. June, 1908.

On the occurrence of newly-forned lymphatic ressels in malignant growths. With a demonstration of their origin and ingrowth in the metasteses of a round-celled sarcoma. Johns Hopkins Hosp. Bull. 19:232-234. lug., 1 gos.

On an instance of two subclasian arteries of the early arm bud of man and its fundamental significance. Anat. Recrel. 2:41142 4. 1)ec., 1908.

$$
1909
$$

On the earliest blood-resseds in the anterior liml) lunds of birds and their retation to the primary subclavian artery. Aner. Jl. Anat. $9: 281-319$. May, $19 \% 9$.

On the development of the aortac, cardinat and mubilicat veins, and the other blood ressels of vertebrate embryos from capillaries. Anat. Recrd. 3:498-518. Sept.. 19o9.

\section{1}

Circular repuest for embryological material.] [Baltimore?: 1911]: 23 p.

Die Entwicklung des Blutgefiissststems. In Handbuch der Entwicklungsgesshichte des Menschen, bearbeitet von Chanles R. Bardeen... Herbert M. Frans ... ietc.. cte.e. Herausgegeben von Fran Keibel . . und Franklin P. Mall ... (Leip/ig: 19)10-1911: 2v.) $2: 551-688.1911$
1912

The developmem of the varulat stsem. In Manual of Human l:mbroblogt. writum b Chartes R. Bardecon ... Herlecet .1. Jisam ...erce, etc. Edited b Fam Keibel. . and Iranklin P. Mall ... (Philadelphia k London: 1980-1912; 5 1.) $2: 570-70(10.1912$. I eber das Verhalten der Lymplngefarse bei experimentell erengter Peritomealeami nose der Maus. Btge. \% hlin. Chir. 78: $10 y$ 12.1. 11ar, 1, 1912.

Ueber die vitale lairbungeses Tuberkels. (With lired B. Bowman \& Miltor C. Minter. nitz.) Cutrlblt. I. Bakteriol, Parasimk. 11. Infektmokm. I. Ibtl. 65:103-f01. July 17, 1912.

Experimentelle Läsionen den Contraluemen srstens, momersucht mit Hilfe der vitalen Fitrbung. (Itith John 1. MacCurdy.) Ber lin. klin. Winschr. 19:1695. sept, 2, 1912

$$
1919
$$

Circular repuest for embroblogical material. [Baltimole: 1913 ; [3] ए).

.. Die vitale Farbung mit samen farbstolfen. (Witl Werner schulemam \& Felis Wil. born.) (Preprint of the following entr. (Sonderablench.) Breslan: 1y13; cos.tit. 6 p. 1913.

$$
191.4
$$

Die vitale läbung mit samen Farbstollen. (Fin Beitrag /m Pharmakologic hochmole kularer Armeistolle.) (With Werner then lemamn \& Iclix Wilborn.) Preprinted as the preceling entr.) Jra-Brelst. Tchles Gichft. f. raterlind. Cult. (19)13:91)1(11:a) $1-(i .19) 1$.

The relation between chemical comstitution. plusical propertices and ability of the ben

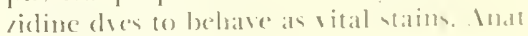

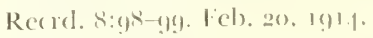

The phrsiologe of endothelimm. Anat. Read s::99-101. 1.ch. 20, 1911.

In experimental study of the histegenenis ot the milian tuluerele in vitall! tamed rab bits. With Fred B. Bowman s. 11 C

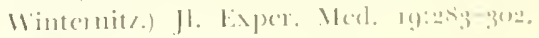
IIar. 1. 1011.

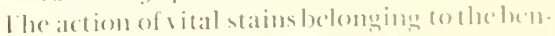

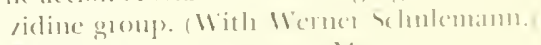

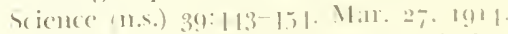

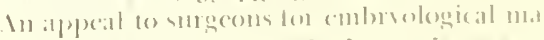

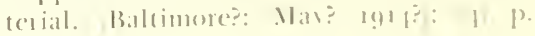


Vital staining of protoplasm. Science (n.s.) 39 : $843^{-844 . ~ J u n e ~ 5, ~} 1914$.

Die vitale Färbung mit sauren Farbstoffen in ihrer Bedeutung für pharmakologische Probleme. Ein Beitrag zur Pharmakologie kolloider Lösungen. (With Werner Schulemann.) Mit einem kolloid-chemischen Beitrag. Von Felix Wilborn. Deutsch. med. Wchnschr. 40:1508-1511. July 23, 1914.

\section{5}

Uber Natur und Genese der durch saure Farbstoffe entstehenden Vitalfärbungsgranula, (With Wemer Schulemann.) Fol. haematol., Arch. 19:207-19. Feb. 25, 1915 . The macrophages of mammals. Aner. Jl. Physiol. 37:213-258. May 1, 1915 .

\section{6}

On the behavior of the ovary and especially of the atretic follicle towards vital stains of the azo group. Anat. Recrd. 10:264. Jan. 20,1916 .

On the behavior of the mammalian ovary and especially of the atretic follicle towards vital stains of the acid azo group. Proc. Soc. Exper. Biol. \& Med. 13:80-81. [Mar.], 1916.

\section{7}

A human embryo of seven to eight somites. (With G. W. Bartelmez.) Anat. Recrd. 11: $355^{-35} 6$. Jan. 20, 1917 .

\section{9}

On the segregation of macrophage and fibroblast cells by means of vital acid dyes and on the cause of the differential effect of these substances. (With Katharine J. Scott.) Anat. Recrd. 16:148-149. May 20, 1919.

\section{0}

The oestrous cycle in the rat and other studies in the physiology of reproduction. (With Joseph A. Long.) (??Preprint of the next but one and the following entries for the year; dated:] March, 1920); 11 p.

Blood volume studies. III. Behavior of large series of dyes introduced into the circulating blood. (With A. B. Dawson \& G. H. Whipple.) Amer. Jl. Physiol. 51:232-256. Mar. 1, 1920.

The oestrus cycle in the rat. (With Joseph A. Long.) Anat. Recrd. 18:241-244. Apr. 20, 1920.

On the attainment of sexual maturity and the character of the first oestrus cycle in the rat. (With Joseph A. Long.) Anat. Recrd, 18:241-245. Apr, 20, 1920.
Effect on the oestrus cycle of the removal of various portions of the reproductive system. (With Joseph A. Long.) Anat. Recrd. 18:245. Apr. 20, 1920.

Rhythmical recurrence of the typical oestrus cycle after ovarian transplantation. (With Joseph A. Long.) Anat. Recrd. 18:245-246. Apr. 20, 1920.

The effect of copulation in delaying the occurrence of the next oestrus cycle and the production of a similar effect by mechanical stimulation of the cervix. (With Joseph A. Long.) Anat. Recrd. 18:246-247. Apr. 20, 1920.

The inhibition of oestrus and ovulation by lactation. (With Joseph A. Long.) Anat. Recrd, 18:247. Apr. 20, 1920.

Corpora lutea of lactation in the rat as distinguished from the corpora of pregnancy and those of ovulation. (With Joseph $A$. Long.) Anat. Recrd. 18:247-248. Apr. 20, 1920.

The survival and time of disappearance of the corpora lutea of pregnancy in the rat under various conditions. (With Joseph A. Long.) Anat. Recrd. 18:248. Apr. 2o, 1920. The experimental production of deciduomata in the rat, with special reference to the phases of the oestrus cycle. (With Joseph A. Long.) Anat. Recrd. 18:248-249. Apr. 20, 1920.

A characteristic sign of pregnancy in the rat detectable from the thirteenth to the sixteenth day. (With Joseph A. Long.) Anat. Recrd. 18:249. Apr. 20, 1920.

\section{1}

On the differential reaction to vital dyes exhibited by the two great groups of connective-tissue cells. (With Katharine J. Scott.) Contribs. Embryol., Carnegie Instn. Washington $10(47): 1-55 \cdot[1921 \cdot]$

Further studies in the physiology of reproduction. (With Joseph A. Long.) (t?Preprint of the next ten entries, together with three other abstracts; dated:] March, 1921); $10 \mathrm{p}$.

Proportion of ova producing full-term young in the rat. (With Joseph A. Long.) Anat. Recrd. 21:56-57. Apr. 20, 1921.

On the production of the condition of 'pseudopregnancy' by infertile coitus or mechanical stimulation of the cervical canal in the rat. (With Joseph A. Long.) Anat. Recrd. 21:57. Apr. 20, 1921.

A characteristic histology of the vaginal mucosa during lactation. (With Joseph A. Long.) Anat. Recrd. 21:58. Apr. 2o, 1921. 
On the production of deciduomata during lactation. (With Joseph A. Iong.) Anat. Recrd. 21:58-59. Apr. 20, $192 \mathrm{x}$.

On the rapid maturation of the onary by tramplantation of the youthful gomad to adults. (With Josepli A. Long.) Anat. Recrd. 21:60. Apr. 20, 1921.

On the association of continned cornification of the vaginal mucosa with the presence of large vesicles in the ovary and the absence of corpus formation. (With Joseph A. Loug.) Anat. Recrd. 21:60-61. Apr. 20, 1921.

The effect of thyroid feeding on the oestrous cycle of the rat. (With Joscph A. Long.) Anat. Recrd. 2ı:61. Apr. 20, 1921.

The effect of thyroidectomy on the oestrous cycle of the rat. (With Joseph A. Long.) Anat. Recrd. 21:61-62. Apr. 20, 1921.

The effect of feeding the anterior lobe of the hypophysis on the oestrons cycle of the rat. (With Joseph A. Long.) Anat. Recrd, $21: 62$. Apr. 20, 1921.

The elfect of the anterior lobe administered intraperitoneally upon growth, maturity, and oestrons cycles of the iat. (With Joseph A. Long.) Anat. Recrd. 21:62-63. Apr. 20, 1921.

Relation of nutrition to the ocstrous cycle. (With Katharine J. Scott.) Anat. Recrd. 21:80-81. Apr. 20, 192 1.

\section{2}

The rhythm of gonadal function with special reference to the relations between uterus and ovary. In Endocrinology and Metabolism ....edited by Lewellys F. Barker ... R. G. Hoskins ... (and Herman O. Mosenthat. (New York, London: 1922; $5 \mathrm{v}$.) 2:572599 .

On an invariable and characteristic disturbance of reproductive function in animals reared on a diet poor in fat soluble vitamine A. (With Katherine Scott Bishop.) Anat. Recrd. 23:17-18. Jan. 20, 1922.

Oestrus and ovulation in the rat, from a large group of animals on a standard dict. (With Katherine Scott Bishop.) Anat. Recrd. 23: 18-19. Jan. 20, 1922.

Characteristic effects upon growth, ocstrus, and ovulation induced by the intraperitoneal administration of fresh anterior hypophrseal substance. (With Joseph A. Long.) Inat. Recrd. 23:19. Jan. 20, 1922.

Absence of monocytes in thoracic duct lymph. (With George WT. Thome.) Inat. Recrel. 23:12. Jan. 20, 1922.

On the relations betwecn fertility and nutrition. 1. The ovulation rhythm in the rat on a standiat mutritional regime. (With hallerine S. Bichop.) Jl. Mecalool. Resich. 1:319-333. Feb., 1022.

On the relations between fortilio and nutrition. 11. The orulation rhwhm in the rat on inalequate mutritional regimes. (With Katharine Scote lishop. Jl. Metabol. Resrch. 1:335-356. Feb., 1922.

Characteristic effects upon growh, oestrus and ovulation induced by the intraperitoneal administration of fresh anterior hypophyseal substance. (With I. 1. I.mg.) l'roc. Natn. Acad. Scis, 8:38-39. Mar. $[15$, 1922.

The oestrous cycle in the rat and its asso. ciated phenomena. (With Joseph A. Long.) Mems. Lniv. California $6:[2], 148$ p. Jume $28,3922$.

On the existence of a hitherto unrecognisal dictary factor essential for reproduction. (With K. Scott Bishop.) Science (n.s.) 56 : $65^{0}-651$. Dec. 8, 1922 .

\section{3}

On the relations betwecn fertility and mutrition. Ill. I he normal reproductive per. formance of the rat. (With Katharine Scott Bishop.) Jl. Metabol. Resrch. 3:201-231. Feb., 1923 .

IOn the relatious between fertility and nutrition. IV.] The production of sterility with nutritional regimes adequate for growth and its curc with other fondstuffs. (With Katharine Scott Bishop.) Jl. Metabol. Resrch. 3:233-316. Feb., 1923.

On the existence of a hitherto unknown dietary factor essential for reproduction. (With K. Scott Bishop.) Amer. Jl. Physiol. 63:396-397. Feb. 1, 1923 .

Separation of the principle in the anterion hypophysis affecting ovulation from that controlling gencral body growth. (With C. F. Flower, C. E. Forkner, M. E. Kellum, A. Г. Walker \&. P. E. Smitl1.) Anat. Recrel. $25: 107$. Apr. 20, 1923.

Stability of hormones in the anterior hs poplusis. (Witly C. F. Flower. C. F. lorhner, W. F. Kellum, A. 1'. Walker \& P. J Smith.) Anat. Recrel. 25:107. 1 pr. 20, 1923.

Participation of the mammary gland in the changes of psendopregnancy in the rat. (Will Mary li. Freycr.) Inat. Recrd. 2.; 108. Apr. 20, 1923.

Independence of the oestrons or hean hor mone from that causing 'uestrots' struc tmal changes in the vaginal muckal of the rat. (Mith K. Scott Bishop.) . Inat. Recol. $25: 128.1$ pr. 20, 1923. 
The cause of reproductive upset in dietary deficiencies due to lack of vitamine $A$. (With K. Scott Bishop.) Anat. Recrd. 25: 129. Apr. 20, 1923.

Existence of a hitherto unknown clietary factor essential for reproduction. (With Katharine S. Bishop.) J1. Amer. Med. Assn. 81: $889-892$. Sept. 15,1923 .

\section{4}

The rhythm of gonadal function with special reference to the relations between uterus and ovary. (Reissue of the first entry in 1922.) In Endocrinology and Metabolism ... edited by Lewellys F. Barker ... R. G.

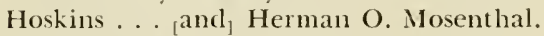
(Reissue; New York, London: 1924 ([C1922]); 5 v.) $2: 57^{2}-599$.

On the existence of a hitherto unknown dietary factor essential for reproduction. Proc. World's Dair. Congr. (1923) 2:10271034.1924.

Preliminary steps in the isolation and concentration of vitamine $\mathrm{X}$. (With George O. Burr.) Anat. Recrd. 27:203. Apr. 25, 1924 .

Stability and solubilities of the food substance or vitamine $\mathrm{X}$ required for reproduction. (With Katherine S. Bishop.) Anat. Recrd. 27:203-204. Apr. 25, 1924.

Proof of the power of the body to store the substance $X$ required for reproduction. (With Katherine S. Bishop.) Anat. Recrd. 27:204. Apr. 25, 1924.

Unique dietary needs for lactation. Science (n.s.) 6o:20-22. July 4, 1924 .

\section{5}

The function of the anterior hypophysis. Harvey Lects. (1923-1924) 19:212-235. [ 1925.$]$

The relations between fertility and nutrition. In Lectures on Nutrition: a series ... given at the Mayo Foundation and the universities of Wisconsin, Mimnesota, [etc., etc. . . 1924-1925. (Philadelphia and Lon. (lon: [C1925]) 209-234.

Preparation of Brilliant Congo R ("Vital Red") and the suitability of various samples of Vital Red for blood volume work. (With Samuel Palkin.) Jl. Amer. Chem. Soc. 47:429-434. Feb. $[5], 1925$.

Characteristics of the anterior hypophyseal hormones. (With Miriam E. Simpson.) Anat. Recrd. 29:356. Mar. 25, 1925.

Distribution of vitamine $\mathbb{X}$ in natural foods. (With George O. Burr. ) Anat. Recrd. 29: 356 . Nar. 25,1925 .
The repair of dwarfism following thyroidectomy by the administration of anterion hypophyseal fluid. (With Charles F. Flower.) Anat. Recrol. 29:383. Mar. 25, 1925.

The anti-sterility vitamine fat soluble $E$. (With George O. Burr.) Proc. Natn. Acar. Scis, 11:334-341. June [15], 1925.

Invariable occurrence of male sterility with dietaries lacking fat soluble vitamine $\mathrm{E}$. Proc. Natn. Acad. Scis. 11:373-377. July $[15], 1925$.

$$
1926
$$

Development of the human embryo during the period of somite formation, including embroys with 2 to 16 pairs of somites. (With George W. Bartelmez.) Contribs. Embryol., Carnegie Instn. Washington $17(85): 1-67$. Feb., 1926.

Elfects of anterior hypophyseal extracts on the male. (With Miriam E. Simpson.) Anat. Recrd. 32:206. Mar. 25, 1926.

The initial infertility of early copulations in the normal mate rat. Anat. Recrd. 32:206. Mar. 25, 1926 .

Increased efficacy of subcutaneous when compared with intraperitoneal administration of the ovarian hormone. (With George O. Burr.) Amer. Jl. Physiol. 77:518-521. Aug. 1,1926 .

\section{7}

A chronological list of the chief discoveries relating to vitamines. Compend. Med. \& Surg. 5:9-11, 20. Jan., 1927.

The oestrons cycle in the dog. I. The vaginal smear. (With Harold H. Cole.) Anat. Recrd. $35: 10$. Mar, 25,1927 .

The oestrous cycle in the dog. II. Coincident changes in the genital organs. (With Harold H. Cole.) Anat. Recrd. 35:11. Mar. $25,1927$.

A new epithelial sensory organ in the raginal mucosa of the dog. Anat. Recrd. 35 : 36 . Mar. 25,1927 .

Resemblance of litter-mates in the clegree of response to anterior hypophyseal fluid. (With Miriam E. Simpson.) Anat. Recrel. $35: 36$. Nar. 25,1927 .

Experimental gigantism--differential effect of anterior hypophyseal extract on normal and gonadectomized males and females. (With Miriam E. Simpson.) Anat. Recrd. $35: 3^{6-37}$. Mar. 25,1927 .

A new dietary deficiency with highly purified diets. (With George O. Burr.) Proc. Soc. Exper. Biol. \& Med. 24:740-743. May, 1927 .

The synthesis of vitamin $\mathrm{E}$ by plants grown in culture solutions. (With Dennis R. 
Itoagland.) Amer. J1. Physiol. 80:-002-701. Nay 1,1927 .

Vitamin E: the ineffectiveness of curative dosage when mixed with diets containimg high proportions of (ertain litts. (With George O. Bum.) Jl. Amer. Med. Issn. 88: 1 162-1465. May 7,1927 .

1 new dietary deficiency produced with highly purified diets. (With (ieorge O. Bum.) J1. Biol. Chem. Ft:1xxii-lxxiii. Juls, 1927 .

The antisterility vitamine: lat soluble $\mathrm{E}$. With George O. Burr \& Theodore L. Mlthausen.) Mems. Univ. California 8: [7], 176 p. Iug., 1927.

New dietary deficiency with highly purilied diets. II. Supplementary requirement of diet of pure casein, sucrose, and salt. (With George O. Burr.) Proc. Soc. Exper. Biol. \& Med. $25: 41-48$. Oct., 1927.

Vitamin E. 11. The destructive elfect of certain fats and fractions thereof on the antisterility vitamin in wheat germ and in wheat germ oil. (With George (). Bum.) Jl. Amer. Med. Assn. 89:1587-1590. Nov. 5 , 1927 .

$$
1928
$$

On the amount of vitamin 13 required during lactation. (With George O. Burr.) J1. Biol. Chem. 76:263-272. Jan., 1928.

Development of paralsis in the suckling young of mothers deprived of vitamin $\mathrm{E}$. (With George O. Bumr.) Jl. Biol. Chem. 76:273-297. Jan., 1928.

A new dietary deficiencr with hight purified diets. I11. The benelicial elfect of fat in the diet. (With George O. Burr.) Proc. Soc. Exper. Biol. \& Med. 25:390-397. 1.el).. 1928.

Vitamine E and anaemia. (With Clara L. Kohls.) Anat. Recrd. 38:52. Mar. 25, 1928.

A new differentiation between the antinenritic vitamin $B$ and the purely growth-promoting vitamin B. (With George O. Burr.) J1. Biol. Chem. 77:231-240. Apr.. 1928.

The effects of inadequate vitamin $A$ on the sexual physiology of the female. Jl. Biol. Chem. 77:651-654. Nis, 1928 .

Spontaneous deciduomata in psendoperg. nance with low vitanin E. Imer. Jl. Plysiol. 85:149-153. Nay 1, 1928.

sterility in inbred rats. Amer. |l. Phvsiol. $85: 15 t^{-157}$. Ma1y $1,1928$.

La vitamine hijo-soluble $\mathrm{E}$ et Je reproduction chez les Mammileres. Bull. Soc. sci. d'hrg. aliment. 16:382-397. 1928 .

The effec of inadequate vitamin 13 upun sexual phrsiology in the male. Jl. Nutrit. 1:1-21. Sept., 1928 .
Relation of vitamin t: to gasteth and vigot 11. Nutrit. 1:23-28, S(.pt., 14,28.

sparing action of fat on lle anti-nemitis vitamin. (With sammel 1, pekerski.) scienes

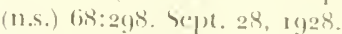

the oestroms acle in the dog. I. The varimal smear. (With Hatold II. (ole.) IR(publica lion of paper issucel in 1927.) (immell l'etrimme 18:352. Oct., 1024.

The oestroms arle in the dog. II. Comeident changes in the genital organs. (With llanold H. Cole.) (Republication of paper issted in 1927.) Comell Veterimm. 18:357. O(t. 1028.

A new epithelial semsort organ in the baginal mucosa of the dog. (Republication ol patpet issucel in 1927.) Cornell Veterimm. 18:381. Oct.. 1928.

I sex dillerence in chromosome lengths in the mammalia. (With Olive swar.) (;enetics 13:532-513. Nov., 1928.

Antagonism of growth and sex hormones of the anterior hypophrsis. With Mitiam E. simpson.) J1. Amer. Ned. ImI1. g1:133-1338. Nor. 3, 1928 .

Occurrence of fitint blecring on a definite intermenstrual das in man. (With Miriam E. Simpson.) science (n.s.) 6x:453. Vor. 9. 1928 .

Comparison of anterior-hpopliscal im. plants from nombal and gonaderomised animals, with reference to theis capratits to stimulate the immature orars. (With Huiam l. Simpson.) Anat. Recri. 42 : 11:11. 25, 1929.

Comparison of ambrior-hpophneal inplants from the male and female, with ref. erence to their capacits $(0)$ stimulate the immature ovars. With Viriam 1 . simpson.) Inatt. Recrol, 12: 1R. Malr. 25,1920 .

Book review of 1 shorl History of Medicine. By Chanles binger. () ford l niversiu l'rew. Vew lork, 1928. I niv. Calitornia Chromel. 31:211-211. 1 pr., 1920.

Book review of $1 \mathrm{n}$ mbroduction to the this tory of Medicine. 13y I iclding 11. (otrivens. Edition ]. Philadelphia. W. B. Tatunder.

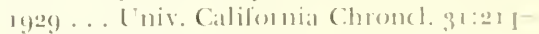
216. Ap) 19.929 .

Impainment of the birth medranism alue (o) hormones from the anterior hopophus

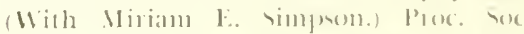

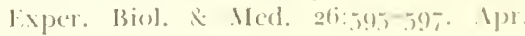
1029.

stimulation of plarentomat reaction in is ginal codonetrimm is leatment with an terior hypephscal hommone. Mitl Mis 
iam E. Simpson.) Proc. Soc. Exper. Biol. \& Med. 26:597. Apr., 1929.

Hyperplasia of mammary apparatus in precocious maturity induced by anterior hypophyseal hormone. (With Miriam E. Simpson.) Proc. Soc. Exper. Biol. \& Med. 26:597-598. Apr., 1929.

Hyperplasia of mammary apparatus of adult virginal females induced by anterior hypophyseal hormones. (With Miriam E. Simpson.) Proc. Soc. Exper. Biol. \& Med. 26:598. Apr., 1929.

A comparison of anterior hypophyseal implants from normal and gonaclectomized animals with reference to their capacity to stimulate the immature ovary. (With Miriam E. Simpson.) Amer. Jl. Physiol. 89:371374. July 1, 1929 .

A sex difference in the hormone content of the anterior hypophysis of the rat. (With Miriam E. Simpson.) Amer. Jl. Physiol. 89: $375-378$. July 1, 1929 .

The effect of pregnancy on the anterior hypophysis of the rat and cow as judged by the capacity of implants to produce precocious maturity. (With Miriam E. Simpson.) Amer. Jl. Physiol. 89:379-38o. July 1, 1929 .

A comparison of the ovarian changes produced in immature animals by implants of hypophyseal tissue and hormone from the urine of pregnant women. (With Miriam E. Simpson.) Amer. Jl. Physiol. 89:381387 . July 1, 1929.

Sparing action of fat on the antineuritic vitamin B. (With Samuel Lepkovsky.) Jl. Biol. Chem. 83:269-287. Aug., 1929.

Technique for determination of the antincuritic vitamin B. (With Samuel Lepkovsky.) Jl. Nutrit. 2:1-5. Sept., 1929 .

The chromosomes in man: sex and somatic. (With Olive Swezy.) Mems. Univ. California $9(1):{ }_{1}, 1-64$. Oct., 1929.

Maturation of human embryonic ova. (With Olive Swezy.) Proc. Soc. Exper. Biol. \& Med. 27:10. Oct., 1929.

Ovogenesis in the mammalia. (With Olive Swezy.) Proc. Soc. Exper. Biol. \& Med. 27: 11. Oct., 1929 .

On some relations of vitamin $\mathrm{B}$ to fat and carbohydrate metabolism. (With Samuel Lepkovsky.) Amer. Jl. Physiol. 90:340. Oct. 1, 1929.

Potent, sterile and low-protein extracts of the growth hormone from the anterior hypothesis. (With Robert E. Cornish \& Miriam E. Simpson.) Proc. Soc. Exper. Biol. \& Med. 27:101-102. Nov., 1929.

\section{0}

Ovarian changes during pregnancy in the rat. (With Olive Swezy.) Science (n.s.) 71:46. Jan. 10, 1930.

Aschheim-Zondek test for pregnancy-its present status. (With Miriam E. Simpson.) California \& West. Med. 32:145-148. Mar. $193^{\circ}$.

The effect of ions on sedimentation of colloidal particles by means of the centrifuge. (With R. E. Cornislı.) Jl. Amer. Chem. Soc. 52:1009-1012. Mar. [6], 1930.

Different effects secured from intraperitoneal as contrasted with subcutaneous administration of the anterior-hypophyseal hormones. (With Miriam E. Simpson.) Anat. Recrd. 45:215. Apr. 25, 1930.

Some effects on the hypophysis of hyperand hypothyroidism. (With Miriam E. Simpson.) Anat. Recrd. 45:215. Apr. 25, 1930.

Subnormal sex-hormone content of the hypophysis of animals with inadequate antineuritic vitamin B. (With Miriam E. Simpson.) Anat. Recrd. 45:216. Apr. 25, 1930.

Glucose tolerance in avitaminosis due to low antineuritic vitamin B. (With Samuel Lepkovsky \& Clarence Wood.) Jl. Biol. Chem. 87:239-25o. June, 1930.

The human ovarian germ cells. (With Olive Swezy.) J1. Morphol. \& Physiol. 49:543-577. June 5, $193^{\circ}$.

Construction and use of Raschig's laboratory fractionating column. (With R. E. Cornish, S. Lepkovsky, R. C. Archibald \& G. Feskov.) Indust. \& Engin. Chem., Analyt. Ed. 2:339343. July $15,1930$.

A condenser for low temperature evaporation of water. (With R. E. Cornish \& J. C. Atkinson.) Jl. Amer. Chem. Soc. 52:43344335. Nov. 15], 1930

\section{1}

On the preparation of a concentrated source of the heat-labile vitamin B, free from contamination with the heat-stabile factor G. (With Samuel Lepkovsky.) Jl. Nutrit. 3: 353-374. Jan., 1931.

Sex differences in the response of the rat to hypophyseal growth hormone. (With Mir-

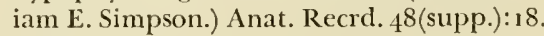
Feb. 25, 1931 .

Anemia and rickets. (With Clara L. Kohls.) Anat. Recrd. 48(supp.):43. Feb. 25, 1931.

Stimulating effect of hypophyseal implants in male rats with inadequate vitamine $G$. 
(With Miriam E. Simpsom.) Inat. Rectel. f8(supp.):43. Fel). $25,1931$.

Treatment of the congenital dwarf with growth hormone (fat). (With Miriam E.

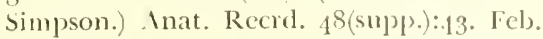
$25,1931$.

Necessary concurrence of orary in mammary response to the hypophysis in the rat. With Miriam E. Simpson.) Anat. Recrd. $t^{8}$ (supp.):4t. Feb. 25. 1933.

The utenus-ovary relationship and its bearing on the time of orulation in primates. (With Olive Swezy.) Amer. Jl. P'hysiol. 96: 628-639. Mar. 1, 1931 .

Ineffectireness of prolan in hypophysectomized animals. (With Frederick L. Reichert, Richard I. Pencharz, Miriam E. Simpson \&. Karl Meyer.) Proc. Soc. Exper. Biol. \& Med. 28:8.43-84t. May, 1931.

Relation of prolan to anterior hypophyseal hormones. (With Karl Mever \& Miriam E. Simpson.) Proc. Soc. Exper. Biol. \& Med. 28:8 $15-8+7$. May, 1931 .

Bencficial elfects of fat in high sucrose diets when the requirements for antineuritic vitamin $B$ and the fat-soluble vitamin are fully satisfied. (With Sammel Lepkorsky.) Jl. Biol. Chem. 92:615-622. Jug., 1931.

The effects of hypophyseal hormones on ovogenesis in the foetal ovary. (With Olive Swezy.) Anat. Recrd. 50:189-192. Aug. 25. 1931.

Effect of adrenalectomy on the testes of the rat. (With S. C. Freed \&. B. Brownfield.) Proc. Soc. Exper. Biol. \& Med. 29:1-3. Oct. 1931.

Hormones of the anterior hypophysis. (With Miriam E. Simpson.) Amer. Jl. l'hysiol. 98: $5^{11-5} 4^{6}$. Oct. 1, 1931 .

Researches on the relation of gaseous metabolism of animals to endocine and vitamin deficiency. Carnegie Instn. Washington Yr. Bk. (3930-1931) 30:461. Dec. 10, 1931.

An introduction to the study of the oestrou. cycle in the dog. (With Harold H. Cole.) Mems. Univ. California 9(2): vii, $65^{-118}$. Dec. 19, 1931.

Ovogenesis and the normal follicular cycle in adult mammalia. (With Olive Swezy.) Mcms. Univ. Califonnia $9(3):_{[} \vee i_{]}, 119^{-224}$. Dec. 19, 1931 .

\section{2}

Orogenesis and the normal follicular cycle in adult mammalia. (With Olive Swezy.) California \& West. Med. 36:60. Jan., 1932.

Testicular degeneration due to inadequate vitamin A in cases where $\mathrm{E}$ is adequate. Amer. Jl. Phrsiol. 99:477-186. Jan. 1, 1932.
Relation of prolan to the anterior hypophyseal homones, Witle fall Meyer \& Miriam F. Simpson.) Inn(1. Jl. I'lusiol. joo: $1.11-1,7^{1}$. Mar. 1, 1932.

Relative ineffectiveness of polam in lyppople. vectomized animals. With I. I. Reichent

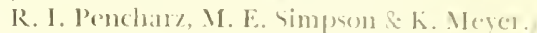
Aner. Jl. P'lysiol. noo:15-161. Mar. 1932.

Distubance of carbohydrate metalolism in normal dogs injected with the hypopluseal growth hormone. (With Karl Mever, Mil iam E. Simpson \& le rederick L. Reichert.) Proc. Soc. Exper. Biol. \& Ned. $29: 8-5,8,5$. Apr., 3992.

Vital necel of the body for certain unsaturated fatty acids. 1. Experiments with fat free diets in which sucrose furnishes the sole source of energy. (With Samuel I.epkor. sky.) Jl. Biol. Chem. 96:1.13-156. A pr. 1932.

Vital need of the body for certain unsaturated fatty acids. II. Experiments with high fat diets in which saturated fattr acids furnish the sole source of energy. (With Samuel Lepkovsky.) Jl. [Biol. Chem. 96:157-16. ipr., 1932.

The sparing action of fat on vitamin B. II. The role played by the melting point and the degree of unsaturation of various fats. (With Samuel Lepkovsky.) Jl. Biol. Chem. 96:165-177. Apr., 1932.

The sparing action of fat on vitamin B. III. The rôle played loy glycerides of single fatty acids. (With Samuel Lepkorsky.) Jl. Biol. Chem. 96:179-188. Apr., 1932.

Cure of the cachexia following hypophysectomy by administration of the growth hormone and its relation to the resulting adreno-cortical repair. (With Karl Mever, Richarel Pencharz \&. Miriam E. Simpson.) Science (n.s.) $75: 1 \cdot 12-4.13$. Apr. 22, 1932.

Vitamin E. Jl. Amer. Med. Assn. 99: $169-175$. Ang. 6, 1932.

Orogenesis and the hypophysis. With Olive swezy.) Anat. Recrd. 51 (supp.):18. Nov. 25. 1932.

Vital need of the body for certitin unsaturated fatty acids. 111. Inability of the sat organ ism to sruthesize the escential umaturated fatty acids. (With Samuel Lepkorsky) Jl. l3iol. Clyem. 99:231-23. Dec., 1932.

The sparing atsion of lat on vilamin $\mathrm{B}$. IS Is it necessary for fat to interact with sitamin $B$ in the alimentars canal to exert its sparing effect? (With sammel lephor sky.) Jl. Biol. (:hem. 99:235-236. Dee., 1932. 
The sparing action of fat on vitamin $B$. $V$. The rôle of glycerides of oleic acid. (With Samuel Lepkovsky.) J1. Biol. Chem. 99:237-210. Dec., 1932.

\section{3}

The hypophyseal substance giving increased gonadotropic effects when combined with prolan. (With Miriam E. Simpson \& Paul R. Austin.) Jl. Exper. Med. 57:897-9o6. June 1, 1933.

The growth and gonad-stimulating hormones of the anterior hypophysis. (With Karl Meyer, Miriam E. Simpson, Alexander J. Szarka, Richard I. Pencharz, Robert E. Cornish \& Frederick L. Reichert.) Mems. Univ. California 11:[xii $], 44^{6}$ p. Aug. 2, 1933.

Present position of our knowledge of anterior pituitary function. Jl. Amer. Med. Assn. 101:425-432. Aug. 5, 1933.

Peculiarities of the prolan-like substance in urine in a case of embryonal carcinoma of the testis. (With Miriam E. Simpson, Paul R. Austin \&: Russell S. Ferguson.) Proc. Soc. Exper. Biol. \& Med. 31:21-23. Oct., 1933.

Further studies on the hypophyseal substance giving increased gonadotropic effects when combined with prolan. (With Miriam E. Simpson \& Paul R. Austin.) Jl. Exper, Med. 58:545-559. Nov. 1,1933 .

The recognition and comparison of prolan and prolan-like substances. (With Miriam E. Simpson \& Paul R. Austin.) Jl. Exper. Med. $5^{8: 561-568 . ~ N o v . ~ 1, ~} 1933$.

Concentration of the gonadotropic hormone in pregnant mare's serum. (With Edwin L. Gustus \& Miriam E. Simpson.) Jl. Exper. Med. 58:569-574. Nov. 1, 1933.

The female sex hormones: the present status of our knowledge of anterior pituitary function. Trns. Congr. Amer. Physns. \& Surgns. (1933) 15:25-46. 1933 .

\section{4}

Hypertrophy of the female pituitary following injection of gonadotropic hormone. (With Miriam E. Simpson \& Morvyth McQueen-Williams.) Univ. Califonnia Publns. Anat. 1 (5): $\mathrm{ii}_{1}, 161-165$. Jan. 27, 1934.

Hypophyseal infantilism; treatment with an anterior hypophyseal extract: preliminary study. (With E. Kost Shelton \& Lyman A. Cavanaugh.) (?Preprint of third following entry.) Trns. Sect. Pediat., Amer. Med. Assn. 1933:235-255. [?Mar., 1934·]

Prevention of [i.e., by] ovariotomy of the hypophyseal hypertrophy following chronic administration of gonadotropic hormone. (With Miriam E. Simpson.) Anat. Recrd. 58(abstr. supp.):62. Mar. 25, 1934.

Scrotal hypertrophy following chronic injection of gonadotropic hormone. (With Miriam E. Simpson.) Anat. Recrd. $5^{8}$ (abstr. supp.):62. Mar. 25, 1934.

Hypophyseal infantilism; treatment with an anterior hypophyseal extract: preliminary study. (With E. Kost Shelton \& Lyman A. Cavanaugh.) (?Reprint of third preceding entry.) Amer. J1. Diseases Childr. 47:719736. Apr., 1934.

Purification of vitamins: fractional distribution between immiscible solvents. (With R. E. Cornish, R. C. Archibald \& Elizabeth A. Murphy.) Indust. \&. Engin. Chem., [Indust. Ed.], 26:397-406. Apr., 1934.

The sparing action of fat on vitamin $B$. (With Samuel Lepkorsky.) Jl. Biol. Chem. 105: xxvii. May, 1934 .

First editions in the history of science. In Exhibition of first editions of epochal achievements in the history of science. Sponsored by a committee of the History of Science Club of the University of California . . (Berkeley: June, 1934) 3-6.

On a selective gametogenic effect of certain hypophyseal extracts. (With Richard I. Pencharz \& Miriam E. Simpson.) Science (11.s.) 80:1.14. Aug. 10, 1934.

Vital need of the body for certain unsaturated fatty acids. IV. Reproduction and lactation upon fat-free diets. (With Samuel Lepkorsky \& Elizabeth A. Murphy.) Jl. Biol. Chem. 106:431-4to. Sept., 1934.

Vital need of the body for certain unsaturated fatty acids. $V$. Reproduction and lactation upon diets containing saturated fatty acicts as their sole source of energy. (With Samuel Lepkorsky \& Elizabeth A. Murphy.) Jl. Biol. Chem. so6:14144. Sept., 1934.

Vital need of the body for certain unsaturated fatty acids. V'I. Male sterility on fatfree diets. (With Samuel Lepkorsky \& Elizabeth A. Murphy.) J1. Biol. Chem. 106: $445^{-45}$ o. Sept., 1934 .

The repair of the reproductive system of hypophysectomized female rats by combinations of an hypophyseal extract (synergist) with pregnancy-prolan. (With Richard I. Pencharz \& Mirian E. Simpson.) Endocrinology 18:601-606. Sept./Oct., 1934.

Maintenance and repair of the reproductive system of hypophysectomized male rats by hypophyseal synergist, pregnancy-prolan and combinations thereof. (With Richard 
I. Pencharz \& Miriam E. Simpson.) Fudecrinology 18:617-618. Sept./Oct., 1931.

The sparing action of fat on ritamin I3. II. The influence of the levels of protein and vitamin G. (With Samuel lepkorsky \& Elizabeth A. Murphy.) J1. Biol. Chem. 10\%: 129-437. Nov., 1934.

The sparing action of fat on vitamin 13. Vil. The effectiveness of varioms natural lats in sparing vitamin B. (With samuel lepkorsky \& Elizabeth A. Murphy.) Jl. Biol. Chem. 107:439-4t2. Nov., 1934 .

The sparing action of fat on vitamin G. (With samuel Lepkorsty \& Elizabeth A. Murphy.) Jl. Biol. Chem. 107:443-147. Nox. 1934.

The response of the gonads of immature pigeons to various gonadofropic homones. (With Miriam E. Simpsom.) Anat. Recrd. 60:405-t21. Nov. 25, 1934 .

Reduction of the thrmms by gonadotropic hormone. (With Miriam E. Simpson.) Anat. Recrd. 60:423-435. Nor. 25, 1934.

\section{5}

The concentration of vitamin $($ b) atsorption and elution from fullers cath. (With Samuel Lepkorsty \& William Popper, Jr.) Jl. Biol. Chem. rok:257-265. Janl., 1935.

the mutritive alue of the tattr acids of lard and some of their esters. (With samuel Lepkorsky \& Roy A. Ouer.) J1. Biol. Chem. 108:431-438. leb., 1935 .

The sparing action of lat on vitamin B. Vill. On the loss of vitamin $B$ from the rats tissues. (With Samuel Lepkorsk!.) Jl. Biol. Chem. 108: $439-455$. Feb., 1935.

Preparation and properties of vitmin L concentrates. With Elizabeth A. Murphr, R. C. Archibald \& R. E. Comish.) Jl. Biol. Clsem. 108:515-523. Feb., 1935.

Clinical manifestations of dystunction of the anterior pituitary. Jl. Amer. Med. Asm. 104: $16.1-172$. Feb. 9. 1935.

Similarits of the urinat gonatotropic hormone occurring in some cases of testicular neoplasm with that found in the urine of pregnancy. (With Miriam E. Simpsour.) Anat. Recrol. 61(abstr. supp.):16-17. Mitr $25.193 \%$

'Deficiency' changes in the testicular Leydig cells after hypophysectomy. (With Miriam E. Simpson \& Richard I. Penchare.) Inal. Recrel. 61 (abstr. supp.):44. Mar. 25, 1935.

Production of superovulation in mormal immature rats by injection of the principle in menopanse urine. (With Miriam $\mathbb{I}$ : simpson.) Proc. Soc. Exper. Biol. \&ed. 32:1046-1047. 1pr., 1935.
Synergism or angmentition poduced b the adelition of an hypopbluseal syergis to menopanse or castration mince Mith Miriam E. Simpson.) Pros. box. Ixpec. Biol. \& Ned. 32:10.17. .1p1., 1935.

A semsitive biological test for memopante or rastration prolan. (With Nirim E. Simp. som.) Proc. Soc. Ixper. Biol. \& .Mal. 32 10 18. Apr., 1935

Gonadotropic ellects in hypophrsectomised female lats of implants of pituitarien foum castrated mates. (With Mirian l:. bimpson \& Richard I. lenchare.) Proc. Soc. Exper Biol. \& Merl. 32:1018-1019. . Ipr., 1995.

The growth bormone of the auteriof pitui tary. Jl. Amer. Med. Amn. 101:1232-1237. Apr. $6,1935$.

The preparation of crstatline vitamin (; (With tammel Iepkorsky \& William Pop) per, Jr.) Jl. Biol. Chem. 1og:lis. Nar, 1935. On the conditions necenaty for the contin. nous growth of hypophisectomised ani mals. (With Richard I. Pencluar R Miriam E. Simpson.) Endocrinolug! 19:509-511. sept./O(t., 1935.

Clinicat manilestations of drelunction of the anterior pituitary. (Republication of papes issued earlier in the same year.) In (ilandu. lar Physiology and Therapy: a simposium prepared under the auspices of the Counril on Pharmacy and Chemistry of the Imerican Mediral Assoriation. (Chicago: 19!35) $5-28$. O(1.+. 1535.

The growth homme of the anterion pituitary. Republication of patper isued carlier in the same !ear.) In Glandular Ploysiolog and Therapi: a srmposium prepared un der the auspices of the Comncil on Phat mary and Chemistry of the Imerncan Medical Association. (Chicago: 1935) 15-59. [Oct.]. 1935.

$$
1936
$$

The isolation fiom whealt germ oil of an alcohol, a-tocopherol. hasing the proper lies of vitamin E. (With Oliver II. Fme on colads 1. Emerson.l jl. Biol. Chem. $113: 319-332$. I.el)., 1936.

Gotladotropic hormones. . I. West. Jl. surg..

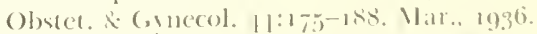

Gomatotropic hommones... II. West. Jl twe.

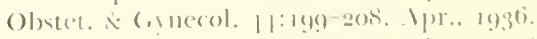

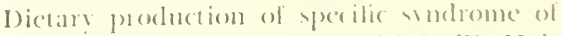
deficience in sitamin $B_{3}$. (With Vedlic Hal

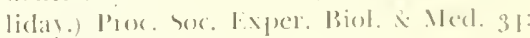

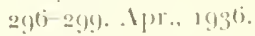

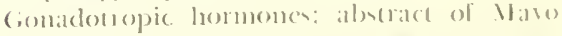
foumdation lectme. Prok. Stall Meetgs. Ino Clin. 11:216-222. Ipr. 1. 1930 
The isolation from cottonseed oil of an alcohol rescmbling alpha tocopherol from wheat-germ oil. (With Oliver H. Emerson \&. Gladys A. Emerson.) Science (11.s.) 83: 421-422. May 1, 1936.

The use of the fractionating column for the separation of fatty acids. (With Samuel Lepkorsky \& George V. Feskov.) Jl. Amer. Cliem. Soc. 58:978-981. June $[5], 1936$.

Hypophyseal infantilism: treatment with an anterior hypophyseal extract; final report. (Witl E. Kost Shelton \& Lyman A. Cavanaugh.) Amer. Jl. Diseases Childr. 52:1001 13. July, $193^{6 .}$

On the separation and properties of the antagonist, a pituitary substance inhibit. ing ovarian responses to gonadotropic hormones. (Witl Karl Korpi, Richard I. Pencharz \& Miriam E. Simpson.) Univ. California Publus. Anat. 1(8): $\left[\mathrm{iii}_{]}, 237-253\right.$. July 29, 1936 .

On the separation of the interstitial cellstimulating, lıteinizing and follicle-stimulating fractions in the anterior pituitary gonadotropic complex. (With Karl Korpi, Miriam E. Simpson, Richard I. Pencharz \& Donald H. Woncler.) Univ. California Publus. Anat. 1(9): ${ }_{[} \mathrm{ii}_{1}, 255^{-273}$. Nov. 16 , $193^{6 .}$

Fractionation of the gonadotropic hormones in pregnant mare serum by means of ammonium sulfate. (With Karl Korpi, Miriam E. Simpson \& Richard I. Pencharz.) Univ. California Publus. Anat. 1(10): ${ }_{[} \mathrm{ii}_{]}, 275^{-281}$. Dec. 21, $193^{6}$.

\section{7}

Gonadotropic hormone in the blood and urine of early pregnancy; the normal occurrence of transient extremely high levels. (With Clara L. Kohls \& Donald H. Wonder.) Jl. Amer. Med. Assn. 108:287-289. Jan. 23, 1937 .

On the fractionation of the vitamin $B_{2}$ complex from various source materials. (With Nellie Halliday.) Jl. Biol. Chem. 118:255267. Mar., 1937 .

Effect of interstitial cell stimulating hormone on hypophysectomized male rats. (With Miriam E. Simpson \& Richard I. Pencharz.) Anat. Recrd. 67 (supp. 3):16. Mar. 25, 1937.

Marked thyroid hyperplasia without change in respiratory metabolism by the treatment of hypophysectomized rats with thyreotropic hormone. (With Evelyn M. Anderson.) Aner. J1. Physiol. 11 9:260. June 1, 1937.

Dietary production of the syndrome of deficiency in vitamin $\mathbf{B}_{6}$. (With Nellie Halliday.) Jl. Nutrit. 13:657-667. June 10, 1937 .
On the claim for a new essential dietary factor in mammalian liver. (With Nellie Halliday.) Jl. Nutrit. 14:45-5. . July 10, 1937.

Alleged vitamin $\mathrm{E}$ content in royal jelly. (With Gladys A. Emerson \&. J. E. Eckert.) Jl. Econ. Entomol. 3o:642-646. Ang., 1937.

The effect of vitamin E deficiency upon growth. (With Gladys A. Emerson.) Jl. Nutrit. 14:169-178. Aug. 10, 1937.

The effect of thyreotropic hormone combined with small amounts of iodine upon the function of the thyroid gland. (With Evelyn M. Anderson.) Amer. Jl. Physiol. 120: 597-603. Nov. 1, 1937.

The chemistry of vitamin E: tocopherols fron! various sources. (With Oliver H. Emerson, Gladys A. Emerson \& Ali Mohammad.) Jl. Biol. Chem. 122:99-107. Dec., 1937.

An anterior pituitary gonadotropic fraction (ICSH) specifically stimulating the interstitial tissue of testis and orary. (With Miriam E. Simpson \&. Richard I. Pencharz.) Cold Spring Harbor Sympsa. Quantit. Biol. 5:229-240. 1937 .

\section{$193^{8}$}

Failure of nicotinic and yeast nucleic acids in "filtrate factor" deficiency in rats. (With Gladys A. Emerson.) Proc. Soc. Exper. Biol. \& Med. 38:195-197. Mar., $193^{8}$.

Growth-stimulating action of alpha tocopherol. (With Gladys A. Emerson \& Oliver H. Emerson.) Proc. Soc. Exper. Biol. \& Med. 38:197-198. Mar., $193^{8 .}$

Stimulation of deciduomata around threads on administration of lactogenic and adrenocorticotropic hormones. (With Miriam E. Simpson \& Kaisa Turpeinen.) Anat. Recrd. 7o(supp. 3):26. Mar. 25, 1938.

The purification of the anterior pituitary growth hormone by fractionation with ammonium sulfate. (With Nao Uyei, Quentin R. Bartz \& Miriam E. Simpson.) Endocrinology 22:483-492. Apr., $193^{8}$.

Atrophy of thymus of the rat resulting from administration of adrenocorticotropic hormone. (With H. D. Moon, M. E. Simpson \&. W. R. Lyons.) Proc. Soc. Exper. Biol. \& Med. 38:419-420. Apr., $193^{8 .}$

The calorigenic action of amino acids in the hypophysectomized animal. (Witl J. Murray Luck, R. I. Pencluarz \& H. C. Stoner.) Amer. Jl. Physiol. 122:533-541. May 1, 1938.

Claim for thyroid subnormality in vitamin E-low rats. (With Ira R. Telford \& Gladys A. Emerson.) Proc. Soc. Exper. Biol. \& Med.

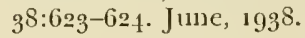


Degeneration of cross striated musculature in vitamin E-low rats. (With Gladys A. Emerson \& Ira R. Telford.) Proc. Soc. Exper. Biol. \& Med. $3^{8: 625-627 . J u n e, ~} 193^{8}$.

presence of antithyrotropic substance in serum of rats injected chronically with rat pituitary extract. (With Erclyn Anderson.) Proc. Soc. Exper. Biol. \& Ned. 38:797-798. J1110, 1938 .

steps in the concentration of vitamin $B_{6}$. (With Gladys A. Emerson, Ali Mohammad \&. Oliver H. Enerson.) Jl. Biol. Chem. 124: $377-383$. July, 1938.

The chcmistry of ritamin E. II. Biological assays of various synthetic compounds. (With Gladys A. Emerson \& Oliver H. Emcrson.) Scicnce (n.s.) 88:38-39. July 8, $193^{8 .}$

Work performance of hypophysectomized rats treated with anteriol pituitary extracts. With Dwight J. Ingle \& H. D. Moon.) Amer. Jl. Phrsiol, 123:620-624. Sept. 1, $193^{8 .}$

The hypophyseal growth howmone-its scparation from the homones stimulating the thryoid, gonads, adremal contex and mammary glands, Resich. Publns. Assn. Resrch. Nerv. \& Ment. Disease (Proc., 1936) 17:175192. [Oct.] $193^{8 .}$

The spirit and task of rescarch. In Iddresses: Dedication of Research Building, Abbott I.aboratories . . . (1 North Chicago, Ill.: c1938 $8^{1} 17-25$.

\section{9}

Predominant features of homonal control of the body by the adeno-hypophysis. (Beammont Foundation Lecumes, 1938.) St. Paul, Minn.: 1939; 54 p.

The occurrence of gamma tocophcrol in corn embryo oil. (With Oliver H. Emerson \& Gladys A. Emerson.) Science (n.s.) 89:1 $8_{3}$. Feb. 21, 1939.

Endocrine glands: gonads, pituitary, and achenals. Annu. Rer. Physiol. 1:577-652. [Mar.], 1939.

Characterization of gonadotropic hommones of the hypophysis by their sugar and glucosamine content. (With H. FracukelConrat, Miriam E. Simpson \& C. H. Li.) Science (n.s.) 89:249-250. Mar. 17, 1939.

Relations between the growth promoting effects of the anterior pituitary and the thyroid hormone. (With Miriam E. Simpson \& Richard I. l'encharz.) Anat. Recid. 73(supp. 2):18. Mar. 25, 1939.

Growth-stimulating action of ferric chloridetreated wheat gem oil. With Gladys A.
Emerson.) Proc. Soe. H:yer. Biol. \& .lel. 11:170-172. 11ay, 1039 .

Histological changes in sheletal musculature of panalyzed suckling voung of E-low rats. (Witl lra R. Telford \& Gladis 1. Emerson.) Proc. Soc. Exper, Biol. I Med. p1: 291-295. May, 1939.

Reeluced muscle (roatine in paralied woung E-low rats. (With tra R. Telford \&. C,ads, A. Emerson. P'roc boc. Exper. Biol, vi Med. $41: 915-318 . J 11110,1939$.

Failure to produce alsdominal neoplasms in xats receiving wheat germ oil extracted in various waxs. (With Gladys A. Encrson. Proc. Soc. Exper. Biol. \& Med. 41:318-320. June, 1039 .

Chemical fractionation of the gonadotropic factors present in sheep pituitary. With H. Jensen, Miriam E. Simpson \& sibylle Tolksdorf.) Endocrinology 25:57-62. July, 1939 .

Degrees of sterility in female ritamin E-Iow rats. (With Glaths A. Emerson.) Amer. Jl. Physiol. 126:P484. July 1, 1939.

Preservation of the seminiferons epithelium and of fertility in male rats by prophsactic administration of alpha tocopherol. (With Gladys A. Enerson \& Oliver H. Emerson.) Aner. Jl. Physiol. 126:1'187P488. July 1, 1939.

The preparation of pituitary growth hor mone free from lactogenic and throtropic hormones. (With Domald L. Mleamber. Heinz L. Fracnkel-Conat \& Mirian I: Simpson.) Science (11.s.) 9o:19-20. July 7, 1939 .

Presertation of scminilerous epithelimm and lentility in male rats on vitamin E-low ralions supplemented by a-tocopherol. (With Gladrs 1. Emerson \& Oliver 11. Emerson. Anat. Recrd. 71:257-271. July 25. 1939.

Role of ritamin $\mathrm{E}$ in the prevention of muscular distrophy in guincil pigs reared on suthetic rations. (With Nobuko shimotori \& Gladrs .1. Emcron.) Science (11.s.) 90:89. July 28, 1999.

Relation between the growth promoting cffects of the pituitary and the throid hormonc. (IIII Mirian I: Simpson S. Richand I. P'anchar\%) lindocrinolog! $25: 1,55^{-1}$ š. A119., 1939 .

Action of hetene on the pituitat lactogenic bormone, Milh Choh HaO Li \& Miriam

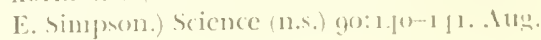
$11,19391$.

The chemistry of vitamin E. NIII. Specificit and relationship between chemical strue [ure and vitamin F: activiu. (With O. I1. 
Emerson, G. A. Emerson, Lce Irvin Smith, Herbert E. Ungnade, W. W. Prichard, F. L. - Austin, H. H. Hochn, J. IV. Opie \& S. Wawzonek.) Jl. Organ. Chem. 4:376-388. Sept., 1939 .

The effect of cysteine on gonadotropic hormones. (With Heinz Fraenkel-Conrat \& Miriam E. Simpson.) J1. Biol. Chem. 130: 243-2.49. Sept., 1939.

Biological studies of the gonadotropic principles in sheep pituitary substance. (With Miriam E. Simpson, Sibylle Tolksdorf \& H. Jensen.) Endocrinology 25:529-546. Oct. 1939 .

Essentiality of primary amino groups for specific activity of the lactogenic hormone. (With Choh Hao Li, William R. Lyons \& Miriam E. Simpson.) Science (n.s.) 90:376377. Oct. 20, 1939.

Multiple nature of the rat "filtrate factor"a component of vitamin $\mathrm{B}_{2}$. (With Ali Mohammad, Oliver H. Emerson \& Gladys A. Emerson.) Science (n.s.) 90:377. Oct. 20, 1939 .

Action of ketene on gonadotropic hormones. (With Choh Hao Li \&. Miriam E. Simpson.) Jl. Biol. Chem. 131:259-266. Nov., 1939.

Restoration of fertility in successively older E-low female rats. (With Gladys A. Emerson.) J1. Nutrit. 18:501-506. Nov. 10, 1939. Aspects of the function of vitamin $E$ irrespective of its relation to the reproductive system. Jl. Amer. Dietet. Assn. 15:869-874. Dec., 1939 .

The vitamin $\mathrm{E}$ activity of $a$-tocoquinone. (With Oliver H. Emerson \& Gladys A. Emerson.) Jl. Biol. Chem. 131:409-112. Dec., 1939 .

Electrophoretic study of pituitary lactogenic hormone. (With Choh Hao Li \& William R. Lyons.) Science (n.s.) 90:622-623. Dec. 29, 1939 .

$$
194^{\circ}
$$

The William Henry Welch lectures. I. New light on the biological rôle of vitamin $\mathrm{E}$. Jl. Mount Sinai Hosp. 6:233-244. Jan./Feb. 1940.

Experimental superfecundity with pituitary gonadotrophins. (With Miriam E. Simpson.) Anat. Recrd. $76($ supp. 2):21. Feb. 24 , $194^{\circ}$.

properties of the filtrate factor of the vitamin $\mathrm{B}_{2}$ complex, with evidence for its multiple nature. (With Ali Mohammad, Oliver H. Emerson \& Gladys A. Emerson.) Jl. Biol. Chem. 133:17-28. Mar., 1940.

Studies on pituitary lactogenic hormone. I. Electrophoretic behavior. (With Choh Hao
Li \& William R. Lyons.) Jl. Genrl. Physiol. 23:433-438. Mar. 20, $194^{\circ}$.

The effect of thiol compounds on gonadotrophins. (With H. L. Fraenkel-Conrat \& Miriam E. Simpson.) Science (n.s.) 91:363365. Apr. 12, 1940.

The endocrine literature of 1939. (With Barbara Cowles.) Endocrinology 26:906-912. May, $194^{\circ}$.

Toxicity of high salt intake in adrenalectomized rats (With Evelyn Anderson, Michael Joseph \& Virgil Herring.) Amer. Jl. Physiol. 129:P301. May 1, 1940.

Growth and reproductive physiology in vitamin $B_{6}$ deficiency. (With Gladys A. Emerson.) Amer. Jl. Physiol. 129: P352. May 1, $194^{\circ}$.

The prevention of muscular dystrophy in suckling young of $\mathrm{E}$-deficient rats by alpha tocopherol and related substances. (With Gladys A. Emerson \& Oliver H. Emerson.) Amer. Jl. Physiol. 129: P354. Nay 1, 1940.

Phosphorus metabolism in the musculature of drstrophic vitamin E-deficient rats. (With Gwei Djen Lu \& Gladrs A. Emerson.) Amer. J1. Physiol. 129:P4o8. May 1, 1940.

Inactivation of pituitary lactogenic hormone by iodine. (With Choh Hao Li, William R. Lyons \& Miriam E. Simpson.) Science (11.s.) 91:530-531. Nay 31, 1940.

Prevention of mutritional muscular dystrophy in suckling E-low rats with alpha-tocopherol and related substances. (With Gladrs A. Emerson.) Proc. Soc. Exper. Biol. \&. Med. 44:636-639. June, 1940.

The prevention of nutritional muscular dystrophy in guinea pigs with vitamin E. (With Nobuko Shimotori \& Gladys A. Emerson.) J1. Nutrit. 19:5+7-554. June 10, 19.40.

Electrophoretic homogeneity of pregnant mare serum gonadotrophin. (With Choh Hao Li \& Donald H. Wonder.) Jl. Genrl. Physiol. 23:733-739. July 20, 19 to. $^{\circ}$

Experimental superfecundity with pituitary gonadotropins. (With Miriam E. Simpson.) Endocrinology 27:305-308. Aug., 1940.

Purification of thyrotropic hormone of the anterior pituitary. (With Jane FraenkelConrat, Heinz Fraenkel-Conrat \& Miriam E. Simpson.) Jl. Biol. Chem. 135:199-212. Aug., 19.40.

Purification of the follicle stimulating hormone of the anterior pituitary. (With Heinz Fraenkel-Conrat \& Miriam E. Simpson.) (? Preprint of second following entry.) An. Fac, de med. de Monterideo 25:617626. 1940. 
The antagonism to gonadotrophim exened 1) pituitary gonadotrophic "xtracts. (With Henz Fraenkel-Comrat, Mirian f. Simpson \& Cloh Hao Li.) (?Preprint of second following entry.) Ail. Fac. de med. de Montevideo $25: 627-636.1910$.

Purification of the follicie stimulating bormone of the anterior pituitary. With Heinz Fraenkel-Conat \& Miriam E. Simpson.) (?Reprint of second preceding entry.) In Anales de la Facultad de Medicima de Montevideo: nimero especial con motivo del homenaje que la "Socicdad de Biologia de Monteridco" ofrece al Prof. Luduig Fracnkel, en ocasión del jo. anizersario de su nacimicnto. (Montevideo: 19.0) 159168. 1910 .

The antagonism to gonadotyophins exerted by pituitary gonadotrophic extracts. (With Heinz Fraenkel-Conrat, Miriam E. Simpson \&. Choh Hao Li.) (־Reprint of second preceding entry.) In Anales de la Facultad de Medicina de Monterideo: nimero especial con motivo del homenaje que la "Sociedad de Biologia de Montezideo" ofrece al Prof. Ludaig Fraenlel, en ocasión del -o. ${ }^{\circ}$ anizersario de su nacimiento. (Montevideo: 1940$) 169^{-17} 8$. 1940 .

Further puritication of the growth hormone of the anterior pituitary. (With Heinz L. Fraenkel-Conrat, Donatd L. Meamber \& Miriam E. Simpion.) Endocrinolog! 27: $605-613$. Oct.. 19.10.

Microscopic lesions without functional impaiment of striated ususculature of suckling E-low lats. (With Tra R. Telford \& Gladys A. Emerson.) Proc. Soc. Exper. Biol. \&. Med. 45:135-136. Oct.. 19/\%.

Growth-stimulating activity of alpha-tocopherol. (With Marjorie M. Velson \& Gladis A. Emerson.) Proc. Soc. Exper. Biol. \&. Med. $45: 157^{-15} 5^{8}$. Oct.. 1940).

Succesive generations of vitamin E-low rats. (With Gladrs A. Emerson.) Proc. Soc. Exper. Biol. \& Med. 45:159-162. Oct., 1910.

Purification of the pituitiry interstitial cell stimulating hormone. (With Choh Hao Li \& Niriam E. Simpson.) Science (11.s.) 92: $355-356$. Oct. 18, 1940.

Interstitial cell stimulating hormone. 1. Biological propertics. (With Heinz Fraenkel Conrat, Chol Ha Li \& Mirian E. Simpson.) Endocrinology 27:793-802. Nov., 1970.

Interstitial cell stimulating homone. 11 . Method of preparation and some physion. chemical studies. (With Choh Hao Li $x^{\circ}$ Miriam E. Simpson.) Endocrinolog! 23: 803-808. No1., 1940.
Interstitial cell stimulating hormenc. III. Methols of estimating the hormonal cous tent of pituituries. (With Ilein/ Fraculed. Comat \& Mirian E. Simpson.) Endoci nology 27:sog-817. Nos., 19 g0.

Purification of follicle-stimulating homono (F)H, of the anterior pituitary. Witt Heinz L. Fraenkel-Contat \& Miriam 1 . Simpson.) Proc Soc Exper. Biol. Merd. $45: 627-630$. Nox.. $19 f^{0}$.

Studies on pituitar lactogenic hormone. II A comparison of the clectrophosetic be havior of the lactogenic hommone as pre pared from heef and from sheep pituitaries. (With Choh Hao Li \& Witlian R. Lons.) Jl. Aner. Chem. Sox. 62:292,-2927. Vos [(b) , ig \{0.

Sudies on pituitary lactogenic hommone. 11 Tyrosine and tryptophane content. (Wich Choh Hao Li \& William R. Lyons.) Jl. Biol. Chem. 136: $709-712$. Dec., 1950.

\section{1}

Synergism of estrogens with pituitary gonar. otsopins in hypophysectomized rats. (With Miriam E. Simpson. Heine L. Tratenkel. Conrat $x$ Choh Hao 1.i.) Endocrinolog! $2 \mathrm{~s}$ 37-11. Ja11., 1911.

Studies on pituitary lactogenic hormone. I11. Solubilities of shecp and beet hormones (With Choh Hao Li \& William R. 1, , (sm. Jl. Genrl. Physiol. 24:303-309. Janl. 20. 19.11.

Effect of pituitary growth hormone on the thumectomized rat. With Willian $O$ Reinhardt \& Walter Marx.) Proc soc. Exper. Biol. \& Med. f(i:[1]:f1, Mar.. $19-11$.

Hormone content of pitnitaries of nestrinised rats. With Mirian E. Simpon, duat. Recrd. 79 (sแ1). 2):57. Mar. 25. 1911.

Las substanciar genartorripicas de la antero hipófisis. Rev. méd. de Rosario 31:311-314. Apr., 19 [1.

Influence of lactogenic prepanations on pro duction of ratumatic placentoma in the rat. With Viriam li. Simpson \& W'illiam R. Lyous.) Proc. Soc lisprer. Biol. \& Veal $16: 580-590.17)+.19+1$.

Growth and gratsing of rate with total " hiltate factor" and with pantothenic acid. Ilith (ilacles 1. Emeroun.) Proc Goc. Baper. Biol.

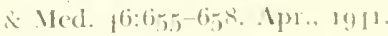

Cofrelation of hiseological dillerentiation with leginniug of function of devetopins throbid gland of frog. Mith lubres (a) man. Prox. Soc. Fixper. Biol. \& Verd. 17 $103-106.1 \mathrm{H}, 1 \mathrm{r}, 1911$. 
Studies on pituitary lactogenic hormone. V. Reactions with iodine. (With Choh Hao Li \& William R. Lyons.) Jl. Biol. Chem. 139: 43-55. May, 1941 .

Vitamin E activities of some compounds related to $a$-tocopherol. (With Max Tishler.) J1. Biol. Chem. 139:241-245. May, 1941.

Anterior pituitary hormones which favor the production of tratumatic uterine placentomata. (With Miriam E. Simpson, William R. Lyons \& Kaisa Turpeinen.) Endocrinology 28:933-945. June, 19.1.

Studies on the salt-treated adrenalectomized rat. (With Evelyn Anderson \& Michael Joseph.) Amer. J1. Physiol. 133:P196-P197. June 1, 1911.

Phosphorus metabolism of the musculature of E-deficient suckling rats. (With Gwei Djen Lu \& Gladys A. Emerson.) Amer. Jl. Physiol. 133: $\mathrm{P}_{3} 67-\mathrm{P}_{3} 68$. June 1, 1941.

O hormônio de crescimento do lobo anterior da hipófise. Resha. clín.-cien. 10:199-201. June 1, 1941 .

Prophylactic requirement for alpha-tocopherol in male and female rats. (With Gladys A. Emerson.) Jl. Nutrit, 21(supp.): 15-16. June 10,1941 .

La hormona de crecimiento del lóbulo anterior de la hipófisis. Medicina (Bucuos Aires) 1:368-374. July, 1941.

Effect of the pituitary growth hormone on the epiphyseal disk of the tibia of the rat. (With Robert D. Ray \& Hermann Becks.) Amer. Jl, Pathol, 17:509-528. July, 1941.

Studies on pituitary lactogenic hormone. VI. Molecular weight of the pure hormone. (With Choh Hao Li s. William R. Lyons.) Jl. Biol. Chem. 140:43-53. July, 1941.

Growth lormone of the anterior lobe of the pituitary gland. Jl. Amer. Med. Assn. 117: $287-291$. July 26,1941 .

Mechanism of action of estrogens on insulin content of the rat's pancreas. (With Heinz L. Fraenkel-Conrat, Virgil V. Herring \& Miriam E. Simpson.) Proc. Soc. Exper, Biol. \&. Med. 48:333-337. Oct., 1941.

Inadequacy for mice of a synthetic diet supplemented with all known vitamin B factors. (With Elizabeth Troescher-Elam.) Proc. Soc. Exper. Biol. \& Med. 48:519-555. Dec., 1941 .

Influence of lactogenic preparations on mammary glands and time of vaginal opening in young rats. (With Wm. R. Lyons \& M. E. Simpson.) Proc. Soc. Exper. Biol. \&. Med. 48:634-637. Dec., 1941 .

Duality of pituitary gonadotrophins. Effects of FSH-ICSH mixture on hypophysecto- mized male and female rats. (With $\mathbf{H}$. Fraenkel-Conrat, C. H. Li \& M. E. Simpson.) Proc. Soc. Exper. Biol. \& Med. 48:723726. Dec., 1941.

The effect of different dose levels of growth hormone on the tibia of young hypophysectomized female rats. (With Edwin A. Kibrick, Hermann Becks \& Walter Marx.) Growth 5:437-447. Dec., 1941 .

The early effect of hypophysectomy and of immediate growth hormone therapy on endochondral bone formation. (With Hermann Becks, Edwin A. Kibrick \& Walter Marx.) Growth 5:449-456. Dec., 1941.

Time of beginning of function in the thyroid glands of fetal rats. (With Aubrey Gorb)man.) Anat. Recrd. 81 (supp.):95-96. Dec. 26, 1941 .

\section{2}

The effect of thiol compounds on the activity of lactogenic hormone. (With Heinz Fraenkel-Conrat \& Miriam E. Simpson.) Jl. Biol. Chem. 142:107-117. Jan., $194^{2}$.

Bioassay of the growth homone of the anterior pituitary. (With Walter Marx \& Miriam E. Simpson.) Endocrinology 30:1-10. Jan., 1942.

Effect of purified pituitary preparations on liver weights of hypophysectomized rats. (With Heinz L. Fraenkel-Conrat \& Miriam E. Simpson.) Amer. Jl. Physiol. 135:398403. Jan. I, 1942.

Effect of purified pituitary preparations on the insulin content of the rat's pancreas. (With Heinz L. Fraenkel-Connat, Virgil V'. Herring \& Miriam E. Simpson.) Amer. Jl. Physiol. 135:404-410. Jan. 1, 1942.

The effect of growth hormone injections on the costochondral junction of the rat rib. With Robert D. Ray \& Hermann Becks.) Anat. Recrd. 82:67-75. Jan. 26,1942 .

Effect of crystalline estrin implants on the proximal tibia and costochondral junction of young female rats. (With Miriam E. Simpson, Edwin A. Kibrick \& Hermann Becks.) Endocrinology 30:286-294. Feb., 1942.

Response to growth hormone of hypophysectomized rats when restricted to food intake of controls. (With Walter Marx, Miriam E. Simpson \&. William O. Reinhardt.) Amer. Jl. Physiol. 135:614-618. Feb. 1, 1942.

Physico-chemical characteristics of the interstitial cell stimulating hormone from sheep pituitary glands. (With Choh Hao Li \& Miriam E. Simpson.) J1. Amer. Chem. Soc. $6_{4}: 3^{6} 7-369$. Feb. $\left[6_{]}, 1942\right.$. 
Growth hormone of the anterion fobe of the pituitary gland. (Republication of preser with same tille issued in previons ycar.) In Glandular Physiology and Therapy: a symposium prepared under the ausprices of the Conncil on Pharmary and Chomistry of the Ameriran Medical Association. (Chi(ago: 1912) 19-31. [Mar.\}, 1942.

Lack of effect of thyroxin on blood sugats and glycogen stores of fasted hypophyscctomized rats. (With Virgil V. Herring \& Heinz Fraenkel-Conrat.) Endocrinology 30 : $483-48$. . Mar.s 1942 .

Effect of thyroxin on the insulin content of the rat's pancreas. (With Heinz FraenkelComrat, Virgil V. Herring \& M. E. Simpson.) Endocrinology 30:485-486, \ar., 1972.

The bone histology of adult male rats thyoparathyoidectomized when one month of age. With Hermann Becks \& Edwin A. Kibrick.) Jl. Exper. Zool. 89:297-303. Nar. 5,1912 .

Increased liver arginase on administration of adrenocortical and corticotropic hormones. (With Hcinz. Fraenkel-Conrat.) Science (n.s.) 95:305-306. Nar. 20, 1942.

Lobulo-alveolar mammary growth in hypophrsectomized rats. (With Wm. R. Lyons \& Niriam E. Simpson.) Anat. Recrd. 82:430. Mar. 25, 1942.

Synergism between thrrotropic and growth hormones of pituitary. Body weight increase in hypophysectomized rat. (With
Walter Marx e. Minian F. Simpson.) Prox.

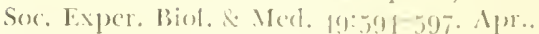
1912.

Urinary gomatotrophins in nomal nem. (With Aubrey Gorbman. J'sue. Soc. Fixper. Biol. \& Med. 49:6-1 - 15-8. 1pr., 1912.

Biological properties of pituitary interstitial. cell-stimulating hormone ICSIl. Ilith Miriam E. Simpson \&. (inchl H:20 1,i.) Lndocrinology 30:969-0)-6. Junc, 1912.

Comparison of methods for standardization of pituitary inferstitial-cell-stimulating hommone (ICSII). (With Mirian $\mathrm{E}$. Simpson \& Cluoh Hao I.i.) Endocrinologs 30:977-98.1. June, 1919.

Influcure of growth hormone on skelcal tissuc. Enclocrinology go:S1021. Junc, 1912.

Effects of crestalline estrin imptants on the tilia of young hypophrsectomized female rats. With Edwin A. Kilnick. Miriam $\mathrm{F}$. Simpson \& Herman,n, Becks, Endocrinolosy 31:93-96. July, 1912.

Effect of thyroxin and the anterior pituitary growth hormone on cudochondral ossification; species used: the rat. With Hermann Becks, Robert D. Ray \& Miriam I:. Simpson.) Archs. Pathol. 31:331-3.7. Aug., $19 t^{2}$.

Effects of purified pituitary preparations on the nonprotein nitrogen constituents of blood. (With Jane Fraenkel. Comat \&. Heins. Fraenkel-Conrat.) Amer. Jl. Plugiol. 137: 200-212. Aug. 1, 19.2. 



\section{CONTENTS}

Kidney-Explantation Experiments in Relation to Arterial Hypertension Frederick if. Ali.en

The Influence of the Endocrine Organs on Intestinal Absorption T. L. Althiuse.

The Impact of the Introduction of Iron on Medical and Religious Thought .

Walter C. Alyarez

The Physiology of the Salt-treated Adrenalectomized Animal EvTLYN ANDERSON

Contributions to the History of the Bird's Egg Previous to Incubation, by Joamne Evangelista Purkinje Translated by GEORgE W. BARTEI.MEZ

The Localization of Lipids in Cytoplasm R. R. BEXSLEY

The Source of Equine Gonadotrophin H. H. Cole and Harold Goss

On the Female Testes or Ovaries, by Regner De Graaf 121 Translated by George W. CORNir

The Biological Standardisation of the Vitamins 139 K ATHARINE H. COWARD

The Prevention of Deafness S. J. Crowe

Gene $H$ and Testosterone in the Fowl 157 C. H. DANFORTII

The Influence of Hormones on the Sexual Behavior of Domestic Fowl . $16 \mathrm{~g}$ David E. Davis and L. V. Domm

Pituitary Gonadotrophins 183

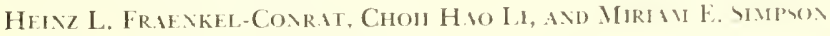

Estrogen Assay in the Human .

S. C. Frelid

Functional Interrelation of Cerebral Cortex with Basal Ganglia and

Cerebellum John F. Fultow

The Solubility of Proteins and Their Separation from Mixtures with Special Reference to Serum. Arda Aldey Green

Gonadotrophic Stimulation of the Ovaries of the Adult Rhesus Monkey 227 Carl G. Hartalan

The Pathologic, Clinical, and Biochemical Corrclation of Tumors of the Testis 
The Symballophone: A Double Stethoscope for the Comparison and Lateralization of Sound

WM. J. KERR

On the Significance of the Forgotten Thermodynamic Theorems of Carnot.

F. O. Koenig

John Banister and the Pulmonary Circulation

Sani ord V. Larkey and Owsei Temkin

Comparison of the Conditions under which Estrogens and Carcinogenic Hydrocarbons are Tumorigenic

Alexander Lipschütz

Lobulo-alveolar Mammary Growth Induced in Hypophysectomized Rats by Injections of Ovarian and Hypophysial Hormones . . . . . . 315 WM. R. LyoNs

Pulmonic Interstitial Emphysema and its Sequelae: An Anatomical Interpretation

Charles C. Macklin and Madge T. Macklin

Charles Edward Brown-Séquard

RALPiI H. MAJOR

The Undischarged Ovarian Follicle

F. H. A. Marshiali

Mechanism of the Descent of the Testicle under the Action of Sex Hormones

Thales Martins

A Hemorrhagic State in the Vitamin E-Deficient Fetus of the Rat 399 KARL E. MASON

Relationships of Sodium and Potassium to Carbohydrate Metabolism . $4^{11}$ Irvine MCQUaRrie

Harvey's Ideas of Embryonic Nutrition 427 A. W. MEYer

Observations on the Pathogenesis of Undulant Fever 437 K. F. MEYER

French Medical Education as a Legacy from the Revolution $4^{61}$ J. M. D. Olmisted

Cytological Differences between Castration and Thyroidectomy Basophils in the Rat Hypophysis .

J. D. ReEse, A. A. KonefF, And P. Wainman

Studies on the Growth of Lymph Nodes, Thymus, and Spleen in the Rat $4_{8} 7$ WILLIAM O. REINHARDT

The Self-Selection of Diets CurT P. Richter 
The Relationship of the Anterior Pituitary to the "Thyord and the

Adrenal Cortex in the Control of Carbohychate Mctabolism . . . 507 J ANE. 1. RusSell

Vesalius and Don Carlos: A Historical Footnote. 529

JoHx B. DEC. M. SAunders

Impotence as a Result of Witchcraft

HENRY E. Sigerist

The Coagulation of Blood: Quantitative Viewpoints

H. P. S.IITH

An Experimental Anatomical Sudy of Sensory Masking . . . . . 5.53 I. MACLAREN ThOMIPSON

The Effect of Progesterone and Lactogenic Hormone upon Prolongation of Pregnancy in the Lactating Mouse . . . . . . . . . 561 Kaisa TURPEINEN

Is Increased Capillary Fragility a Sign of Ascorbic Acid Subnutrition? 57 Osmo Turpeinex

The Experimental Production of Pseudohemaphroditism in the Monkey .

G. van Wagenen and James B. Hamilton

The Heart in Myxedema JAMES J. WARING

Studies on Growth of Deer Antlers: II. Seasonal changes in the male reproductive tract of the Virginia deer (Odocoilens airginianus borealis); with a discussion of the factors controlling the antler-gonad periodicity .

GEORGE B. WISLOCKI

Sex Differentiation in Heterogenous Parabiotic Twin (Ambystoma $x$ Triturus)

Emil Witschi and Harriet M. M. McCurdy

Ovum, Cycle, and Menstruation

BERNHARD ZONDEK 



\section{KIDNEY-EXPLANTATION \\ EXPERIMENTS}

\section{IN RELATION TO ARTERIAL}

HYPERTENSION

\section{By'}

FREDERICK M. ALLEN, M.D.

\section{綵}

From the

DEPARTMENT OF PHYSIOLOGY AND BIOCHFMISIRY NEW YORK MEDICAL COILEGF, NEW YORK CITY 



\title{
KIDNEY-EXPLANTATION EXPERIMENTS IN RELATION TO ARTERIAI. HYPERTENSION
}

\begin{abstract}
A TER various experiences with Minkowski's method of explanting the uncinate process of the pancreas under the skin, ${ }^{1,2}$ this method was first extended to the spleen about 1916 . The purpose then was to provide a simple means, without laparotomy, of in jecting various substances, particularly sugar. into the portal circulation. This could be accomplished by injecting into the splenic parenchyma by needle puncture; or by a small skin incision the injection could be made into a branch of the splenic vein. This method was cliscussed at the time with Dr. H. M. Evans, and though the experiments were broken off because of adverse conditions it seems possible that the method may still be found useful for some purposes.

Explantations of the spleen and kidney were used for other purposes in Morristown from 1922 onward. Loesch, Witts and Zimmermann ${ }^{3.4}$ in their studies of splenic physiology found that the normal rolume changes of the organ were hindered by adhesions to the subcutaneons tissue, and. after the return of Dr. Witts to England, Barcroft and Stephens orercame this difficulty by the remarkable device of placing the naked spleen outside the sin and demonstrating that it can survive and function thus indefmitely. Explantations of the kidney were mentioned in several publications ${ }^{6, \pi, 8}$ and also in unpublished statements at medical meetings, particularly at the congress on kidney diseases in Minneapolis in 1930. According to the papers published by Rhoach. Van Slyke, and other writers, "10,11 they apparently derived sugentions only from the Barcroft and Stephens work, ${ }^{5}$ which was by an altogether different method, and knew nothing of the above-mentioned explantations at Morristown and at the Rockefeller Institute Hospital, of which the "Rhoads methol" was a precise copy. Previous reminder ${ }^{12,13}$ of these facts have passed unnoticed.

In this renal-vascular research, now resumed after long suppresion, kidney explantation is being employed for some of the purposes for which it was originally devised. The present paper will correlate the former work with that now in progress, by giving a synopsis, in the nature of a preliminary communication, of results to be described in a series of forthcoming papers. The topic may be divided into: (1) diet in relation to blood pressure and kidnev vize: (2) production of acute and chronic hypertension: (8) pathology of the kidneys.
\end{abstract}

\section{Diet in Rilation to Bloon Prisstre and KinNiy SIZ}

Both femoral and brachial blood pressures are eletemined hy a newly reported auscultatory method ${ }^{1 t}$ suitable for frequent readings without distubince. 'The' three dimensions of explanted kidneys can be measured with calipers within limits of error which are appreciable but still not sulficient to conluse the 
actual changes that occur. Table 1 illustrates typical effects on the blood pressure as observed in individual animals.

On the basis of fuller data along these lines in a forthcoming paper ${ }^{15}$ it is concluded: (1) The kidneys are subject to transitory functional changes of volume, which according to available evidence are most probably due to hyperemia. (2) The blood pressure of dogs also fluctuates in connection with feeding. (3) Protein meals may cause no change in kidney volume, or, if the

TABLE 1

Examples of Dietary Influence on Blood Pressure and Kidney Dimensions.

Dog No. i, Normal; No. 2, with Chronic Hypertension.

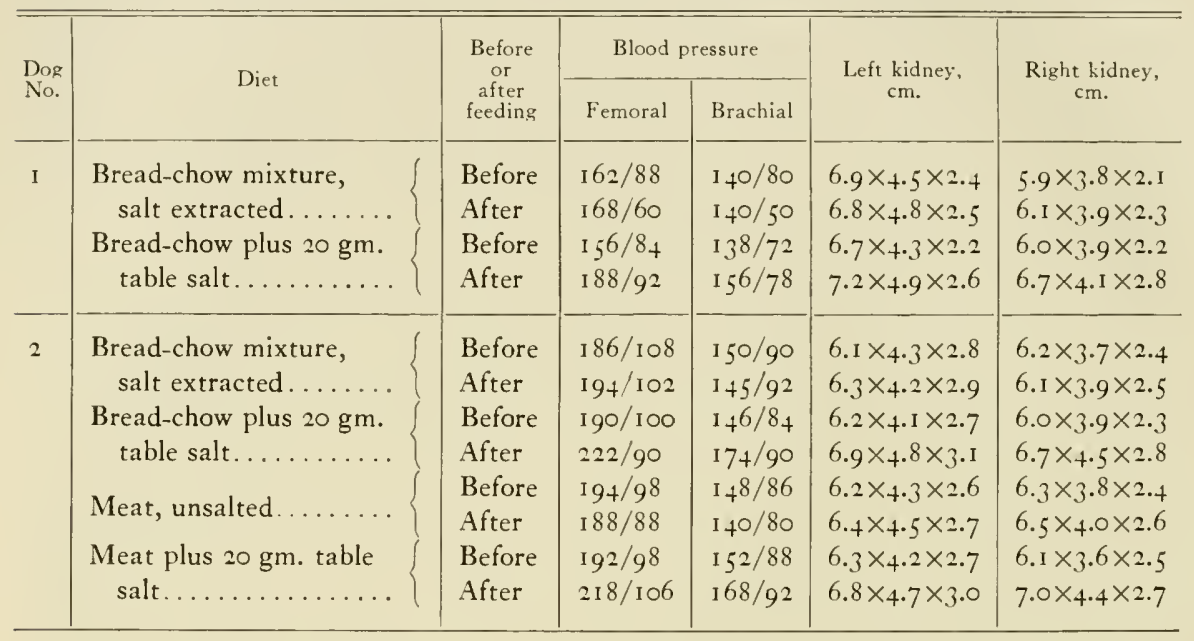

quantity of protein is sufficiently large, may cause a moderate increase, but the blood pressure tends to fall. (4) Salt, water, or especially the two together, regularly produce increases in both blood pressure and kidney volume. (5) The changes in blood pressure and kidney volume are not strictly parallel, inasmuch as: (a) they are not strictly simultaneous; $(b)$ an increase of one may accompany a decrease of the other, as mentioned under protein feeding; $(c)$ there may be discrepancies in degree; for example, with salt the increase in kidney volume is similar in normal and hypertensive dogs but the rise of blood pressure is slight in the former and much more marked in the latter.

\section{Acute and Chronic Hy'pertension}

In experiments from 1916 onward, ${ }^{16}$ it proved possible to produce diabetes by brief clampings of the blood supply of a large pancreatic remnant in successive laparotomies. Such experiments, applied to renal-vascular disease, have a theoretical relation with the arterial spasms which are clinically familiar both in local areas and in the general circulation.

The pedicles of explanted kidneys can easily be clamped by inserting the jaws of elastic intestinal forceps subcutaneously, as described by Loesch. ${ }^{3,4}$ In 
the recent resumption of this wort a still simpler method has becul introluced by the use of either clamps or rubloce ligatumes applied outside the skin. The results, presented in a paper before the American Society for Experinental Pathology in April, 1941, are divisible into acute and chonic hypertension.

Table 2 illustrates the results when the pedicles of explanted kidneys are clamped or ligated by this method. There is an elevation of blood pressure, rising sharply to a maximum, holding a plateau for a variable time, and in the course of several hours declining slowly but not to normal. Whenever the clamp or ligature is removed during this time. the pressure falls rapidly, so that in the course of ten to twenty minutes it is found near or frequently be-

TABLE 2

Male Dog, i i kg. Aclite Hypertension with Clamping of Pedicles of Explanted Kidneys, for 35 Minutes.

\begin{tabular}{|c|c|c|}
\hline \multirow{2}{*}{ Time } & \multicolumn{2}{|c|}{ Blood pressure } \\
\hline & Femoral & Braclial \\
\hline Before clamping & $16+66$ & $1+880$ \\
\hline Before release... & $262 / 132$ & $196 / 120$ \\
\hline 5 minutes after release. & $212 / 108$ & $165 / 100$ \\
\hline 20 minutes after release. & $175 / 7^{8}$ & $1+5 / 88$ \\
\hline 2 hours after release... & I $56 / 70$ & $1+0 / 9^{2}$ \\
\hline
\end{tabular}

low the original level. There are reasons for regarding this hypertension as nervous in character, apparently comprising both psychic and reflex components. The slow decline of pressure during prolonged clampings is attributed to nervous paralysis. The sharp fall when the clamps are remored evidently represents cessation of the nervous stimulus.

This form of acute hypertension is interesting for several reasons. It may be regarded as the result of an artificial spasm in the renal circulation, although specificity is lacking, as explained below. It is also a hypertension occurring in the absence of any possible substance derived from the kidneys. Furthermore, the results are precisely opposite to those obtained under special conditions by Taquini ${ }^{17}$ and Prinzmetal. ${ }^{18}$ They are not necessurily contradictory. because the fact of humoral hypertension, in particular the protuction of a hypertensive substance in the totally asphyxiated kidney, las been established in carefully controlled experiments. The question whether this substance is identical with that which is produced in partial renal apphyia of the coldblatt type, or whether it can rank as anything more than a post-mortem product, still remains open. The humoral factor is demonstrated in "pulue" experiments in which, by anesthesia or otherwisc. nervous and other interfering factors are excluded as completely as possible. The experiments with explanted kidneys are important as showing the behavior of the intact animal. In this intact state there is no humoral hypertension following total renal asphrsia. 
cither because the response is somehow different or because of compensation and adjustment by an overwhelmingly powerful nervous control. If a delayed hypertension follows extremely long ligations of explanted kidneys, such as six or seven hours, there is evidence that this is merely a nervous or psychic phenomenon due to the pain of local inflammation. Attempted general theories of hypertension must therefore take account of the complexity of blood pressure regulation.

The proof of the specificity of the hypertensive substance obtained from kidney extracts or from the asphyxiated living kidney is that it is not obtainable from any other organ. One of the proofs of the nervous character of the above-described form of acute hypertension is that it is nonspecific. The results of kidney ligation are fully duplicated by ligations of the testes, legs, tail and other parts. A tourniquet on the tail offers the most convenient routine method, because of absence of the paralysis which results in the legs. With any of these methods there is the same acute hypertension as with the kidneys and also the same rapid fall after removal of the tourniquet. Particularly with ligations of the scrotum for three to four hours and of the tail for seven or eight hours it is possible to demonstrate a secondary hypertension following removal of the tourniquet, due to inflammatory pain, especially in nervous dogs. With this exception, a hypertension following restoration of circulation is as completely lacking with these various organs as it is with the kidney.

When the ligations are repeated, whether at intervals of one or many days, the same acute hypertension continues to occur and there is no loss of response with either the kidneys or the tail. But no chronic hypertension results in the case of the tail, as far as observable with frequently repeated ligations for six months. Also, no chronic hypertension has yet been obtained with ligations limited to one kidney, leaving the other intact. Chronic hypertension is obtainable, as described years ago by Loesch, by repeated clamping of the pedicles of both kidneys, or of one kidney when the other has been removed. The reasons why the original Loesch method is more effective than clamping or ligation outside the skin, also why some dogs develop uremic tendencics while the majority retain good kidney function, and various other questions remain at present undecided because of the long suppression of the work.

\section{Pathology of the Kidneys}

Loesch was not only the first to produce true chronic renal hypertension in dogs by means of the above-described method of intermittent clamping, but also as a pathologist he gave special attention to the accompanying anatomic changes in the kidneys. Figures 1, 2, and 3 are reproduced from microphotographs prepared by Loesch, and his papers sufficiently pointed out the similarity of such lesions with the infiltrating and sclerosing processes found in some human cases with hypertension.

In the recently resumed research the pathological examination has been undertaken by Dr. W. E. Youland. In view of the intervening developments 
in the subject, interest may now be focused on the occurrence of hypertension with minimal degrees or even absence of kidney lesions according to the (ustomary examination of routincly stained sections. Any conchusions must be withheld during a study of possible funer changes, such as the Volhand-Fahs pre-sclerosis, particularly Goormaghtigh's afibrillar juxtaglonerular bodies.

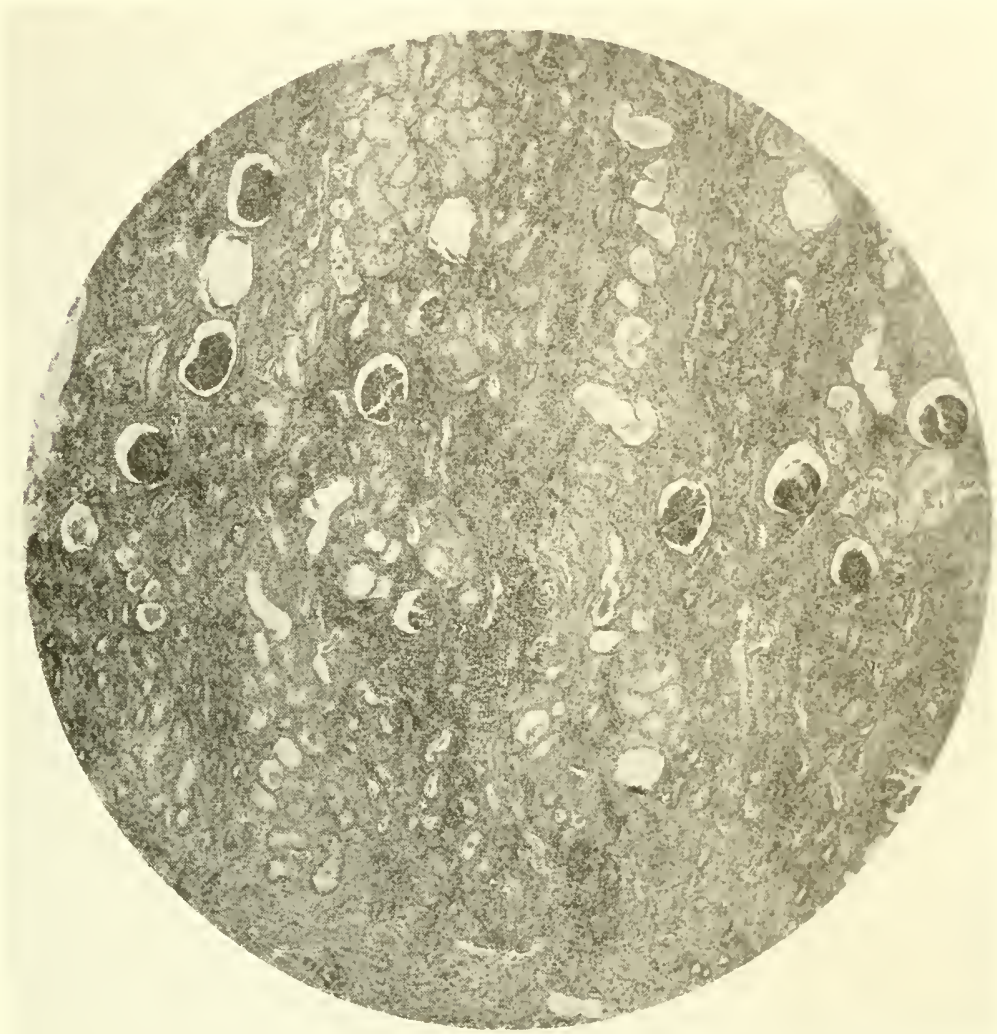

Fig. 1. Example of lesions in dogs with chronic hypertension. produced by intermittent clamping of kidney pedicles (Loescli).

The Loesch method was not only earlier than that of Goldblatt but ma! also be held superior to it in many respects as a reproduction of clinical essential hypertension. One of these respects is the absence of the gross atrophy of the kidneys, which in itself sharply distinguishes the Goldblatt condition from all but rare cases in man. Explantation also furnishes a neans of obtaining any desired series of biopsy specimens with a minimum of inconvenience or disturbance, and thus of tracing the progress of changes which may be either causative of or secondary to the hypentension. For this purpore an experimental form of hypertension which resembles the clinical essential hyper tension in the absence of gross renal abnormalities has obvious importance. 


\section{Summary and Conclusions}

1. Explantation experiments in dogs reveal that the kidney is an organ of variable size, with measurable changes dependent upon diet, probably due to changes in blood supply. The enlargement is comparatively slight with protein and more marked with salt and water.

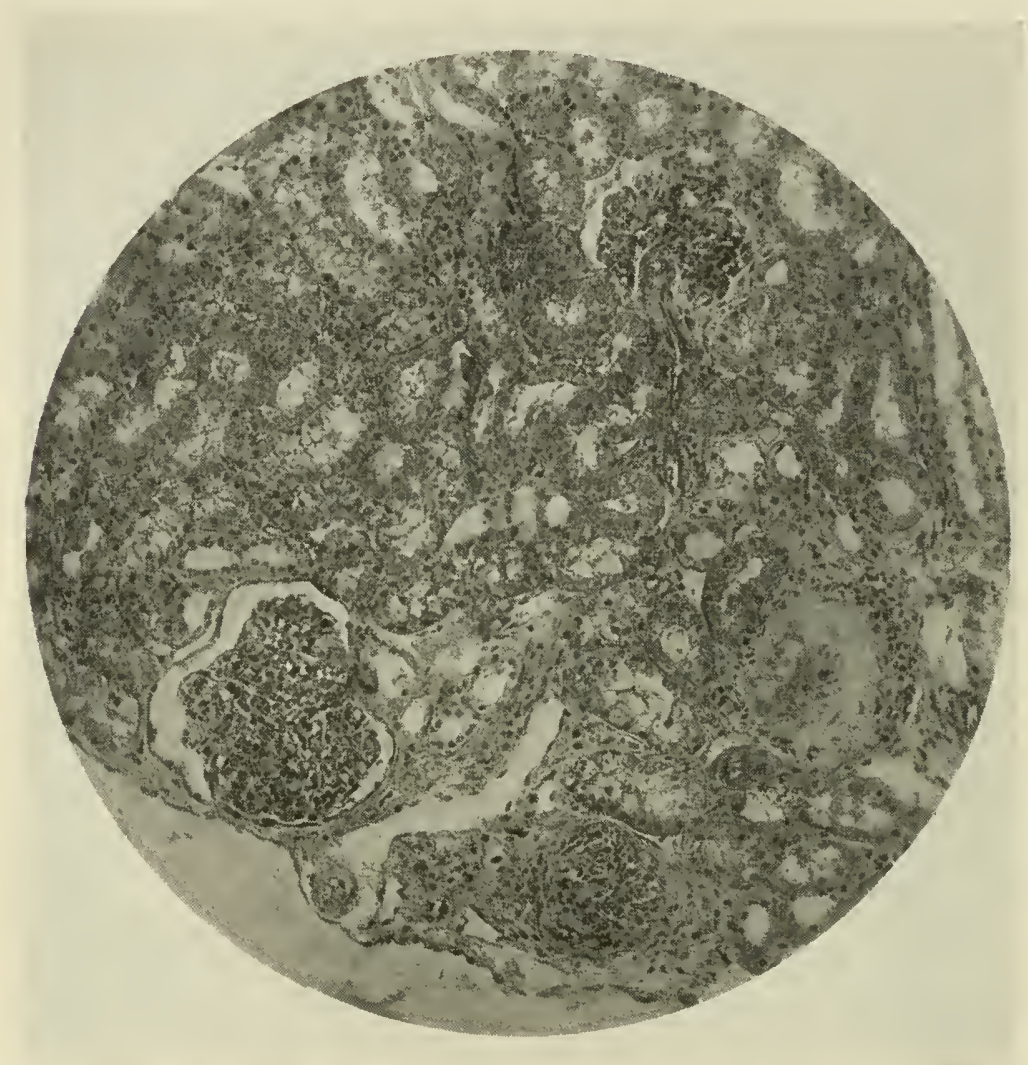

Fig. 2. Example of lesions in dogs with chronic hypertension, produced by intermittent clamping of kidney pedicles (Loesch).

2. The blood pressure of dogs, determined by auscultation, is also subject to fluctuations due to diet. The slight rise from salt and water in normal dogs is magnified in those with chronic hypertension.

3. An acute hypertension of nervous character is produced by clamping or ligation of explanted kidneys and also of other organs such as the testes, legs, and tail. The opposite condition which has been described by former writers under special conditions, namely a rise of pressure following restoration of circulation, due to chemical substances flushed out from the asphyxiated kidneys, never occurs in the intact animal. 
4. The production of chronic hypertension by intermittent clamping of the pedicles of explanted kidneys, described by Loesch prior lo Goldhlatt's work, is confirmed.

5 . One of the features of superionity in the Loesch methos is its suitability not only for the above-described physiological observatioms but also for studies of renal pathology, which are now in progress.

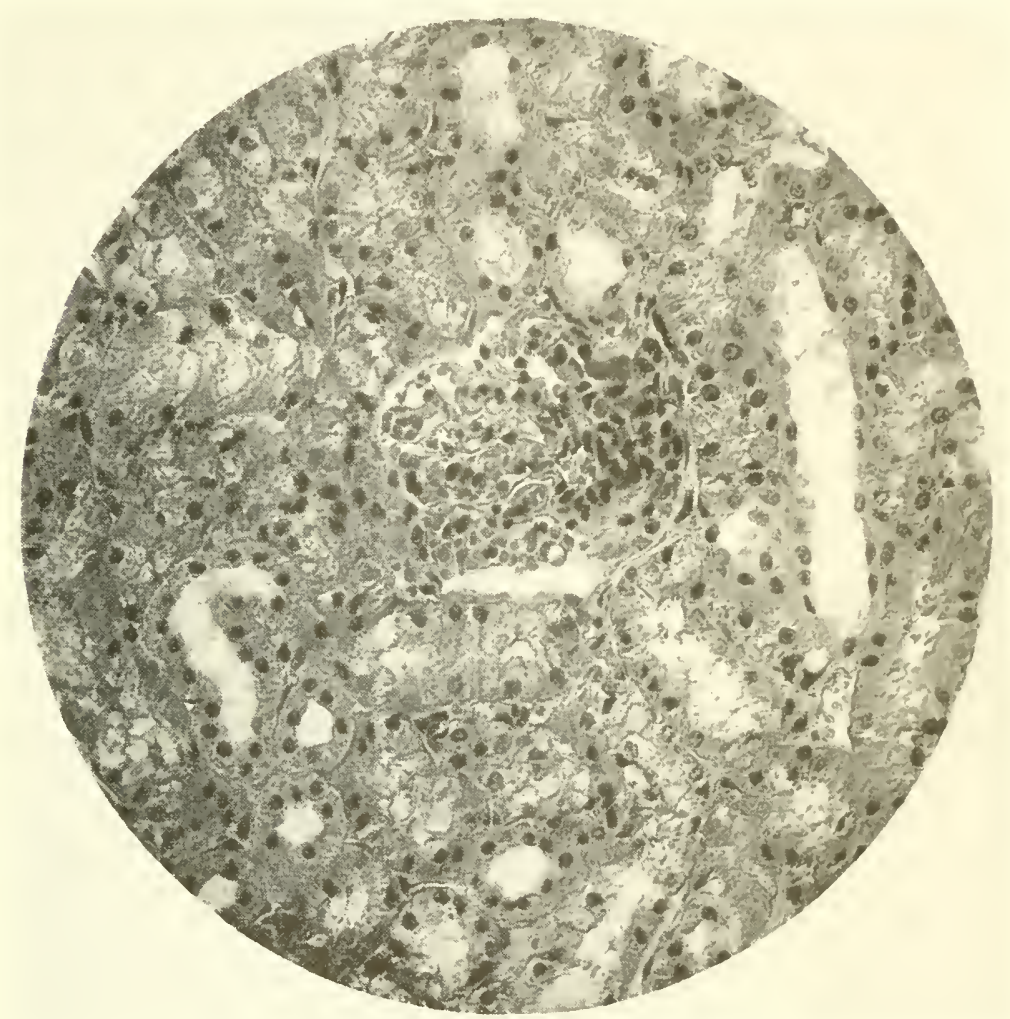

Jig. 3. Example of lesions in dogs with chronic hypertension, produced by intermittent clamping of kidney pedicles (Loesch).

\section{REFERENCES}

1. Allen, F. M.: Studies concerning Glycosuria and Diabetes (Cambridge, Mass.: rg13).

2. Allen, F. M.: Jl. Metabol. Resrch. 1:221, 1922.

3. Loesch, J.; Witts, L. J., and Zimmermann, A.: J1. Metalxol. Resich. 6:297, 192 I.

4. Loesch, J., and Witts, L. J.: Jl. Metabol. Resrch. 6:339, 1924.

5. Barcroft. J., and Stephens, J. G.: Jl. Plyysiol. 64:1, 1927-28.

6. Allen, F. M.: Jl. Metabol. Resich. 7/8:217, 1925-26.

7. Loesch, J.: Archs. Pathol. 4:495, 1927.

8. Loesch. J.: Zntrlblt. f. imner. Med. $54: 145,177,1933$.

9. Rhoads, C. P'.: Science (11....) 73:117, 1931 .

1o. Rhoads, C. P.: Amer, Jl. Physiol, 109:32 f, 193 I. 
11. Rhoads, C. P.; Van Slyke, D. D.; Hiller, A., and Alving, A. S.: Amer. J1. Physiol. 110:392, $1931-35$.

12. Allen, F. M.: New York State Jl. Med. $3^{8: 14}, 193^{8 .}$

13. Allen, F. M.: Trns. Assn. Amer. Physns. 54:80, 1939.

14. Allen, F. M.: Jl. Laborat. \&. Clin. Med. 27:371, 1911.

15. Allen, F. M., and Cope, O. M.: J1. Urol. 47:751, 1912.

16. Allen, F. M.: Jl. Metabol. Resrch. $1: 89,165,1922$.

17. Taquini, A. C.: Amer. Heart J1. 19:513, 1940.

18. Prinzmetal, M.: Jl. Exper. Med. 72:763, 1940. Amer. Heart J1. 20:525, 1940. Ibid. 21:319, 1911. 


\section{THE INFLUENCE OF THE ENDOGRINE ORGANS \\ ON INTESTINAL ABSORPTION}

$$
\text { By }
$$

T. L. Althausen, M.D.

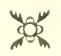

From the

DIISION OF MEDICINE

UNIVERSITY OF CAIIFORNIA MHDICII SCIIOOL

S.IN IR.1NCISCO 



\section{THE INFLUENGE OF THE ENDOCRINE (ORGANS ON INTESTINAL ABSORPTION}

Qeveral of the glands of internal secretion influence intestimal absorption. $\checkmark$ In table 1 are recorded the rates of absorption for dextrose in female rats subjected to removal of the thyroid, the adrenals, the liypophysis, or the ovet ries. These data were obtained by experiments on young rats weighing luttween $15^{\circ}$ and $25^{\circ} \mathrm{gm}$. which, after they had been fasted for went-lour hom to clear their intestines, were given by stomach tube known amounts of various

T.ABLE 1

Intestinal Absorption of Dextrose in Female Rats Following Remoral of Thyroid, Adrenals, Oraries, or Hypophysis

\begin{tabular}{|c|c|c|}
\hline Experimental conditions & No. of rats & $\begin{array}{l}\text { 112. absorbed } \\
\text { in: } 1 \mathrm{hr} \text {. } \\
\text { per } 100 \mathrm{gm} \text {. of wt. }\end{array}$ \\
\hline Normal.... & 19 & $171 \pm I_{4}^{*}$ \\
\hline Thyroidectomized. & 8 & $91 \pm 5$ \\
\hline Adrenalectomized. & 15 & $87 \pm 2.3$ \\
\hline Spayed ......... & 9 & $12,3 \pm 26$ \\
\hline Hypophysectomized. & 17 & $105 \pm 24$ \\
\hline
\end{tabular}

* Standard deviation.

substances. After a certain period of time, the resiche in the digestive tract was determined and the amount absorbed per $100 \mathrm{gm}$. of weight was calculated.

After it had been ascertained that a particular endocrine organ plays a part in intestinal absorption, experiments were devised in an attempt to determine the mechanism of its action. Our findings are set forth under the headings of the various endocrine organs.

The Thyroid Gland. It has been shown by us that intestinal absorption of dextrose not only is decreased by thyroidectony in rats but also is increased by administration of thyoxin to nommal animals. Therefore the effect of the thyroid gland on absorption of various substances was studied in rats rendered hyperthyroid by daily injections of doses of thyroxin that increased the basat metabolic rate to approximately 50 per cent plus.

The data in table 2 show that administration of thyord hormone increases the intestinal absorption of dextrose, galactose, starch, and oleic acid. These substances enjoy preferential absorption thromgly a chemical mechanism in the intestinal mucosa and are susceptible to phosphorylation. Administration of thyroid hormone does not increase the absorption of xylose. alanin. calcium lactate or thiamine chloride-substances which alle absorbed by simple dillusion and which are incapable of phosphorylation. These experiments indicate that the thyroid gland infuences alsorption not by increasing lle permeabilits

$$
[1,3]
$$


of the intestinal mucosa in general but by stimulation of the chemical mechanism in the intestinal mucosa which is responsible for preferential absorption. Other experiments ruled out as factors which significantly accelerate absorption: relative starvation, depletion of carbohydrate, a rise in body temperature, an increase in basal metabolism, a rise in the velocity of the blood flow, acceleration of gastric emptying, stimulation of intestinal peristalsis, and adjustment to an increased food intake. The last factor was shown to be unimportant by an experiment according to which, when food intake of hyperthyroid rats was limited to that of normal rats, the rate of absorption for dextrose remained

TABLE 2

Intestinal Absorption of Various Food Elements in Normal and in Hyperthyroid Female Rats

\begin{tabular}{|c|c|c|c|c|c|}
\hline \multirow[b]{2}{*}{ Substance } & \multirow{2}{*}{$\begin{array}{l}\text { Time of } \\
\text { absorption } \\
\text { in hrs. }\end{array}$} & \multicolumn{2}{|c|}{ Normal rats } & \multicolumn{2}{|c|}{ Hyperthyroid rats } \\
\hline & & No. & $\begin{array}{l}\text { Mg. absorbed } \\
\text { per } 100 \mathrm{gm} \text {. wt. }\end{array}$ & No. & $\begin{array}{l}\text { Mg. absorbed } \\
\text { per Ioo gm. wt. }\end{array}$ \\
\hline Dextrose......... & I & 19 & $171 \pm 1 t^{*}$ & 8 & $28+ \pm 30$ \\
\hline Galactose........ & I & 8 & $187 \pm 27$ & 8 & $273 \pm 18$ \\
\hline Starch & I & 10 & $126 \pm 24$ & 10 & I $96 \pm I_{4}$ \\
\hline Oleic acid ....... & 3 & 10 & $27^{1} \pm+4$ & I I & $593 \pm 125$ \\
\hline----- & ---- & - - & ---- & - - & $--\cdots--$ \\
\hline Xylose... & I & 8 & $31 \pm 3$ & + & $35 \pm 3$ \\
\hline Alanin.......... & I & 8 & $9^{6 \pm 6}$ & 8 & $9+ \pm 10$ \\
\hline Calcium lactate. & 6 & IO & $15 . I \pm 2 . I$ & I 2 & $16.3 \pm 1.5$ \\
\hline Thiamine chloride. . & 2 & 6 & $2 \mathrm{I} \pm 0.002$ & 6 & $2+ \pm 0.002$ \\
\hline
\end{tabular}

* Standard deviation.

abnormally high $(252 \pm 10 \mathrm{mg}$.). A separate experiment with repeated intragastric feedings proved that the increased rate of absorption persisted for at least three hours after administration of dextrose was begun.

Experiments were carried out on normal and on hyperthyroid rats to test a possible mechanism of action of the thyroid hormone in intestinal absorption based on the theory of Verzar ${ }^{2}$ that preferential absorption of sugars and fats is due to phosphorylation in the intestinal mucosa. For the purpose of inhibiting phosphorylation locally in the mucosa, $50 \mathrm{mg}$. of phlorizin were added to a solution of dextrose, to oleic acid, and to olive oil. The phlorizin reduced the absorption of these substances (table 3 ) to the same level in normal and in hyperthyroid rats-an indication that the entire mechanism of preferential absorption of these substances was paralyzed. This conclusion was confirmed by the observation that the reduced rate of absorption for glucose induced by phlorizin was equal to that for xylose, which is absorbed by simple diffusion. The possibility that phlorizin may decrease intestinal absorption in general was ruled out by showing that it did not affect the absorption of calcium lactate.

In an effort to elucidate further the mechanism of selective intestinal absorp- 


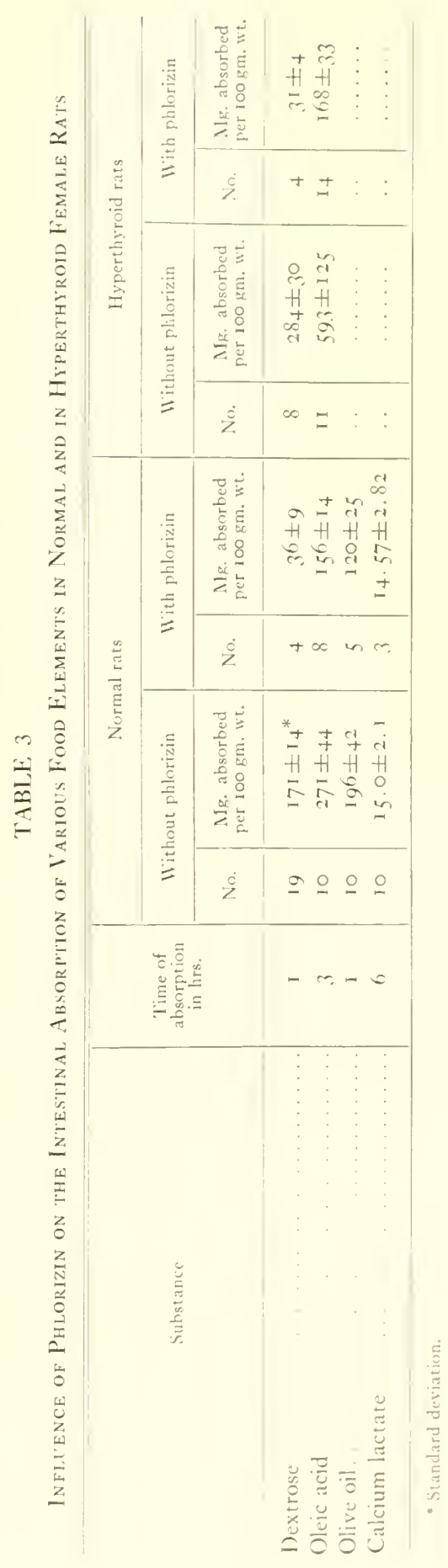


tion of sugars, we studied the concentration of the various fractions of acidsoluble phosphate in the intestinal mucosa during absorption of dextrose in normal, in hyperthyroid, and in thyroidectomized rats, and compared it to that observed during the absorption of sodium chloride. ${ }^{3}$ The results indicate that the absorption of glucose is accompanied by a slight increase (15 per cent) in the acid-soluble phosphate esters over that observed during the absorption of sodium chloride. On the other hand, the rate of absorption of dextrose as influenced by the thyroid gland had no statistically significant effect on the concentration of these esters. A positive correlation between the concentration of various phosphates in the mucosa and the rate of absorption would have supported the hypothesis that phosphorylation is concerned with selective absorption of dextrose. A lack of correlation need not militate against this assumption because, if the velocity of formation and the velocity of disappearance of the esters are equal, the concentration of the hexose phosphate will be governed by the conditions of the steady state. Accordingly, a difference in the rate of turnover of the acid-soluble phosphates need not be accompanied by a change in concentration.

The question has been raised whether a similarity exists between the mechanism of absorption of dextrose in the intestinal mucosa and that of resorption of dextrose from the glomerular filtrate in the renal tubule., ${ }^{4,5}$ In both instances absorption involves a selective and active transfer of dextrose across an epithelial barrier at a rate independent of concentration. Also, phlorizin decreases the rate of absorption of dextrose in both organs. Therefore a study of the rate of absorption of dextrose in the renal tubules of three female dogs was made by the method of Shannon and Fisher ${ }^{6}$ before and after the dogs were rendered hyperthyroid. The renal tubules of the first dog resorbed 170 $\mathrm{mg}$. of dextrose (average of four experiments) in the nomal state and $250 \mathrm{mg}$. (average of three experiments) after administration of thyroxin. In the second $\mathrm{dog}$, thyroxin increased tubular resorption from $200 \mathrm{mg}$. (average of three experiments) to $280 \mathrm{mg}$. (average of two experiments). ${ }^{7}$ In the third dog the figures were $214 \mathrm{mg}$. (average of four experiments) and $335 \mathrm{mg}$. (average of two experiments), respectively. The possibility that this increase was due to an elevation of body temperature was ruled out as far as possible by measurements of the rectal temperature.

This experiment supports the conception of an essential similarity between the absorptive mechanism of dextrose in the intestinal mucosa and in the renal tubule. It also strengthens the hypothesis that preferential intestinal absorption of dextrose takes place through phosphorylation because Kalckars and Colowick, Welch and Cori ${ }^{9}$ demonstrated that extracts of the kidney possess the ability to phosphorylate dextrose. Finally, the data obtained from these experiments offer strong evidence in favor of the specificity of the stimulating action of the thyroid hormone on selective absorption of dextrose in the intestine and in the kidneys; they rule out the indirect influence of any physiological mechanism which these two organs do not share. 
The results of our experinents with induced hyperthyroidism and hypen. thyroidism in rats were confirmed by our work on patients with spontaneous hyperthyroidism and with myxedema. The rate of intestinal absorption in man was determined by administering a solution of galactose by mouth and subsequently measuring at intervals the amount of galactose in the blood. On this basis a new diagnostic test for the activity of the thyoid gland was devised which, in a series of 130 patients with hyperthyroidism and of 97 persons without thyroid disease, proved to be as reliable as are determinations of the basal metabolic rate. ${ }^{10}$ This work also furnished certain therapeutic applications in clinical hyperthyroidism, especially by establishing that glycosuria, postprandial hyperglycemia, and high dextrose-tolerance curves in patients with hyper. thyroidism do not indicate the coexistence of diabetes mellitus unless the fasting blood sugar is also high. ${ }^{11}$ This is important because dietary limitation of carbohydrates and administration of insulin are contraindicated in hyperthyroidism. Finally, our data point to reduced intestinal absorption as a logical explanation for the low dextrose-tolerance curves in patients with myxedema. Heretofore these usually had been ascribed to greater than normal utilization of dextrose.

The Adrenals. Wilbrandt and Lengye $\mathrm{f}^{12}$ found that adrenalectomy decreases the intestinal absorption of dextrose and of olive oil in rats and that administration of adrenal cortical hormone restores it to normal. Issckutz, I aszt and $V_{\text {erzar }}{ }^{13}$ reported diminished absorption of dextrose and of butter fat from isolated jejunal loops of adrenalectomized cats. Deuel, Hallman, Murray and Samuels ${ }^{14}$ found no impairment in the absorption of dextrose in adrenalectomized rats that had received the Rubin-Krick salt mixture. We extended these experiments and found that untreated adrenalectomized rats showed marked impairment of intestinal absorption of dextrose (table 4). After aministration of 1 per cent of sodium chloride in drinking water, their intestinal absorption of dextrose was restored to normal; howerer, the rate of absorption in female rats was not higher than that in males, as is the case in intact animal ${ }^{15}$ (see following section on Gonads). Recently Marrazzit in a similar experiment found diminished absorption of dextrose in adrenalectomized rats in spite of the fact that they had received sodium chloride. She ascribed the normal absorption of dextrose in our adrenalectomized animals that had received salt to the fact that we had allowed them access to sucrose during the firt eight hours of the 24 -hour fasting period in order to avoid excessive weakening. In control experiments conducted since then with nomal rats that had access to sucrose in a like manner, we found that the intestinal absorption was not altered. Furthermore, Anderson, Herring and Josepll17 demonstrated nosmal intestinal absorption of dextrose in adrenalectomized rats that had received salt for periods up to 176 days after adrenalectomy in experiments in which both the adrenalectomized and the control rats lad been fanted for twenty hours. In our experience an important condition for successful experi. mentation with animals deprived of an endocrine organ, especially of the 


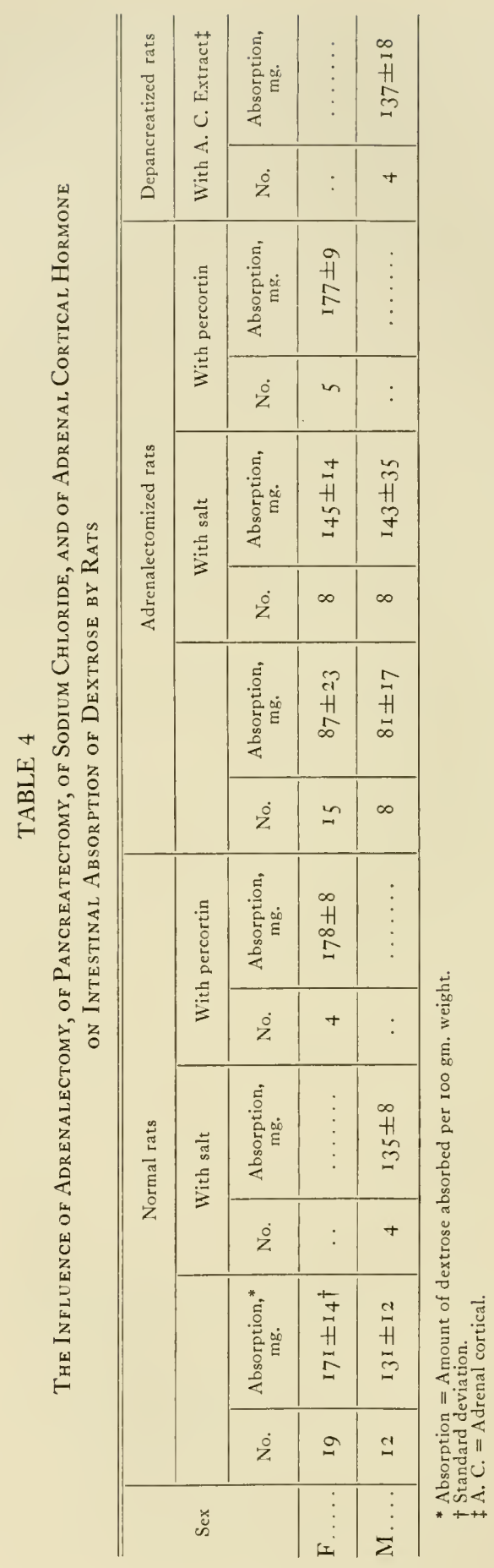




\section{T. L. Althausen}

adrenals, is their maintenance in a room of constant temperature. If such a room was not used this might accomt for the divergent results of Marrari. Withdrawal of salt from adrenalectomized rats for two days bionght about the characteristic fall in rate of intestinal absorption for dextrose.

We also studied the effects of an excess of adrenal cortical liomone on intestinal absorption. Percortin, in closes of 1 cc. injected daily for ten days into the peritoneal cavity of nomal rats, had no effect on intestinal absorption of dextrose. An even more drastic experiment was performed with rats which had been pancreatectomized in order to render them nore susceptible to the adrenal cortical hormone. ${ }^{19}$ At the end of three days, during which 1 ce. of adrenal cortical extract* was injected three times a day and also one hom before the absorption experiment, the intestinal absorption of dextose in these rats was still normal.

From these experiments the conchusion was drawn that the adrenal cortical hormone has no direct effect on intestinal absorption of dextrose and that the diminution in absorption after adrenalectomy is probably duc either to a general impairment of health of the operated rats or to disturbed metabolism of sodium chloride. Clinically these conclusions were confirmed by the fact that patients with hypoadrenalism in Addison's disease absorbed galactose from the intestine at an abnomally low rate, while patients sulfering from hyperadrenalism (Cushing's syndrome) did not have abnomally high intestimal absorption of this sugar.

The Gonads. Early in our work we found that female rats absorbed clextrose at a consistently higher rate ( 31 per cent) than male rats (table 4 ). The sanc observation was made by Deuel, Hallman, Murray and Sanuels. ${ }^{14}$ The fact that we found no difference between the sexes in the absorption of calcium lactate indicates that the process involved is not absorption through simple diffusion, but that it may be the same chemical mechanism which is stimulated by the thyroid hormone.

We studied the influence of the gonads on intestinal absorption of dextrose by performing absorption experiments on animals from which the gonads had been removed. ${ }^{19}$ Castration in aclult male rats tested eighteen days after the operation and in male rats operated at three weeks of age and tested seren weeks later did not alter the rate of intestinal absorption for dextrose. Therefore we concluded that the testes have no influence on the absorptive processen in the intestine. On the other hand, spaying of thee-weck-old female rats tested seren weeks later reduced the rate of absorption for dextrose to that of mate rats. This finding was a confirmation of the observation that the orarics have a stimulating influence on the absorption of dextrose. I Iowever, orariectomy in adult female rats did not affect the absorption of dextrone when they were tested eighteen days later, at which time all the female sex hormone presumably had been excreted. These observations indicate that the ation of the ovaries in intestinal absorption is due not to the inmediate presence of the

\footnotetext{
* The achenal cortical extrace was kindly supplied by the Milson Labonalories of (hicago.
} 


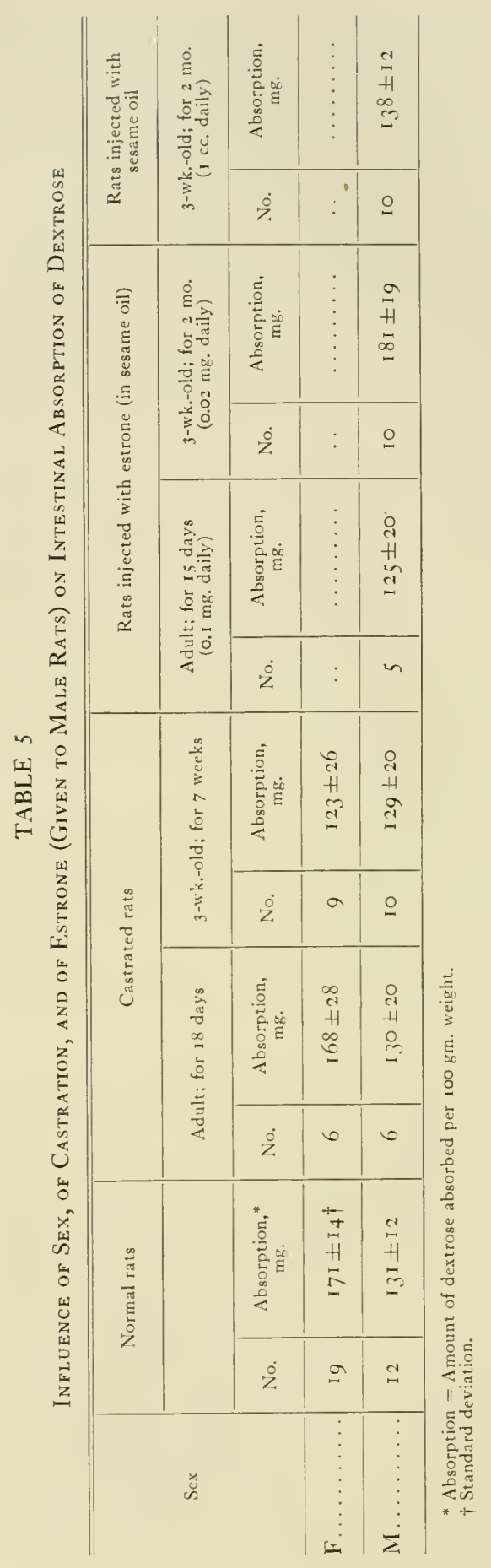


female sex hormone but to an indirect effect, possibly on some onler condocrinc organ or on the metabolism of sodium (lyloride, which is known to diflet quantitatively in the two sexes. Experiments to test the latter possibility are in progress.

The intestinal absorption of elextrose was measured in male rats which latel been injected with female sex homone. Daily intramuscular athministation of $0.02 \mathrm{mg}$. of estrone for ten weeks to three-weck-old males increased their intestinal absorption of clextrose to the level chatucteristic of fomale rats (table 5). In a control experiment, injections of sesame oil* failed to alter the rate of intestinal absorption. On the other hand. similar injections of o. mg. of estrone daily for fifteen days 10 adult male rats failed to increase their

TABLE 6

The Influence of Hypophysectomy on lntestimal Absorption of Dextrose in Female and Male Rats

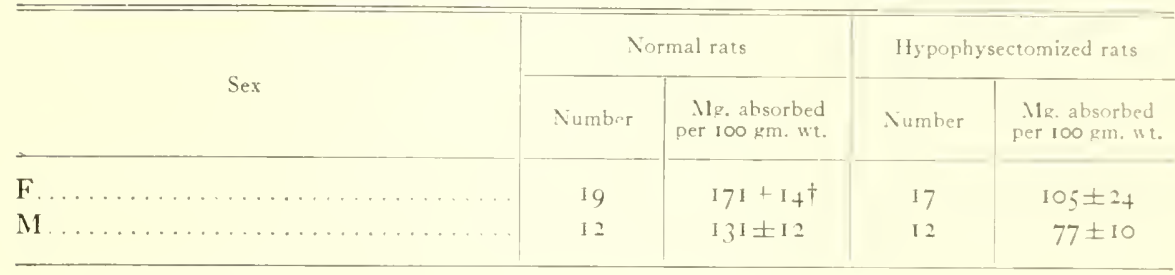

$\uparrow$ Standard deviation.

intestinal absorption of clextrose. These experiments confum our conclusions that the female sex hormone has a stimulating influence on intestinal absorp. tion and that it acts in an indirect manner.

The Hypophysis. In the course of an extensire investigation of the influence of the hypophysis on carbohydrate metabolism, Russell ${ }^{20}$ found that hypophysectomy caused a marked decrease in the rate of intestinal absorption for dextrose in male rats. Our experiments confirm this finding in both male and female rats (table 6). Furthermore, Russell showed that injections of a standard alkaline extract of beef anterior pituitary dicl not increase intestinal absorption of dextrose in nomal rats when given daily for twenty days, and did not raise the rate of absorption for dextrose in hypophysectomized rats when given as a single injection one to three hours before the lextrose was fed. On the other hand, she observed that the abmormally low blood-sugar level of hr. pophysectomized rats was raised to normal by a single injection of pituitary extract shortly before feeding the dextrose. Therefore we conduded that the hypophysis must influence intestinal absorption indirectly, possibly through the thyroid gland by way of the thyrotrophic hormone. I his possibility was supported by results of experiments with "orss replacement" of homones.

Cross Replacement Experiments. With the object of obtaining more information on the interrelationship of various cndocrine organs as far als their

\footnotetext{
* Sesame oil is the vehicle in "Estrone" (I,illy) which was employed in this experiment.
} 
influence on intestinal absorption is concerned, several experiments were performed in which, after lowering intestinal absorption by removal of one gland of internal secretion, the effect of administration of the hormone of another gland was determined. Russel1 ${ }^{21}$ had observed that daily administration of very small amounts (0.01 to $0.02 \mathrm{mg}$.) of thyroxin to hypophysectomized rats increased their ratc of absorption for dextrose to normal but did not affect other phases of carbohydrate metabolism, although the amount of oxidation of carbohydrates was increased approximately in proportion to the increase in oxygen consumption. This experiment appears to support the conception that hypophysectomy affects intestinal absorption through lack of the thyrotrophic hormone.

By administering thyroxin to a number of adrenalectomized animals in doses sufficient to render normal rats hyperthyroid, we also were successful in bringing their rate of intestinal absorption for dextrose up to nomal. The fact that relatively large amounts of thyroxin (o.1 mg.) were required to produce this effect while small amounts were ineffective was interpreted as indicating that thyroxin produced an increase in the rate of absorption for dextrose, not by supplying a deficiency, but by its presence in excessive amounts.

When large amounts of adrenal cortical extract (Wilson) were administer ed to thyroidectomized rats, no increase in intestinal absorption of dextrose took place. The same was true when adrenalectomized female rats were injected with large doses of estrone.

\section{Summary}

1. Thyroidectomy significantly diminishes intestinal absorption of utilizable carbohydrates and of fats in the rat. Administration of thyroxin markedly increases the rate of intcstinal absorption for these foodstuffs in normal rats and in animals subjected to removal of the hypophysis or of the adrenals. Since administration of thyroxin cloes not affect the absorption of xylose, alanin, calcium lactate, or thiamine chloride we conclude that the thyroid hormone is a stimulant for intestinal absorption of substances susceptible to phosphorylation.

2. Adrenalectomy significantly decreases intestinal absorption of utilizable carbohydrates and of fats in the rat. Administration of large amounts of adrenal cortical hormone to normal, to pancreatectomized, and to thyroidectomized rats has no effect on absorption of these substances from the intestine. The addition of salt to drinking water restores the intestinal absorption of adrenalectomized rats to normal. These data indicate that the hormone of the adrenal cortex has no direct effect on intestinal absorption but that its absence may lower intestinal absorption by impairing the general health of the aninal or by disturbing its metabolism of sodium chloride.

3. The rate of intestinal absorption for utilizable sugars, but not for calcium lactate, is higher in female than in male rats. Spaying reduces the intestinal absorption of dextrose in the young femalc to the level of the male. Castration in the male has no effect on intestinal absorption. Administration of large 
amounts of estrone to adult males and to adrenalectomized ats does not influence their absorption of dextrose. Administration of estrone to foung nuale rats over a long period of time increases their intestinal absorption of elextrose to the level of female rats. These data indicate that the male sex hom none lias no influence on intestinal absorption, whereas the fenule sex hommone in an indirect way has a stimulating effect on the absorption of substances suscep. tible to phosphorylation.

4. Hypophysectomy significantly lowers the rate of absorption for dextrose in rats. Administration of an active extract of the anterior pituitary to nomal rats fails to alter intestinal absorption. Since very small anomnts of thyroxin restore the absorption of dextrose in hypophysectomized rats to nomal, it is possible that the absence of the hypophysis exerts its effect on absorption in. directly through lack of the thyrotrophic hormone.

\section{Conclusions}

The thyroid hormone exerts a direct stimulating influence on intestinal absorption of substances susceptible to phosphorylation. The female sex homone and the hypophysis have a similar but indirect influence. The adrenals and the testes do not affect intestinal absorption except when lack of adrenal cortical hormone produces impairment of general health or of sodium metabolim.

\section{REFERENCES}

1. Althausen, T. L., and Stockholm, M.: Amer. J1. Physiol. 123:577, 1937.

2. Verzar, F., and McDougall, E. J.: Absorption from the Intestine (London. Vew lork, and

Toronto: 1936).

3. Eiler, J. J.; Stockholm, M., and Althausen, T. L.: Jl. Biol. Chen. 131:283, 19 fo.

4. Lundsgaard, E.: Skandinav. Arch. f. Physjol. 72:265, 1935.

5. Walker, A. M., and Hudson, C. L.: Amer. Jl. Physiol. 118:130, 1937.

6. Shannon, J. A., and Fisher, S.: Amer. Jl. Physiol. 122:765, $193^{8}$.

7. Eiler, J. J.; Althausen, T. L., and Stockholm, M.: In preparation.

s. Kalckar, H.: Biochem. J1. 33:631, 1939.

9. Colowick, S. P.; Welch, M. S., and Cori, C. F.: Jl. Biol. Chem, 133:359, 1910.

10. Althausen, T. L.; Lockhart, J. C., and Solcy, M. H.: Amer. Jl. Med. Tris. 199:312, 1910.

11. Althatsen, T. L.: Jl. Amer. Med. Assn. 115:101, 1910.

12. Wilbrandt, W., and Lengyel, L.: Biochem. Zischr. 26-:201, 1933.

13. v. Issekutz, B., jum.; Lašt, L., and Verzar, F.: Pflügers Irch. I. 1. gsml. I'h!ciol. $240: 612$. $193^{8}$.

14. Deuel, H. J., Jr.; Hallman. L. I.; Mumay, S., and Samucls. I. T.: Jl. IBiol. Chem. 119:607, 1937 .

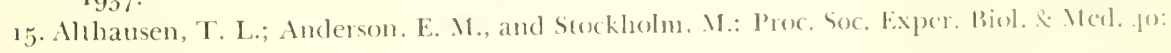
342,1939 .

16. Marrazzi, R.: Amer. Jl. Physiol. 131:36, 1910.

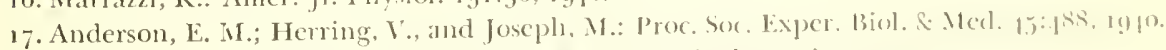

18. Long, C. N. H.; Katzin, B., and Frey, E. A.: Endocrinology g(i:gen) 19!fo.

19. Althansen, T. L.; Stockholm, M., and Anterson, R.: Amer. Jl. Phyciol. 126: 121, 1913!1.

20. Russell, J. A.: Amer. Jl. P'hysiol. $121: 755,1938$.

21. Russell, J. A.: Proc. Soc. Exper. Biol. \& .11 ed. $37: 569,1937$. 



\section{THE IMPACT OF \\ THE INTRODUCTION OF IRON \\ ON MEDICAL AND \\ RELIGIOUS THOUGHT}

B)'

WALTER C. ALVAREZ, M.D.

綕

From the

DIVISION OF MEDICINE, MAYO CIINIC

ROCIESTER. MINNESOTA 



\section{THE IMPAGT OF THE INTRODUCTION OF IRON ON MEDICAL AND RELIGIOUS THOUGHT}

Years AGo, when I was a boy, I was puzzled because whenerer I went to pick 1 a sliver out of my finger with a pin my mother promptly stopped me and insisted that I use a needle. Being of an inquiring turn of mind, I kept asking for some reason for this injunction, which evidently all mothers and grandmothers considered highly important, but I never received a logical answer. All that the elderly women whom I questioned could say was that the pin wis brass and the needle was steel. The essential point was that stecl should be used. During the next thirty years I asked many an old woman if she could throw light on this matter, but no one was ever able to help me.

\section{Cold Iron Prevents the Festering of Wotons}

In an effort to learn more. I read all the books and articles I conld find on medical folklore and gradually accumulated a small library on the subject. Although I have never found a direct reference to this common custom and belief, I long ago became satisfied as to the original reason back of the injunction to use steel. It almost certainly was that "cold iron" conld be trusted to keep out those powers of evil that might cause the wound to fester. Brass could not be expected to work in this way. According to Frazer, among some primitive peoples an iron nail is commonly put with food so that no demon can enter in and so injure the riands as to make the eater ill. A man with a sore on his body will also keep a piece of iron near it to kecp aray the demons.

\section{Iron Protects from the Powers of Darkness}

All over the world one finds this belief in the protective power of iron, and one of the commonest manifestations of it is to be seen in the use of the hor resloc, nailed orer the door or on the threshold. Over the barn door it will kecp ont bad fairies who might ride the horses all night or might bewitch the churn so that the butter will not form. The Slays think that a horseshoc on the threshold will keep disease from coming into the house. In some parts of treland they even put a horseshoe over the church door to help keep the devil out. The people admitted that the holy water ought to do the trick, but they thonght it would do no harm to use some iron too.

In Scotland, a superstitious man going over the moors at night will carry at little piece of iron to protect him from the pranks of the fairies. Scottish satilors may also carry a bit of iron or they may nail a horseshoe to the mast of their boat to protect them from the sea.

In some parts of the world those men who olficiate at a funcral must carry iron to protect themselres from possible injury by the glost of the dead man.

$$
\text { [2 } 2 \text { T }
$$


and in the highlands of Scotland, after a death, someone may want to stick some iron object into all foods in the house "to prevent death from entering them."

Naturally, in many parts of the world iron is used as an amulet. In Italy one of the many charms used against the evil eye is a tiny horseshoe worn on the watch chain. In parts of Africa women and children are weighed down with iron rings. In India and elsewhere protective bits of iron are placed in the lying-in bed and in the child's cradle. Iron is placed in or under the bed to keep away the nightmare or to cure illness. In Wales, when a man has had two strokes, a hatchet is laid on the threshold to keep away the third and fatal attack.

\section{IRON FINGER RINGS}

In my intern days in a big county hospital, I used to see persons wearing a ring made of a horseshoe nail, which was supposed to protect from rheumatism and cramps. Interestingly, Professor Badé, when he excavated Mizpah in Palestine, found several such iron finger rings, doubtless used to protect the wearer against evil spirits. Similar rings were worn by some of the Greeks who fought in the Trojan War.

Centuries ago in England cramp rings were worn by women between their breasts. Sir Christopher Hatton sent one to Queen Elizabeth and directed that it be worn "betwixt the sweet dugges." The best cramp rings were made from iron that had been used as a hinge for a coffin.

Even children in their games have used this idea of the protective power of iron. In olden days if, in a game of tag, a boy being chased could only touch cold iron, he was safe.

\section{Iron and Magic Do Not Mix}

All over the world, alongside of this idea that iron is so abhorrent to the powers of darkness and evil that it can be used to ward them off, is the closely related idea that if one is to invoke the aid of these powers in the working of some magic one must not use any iron in the ritual. For instance, and here we get back to pins, when in certain parts of Europe a child has sore eyes, and an old woman by hocus pocus has transferred the disease to a lizard's eyes, in order to keep the disease from returning to the child she picks out the animal's eyes with a brass pin. To use a needle here would be to invalidate the spell.

Similarly, when in the highlands of Scotland or in Tibet an old woman is cleaning the scapula of a sheep to use it for telling fortunes she must use an old flint and never an iron knife. Even today in Central Africa when a boy is being circumcised according to ancient ritual the priest must use a paleolithic flint knife. He might possibly use a bronze one, but certainly never a steel one. Also, in old Mexico, midwives felt it essential to cut the umbilical cord with a sharp flake of obsidian and not with a metal knife. Frazer found that in this country the Indians, even after they had good steel knives and 
tomahawks. felt the need for using their old stone ones in all religious cere. monials. Similarly, iron was taboo in the religious cerenonies of many andicn nations. In some parts of the world and in different ages at man might not eren enter the presence of his god if he had a bit of iron on his person. Thus the Negroes of the Gold Coast remove all metal from their clothing when they go to consult their fetish, and years ago in Scolland the men who made the "needfure" had first to divest themselves of all metal.

\section{IRON AND ANCIENT RELIGIONS 1)ID NoT MIX}

In ancient times priests of certain gods were forbidden cren to touch iron. Frazer stated that the Roman and Sabine priests condd not shave with a steel razor but only with one made of bronze. When the druids gathered mistletoe their ritual demanded that the knife used be not made of irom. Similarly, when collecting roots of mandragora the injunction was, "When thou seest it head. inscribe or surround it with iron, lest it flee from thee. . . and thou shatt delve about it so that thou touch it not with the iron."

In several parts of the ancient world one finds that priests so leared to offend their god with iron that they were careful to build his temple withoun any scrap of this metal in it. In some cases they were even careful not to use irom tools in the shaping of the stones and timbers. As the Bible says (Exodus 20:25): "and if thou wilt make me an altar of stone thou shalt not build it with hewing: for if thou lift up thy tool upon it, thou hast polluted it." Accordingly when the Temple was built, "there was neither hammer nor ax nor any fool of iron heard in the house while it was in building" ( $\mathrm{King}$ 6: $6: 7$ ).

Similarly, some of the Roman temples and the sacred bridge rere made and kept in repair without the use of any iron. Even in England, in Exeter Cathedral, one funds the huge Bishop's throne. whth its camopy sixty feet high, constructed without a single bit of iron (Elworthy, ${ }^{2}$ ). 220). In parts of India buildings are made without iron in order that the people be spared epidemics and disasters.

\section{WHY THIS AVERSION TO IRON?}

The question is, of course, why all this great arersion of the gods and powers of darkness to iron: There is some aversion to bronze but nowhere nearly so much as to iron. After steeping myself in the literature on the subject. I lecl that Frazer was right, and the main reason for the distrust and dislike of iron was that for centuries it was a novelty, newfangled, and therefore unsuitable for the gods who began their lives in the paleolithic perind, and therefore were used to knives and tools of chipped stone.

As Frazer pointed out, there is nothing so conscrvative in this world as religion. This must always be true because nothing gives priest and worshipers such satisfaction as the feeling that every bit of their ritual las come down unchanged from that ancient time when the god spoke and dencribed the wa!s in which he wished to be approached. Even the most intelligent of us todity 
cannot think of our God as modern in appearance. We just cannot think of Jahveh with a clean shave, and dressed in an ordinary sack suit, a soft hat, and modern shoes. We can think of Hin only as an old man with a long beard. He must wear a robe and His feet must be in sandals. We can hardly imagine Him as riding in an automobile, but rather in an ancient chariot. Even when we address Him we must use the archaic "Thou."

Since, at the beginnings of ancient worship, a flint knife was used in the sacrificing of offerings, thousands of years had to pass before any priest could think of changing to a metal knife. Finally, when a change did come and the more intelligent classes in many parts of the world accepted Buddhism, Mohammedanism, or Christianity, the people in the streets, who still clung to some belief in or fear of their ancient gods, the more ancient demons, and the witches, pixies, fairies and other "little people," felt sure that these beings had kept to the old ways and would never be able even to come near the newfangled iron.

It is possible, also, that there were other minor reasons for the distrust and fear of iron and the institution of taboos against its use. In the years before 1000 B.c. what little iron the ancients had came blazing down from heaven, and that doubtless caused most people to fear even to touch it. According to one authority, the people of early Egypt looked on the crude product of the first iron smelters as too impure for any religious purpose. They thought also that it had its origin in the spirits of evil. The early blacksmiths were looked on with considerable fear, and possibly because of this and partly because the products of their skill were so much desired by kings and warriors, when a city was captured and the inhabitants put to the sword, the smiths were usually not molested.

Another reason for the distrust of iron may have been the common tendency of men, after trying out something new, to ascribe any disaster that later befalls them to their impious break with past customs. Thus, Frazer stated that in Poland iron plowshares long were banned because, following their introduction, there were three bad harvests. That was enough to send the farmers back to their old wooden plows.

It is possible, also, as Budge ${ }^{3}$ said, that in some places there was fear of magnetite with its strange properties. In more recent years the devil was thought to reside in it, and hence no one should have a piece of it in his pocket when he went to Mass.

There is a possibility also that among some subject races iron came to be looked on with fear because the conquerors had decreed that their neighbors were not to have the efficient weapons that could be made from this metal. Thus, we learn from the Bible that "there was no smith found throughout all the land of Israel; for the Philistines said, lest the Hebrews make them swords or spears." 
THE INIROLUCION OF IRON

But if iron was distrusted mainly because it was a newlangled metal, when dict it first come into use? Archacologists tell us that in Egypt and Meropuntania iron did not come into general use until around 700 B.C. For three thensand years or more before this it was known as a rare metal, something like gold, that could be made into beads or ormaments or perhaps into a dagger or spearhead for a king. Such articles of iron werc probably all matle from meteorites and, as was to be expected, chenical analysis has shown licm (o) contain nickel.

As one would expect also, in the ancient civilizations there were two nanes for iron. Thus, in Egypt bia-en-pet was metal from heaven, and bia-en-ta was metal from earth. The Hittites of 1400 B.c. spoke of "black iron from the sky," and the Summerians called it an-bar or sky fire. Accolding to Hammurabi, in 1926 B.c. iron was called pa-ar-zi-li, which was an imported word. It apparently was taken over into Hebrew, and in II Samuel (19:31) we read that Barzillai, a friend of Darid, was a man of iron. In Greece iron was called sideros, and even today siderite is a name for meteoric iron.

In India iron is mentioned in the Vedas, from the period 1200101000 B.C. In China the earliest recorded use of iron was about 7 OO B.C. $\left(\right.$ Rickard $\left.^{4}\right)$. Bishop ${ }^{5}$ says it came into general use there about 5 oo B.c.

\section{I'Hinere W'as Iron First Produced?}

No one knows where iron was first produced in commercial quantities, but much evidence points to Hallstatt in the neighborhood of the present city of Salzburg, in Austria. About 1 goo B.c. the Egyptians began to hare trouble with the Hittites of Asia Minor because they had better weapons, made of iron. A certain Hittite king wrote once, promising to send the Pharaoh a supply of iron, but the impression he gave was that he would have to buy it from someone else. About 1000 B.c. the Dorians brought iron down to Greece and the Mediterranean coast. They brought it from beyond the Danube and probably from around Hallstatt, where an ancient cemetery has been found filled with beautifully made iron weapons and utensils. It would appear that these people must have begun to develop their great metallurgic skill some time before 1300 B.C.

IRON USED AS MEDICINE

Iron has been used as a medicine since ancient (imes. D) ioskorides gave iron rust to women who were flooding. Water or wine in which a glowing piece of iron had been quenched was long used as a treatment for diarheas and dysenteries.

As one would expect, iron was used often for exorcising disease. A curious idea was that of the Romans, who drove nails into the walls of the Temple of Jupiter in order to ward off epidemics. Perhaps with somewhat similar ideas the Germans in the last war drove nails into it wooden bust of Bismarck. 


\section{SUMMARY}

It appears that when a mother insists that her child use a steel needle and not a brass pin when he picks a sliver out of his finger, she does it because her remote forbears in 700 B.c. thought that the newly introduced iron would keep away those evil spirits and fairies who might cause the wound to fester. The reason the fairies would not come near the iron was because it was so newfangled that they distrusted and strongly disliked it.

\section{REFERENGES}

1. Frazer, Sir James: The Golden Bough. A study in magic and religion (New York: 1926).

2. Elworthy, F. T.: The Evil Eye. An acconnt of this ancient and widespread superstition (London: 1895 ).

3. Budge, Sir E. A. Wallis: Amulets and Superstitions (London: 1930).

4. Rickard, T. A.: Man and Metals: a history of mining in relationship to the detelopment of civilization, II (New York: 1932), 507.

5. Bishop, C. W.: "The neolithic age in northern China" Antiquity $7: 389,1933$.

\section{Relevant Articles Not Referred to in the Text}

Friend, J. N.: Iron in Antiquity (London: 1926).

Hazlitt, W. C.: Faiths and Folklore. [Based on Brand and Ellis' The Popular Antiquities of Great Britain], II (London: 1905).

Hovorka, D. von, and Kronfeld, A.: I'ergleichende l'olksmedizin, I (Stuttgart: 1908).

Payne, J. F.: English Medicine in Anglo-Saxon Times (London: 190.1).

Richardson, H. C.: "Iron, prehistoric and ancient" Amer. Jl. Archaeol. $3^{8: 553, ~} 1934$.

van Patten, N.: "Obstetrics in Mexico prior to 1600" Ann. Med. Histor. (11.s.) 4:203, 1932.

Wainwright, G. A.: "The coming of iron" Antiquity 10:5, 1936. 


\section{THE PHYSIOLOGY OF THE}

\section{SALT-TREATED}

\section{ADRENALEGTOMIZED}

ANIMAL

By

EVELYN ANDERSON

\section{䊏}

From the

INSTITUTE OF EXPERIMENTAL BIOLOGY AND TIE DIVISION

OF MEDICINE, UNIVERSITY OE CALIFORNIA

BERKELEY AND SAN FRANCISCO 



\section{THE PHYSIOLOGY OF THE SALT-TREATED ADRENALECTOMIZED ANIMAL}

7 HE EARLIER physiological studies on the adienal led to the conchusion that I bilateral removal of this gland was invariably and rapidly fatil. Recent work has made it clear, however, that the administration of sodium chloride greatly prolongs the survival time of the adrenalcetomized animal. These studies on the adrenal run parallel to the observations that have been made on the parathyroid gland. Both glands have been considered necessary for life, and as the knowledge of their functions has grown it has been found in each case that the administration of one of the important electrolytes of the body in the appropriate amount restores the animal to a state of existence which approaches that of the normal animal.

Current opinion of adrenal cortical function holds that the adrenal cortex has various far-reaching functions. Kendall ${ }^{1}$ divides the adrenal cortical hormones from the physiological standpoint into two groups: one, to which desoxycorticosterone belongs, is said to influence the permeability of membranes and the distribution of inorganic ions; the other, represcnted by corticosterone, is said to stimulate gluconeogenesis and the deposition of glycogen in the liver.

Long $^{2}$ seems to hold a similar view, that the control of inorganic and organic metabolism by the adrenal cortex necessitates the acceptance of two different hormones. He points out, howcrer, that the changes in organic metabolism influence the inorganic metabolism in that the stimulation of protein catabolism and the increased rate of gluconcogencsis induced by corticosterone result in an increased rate of excretion of potassium and phosphate.

Still another view has been emphasized by Hartman: ${ }^{3}$ namely, that the action of the adrenal cortical hormone is not restricted to a single tissue but that by its influence on metabolism, and upon membrane permeability and enzyme action, and probably by its effect on the nervous system, it plays a dominant role in the whole organism.

Our studies on the salt-treated adrenalectomized rat have led us to the conclusion that the adrenal cortex is not indispensible to life under all circumstances and that its function is not limited to any specific mechanism. It may well be that any mechanism requiring sodium chloride is affected by adrenal cortical hormone.

\section{The Effegt of Salt on Survimal and Gromth in Idrinal Dhi iciency}

Soddu, ${ }^{4}$ in 1898 , using the dog, was apparently the first investigator to administer saline following adrenalectomy; he reported litule benefit therefrom. Ycars later, in 1926, Banting and Gairus repeated this procedure and were able to prolong the survival period of their dogs a few days. Mucli more success 
attended the work of Stewart and Rogoff. ${ }^{6,7}$ They were the first to effect a significant increase in the survival period of adrenalectomized animals by giving sodium chloride. Their adrenalectomized dogs received Ringer-dextrose solution, 10 cc. per kilogram body weight per day, by the intravenous route. Not only did this treatment prolong the survival period but it kept the animals in a state of good health. In some instances the Ringer-dextrose solution rescued comatose animals and enabled them to live for several wceks. Of seventeen adrenalectomized dogs so treated, eight survived beyond the eighteenth day; of these, three lived between 30 and 40 days, and one 54 days. The untreated controls survived on the average of 7 days. Stewart and Rogoff believed at that time that the symptoms of adrenal insufficiency were due to the presence of a toxic substance and that the intravenous injections were beneficial by virtue of "washing out of the poison."

Much the same results were obtained by Marine and Baumann ${ }^{8}$ on adrenalectomized cats. The administration of 0.9 per cent salt solution intraperitoneally (a total of $0.45 \mathrm{gm}$. sodium chloride daity) enabled the adrenalectomized cats to survive for an average of 15 days, the shortest survival period being $7 \cdot 3$ days and the longest 30.8 days. They observed that physiological salt solution, Ringer's solution, and isotonic sodium acetate were about equally effective in prolonging life; moreover they noted that a hypertonic solution of salt definitely shortened the survival time. Isotonic glucose had virtually no effect on the outcome. They suggested that sodium might have a "specific action" in the prolongation of life.

Clinical application of these findings was initiated by Loeb. ${ }^{\circ}$ A patient with Addison's disease given sodium chloride ( $7 \mathrm{gm}$. daily) was kept in a state of relatively good health for more than 6 months. An adrenal crisis was precipitated in this paticnt by lowering the salt intake and prompt relief was obtained by resuming the use of sodium chloride.

Following these fundamental observations there have appeared numerous confirmatory reports on the effects of salt on the adrenalectomized animal. Rubin and Krick ${ }^{10}$ showed that adrenalectomized rats given salt in their drinking water remained in a state of good health for a period of 4 months. Swingle, Pfiffner, Vars and Parkins ${ }^{11}$ found in adrenalectomized dogs that the feeding of sodium chloride somewhat prolonged the interval between cessation of adrenal cortical hormone therapy and the onset of adrenal insufficiency. Three of their seven adrenalectomized dogs survived 19, 21, and $5^{0}$ days, respectively, on sodium chloride after injections of hormone had been discontinued. When salt was withdrawn from the diet of the animal that had survived 50 days, it exhibited in 4 days a severe adrenal insufficiency. Even better results on sodium therapy in the dog were obtained by Harrop, Soffer, Nicholson and Strauss; ${ }^{12}$ their adrenalectomized dogs were maintained in apparently normal condition over periods up to 5 months with no other therapy than sodium chloride and sodium bicarbonate.

Continuing the study on the use of sodium chloride in adrenalectomized 
animals, Anderson, Joseph and Herring": observed the growth rate and lomel consumption of adrenalectomized rats kept for several nuonths in a state of good health with sodium chloride. In this study, male rats, o wechs of age and weighing approximately 200 gm, were subjected to adrenale(tom). Of twenty-five adrenalectomized rats given 3.0 per cent sodium (hloride w dink, fifteen survived on the average of 45 days (range i $8-80$ days) and ten lifed beyond the 11 oth day (post-adrenalectomy). Eight of these animals were sacrificed on the 176 th day. The control group of adrenalectomierl rats, five in number. which were not given sodium chloride in their drinking water died betweren the $14^{\text {th }}$ and 31 st days.

During the first month after operation the adrenalectomied lats on salt solution ate the same amount of food as the nomal control rats, nanels, between 12 and $16 \mathrm{gm}$. daily. The adrenalectomised rats when on tip water in place of salt solution ate $9 \mathrm{gm}$. ol food daily until two days before death, when the food intake dropped shaply. The food intake was not measured after the first month; however, it is evident that the amount consmned was sirtually the same in the salt-treated adrenalectomized rats and the normal contuols since the growth curves of the two groups were almost parallel. The fonmer group of animals (six in number) gained an average of 260 gnu. of bods weight in 5 months, the latter group) (ten in all) 280 gm.

The animals used in this study were tested for completeness of adrenalcetomy by withdrawing the salt solution. All promptly developed a state of adrenal insufficiency in 2.4 to 48 hours as manifested by a striking decrease in food intake and a loss of 10 to $20 \mathrm{gm}$. of body weight. It was lound unsale on $^{\circ}$ permit the animals to continue without salt solution for more than fs hour . At autopsy a block of tissue was removed from each adrenal site and rerial sections made. No adrenal tissue was found in ant of the rats used in this rerien.

In a recent report Grollman" has stated that "salt alone. cren when administered in optimal doses, fails to maintain the completely adrenalectomized rat indefmitely." In a group of eighty rats in his series only mo ran survived more than one month. Since these findings are so strikingly divergent from the several observations described above. one must assume that the conditions of his experiments were different from those of all the rent.

\section{SAL T RIQQUREMENT IN IDRENAI DHFICHACY}

The importance of giving adequate anounts of sodiun chloride in adrenal insufficiency has been emphasized by Loeb and others. That there is an of)timal level of sodium chloride intake is suggested by the following obserration of Anderson, Joseph and Herring. In three gronpes of rats the salt intate war meastred. One group of adrenalectomized lats was given litp water and at stock diet which provided about $3 f^{\circ}$ mg. wedium chloride per ratt dials. I second group was given so per cent sodium diloride solution to drink and libitum in addition to the salt in the stock diet. The daily intike amounted on $940 \mathrm{mg}$. sodium chloride per rat. A third group. which received tap wated and 
stock diet, was given 4 cc. of 5 .o per cent sodium chloride four times a day by stomach tube-a daily intake of 1,234 mg. of sodium chloride per rat. None of the rats of the first group (low salt) survived beyond the zoth day postadrenalectomy. The rats of the second group (1.o per cent sodium chloride) remained in excellent health for about 5 months. The animals of the third group (high salt) did not survive beyond the 28 th day, the average survival period being 19.5 days. The latter finding suggests that the adrenalectomized animal is more sensitive to the injurious effects of a high salt intake than is the normal animal.

Reference has already been made in this paper to Harrop' ${ }^{12}$ success in maintaining adrenalectomized dogs over a long period of time on salt therapy. There is no doubt that his dogs received an optimal amount of sodium. Dogs weighing $8 \mathrm{~kg}$. received $5 \mathrm{gm}$. sodium chloride and $2 \mathrm{gm}$. sodium bicarbonate daily in divided doses dissolved in small amounts of water and administered by stomach tube. The reason given by Harrop for the use of sodium bicarbonate with the sodium chloride was to avoid an acidosis. Loeb ${ }^{15}$ has expressed the view that in his experience with patients the addition of sodium bicarbonate "has rarely proved necessary." He has recommended that 7 to $20 \mathrm{gm}$. of salt in addition to the salt of the diet be given to patients not receiving specific hormone therapy.

The salt requirement in adrenal deficiency depends to some extent upon the potassium intake: the higher the potassium the greater the need for sodium. Zwemer and Truszkowski ${ }^{18}$ have emphasized the susceptibility of adrenalectomized animals to the ingestion of potassium salts. Allers and Kendall ${ }^{17}$ showed that a low potassium diet in addition to a high intake of sodium chloride and sodium citrate permitted adrenalectomized dogs to continue in good health for many months.

\section{Urinary Excretion of Sodium and Potassium}

The urinary exretion of sodium and potassium is altered in adrenal insufficiency. Loeb, Atchley, Benedict and Leland ${ }^{18}$ first showed a marked increase in the renal excretion of sodium in dogs suffering from adrenal insufficiency. Because of this wastage of sodium in adrenalectomized animals, it has been assumed that the benefit derived from the giving of sodium chloride to such animals is due to a replenishing of the lost sodium $\left(\mathrm{Hartman}^{3}\right)$.

A different interpretation has been suggested by Anderson and Joseph, ${ }^{19}$ namely that sodium chloride given to adrenalectomized animals restores the mechanism responsible for the normal excretion of sodium and potassium. This view is supported by the data summarized in tables 1 and 2 (Anderson, Joseph and Herring ${ }^{13}$ ). The methods used have been described by Anderson and Joseph. ${ }^{19}$ Four groups of rats were given either radioactive sodium or radioactive potassium in isotonic solution intraperitoneally, and the percentage of the total dose excreted in the urine in 48 hours was determined. The total amounts of regular sodium and potassium excreted by all groups were also measured. In order to compare the rates of excretion of sodium and 


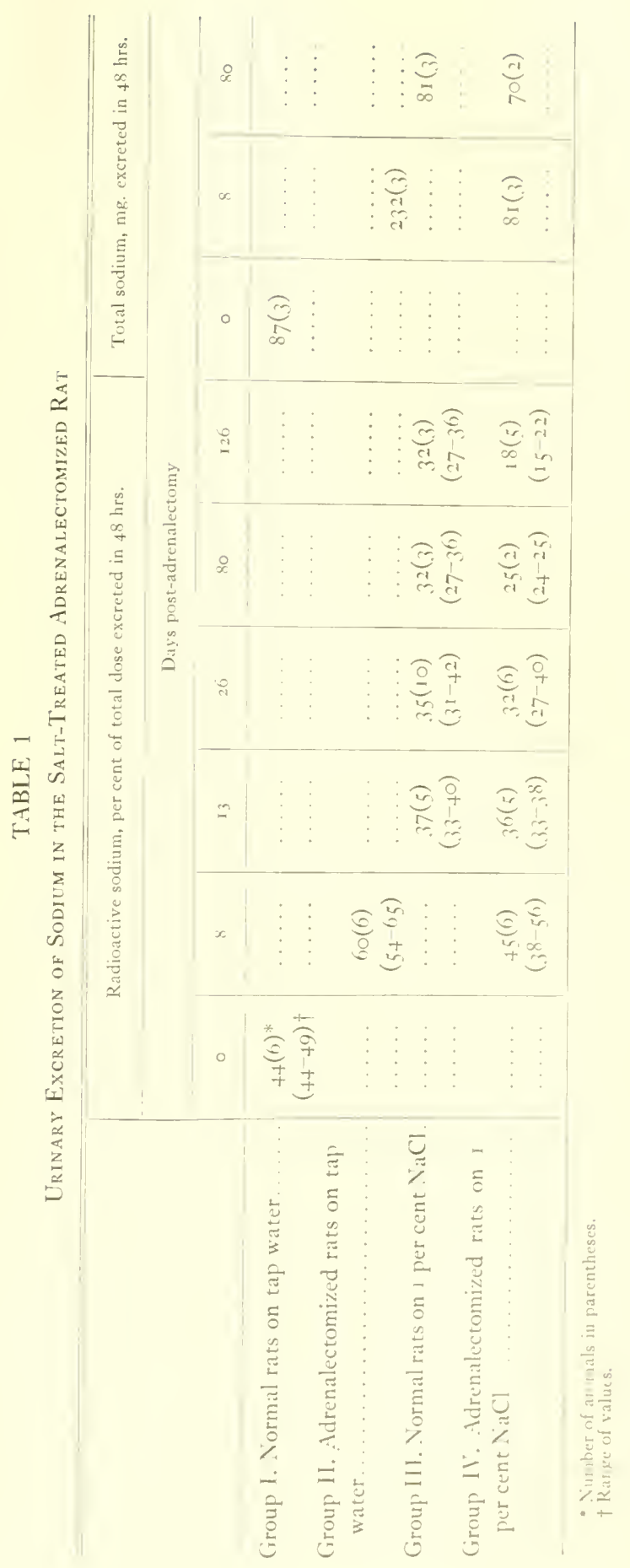




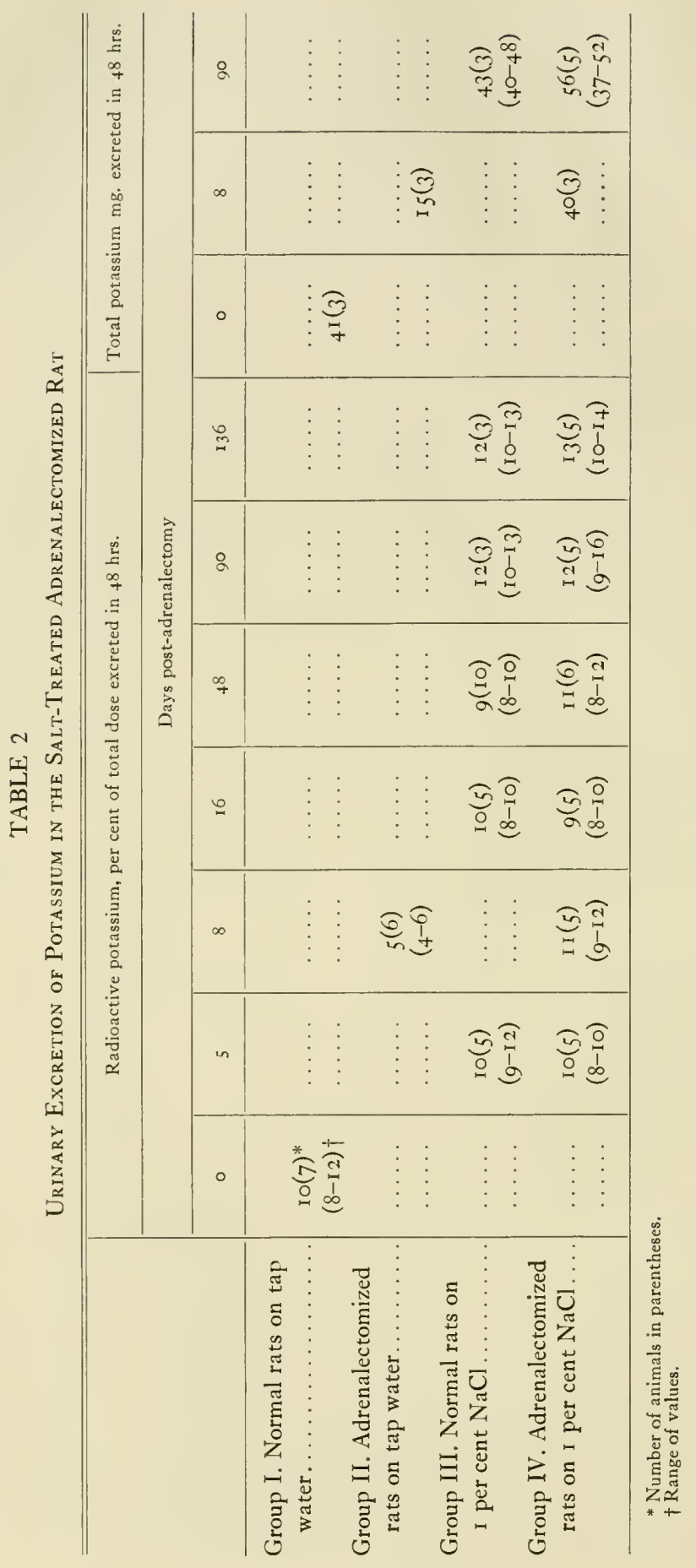


potassium in the salt-treated animals with those not so treated, all animals were given $30 \mathrm{cc}$. Locke's solution containing 6.0 per cent glucose daily for 24 hours before the urinary collections were made and duing the two-day collection period. The Locke's solution was administered by stonuch tule, in amounts of $10 \mathrm{cc}$. three times a day. In table 1 it will be noted that eight days after adrenalectomy the rats which received tap water excreted a greater percentage of radioactive sodium in $4^{8}$ hours (6o per cent) than the normal animals ( $4+$ per cent); the adrenalectomired rats maintained on 1.0 per cent sodim chloride from the time of operation excreted the same amount of radioactive sodium as the normal rats (45 per cent). Corresponding diflerences in the excretion of regular sodium were found in the three groups. The adrenalectomized animals that survired for several months on 1.0 per cent sodium chloride showed a diminishing amount of radioactive sodium excreted per $4^{8}$ hours. In table 2 it is shown that the excretion of radioactive potassium by the salt-treated adrenalectomized rats was the same as that of the nomal animals and it remained normal throughout the four months in which excretion studies were done. Thus the alteration in the excretion of sodium and potassium after adrenalectomy is remedied by the giving of sodium chloricle. If the benefit from the salt were nothing more than a replacement of lost sodium chloride, the total quantity of sodium excreted should, if anything, be increased. A recent report by Kottke, Code and $\mathrm{T}^{\top} \mathrm{ood}^{20}$ on urine dilution and concentration tests in adrenalectomized dogs would seem to confirm these findings. They found that the kidney of the adrenalectomized mimal maintained in good condition on a high-sodium, low-potassium diet, when sul)jected to a dilution test, was able to elaborate as dilute, or nearly dilute, a urine as that of an intact animal; howerer, the concentrating ability of the kidney of such an animal was less than that of the normal dog.

\section{Intestinal Absorption of Sodum, Chioride, ini Potasolum}

The rate of absorption of sodium, chloride, and potassium from the intestinal tract is altered after adrenalectomy. Clark ${ }^{21}$ showed that adrenalectomized rats kept in a healthy condition by salt therapy absorb sodium chloride more slowly than their controls. Moreover, Dennis and Wond ${ }^{22}$ found in adrenalectomized dogs maintained on a diet high in sodium chloride and sodium bicarbonate and low in potassium a very marked clecrease in the rate of absorption of sodium, potassium, and chloride from chronic loops of ileum. The rate of absorption of sodium declined more than that of potamimm and often there was an actual reversal in the direction of the net movenent of sorlium, the sodium being excreted into the gut in relatively large anomus although potassium was still being absorbed. These anthors suggest that the funditmental defect in metabolism resulting from removil of the adrenals maty be a decreased ability to perform osmotic work. Stein and Wertheines hase confrrmed these observations in the rat. These obscrvations mat powibly throw light on the finding of Anderson, Joseph and Heringe" that adrenalece 
tomized rats maintained for several months on $\mathbf{1 . 0}$ per cent sodium chloride excrete less of an injected tracer dose of radioactive sodium than normal rats given 1.o per cent sodium chloride for the same period of time.

\section{Carbohydrate Metabolism}

A. Intestinal Absorption of Glucose.-A decrease in the absorption of glucose has been observed in adrenalectomized animals. This was first reported by Wilbrandt and Lengyel ${ }^{25}$ from Verzár's laboratory. Their absorption studies were carried out on rats between the third and sixth day after adrenalectomy. On the other hand, Deuel, Hallman, Murray and Samuels ${ }^{28}$ found that the absorption of glucose was normal in adrenalectomized rats which had been kept on the Rubin-Krick salt solution for 12 to 20 days postoperatively. The use of salt in the latter experiments accounts for the difference in the results of these two groups of workers, for as Althausen, Anderson and Stockholm ${ }^{27}$ have shown, adrenalectomy markedly diminishes intestinal absorption of glucose while the use of 1.0 per cent sodium chloride after adrenalectomy restores the absorption of glucose to normal. Moreover, Anderson, Herring and $\mathrm{Joseph}^{28}$ have found that rats maintained in good health from 10 to 176 days postadrenalectomy are able to absorb glucose almost as well as normal animals. (Tables 3 and 4 .)

B. Storage of Fed Glucose.-It has been stated by Long, Katzin and Fry ${ }^{29}$ that adrenalectomized animals that are well fed may show normal levels of glycogen in the liver and muscles. It has not been generally recognized that this capacity of the adrenalectomized animal to store fed glucose is dependent upon an optimal intake of sodium chloride. Anderson, Herring and Joseph ${ }^{28}$ found that adrenalectomized rats given the stock diet and 1.0 per cent sodium chloride to drink absorbed fed glucose and stored liver glycogen in amounts which approached the normal level; on the other hand, the animals which were on tap water in place of the salt solution had significantly lower levels of liver glycogen even though the absorption of glucose was only slightly impaired. These data have been summarized in table 3 under groups I and II. These findings lend support to the contention of Britton ${ }^{30}$ that "in the absence of the adrenal the animal is unable to fix or synthesize glycogen in the liver to any noteworthy degree," but they also show that the giving of salt in optimal amounts corrects to a large extent this disability. The giving of an excess amount of salt diminishes the ability of the adrenalectomized rat to store fed glucose. This is shown in group III of table 3. The rats of this group were given $4 \mathrm{cc}$. of 5.0 per cent sodium chloride four times a day. The adrenalectomized rats so treated were in a state of health comparable to adrenalectomized rats on a low salt intake.

The adrenalectomized rat on an optimal intake of salt retains the capacity to absorb fed glucose and to store it as liver glycogen for several months after operation (Anderson, Herring and Jose $\mathrm{ph}^{28}$ ). The data on this are summarized 


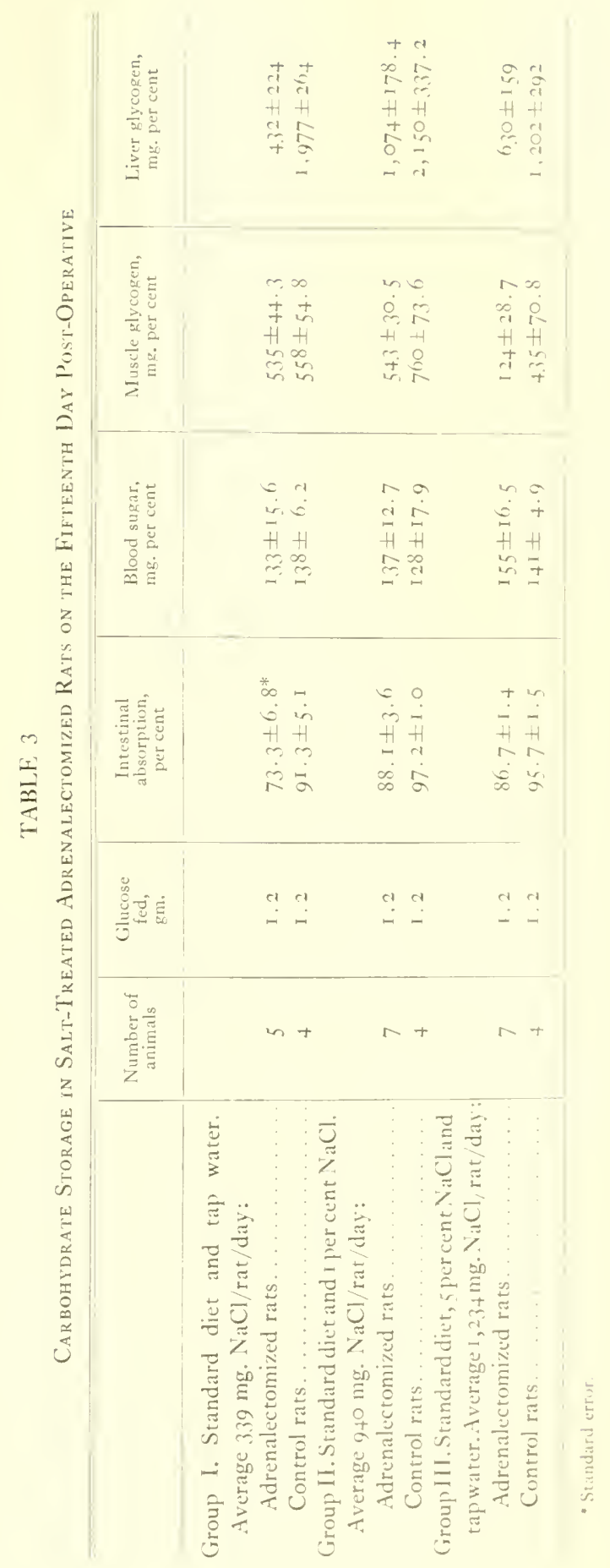




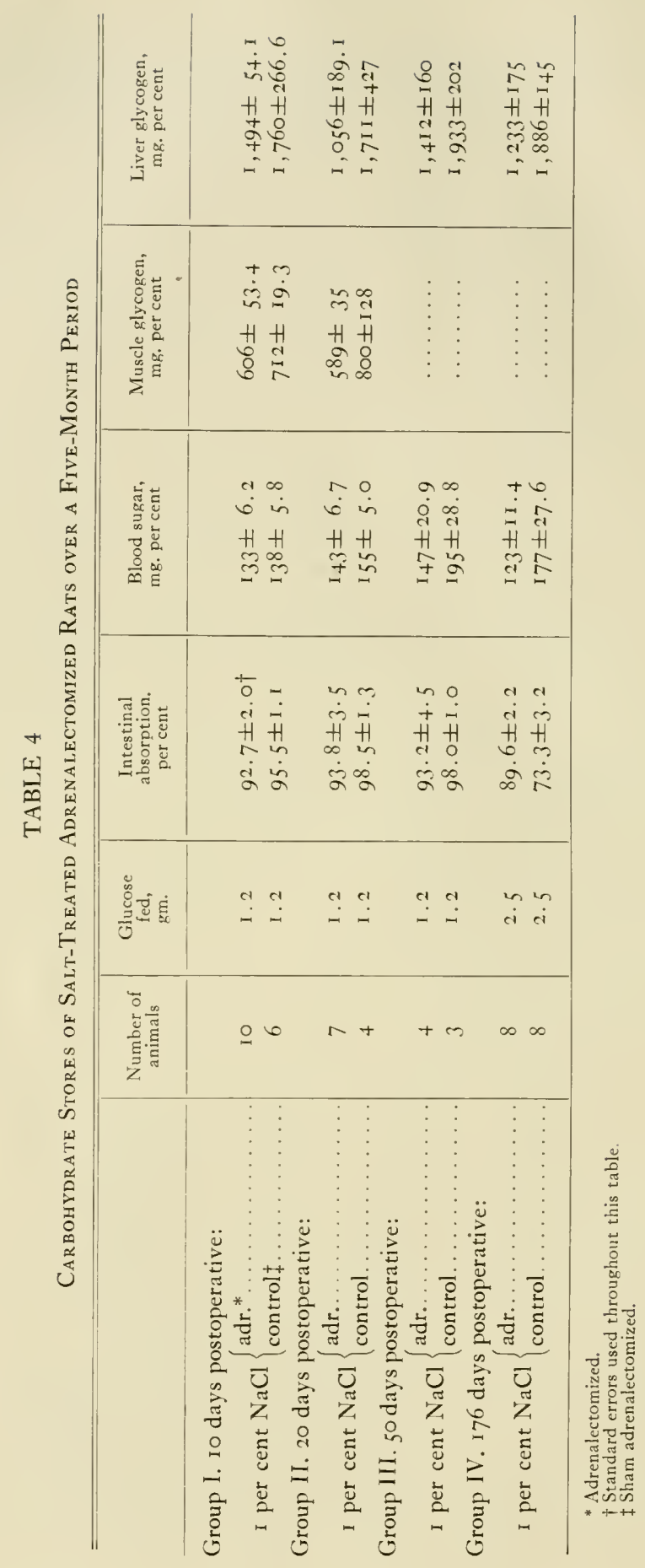


in table 4. It may be added that Harrop and his associates obsersed no disturbance in carbohychate metabolism in the adrenalecomized clogs which survived for five months on salt therapy.

\section{FAT MLTABOLISM}

That the salt-treated adrenalectomized rat is able to absorb fat from the in. testinal tract as well as the normal animal has been shown by Clark and Wrick, and Barnes, Wick, Miller, and Mackay. ${ }^{32}$ Using radionctire phosphonus, Stillman, Entenman, Anderson and Chaikoft ${ }^{3}$ were able to demonstrate that there is no interference in the phosphorylation of fat in adrenalecomized rats whether they be given salt or deprived of it. Moreover, Barnes, Miller and Burr, ${ }^{34}$ using tagged fatty acids, have demonstrated that the intestinal albsorption and the rates of incorporation of latty acid into neutral fat and phospholipids of the intestinal mucosa were similar in nomal rats and adrenalectomized rats given salt solution to drink. However, the rate of entrance of the tagged fatty acid into the neutral fat of the liver was interfered with in adrenalectomized rats; salt solution did not restore this function to normal. The above findings are not entirely in accord with the recent reports of Batvetta, Hallman, Deuel and Greeley, who studied the rate of absorption of hydrogenated cotton-seed oil and found a decrease of 24 per cent in the rate of absorption of fat in the salt-treated adrenalectomized rat and a decrease of 38 per cent in the untreated adrenatectomized rat. It is apparent that salt therapy is beneficial for fat absorption in the adrenalectomized animal, but the degree of restoration seems to vary with conditions of the experiment.

\section{Urinary Nitrogen and Survilil, Time of thl; Fastlp Silt-Triathl} Adrenalectomize Anmal

When the adrenalectomized rat is fasted the nitrogen excreted in the unine in about 25 per cent less than that of normal rats lasted a similar period (Evans ${ }^{3 n}$ ). This is associated with a marked fall in blood sugar and in liver glycogen. Long, Katzin and Fry have shown that the giving of adrenal cortical hormone to fasted adrenalectomized rats increases the urinary nitrogen excretion to a level above that excreted by fasted nomal rats, and it also raises the blood-sugar level and the liver glycogen stores. From these finclings the deduction is made that one of the properties of the adrenal cortical hormone in to stimulate protein catabolism. Anderson and Joseple: have found that 1.0 per cent sodium chloride solution to chrink has a beneficial cffect upen ilue fasted adrenalectomized rat both by increasing the survival period during ahe fast and also by increasing the urinary nitrogen excretion. A summart of the findings is given in table 5 . Male rats 10 wecks of age and weighing alphorimately $200 \mathrm{gm}$. were started on a fast immediately following operation. The rats of the control gromp were subjected to a shan adrenalectomy in which the adrenal gland was merely manipulated with forceps. I lie rass in the experimental groups were adrenalectomized. One gromp received only tap water 


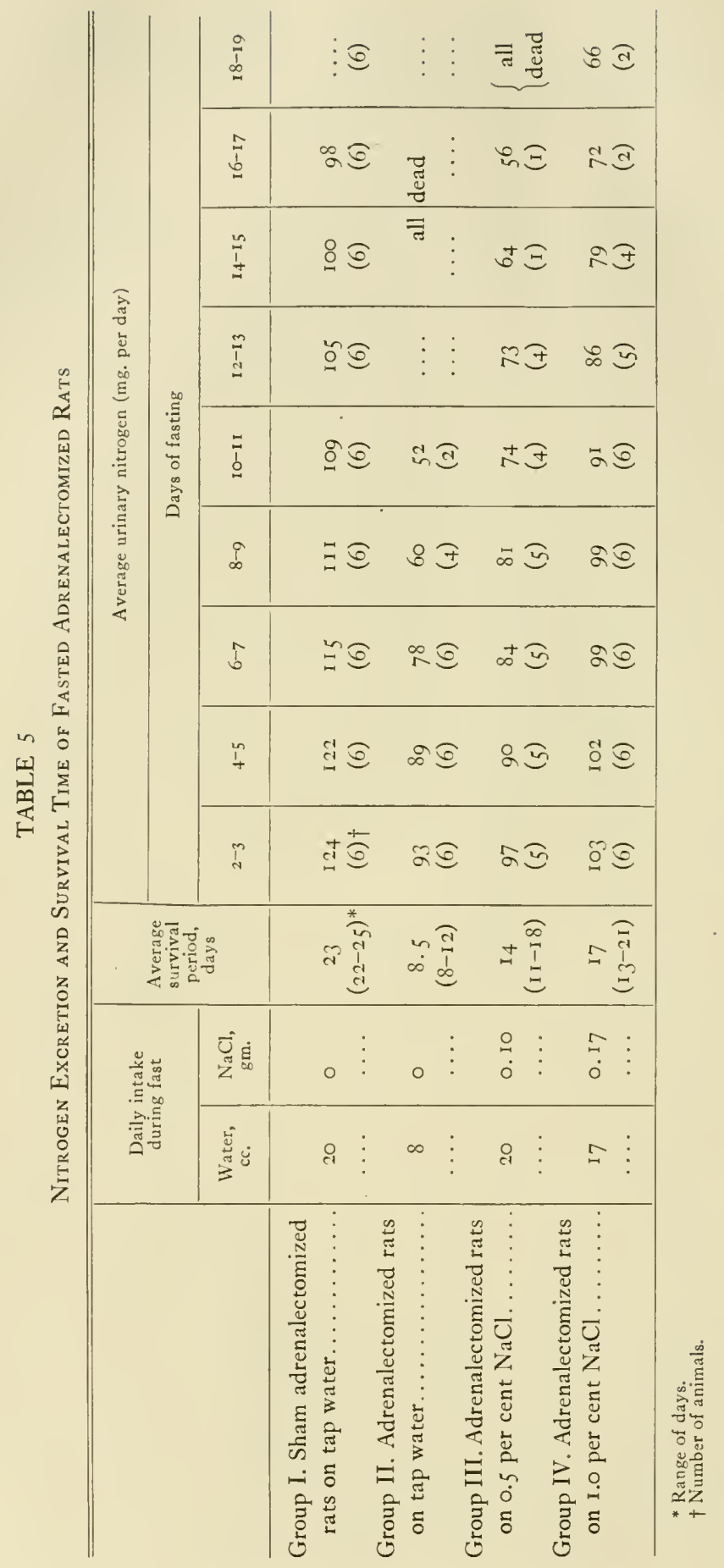


to drink, a second group received o.5 per cent sodiun chloride solution, and a third group received 1.0 per cent sodium chloride solution. The fasted adrenalectomized rats on tap water survived an average of 8.5 days postoperatively, which was about one-third the survival time of the control rats (sham adrenal. ectomized rats on tap water). The urinary nitrogen was decreased 25 per cent below that of the controls. The giving of 1.0 per cent sodium chloride: enabled adrenalectomized rats to survive 17 days postoperatively, which was double the survival period of the adrenalectomized rats on tap water and ap)proached the survival period (23 days) of the control rats. The urinary nitrogen was decreased only 17 per cent below that of the control group. The ditil on the adrenalectomized rats receiving 0.5 per cent sodium chloride to drink showed that, although benefit is derived from a lower salt intake, it is not equal to that obtained when an optimal amount of salt is taken. Since the adrenalectomized animal given sodium chloride solution has a greater protein breakdown during fasting than a similar rat given tap water instead of salt solution, and survives for a longer period, it would seem that the salt treatment has restored to a slight degree the animal's capacity for gluconeogenesis.

\section{Miscellaneous Functions Partially Restored in Salt-Treated Adrenalegtomized Animals}

Ingle $^{38}$ found that adrenalectomized rats which were maintained on a diet high in sodium and low in potassium performed more work than adrenalcetomized rats on a standard diet; however, the work performance of both groups of adrenalectomized rats was very small compared to that of animals with intact adrenals.

It has been shown by Koneff, Holmes and Reese ${ }^{39}$ that the administration of 1.0 per cent sodium chloride solution to adrenalectomized rats prevents the cytological changes in the anterior pituitary which are characteristic of adrenal insufficiency, namely degranulation of acidophils and degeneration of basophils.

Adrenalectomized dogs maintained in good condition with sodium salts have been found by Brownell and Hartman ${ }^{\text {so }}$ to have a normal basil melitbolic rate. Crafts ${ }^{41}$ showed that the hemoglobin of adrenalectomized rats given 1.o per cent sodium chloride fell during the first 10 dars postoperatively and then rose until on the twentieth day after operation it was "only slightly les than normal." It remained there for the duration of the experiment which was

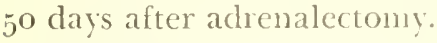

Both male and female adrenalectomized rats given 1.0 per cont sodium chloride remain fertile. The female rats are able to support a momal pregnancy. Griffiths ${ }^{12}$ found that female rats so treated were able to latctite sufficiently to keep a small number of their litters alire until reaning. but the growth of the surviving young was subnormal. 


\section{Conclusion}

This presentation deals with the functional rehabilitation that occurs in the adrenalectomized animal when an optimal amount of salt is administered. It has been found that sodium chloride has a beneficial influence on many functions that are disturbed by removal of the adrenals: in some instances the degree of restoration is slight while in others it is virtually complete.

Given in optimal amounts, sodium chloride protects the animal from the serious consequences of adrenalectomy. Thus in the adrenalectomized animal the use of salt and of adrenal cortical hormone is interchangeable to a certain degree. This interchangeability does not obtain, however, under any other conditions as far as we know. The effect of salt administration in the normal animal does not simulate the action of adrenal cortical hormone. Moreover in the adrenalectomized animal the giving of large amounts of salt fails to produce those effects ordinarily associated with exaggerated adrenal cortical function-in fact, an excess of salt is injurious to the adrenalectomized animal.

Just as sodium chloride protects the animal from an adrenal cortical insufficiency, so does adrenal cortical hormone protect against salt deficiency. The fact that the intact animal may survive on an exceedingly low intake of sodium (Orent-Keiles, Robinson and $\mathrm{McCollum}^{\text {33 }}$ ) is evidence of the protective action of adrenal cortical hormone. Moreover the observation that the adrenalectomized animal needs more salt than the amount required by the normal animal also bears out this point. All these data strongly suggest that the adrenal cortical hormone acts on the mechanisms of the body which require salt.

From these observations it is clear that adrenal cortical hormone has a much wider range of action than salt in the adrenalectomized animal. Salt partially restores altered function caused by removal of the adrenals; the adrenal cortical hormone carries this restoration to completion. It would seem, therefore, that the role of the adrenal cortical hormone is that of enabling the mechanisms requiring salt to function more adequately.

\section{REFERENCES}

\footnotetext{
1. Kendall, E. C.: J1. Amer. Med. Assn. 116:2394, 1941.

2. Long, C. N. H.: Endocrinology 30:87o, 1942.

3. Hartman, F. A.: Jl. Amer. Med. Assn. $117: 1405,1941$.

4. Soddu, L.: Sperimentale $52: 8 \overline{7}, 1898$.

5. Banting, F. G., and Gairns, S.: Amer. Jl. Plıysiol. 77:100, 1926

6. Stewart, G. N., and Rogoff, J. M.: Proc. Soc. Exper. Biol. \& Med. 22:394, 1925.

7. Stewart, G. N., and Rogoff, J. M.: Amer. Jl. Physiol. 84:649, 1928.

8. Marine, D., and Baumann, E. J.: Amer. Jl. Physiol. 81:86, 1927.

9. Loeb, R. F.: Proc. Soc. Exper. Biol. \& Med. $30: 808,1932$.

10. Rubin, M. I., and Krick, E. T.: Proc. Soc. Exper. Biol. \& Med. $31: 228,1933$.

11. Swingle, W. W.; Pfiftner, J. J.; Vars, H. M., and Parkins, W. M.: Amer. Jl. Physiol. 108: 159,1934 .
} 


\section{Evelyn Anderson}

12. Harrop. G. A.; Soffer, L. J; Nicholson, W. M., and Strams, M.: J1. I:xper. Mfed. 61:839, 1935.

13. Anderson, E.; Joseph, M., and Herring, V': Proc. Soc. Exper. Biol. \& Me(l. 11:17, , 1911.

1. Grollman, 1.: Endocrinology $29: 862,1911$.

15. Loeb, R. F.: Jl. Aner. Med. Issil. $116: 2195,1911$.

16. Zwemer, R. L., and Truszhowski, R.: Endocrinology 21:f0, 1937.

17. Allers, Wr. D., and Kendall, E. C.: Amer. jl. Physiol. 118:87, 1937.

18. Loeb, R. F.: Atchley, D. W.: Benedict, E. .1., and Leland, J.: Jl. Exper. Med. 57:77,, I993,

19. Anderson, E., and Joseph, M.: Proc. Soc. Expes. Hiol. \& Med. fo:347, 1939.

2o. Kottke, F. J.; Code, C. F., and Wood, L. H.: Amer. J1. Phriol. 136:2:29, 1912.

21. Clark, W. G.: Proc. Soc. Exper. 13iol. \& Med. .0:. 68 , 1939.

22. Dennis, C., and Wood, E. H1.: Amer. Jl. Physiol. 129:182, 19/0.

23. Stein, L., and Wertheimer, E.: Proc. Soc. Exper. Biol. \& Med. q6:172, 1917.

24. Anderson, E.: Joseph, M., and Herring, I': Proc. Soc. Exper. Biol. \& Med. 11: 182, 19 fo.

25. Wilbrandt. W., and Lengiel, L.: Biochem. Ztschr. 267:201, 1933.

26. Deuel, H. J.; Hallman, L. f.: Murras, S., and Samuels, L. T.: Jl. Biol. Chem. 189:607, 1937.

27. Mlthausen, T. L.: Anderson, E., and Stockholm, M.: Proc. Soc. Exper. 13iol. \& Med. fo:312, 1939 .

28. Inderson, E.; IIerring, V... and Joseple, M.: Proe. Soc. Exper. Biol. \& Med. 15:188, 1910.

29. Long, C. X. H.; Katzin, B., and Fry, E.: Endocrinology 26:309. 19.10.

3o. Britton, S. WI.: Amer. Jl. Phrsiol. 126:413, 1939.

31. Clark, W. G.: Proc. Soc. Exper. Biol. \& Med. 12:336, 1939.

32. Bames, R. H: Wick, A. N.; Miller, E. S., and Mackay, F. M.: Proc. soc. Wixper. Biol. Med. $40: 651,1939$.

33. Stilhuan, X.; Entenman, C.; Anderson, E., and Chaikoft, I. I ..: Endoctinolog! 31: 1ㅅ. 1912.

34. Barnes, R. H.; Miller, E. S., and Burr, G. O.: Jl. Biol. Chem. 1.10:2 11, 1941.

35. Bavetta, L.; Hallman, L.; Deuel, H. J., and Greeley. P. O.: Amer. J1. Physiol. 191:(jıg, I9)1.

36. Evans, G. T.: Imer. J1. Physiol. $114: 297.1936$.

37. Anderson, E., and Joseph, M.: Proc. Soc. Exper. Biol. \& Med. $46: 321,1911$.

38. Ingle, D. J.: Amer. Jl. Phrsiol. 129:2-8, 19.10.

39. Konetf, 1. A.; Holmes, R. O., and Reese, J. D.: Inat. Recrd. 79:275, 1911.

40. Brownell, K. A., and Hartman, F. . 1.: Endocrinology 29: 130, 19|1.

41. Crafts, R. C.: Endocrinolog! $29: 596,19+1$.

12. Griffiths, M.: (Master's thesis, Eniversity of California, 1942).

43. Orent-Keiles, E.: Robinson. A., and Me Collum, E. V.: Aner. J1. Physiol. 119:651, 1937. 



\section{CONTRIBUTIONS TO}

\section{THE HISTORY OF THE BIRD'S EGG}

\section{PREVIOUS TO INGUBATION}

$$
\text { By }
$$

JOANNE EVANGELISTA PURKINJE

\section{Translated by}

GEORGE W. BARTELMEZ

\section{בof}

\section{From the}

DEPARTMENT OF ANATOMY UNIVERSITY OF CHICAGO, CIICAGO, HLLINOIS 



\section{HERBERT MCLEAN EVANS}

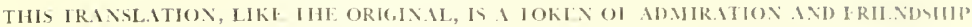
FOR A BRILLIANT, INDEFATIG ABLE INUISTIGITOR AND I SIMIULATING I.I ADYR ON THE OCCASION OF HHS SIXILTH BIRTHD.1Y. IT IS S B BUIIII IS I HUMBLE REILECTION OF THE GREIT ORIGINAS, 



\section{FOREWORD*}

No detalled biographical study of Purkinje has as yet becn written but 1 several excellent summaries are readily available (Heidenláin, ${ }^{2}$ Robinson $^{2}$ and $\left.H_{y k e s}{ }^{3}\right)$. Here it will suffice to indicate the place of the Symbolac ad Ovi Avium Historiam in his scientific career. The monograph has recciverl only cursory attention in the various reviews of his work (Eiselt," Thomsen," Studnička ${ }^{b}$ ) and none of the authors appears to have read it. Indeed one biographer sagely remarks that it reports the "discovery of the sperm cell in the egg of the hen"! The work was first published (1825) as a "Gratulationsbrief an Blumenbach" sent by the medical faculty at Breslau as a tribute to the "Nestor among Naturalists" on the fiftieth anniversary of his doctorate. Purkinje's study was chosen in spite of the fact that his appointment only two years previously had aroused a storm of resentment in the medical faculty. The situation was as follows: The first chair of physiology in Gernany was created in 1811 when the University at Frankfurt-an-der-Oder was reorganized and moved to Breslau. The chair became vacant when Bartels left in I 821 and the Prussian Ministry of Education appointed Purkinje, in spite of the protests of the Curator and Medical Faculty who rere especially displeased at the introduction of a Czech in to the faculty. Nationalistic animositics seem to have been as violent at Breslau near the Polish border as at Prague where quarrels between Czechs and Germans disturbed Purkinje's later years.

The appointment at Breslau was made on the advice of Geheimrat J. N. Rust who had been most favorably impressed by Purkinje when he met him at Prague in 1817 . The candidate had also been endorsed by Gocthe, Alexander von Humboldt and K. A. Rudolphi, the professor of anatomy at Berlin. Goethe was still much interested in his Farbentheorie and his attention had been attracted by Purkinje's doctor's dissertation (Beiträge zur Kenntniss des Sehens in Subjectiver Hinsicht, 1819). They did not meet personally until after the matter of the Breslau professorship had been settled.

Purkinje undertook to write the "Gratulationsbrief" in May, 1825, and in the following September it was sent to Blumenbach. It has been suggested that the investigation was begun, completed, and the paper written during the summer of $18_{25}$, but there appears to be no eridence for this.

The need for the second edition of the Symbolae $\left(18_{30}\right)$ is set forth in Purkinje's "Praefatio." The following translation was made from this revised and augmented version. Only this edition is included in the volume of Purkinje's Opera Omnias (1918). He made further observations on the bird's egg between 1825 and 1830 , notably on the formation of the shell membrane, but most of the changes were the results of "Reflexion" after the original had been sent to Blumenbach.

* This study was aided by a grant from the Dr. Wallace C. and Clina A. Abhors Memorial Fund of the University of Chicago. 
During the interim between the two editions the bitter personal animosity of the anatomist Otto had developed, and to such a degree that the Curator was instructed by the Medical Faculty to recommend that Purkinje be made subordinate to L. C. Treviranus, the botanist. This was not the first or the last time that there was a violent disturbance in a university circle when the reflected glimmer of established dignity began to fade in the light of a major luminary. But Prussian officialdom was still young, and enlightened opinions were not taboo. The authorities knew of Purkinje's heterodox ideas on the teaching of physiology and in 1824 had supported his plan of using laboratory demonstrations to the extent of contributing $5^{\circ}$ thaler ( $15^{\circ}$ marks) toward the necessary expenses. Recognizing the importance of his pioneering they replied to the proposal of the faculty by instructing the Curator to express to Purkinje their appreciation of the work he was doing in teaching and research.

Purkinje's first published work (1819 to 1825 ) was devoted to the physiology of the sense organs. This work was continued when he struck out into a new field, the early history of the bird's egg. The trail of the germinal vesicle led back to the early ovarian oöcytes and taxed the resolving powers of his simple lenses to the utmost. This was true also of the next major investigation, namely the study of the anthers and pollen grains of plants. The need for better optical equipment became increasingly great, for he was fully aware of the possibilities of the newly perfected achromatic microscope. His efforts to obtain one met at first with the most determined opposition. The idea of spending 200 thaler for an instrument to be used by only one professor was called preposterous! However, Purkinje had already laid his plans for a systematic histological survey of all tissues and organs so that as soon as the microscope was obtained (in $1_{32}$ ) the great series of histologic studies began (see Studnička ${ }^{6}$ ). The microscope was also used for projection demonstrations and later for photomicrography.

In 1826 Purkinje demonstrated the germinal vesicle to the Schlesische Gesellschaft für Vaterländische Cultur, the reports of which mirror his scientific activity during the Breslau period. At this time he was also studying vertigo, the investigation including experimental lesions of the brain of animals as well as pharmacological experiments on himself.

Only a small edition of the Symbolae was published by the University of Breslau in 1825; according to Cole ${ }^{9}$ there are only half a dozen copies of it known at the present time. In the second edition, published by L. Voss in Leipzig (1830), the format is larger, the type bolder, and section headings are included. Various footnotes with references to the literature were added (see translator's note 11) and several paragraphs were rewritten, especially those dealing with the disappearance of the germinal vesicle and the formation of the shell membrane. The personal remarks addressed to Blumenbach at the beginning and end of the "Gratulationsbrief" of 1825 were condensed into the brief "Praefatio" of the 1830 edition. 
The renewal of interest in clescriptive embryology was one aspeed of the reaction to the theoretical argumentation so characteristic of the eightecuth century. By the beginning of the nineteenth century Wollt, Joln Hunter, Tredern, Pander, E. Geoffroy Saint-Hilaire, and Dutrochet had already ic. turned to the detailed stucly of the bird's egg, and in 1819 Dutrochet published his investigation ${ }^{70}$ on the oviducal history of the hen's egg. Purkinje wal the furst to see the need of tracking the cicatricula from laid eggs back to ovarian stages. He naturally interpreted the vesicle which he foumd in the orarim oöcyte at the center of the blastodisc as the female germ itself, "for it appeared to be the first structure in the egg that is "stimulated to germinate." "His proof that the supposed hole in the theca folliculi, the porus pellucidus, is in realits a crystal clear vesicle, involved the isolation for the first time of what we now call a nucleus and the first demonstration of a nuclear nuembrane. Nore important was the stimulus it gave to others, especially those who hat compound microscopes, to look for similar structures in other eggs and erentually in other cells. By 1827 von Baer had iclentified the "vesicula Purkinjii," as he called it, in all the vertebrate and invertebrate eggs he could obtain, including the early ovarian eggs of mammals (see translator's note 1). In 1893 Coste demonstrated it in full-grown eggs of the rabbit. By 1836 Wagner $^{12}$ had described the nucleolus ("germinal spot") in many eggs and proclaimed it the prime mover in development. All this obviously played an important role in the development of the cell theory (see Studnička ${ }^{6}$ ).

The demonstration of the germinal vesicle is the only discovery ordinarily credited to Purkinje's monograph. Another outstanding contribution was the observation that the resicle disappears at the time of orulation and that its contents mix with the substance of the "cumulus," as he termed the surrounding thickened part of the blastodisc. O. Hertwig, ${ }^{13}$ who scems to have been the last embryologist to read Purkinje's monograph, credits him with this discovery. Hertwig apparently knew only the 1830 edition for he errs in saying that Purkinje found that the germinal vesicle had already disitppeared before the egg had left the ovary (see translator's note 5 ).

There are various other important discoveries in the Symbolae which hive been neglected or totally forgotten. Purkinje described the change in the nucleo-cytoplasmic ratio as the ovarian oöcyte grows. He pointed out that the egg passes down the oviduct with the pointed end foremost and that it may become reversed at the time of laying so that the blunt end is often extmuded furst. He found that the yolk has one axis longer than any other and that the cicatricula of large ovarian oöcytes may occupy various positions with refurence to the stigma and petiole. Actually it can rotate freely in the plane of the polar axis (Bartelmez ${ }^{14}$. Purkinje was the first 10 note the increase in peritoneal thuid at the time of ovulation, the appearance of the perivitetline spatce and the change in the consistency of the yolk during the oviducal jomme?. He nimerl the latebra and gave the first adequate description of its form, its development. and its relation to the cicalricula. 
So when von Baer wrote the preface to his Entwickelungsgeschichte ${ }^{15}(1828)$ he said (p. xıx), smiling: "Wenn ich [bei der Bildung des Vogeleies] . . wenig Eigenes gebe, so ist hierüber Niemand anzuklagen als Purkinje, der mir wenig Neues zu sagen und zu finden übrig gelassen hat."

Since the inauguration of research on the reproductive system of the hen in American agricultural institutes by Pearl and Surface ${ }^{16}$ in 1908, many of the problems which interested Purkinje have been restudied and extended, as may be seen in the recent review of Conrad and Scott. ${ }^{17}$

The studies of Cole, ${ }^{18}$ Corner, ${ }^{19}$ Sarton, ${ }^{20}$ Meyer, ${ }^{21-23}$ Adelmann, ${ }^{24,}{ }^{25}$ and others indicate a revival of interest in the history of embryology, which has recently blossomed in three comprehensive surveys: Needham's $A$ History of Embry$o \log y{ }^{28} \mathrm{~A}$. W. Meyer's The Rise of Embryology ${ }^{27}$ and Adelmann's Fabricius. ${ }^{25}$ All three are detailed and learned treatises yet delightfully written, and, unlike the older historical accounts, they are generous and judicial, not marred by personal and nationalistic prejudices.

Dr. Adelmann has checked my translation in detail and I am indebted to him for many suggestions such as could be made only by a Latin scholar who is also a biologist and deeply read in the history of biology. He has given me the privilege of seeing his work on Fabricius in manuscript. To Drs. G. W. Corner, William Bloom, H. B. Van Dyke, and Mr. Thomas Cowles I am grateful for various helpful suggestions. 


\author{
Srmbolae \\ ad \\ Ovi Avium \\ Historiam \\ ante Incubationem
}

Auctore
Joanne Evangelista Purkinje
Professore Medicinae P. O. Vratislariensi.

Adjectae sunt tabulae duae lithographicac. Lipsiae, sumptibus Leopoldi V'ossii.

MDGGCXXX 



\title{
CONTRIBUTIONS TO THE HISTORY OF THE BIRD'S EGG PREVIOUS TO INGUBATION
}

\author{
PREFACE
}

$\mathrm{M}$

Y' LITTLE Dissertation on the derelopunem of the bird's egg before incubation was submitted five years ago when the medical faculty of Breslan offered felicitations to Bhumenbach who was celebrating his fiftieth anniversary under the happiest auspices. It was not publicly printed at that time and came into the lands of only a few: Nevertheless, becanse of the novelty and importance of the material it was very kindly received by many whom you would readily include among the most celebrated men in the world of letters, indeed it hat even brought forth fruit which appears to be more significant than the original material ${ }^{b}$ (see C. E. von Baer: De Ovi Mammalium et Hominis Genesi [1827]). At the request of many scholius we have undertaken to revise it making only a few slight changes and adding notes; there are certainly not as many such as might be desirable because we are doing other things at present. It is to be hoped that when this cn-

[IV] larged work comes into the hands of a larger number of investigators of natural history some of them will perhaps be stimulated to penctrate deeper into the subject we have opened up or to develop it further. We particularly urge an investigation of the sudclen disappearance of the geminal vesicle at the time when the ovarian egg is taken up by the infundibulum. Other problems arise spontaneously before the diligent student. In conclusion may these lew pages be again dedicated to Blumenbach, certainly the Nestor anong students of nature, now that the fifth year after his annirersary is ending with favorable omens.

Breshat, May goth. 1830.

[1]
$\S 1$
A more detailed inquiry into the cicatricula of the ovarian egg; the detection of its vesicle.

While I was diligently hunting for the earliest printordium of the developing chick, the trail led finally to the cicatricula of the ovarian

\footnotetext{
a Numbers in margin enclosed in brackets indicate page numbers of original.

'Durkinje's footnotes are left as in the original at the botum of the page. Superior figures enclosed in parentheses indicate the translator s notes. Occavional words

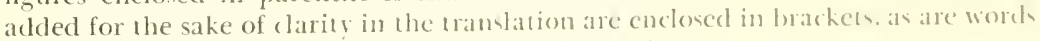
of the original which have heen insented here and there.
} 
egg. The ovarian ovule is known to have two membranes which constitute the calyx. The outer membrane is thin but quite firm and in continuity with the abdominal air sacs. It leads blood vessels to and from the egg by way of its petiole and surrounds the inner [membrane] with a loose areolar tissue except where it is firmly fused to it. This [inner one] is somewhat thicker; the terminal branches of the vessels are on its outer and rougher surface, its inner surface is woolly and dotted with equally spaced blood vessels.

Next comes the cuticle belonging to the yolk which is exceedingly delicate and closely invests the yolk and its cicatricula. As a whole the ovarian egg is a bit elongate as it approaches maturity and a trifle flattened out on two sides, corresponding in form to the opening of the infundibulum of the oviduct. The smaller ovules approach the spherical in form; the smallest protrude barely half way from the covering of the ovary and resemble a miliary skin eruption.

The cicatricula (Hahnentritt) is a distinctive feature of one or another part of the egg, lying more often nearer the petiole than the stigma; although I have found it even under the petiole or directly under the stigma, it was never at the ends; otherwise it would be corered by a chalaza when the yolk is propelled in the direction of its long axis along the beginning of the oviduct. (2) I have always found the inner surface of the vitelline membrane covered with a very thin uniform layer of globules which have the size and sliape of [red] blood corpuscles under the microscope, though they are clearer and also arranged in an organized fashion, not haphazardly jumbled. Globules of this sort are heaped up about the cicatricula to form a zone around about it more than $1 / 2$ a line in width. ${ }^{(3)}$ Within this there

[2] is a teat-like whitish hillock of similar globules, almost two lines across, extending toward the interior of the yolk (figs. 1 to 4). At the summit of the hillock [that is, superficially] the so-called porus pellucidus $^{(t)}$ is to be seen both from the upper and the lower surfaces of the cicatricula. It appears perfectly circular and has a diameter of about $1 / 6$ of a line. This porus is not to be found in the cicatricula of [full] grown ${ }^{(5)}$ eggs nor in the cicatricula of eggs within uterus or oviduct. Nor have I found in the literature that any distinction has been made between the cicatricula of the egg and that of mature ovarian ovules. Hence I judged this matter sufficiently important to justify more careful study.

So under a simple lens of one-and-a-half line focus I undertook to break up the teat-like hillock with steel needles, working toward the center so as to come at the porus pellucidus. Nothing came of many attempts except the tearing of the most delicate of pellicles which incloses a clear fluid. One could infer rather than know with certainty that it approaches the globular in form. Chance finally came to the 
help of many a futile antempt; while sucking up the watce an in which the specimen had been immersed, the hillock descilfed albove wat Grawn to the dry central boss at the bottom of the dish, it collapesed and almost distintegrated so that its central porns was dilated in all directions to almost double its orn dianeter. When I exinnined it under a lens I was filled with no little wonder as a most cipuisite resicle appeared, free in part, in part adhering to the margin of the porus. Now it was not difficult to separate it and to isolate it complete and intact (figs. 5 to 9 ).

So it is that the porns which appears to penctrite the hillock of the cicatricula is occupied by a rery small perfectly clear resicle which. immersed in a substratum filled with globules, presents only two fuce surfaces, one toward the external vitelline membrane, the other $(0)$. ward the interior of the yolk where at the summit of the hillock it is surrounded by a small crater.

The relations are nerertheless such that its external surface clings a bit to the vitelline membrane so that it is casily torn when they are separated, whereas on the inner surface a single layer of mutually adherent globules is continued over it from the hillock; so it is that the appearance of an opening [porus] is simulated.

When you have succeeded in uncovering this vesicle completcly you will find that it has the shape of a somewhat flattened sphere en-

[3] veloped by a most delicate membrane and containing a perfectly clear watery fluid. Sometimes a fringe of the white material of the hillock persisted in sticking to its lateral periphery but usually a little manipulation completely freed it of this. Traces of atherent vitelline membrane were sometimes to be seen (fig. 8). There was still some question as to whether the vesicle of the hillock grew fast on all siden to the material at the marginal zone and whether the edges of the porus were closed by special membrancs. Many observations leave 110 doubt but that the resicle is discrete and distinct.

If one may bring the imagination to the aid of the adroitness of senses and hands I would venture the opinion that a membrane [consisting of] globules extends from the margin of the porus of the hillock [cumulus] to the periphery of the vesicle and that the membrane is continued all over both the outer and inner hemispherical surfates of the vesicle, the cuticle of which remains intact.

So it is that the cicatricula of the ovarian egg has a distinctive and characteristic structure in the form of a somewhat compressed spheroidal vesicle which consists of the most delicate of membranclles inclosing a characteristic watery fluid, perchance gencrative in nature (and so I would call it vesiculn germinativa). It is intrenched in il white mammiform hillock composed of globules. perforated at the center [by the porus]. The cumulus is surrounded by a flat whitish 
zonule which is then continued into the layer of globules, referred to above, which invests the inner surface of the vitelline membrane. It may be added that the cicatricula is so closely applied to the inner surface of the vitelline membrane that the two always remain in contact when separated from the yolk.

\section{$\$ 2$}

\section{The distinction between the cicatricula of ovarian ovules, oviducal eggs and laid eggs.}

My overhasty imagination [imaginatio praecox] was already divin. ing that this vesicle was tenanted by the female germ from which the chick in its turn would develop. The next thing then was to investigate with the utmost care the cicatricula of a recently laid egg before there had been any incubation whatever, to see what transformation our vesicle had undergone in it.

An entirely new state of affairs was found here since the cicatricula

[4] of the newly laid egg does not stick to the vitelline membrane although that of the ovarian egg separates from it with difficulty. On the other hand, the cicatricula of the latter is easily separated from the underlying yolk while that of the laid egg is closely attached to the yolk. Furthermore, the zona of the cicatricula of the ovarian egg is still thin and in closer relation to the colliculus where the formative substance is gathered, as it were; however in the cicatricula of the laid as well as of the oviducal egg, everything is spread out diffusely to all sides, the colliculus has already been dissolved, the semi-transparent blastoderm is everywhere uniform in thickness, nor is there any trace of the vesicle to be found. The cicatricula of the fully formed egg takes the form of a double circle, of which the outer is fused to the yolk, the inner, which is continuous with it, is separated from the yolk by a shallow little fossa (perchance Malpighi's "colliquamentum"). ${ }^{(7)}$ This circular little fossa persists in the yolk and presents at its center a whitish knob (nucleus of Pander) covered with a viscid semi-transparent substance through which white farinaceous granules are scattered. Similar granules also besprinkle the inner surface except at the center (fig. 11) which rests upon [Pander's] nucleus but does not stick to it. This central part of the blastoderm is so semi-translucent that the darker region of the fossa has a leaden color while the nucleus shimmers white (figs. 9-11). It would seem therefore that the vesicle of the ovarian egg had burst in the laid egg and had been converted into a fluid [colliquamentum].

It was still [necessary] to investigate the cicatricula, while the egg was in the uterus, and while the yolk still remained in the oviduct. In the former I have found the same conditions as in the laid egg. But in 
the yolk within the oviduct there was no trace of lle gen minal vesicle, although at the beginning, while it was still (linging (o) the infunclib)ulum, the remains of the colliculus rere present, casily scparable from the yolk. So it appears that the resicle is burst or dissolved by contractions of the oriduct when the semi-fluid yolk is takcn up by the infundibulum and that its flud is so mixed with the substance of the colliculus that from it that fluid [colliquamenlum] with white granules is produced; from the rest of the colliculus, the nucleur [ol Pander] is formed.*

$$
\begin{gathered}
\text { On the development of the } \\
\text { germinal vesicle (Keimbläschen). }
\end{gathered}
$$

[5] The next job was to investigate this same vesicle in the cicatriculac of still smaller eggs, an easy matter, especially in cases where the yolk material has not yet attained the usual density and flows like milk. Then when the orum is cut open under water, the membrane is promptly freed of yolk. On its inner surface a diaphanous vesicle protrudes slightly, surrounded by a narrow halo of white globular material, which in the mature ovum constitutes the cumulus. At this stage the vitelline membrane is of the softest texture and is covered with a rather thick layer of globules. The vesicle does not increase in sire from the beginning to maturity in proportion to the egg as a wholc. In the smallest it is scarcely less than half the size it attains in matnre eggs, so that it then may fill almost all the space destined lor the yolk. If you were to look back over the course of developmen, you would say that the resicle is the first structure in the orule to be stimulated to germinate but at a slow rate which later and up to maturity is far surpassed by the yolk and its envelopes, so that from the mathematical point of view there are two series of equal length beginning with equal volumes, one of them increases more slowly, the other more rapidly, so that while the ratio is at first practically one of equality they eventually differ from one another many thousand times in magnitude. In ovules that have reached the diameter of one line and lew, a circular spot corresponding to the resicle is to be seen from the exterior under a lens of medium power, shadowed forth [trom the yolkladen oöplasm] by its transparency [umbrosa ob pellucidilatem] (figs, $12-15)$. It is easily detected in ovules of to 6 lines where it stands out immediately when the membranes are cut open under water and the vitelline membrane is removed. Here I must call allention (1)

* [This note was added in the 1830 edition.] It now secus more probable lu nte that the vesicle forms the basis of the dark central part of the blastoderm referred to above (fig. 13) and that is hemisphere is expanded into a double membrane [that is, the two-layered blastoderm]. 
the passage in Tiedemann* where he says that the cicatricula is comparable to the Graafian ovules in mammals, because it is the first structure to develop in the ovule and that it has the form of a compressed vesicle or white spot. It is certainly not difficult to remove this vesicle of ours in small eggs where it is not yet surrounded by white globular material; in mature ova this is a more difficult undertaking. The following method, which I hit upon by chance at first, was of the greatest help to me later. After you have very carefully separated the cumulus with its porus from the vitelline membrane under water, using a probe or curved needle, allow it to settle to the bottom of a dish which must have a convex bottom; then as the water is pipetted off, the cumulus will spread and the vesicle will stand revealed, if not at first,

[6] at least after several trials. But you must be exceedingly careful lest you suck up the specimen with the water and destroy it. Indeed, the consistency of the vesicle is so delicate that in the smaller eggs it may burst like a water bubble at the slightest touch.

\section{$\$ 4$}

The vesicle of the cicatricula as a normal female organ in birds.

In reflecting on the significance of our vesicle, the first thought that arose was that it might be a sign of mating and that it would not be found in the ovules of hens which had not been kept with the cock. ${ }^{(8)}$ However, it was also found in isolated hens, all of whose eggs were cxamined to make sure, and found to be infertile. In some it seemed to me more delicate and much more difficult to isolate; in others absolutely no distinction was found.

\section{$\$ 5$ \\ Concerning the development of the yolk and its central latebra.}

With regard to the development of the yolk, I find only a few things to be noted. At the beginning, clear miliary vesicles can be observed projecting out in great numbers from the ovarian surface like a skin eruption. At this time the yolk is a clear fluid material not easily differentiated from the vesicle of the cicatricula. By the time the ovule has attained the diameter of one line, the whitish yolk becomes turbid and the vesicle appears transparent through the external membranes. When it has reached the size of a pea, the yolk has taken on the color of thick yellowish milk. Then oily droplets can be recognized, though

* Zoologie, Vol. III, p. 100. [Friedrich Tiedemann $(1-81-1861)$. His text was published in 3 volumes between 1808 and 1814 . Vol. III has the subtitle Anatomie und Naturgeschichte der Vögel.] 
rather infrequently, since at sero-albunimous fluid prefominates. Mith increasing size the yolk becomes more yellow, untif it the fully mat ture egg it has attained almost a golden color. I he yolk in the mitture ovule, and while it is still in the beginning of the oriduct, is fonucl on be much more viscid and colnesive than it was previonsly and than it afterwards becomes while the albumen is being laid down; per liaps it takes up some of the fluid of the latter. ${ }^{(3)}$ Eren at the time when an orule begins to grow yellow, there may be recognized at its center it whiter and more fluid material such as you will fincl rather cloncls [7] resembles the cicatricula in mature orules. This white rolk material is best seen for the first time in laid eggs. ${ }^{(10)}$ It is this no donbt which in its time gave rise to the problem of Bellini, * for it is found not onls in boiled eggs but also in the very freshest and in every orule from the time that it becomes clearly visible. Thus, when you have cut off parts of the yolk under water with a pair of Cowper's scissors. beginning at the cicatricula, the fresh surface exhibits three concentric zones of different colors; ${ }^{(13)}$ the outer of these is rather pale, the middle a deeper yellow, the inner again paler surrounding the latebra of more fluid white material. This fluid is situated at the center and appears to send out a delicate canal toward the middle of the cicatriculat (figs. 16-18).

At all events this white center with concentric strata surromeling

* [This footnote was added in the 1830 edition, but the "problem of Bellini" is dis. cussed in the sst edition.] Sce Laur. Bellini: Opuscula aliquot ad trchibald. Put. carnium, Lugd. Bat., 171.4. p. 11; and further: Comment. Bononiens. Vol. II, P'. I. P. 85; Pt. II, p. 369 and following: Comm. I'auli Bapt. Ballbi de Belliniano prob. lemate; also Miscell. soc. Taurinens. Vol. I, p. 3 and following in Commentario Joannis Franc. Cigna, who was the first to refute Bellini in the matter of the cicatricula of boiled eggs. ${ }^{(11)}$

[The first of these references is to an "opusculum" addressed to Archibaid Pitcairn in 1693 , namely De motu cordis intra b extra uterum. Bellini's great discoverv is set forth on P. 112 of the Opera ()minia. Part II (ed. of 17os).

Balbi's contribution occurs in De Bononiensi fcientiumm et frtimum Institulo atque Academia commentarii, 1731 .

Cigna's refutation of Bellini is in Miscellanea philosophico-mathematica Socie' tatis Privatae Taurinensis, Vol. I: "De Belliniano problemati sen de orormu clixatorum cicatricula."']

$\uparrow$ [Footnote added in 1830 .] Later investigations late raised doubts in mu mind concerning this structure. Von Bacr, to be sure, in his work (Liber die lintickelungsgeschichte der Thiere, Erster Theil, königslocig. 182s) Iras applied our ol, servations on the central latebra of the wolk 10 his theory of halos. "but whether he has confirmed it by his own observations does not appear in anv published work. Unless the arrangement of the chalatac and their firm attachment to the rolk b the intervening membrane of Dutrochet suffices to explain the constant position of the cicatricula at the upper surface. I should say that the central fluid with its canaliculus extending to the cicatricula acts like a plumb line so that the yolh. tending of its own accord to rise upward withim the mass of albumen is preventer from further rolling so that the cicatriculat alwass preserves the same povilion uppermost. At any rate it can be justly assumed that the watert fluid of the latebra] has a higher specific gravity that the semioleaginous substance of the yolh. 
it, is so similar in form to the cicatricula that it is no wonder that for some time an absurd opinion confused the one with the other, especially since in the hard-boiled egg the albuminous cicatricula could hardly be distinguished from the albumen to which it adheres.

The white substance contained in the central latebra of the yolk, as seen under the microscope, consists of rather large white globules suspended in an albumen. It has almost the same consistency and structure as that which makes up the fluid part of the cicatricula, so it would seem that there is some developmental relationship between the two regions. The rest of the latebra is filled with a rather fluid lymph. It is more convenient to look for this structure of the yolk in boiled eggs, so long as you are sure that it was not produced

[8] in the first place by the cooking. At times between the first and middle strata [of yolk] I have found a spherical lamella of coagulated albumen, or here and there albuminous projections from the center, especially in eggs that had already been incubated for some hours. In the boiled yolk it appears that the central latebra often presents an irregular figure and at the same time the concentric strata have corresponding irregularities. In the boiled yolks the central latebra contains a milky substance somewhat salty in flavor so that from this it is clear that it differs chemically from the rest of the yolk. In many eggs I have found the inner layer of yolk rather oily, translucent and deep yellow, but I have not yet discovered on what conditions this depends. What further changes the yolk may undergo during incubation, how the halos around the cicatricula are produced in it, how the albumen is gradually mixed with it, must remain for later investigations. For the sake of those who enjoy microscopic observation, I may add that the boiled yolk, which readily disintegrates into a powder, shows masses of the most beautiful corpuscles, simulating crystals in form, and indeed those removed from different parts of the yolk show different patterns.

\section{$\S 6$}

Concerning the vitelline membrane.

The vitelline membrane is uniformly delicate and exceedingly transparent and shows no organic structure under the microscope, no matter how it is cut up or teased. It is a perfectly intact closed vesicle, pierced by no opening. In the ovarian ovule, to be sure, you can scarcely differentiate it in early stages from the layers of globules which are laid down by the yolk peripherally; at that time also the vesicle of the cicatricula is so joined to it that it is not possible to separate one from the other without injury. Even in older ova, the membrane of the germinal vesicle sticks so fast to the vitelline membrane that very often in separating them you tear the latter, leaving 
a circular fragment (fig. 8\%). Thus the vesicte scems, ats it were, to nestle on the vitelline membrane itself and to develop with it. ${ }^{(16)}$

So long as the ovule remains in the ovary, its external membranes are so thick as compared to the exceedingly delicate vitelline menbrane that only the most persistent efforts suffice to separate them conl-

[9] pletely from the vitelline membrane, without injuring it. It would be well worth while to inquire into the relation between this membrane and the inner surface of the external vascular membrane in the oval. ian ovule, how it comes about that the blood provides for the secietion of the materials of the yolk. It is at least certain that the whole inner surface of the vitelline membrane is, at this time, covered with clear globules uniform in size, resembling blood corpuscles in form and easily differentiated from oily yolk globules.

The vitelline membrane while it is still in the infundibulum appears wrinkled and quite pliable so that the yolk, which is more viscid and of a firmer consistency at this time, can take on the extremely clongated shape necessary for it to pass the rather narow canal of the infundibulum to the oviduct with its looser walls, without any tearing of the vitelline membrane.

\section{$\$ 7$}

Concerning the membranes of the calyx.

Now while the ovarian egg is approaching maturity, the petiole is elongated to almost $1 / 2$ a thumb's length, so that the wost mature orum hangs down beyond the rest toward the uropygium and is pressed into the wide open mouth of the infundibutum by the underlying intestines aided by the abdominal muscles. ${ }^{(15)}$ Then the stigma of the orum becomes more and more pale and while it is not thinned out, it nevertheless becomes softer so that at last it is very easily torn and releases the ovum. At this time, the external vascular membranc contains a loose mesh of broad thin-walled veins, beginning on buth sides of the stigna with the branches disposed like very line combls. It appears to be a resorbing mechanism by which the tissue of the stigma is gradually and imperceptibly dissolved and ovulation is prepared for. ${ }^{(16)}$

The stigma does not first appear in the latest stage ol the orule but it is already present as a fine, dill, whitish line in orules of 1 in the full size which are still semi-transparent. The internal lanini of the follicular membrane which adjoins the vitelline menbrane is not of a veil-like texture, as some would have it, and as it does indeed appear superficially, but it is very smooth and tranplatent and within it minute corpuscles are scattered. which are perhaps glandular or vascular tufts fairly regularty distributed. ${ }^{(15)}$ 


\section{$\$ 8$}

\section{Concerning the movements of oviduct and infundibulum and their muscular mechanism.}

When you open a recently killed hen which has an already fully developed egg in the uterus and you remove the intestines so that the egg-bearing organs are fully exposed, you will observe the whole oviduct and the uterus writhing in continuous peristalsis; especially if you immerse it in warm water, the ruffled fimbriae which crown the free margin of the infundibulum are curled by the most beautiful alternating contractions and expansions. But if you seek for the truc seat of the movements by stimulating the parts of the oviduct you will find it with little effort in the mesometrium. No one who looks carefully will deny that this is provided with numerous unmistakable muscle fibers. * Perhaps it will not be superfluous to devote one or tro lines to the description of this apparatus.

In the Iaying hen the mesometrium is quite different from the mesentery which merely conveys vessels to the intestine. It is a true muscle or rather a muscular membrane, which to be sure also distributes vessels to the oviduct. Two parts of the mesentery are to be recognized, an inferior and a superior. The inferior is inserted on the lower surface of the uterus if we may so term the lowermost part of the oviduct where the shell is formed and which plays the major role in the laying of the egg. Here a cross-shaped, rather compact plexus of muscle fibers (fig. 19,c) spreads out about the uterus from both sides; at the posterior part of the uterus, where the vagina is inserted into it, a rather slack muscular sac is formed, which at laying encompasses the vagina dilated by the egg and helps in its delivery. At the other end, however, it is dilated into a muscular membrane which is reticulated with fibers that spread like a fan; its periphery begins at the insertion of the oviduct into the uterus and ends at the insertion of the posterior angle of the infundibulum into the uterus, thus folding back on itself.

Now the other, namely the anterior, angle of the infundibulum is gathered into a rather compact elastic ligament, perhaps wholly muscular, which is attached for the most part at the root of the penultimate rib of the left side but elsewhere it is attached less conspicuously

[11] by many delicate projections about the pulmonary tubes [poros aeriferos pulmonum] (fig. 19). In the midst of the ligament the upper part of the wall of the abdominal air sac [sacci aeriferi abdominalis] is attached on all sides (fig. $19, h$ ).

* [Footnote added in 1830.] See Ge. Spangenberg: Disquisitio [inauguralis ana. tomica] circa partes genitales foemineas avium (Göttingen: 1813), p. 5 o. 
From this ligament* the sheet of the superior messmentum takes its origin. Together with the air sac it arises from the peritonemm at the left side of the vertebral column and passes on to the clon sal wall of the uterus. From here muscle fibers descend to the superion pant of the oviduct on the sufface of which they are so thinned out that they are hardly visible, and, forming the exceedingly delicate musenlar tunic of the oriduct, they extend to the inferior mesometrium. The internal glandular tunic of the oriduct is thimed out to the utmont in the infundibulum, ending at its finbriated border; the evtension of the mesometrial muscle on the other hand is mose developed so that this border seems to be composed entirely of muscular tissuc. t As a matter of fact, the muscle fibers of the fimbria [limbus] form it rery delicate and complex net; toward its margin the meshes become smaller and more numerous, ending as rery fine ones in the somer hat crenated margin (fig. 20). The principal direction of the transwere fibers is perpendicular to the margin of the inlundibulum. In the mid-sagittal line of the infundibulum the muscle fibers run together from both sides of the fimbriac so that they produce a transversely striated suture; but where the mouth of the infunclibulum gapes open they are continued through its walls to the oriduct. In addition, other fibrils parallel to the margins of the fmubriae are interworen at right angles to the fibers mentioned above. These fibrils take their origin from the margins of the infunclibulum, nancly from the anterior ligament and from the uterus, and extend on both sicles throughout its length. When these fibers contract, they bring about the utmost wrinkling of the fumbriae. The remarkable mobility of the infundibutum mentioned above is ascribed to these fibers. The rest of the mesometrial muscle fibers are prolonged transwersely to the oviduct, communicating with one another and mutually intentwing by means of elongate folds and branches so that transparcnt areas

[12] remain. These areas comsist solely of the layers of the serous mem. brane and are also interworen with rery delicate nere filsers that rum transwersely and with secondary ovichual ressels that intersect at shanp angles; the principal ressels. howerer, which are closest to the origin of the mesometrium, rum parallel to the oviduct.

The width of the mesometrimm is not ererythere the sance. For. as the oriduct bends up or down in thee flexures, the mesometrimm also becomes shorter or looser. The muscle fibers of the mesomecrimm. just as they reach the oviduct, diverge from each other and pars about it. surrounding it with a very delicute muscular membrane, in which you will humt in rain for the longitudinal fibers of which anthors

\footnotetext{
* Perhaps the laemia of Spang('nl)erg as cited. 1) \%.

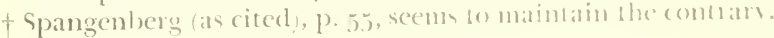


speak* except in the lowest part of the oviduct where, passing over into the uterus, it is constricted for the extent of about 2 thumbs' breadth. $\dagger$ Here perfectly distinct longitudinal muscle fibers extend from the uterus and they promptly ranish in the region where the oviduct widens out again. The uterus itself is covered by a double muscular layer. In the external layer the fibers run in a longitudinal direction from the end of the oviduct to the beginning of the vagina; in the internal layer they encircle the membrane which secretes the shell for the egg. Longitudinal fibers also predominate in the vagina; the circular fibers are rather gathered together into its sphincter. The vagina and infundibulum are remarkably distensible where the canals are almost wholly muscular, so that by gradually dilating them you can easily introduce several fingers. Here distensibility has been associated with contractility, since they are adapted to the moving forward of bodies and, at the same time, holding them without their escaping although they are close to the external openings.

\section{$\$ 9$ \\ Concerning the taking up of the ovarian egg by the infundibulum of the oviduct. +}

The further history of the mature ovule may now be considered [13] in the hope that it may throw light upon a field so buried in darkness. At the time when the yolk has attained the requisite size, the peduncle of the calyx is elongated to such an extent that, moving back between viscera and ovary, it touches the opening of the infundibulum. If, after removing all the viscera, you look at the ovule hanging from the ovary, you will see its less rounded surfaces turned to right and left, the stigma however looking downward. But if you now replace the viscera, they press the ovule to the mouth of the oviduct in such a way that the flattened parts are turned up and down, whereas the stigma is actually kissed by the mouth of the infundibulum. The muscular structure and well known mobility of the infundibulum

* [Footnote added in 1830 .] These longitudinal fibers are simply folds of the internal albumen-secreting membrane of the oviduct, which shimmer through the serous membrane and muscle as very delicate lines. Once these membranes have been drawn aside, it appears to be easy to smooth out the folds of the secretory membrane by opening up the folds with a spatula.

$\dagger[$ Footnote added, 183o.] The isthmus of the oviduct I would term it. This part, as I have said, is adapted for the secretion of the shell membrane. While the ovum, now surrounded with albumen, is entering the beginning of the isthmus, the first part [of the albumen] is compressed by the resistance of the walls as it enters and thus the sharp end of the egg is moulded; as its journey continues, the passage is already dilated so that the albumen is rounded off at the blunter end; in this constriction we should perhaps look for the [origin of the] narrower strand of albumen which they call the ligament of Tredern.

+ See Spangenberg (as cited), p. 59 and following. 
and its fumbriac casily prove that they are not inest at this time when they embrace the orule by licking it on all sides.

As I understand the situation, it is as follows: The moutle of the infundibulum is dilated by its longitudinal muscles and it lakes up the ovum in its entirety, the fimbriac on the other land are wrinkled by the fibrillac which run down the sagitally directed infundibulin margins and are constricted about the stalk of the orule. I hus the calyx of the ovule is, at it were, softened both by the motions of the infundibulum and its secretions. When the blood flow is imperted by the constriction and pressure, and all mutrition is stopped, the calyx is stretched even to the point of rupture of the stigma; then the yolk is rolled out to be taken up later by the infundibulum. At that time the characteristic transverse fibrils of the infundibulum, which form the suture described above, as well as the fibers at the beginning of the superior and inferior mesometrium, contract alternately toward the interior of the canal and force the yolk completely out of the open calyx. ${ }^{(18)}$ The yolk is now propelled along the infundibulum and arrives at the intermediate part of the oviduct which secretes albumen. The infundibulum then opens again and expels the cmpty calyx. Such an idea of the advance of the ovule by the oviduct seems fairly surely determined by the anatomical structure of the organs, although it rarely ever happens that the process is actually witnessed in the living animal. It is unlikely that these movements are accomplished by a swelling up of the infundibulum, since it does not present that vascular spongy structure peculiar to erectile organs, nor is it necessary to resort to this explanation if we consider its muscular apparatus.

[14] I have found that in recently killed hens the position of the infundibulum is very variable with respect to the oriduct. In one case the infundibulum hangs down perpendicularly, in another it falls over to the left, in another to the right side; it is not necessarily turned toward or away from the oviduct, ${ }^{*}$ but it is suspended near the latter, attached by its extremities to the left penultimate rib and to the uterus.

$$
\$ 10
$$

The superabundance of secretion, and the involution of the reproductive organs.

In many hens which carry a fully developed egg in the uterus, I find the surface of the most mature [ovarian] ovum already macerated as it were, wherefore I should renture to infer that it has experienced some softening from the activity of the fimbriac. At this time you will

\footnotetext{
* See Al. Monro: Versuch einer Abhandlung über V'ergleichende Anatomie, aus dem Englischem (Göttingen: 1790), P. So. [Alexander Monro primus: An Essay on Comparative Anatomy (London: 1711; $3^{d}$ ed. edited by his son, Alex. Monro 11 . $1,82)$.]
} 
usually find in addition a yellowish fluid in the abdominal cavity as if mixed with a kind of albumen solution, and you will not infrequently find the same fluid poured out between the layers of the calyx. I do not know what interpretation to place on it; it is perhaps to be derived from an excessive effort of the blood to secrete yolk, like the post-partum lactiferous abscesses in women. Never, to be sure, have I found a mature ovum so ruptured that the yolk was diffused between the layers of the calyx and the spherical form of the ovule distorted into an irregular one.

If, however, laying hens are under-nourished, the formation of eggs ceases and those ovules which were approaching maturity undergo a peculiar transformation; the inner membrane of the calyx is ruptured, the yolk flows out into the spaces of the outer membrane, the ovule decreases in size, the yolk becomes whitish and is resorbed; at that time even the smaller ovules lose their spherical form and hang, flabby and wrinkled, devoid of yolk.

It is remarkable how quickly the muscle fibers vanish in the mesometrium of fowls which have stopped laying, so that even after a few days you can discover only traces of them, milky in color and hardly visible. But these matters require much detailed discussion.

$\$ 11$

Concerning the disappearance of the germinal vesicle.

After the yolk has been received by the oviduct, it is invested during its progress with chalazae, the chalazal membrane, albumen, the [15] Iouble shell membrane, and the shell. You will best understand the internal structure of these if you follow the changes the egg undergoes as it passes through the oviducal canal.

If, in the first place, you investigate the cicatricula after the yolk lias been taken up by the infundibulum, you will nowhere find the resicle which has been described above in the cicatricula of the ovule. Instead of the porus an internal circle of the blastoderm is now to be seen, the cumulus seems to have been changed into a white center. and between the two a small circular area will be noted, besprinkled with white granules. If a mechanical explanation of this transformation be adequate, I would say that the yolk, in bursting from the calyx and in being taken up by the infundibulum, is subjected to such disturbance by the contractions of the latter that the exceedingly delicate vesicle is ruptured. However, an account based on an opinion will not fill up gaps in observation. ${ }^{(19)}$ Repeated observations must be made with the utmost acumen, unless perchance this naturally difficult matter has withdrawn itself among mysteries not to be approached. 
$\$ 12$

Of the formation of albumen and chatarate.

I turn now to the later stages in the formation of the egg. It the upper end of the oviduct, where the longitudinal folds of the numcrus membrane begin, a first thin layer of albumen appeas enswathing the vitelline membrane; at opposite ends where the oviduct is ronstricted above and below [the ormm], solt, clear, albuminous nodules are laid down, from which on both sides a strand of albumen is continued, surrounded by the folds of the internal lamina of the oviduet: these strands are the rudiments of the chalazie (fig. 21). Up to this time there is no hint of the white twisted strands which occupy the center of the fully developed chalazae, nor is the vitelline membrane as yet marked by radial folds through the twisting of the chalazac. Now, as the yolk is moved along by the peristalsis of the oviduct, layer upon layer of albumen secreted by the walls is added in the form of a spiral band. Meanwhile, the first lamina of albumen begins to thicken against the yolk and is converted into a rather firm envelope, adhering rery closely to the vitelline membrane. From this envelope the internal whitish strands of the chalazae extend. The yolk with the surrounding albumen is movable about its [longest] axis. The chalazae attached to the membrane [of chalaziferous albumen] are produced

[16] by twisting, as a thread is spun from a distaff and twisted upon itscll again and again. Accordingly you will also find spirally wound layers on the very surface of the albumen which is subsequently laid down. It will be most obvious that this is not a figment of the imagination il you will take out an egg already fully surrounded by albumen from near the lowest part of the oviduct and study it after about an houl immersion in perfectly fresh cold spring water. The albumen which was at first clear and transparent is gradually made turbid and opalescent by the water and shows strands on its surface which run spirally from left to right proceeding from the blunt to the more pointed cul. If you tease them away with volsella forceps, they come off in lamellate all running in the same direction until the whole albumen is unwound down to the chalazae (fig. 22). Now when you have come almost to the chalazal membrane which covers the yolk, the last layer are very soft, so that you almost think the space empty; the rest of the albumen passes to the chalazae and hangs like a hood from them. From these facts it may be inferred that Fabricius ab Aquapendente proposed a perfectly correct interpretation of the formation of allummen and chalazae, and no one should belicre that they arise from the vitelline membrane and grow like plants. 
Of the chalaziferous membrane of Dutrochet.

At first the chalaziferous membrane of Dutrochet* is assuredly albumen. In its progress through the oviduct it becomes solid and finally takes on almost the same character as the vitelline membrane. The internal whitish strand of the chalazae is the continuation of the chalaziferous membrane and is prolonged from it to the interior of the clialazae like a tube twisted on itself and closed by torsion, just as if you were to invest a sphere with a membraneous sac open at both ends and close it by twisting at both poles.

The vitelline membrane itself remains unchanged and intact as it was in the ovarian ovule. There is no communication through it with the chalazal canal by which albumen might be conducted to the

[17] interior of the yolk. ${ }^{(21)}$ The canal which Léveilléf saw can be readily demonstrated if you will but cut across a chalaza under water. The demonstration is successful only in chalazae which are doubly twisted on themselves so that the mutually opposed turns necessarily form an inner canal like the modiolus of the cochlea. This nevertheless does not communicate with the yolk in any way (fig. 22). Although the vitelline membrane does not appear porous under the microscope, it scems permeable everywhere to nutrient fluids, just as is the case in the ovarian ovule where it takes blood from the vascular [thecal] membrane, transfers it to the interior and converts it into yolk material (fig. $22 *$ ). We see the same thing happen at the beginning of the development of the chick when the albumen above the cicatricula disappears and enters the interior, producing a crater. We readily inler, therefore, that a similar thing probably happens to albumen over the whole surface of the vitelline membrane; there is no need to conjure up suctorial ducts. It is not difficult to separate the chalaziferous membrane from the underlying vitelline membrane in the place where the chalazae are inserted, even where that part of it which is twisted into a strand opens up in the [chalaziferous] membrane. To do this successfully you should take the chalaza near its vitelline root with a pair of volsella forceps and at the same time cut from the yolk hanging below it a piece of the vitelline membrane, wash it, and then, under a medium-power lens tear the two membranes [vitelline

* Journal de Physique [de Chimie, d'Histoire Naturale et des Arts], Vol. 88, p. 170 [to 178, 1819:--Henri Dutrochet: "Histoire de l'oeuf des oiseaux avant la ponte." Translation in Deutsch. Arch.f. Physiol. 6:379-385, 1820.].

†Reils Archiv [für die Physiologie], Vol. 4, p. 418 [1800; this is an abstract of J. B. F. Léveillé: "Dissertations physiologique sur la formation des foetus dans les mammifères et dans les oiseaux" J. de physiq., de chim., d'histoir. natur. et d. arts, Ann. 7 de la République (1799), p. 386]. 
and chalaziferous] apart umder water, using two pairs of forceps. There are eggs in which it is obvious to the naked eye that the clialayiferous membrane is loosely attached to the vitelline [memlorane] only at the insertion of the chalazae (fig. 23). There are others in which the central strand does not end at the vitelline menbranc but all all interpolated globule of albuminous substance covered by the chilliziferous membrane. ${ }^{(29)}$

$$
\$ 14
$$

\section{Of the whitish zone on the surface of the yolk.}

In a great many eggs (fig. 24) one or several white strands cxtencl from one or the other central chalazal strand through the chalaziferous membrane on the surface of the yolk, running in no regular way, now on one side, now on the other, or encircling the whole yolk, as if the membrane had been thickened or folded there. These con-

[18] stitute what Vicq d'Azyr* calls the zona albicans; they are very differently disposed in different eggs and do not, as some claim, have a constant form and relation to the yolk. They are nothing but unmistakable remains of the chalaziferous membrane. These surands usually run out from the smaller chalaza at the blunter pole, which being sometimes twisted obliquely passes over into them. There are frequently many of them rumning over a part or the whole of the surface of the yolk, avoiding in general the cicatricula; but sometimes they pass over the middle of it. If you tease off the chalaziferous membrane. it is sometimes possible to demonstrate folds; but usually they are not folds but thickened matter of the membrane itself, giving a silvery sheen like a tendon.

At times strands of this kind are to be found only at the blunter pole of the egg and there is no sign of a chalaza. T Then the allumen. too, is found to be much diminished at the blunter pole of the cogg. almost all of it being gathered at the sharper end. If you were to look into the origin of this condition in the oviduct, you wonlel say it is due to a too rapid secretion of albumen, namely that the part of the yolk which precedes in the passage down the oviduct stimulates its membrane to a copious secretion and quickly exhausts it so that when the upper end of the yolk moves into the same region little is left to be secreted. These conditions in isolated acciclental cases also explain why, under normal conditions, there is a smaller chalazat at the blunter pole of the egg as well as a lesser amount of albumen.

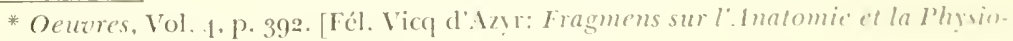
logie de l'Oeuf, etc. (Paris: 1805).]

+ See Léveillé (as cited), P. 116 .
} 


\section{$\S 15$ \\ Concerning the so-called third albumen and the zone of the chalazae.}

In investigating the question of a third albumen, beware lest you delude yourself as others* have done and as I, too, did for a long time. It is true, of course, that the albumen about the central whitish strand of the chalaza is thicker and almost approaches gelatin, and if you wish to call it the third albunen to distinguish it more precisely, I have no objection, although it does go over gradually at the extremities of the chalazae into the rest of the albumen so that it cannot be

[19] delimited in any way. The mound, however, which the cited author figures about the chalaza and which is continued in the form of a girdle to the other end of the egg, where it surrounds the chalaza, and also what he calls the "ambient chalaza" and the "third albumen," all this is not real, but an oblique view of the outer surface of the second albumen, closely applied to the yolk and chalazae after the rest of the albumen has settled to the bottom of the dish by its own weight and diffused. In my opinion, at least, it seems to present an optical illusion because of a peculiar surface. Those who used to talk about a normal girdle of the chalaza surrounding the cicatricula and embracing the yolk sphere [dividing it] at a ratio of $80: 100$ seem to have suffered from a similar illusion.

$$
\$_{1} 6
$$

A membrana propria of the albumen is denied.

Writers are also wont to talk about a membrana propria of the albumen, but I greatly doubt whether anyone has seen it unless he has first produced it artificially, since fresh water forms it by coagulation wherever the water has touched the albumen. I have succeded best in making a membrane of this sort apparent by the following procedure: You kcep a fresh egg after removal of the shell immersed in cold water for several hours. The albumen then develops a rather solid whitish surface. You may now suck off the water surrounding the albumen and insert a slender tube into it as far as the root of the chalaza and inflate the albumen by blowing gently. It gradually swells up into a bubble almost 6 times the volume of the egg. If the operation goes off well, it retains its shape and remains intact. You may then again gently pour on water so that the ovum, now floating freely, may be expanded on the under side where the bottom of the dish pre-

* Comes ab Tredern [Louis Sébastien Marie de Lézérec de Tredern]: Diss[ertatio Inauguralis Medica] sistens Ovi Avium Historiae [et Incubationis] Prodr[omium. (Jenae: 1808)], Figs. 2 and 3. [German translation by L. Stieda, Wiesbaden: 1901.] 
viously compressed it. You then see the yolk with halatale almost free. except where at their ends they pass on both sides inte the albumen. all included in a large expanded cog-shaped sac, lairly firnu and floating on the surface of the water. If you cut into the surface gently, it is possible to strip ofl from it a lairly thick whitish menbranc. I new membrane of the same kind is formed as often as you pour on wate or spirits of wine.

$$
\$ 17
$$

So long as the egg remains in the oriduct, the first or fluid albumen is not present. Neither is it to be distinguished in eggs within the uterus, even when they are aheady covered with a shell. The sconnd albumen at that time sticks to the shell membrane and no ligamsm $\mathrm{mm}$ albuminis is to be recognized at the more pointed end. The first albumen does not diffuse when the newly laid egg is opened under watcr but, remaining ovoid in form and more transparent, it surrounds the second albumen, although it is still at that time much more fluid. The effect of atmospheric air seems to be of chief importance in the formation of this albumen, as in the formation of a blood clot. Perhaps even the air pressure draws the more fluid part from the interstices of the lamellae of the second albumen toward the periphery. It is certain that before the more fluid part has been separated from it, the second albumen is much more readily penctrated by fresh water in which it is placed and the lamellar structure is brought out. The fluid albumen possesses a very great plasticity, as appears when you open the egg under fresh water and after it has diffused it promptly coagulates into exceedingly delicate films and fibers.

If you wish some pleasant amusement, break an egg into a flat dish without adding any water; the fluid albumen which has spread orer the bottom of the dish is easily distinguished from the thicker albumen surrounding the egg. You may then suck up part of the former in a slender tube and drop it into fresh water or a solution of galls diluted with water, or you may pour it so that it setules slowly to the bottom. Then the most exquisite saccules, tubes, membrancs, cell. and fibers are produced, which you can hardly differentiate from une organic structures, and the process gocs on to the point where nature seems to build up structures of her own.

$$
\$ 18
$$

Concerning the origin of the chalarae and their mechanical use.

While the yolk is being invested witl albumen in the oriduct. it is moved along gradually until it reaches the isthmus. Its progress is 1101 like that of the intestinal contents prepelled by muscular walls. I he 
muscular fibers of the mesometria play the most important role as they draw the oviduct hither and thither, bellying, twisting, and con-

[21] stricting it. At this time the part of the mucous membrane which envelops the yolk secretes albumen which takes the form of membranes and promptly sticks to the yolk; on the other hand the part before and behind the ovum is constricted and moulds the secreted albumen into a column, which is twisted upon itself as it is moved along spirally and is gathered up at both poles of the egg; as a result of this torsion it is in general drawn toward the root by which it is attached to the yolk, and there it merges into the rest of the albumen (fig. 24). Since the chalazae are inserted on the ends of the axis of the yolk, their purpose seems to be chiefly to keep the axis rotating always in a single plane. So it comes about that the cicatricula is always the uppermost part of the yolk and nearest the heat of the incubating hen.

If you rapidly twirl an egg in a mechanical device, the chalazae do not acquire more convolutions but the twisted ligamentum albumenis is torn from the shell.

$$
\S 19
$$

\section{Concerning the formation of the shell membrane.}

The shell membrane begins to be laid down on the external surface of the albumen in the lowermost part of the oviduct, which lies between its isthmus and the uterus. First the sharper end enters and is invested with [shell] membrane so that at the blunter end the albumen may often be seen still bare. The isthmus region is so stretched in this period of activity that the folds of the lining membrane are completely wiped out and there is very great tension in this distinctly narrower part of the oviduct. Perhaps the greater irritation of the membrane elicits a denser secretion which produces the membrane. The brief interruption of the mucous folds at the level of the isthmus constriction should also be noted. At this point the transition between the albuminous and membrane secretion is made, and here perhaps the conditions are provided for the formation of the ligamentum albuminis at the sharper end of the egg. The shell membrane is laid down double; the inner is composed of straight fibers of microscopic dimensions, the outer presents no distinctive structure* (fig. 25).

\footnotetext{
* In the egg of Coluber Natrix this internal layer consists of the most beautiful wavy fibers. See G. R. u. L. Ch. Treviranus: Verm [ischte] Schriften [Anatomischen und Physiologischen Inhalts (Göttingen: 1816-21).] Vol. 1, p. 142. [The particular

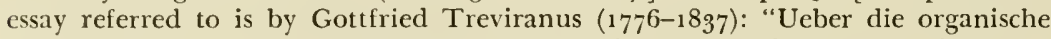
Elemente des thierischen Körpers." The description and figure refer simply to "Eierschale" so that the observations on Coluber were Purkinje's own.]
} 


\section{$\$ 20$}

Concerning the position of the egg in the uterus and the formation of the shell.

I have always found the position of the egg, newly arrived in the uterus, such that the sharper end is pointed towat the vagina, the blunter end toward the interior. In the fully formed egg, horieber, when an effort has already been made to lay, I have somctimes found the blunter, sometimes the sharper, end applied to the opening of the vagina. ${ }^{(23)}$ Perchance in the labor of laying the egg it is often turned until it assumes a comfortable position.

When the shell is beginning to form, you will fund its menbrane al first besprinkled with the most minute calcareous flakes all about the same size and polygonal in form (figs. 26 and 27). Then they keep accumulating and fusing together, but so as to have inconspicuoms interstices which serve for transpiration.

If now you will examine an oviduct which has been opened up from its infundibulum to its entrance into the cloaca, you will find its various parts differentiated for the following functions: The mouth of the infundibulum receives the yolk as it is extruded from the calyx: the following part of the oviduct, which comprises aboul $1 / 4$ of its total length and which is provided with a rather scant glandulan apparatus, secretes the membrane of Dutrochet and the innernout strands of the chalazae; farther along, the internal membrane of the canal is covered by a mucous-producing parenchyma consideribly thickened. This comprises almost two of the four parts of the whole or more, and provides the great investment of albumen for the yolk. Thereupon the oviduct is narrowed at the isthmus and in the follon: ing portion as far as the uterus, [comprising] almost 1,3 of the whole, the shell membranes cover over the albumen. The utcrus, in its turn. serves to secrete the shell; the vagina extrudes the egg through its omm external opening and through the cloaca. The purposes of these organs are readily visible and there is no need of calling in hypotheres (1) build up a "counterfeit presentment" of nature. 


\section{TRANSLATOR'S NOTES}

(1) This is a cordial and generous reference to von Baer's Epistola ${ }^{28}$ announcing the discovery of the mammatian ov'um. It included a complete confirmation and extension of Purkinje's observations $^{7}$ (see translator's note 5). Anyone who has studied the various types of yolk granules in the bird's egg can readily understand how natural it was for von Baer in 1827 to homologize the "granules" of the mammalian "cumulus oophorus" with the white yolk granules of Purkinje's "cumulus" (see Sarton ${ }^{20}$ ). Von Baer saw the germinal vesicle in young mammalian follicles but failed to see it in his "ovulum." He concluded that the entire Graafian "vesicle" is homologous with the oöcyte of the hen and that the "orulum" is the transformed germinal resicle.

In 1833 Coste $^{11}$ reported at a session of the Paris Académie des Sciences that he had identified the germinal vesicle in the rabbit's egg and this was noted a month later in Froriep's Notizen. Purkinje referred to these observations in his 1834 article 29 "Ei." Since his own efforts to find the germinal vesicle in mamnals had been in vain, like Coste's earlier ones, he was not prepared to accept the finding at the time. In the following year, however, Valentin and Bernhardt in Purkinje's laboratory confirmed Coste and this was published in Bernhardt's thesi $\mathrm{s}^{30}$ (1834). In the 1834 mémoire, ${ }^{31}$ Coste reported the disappearance of the germinal vesicle before ovulation in the rabbit, although in the previous year he thought he had recognized it in an oriducal egg. Purkinje's suggestion that the disappearance of the germinal vesicle at the time of ovulation be investigated did not bear fruit for fifty years. At the time the whole situation was fraught with insuperable difficulties, and Purkinje's fear that "this naturally difficult matter might be an unapproachable mystery" was justified (see Meyer, ${ }^{2 \pi}$ chap. VIII). Von Baer thought he had seen the germinal vesicle, as such, extruded from the ripe frog's egg. He was probably observing polar body formation. After his convincing evidence that the germinal vesicle is no longer present just before ovulation in hen and frog he would have been confused indeed if he had known that it was still intact in the tubal eggs of the dog. This is one of the few vertebrates in which the first maturation division does not begin until after ovulation (Van der Stricht, ${ }^{32,33}$ Evans and Cole ${ }^{34}$ ). The understanding of maturation had to wait upon the discovery and interpretation of mitosis and on the unraveling of the histogenesis of the spermatozoon and they in turn depended on the development of staining methods.

(2) See Bartelmez, ${ }^{14}$ p. 328 .

(3) Purkinje does not say here which of the "lines" he means. There were some eight "lines" in use in various European countries at the time, all in the neighborhood of $2.2 \mathrm{~mm}$. In his article "Ei"29 (1834) he gives a series of measurements of hens' oöcytes in "Vienna" lines and his collaborator Valentin ${ }^{35}$ in 1835 employed the same unit. The Vienna line corresponds to $2.195 \mathrm{~mm}$. It would be interesting to know whether the line developed from Aristotle's smallest unit of measurement, a millet seed. A hundred of the dry seeds which I have measured areraged $2.85 \mathrm{~mm}$. in length and $1.82 \mathrm{~mm}$. in width.

(1) Purkinje mentions this term casually as if it were familiar to his readers. When he introduces a new name he is careful to call attention to the fact, so it must be assumed that this one had been used before. I have, however, failed to find it anywhere except in the two editions of the present work. Valentin in his textbook ${ }^{35}$ (1835) implies that the observation of "a clear agranular and perfectly transparent spot at the center of the cicatricula had been made by Fabricius ab Aquapendente, Harvey, and others and had been readily repeated by many naturalists." There is nothing in Fabricius, or Harrey, or any eighteenth-century author I have read, to indicate that the "porus" had been seen in the hen's egg. There are severat figures in the literature before 1825 which show what can readily be interpreted as the germinal vesicle of other eggs. The best of these are Poli's figures in his sumptnous work ${ }^{36}$ on "testaceous" molluscs (1791; see pl. 16, fig. 18, showing a group of young oöcytes from the 
oxary of Cardium). The description of fig. 11, pl. 3, reads: "Eodem microscofno amflifuata et puncto veluti lucido centrali insignila, repraesantur." It secus to be inclicated by I. Geoffroy Saint-Hilaire ${ }^{37}$ in a drawing of a hen's ovary as a clear spot at the conter of the cicatricula in two large oöcytes. There is no reference to it in the legend of text. In 1 sige Home, $^{38}$ describing drawings nade by $\mathrm{F}$. Batuer, referred to "an aperture in the inner uncus brane" of the ovarian oöcyte of the hen, which, he says, "has not hecn before taken notice

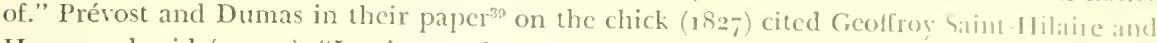
Home and said (p. 421), "Les jaunes de l'ovaire ont une cicatricule tris apparent ... F Hle (") marquée de deux cercles concentriques et d'un point plus trauspanent qui cn oucupe le centre. Ce dernier semble produit par une ouverture de la membrane du jaune." (o) ioms they knew nothing of Purkinje's "Gratulationstrief" of 1825.

It is interesting to note that this interpretation differs from the original ideas of frewont as indicated by Dumas in his 1825 article $^{40}$ in which he wote concenning ovarian hems' "gges:

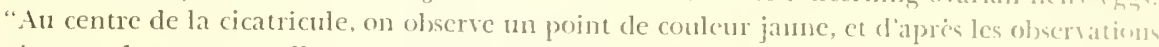
récentes de notre excellent ami le doctcur Prévost de Genève, celui-ci est dì is une peritc zesicle transparente, entièrement semblable à celle qui se rencontre dans la corne les mam. mifères dès les premières jours dẹ l'accouplement." lurthermore, Prévost, in a paper on the development of Unio (p. 450), had described a "cleares disc" in the orarian oümu. Prévost's original idea of a vesicle or disc secms to have been replaced in 182 ; 1 , the notion of an aperture, possibly because Dumas was more impressed by Home's remarks than by his good friend's conclusions. It would appear then that prevost ancl Dumas missed the discorem of the germinal vesicle by as narow a margin as they missed recognising the mammalian orum (see Corner ${ }^{19}$ ). Whoever may have seen the "porms" first, there is no question but that Purkinje's isolation of the vesicle was the furst evidence that it is a discrete structure within the egg.

(5) In the 1825 edition (p. 3) this passage reads: "Porus hic in cicatricula onorum enixorum, et qui in utero atque in oviductu latent nusquam incenitur." In 1830 "cnixorum" (that is, "laid") is changed to "anctorum" (that is, "grown" eggs). Von Bacr had stated in 182 r $^{33}$ that he had in a single instance found a ripe overian egg of the hen in which the germinal vesicle had disappeared (p. 28): "Semel cmim in ovo gallinaceo maturo, in oriario quidem retento sed ad ejectionem parato, vesiculam non inveni." In 1828 he had demonstrated the doers egg to Purkinje, A. Retzius, J. Müller, and E. W' Weber (see Corner, ${ }^{19}$ p. 86) and this matter of the disappearance of the germinal resicle may well have becn discussed at that time. In atnt case, Purkinje stressed the matter in the 1830 "Praefalio" and chaned the text.

(6) The students of spermatozoa and of blood appear to have becn the first to note the untoward effects of water on living cells. Charles Bonnet ${ }^{42}$ in 1759 states that lie had obscriced in 1773 "Si on fait toucher sur les animalcules du sperme humain une goute d'eau de pluic ou mème d'eau distillé, ils perdent à l'instant le mourcment, mais ils le conscrsent dans las salive chaude on froide." William Hewson, ${ }^{43}$ in 1777 , described the change of form and the plasmolysis of red blood corpuscles on the addition of warce to blood. l’urkinje found. as soon as he had his compound microscope (1832), "dass manche Gegcnstände in ihrer Jorm und Gestalt durch Wasser verïndert werden" (articlew on "Ei," 1831, p. 11 j). 11e recommended the use of the thin (outer) albumen of the hen's egrg as a mounting medium. In the first edition of his Handbuch der Physiologie $(1831)$ Johimnes Mithler referred canuall w the effects of water on red blood corpuscles and recommended diluting the blood with weitk salt or sugar solutions. J. Henle 45 in 1841 says regarding the study of fresh tisires, "Nicht ohne bittere Erfahrungen hat man geternt, dass die Wahl der Flüssigkeit, deren man siclı... bedient, nicht gleichgültig ist" (p. 1.13). He advises the use of aqueous and vitreus humors, blood serum, and dilute solutions of sugar, cooking salt, and other neutal salts. I his secums to have led gradually to the general use of normal salt solutions. The carlicst sululy of the exact concentrations of salts necessary to prevent cell injury that I have fonmel is thatt of de Vries ${ }^{46}(1871)$ on the cells of the red beet. 
(7) This is the fluid of the subgerminal cavity which had been of great importance since Aristotle in the discussions of the interchange between the "moist" albumen and the "earthy" yolk (sce Fabricius in translation of Adelmann, ${ }^{25}$ p. 176 ss.).

(8) The fact that a hen may lay fertile eggs for weeks after isolation from the cock was known to Aristotle and was responsible for much of the mysticism surrounding the process of fertilization. William Harvey believed that the "aura seminalis" fertilized the clutch of eggs in the ovary. This idea is not compatible with Aristotle's statement that if a hen is mated and subsequently trodden by a second cock "while the eggs are still yellow," that is, still in the ovary, the chicks will resemble the second cock. It is quite possible for part of a clutch to be fertilized by one cock, the rest by another. (See Fabricius in Adelmann, ${ }^{25}$ pp. 191 ss.). Intraovarian fertilization was actually advocated in 1924 by Iwanow (see Hartman ${ }^{47}$ ). The problem of where the spermatozoa remain during this period of great oviducal activity has yet to be solved, but the suggestion of intraovarian fertilization at the present time indicates only ignorance of the histology of the avian ovary and the early history of the bird's egg.

(9) The pigeon's egg is over a millimeter greater in dianeter after ovulation than the entire follicle was before rupture. This would indicate a rapid resorption of fluid by the yolk at this time and during the condensation of the chalaziferous albumen (Bartelmez, ${ }^{48}$ p. 293). There is considerable fluid in the abdominal cavity at the time of ovulation; see $\$ 10$ of the text.

(10) The original in both editions reads: "alba haec vitelli substantia in enixis primum ovis luculentissime observatur."

I owe to Dr. Adelmann the interpretation of "primum" indicated in the translation, namely, that Purkinje advises anyone who looks for the latebra for the first time to begin with the readily available laid eggs. As a matter of fact the boundaries of the latebra are clearest in large ovarian oöcytes and they rapidly become hazier with incubation. It is possible that Purkinje intended "primum" to signify "newly" laid eggs.

(11) This footnote sounds a bit as if Purkinje had his tongue in his cheek as he replied to a criticism that he had not adequately considered the older literature after the manner of "scholars" who had nothing to write about except what they had read in books.

Bellini developed the notion that the primordium of the chick, which he identified with the cicatricula and with the "sacculus amnii" as well, must be kept away from the air space until incubation had begun, otherwise there would be a great accumulation of gas as in the rotten egg! ("Digressio de ovo," "Ovi aere," etc., in his De Motu Cordis, ${ }^{49}$ 1693). He believed that the cicatricula passes from the surface into the "viscera" of the yolk on boiling as the result of the evaporation of a "liquidum tenuissimum" from the "central cavity."

(12) The original reads: "De Baer ... nostram de latebra centrali vitelli ad theoriam de halonibus applicavit." The translation implies that Purkinje was punning and using the original meaning of $\theta \epsilon \omega \rho \iota a$ (a viewing) for his own observations in contrast to the derived meaning, namely, "theory," for von Baer's application. This theory may be found on p. 10 in Vol. I of von Baer's Entwickelungsgeschichte. ${ }^{15}$

(13) Concentric bands in the yolk were described by William Harvey. Riddle ${ }^{50}$ in 1911 wals the first to explain the differences between the alternate strata of white and yellow yolk.

(14) There is, however, a period in the early growth of the ovarian egg (oöcytes from 0.3 to $1.0 \mathrm{~mm}$. in diameter) when the germinal vesicle is not peripheral, although it is always eccentric, so that the polar axis remains obvious (Bartelmez ${ }^{48}$ ).

(15) This matter was not again carefully studied until 1910 by Maynie R. Curtis ${ }^{51}$ (see translator's note 16$)$.

(16) Phillips and Warren ${ }^{52}$ lave described the process of ovulation in detail. Certain findings eliminate oviducal activities as factors in ovulation. Thus it may occur in the absence of the oviduct (Pearl and Curtis), ${ }^{53}$ or after the petiole has been tied off and the entire follicle has been cut from the ovary and left free in the body cavity (Phillips and Warren ${ }^{52}$ ). This may represent an altered permeability of the vitelline membrane and the taking up of water from the fluid which is abundant in the coelom at this time (see translator's note 9). 
(17) These "corpuscles" do not appear to be the follicular epithelial cells, which could hardly have been resolved by Purkinje's lenses. In a $9 \mathrm{~mm}$. hen's oöcyte on which 1 have tried to repeat his observations the capillaries were so disposed as to give a punctatc appear. ance to the theca interna when viewed fom the imner surface at low magnification.

(18) The pendant ovarian follicle is completely cnfolded by the thythmically contracting fimbriae for some time before ovulation as well as during this momentary encnt itself. $\left(\right.$ Coste; ${ }^{54}$ Bartelmez $\left.^{45}\right)$. As von Baer says, "so schlürft sich der Eileiter des IHulnns die Dotterkugel ein" (von Baer, ${ }^{15}$ vol. II, p. 29).

(19) This passage has been translated by A. W. Meyer,27 p. 130 . Purkinje wrote: "Ast observationis lacunas opinionum commenta non supplebunt." This aphorism replaces screral sentences of the 1825 edition. One of these is worth quoting: "This fluid of the cicatricula of the [laid] egg is by no means to be confused with the vesicle of the ovarian ovulum which I have been describing, although Buffon and Malpighi express themsclice in such a way that anyone who confines his attention to words rather than things might casily cxclaim [clamitel] about my repeating old stuff [crambem]." Purkinje's crisp and conchisive presentation of his discovery was fully accepted by all who understood the matter.

(20) A gibe at Carus, Pander, Joerg, and others who still believed that the orum drops from its ovarian pedicle like an apple from the tree and that the follicular cuvelopes become the shell membranes. It was based on an interpretation of a passage in Aristotle (sce Adelmann, ${ }^{25}$ notes $5^{-10}$, pp. 698-700). Meckel von Hemshach ${ }^{55}$ (1851), von Nathusius ${ }^{50.57}$ (188.j, and others who saw only what they wished to sce, continued this mytl.

(21) The idea is a development of the Aristotelian tradition which homologized the chalaza with the mammalian umbilical cord. It was developed by Bcllinit and Maître-Jan ${ }^{54}$ in 1722 and was revived by Léveillé.

(22) This is the usual condition in pigeons' eggs, especially at the last formed chalaza (that of the blunt end) which when present at all is always the smaller. Harvey, ${ }^{\text {,9 }}$ following Fabricius, says that the chalaza at the blunt end is the larger, but Bellini correctly describes the relations in his "Digressio de ovo." 19

(23) This was forgotten and much printer's ink was wasted (see Bartelnee, "1. 331). 


\title{
REFERENGES
}

1. Heidenhain, R.: Article on Purkinje, in Allgemeine Deutsche Biographie, XXVI (Leipzig: 1888), 717 .

2. Robinson, V.: "Johannes Evangelista Purkinje (1787-1869)" Sci. Month. 29:216, 1929.

3. Hykeš, O. V., and Studnička, F. K.: "Jan Evangelista Purkyně" Osiris 2:ł63, 1936.

4. Eiselt, T.: "Purkyně's Arbeiten" Prager V'rtljrschr. f. prakt. Heilk. Beilage 63:1, 1859.

5. Thomsen, E.: "Über Johannes Evangelista Purkinje und seine Werke . . "Skandinav. Arch. f. Plyysiol. 37:1, 1919.

6. Studnička, F. K.: “Joh. Ev. Purkinjes histologische Arbeiten” Anat. Anzgr. 82:11, 1936.

7. Purkinje, J. E.: Symbolae ad Ovi Avium Historiam ante Incubationem (Breslau: 1825).

The title page of this work reads as follows:

\author{
JOAN. FRIED. BLUMENBACHIO \\ EQ. GUELPH. \\ VI R O \\ DE OMNI SCIENTIA NATURALI \\ UNI OMNIUM MAXIME MERITO \\ UNIVERSITATIS GEORGIAE AUGUSTAE \\ DECORI EXIMIO \\ DIE XIX. SEPTEMBRI MDCCCXXY \\ SUMMORUM IN MEDICINA HONORUM \\ SEMISAECULARIA \\ FAUSTIS OMINIBUS CELEBRANTI \\ GRATULITUR \\ ORDO MEDICORUM I'RATISLAVIENSIUM \\ INTERPRETE \\ JOANNE EV. PURKINJE, \\ P. P. O.
}

\section{SLBJECTAE SUNT SYMBOLAE AD OVI AVIUM HISTORIAM ANTE \\ INCUBATIONEM, \\ CUM DUOBUS LITHOGRAPHIS.}

\section{VRATISLAVIAE, \\ TYPIS UNIVERSITATIS.}

8. Purkinje, J. E.: Opera Omnia (Prague: 1918). (Only the 1830 ed. of the Symbolae is included in these collected papers: p. 195-218.)

9. Cole, F. J.: "Bibliographical reflections of a biologist" Proc. Oxford Bibliog. Soc. 5:169, 1938.

10. Dutrochet, H.: "Histoire de l'oeuf des oiseaux avant la ponte" Jl. de physiq. de chimie etc $88: 170,1819$.

11. Coste, J. J. M. C. V.: "Mémoire sur la développement des mammifères" Institut 1:202, 1833 .

12. Wagner, R.: Article on "Ei," in Allgemeine Encyclopädie der W'issenschaften und Künste, ed. by I. S. Ersch and J. G. Gruber, XXII (Leipzig: 1839), 1. 


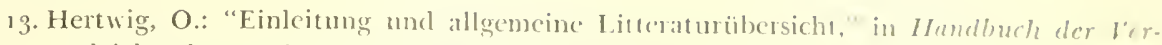
gleichenden and Experimentellen Entadelungslehe der 11 irbelthiere, ed. by (). Hertwig, I. Bd., I. T1., I. HIft. (Jena: Igo6), 1-8,

14. Bartelmez, G. W.: "The relation of the embryo to the principal axis of sumunctry in the bird's egg" Biol. Bull. 35:319, 1918 .

15. von Baer. K. E.: Ueber Entwickelungsgeschichte der Thiere-Beobachiung und lidfexum, I. T1. (Königsberg: 182S); II. T1., |1. H1ft.! (Königsberg: 1837); II. T1., Schlushlıf., cd. by L. Stieda (Königsberg: 1888).

16. Pearl, R., and Surface, F. M.: "Resection and end-to-end anastonosis of the oridnct in the hen, without loss of function" Amer. Il. Physiol. 22:357, 1908.

17. Conrad, R. M., and Scott, H. M.: "The formation of the egg in the clomestic fowl" Plyviol. Revs, 18:481, 1938.

18. Cole, F. J.: Early Theories of Sexual (ieneration () () ford: 1930).

19. Corner, G. W:. "The discovery of the mammalium orum" Quert. Phi Bela Pi Mred. Fratern. 27:76, 1930; also in Lectures on the History of Medicine; a series . . at the Mayo Foundation ... 1926-1932 (Philatelphia and London: ‘c 1933 ), .jo1.

2o. Sarton, G.: "The discovery of the mammalian egg and the foundation of modern cm. bryolog!" Inis 16:315, 1931 .

21. Meyer, A. W.: "Essays on the history of embryology" California \& West. Mc‘l. 35:117. $1931 ; 3^{6: 40,105,176,2.41,341,391,1932 ; 37: 41,111,181,2.13,1932 .}$

22. Meyer, A. W.: "Mr. John Hunter on generation" Califormia \&. West. Med. 13:1.15, 222. $283,358,1935$.

23. Meyer, A. W.: An Analysis of the De Generatione Animalium of Jlilliam Haref (Stanford University, Calif.; London: 1936).

24. Adelmann. H. B.: "The De ovomm gallinaceormm generationis primo exordio progres. suque, et pulli gallinacei creationis ordine of Volcher Coiter" Ann. Mecl. Histor. (n.s.) $5: 327,444,1933$.

25. Adelmann. H. B.: The Embryological Trealises of Hieronymus Fabricius of dquapen. dente (Ithaca, N. Y: 1912 ).

26. Needham, J.: A History of Embryology (Cambridge, Engl.: 1931).

97. Meyer, A. W.: The Rise of Embryology (Stanford University, Calif.; London: 19.99).

28. von Baer, C. E.: De Ori Mammalium et Hominis Genesi Efristolam ad .Icatemiam Imperialem Scientiarum Petropolitanem (Leipzig: 1827). (For "Commentar" on this see Heusinger's Ztschr. f. d. organ. Physik 2:124, 1828.)

29. Purkinje, J. E.: Article on "Ei," in Encyclopädisches Hörterbuch der Medicinischun Irissenschaften, ed. by C. F. V. Grïfe, C. W. Hufeland, H. I. I.ink, K. I. Rudolphi, and E. v. Siebold, X:107 (Berlin: $18_{34}$ ).

3o. Bernhardt, - _.: Symbolae ad Ori Mammalium Historiam ante Praegnationem Thenis; Breslan: 1834).

31. Coste, J. J. M. C. V'.: Recherches sur la Génération dés Mammiféres (Paris: 1831 ).

32. Van der Stricht, O.: "La structure de l'oeuf de chienne et la gendese du corps jaune" C.pls. rd. Assn. d. anatsts. 10:1, 1908.

33. Van der Stricht, O.: "Etude comparée des orules des mammiferes aux différentes périodes de l'ovogenèse d'apres les travaux du Laboratoire d'Ilintologie et d'imbryologic de l'Unirersité de Gand" Archs. de biol. 33:229, 1923.

34. Evans, H. M., and Cole, H. H.: "An introduction to the study of the ocstrous crele in the $\log$ " Mems. Univ. California 9:65, 1931.

35. Valentin, G. G.: Handbuch der Entivickelungsgeschichte des Mcnschen (Berlin: 1835). 36. Poli. G. S.: Testacea utriusque Siciliae enmmque II storia el Inatome (1'arma: 1791-0,j). 37. Geoffroy Saint-Hilaire, E.: "Organes sexucls de lit l'oule: ler memoinc. Iormation ct rapports des deux oviductes" Méms. Mus, d'histoir. natur. 10:57, $182,3$. 
38. Home, E.: "Observations on the changes the egg undergoes during inculation in the common fowl" Philos. Trns. Roy. Soc. (London) 112:339, 1822.

39. Prévost, J. L., and Dumas, J. B. A.: "Mémoire sur le développement du Poulet dans l'oeuf" Ann. d. scis, natur, 12:415, 182\%.

40. Dumas, J. B. A.: Article on "Génération," in Dictionnaire Classique d'Histoire Naturelle, ed. by Baron Bory de Saint-Vincent, VII (Paris: 1825), 194.

41. Prévost, J. L.: "De la génération chez la Moule de peintres (Unio pictorum)" Ann. d. scis. natur. $7: 447,1826$.

42. Bonnet, C.: Considérations sur les Corps Organisés (A Neuchâtel: 1779; "Oeuvres," III).

43. Hewson, W.: Experimental Enquiries, III (London: 1777).

44. Müller, J.: Handbuch der Physiologie, I (Coblenz: 1834), 96.

45. Henle, J.: Allgemeine Anatomie (Leipzig: 1841; "Samuel Thomas von Sömmerring vom Baue des Menschlichen Körpers," neue umgearb. u. vervollst. Orig.-Ausg., IV).

46. de Vries, H.: "Sur la perméabilité du protoplasma des betteraves rouges" Archs. néerland. d. scis. exact. et natur. $6: 117,1871$.

47. Hartman, C. G.: "Ovulation, fertilization and the transport and viability of eggs and spermatozoa," in Sex and Internal Secretions, ed. by E. Allen (2d ed.; Baltimore: 1939), 630 .

48. Bartelmez, G. W.: "The bilaterality of the pigeon's egg" Jl. Morphol. 23:269, 1912.

49. Bellini, L.: See translator's note 11.

50. Riddle, O.: "On the formation, significance and chemistry of the white and yellow yolk of ova" J1. Morphol. 22:455, 1911.

51. Curtis, M. R.: "The ligaments of the oviduct of the domestic fowl" Maine Agricult. Exper. Statn. Bull. no. 176, 1910.

52. Phillips, R. E., and Warren, D. C.: "Observations concerning the mechanism of orulation in the fowl" J1. Exper. Zool. $76: 117,1937$.

53. Pearl, R., and Curtis, M. R.: ". . . On some physiological effects of ligation, section, or removal of the oviduct" J1. Exper. Zool. 17:395, 1914.

54. Coste, J. J. M. C. V.: Histoire Générale et Particulière du Développement des Corps Organisés (Paris: 1847).

55. Meckel von Hemsbach, H.: "Die Bildung der für partielle Furchung bestimmten Eier der Vögel, im Vergleich mit dem Graffschen Follikel und der Dedicua des Menschen" Ztsclur. f. wissnschft. Zool. 3:420, $185^{1}$.

${ }_{5}^{6}$ 6. v. Nathusius, W.: "Besteht eine ausnahmslose Regel über die Lage der Pole des Vogeleies im Uterus im Verhältnis zur Cloakenmündung?" Zool. Anzgr. 8:415, $188_{5}$.

57. v. Nathusius, W.: "Über die Lage des Vogeleies im Uterus" Zool. Anzgr. 8:713, 1885.

58. Maître-Jan, A.: Observations sur la Formation du Poulet (Paris: 1722).

59. Harvey, W.: The Works, tr. by R. Willis (London: 1847), 213. 
DESCRIPTION OF PLATES 


\section{PLATE 1}

Fig. 1. A small piece of a vitelline membrane with adherent cicatricula in the center of which the clear porus is to be seen.

Fig. 2. The same magnified by a lens; the vesicle in the porus is obvious.

Fig. 3. The cumulus of the cicatricula viewed from the side toward the interior of the yolk; on its summit is a minute crater, the inner opening of the porus (interna pori apostomosis).

Fig. 4. The same cumulus of the cicatricula seen from the other side.

Fig. 5. The cumulus spread out in the bottom of a vessel after the water has been removed, so that the porus is expanded and shows the vesicle at its center.

Fig. 6. The vesicle brought more clearly to view after half of the substance of the colliculus had been removed.

Fig. 7. The vesicle after the cicatricula was turned over. Profile view.

Fig. 8 . The vesicle attached to a portion of vitelline membrane.

Fig. $8 *$. A part of vitelline membrane with traces of the zonule and of the torn resicle.

Fig. 9. Vesicle and colliculus cut through the middle.

Fig. 10. Magnified cicatricula of a laid egg with the double circle of the blastoderm and the whitish nucleus in the center.

Fig. 11. The same cicatricula with the internal circle of the blastoderm removed, so that the fluid cavity with the uncovered nucleus and the farinaceous granules may be seen.

Fig. 12. Immature ovarian ovule in which a trace of a cicatricula is to be discerned.

Fig. 13. Same cicatricula removed from the ovule hanging to a bit of vitelline membrane.

Fig. 14. An even smaller ovarian ovule with a suggestion of the vesicle.

Fig. 15. The same containing the vesicle cut open and magnified.

Fig. 16. The yolk divided by a perpendicular cut beginning at the cicatricula. In the center the latebra containing a white fluid; from it a canal is continued to the cicatricula.

Fig. 17. Yolk cut horizontally; the varicolored strata of yolk material are visible.

Fig. 18. Portion of yolk with canal to cicatricula.

Fig. 21. A yolk with first stratum of albumen from which the chalaziferous membrane arises; attached to it are the first beginnings of the chalazae which are found above and below it among the folds of the oviduct.

Fig. 22. Shows the lamellar structure of the albumen surrounding the yolk.

Fig. $22 *$. A part of the chalaza cut off, within it a canal is seen produced by the spirals of the internal strand of the chalaza.

Fig. 23. Part of a vitelline membrane with attached chalaziferous membrane continued into the chalaza [see plate 2].

Fig. 24. Yolk with its chalazae and the whitish girdle of Vicq d'Azyr. 


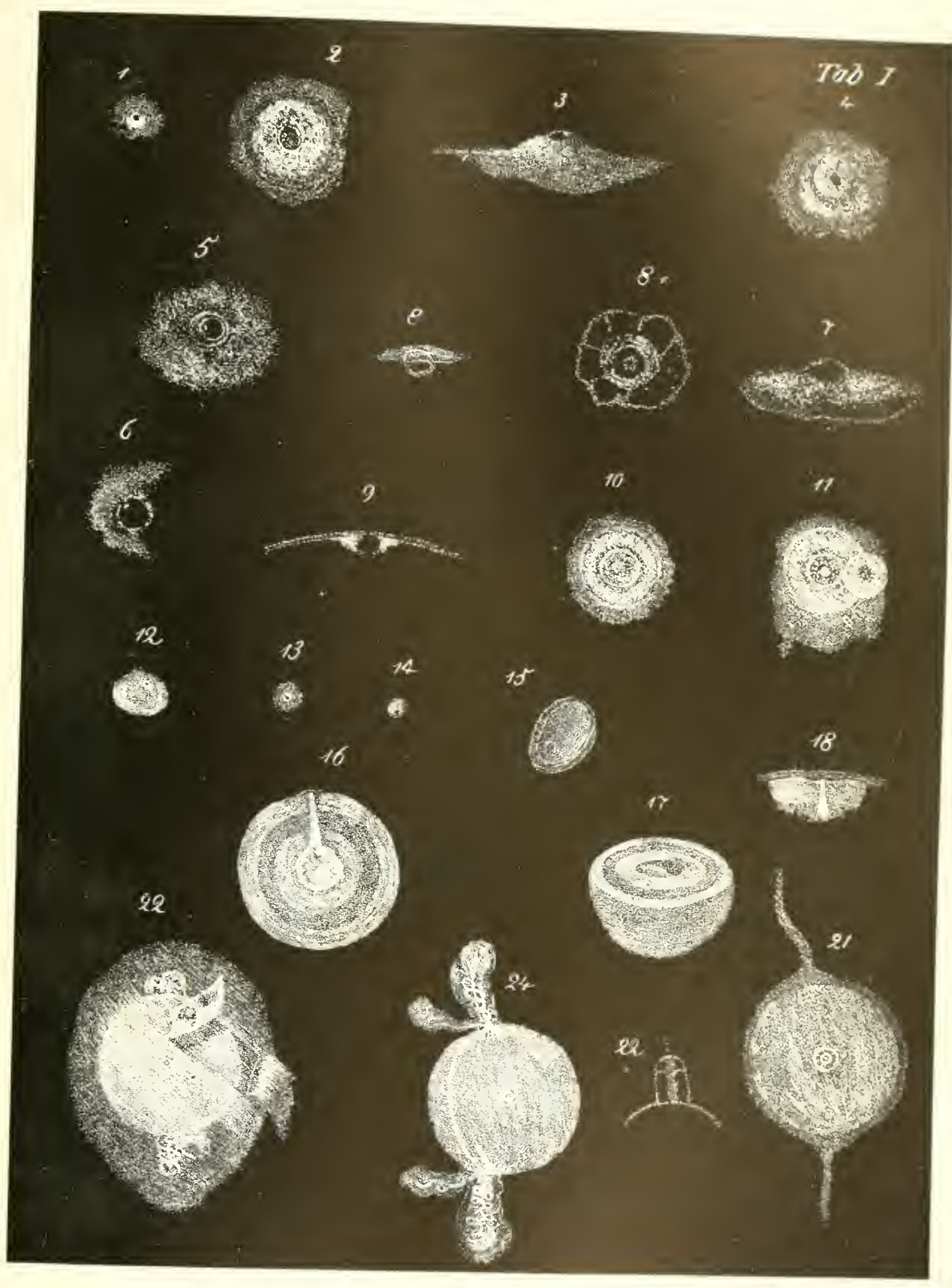

Plate

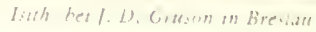


[9o] 


\section{PLATE 2}

Fig. 19. Shows the oviduct of a hen with infundibulum, uterus, and part of vagina.

a. Uterus great with egg.

$b$. Vagina.

c. Muscular fibers which spread out to the vagina, to the sides of uterus, and to the inferior mesometrium.

$d d d$. Inferior mesometrium; muscular fibers are to be seen in this and vessels running parallel with oviduct.

$e$. Fimbriated edge of infundibulum.

$f$. Mouth of infundibulum.

g. Ligament of infundibulum, attached to root of penultimate rib on left side. $h$. Cut-off part of air sac attached to ligament.

Fig. $19 *$. Posterior part of oviduct where it passes into isthmus with the attached mesometrium, composed of interwoven muscle fibers, nerves, and vessels.

Fig. 20. Fimbriated part of infundibulum composed of interwoven muscular network (magnified).

Fig. 25. Part of shell membrane whose margin shows the "woolly" structure.

Figs. 26-27. Bits of shell with underlying membrane while it is being formed by crystallization.

Fig. 28. Elucidating the form of the oviduct. 


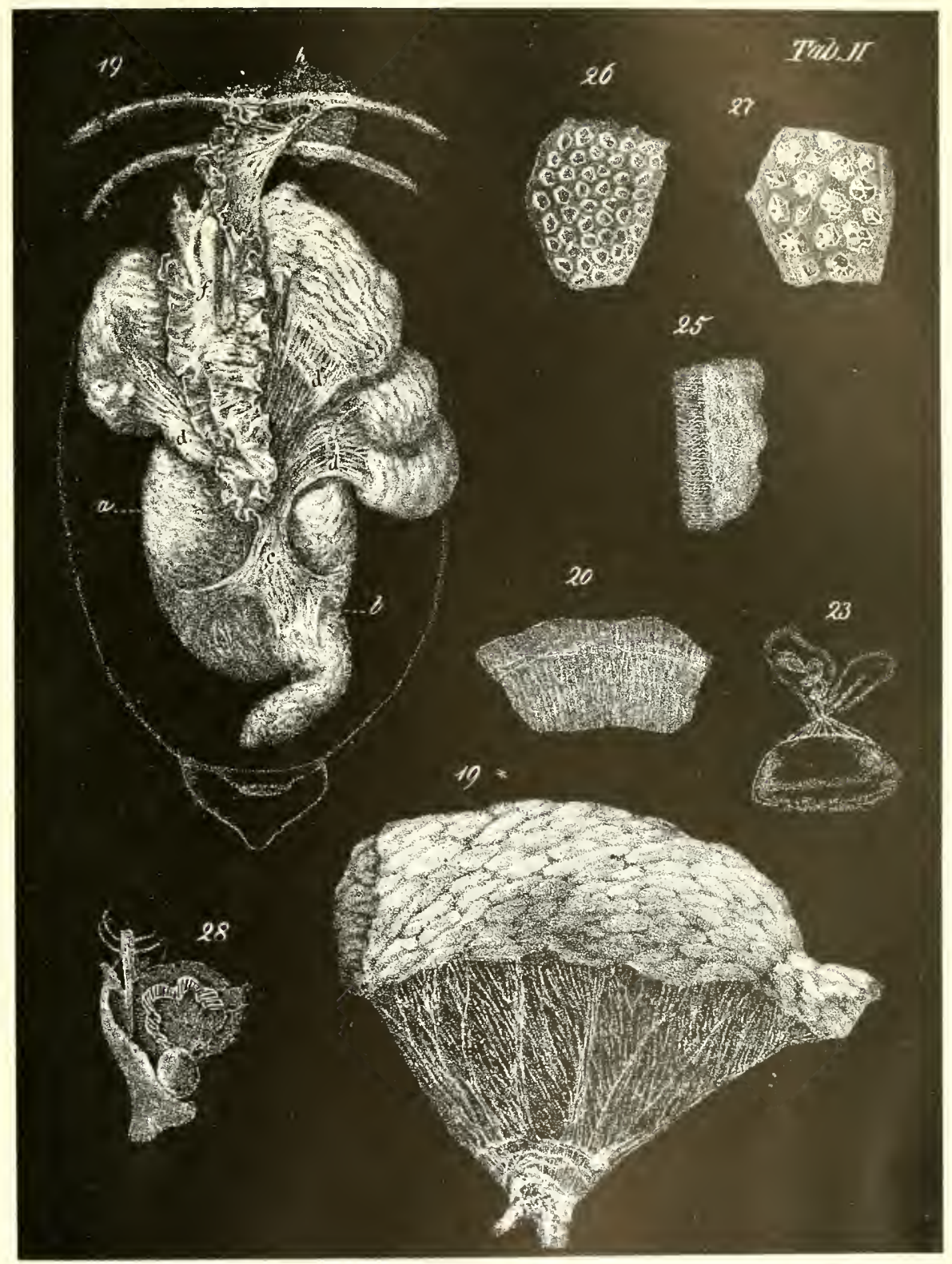

Plate? 



\section{THE LOCALIZATION OF LIPIDS \\ IN CYTOPLASM}

$$
\text { By }
$$

R. R. BENSLEY

\section{策}

From the

DEPARTMENT OF ANATOMY

UNIVERSITY OF CHICAGO, CHICAGO, ILLINOIS 



\section{THE LOCALIZATION OF LIPIDS IN GYTOPLASM}

I

T HAS BEEN obvious for some time that the usual histological methods for the detection of intracellular fat are as a rule successful only in displaying the fats present in the form of discrete globules and leave a large portion of the lipid content undetected. It is even true that cellular organs which display no visible fat may yield a considerable quantity to chemical methods of analysis. This fact has been recently emphasized by the work of Grafflin, ${ }^{1}$ and of Marble, Grafflin, and Smith, ${ }^{2}$ who made coördinated histological and chemical investigations on the fat content of the guinea-pig liver.

The animals used by these observers were kept in a well-fed condition by having food always available, and showed a substantial content of lipids (1.94-3.16 per cent of wet weight equivalent to $6.5-10.5$ per cent dry weight), yet the microscopically demonstrable fat was small in amount and irregular in distribution. The majority of hepatic cells were devoid of fat.

Pathologists will recall that Rosenfeld ${ }^{3}$ showed long ago that the fat content of kidneys containing little or no visible fat yielded on chemical analysis as much as, or even more than, those in an advanced state of fatty change.

Notwithstanding these facts and the warning of Leathes and Raper that a clear solution might yet contain a considerable amount of fat, histologists have continued to accord to histological methods an undeserved measure of confidence for the detection and localization of lipids. Among the latter the phospholipids have particularly captured the interest of investigators and, one after the other, the visible components of protoplasm, such as mitochondria, Golgi apparatus, secretion granules, etc., have been identified as phospholipid in nature.

Experimental cytologists, on the other hand, have paid little attention to these pseudomicrochemical studies and have in gencral assumed that the phospholipids were either dispersed in the cytoplasm or disposed on cellular or intracellular surfaces. Since the publication of the Overton theory of the lipoid nature of the semipcrmeable membranes this point of ricw has been increasingly popular. The studies of Gorter and Grendel, ${ }^{5}$ who deternined that the amount of lipid extractible from erythrocytes was just sufficient to form a bimolecular layer of lecithin on the cell surface; the observations of Mudd and Mudd $^{8}$ on the ready entrance of erythrocytes into an oil layer witl which they were brought into contact; and those of Chambers on the penetration of oil droplets into marine eggs denuded of their ordinary corerings and on the repair of broken cell surfaces-all support the iclea that the surface of the cell either consists of or contains lipids.

The discovery by Bensley and Hoerr ${ }^{8}$ that mitochondria of the hepatic cell could be separated from other cell components for analysis by differential 
centrifugation of suspensions in saline solutions opened up a new line of approach to the problem of the composition of intracellular structures, and in particular the distribution of lipids in cytoplasm. The possibilities of this method were further extended when Claude announced the successful recovery, by high speed centrifugation, of a submicroscopic particle from filtered saline extracts of chick embryo. This fundamental discovery, that protoplasm contained particles of complex composition of a size too small to be seen under the microscope except by the use of the dark field, not only clears the way for the investigation of the chemical nature of these constituents of protoplasm but also reveals the nature of the pitfalls which await the biochemist in his attempts to separate the constituent proteins of cells. These particles, both microscopic and submicroscopic, have considerable stability within certain $\mathrm{pH}$ ranges and electrolyte content, and the answer to the question as to whether the extract contains only the mobile protein dissolved in the cell water or, in addition, in a state of suspension, the special proteins of submicroscopic particles, mitochondria, nuclei, and other structural elements, can be achieved only by meticulous study at each stage of differential centrifugation with microscopic and chemical examination of each precipitate obtained. The extracts of liver examined by Plosz ${ }^{10}$ and Haliburton ${ }^{11}$ undoubtedly contained both mitochondria and submicroscopic particulates. The extracts of the liver made by Luck $^{12}$ using 5 per cent saline at a $\mathrm{pH}$ of 5.0 were probably free from particulates but contained some of the structural proteins and nucleoproteins which are insoluble in $0.85 \mathrm{NaCl}$ at $\mathrm{pH} 6.8$, but are soluble in higher concentrations of salt even at relatively low $\mathrm{pH}$.

It is unfortunate that Claude, misled by an incorrect estimate in the literature of the size of mitochondria should have identified the submicroscopic particles with mitochondria. Mitochondria maintain a certain uniformity of size and type for a given species and physiological state and do not grade in size down to invisibility. On the other hand, the possibility of fragmentation of mitochondria into submicroscopic elements in saline solution, foreign in composition to the cell water, should not be overlooked. These relations will be fully discussed in papers now in preparation dealing with the composition of the particulates. For the purposes of this article it is sufficient to mention that both mitochondria and the submicroscopic particles have a higher percentage of fat than that found in the intact cell. The writer's report on the fat content of mitochondria $\left(\right.$ Bensley $\left.^{13}\right)$ must now be revised, since the discovery of the submicroscopic particles and of the particulate nature of intracellular glycogen $\left(\right.$ Lazarow $\left.^{14}\right)$ makes it certain that the original preparations were contaminated to a varying degree with the other two products. Furthermore, the phospholipid determinations were far too low, because of the use of the unreliable acetone precipitation method.

Mitochondria, separated at centrifuge speeds too low to permit the precipitation of either glycogen or submicroscopics, have a narrower range of variability in fat content than previously reported. The total fat amounts to 
$32-3^{8}$ per cent of the dried product, with a grcat many preparations yielding about 34 per cent. The phospholipid content of this fat, computed as lecithin from phosphorus determinations, is from $45^{-5} 8$ per cent by weight of the whole fat, and corresponds well with the ratio lecithin $\times 100$
liver.

The submicroscopic particles other than glycogen have a higher fat content, ranging from $42-5^{1}$ per cent of dry weight with about the same or slightly higher percentage of phospholipid. Both particles also contain sterols, and, as pointed out by Claude, the extracted lecithin dissolved in glacial acetic acid gives a positive reaction with Schiff's reagent for aldehydes, indicating a content of acetal-phosphatide.

The fat content of the liver in different nutritional states varies within wide limits, but rarely rises above 20 per cent of the dry weight. Mitochondria and submicroscopic particulates therefore contain a much higher percentage of their dry weight in the form of fat than the whole liver. This indicates that some other portion of the cell contains less.

It may be recalled at this point that in a series of splendid and significant researches Bungenberg de Jong ${ }^{15}$ has explored the conditions of precipitation in lecithin emulsions and in mixtures with known content of lecithin, protein, fat, fatty acids, and various electrolytes. The precipitations observed under these conditions he termed "coacervates." These observations and experiments have received little consideration from cytologists, who did not perceive that they had a bearing on the structure of protoplasm. Others brushed them aside with the statement that it was just a new name for flocculation, without perceiving that for the first time a quantitative study of flocculation had been made which gave us an insight into the complex composition of particles visible in cells or separable from them. Bungenberg de Jong's speculations are fully confirmed by the discovery of the true composition of mitochondria and of the cytoplasmic submicroscopic particulates of Claude.

The experiments of Bungenberg de Jong definitely raise the question as to whether lecithin and fats can exist as molecularly dispersed substances in cytoplasm, a question already answered tentatively in the negative for lecithin by McLean and McLean ${ }^{16}$ and by Bloor. ${ }^{17}$ This problem can now be solved by the use of the methods of investigation introduced by Bensley and Hoer and extended by Claude. In some types of cell, as for example the liver, the various particulates can be removed seriatim, examined chemically, and the residual suspension in turn explored for its contents of protcins and lipids.

In a long series of investigations directed principally to the problem of the composition of the particulates in the liver cell of the guinca pig my assistant Dr. Lazarow and I have been impressed with the fact that, as the particulates are removed by mechanical means, both the protein content and the lipid content of the supernatant solution are reduced, but that the lipid diminishes at a more rapid rate than the protcin. A series of experiments 
were therefore undertaken to determine what proportion of the total proteins and lipids respectively were tied up in those little packets which we call the submicroscopic particulates, in the mitochondria, and in the structural proteins of the cell, and also what portion might be considered to be free in the cell water.

At this point $I$ wish to make it clear that we have no assurance at present that the submicroscopic particulates constitute a group uniform in composition. Until all the arts of the biochemist are exhausted in the effort to separate them into uniform categories we shall suspect that many different kinds of particles may be included in this group.

The cell emulsions for this study were prepared by the methods previously described. The animals were stunned, quickly bled, and perfused with 0.85 per cent solution of sodium chloride buffered to $\mathrm{pH} 6.8$ with phosphate buffer and cooled to $2^{\circ} \mathrm{C}$. Then the livers are removed and homogenized with three times their weight of the same saline, by forcing through gauze and then through bolting silk. The resulting emulsion was centrifuged at 1,900 r.p.m. for 15 minutes to remove intact cells and cell debris. Most of the free fat rises to the surface of the centrifuge tube and may be skimmed off, but since the fat globules in the suspension become surrounded with a membrane of surfacedenatured protein some may be carried down with the mitochondria and cell debris. For this reason livers that contained few visible fat globules were selected for these studies. The supernatant from the first centrifugation contains mitochondria, submicroscopic particulates, and various substances in solution. A second centrifugation for 15 minutes at the same speed removed most but not all the mitochondria. The supernatant was next submitted to a 15 -minute centrifugation at 6,00o r.p.m. A new copious precipitate appeared, which is a mixture of mitochondria and submicroscopic particulates.

A final centrifugation of the supernatant at 12,00o r.p.m. yielded a clear supernatant and a transparent cherry-red pellet (see also Claude ${ }^{18}$ ) at the bottom of the tube. If the liver contains particulate-glycogen, there will be below the red pellet a transparent colorless layer of glycogen. Three and onehalf hours at 12,000 r.p.m. usually suffices to clarify the solution completely, although one must keep in mind that there may be particulates of even smaller size in suspension which could be sedimented by higher rotational speeds. However, at the speed used we are well below the gravitational field at which Wyckoff and his associates recovered their macromolecular substances.

Equivalent volumes of the original suspension, before and after centrifugation at the speeds indicated, were analyzed for total protein, total fat, and lecithin content as follows:

The suspension was precipitated by the addition of about three volumes of absolute alcohol. The precipitate, recovered by centrifugation, was transferred to a weighed pyrex extraction thimble and extracted for 48 hours with boiling alcohol, then an additional 24 hours with ether. The extracts were added to the original supernatant from alcohol precipitation, and the whole 
eraporated to dryness on a water bath under a continuous strean of carbon dioxide. This extract contained, in addition to the lipids, neutral salts and organic extractives. The residue was extracted with dry chloroform, filtered into a small weighed flask, and eraporated to dryness in a stream of carbon dioxide. The flask and contents, dried to constant weight in vacuo, gave the total lipids. The fats were then dissolved in alcolnol, the solution transferred to a volumetric flask and diluted to volume, after which an aliquot was taken for phosphorus determination, from the results of which the total phospholipid content, estimated as lecithin, was computed.

TABLE 1

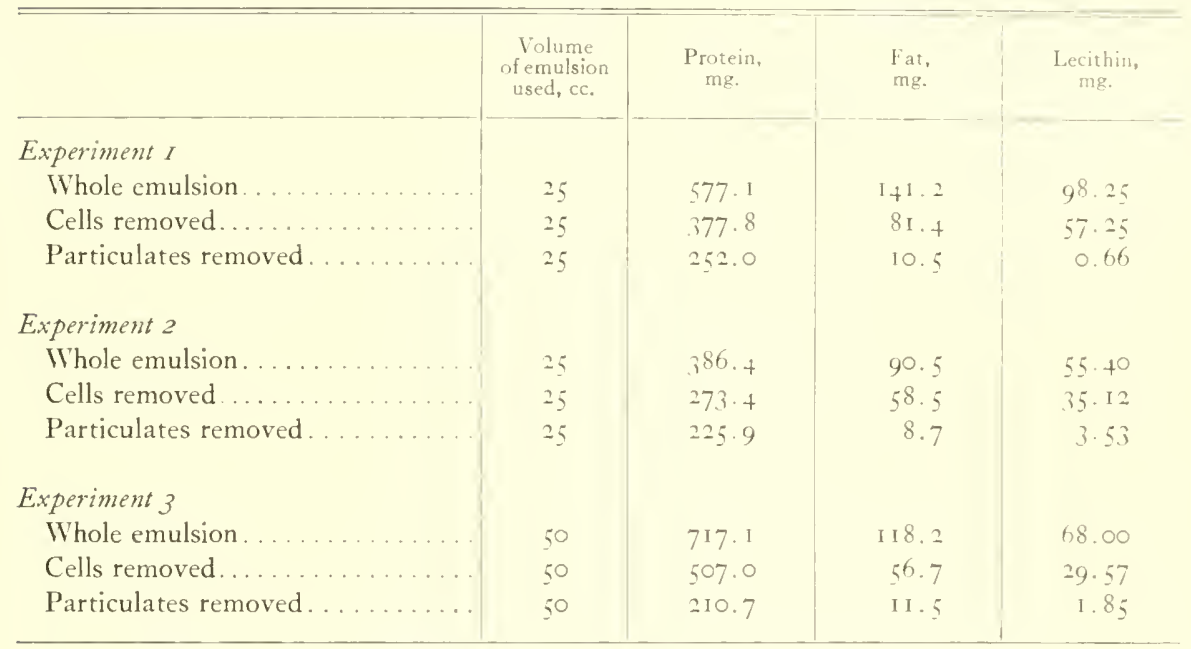

The phosphorus determinations were made by a modified Fiske and Subarrow method, for the details of which I am indebted to Dr. Grafflin of the Harvard Medical School.

Table 1 shows the results of these analyses in three separate experiments.

The striking feature of these analyses is the almost complete disappearance of fats and phospholipids from these enulsions on long-continued centrifugation, indicating that these substances are associated in the intact cell with stable structural elements, and are present only in traces in the intergranular medium.

Since the liver cell is a somerwhat specialized form of the cell, a similar experiment was carried out with the testis of the guinea pig. Four adult guinca pig testes were freed from their capsules and homogenized, as described above. with buffered saline. The emulsion was transferred to a 50 cc. voluntetric flask. diluted to the mark, and thoroughly mixed. Twenty-five cc. were taken for analyses for total fats and phospholipids and the remaining $25 \mathrm{cc}$. centrifuged for $3 \frac{1}{2}$ hours at 12,000 r.p.m. The results are expressed in table 2.

In this experiment the loss in phospholipid content as a result of high specel 
centrifugation is directly comparable to the results obtained in the liver. The percentage loss of other fats is less than in the case of the liver and the ratio of residual fat to residual protein is higher.

The difference in the completeness of the removal in the different experiments is probably due in part to small globules of fat surrounded by protein haptene membranes failing to precipitate or to rise in the process of centrifugation, and to carry-over of part of the precipitate in pouring off the supernatant because of loose packing in the centrifuge tube.

In spite of the completeness of removal of dispersed fats and phospholipids in these experiments, I do not wish to convey the impression that all these substances are contained in mitochondria and submicroscopic particulates.

TABLE 2

QUANTITY

\begin{tabular}{|c|c|c|c|}
\hline & $\begin{array}{c}\text { Protein, } \\
\text { mg. }\end{array}$ & $\begin{array}{c}\text { Total fats, } \\
\text { mg. }\end{array}$ & $\begin{array}{l}\text { Lecithin, } \\
\text { mg. }\end{array}$ \\
\hline $\begin{array}{l}\text { Whole emulsion.............. } \\
\text { Cells and particulates removed. }\end{array}$ & $\begin{array}{r}189.6 \\
78.1\end{array}$ & $\begin{array}{l}79.8 \\
15.7\end{array}$ & $\begin{array}{l}35 \cdot 3 \\
0.26\end{array}$ \\
\hline
\end{tabular}

The neutral fats, sterols, and sterol esters occur also as discrete globules which, however, contain no phospholipid. The structural proteins of the cell remaining undissolved after successive extraction of the cell with normal saline, 10 per cent saline, and $0.00_{5} \mathrm{~N}$ ammonia in distilled water still contain approximately 25 per cent of their dry weight in the form of lipids.

The active participation of lipids must be suspected in the formation of intracellular droplets of a transient sort such as secretion granules, in particular those which brown with osmic acid, such as the zymogen granules of the stomach and pancreas, and artificial droplets such as the neutral red granules of Parat. Nencki and Sieber ${ }^{19}$ found 10 per cent of lecithin in the crude pepsin obtained by dialysis against distilled water from clear gastric juice obtained by sham feeding from a gastric fistula.

\section{SUMMARY}

It has been found that nearly all of the invisible lipids of the cytoplasm of the hepatic cell of the guinea pig are contained in the particulate components of the protoplasm and in other structural elements, and that the interparticulate cell water, while containing much protein, contains a negligible quantity of lipids.

\section{REFERENCES}

1. Grafflin, A. L.: Anat. Recrd. 77:473, 1940.

2. Marble, H.; Grafflin, A. L., and Smith, R. M.: Jl. Biol. Chem. 134:253, 1940.

3. Rosenfeld, G.: Ergbne. d. Physiol., I. Abtl. (Biochem.) 2:5o, 1903.

4. Leathes, J. B., and Raper, H. S.: The Fats (2d ed.; London: 1925).

5. Gorter, E., and Grendel, F.: Jl. Exper. Med. 41:439, 1925. 
6. Mudd, S., and Mudd, E. B. H.: Jl. Exper. Med. $43: 127,1926$.

7. Chambers, R.: Amer. Naturlst. $72: 111,193^{8 .}$

8. Bensley, R. R., and Hoerr, N. L.: Anat. Recrd. 60:449, 193.t.

9. Claude, A.: Science (n.s.) $91: 77,1910$.

10. Plosz, P.: Pflügers Arch. f. d. gsmt. Physiol. 7:371, 1873.

11. Haliburton, W. D.: Jl. Physiol. 13:806, 1892.

12. Luck, J. M.: Jl. Biol. Chem. $115: 491,1936$.

13. Bensley, R. R.: Anat. Recrd. 69:341, 1937.

14. Lazarow, A.: Science (n.s.) 95:49, 1942.

15. Bungenberg de Jong, H. G.: Protoplasma 15:110, 1935.

16. MacLean, H., and MacLean, I. S.: Lecithin and Allied Substances (2d ed.; London: 1927).

17. Bloor, W. R.: in A Textbook of Biochemistry, ed. by B. Harrow and C. P. Sherman (Philadelphia and London: 1935$), 5^{84}$.

18. Claude, A.: Cold Spring Harbor Sympsa. Quantit. Biol. 9:263, 1941 .

19. Nencki, M., and Sieber, N.: Gaz. lekar. 21:422, 455, 482, 500, 1901; Hoppe-Seyler's Ztschr. f. physiol. Chem. 32:291, 1901. 



\title{
THE SOURCE OF EQUINE GONADOTROPHIN
}

\author{
By \\ H. H. COLE AND HAROLD GOSS
}

\section{絽}

From the

DIVISION OF ANIMAL HUSBANDRY

UNIVERSITY OF CALIFORNIA, DAVIS, CALIFORNIA 



\section{THE SOURCE OF EQUINE GONADOTROPHIN}

$\mathrm{T}$

THE BLOOD and tissues of a mare at the 7oth day of pregnancy contain 1 to 4 million I.U. of gonadotrophin. This paper relates to the source of this hormone. Catchpole and Lyons ${ }^{1}$ considered this question and concluded that the chorion produced the hormone on the basis of their findings:

1. The mare pituitary gives very little histological or physiological evidence of increased secretory activity at the time when the hormone level is increasing rapidly.

2. Large amounts of hormone are stored in the endometrium. To accept the view of hypophysial origin one must assume that the hormone is selectively accumulated in the fertile horn of the uterus.

3. One case of early pregnancy was found in which hormone was present in the chorion but not in the blood or endometrium. This, they felt, gave evidence that hormone was first formed in the chorion from which it later passed to the endometrium and maternal blood.

4 . The endometrium in contact with the chorion is much richer in gonadotrophin than is the endometrium of the infertile horn, though marked progestational proliferation occurs in both.

In 1937 we had occasion to test the potency of the endometrium of several mares and were struck by the cup-shaped structures distributed over that part of the endometrium in contact with the chorion. Testing of these cups revealed an extremely high potency as compared to the intervening endometrium. As we did not take samples of these organs for histological study or attempt to make quantitative studies on the amount of hormone in various tissues. publication was withheld until more complete data were available. In 1941 we had an opportunity to obtain material from four grade IV'elsh pony mares at known stages of pregnancy, and this material forms the basis of the present report. The high concentration of gonadotrophin in these cups led us to suspect that they might be the source of the hormone. The present studies were initiated to determine the validity of this view.

We shall first describe these structures briefly and then present the data comparing the potency of these cups with other tissues of the mare.

\section{Description of the Endometrial Cups}

Most of the early workers studying the changes in the endometriun of the pregnant mare failed to observe these structures because of lack of material during the stages in which they are present. Schauder ${ }^{2}$ has described them, however, in considerable detail and we shall only attempt to add to his description. He expressed the view that the hippomanes of the horse are derived from these cups-an opinion which we can confirm, in part at least, for in mare 4 , sacrificed at the $105^{\text {th }}$ day of pregnancy, the cups appear as pendulous structures from the allanto-chorion extending into the allantoic cavity. 
Three mares were sacrificed between the 6oth and 7oth days of pregnancy. In all instances the cups appeared as elevated oval structures varying in maximum diameter from a few millimeters to $3 \mathrm{~cm}$. They are distributed, sometimes in a circular arrangement, over only a portion of the endometrium in apposition with the chorion. From a cursory examination one might conclude that they were cotyledons provided as a special means of attachment between the maternal and fetal membranes. Actually there is no attachment of these membranes at this point; rather, the membranes are separated, due to the fact that the cups are filled with a yellowish-brown, waxy, or glue-like material. In mare 4 , killed at the $105^{\text {th }}$ day, this material was so thick that it could be peeled out with its almond shape intact. In the other cases, however, it adhered like thick glue to the cup or to the chorion. In our opinion, adherence of this material to the chorion explains the one case $\left(\mathrm{K}_{5}\right)$ cited by Catchpole and Lyons ${ }^{1}$ in which the chorion gave a positive response while the endometrium was still negative. We find the potency of the endometrial-cup secretion to be 10 to 30 times greater than that of the cups. Schauder ${ }^{2}$ has well illustrated the gross appearance of these cups.

Histologically the cups have a unique appearance in contrast to the remaining endometrium, as also does the chorion overlying these cups. As Schauder has pointed out, the chorion at these points is devoid of villi (pl. 1, figs. 1 and 2). Mossman, ${ }^{3}$ speaking generally, states that chorionic villi are frequently lacking in areas where the chorion does not come in contact with the endometrium. No doubt, the separation of maternal and fetal membranes by the endometrial-cup secretion explains the lack of both chorionic and endometrial villi at these points. The epithelial cells of the chorion in the cup region are of the tall columnar type and give evidence of greater secretory activity than does the chorion in other regions.

The lumens of the uterine glands are greatly enlarged, having a crossdiameter several times that of the glands in other portions of the endometrium. The lumens are filled with secretion and the pouring out of this material accounts in part for the endometrial-cup secretion. Between the 6oth and 7oth days the necks of the glands are in a poor state of repair; the basal glands have a much healthier appearance (pl. 1, fig. 2). At the $105^{\text {th }}$ day the uterine glands are the conspicuous feature of the endometrial cups (pl. 1, fig. 1 and pl. 2, fig. 4). The glandular epithelium is extremely low and still the glands appear to be secreting rapidly (pl. 2, fig. 4).

The tissue between the uterine glands in the cup area does not present a constant picture. In mare 2, sacrificed on the 63d day of pregnancy, many small cells with scanty cytoplasm are packed between the basal uterine glands (pl. 2, fig. 3). In the upper part of the cup there is evidence of autolysis of both glandular and interglandular tissue (pl. 1, fig. 2). In the other two cases (mares 1 and 3 ), sacrificed between the 6oth and 70 th days, extremely large polyhedral cells are present between the glands, though some of the smaller cells similar to those seen in mare 2 are also present (pl. 2, figs. 5 and 6 ). As the cup from 
mare 2, selected for study, is much smaller than thosc selected from the other mares, it is likely that this case represents an earlier stage. Cups of various sizes are found side by side at this stage of pregnancy. We saved a 11111inum of nuatcrial for histological study because of our interest in hormonal concentration.

This development of the interglandular tissue is comparable to the decidual responses of the endometrium during pregnancy in other forms. Plate 1 , figure 1 , gives evidence, in truth, that the superficial part of the cup is sloughed, as the outline of the cellular debris is still evident. This sloughing begins early in pregnancy, as plate 2, figure 6, shows; the epithelium of the mucosa is alrearly completely lost. In plate 1 , figure 2, the uterine epithelium is still intact at the lips of the cup but completely lacking in the central portion. Perhaps one is justified in referring to this as a decidual response, even though the tissue is shed prior to parturition.

Plate 1, figure 1, shows the pendulous character which the cups assume at the $15_{5}$ th day of pregnancy. These bodies extending into the allantoic cavity are, no doubt, an early stage of the pendulous hippomanes.

\section{Concentration of Gonadotrophin in Endometrial Cups and}

Other Selected Tissues of the Mare

Preparation and Assay of Tissue Extracts. Only a small amount (37 mg.) of endometrial secretion was taken for assay from the endometrial cups of mare 1. This was dried in a vacuum desiccator, again weighed, and then taken up in $10 \mathrm{cc}$. of sterile saline for assay. This secretion was found to contain 29.5 per cent solids. The amount of secretion in this mare was very small. We did not, however, attempt to remore it quantitatively, for we did not know of its unusual activity prior to this time. The endometrial secretion in mares 2, 3, and 4 was much more abundant. These thick mucus-secretions were carefully scraped from the cups and weighed, then taken up in either 1 oo or $200 \mathrm{cc}$. of sterile saline, forming a uniform opalescent solution. A small aliquot was removed from each solution for assay and the remainder frozen at once.

The endometrial cups, the endometrium between the cups, and the chorion were weighed and ground with sand under sterile saline. The mixture was centrifuged and the residue reground and extracted as before. This process was repeated three or four times and the extracts combined. The rolume of the extract was noted, a sample removed for assay, and the remainder frozen.

The pituitary was extracted by repeated grinding with sand and 2 per cent pyridine solution, separating the extract by centrifuge (Fevold ${ }^{*}$ suggested using 2 per cent pyridine for extraction of pituitary tissue). To the combined extracts were added 6 volumes of 100 per cent acetone. The precipitated material, after standing at $2^{\circ} \mathrm{C}$. over night, was removed by centrifuging, and taken up in $20 \mathrm{cc}$. of sterile saline for assay.

The tissues, with the exception of the pituitaries, were assayed by the method of Cole and Erway. ${ }^{5}$ The pituitary extracts were assayed by the weight method of Cole and Saunders ${ }^{6}$ suggested for mare serum, with the exception that the 
injections were made on three consecutive days with autopsy 120 hours after the initial injection. This is an arbitrary procedure,-attempting to make the assays as comparable as possible to those of the other tissues. Inasmuch as the nature of the gonadotrophic response of pituitary tissue differs from blood and embryonic tissues, it is impossible to make a direct comparison. For example, $64 \mathrm{mg}$. of fresh pituitary tissue of mare 4 gave an average ovarian weight of $14.5 \mathrm{mg}$, in a group of four rats and there was no evidence of develop-

TABLE 1

Amount of Gonadotrophin (I.U. per gm.) in Fresh Tissues and in Endometrial-Cup Secretion of Pregnant Mares

\begin{tabular}{|c|c|c|c|c|c|c|c|c|}
\hline \multirow{2}{*}{$\begin{array}{l}\text { Mare } \\
\text { No. }\end{array}$} & \multirow{2}{*}{$\begin{array}{c}\text { Days } \\
\text { pregnant } \\
\text { at } \\
\text { autopsy }\end{array}$} & \multirow{2}{*}{$\begin{array}{l}\text { Crown- } \\
\text { rump } \\
\text { length } \\
\text { of fetus } \\
\text { in } \mathrm{cm} .\end{array}$} & \multicolumn{6}{|c|}{ I.U. per gm. of fresh tissue } \\
\hline & & & $\begin{array}{l}\text { Endometrial- } \\
\text { cup } \\
\text { secretion }\end{array}$ & $\begin{array}{c}\text { Endometrial } \\
\text { cups }\end{array}$ & $\begin{array}{l}\text { Endome- } \\
\text { trium be- } \\
\text { tween cups }\end{array}$ & Chorion & Blood serum & Pituitary* \\
\hline I & 62 & 6.2 & $70, \infty 00$ & $6,75^{\circ}$ & 380 & 10 & 200 & 500 \\
\hline 2 & 63 & $7 \cdot 7$ & $1_{44}, 000$ & 4,100 & 200 & 20 & I 20 & 250 \\
\hline 3 & 67 & 8. I & $3^{I} 4, \infty 00$ & I 2,900 & 750 & 250 & 170 & 250 \\
\hline 4 & 105 & 19.7 & 50,000 & 4,500 & 17 & 5 & 70 & 50 \\
\hline
\end{tabular}

* The assay of pituitaries is not in terms of I.U. but on an arbitrary basis. See text for details.

ment either of the ovaries or of the accessory reproductive organs, while 128 $\mathrm{mg}$. gave an average ovarian weight of $38.2 \mathrm{mg}$. with estrous uteri and vaginal smears in all animals. With mare serum one regularly obtains a clearcut ovarian and accessory organ response with one-sixth of the dose necessary to produce ovaries weighing $38 \mathrm{mg}$.

Gonadotrophin in Various Tissues. Table 1 gives the amount of gonadotrophin per gram of fresh tissue. The endometrial cups contain 50 to goo times more hormone per gram than the chorion and 17 to 260 times more than the endometrium between the cups. The endometrial-cup secretion contains 10 to 35 times more hormone per gram than do the endometrial cups. The slight activity of the chorion could easily be explained by the adherence of a small amount of this secretion to it.

Table 2 gives the total amount of gonadotrophin in various tissues. One endometrial cup with the chorion attached was saved for histological study in each case and this was not taken into account in the computation. Thus, the figures on the amount of hormone in the endometrial cups, endometrialcup secretion, and chorion are somewhat low-approximately $1-5$ per cent of the total tissue was saved for histological study. 


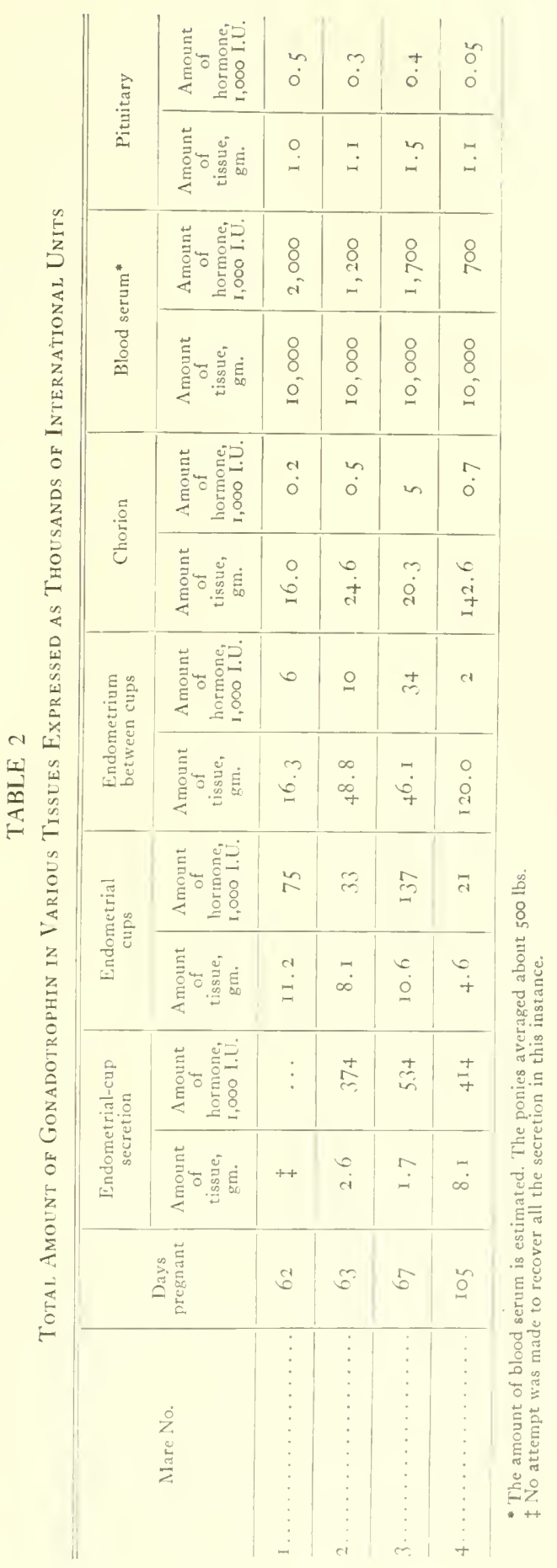




\section{Discussion}

With the additional facts which we now have at hand, let us again consider the question of the source of equine gonadotrophin. The pituitary, chorion, and endometrium can be considered to be the most likely sources.

Pituitary. If the pituitary secretes the hormone, one must consider the possibility that gonadotrophin is selectively taken up by endometrium and more particularly by the endometrial cups, as the hormonal concentration of the cups is much greater than that of the blood. Then one must assume that the cups in turn secrete the hormone into the space between the maternal and fetal tissues in a still more concentrated form. In other words, the cups would be serving as excretory organs. Such a sequence of events seems to us extremely unlikely. If the pituitary were the origin of the hormone then one must assume an unusual activity for this gland. For instance, in mare 3 there is a total of 2.4 million I.U. of hormone accounted for, whereas the pituitary contains only 400 I.U. (table 2). This amount of hormone has accumulated in the tissues over approximately a 25 -day period, as the hormone first appears in the bloom stream at about the $42 \mathrm{~d}$ day of pregnancy. Thus it would be necessary for the pituitary to secrete its total hormonal content 240 times daily to account for the total hormone. It is true, of course, that some complications arise in attempting to compare hormonal concentrations in the pituitary with those in other tissues, as we have previously pointed out. Part of these differences in action may be explained by the finding that the pituitary, unlike mare serum, contains antagonistic substances and further that the pituitary gonadotrophin is excreted in the urine (Evans and co-workers ${ }^{7}$ ). The differences in biological action of gonadotrophin obtained from the pituitary and from serum or placental tissue might be used for a further argument against the view of pituitary origin of serum gonadotrophin.

Chorion. We have reviewed above the arguments used by Catchpole and Lyons $^{1}$ for the chorionic source of the hormone. The fact that the chorionic epithelium overlying the cups gives evidence of special secretory activity could be used in further support of this view. A study of hormonal concentrations in the tissues, however, does not, in our opinion, support this theory. The endometrial cups contain from 50 to 900 times more hormone per gram than the chorion in the 4 mares of the present study (table 1). The endometrium in the cup region is separated from the chorion by the mass of edometrial-cup secretion (pl. 1, fig. 1). If the hormone is produced by the chorion, one can account for the high activity of the endometrial-cup tissue in two ways: gonadotrophin can diffuse slowly into the tissue from the mass of material which we have referred to as endometrial-cup secretion; or it can pass to the fetal blood, thence to the maternal blood at areas where there is close apposition of maternal and fetal membranes, and then be selectively absorbed from the maternal blood by the endometrial cups. The fact that the hormone is a protein and thus diffuses slowly renders the first possibility less tenable. The 
fact that practically no hormone is present in Cetal tissues (Catchpole and Lyons $^{1}$ ) makes the alternative supposition untenable.

Endometrium. It is our belief that equine gonadotrophin is produced in the endometrium and for the most part by the endometrial cups. Catchpole and Lyons ${ }^{1}$ were the first to draw attention to the high concentration of hormone in the fertile endometrium. Against the view that the endonctrium secretes the hormone, however, they cited the fact that the fertile endometrium is high in hormone, whereas the infertile horn is low, even though both horns undergo progestational proliferation. The finding of specialized structures, the endometrial cups, confined solely to the fertile endometrium and very rich in hormone, removes this objection. Another point which they raised against the secretion of the hormone by the endometrium was that in one early pregnancy case gonadotrophin was found in the chorion but not in the endometrium or blood plasma. In this case, they reasoned, the hormone had been produced in the chorion but had not as yet passed in recognizable amounts to the other tissues. As previously pointed out, this case may be explained by assuming that the gluelike endometrial-cup secretion had adhered to the chorion rather than to the endometrium. As this secretion is extremely potent, a few milligrams of it would account for the total activity manifested by the chorion. Even though the assumption of adherence of endometrial-cup secretion to the chorion were false, the finding of hormone in the chorion while it is absent in the endometrium of this mare $\left(\mathrm{K}_{5}\right)$ is nullified as an argument for chorionic source of the hormone by the fact that in two other cases of early pregnancy which they studied ( $\mathrm{D}_{3} 1$ and $\mathrm{D}_{23}$ ) relatively large amounts of hormone were present in the endometrium while the chorion contained none.

Now that we have considered the objections raised to the secretion of gonadotrophin by the endometrium, what is the positive evidence in favor of this view?

1. The endometrial cups contain more hormone per gram than any other tissue. The relatively minute amount of hormone in the chorion, in fact, almost precludes it as a possible source (tables 1 and 2 ).

2. The waxy material in the endometrial cups contains more hormone than any tissue of the mare (in mare 3 up to 300 I.U. per milligram of fresh secretion or 600 I.U. per milligram of total solids) and a major part of this material which we have referred to as endometrial-cup secretion certainly is derived from the endometrium.

3. One can account for the coincident high concentration of the hormone in the endometrial-cup secretion and in the blood most easily by assuming an endometrial source.

4. The endometrial cups are specialized structures to which one can attribute special secretory activity.

5. Considerable hormone is present in the endometrium betwecn the cups (table 2). This strongly suggests that the hormone is not formed exclusively by the endometrial cups. If one were to assunc chorionic production of the 
hormone, the endometrium between the cups might be expected to contain more hormone than the endometrium in the cup area because of the close apposition of maternal and fetal tissues and consequently the better opportunity for exchange (pl. 1, fig. 1). On the contrary, however, the cups contain twenty times or more hormone per gram and the total hormone in the cup is at least three times greater, even though the total weight of the cup tissue is much less than that of the intervening endometrium (tables 1 and 2).

To what cells of the endometrium should one ascribe the secretion of gonadotrophin? Presumably both the glands and the interglandular tissue contribute to the endometrial-cup secretion. Also both tissues differ markedly histologically from the endometrium between the cups. A number of cases sacrificed just prior to and after the appearance of hormone in the blood should provide additional evidence on this point.

\section{Summary and Conclusions}

Quantitative studies on the gonadotrophic concentration in the tissues of four mares, sacrificed between the $62 \mathrm{~d}$ and $105^{\text {th }}$ days of pregnancy, were made, coincident with histological studies of the endometrium and chorion, in order to elucidate the source of equine gonadotrophin. Distributed over a part of the endometrium in apposition to the chorion, specialized structures are found which we have referred to as endometrial cups. These cups contain 4 to 12 I.U. of gonadotrophin per milligram of fresh tissue and furthermore they elaborate a secretion into the uterine space containing 50 to 314 I.U. per milligram of secretion in the fresh state. The histological character of both the glands and the interglandular tissue of these cups differs conspicuously from the endometrium in other areas. We conclude that these endometrial cups are the chief source of equine gonadotrophin.

\section{REFERENCES}

1. Catchpole, H. R., and Lyons, W. R.: Amer. JI. Anat. 55:167, 1934.

2. Schauder, W.: Arch. f. Anat. u. Entwcklgsgeschte. 1912:259.

3. Mossman, H. W.: Contribs. Embryol., Carnegie Instn. Washington 26:133, 1937.

4. Fevold, H. L.: Endocrinology 24:435, 1939.

5. Cole, H. H., and Erway, J.: Endocrinology 29:514, 1941.

6. Cole, H. H., and Saunders, F. J.: Endocrinology 19:199, 1935.

7. Evans, H. M.; Simpson, M. E., and Austin, P. R.: Jl. Exper. Med. 58:561, 1933. 
DESCRIPTION OF PLATES 


\section{PLATE 1}

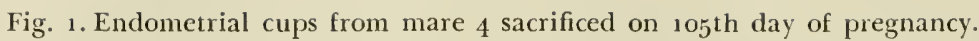
The cups are pendulous at this stage. Note the tremendous enlargement of the lumens of the uterine glands in the cup area. al. c., allantochorion; e.c.s., endometrial-cup secretion; u.g.c., uterine glands in cup area; u.g., uterine glands outside of cup area. $\times 7$.

Fig. 2. Endometrial cup from mare 2 sacrificed on $63 \mathrm{~d}$ day of pregnancy. The uterine epithelium is entirely absent and there is autolysis of all tissues in center of cup. $\times 14$. 


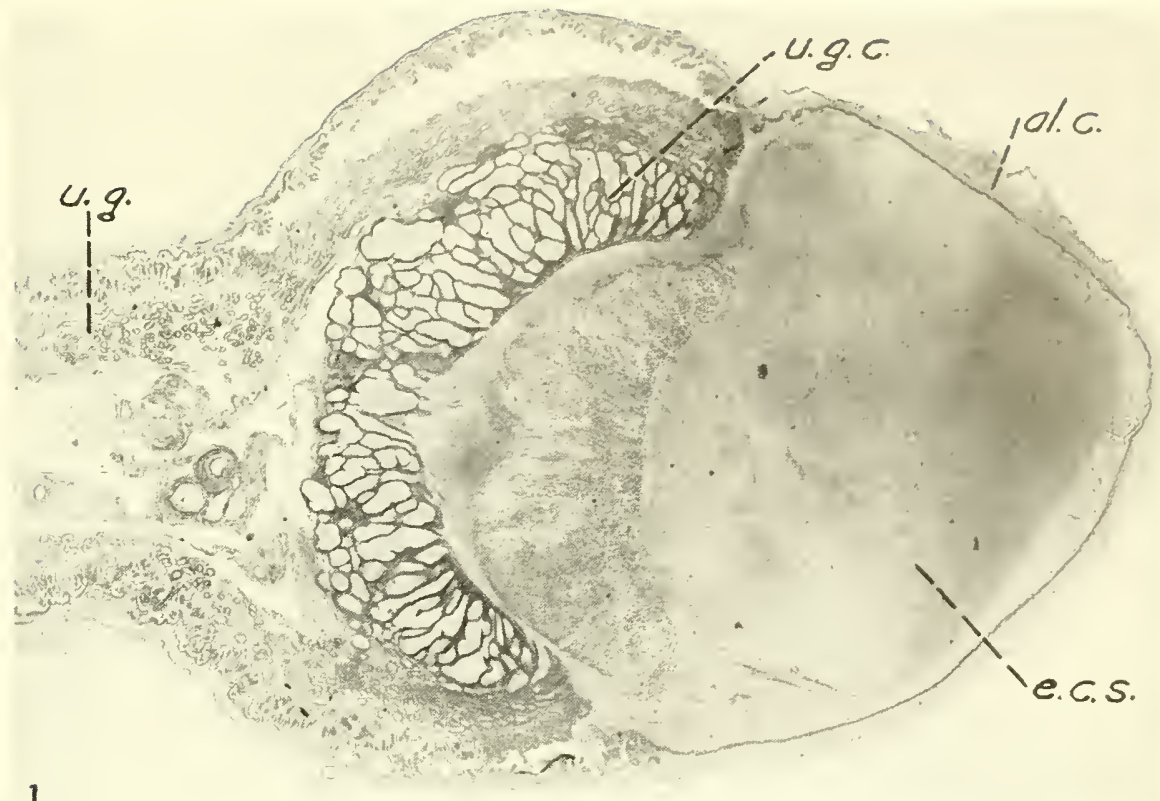

1
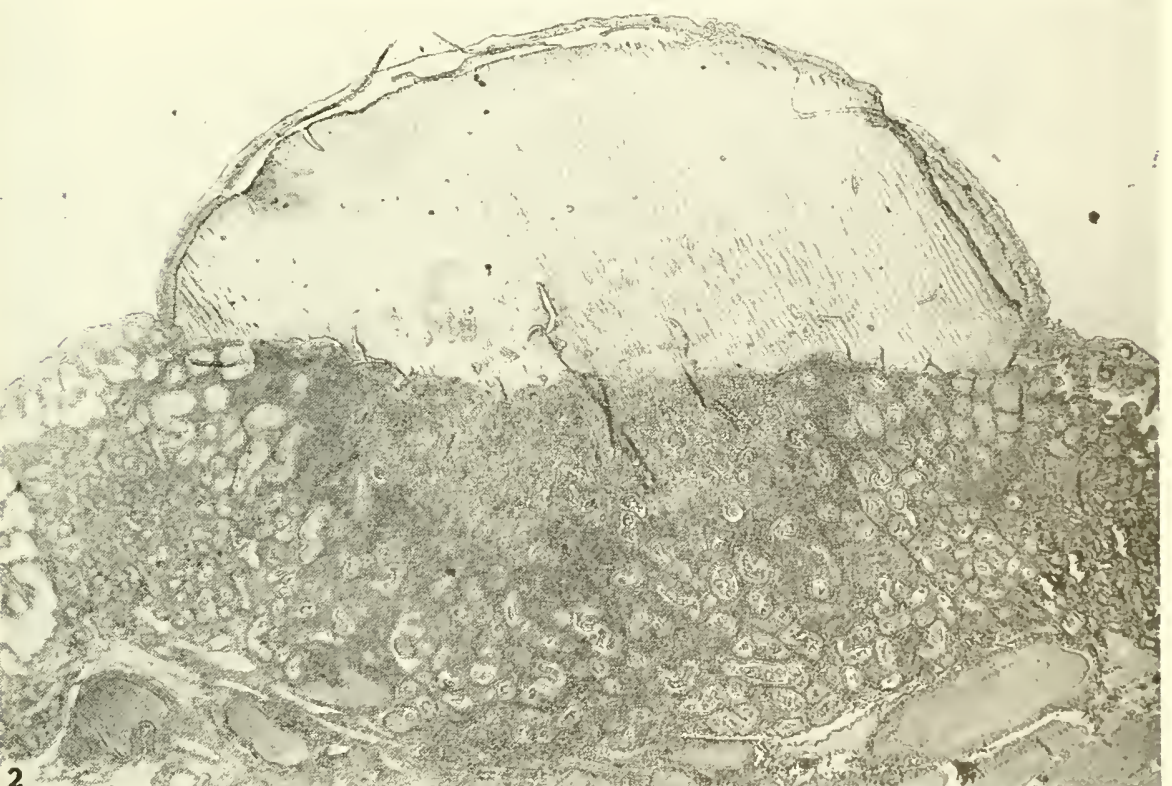

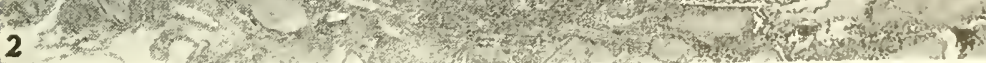

Plate I 


\section{PLATE 2}

Fig. 3. Higher magnification from area near base of cup shown in figure 2 . Compare with figure 5 for variations in character of the interglandular tissue. $\times 170$.

Fig. 4. Higher magnification from area of cup shown in figure 1, to show the sparseness of interglandular tissue at this later stage. Compare with figure 6 . Though the glandular epithelium is low, an abundant secretion is pouring out from the wide-necked uterine glands. $\times 29$.

Fig. 5. Large polyhedral cells in endometrial cup from mare 3 sacrificed on 67 th day of pregnancy. Decidual cells of this type were present in two of three mares sacrificed at this stage. We have not observed them in the endometrium outside of the cup area. $\times 156$.

Fig. 6. To show the character of the endometrial cup of mare 3 from the base to the surface. Though autolysis is not evident in this case, the uterine epithelium is completely absent and the superficial lavers of decidual cells are being sloughed. $\times 29$. 

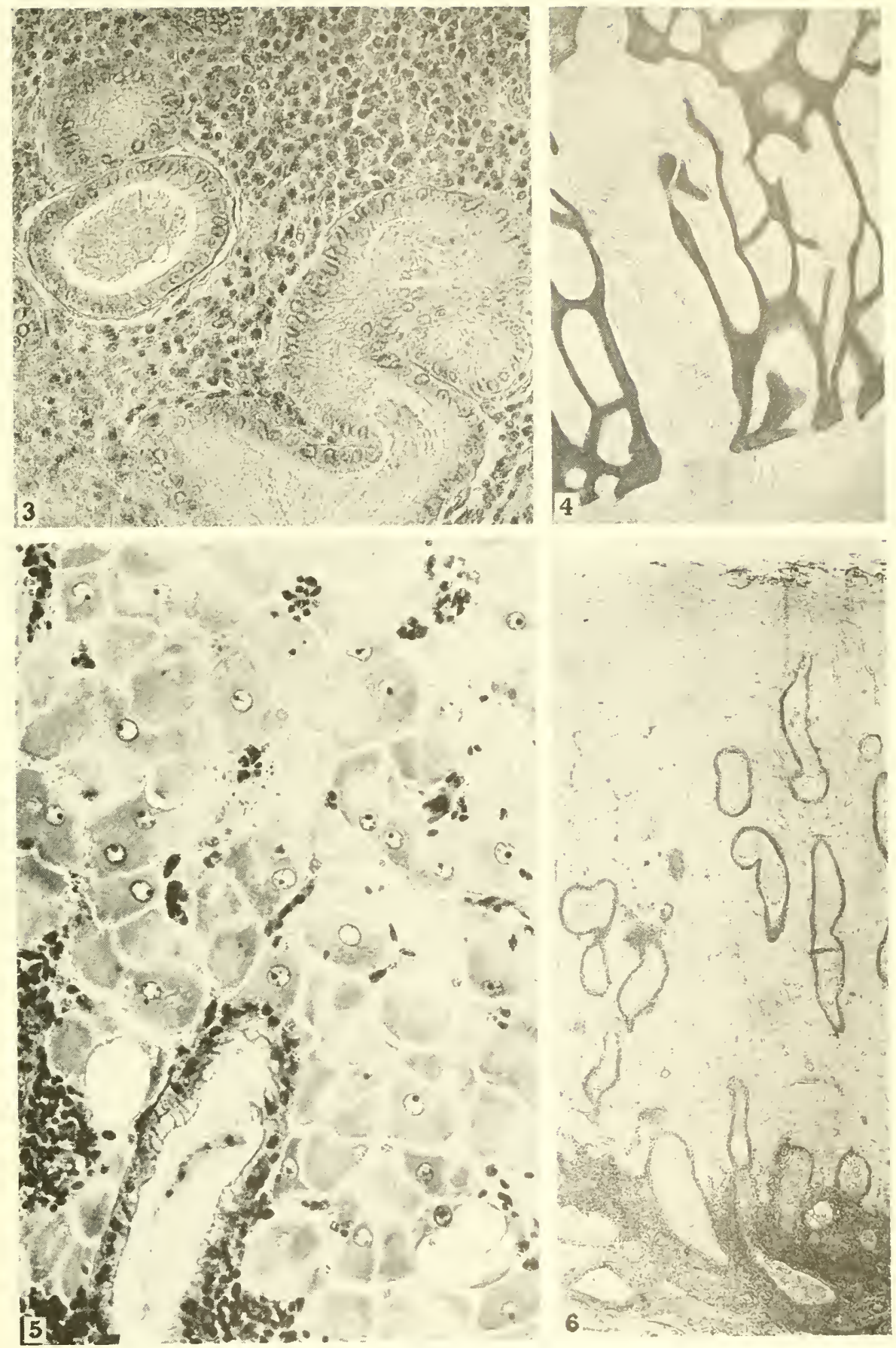

Plate 2 



\title{
ON THE FEMALE TESTES OR OVARIES
}

\author{
By \\ REGNER DE GRAAF
}

Chapter XII of De Mulierum Organis Generationi

Inserientibus (Leyden: 1672)

Translated by

GEORGE W. CORNER

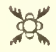

From the

DEPARTMENT OF EMBRYOLOGY

CARNEGIE INSTITUTION OF WASHINGTON

BALTIMIORE, MARYLAND 



\section{TRANSLATOR'S NOTE}

I OFFER THIS English version of DE GRAAF's famous description of the ovaries, for publication in honor of Herbert MCLEAN Evans, in the hope that it will recall to him the happy days when he and I worked side by side in his laboratory, students of the ovary no less enthusiastic than our predecessor De GraAf. Himself, like DE GraAF, a distinguished contributor to the physiology as well as the anatomy of the reproductive system, he will (I hope) find pleasure in reading this masterpiece of the brilliant young Dutchman.

In another place (Corner, 1930) I have discussed the background and the relative importance of the contribution made by DE GRAAF. It will be sufficient to say here that what follows is the first thorough description of the mammalian female gonad and that it proved and established the fact that this organ, like the ovary of birds, is actually an ovary. DE GRAAF did not, of course, identify the actual orum; by a very excusable error he assumed that the whole contents of the follicle is the egg. He was, indeed, much surprised when he traced the rabbit's embryos back to the third day after copulation, when they were still blastocysts in the oviduct, to find them so much smaller than the follicle. This discrepancy DE GRAAF never solved.

His name has long been attached to the ovarian follicle, but it might with more justice have been applied to the corpus luteum; for the latter receives in this chapter its first good description, whereas the follicles had been seen previously and the description given of them here is not much more extensive than that of his predecessors.

The chapter has, to the best of my knowledge, been translated into modern languages only twice before. The whole book on the female reproductive system is included in the Dutch translation of the complete works of DE GrAAF, published at Leyden in 1686. Our chapter on the ovaries was translated into English by that remarkable anatomist of Edinburgh, Robert Knox, in 1848 . This version, published in an obscure place, is now scarce. The Army Medical Library kindly permitted me to have it photographed. In polishing my own version I have not hesitated to borrow a happy word from Knox now and then, and in return I believe I have corrected one or two errors in his translation. In doubtful cases $I$ have accepted as probably correct the reading of the Dutch translation, made within a few years of the original Latin text.

The three plates which accompany the chapter have been photographed from a copy of the first Latin edition in my possession.

The portrait of DE GRAAF has been redrawn by Mr. D. K. Winter from the contemporary engraving which was used as the frontispiece of De Mulierum Organis and of the complete Opera. 


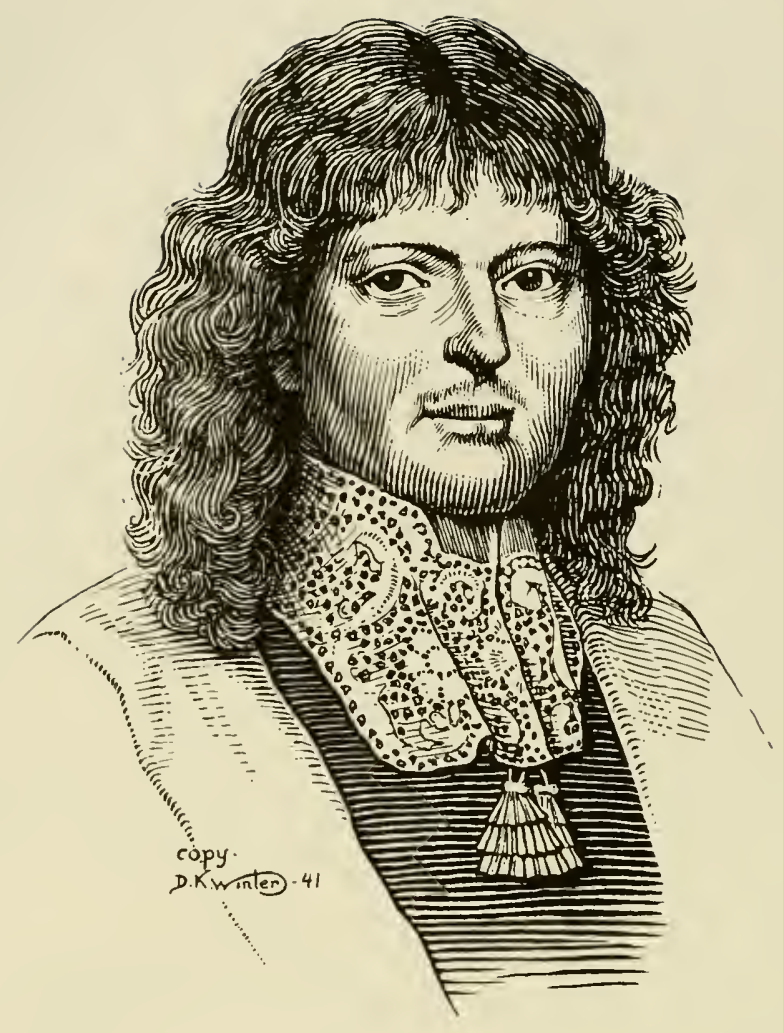

REGNER DE GRAAF

$164^{1-1673}$ 


\section{$[171]^{*}$ ON THE FEMALE TESTES OR OVARIES}

THE TESTES of women differ much from those of the male as to posi1 tion, form, size, substance, integuments, and function, as we are about to describe.

Thus, they have not an external position as in men, but are located in the lowest portion of the abdominal cavity about two finger breadths from each side of the fundus of the uterus, to which they are attached by a strong ligament which is called "Vas Deferens" by many anatomists, because they believed that semen was transferred through it from the testes to the uterus; on the other sides they are firmly attached to the peritoneum about the region of the iliac bone by the spermatic vessels, which supply them, and by the membranes with which the spermatic vessels are involved; so that the testes, fixed

$[172]$ on each side, as if suspended, reach about the same level as the fundus of the uterus in the non-pregnant; in the pregnant, however, although they follow the fundus of the uterus to some extent, they do not rise to an equal degree, and thus, the more the fundus of the uterus rises, the farther they are from it, always keeping a lower position.

The testicles are not suspended by any cremaster muscle, although some state this opinion, following Soranus.

They are located in the interior cavity of the abdomen, in order that they may be nearer the uterus and serve the better and more easily their intended purpose, which will be fully demonstrated below.

The testes of women, since they are broad and flattened on their anterior and posterior sides, differ much from those of men, for in their lower part they have a semi-oval bulge, while in the upper part, which the blood vessels enter, they appear more flat than humped,

[173] so that the testicles when separated from the blood vessels and the ligaments present a somewhat flattened semi-oval form.

The surface is more uneven than in males, because on account of the contents it projects unequally here and there, and displays certain small fissures in different places from time to time, due to depression or retraction of its coverings. Moreover, their size varies not a little with age, for in developing girls and [in women] in the flower of their life they weigh almost one and a half drachms, so that they attain a size about half that of the male testis, although in proportion they are wider and more succulent. In the old and decrepit, they are smaller, firmer, and more dried up, and slowly wither more and more,

* Numbers in the margin indicate the pages of the original Latin text of 1672 . Words in brackets are explanatory additions by the translator.

$$
[125]
$$


but never disappear completely; we have observed that the smallest testicles of old women weigh one scruple. In newborn and young

[174] infants they usually weigh from five grains to half a scruple; and therefore are smaller in these than in the very old, although most anatomists say they are larger in infants and gradually diminish with the thymus gland. In exceptional cases, however, the testicles grow to a remarkable size and contain within them such a quantity of fluid that they are dropsical: of which condition Schenck gives many examples in his observations, and Riolan and others, as well.

Moreover, the coverings of these testicles differ much from the male, for the latter are enveloped by many tunics, so that although hanging freely, they are protected from all injury; but the former are not altogether deprived of such protection, since they are invested by a tunic peculiar to themselves, called dartos by Galen; which although it is only moderately tough, is not easily removed from the substance

[ 175$]$ of the testes, for it adheres to them as if continuous with their substance.

A membrane arising from the peritoneum covers the upper part of the [male] testicles and the blood vessels supplying them, and the same is generally consiclered to be true also of the female testicles. Some, however, who neither by boiling [the ovary] nor by any other artifice have been able to distinguish this membrana propria from the peritoneum, by a different appearance, agree with us that the [female] testes are covered with a single membrane originating from the peritoneum, and that it seems thicker [than the covering of the male testis] because it is so much more firmly bound and united to the [subjacent] parenchyma that one can scarcely see how it may be separated from it or divided into many membranes; but since this is not a matter of great importance, let us leave the decision as to the number of these coverings free to everyone.

$[176]$ When the covering of the testes is removed, their whitish substance is revealed, which in every way differs from the substance of the male testicles, for the former, excluding from consideration certain membranes and nutritive vessels, are composed of seminal vessels which if mutually joined to each other, would exceed twenty or even forty ells in length; the testicles of women are not composed of similar vessels and no one, diligent as he may be, can in the least separate them [into vessels].

Their internal substance is chiefly composed of many membranes and fibrils, loosely bound to one another, in the interstices of which are found many bodies which are either normal or abnormal. The normal structures, regularly found in the membranous substance of the testicles just described, are vesicles full of liquor, nerves, and [ 177 ] nutritive vessels, which [that is, the blood vessels] run to the testes 
in almost the same way as in males, as we have already described, and course throughout the whole of their substance, and enter the vesicles, within whose tunics many branches end after free division, in just the same way as we have seen happening in the ovaries of fowls composect of clustered egg yolks.

As to whether the lymphatics found in the testes enter their substance, we have not yet determined with sufficient clearness to venture an assertion, although this seems probable.

Those structures, which though normal, are only at certain times found in the testes of women, are globular bodies in the form of conglomerate glandulae which are composed of many particles, extending from the center to the circumference in straight rows, and are enveloped by a special membrane. We assert that these globules do not exist at all times in the testicles of females; on the contrary, they are [ 178$]$ only detected in them after coitus, [being] one or more in number, according as the animal brings forth one or more foetuses from that congress. Nor are these always of the same nature in all animals, or in the same kind of animal; for in cows they exhibit a yellow color, in sheep red, in others ashen; because a few days after coitus they are composed of a thinner substance and contain in their interior a limpid liquor enclosed in a membrane, which when ejected with the membrane leaves only a small space within the body which gradually disappears, so that in the latter months of gestation they seem to be composed of a solid substance; but when the foetus is delivered these globular bodies again diminish and finally disappear.

Finally, the abnormal objects sometimes found in the testes of romen are hydatids, calculi, steatomata, and other similar things.

[179] From what has just been said, everyone will readily gather that it is the vesicles or their contents solely, which the nerves, arteries, veins, integuments, and the other structures normally obscrved in the testes are designed to serve.

These vesicles have been described under various names by Vesalius, Fallopius, Volcher Coiter, Laurentius, À Castro, Riolan, Bartholin, Wharton, Dom. de Marchettis, and others, whose accounts it would be too tedious to repeat here in full; it will not, however, be amiss to quote two of them at the present time, in order that the truth nay be confurmed by their words. Fallopius says in his anatomical observations: "I have seen in them indeed certain resicles, as it were, swollen out with a watery humor, in some yellow, in others transparent”; À Castro, also (lib. 1, cap. 4: “De Natura Mulierum"), silys: "The testes have within them, besides the ressels, certain cavities full

[ 180$]$ of a thin and watery humor which is like whey or white of cgg." Some call these vesicles hydatids, but the celebrated Dr. wan Horne in his Prodromum prefered to call them owa, a term which since it seems 
to me more convenient than the others, we shall in the future use, and we shall call these vesicles ova as does that distinguished man, on account of the exact similitude which they exhibit to the eggs contained in the ovaries of birds; for these, while they are still small contain nothing but a thin liquor like albumen. That albumen is actually contained in the ova of women will be beautifully demonstrated if they are boiled, for the liquor contained in the ova of the testicles acquires upon cooking the same color, the same taste and consistence as the albumen contained in the eggs of birds.

It is of no importance that the ova of women are not, like those of [181] fowls, enveloped in a hard shell, for the latter are incubated outside the body in order to hatch the chickens, but the former remain within the female body during development, and are protected as thoroughly from all external injuries by the uterus as by a shell.

But before we proceed farther in their description it must be determined whether they are found in animals of all kinds and in what way they differ from hydatids.

We may assert confidently that eggs are found in all kinds of animals, since they may be observed not only in birds, in fishes, both oviparous and viviparous, but very clearly also in quadrupeds and even in man himself. Since it is known to everyone that eggs are found in birds and fishes, this needs no investigation; but also in rabbits, hares, dogs, swine, sheep, cows, and other animals which we have dissected, those structures similar to vesicles exhibit themselves to the eyes of the dissectors like the germs of eggs in birds. Occurring in the superficial part of the testicles, they push up the common tunic,

[ 182$]$ and sometimes shine through it, as if their exit from the testis is impending.

These ova differ much in animals of various kinds, for we have observed that in rabbits and hares they scarcely exceed the size of rape seeds; in swine and sheep they reach the size of a pea or larger; in cows they often exceed the size of a cherry.

It must be noted, however, that in these animals, besides the large ova, lesser ones are found, of which some are so minute that they may scarcely be seen, for age and sexual intercourse cause great changes in the ova. In younger animals they are smallest, in older animals they become greater, and after coitus they are changed into the globules formerly described, of which one or more are formed, according to the number of embryos produced by the animal. These ova are so

[ 183 ] plentiful that we have sometimes seen twenty or more, filled with very clear liquor, in one testicle. Believing that these conditions are found in all animals dissected as yet by us, we asked the eminent Dr. N. Steno if he would deign to communicate to us what he had observed of the female testes in various other animals, of which we had not 
sufficient specimens, or which we had had no opportunity to dissect. He granted our request and generously informed us that in fallow deer, guinea pigs, badgers, red deer, wolves, asses, even in mules, and in other animals he had found ora of diverse sizes. These observations, combined with our own, more than sufficiently confirm the finding of ova in the fenales of all species. If any one inquires why they are present in the aged and in mules, which are incapable of reproduction, we say only that they are no more serviceable than the uterus, [male] testes and other reproductive organs customarily found in these as

[ 1 84] well as in fertile animals; many reasons may be given for their sterility, as for instance an improper conformation of their organs, insufficiency of the material of the ova for conception, or many other of the possible causes for sterility.

Since we have said above that we have sometimes found in the substance of the testicles or in their membranes vesicles of another kind very similar to the ova, it becomes important to cite in this place the chief differences between them and the ova.

Vesicles of the other kind, called hydatids, are usually formed with a double tunic. The interior layer, although very thin, is by no means difficult to separate from the exterior and the liquid contents is not easily coagulated by boiling. On the contrary, the common coats of the ova are separated from each other with great difficulty and their liquor is coagulated by boiling; hence, whenever we have found in testes which have been boiled some vesicles filled with hardened sub-

[ 185$]$ siance and others with a liquid humor, we have considered the former ova, the latter hydatids. It must be added that the hydatids now and then are suspended from the membranes of the testicles as if by a peduncle, which as yet we have never found to be the case with true ova.

These ova arise and are devcloped in the testes in exactly the same way as the eggs in the ovaries of birds, inasmuch as the blood flowing to the testes through the nutritive arteries deposits in their membranous substance materials suitable for the formation and nourishment of the ova, and the residual humors are carried back to the heart through the nutritive veins or lymphatic vessels. After the ova acquire their normal size they become invested with numerous tunics or follicles and in these immediately after sexual intercourse a kind of glandular substance grows up, of which the contents of the globules just described is composed. We shall attempt below to explain the

[ 186] purpose for which nature has so arranged [them].

Thus, the general function of the female testicles is to generate the ova, to nourish them, and to bring them to maturity, so that they serve the same purpose in women as the ovaries of birds. Hence, they should rather be called ovaries than testes because they show no 
similarity, either in form or contents, with the male testes properly so called. On this account, many have considered these bodies useless, but this is incorrect, because they are indispensable for reproduction. This is proved by the remarkable convolutions of the nutritive vessels about them, and is confirmed by the castration of females, which is invariably accompanied by sterility. Varro writes that spayed cows will conceive, if they copulate immediately; a thing which is no doubt true of males, in which the seminal vesicles are still filled with spermatic fluid [after castration], but not of females, in which such vesicles are not present. Hoffmann's assertion appears incorrect, a fact which we should amply demonstrate, if it had not already been done by Wharton. How the ova are fertilized and proceed to the uterus will be explained in the following cliapters.

\section{REFERENCES}

Corner, George W.: "The discovery of the mammalian ovum" Quart. Phi Beta Pi Med. Fratern. 27:76, 1930; also in Lectures on the History of Medicine; a series . . at the Mayo Foundation . . 1926-1932 (Philadelphia and London: $\left.{ }_{[\mathrm{C}} 1933\right]$ ). 401.

De Graaf, Regner: De mulierum organis generationi inservientibus tractatus novus demonstrans tam homines et animalia caetera omnia, quae vivipara dicuntur, haud minus quam ovipara ab ova originem duccre (Leyden: 1672).

- - "Een niew ontwerp van de ledematen der vrouwen tot de voort-teelinge dienstig" etc., in Alle de wercken, so in de ontleed-kunde als andere deelen der medicyne, beschreven door de Hr. Regnerus de Graaf, en sijn leven naukerig ontleder en gelukig geneesheer tot Delft (Amsterdam: 1686).

On the Female Testes or Ovaria. Translated for "The British Record" (edited by Charles Clay, M.D., Manchester) from the original edition of 1688 , by R. Knox, M.D., F.R.S.E., Edinburgh (Manchester: 18.8). The copy in the Army Medical Library is bound with: The British Record of Obstetric Medicine and Surgery, for $I S_{7} \&$, vol. $I$. 
EXPLANATION OF PLATES 


\section{PLATE FOURTEEN}

Showing the ovaries of the cow and sheep, indicating what takes place in them after coitus.

Fig. 1. Showing the testicles of the cow.

AA. The testicle opcned lengthwise.

BB. The glandular substance which is found in the testcs after expulsion of the ovum, cut through the middle.

CC. A cavity, in which there was an ovum, almost obliterated.

$\mathrm{DD}$. Ova of various sizes contained in the ovary.

EE. Blood vessels running to the ova.

F. Complex menbranous expansion of the Fallopian tube.

G. Orifice in the end of the tubes.

H. Part of the Fallopian tube cut away, with the ovary.

Fig. 2. Showing the unopened testicle.

A. Testicle.

B. Glandular substance protruding from the testicle.

C. Opening in the center of the foregoing.

D. Part of the membranous expansion of the Fallopian tube.

Fig. 3. Showing the tcsticle of a sheep with transparent ova not yct acted upon by male semen.

Fig. 4. Showing the glandular substance of the globules, rcmoved from the testicle of a sheep, and still containing the ovum.

A. Glandular substance of the globule, opened.

B. Region from which the egg has been removed.

C. The ovum, removed from foregoing.

Fig. 5. Showing a testicle of a shecp from which the otnum was expelled a few days before.

A. Testicle divided through the middle.

B. Glandular substance of the globulcs with its cavity almost obliterated.

CC. Ova of various sizes remaining in the superficial part of the testes.

DD. Blood vessels runing to the ova.

E. Part of the ligament of the testicles. 


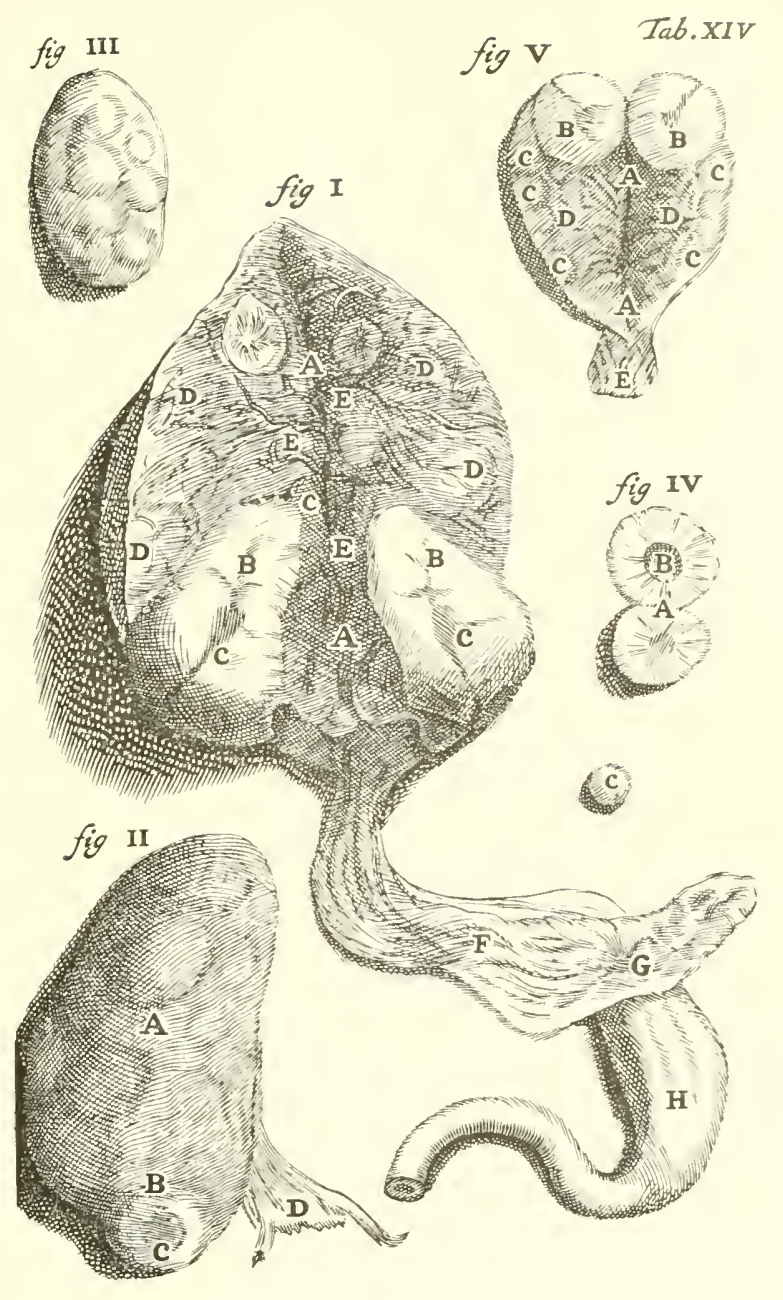

[133] 


\section{PLATE FIFTEEN}

Showing the testicle or ovary of the cow opened, as it is observed before coitus.

AA. The testicle opened lengthwise.

B. Very large or mature ovum still contained in the testicle.

CC. Smaller or immature ova remaining in the testicle.

DD. Membrane of the testicle called Dartos.

E. V'ery large ouum removed from the testicle.

F. Membranous expansion of the Fallopian tube.

G. Contracted orifice in the end of the tube.

H. Extremity of the Fallopian tube.

II. Rest of the tube.

K. Detached part of the utcrine horn.

L. Ligament of the tube, which in humans is like a bat's wing. 


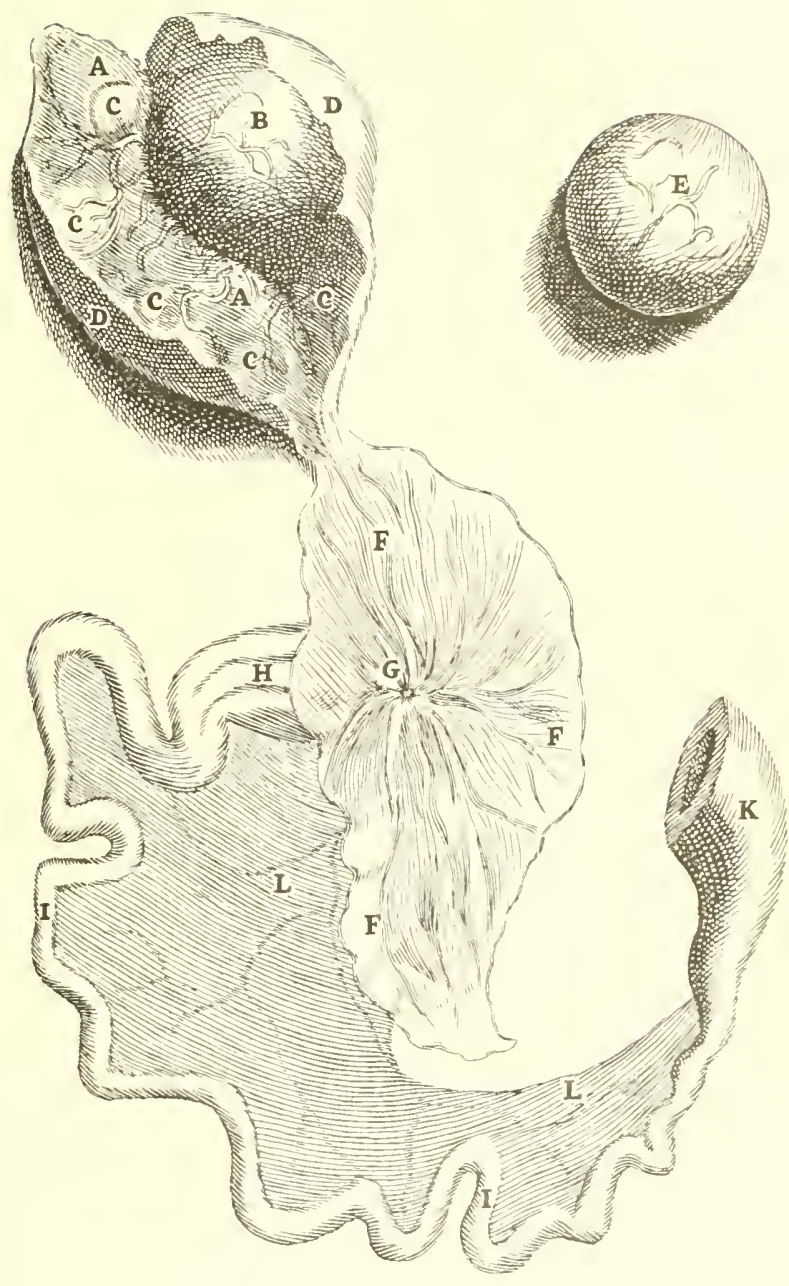




\section{PLATE SIXTEEN}

Showing the testicle or ovary of a woman, with the end of the tube attached.

A. Testicle opened lengthwise at its lower side.

BB. Ova of diverse sizes contained in the membranous substance of the testes.

CC. Blood vessels passing copiously into the center of the testis from its upper part, and ruming to the ova.

DD. The ligament of the testicles, by which they are attached to the uterus, cut.

E. Detached part of the Fallopian tube.

F. Cavity of the detached tube.

GG. Orifice in the end of the tube.

H. Foliaceous expansion of the tube.

I. Foliaceous expansion of the tube attached to the testes. 


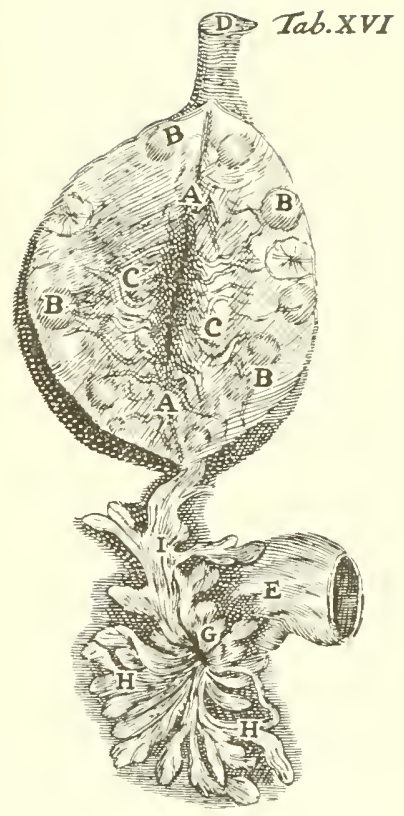

[137] 



\section{THE}

\section{BIOLOGICAL STANDARDISATION OF THE VITAMINS}

$$
B y
$$

KATHARINE H. COWARD

\section{प्र"}

From the

PHARMACOLOGICAL L.ABORATORY OF THE COLLEGE OI THE

PHARMACELTHCAL SOCIETY, LNHERSHTY OF IONDON IT THE NATIONIL INSIFTLE FOR RESEARCH IN DAIRIYAG SHFIFII LD, RE.IDING, BERKSIIRE

E.NGI.IND 

Herbert MaLean Evans

IN WHOSE LABORATORY I FIRST HEARD OF THE EVALIATION

OI: BIOLOGICAL RISULTS BY' STATISTIGAL METHODS 



\section{THE BIOLOGICAL STANDARDISATION OF THE VITAMINS}

CIR HENRY DALE has said that "the object of every committee on biological Standardisation is self-extermination." Chemical and physical determinations are more quickly carried out and, in general, are more accurate than biological determinations, and one of the chief functions of workers on biological assay is to correlate their results with those obtained by chemical and physical methods in order to find out how far these latter methods really measure the activity in question. It therefore behoves workers in the biological field not only to make their determinations as accurate as possible under the very difficult conditions inherent in the nature of their task, but also to apply to their results accepted methods of estimation of the accuracy of their deterninations. Otherwise it is only too easy to blame the inaccuracy of the biological method for differences between chemical and biological results and for differences between two or more biological results.

The same statistical examination of results is needed when two determinations appear to be equal, for there is nearly always good internal evidence from the experiment that there is a fair chance that the results are not in fact equal. The accuracy of a biological determination is generally stated as, for example, a one-in-two chance $\left(5^{\mathrm{O}: 50}\right.$ ) that the result obtained lies outside, plus or minus a certain percentage, of the true result ("the probable error"), a one-in-three chance that it lies outside somewhat larger limits ("the standard error"), a one-in-twenty-two chance that it lies outside larger limits, a one-in-a-hundred chance that it lies outside larger limits still. These chances are often stated as probabilities that the result lies within the corresponding limits when they are designated as the limits of error for $\mathrm{P}=0.5^{0}, 0.67,0.95,0.99$ respectively. Every biological determination should be stated as the result obtained together with the limits of error corresponding to the probability most likely to be of use in evaluating the result. The Sub-Committee on the Accuracy of Biological Determinations, of the British Phamacopocia Commission, chose to express the limits of error of the tests it described for $\mathrm{P}=0.95$ as being the figure in rather general use, and also for $\mathrm{P}=0.99$ as being a figure which a court of law would probably consider large enough in possible legal proceedings. ${ }^{1}$

\section{Essentials of the Biological MethoD}

Workers on the biological assay of vitamins now generally recognise certain essentials for their task. Some of these were apparent almost at the beginning of the attempts to measure these factors; others have become evident only through arduous and most painstaking labours.

1. Standard of Reference.-Every worker is faniliar with the variation in

$$
[1,1,7
$$


response of different animals to the same dose of any vitamin. Every worker who has tested the same dose of a vitamin at several different times is familiar with the fluctuation in the average response of the groups of animals used, and hence he has realised that it is impossible to make a direct comparison between a result obtained with a dose of a particular preparation at one time with the result obtained with a similar dose of another preparation at a different time. For example, it is impossible to compare summer and winter milk by determining the average responses of two groups of rats which were dosed in the summer and winter months respectively. The only way of comparing summer and winter milk is by comparing each separately with a preparation known to be stable throughout the interval elapsing between the tests and thus indirectly to make the comparison between the two samples. The same method is even more necessary if results obtained in one laboratory are to be compared with results obtained in another.

A standard of reference for this purpose may be any preparation of the substance to be determined provided it conforms to accepted criteria of purity; but if there is any doubt as to the possibility of obtaining the substance in a nearly enough pure form, or, as has often happened, a standard is required before even the identity of the substance has been recognised, then one preparation of the substance in possibly a very impure form should be made available to workers throughout the world and a particular weight of that particular preparation should be accepted as a unit of the activity it is designed to measure. When the active substance itself becomes available in acceptable form, then the impure standard and its unit can be discarded. Probably by that time, the chemistry and physics of the vitamin will be so far known that the potency of a preparation for therapeutic use will be determinable by chemical or physical methods, although the activity of a food substance may, through difficulties of extracting the vitamin quantitatively, still have to be determined by a biological comparison with the pure substance or the original standard of reference. If compared with a sample of the pure substance which is not the actual preparation adopted as an International Standard, then the potency of the food substance should be stated as the weight of active substance per gram, not as a number of International Units.

Up to the present, four standards of reference for vitamin determinations have been adopted for international use by the Health Organisation of the League of Nations. ${ }^{2}$ For vitamin A, in 1931, a preparation of carotene was made available. With increased knowledge of the chemistry of carotene, this preparation proved to be a mixture of $\alpha$ - and $\beta$-carotenes, and in 1934 it was replaced by a pure sample of $\beta$-carotene, the weight of the new preparation accepted as a unit being adjusted so that the unit of activity remained the same. For vitamin $B_{1}$ a preparation made by Prof. B. C. P. Jansen was adopted which was an adsorption product on fuller's earth from an extract of rice polishings. When the supply was nearly exhausted a similar preparation was 
made by Professor Jansen and biological tests carricd out by workers in several laboratories showed that its potency was equal to that of the original preparattion. When ritamin $B_{1}$ was synthesised, a large sample of it was adopted as the International Standard of reference and workers in eleven different laboratories established the relation between the pure substance and the original standards. Three micrograms of the crystalline material were equivalent in biological activity to $10 \mathrm{mg}$. of the standard, that is, to 1 International Unit. ${ }^{3}$

For vitamin C, in 1931, there was no known preparation stable cnough to use as a standard of reference, and the juice of fresh lemons, thought from its antiscorbutic effect on guinea-pigs not to vary greatly in potency, was adopted. By 1934, however, ascorbic acid had been prepared in a pure state and l'rof. A. Szent-Györgyi prepared $200 \mathrm{gm}$. for use as an International Standard of reference. Since then ascorbic acid has been synthesised and the British Pharmacopoeia now accepts chemical and physical tests of purity without biological evidence of activity. ${ }^{4}$ For vitamin $\mathrm{D}$ the original preparation of irradiated ergosterol is still in use. For vitamin $\mathrm{E}$ a standard of reference will almost certainly have been adopted by the time this book is in print. It is a preparation

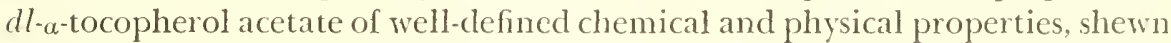
to be stable for many months, not only when kept under the best conditions known but also during the varied conditions of actual dosing in the experiments carried out by workers in twelve laboratories to determine its activity and the shape of the curve of response given by female rats. Other standards of reference will become necessary as further vitamins are discovered (for example, vitamin $\mathrm{K}$ ), but it is possible that their chemistry and physics may be so well known by the time their function is recognised that therapentic preparations, at least, may be determined without biological tests.

2. Criterion for the Test.-Long before any attempt is made to detcrmine the amount of a vitamin in any substance, a fair idea will have been gained as to its action on some animal suitable for laboratory experiments. Sometimes a vitamin has several functions; for instance, vitamin $B_{1}$ is necessary for growth (increase in weight in rats), for preventing or curing polyneuritis in pigeons, and for preventing or curing "convulsions" in rats. When increase of weight is the criterion adopted, it is specially important that the basal diet should contain abundance of all substances necessary for growth other than the vitamin in question. This criterion for vitamin $B_{1}$ has lower limits of crror (79126 per cent for $\mathrm{P}=0.95$ ) than the cure of polyneuritis in pigeons whose linits of error are $24-417$ for $\mathrm{P}=0.95$. The cure of convulsions in rats produced by a deficiency of vitamin $B_{1}$ and cured by giving that substance has a high degree of accuracy in the hands of Dr. E. M. Nelson. ${ }^{5}$ It must never be assumect that any method has the same degree of accuracy when performed by all workers, nor indeed by any one worker in all his tests. ${ }^{8}$

All criteria but increase in weight have the clisadvantage of uncertain starting-points and end-points. The onset of xerophthalmia is ill-defined, as also 
its cure. The length of time taken to effect a cure is therefore difficult to estimate. Even the increase in weight is not very accurate, for a rat's weight varies almost from hour to hour and may not be the same (or increase steadily) at the same time on successive days.

3. Adequacy of the Basal Diet.-For a simple comparison between two substances (for example, the standard of reference and a food substance) with respect to a particular vitamin, it is obvious that the diet of the animal used should contain abundance of all substances known to be necessary for the well-being of the animal, except the one vitamin which is to be assayed. Otherwise, the food substance or even the standard preparation may supply some factor which is helpful to the work of the vitamin under assay and the results may thereby be vitiated. A slight deficiency of one of the vitamins does in fact limit the steepness of the curve of response to another vitamin. ${ }^{7}$

4. Statistical Examination of Results.-More and more workers are submitting the results of their experiments to statistical examination to determine how much confidence may be placed in them. The accuracy of an assay depends on three factors: (1) the standard deviation of the individual observations, (2) the number of animals from which the average result is calculated, and (3) the steepness of the curve relating response to dose of vitamin given. It is evident that the less the individual results differ from each other, the greater confidence one may have in the reliability of the average, and that the larger the number of animals used, the more nearly will the average approach the true value. It is only necessary to draw two curves of response, one much steeper than the other, to discover that a particular standard deviation of a result corresponds to a smaller deviation of dose in a steeper curve than in a less steep curve. The significance of a difference between two means is determined by a simple formula $t=\frac{m_{1}-m_{2}}{\sqrt{\epsilon_{1}{ }^{2}+\epsilon_{2}{ }^{2}}}$ and by reference to a table of $t$ which indicates the probability of the difference being significant. ${ }^{8}$ When $t=3$ and the number of animals used has been about twenty, it is generaly considered that the difference found is significant. Some workers of a more optimistic temperament are satisfied with a value of 2 for $t$. It can only be suggested that these should repeat their experiment on the same or similar lines.

The selection of doses for an assay leaves something to choice. If any dose produces a maximum or nearly maximum result, or a minimum or nearly minimum result, it cannot be used in the calculation of potency. Some workers like each experiment to be self-contained and to give one group of rats a dose of the standard and several different groups of rats different doses of the substance under test. They then equate the dose of standard to the dose of test substance which gave the result most nearly equal to that given by the dose of standard. This way of calculating the result makes no use of the information furnished by all the rats in the other groups which were given other doses. The defect can be remedied by drawing a smooth line as nearly as 
possible through the points plotted from the results of the different doses and then finding the dose corresponding to the result obtained from the one dose of standard. If the relation between effect and dose is logarithmic, the line relating effect to the logarithm of the given close is a straight one and can be calculated mathematically with very little difficulty. The whole process is then independent of judging where exactly the line should go.

Other workers like to give two groups of rats two different closes of the standard and two other groups two different doses of the test substance. Then two curves of response are obtained, their average slope determined and the relative potencies of test and standard found by the distance between the two parallel lines. On the other hand, some workers prefer to establish a general curve of response for their test and compare the results from dose of standard and dose of test substance through the doses corresponding to these results on the general curve. Unless it has been shown that the slopes obtained in various experiments are significantly different from each other, then the method of using the general curve of response is probably the best one, as having been determined by the use of a much larger number of rats than would be used in any one assay alone.

It is well worth while to realise, as R. A. Fisher has so clearly shown in his Design of Experiments, ${ }^{9}$ that, by careful planning, an experiment can be made to yield far more information than the one point primarily needed and that by such planning the information on the chief point is also made nuch more reliable. For example, the writer has lately compared two samples of irradiated ergosterol for vitamin D activity. It was also desired to discover without independent experimentation whether the differences in response to vitamin $\mathrm{D}$ were greater between different litters than betwecn different rats of the same litter. Screral years ago the writer had shown that there was a fair correlation between the amount of healing brought about by vitamin $\mathrm{D}$ and the weight of the rat when it was first given the rachitogenic diet. By careful arrangement of the rats within each litter given the particular doses (three of one sample of irradiated ergosterol and three of the other sample) it was possible to arrange the results (a) as a "square" in which the rows were litters and the columns were doses, and $(b)$ a second "square" in which the rows were litters and the columns were rats in ascending order of initial weight. Thus, information was gained on two points of importance in addition to the one for which the experiment was originally needed.

Discarding the principle of standardising the conditions of experiments by varying only one factor at a time, but varying several conditions instead, makes it possible to gain not only more information on different points but also information on the interaction of these conclitions. The interaction of the vitamins, aheady indicatect almost by chance, is only one of man! fascinating lines which this method of procedure suggests in planning cren routine assays. 


\section{REFERENGES}

1. British Pharmacopoeia Commission: Report of the Sub-Committee on the Accuracy of Biological Assays (London: 1936).

2. Leag. Nats., Quart. Bull. Hlth. Organisatn. 3:428, 1934.

3. Leag. Nats., Bull. Hlth. Organisatn. 9:371, 1940-41.

4. British Pharmacopoeia: Addendum 1936 (London: 1937), 4.

5. Kline, O. L.; Tolle, C. D., and Nelson, E. M.: Jl. Assn. Offic. Agricult. Chemsts. 21:305, 1938.

6. Coward, K. H.: The Biological Standardisation of the Vitamins (London: 1938), 196.

7. Coward, K. H.: The Biological Standardisation of the Vitamins (London: 1938), 138.

8. Fisher, R. A.: Statistical Methods for Research Workers (7th ed.; Edinburgh, London: 1938), 177 .

9. Fisher, R. A.: The Design of Experiment (2d ed.; Edinburgh, London: 1937), 118. 


\section{THE PREVENTION OF DEAFNESS}

$B)$

S. J. CROWE

\section{次}

From the

OTOLOGICAL RESEARCH LABORATORY

OF THE JOHNS HOPKINS UNIVERSITY BALTIMORE, MARYLAND 



\section{THE PREVENTION OF DEAFNESS}

$\mathrm{T}$ He White house CONFERENCE called by President Hoover in 1931, and composed of public health officials, social workers, psychiatrists, those interested in child labor, and members of other agencies dealing with the wellare of children, estimated that three million school children in the United States are handicapped by impaired hearing. This figure probably represents only the more advanced cases. Our impression after seventeen years of study of the causes and prevention of impaired hearing is that deafness is incipient in a much greater number, and in many it will slowly progress and become a handicap later in life unless something is clone to correct the cause in the early stages of the disease. Almost every variety of deafness in adults is also found in children. Many types, such as otosclerosis, hereditary nerve deafness, Ménière's disease, acoustic tumors, and developmental anomalies, cannot be helped by operation or treatment, but in the large group caused by infections and mechanical interference with the function of the Eustachian tubes the progress of the clisease can be stopped and often the hearing can be restored, provided the condition is recognized early and treatment instituted before the middleand inner-ear structures are damaged. After years of trial of the method used in general pathology, namely, the correlation of clinical examinations and functional tests with the gross and histologic appearance of the middle and inner ear after death, my associates and I have become convinced that most of the remedial kinds of deafness begin in childhood, and that to learn more about causes, treatment, and prevention we must concentrate our studies on living, growing children. Deafness in adults is rarely cured, but it is truly astounding how often hearing can be restored in children under fourteen with a middle-ear type of deafness severe enough to place them in a lip-reading class.

With the coöperation of the Baltimore Department of Health and Board of Education we have examined for three successive years the hearing and upper air passages of an unselected group of 1,365 school children between the ages of eight and fourteen years. The hearing of each child has now been tested from eight to ten times in sound-proof rooms, for all octares from 32 to $\mathbf{1 6 , 3} 8_{4}$ d.v. We were fortunate to have for this purpose audiometers built by the W'estern Electric Company for research. Commercial audiometers are not designed to test the frequencies above $8,000 \mathrm{~d} . \mathrm{v}$. and for this reason the fact had not been previously observed that almost every variety of midclle- as well as inner-ear deafness begins with impaired hearing for the higher tones, and progressively involves the lower tones and the speech range (250 to 3,500 (l.v.). In addition to the hearing tests, the tympanic membranes, nasal pansages, nasopharynx, and particularly the pharyngeal orifice of the Eustachian tubes were examined with a nasopharyngoscope, which provides as clear a view of these regions as a cystoscope does of the interior of the bladder. All but a small percentage of these 1.965 children were thought by their teachers and

$$
[151]
$$


parents to have good hearing. We found, however, that only $5^{8.8}$ per cent have normal hearing for all tones; 36.3 per cent have impaired hearing for the three or four octaves at the upper end of the scale, with normal hearing for all lower tones and for the voice-in quiet surroundings. This pictureimpaired hearing for high tones with good hearing for low tones and for the voice in a quiet place-is identical with the common type of partial deafness in old age. Elderly people may understand conversation perfectly if the frequencies used in speech ( $25^{\circ}$ to 3,500 d.v.) are not masked by other voices or by the roar of traffic. Under the latter conditions, however, they have difficulty in understanding unless the speaker raises his voice above the decibel level of the surrounding sounds. All of us with normal hearing throughout the entire scale would be similarly handicapped in noisy surroundings if we had not unconsciously trained ourselves since childhood to interpret properly the overtones of words, just as a stenographer in reading her notes interprets shorthand symbols. Most of our city schools are on streets with heavy traffic, and children with impaired hearing for only the higher frequencies have difficulty in hearing the teacher when there is a background of noise in the classroom. This leads in many instances to an erroneous diagnosis by the teacher of indifference, stupidity, or mischievousness, and explains their failure to do well in their school work.

Lymphoid hyperplasia in the pharynx and nasopharynx is responsible for ear infections, and through interference with the ventilating function of the Eustachian tubes is an important cause of impaired hearing in childhood. Thousands of children would be spared the disabilities of impaired hearing and other complications of enlarged and infected lymphoid tissue, if we understood better the basic problem of why some children are more susceptible than others to respiratory infections, and knew more about the relation between allergy, dietary deficiencies, and ductless gland disorders to lymphoid hyperplasia. The cause could then be corrected at the source, and it would rarely be necessary to remove tonsils and adenoids or operate for infected ears. A large percentage of childhood deafness is caused directly or indirectly by hypertrophy and infection of lymphoid tissue in the nasopharynx. Infections are easily recognized and as a rule are adequately treated with chemotherapy and operation. The greatest danger to the hearing during childhood is partial or intermittent closure of the Eustachian tubes by hypertrophied nodules of lymphoid tissue in and around their pharyngeal orifice, and the thick mucous secretion that accumulates in the tubes, the middle ear, and in the pneumatized spaces throughout the temporal bones. These changes in the middle ear and tubes are not associated with pain, sudden loss of hearing or other symptoms that would direct the attention of the child, the parents, or the family physician to the ears. The earliest evidences are retraction and opacity of the tympanic membranes and impaired hearing for the tones above 8,ooo d.v. The hearing defect at this stage can be demonstrated only with the audiometer. Impaired hearing for the high tones is also due to causes that 
cannot be cured, but this finding in a child demands an examination of the nasal passages and nasopharynx with a nasopharyngoscope, and a correction of any condition that interferes with Eustachian-tube function and so leads to a further loss of hearing. Lymphoid tissue is an integral part of the mucous $11 \mathrm{~cm}$ brane of the pharynx and nasopharynx and cannot be removed unless the entire thickness of mucous membrane is taken out. After removal of tonsils and adenoids before the age of puberty, it is a common occurrence to see numerous nodules on the posterior and lateral walls of the pharynx-a "granular pharyngitis." A similar condition is almost invariably seen in the nasopharyx if the examination is made with a nasopharyngoscope. These nodules may not be large enough to cause mouth breathing, but nevertheless are a source of potential danger to the hearing. Physicians are too prone to think that adenoids can be removed in their entirety, and after operation the nasopharynx is dismissed without further examination as a source of trouble. Recurrence is so frequent, however, that it must be regarded as normal. It is not the size but the location of lymploid nodules that leads to deafness.

Frequently children with beginning deafness due to these causes spontaneously recover their hearing, or further loss is prevented by the regression of lymphoid tissue and restoration of the patency of the Eustachian tubes which occurs at puberty. Our duty is to recognize the fact that good hearing depends on open Eustachian tubes, to examine school children with this point uppermost in our mind and to institute some form of safe, conservative therapy that will tide the child over the dangerous period, which usually ends at puberty. Every year the hearing of millions of children is tested with some type of audiometer. Those with severe impairment are recognized and placed in vocational classes, but the incipient cases, the ones which can be benefited the most, are either not recognized or are inadequately treated. Surgical removal of tonsils and adenoids often fails to remedy permanently the conditions that may cause deafness; certainly a second or third operation is not the proper treatment for a recurrence.

It has been known for nearly forty years that lymphoid tissue is more sensitive to irradiation with $\mathrm{X}$ ray or radium than any other structure in the body. Therefore in treating hyperplastic lymphoid tissue with these rays the size of the mass may be reduced in three or four treatments with a dosage so small that there is no danger of a burn, or injury to bone, cartilage, hypophysis, or central nervous system structures. The life cycle of the lymphocyte is short, certainly less than a month. Irradiation treatment effects a reduction in size of a mass of lymphoid tissue by retarding or entirely stopping cell division and the formation of new lymphocytes to replace the ones that have been cast off.

For nearly twenty years we have used $\mathrm{X}$ rays and radon, sometimes as a substitute for, and often to supplement, surgical removal of tonsils and adenoids in children, and have come to the conclusion that radon is a much simpler, safer, and more effective method for irradiation of the nasopharynx. The objections to the use of $\mathrm{X}$ rays for this purpose are: the difficulty of direct- 
ing the central beam of the rays from the various portals in the neck so that they will cross or converge at the exact spot where they are needed; the time consumed and the expense of the treatments, which must be divided over a period of two or three weeks; a large percentage of the rays is absorbed by skin and muscle, and never reaches the nasopharynx; therefore the total irradiation used is much greater than the amount necessary to reduce the size of adenoids. It is not wise unnecessarily to irradiate the base of the skull and centers of ossification to this extent in a growing child, especially since the series of treatments may have to be repeated several times to maintain the patency of the tubes. The chief objection is the inaccuracy of this method in young children. On the other hand, radon can be compressed and an amount equivalent to a gram of radium salts may be sealed in a capillary glass bulb, placed in an applicator small enough to pass along the floor of the nose without anaesthesia and without pain, and brought into direct contact with the tissue to be treated. The applicator remains in place from three to five minutes, depending on the number of millicuries it contains. The effect of the treatments is determined by direct inspection with a nasopharyngoscope and by audiometer tests. When necessary the treatments are repeated at intervals of a month, but rarely more than three or four are required. We have often irradiated from fifteen to twenty school children in an afternoon. Many children have been followed for a decade or more and we are confident that no untoward local or systemic effects occur. Partially occluded Eustachian tubes set in train a series of physical changes in the membranes of the middle ear and mastoid cells that eventually impede the movements of the ossicles. The earlier the condition is recognized and treated the better the results. For this reason children over fifteen and adults are rarely benefited.

Irradiation does not cure any and every type of deafness. Its purpose is to remove lymphoid tissue from locations that will cause deafness. Detailed results of a study of 1,365 school children have been published and need not be recounted here. It is a type of experiment that requires years for its completion, and further reports will appear from time to time. The method is safe and inexpensive and if applied in schools would in time greatly reduce the recent estimate of three million children with seriously impaired hearing. 


\section{Relevant Literature}

1938

Crowe, S. J., and Guild, S. R.: "Impaired hearing for high tones" Art. Otolaryngol. 26:138, 1938.

Crowe, S. J.: "Diagnosis and differential diagnosis of deafness" Archs. Otolaryngol. 28:669, $193^{8}$.

1939

Crowe, S. J., and Baylor, J. W.: "The prevention of deafness" Jl. Amer. Med. Assn. $112: 54$, 1939 .

Crowe, S. J.: "The prevention of deafness in children" Laryngoscope 19:591, 1939; also in Trns. Amer. Otol. Soc. 29:112, 1939.

$$
194^{\circ}
$$

Crowe, S. J.: "The recognition, treatment and prevention of hearing impairment in childrcu" Laryngoscope 5o:658, 1940; also in Trns. Amer. Otol. Soc. 30:27, 1940.

Burnam, C. F.: "Irradiation treatment of hyperplastic lymphoid tissue" Laryngoscope 5o:663, 1940; also in Trns. Amer. Otol. Soc. 30:32. 1940.

Polvogt, L., and Babb, D. C.: "Histologic studies of the Eustachian tube of individuals with good hearing" Laryngoscope 5o:671, 1940; also in Trns. Amer. Otol. Soc. 30:41, 19 fo.

Guild, S. R.; Polvogt, L. M.; Sandstead, H. R.; Loch, W. E.; Langer, E.; Robbins, M. I1., and Parr, W. A.: "Impaired hearing in school children" Laryngoscope 50:731, 19ןo; also in Truss. Amer. Otol. Soc. 30:47, $19-4$.

Bordley, J. E.: "The treatment and prevention of deafness in children" South. Med. Jl. 33: $1159,19.10$.

Crowe, S. J.: "The nasopharynx" Trns. Amer. Liryngol. Assn. 1940:145; also in Archs. Oto. laryngol. $33: 618,194^{1}$.

$$
1941
$$

Crowe, S. J., and Bumam, C. F.: "Recognition, treatment and prevention of hearing impairment in children" Ann. Otol., Rhinol. \& Laryngol. 50:15. 1941.

$$
194^{2}
$$

Crowe, S. J.; Guild, S. R.; Langer, E.; Luch, W. E., and Robbins, M. H.: "Impaired haring in school children." Laryngoscope 52:790, 1942. 



\section{GENE $H$ AND TESTOSTERONE}

IN THE FOWL

B)'

C. H. DANFORTH

\section{9}

From the

DEPARTMENT OF ANATOMY

STANFORD UNIVERSITY, CALIFORNIA 



\section{GENE $H$ AND TESTOSTERONE IN THE FOWL}

$\mathrm{I}^{\mathrm{N}}$ MANY birds the plumage of the male is appreciably different from that of the female. Such a difference is particularly noticeable in the Phasianidae, of which the common fowl is a familiar example. But there are also species in which this dimorphism in plumage does not occur, and even in the domest ic fowl some races fail to show it. In these races, while other secondary sexual characters are essentially as usual, the plumage of the male is almost identical with that of the female. This type of feathering is called henny* and has been shown to be due to a dominant autosomal gene designated as $H$. Males that are homozygous $(H H)$ and usually those that are heterozygous $(H h)$ for this gene are characterized by henny plumage, while those homozygous for the recessive allele $(h h)$ develop the normal cocky plumage. Females of the formulas $H H$ and $h h$ are indistinguishable except by genetic or involved endocrine tests. This interesting situation raises the question of how gene $H$ is related to other genes and how it affects feather development. In this paper the role of gene $H$ in relation to testosterone will be considered.

The heredity of hen-feathering in the male was studied many years ago by T. H. Morgan, by R. C. Punnett, and by a number of others, all of whom were fairly unanimous in their interpretation of the genetic behavior of the trait. More recently Punnett ${ }^{1}$ has suggested that the normal locus of the $H$ allele is in the $Y$ chromosome of the female and that it becomes autosomal and potentially present in the male only through translocation. This hypothesis may explain several puzzling observations that are on record, but whatever the exact cytological relations may be, the somatic manifestation of the gene has been known for a long time and in many different breeds. There are several records of new appearancest which may reasonably be attributed to fresh nutations or, on Punnett's theory, to translocations following earlier mutations. In any erent, when the gene once appears in an autosome its subsequent genetic behavior is fairly simple. There is no evidence known to the writer which suggests that the trait may have a prototype in any wild species.

* In early days when cock fighting was permissire in England there riere some pit games in which the males were hen-feathered and, because of the supposed adrantages accruing from such a camouflage, hen-feathered cocks attained a certain popularity. In the argot of the day they were called "hennies"-whence, presumably, our current scientific term henny and, by analogy, its correlative cocky, terms which are now used lo characterize the two distinctive types of plumage that may occur in male fowls.

+ As long ago as 1873 , Tegetmeier, whose name appears often in Darwin's Inimals and Plants under Domestication, recorded one fresh occurrence of the [rait. A game bantam "of known purity" which hatched in the spring of 1859 at first derefoped nomal plumage, after which it became "strictly hen-feathered both as to form and colour" and produced some henfeathered male offspring. Others of its offspring were nomal and took second prize at the Crystal Palace show. It was exhibited at a meeting of the Zoölogical Society on March 16, 1861. "Nothing would have been easier than to have established a permanent breed." said "Tegermeier-and he was probably right.

$$
[1,5 !]
$$


The experimental form used for this study was the Sebright bantam. This is a small breed established about the year 1800 by Sir John Sebright, who combined the color of a crested Polish, the size of a bantam, and the henny plumage of another fowl in the "laced bantam" which later came to bear his name.* The breed in its "golden" and "silver" phases was apparently soon perfected and has remained practically unchanged for many years. Colored illustrations done by Harrison Weir about 1870 show Sebrights that would be favorably rated today. Because of its distinctive traits, stabilized genetics, and small size, the Sebright has become a favorite with experimenters.

A certain amount of lore concerning the control of differences between male and female plumage dates back to the nineteenth century, but it was not until well into the present century that the subject became a matter for active, critical experiment and analysis. Work in this field is well summarized by Pézard, Sand and Caridroit, ${ }^{5}$ by Greenwood and Blyth, ${ }^{6}$ and by Domm. ${ }^{7}$ Briefly stated, it has been found that in the brown Leghorn and other $h h$ breeds presence of the testes or injected male hormones has little influence on the plumage, but functional ovaries or circulating estrogens have a feminizing effect on developing feathers of either sex. These findings, which have been verified on many breeds, might have been considered of general application to all fowls had it not been for the atypical reaction cliaracteristic of the Sebright.

Soon after Goodale ${ }^{8}$ had demonstrated the effect of ovariectomy in the brown Leghorn it occurred to Professor T. H. Morgan that the Sebright test is might produce a certain amount of female hormone and thus account for the henny plumage. His experiments, ${ }^{9,11}$ showed that removal of the test is did in fact lead to the production of cocky plumage in the hitherto hen-feathered male. So-called luteal cells were tentatively identified in the Sebright testis and for a time it seemed that the explanation had been found for henny plumage, not only in the Sebright bantam but in wild species in which the sexes are similar. This view was not long sustained. Nonidez ${ }^{12,13}$ showed that the "luteal cells" were not gland cells; Roxas ${ }^{14}$ demonstrated by exchange

* The account of the synthesis of this breed is repeated in many of the older books on poultry. Sir Thomas Sebright's report, which is quoted by Dr. Horner in Tegetmeier's volume, is apparently authentic and also quite plausible genetically. The statement in the Encyclopedia Americana ${ }^{3}$ (1941 ed., vol. 3. p. 215 ), that "the golden and silver Sebright bantams originated in America," is apparently entirely without foundation. We may also discount the interesting notion of the Rev. Mr. Dixon ${ }^{4}$ (1848) who linked in some mysterious way the sprightly virtues of the diminutive fowls with those of the dainty human inhabitants of Bantam, Java. Some French writers have implied that bantams originated in England, but the "grigs" of seventeenth century England were not the original dwarf fowls. Pliny is one early writer who makes no attempt to trace them to some remote source, contenting himself with: "Est et pumilionum genus non sterile in his, quod non in alio genere alitum, sed quibus certa fecunditas rara, et incubatio ovis noxia." (Nat. Hist. X:77.) Probably dwarf specimens have appeared from time to time in many large breeds, but with genes for namnism once in their armamentarium it has been easy for breeders to produce bantam forms at will. In the 1941 exhibit at the California State Fair a trio of "Black Minorca Bantams" deemed worthy of a premium were said by their exhibitor to have had a full-sized black Minorca grandparent. 
operations that in their effects on plumage Leghorn and Sebright testes are interchangeable; and Danforth and Foster ${ }^{15}$ found by transplantation of skin that the differential factors involved actually resicle in the skin itself, presumably in the feather follicles. Two pieces of skin healed together and growing adjacent to each other on the same host will, if one is hh the other $H I I$, produce feathers respectively of the cocky and henny type. This observation was substantiated by Champy ${ }^{18}$ who transplanted skin of a Phocnix cock to a Sebright and got typical male plumes surrounded by the henny feathers of the host. Nevertheless, as late as 1936, when Callow and Parkes ${ }^{17}$ failed to get a response in the plumage of Sebright capons injected with androsterone, it was again suggested that henny plumage of the Sebright cock must be due to another substance secreted by the testis, "probably oestrin." Later experiments with other androgens have caused this opinion to be revised.

Gallagher, Domm and Koch, ${ }^{18}$ and Danforth ${ }^{10}$ next showed that extracts from bull testes would "feminize" the plumage of Sebright capons, and the latter also found that an ordinarily subthreshold dose of the extract could be made to supplement a hitherto inadequate output of a testicular fragment. Perhaps even more interesting was the demonstration, which has been repeated in connection with the present experiments, that the comb, "psyche," and feather follicles have different threshold levels, the level for the latter being appreciably higher. Taking advantage of this fact one can, by incomplete castration or injection of sufficiently small amounts of testosterone into capons, convert genetically $H H$ birds into phenocopies of the $h h$ form that would be likely to deceive even a critical observer.

Transplantation of avian testes, and injection of extracts from testes of nummals, is not entirely satisfactory, however, since the composition of the extracted hormones is at least somewhat uncertain and there is also the possibility that the effects observed may be mediated indirectly through some other gland. The latter possibility is mentioned again and again in the literature, particularly with reference to the thyroid. Since the discovery by Torrey and Horning ${ }^{93}$, of the effect of desiccated thyroid on plumage the question has been discussed, pro and con, by Crew; ${ }^{22}$ Danforth; $;^{23}$ Parkes and Selye: ${ }^{24}$ Emmens and Parkes; ${ }^{25}$ and Chu. ${ }^{20}$ The relation of hypophysial and suprarenal secretions to plumage types is still less well known. Various aspects of their possible relations have been considered by Danforth; $;^{19,27}$ Hill and l'arkes;" and Witschi.9 A survey of this literature, which need not be undertaken here. makes it apparent that with the partial exception of those on the thyroid and ovary the experimental studies thus far have not sufficed to differentiate between the direct and indirect effects of the rather numerous hormones which show evidence of playing some role in the determination of plumage characteristics. In an attempt to meet this objection in the case of testosterone the synthetic drug* was administered in varions ways to Sebright capons.

* The writer is indebted to the Schering and Ciba firms for gencrous supplies of tescrerone propionate made up in the desired vehicles. 
Synthetic testosterone propionate dissolved in sesame oil was injected in $0.5^{-1.0} \mathrm{mg}$. doses into the breast muscles of young bantam capons which had already developed cocky plumage. In $H H$ birds the usual effects were obtained: a slight temporary drop in weight or retardation in growth, an almost immediate increase in size and color of the comb, an increase in activity and morale (which, however, is by no means entirely under humoral control), and a more or less complete "feminization" of such potentially dimorphic feathers as happened to be growing at the time of injection. Similar results with synthetic testosterone have been obtained by Parkes and Selye, ${ }^{24}$ Champy, ${ }^{30}$ and others. In this series there was some evidence, difficult to measure, that the testosterone slightly accelerated growth, which perhaps helps to account for a somewhat greater than usual length of some of the feminized feathers (pl. 1, fig. 1, d). The similarity of this testosterone effect to that produced by theelin is indicated in plate 1 , figure 2, where there are shown partially and completely "reversed" feathers resulting from both types of treatment.

The foregoing experiments throw no additional light on whether the action of the hormone is direct or indirect. This phase of the problem was next attacked by the use of relatively minute quantities of testosterone which was tested for its direct local action-a technique which has been used successfully in studying the effects of estrone by Lyons and Sako ${ }^{31}$ with mammals, and Greenwood and Blyth ${ }^{32}$ with birds. For these purposes testosterone propionate was employed as pure crystals, as an ingredient of a salve, and as an ointment dissolved in sesame oil.

The oil solution was applied directly to the skin, beginning soon after an area on the back had been plucked. Usually about thirty feathers were removed from each area to be tested, with others from one or more control areas at a distance. Plate 1 , figure 1 , shows the effect of such treatment. Similar results were obtained with both the silver and the golden Sebright. The chief objection to this method is that the oil tends to diffuse widely over the surface and cannot easily be confined to a limited area. It is sufficiently selective, however, to reveal that regenerating feathers in the treated area are more affected than those at a greater distance.

The salve proved more satisfactory for topical application than did the oil. When applied over any appreciable area the observed effects were similar to those following the application of the oil solution and generally involved slight, but definite, effects on the comb as well as the feathers. Better results were obtained from applying it in very small amounts to individual pin feathers. The procedure was to find an area in which at least one pinfeather was barely visible above the skin and then pluck all the surrounding feathers and pinfeathers. The selected pinfeather was then painted with a tiny bit of salve at regular intervals. A protocol will serve to illustrate the method and results.

Golden Sebright, hatched Apr. 20, castrated May 27. Aug. 9: weight 440 gm.; comb 35 (length $25 \mathrm{~mm}$. + width $7 \mathrm{~mm}$. + height $3 \mathrm{~mm}$.), pale. An area about $25 \mathrm{~mm}$. in diameter plucked clean 


\section{H. Danforth}

except for three pinfeathers, the middle of which was selected for treatment. Ippoximatcly $10 \mathrm{mg}$. of salye, presumed to contain $0.02 \mathrm{mg}$. of testosterone propionate appliced with the tip of a small camel's-hair brush. This treatment was repeated daily from 1ug. $11-22$ inclusive. Aug. 22: weight $495 \mathrm{gm}$.; comb 38, pale. Aug. 29: weight 52.5 gm.; comb 36 .

When fully developed the treated feather and one other of the same agc showcil a cocky tip and henny vane, resembling somewhat the midlle specimens in ligure 2. The third feather of the same age was somewhat intermediate, lut at least a dozen younger ones were almost completely feminized and similar to the two on the right in figure 2. Orlicrs, medial and slightly anterior, were intermediate, while still others further anterior were cokly and apparently entirely uninfluenced.

It is doubtful if the comb was really affected at all in this case in spite of the rather widespread effect on the feathers. Considering the number of leathers influenced, it would appear that when applied to the skin as a salve less than 1.5 gammas of testosterone propionate a day for each feather is adequate to produce feminization of the plumage with little, if any, other effect.

The crystalline testosterone was applied by pushing small particles in to the skin. The exact amount administered was generally difficult to determine since the pieces frequently crumbled somewhat in the process of being embedded. Similar pieces, or group of pieces, carefully compared with the original were weighed on a delicate balance and the amount implanted estimated on that basis. Another protocol will show the procedure and results with this method.

Golden Sebright, hatched Apr. 20, castrated May 27. July 30: not weighed; comb about 31. Seren $\mathrm{cm}$. anterior to the uropygial gland, areas $23^{-2}+1 \mathrm{~mm}$. in diameter were plucked on each side of the midline. In the center of the right area a bit of testosterone propionate, not more than $0.5 \mathrm{mg}$. in weight, was pushed into a pocket in the skin and the whole area corered with a protecting fim. The left side was treated in exactly the same way except that no testosterone was administered. Aug. 5: weight 450 gm.; comb 37, tip bleeding. Aug. 9: weight 470 gm.; comb 41, red. Aug. 15: weight 480 gm.; comb 39. Growth of pinfeathers greater on the right side. Aug. 29: Weight $590 \mathrm{gm}$; comb 40 , fairly good color. New feathers on left all definitel! cocky in form and color. Those on the right similar except for three in the center of the area. Two of these appear to be typically hemny, one imemediate. When fully grown the wo former proved to be entirely hemmy in form and color, but rather longer than wall. ligure 3 shows similar results in an experiment in which a silver Sebright was usecl. It would appear that in these cases enough testosterone was absorbed to raise the general level above the threshold for comb response but not to the threshold for feather response, except in the immediate vicinity of the implant itself.

These experiments seem to make it clear that the effects observed in $H H$ birds following the injection of testosterone are not due to any gencral effect mediated indirectly through the thyroid. They do not elininate the possibility that thyroid secretion and possibly several other hormones are ordinarily more or less involved in the production of henny plumage. At the present time we know that in birds of the formula HH which have been deprived of their testes but not their thyroids the reaction of developing pinfeathers can be changed from that shown in plate 1 , figure $1, b$, to that in plate 1 . figure $1, c$, by the application of thyroxin, ol estrone, or of testosteronc, and that the effects of the two latter are clirect and local. Whether or not there are other hormones 
which separately and independently will give the same effect remains to be determined. Capons of the formula $h h$ respond in the same way to thyroxin and estrone but not to testosterone, and this suggests once again that it is not so much the hormone as the way in which the tissues have come to respond to it that is of fundamental importance. In the case under consideration one simple genetic alteration-a change in the character or position of a single gene-suffices to convert tissues of the feather follicle from a condition of sensitivity to estrone and indifference to testosterone to one in which they are apparently insensible to the difference between these two hormones and respond equally to both of them.

In this paper the convention has been followed of considering the deposition of pigment as if it were a passive phenomenon, but of late it has been shown that the pigmentophores have a great deal of autonomy and may play a definite and largely independent role in the determination of pattern (Willier and Rawles; ${ }^{33}$ Danforth $\left.{ }^{34}\right)$. Studies on plumage have paid little attention to the question of whether or not gene $H$ affects the pigmentoblasts directly, or only alters the character of the "parade ground" on which they may deploy. It may be remarked in passing that in plate 1 , figure 3 , here, and in many figures by Parkes and others, both the laced henny and the striped cocky feathers are shown to be characterized by the alignment of black pigmentophores along the most distal barbules in the vane wherever those barbules may be. This suggests that the underlying factor may be related more to pigmentophore orientation than to mere pigment deposition, but this is a problem yet to be solved.

In conclusion it may be pointed out that thus far we seem to have gotten no inkling as to the underlying basis for sexual differences in plumage, but we have succeeded in gathering considerable information about some of the factors which condition the appearance of one or the other of the alternative types. That the whole situation may be fundamentally altered by a simple cytological change is apparent in the effects produced by gene $H$.

\section{REFERENCES}

1. Punnett, R. C.: Jl. Genet. 35:129, 1937.

2. Tegetmeier, W. B.: The Poultry Book (London: 1873).

3. Article on "Bantam," in Encyclopedia Americana, III (1941 ed.; New York: 1941), 215.

4. Dixon, E. S.: Omamental and Domestic Poultry (London: 1848).

5. Pézard, A.; Sand, K., and Caridroit, F.: Archs. de biol. 36:541, 1926.

6. Greenwood, A. W., and Blyth, J. S. S.: Jl. Genel. 36:53, $193^{8}$.

7. Domm, L. V.: in Sex and Internal Secretions, ed. by E. Allen (2d ed.; Baltimore: 1939), 227.

8. Goodale, H. D.: Amer. Naturlst. 47:159, 1913.

9. Morgan, T. H.: Proc. Soc. Exper. Biol. \& Med. 13:31, 1915.

10. Morgan, T. H.: Proc. Soc. Exper. Biol. \& Med. 15:3, 1917.

11. Morgan, T. H.: Carnegie Instn. Washington, Publn. no. $285,1919$.

12. Nonidez, J. F.: Jl. Anat. 31:109, 1922.

13. Nonidez, J. F.: Jl. Anat. 34:359, 1924.

14. Roxas, H. A.: Jl. Exper. Zoöl. $46: 63,1927$.

15. Danforth, C. H., and Foster, F.: Proc. Soc. Exper. Biol. \&. Med. 25:75, 1927. 


\section{H. Danforth}

16. Champy, C., and Demay, M. L.: Cpts, rd. Soc. de biol. 109:85,5, 1932.

17. Callow, R. K., and Parkes, A. S.: Jl. Exper. Biol. 13:7, 1936.

18. Gallagher, T. F.; Domm, L. V., and Koch, F. C.: Jl. Biol. Chem. 10o:xlvii, 1933.

19. Danforth, C. H.: Proc. Soc. Exper. Biol. \& Mecl. 32:1474, 1935.

2o. Torrey, H. B., and Horning, B.: Proc. Soc. Exper. Biol. \& Med, 19:275, 1922.

21. Torrey, H. B., and Horning, B.: Anat. Recrd. 21:395, 1923.

22. Crew, F. A. E.: Proc. Roy. Soc. Edinburgh 45:252, 1925.

23. Danforth, C. H.: Jl. Exper. Zool. 65:183, 1933.

2.4. Parkes, A. S., and Selye, H.: Jl. Genet. 34:297, 1937.

25. Emmens, C. W., and Parkes, A. S.: Jl. Genet. 39:485, 1940.

26. Chu, J. P.: Jl. Genet. 39:493, 194 o.

27. Danforth, C. H.: in Sex and Internal Secretions, ed. by E. Allen (Baltimore: 1932), 12. 28. Hill, R. T., and Parkes, A. S.: Proc. Roy. Soc. London, S.B $116: 221,1934$.

29. Witschi, E.: Proc. Soc. Exper. Biol. \& Med. $35: 484,1936$.

3o. Champy, C.: Cpts. rd. Soc. de biol. 125:329, 1937.

31. Lyons, W. R., and Sako, Y.: Proc. Soc. Exper. Biol. \& Med. 44:398, 1940.

32. Greenwood, A. W., and Blyth, J. S. S.: Proc. Roy. Soc. London, S.B. $119: 97,1935$.

33. Willier, B. H., and Rawles, M. E.: Proc. Natn. Acad. Scis. $24: 44^{6,} 1938$.

34. Danforth, C. H.: Jl. Hered. 30:173, 1939. 


\section{DESCRIPTION OF PLATE}

Fig. 1. Four successive feathers; $a, b$, and $c$ definitely, $d$ almost certainly, from the same follicle. These are from a golden Scbright which hatched Apr. 20 and was castrated May 27. The first two are cocky, the second two henny in character.

1a. Immature feather plucked Sept. 3 .

$1 b$. Small section of the pinfeather which immediately replaced the above. This was plucked Sept. 17. The section is taken from well out toward the tip where barbules are lacking. The regions marked with crosses contain cells which degenerate without forming barbules. The six barbs shown are brown, not black as the photograph might suggest.

1c. Section of the next pinfeather, which was plucked Oct. 2. The region is comparable to that shown in $b$. Beginning Sept. 19 and continuing till Oct. 5, about $0.5 \mathrm{mg}$. of testosterone propionate in oil was placed on the skin each day in the region of the follicle or on the dereloping pinfeather. It will be seen that under these conditions cells comparable to those marked with crosses in $b$ clereloped barbules and were invaded by pigmentophores, black to the left, brown to the right.

1d. Immature feather plucked Nov, 11 after the treatment had been resumed Oct. 10 and repeated daily from Oct. 12 to 17.

Fig. 2. Feathers from a golden Sebright which hatched Apr. 20 and was castrated May 23. The upper row shows the effect of testosterone, the lower row the comparable effect of theelin. A total of $5.6 \mathrm{mg}$. of testosterone propionate in oil was injected into the breast muscles during the period from Sept. 12 to 17 . The upper row shows the tips of three feathers which were in different stages of development when the injections became effective. The one in the middle was affected in its proximal part, the one to right throughout its whole extent. (Only $H$ - birds respond in this way; two $h h$ birds of approximately the same size, age, and history treated in the same manner showed no detectable effects on their plumage. All similarly treated specimens showed marked growth of comb and change in attitude.) In the second row are shown tips of three more feathers from the same bird plucked on Dec. 11 after $0.7 \mathrm{mg}$. of theelin in oil had been administered during a period of one week when these feathers were in different stages of development.

Fig. 3. Feathers from a silver Sebright capon approximately one year old. On Aug. 2, about $1.4 \mathrm{mg}$. of testosterone propionate was embedded in, or slightly under, the skin near the center of a recently plucked area. The feathers shown are from replacements plucked Sept. 9. They are arranged as nearly as possible in the relative positions in which they grew and the approximate site of the testosterone implant is indicated by a cross. The four central feathers show varying degrees of "feminization"; the three peripheral ones and all the others that grew in this region failed to show any effect from the treatment. 

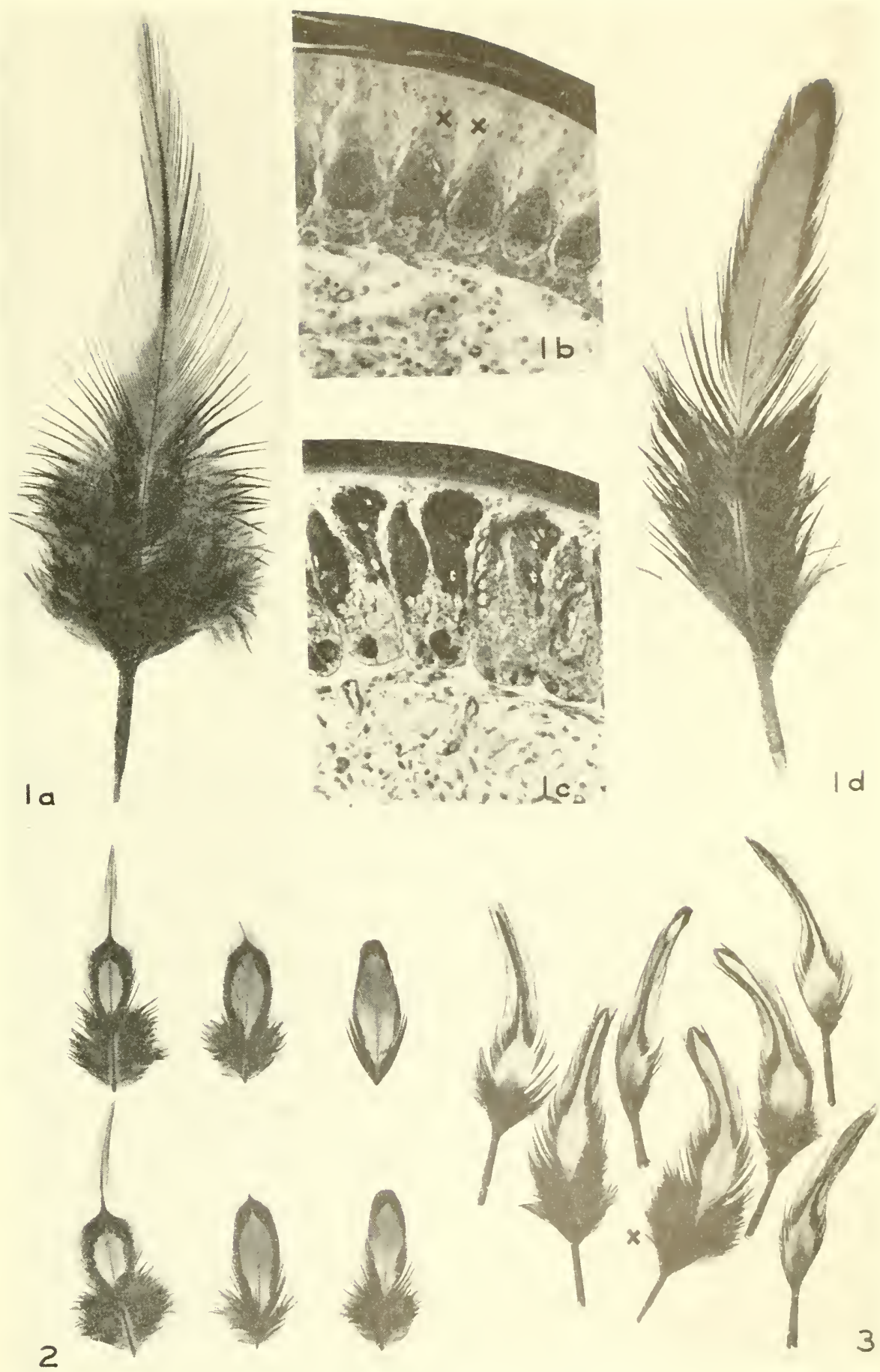

Plate 1 



\section{THE INFLUENGE OF HORMONES ON}

\section{THE SEXUAL BEHAVIOR OF}

\section{DOMESTIC FOWL}

$$
\text { By }
$$

DAVID E. DAVIS

Fellow, International Health Division, Rockefeller Foundation Rio de Janeiro, Brazil

$$
\text { AND }
$$

L. V. DOMM

\section{䟢}

\section{From the}

WHITMAN LABORATORY OF EXPERIMENTAL ZOÖLOGY

THE UNIVERSITY OF CHICAGO

CHICAGO, ILLINOIS 



\title{
THE INFLUENGE OF HORMONES ON THE SEXUAL BEHAVIOR OF DOMESTIC FOWL*
}

\author{
INTRODUCTION
}

I Ax ATIExpT to analyze the results obtained from a study on the sexual be havior of intersexual males produced by the injection of estrogens into incubating eggs (Domm and Davis ${ }^{1}$ ), a series of experiments was begun to determine the effect of androgens and estrogens on the behavior of the domestic fowl (Davis and Domm ${ }^{2}$ ). In the above investigation it was found that males in which one or both gonads were ovotestes showed various degrees of masculine behavior which roughly coincided with the degree of masculinity of the plumage. The plumage in turn is known to be an excellent indicator of the relative proportions of testicular and ovarian components comprising the gonad $\left(\right.$ Domm $\left.^{3}\right)$. In brief, this study showed that males in which the plumage was essentially normal behaved in a definitely masculine manner while those in which the plumage was female, or nearly so, behaved in an essentially neutral manner. Gradations in behavior between these extremes were encountered.

The observations to be discussed in this paper represent the beginning of an analysis of the function of certain hormones in the behavior of the fowl. Experiments designed to analyze the behavior of animals must necessarily be extensive because of the difficulty in isolating the numerous factors controlling behavior. For this reason it was considered desirable to conduct an initial series of general experiments, leaving the details to a subsequent, more extensive study. Therelore, the experiments reported at this time must be considered as an analysis of the general responses of capons and bilaterally ovariectomized poulards to androgens and estrogens; further refinements, such as the minimal amount of hormone necessary to initiate a particular response, the effects of learning or conditioning, etc., are reserved for a future time. Some incidental experiments upon males and sinistrally orariectomized poulards are also considered.

\section{Materlals and Methons}

The brown Leghorn, a highly dimorphic breed of domestic fowl, was used throughout the experiments. The birds were kept in large pens at the Whitman Laboratory poultry house and fed a standard ration of wet mash, dry mash, corn and greens, etc. (for details see Daris and Domm ${ }^{4}$.

The experiments consisted of exposing the injected capons, roosters, and

* This investigation was aided by a grant from the Dr. Wallace C. and Clara A. Abbott Memorial Fund of The University of Chicago. Grateful acknowleclgment is made to Dr. Erwin Schwenk of the Schering Corporation for the testosterone propionate and a-cstradiol (Progynon-B) and to Dr. J. A. Morrell of Squibb and Sons for the stilbestrol used in these experiments.

$$
[171]
$$


poulards to one or more of three stimulus situations. Depending upon the type of injection, the bird was exposed to a normal rooster, to a normal female, or to a dummy. In all cases possible the bird was tested in its own pen so that it was familiar with its surroundings. The normal roosters used were healthy individuals of the same age as the capons and in the prime of sexual vigor, except as mentioned in one experiment. The females also were normal vigorous birds which were good layers and receptive. The dummy was a normal hen stuffed and mounted in the pose of invitation to copulation (squatting). The routine experiment consisted of placing the test bird (rooster, hen, or dummy) in the empty pen and then introducing the experimental bird. Although the observer stood in the pen at a distance of a few feet, it is certain that his presence had no effect on the behavior. The reader is referred to the paper by Davis and Domm ${ }^{4}$ for a detailed description of the normal sexual behavior of the fowl.

The birds were injected daily at about 11:00 a.m. In a few days they became tame, and readily submitted to the treatment so that there is little if any possibility that the ordeal of injection influenced their behavior. The reader is referred to the table which gives a summary of pertinent data.

\section{Observations}

The series of injections was designed to indicate the action of androgens and estrogens in controlling behavior. Since in general the end result is the important point, description of the developmental stages will be omitted for the most part in this paper.

1. The Effect of Androgen in the Capon. Two capons under the influence of testosterone propionate copulated repeatedly with both the dummy and females. Bird $149 \mathrm{M}$ was first observed to crow on the eleventh day and to tread on the fourteenth day of injection. Bird ${ }_{15}{ }_{3} \mathrm{RM}$ copulated first on the seventh day and crowed on the tenth. Since the birds were not under continuous observation it is quite likely that they crowed several days before the dates mentioned.* A third bird, $143 \mathrm{R}$, which received the lowest dosage, was very excitable during the experiments and this excitability had not noticeably vanished six months after injections were stopped. He never copulated perfectly although, in contrast to a normal capon, he perceived the dummy. Our evidence is not sufficient at present to state that the dosage received in this case is below the threshold necessary for copulation.

2. The Effect of Estrogens in the Capon. All three capons copulated under the influence of $\alpha$-estradiol (Progynon-B). The action was brief but complete; wing-fluttering and movements of tail and cloaca were typical. The birds getting the higher dosages (149M and ${ }_{153} \mathrm{RM}$ ) mounted, although weakly, on the sixteenth day (Oct. 7 ) of injection. Bird $170 Y$ mounted two days later. However, these birds, when compared with the testosterone-treated individuals, did

* We have since observed crowing in 48 hours and treading within 90 hours in capons receiving daily injections of testosterone. 
not show such intense libido and did not run as rapidly towat introduced females. There was no crowing or "tidbitting." A rery weak "waltz," consisting merely of lowering the wing, occurred occasionally. "Waltzing," which is used by the male to induce the newcomer to indicate its sex by either squatting (female) or raising the neck hackle (male), consists of a lowering of the wing nearest the newcomer and a kicking of the leg on the same side against the lowered wing. It must be remembered that "waltzing" does occur, although rarely, in capons which appear to be deroid of testicular tissue. "Tidbitung" is a characteristic coaxing, clucklike call accompanied by pecking at or tip)ping the ground or floor of the pen with the beak, which usually holds a morsel. This pattern is a substitute behavior, usually observed when a male is frustrated in his attempt to copulate.

Since the effect of estrogen in causing the capons to copulate was heterodox, another series was begun in order to check the results. As indicated in the table, three birds were injected with a-estradiol and three with stibestrol. Of the estradiol birds, $169 \mathrm{R}$ Y copulated on the sixth day, $192 \mathrm{YY}$ on the filth day, and $193 \mathrm{MY}$ on the fourth day of injection. Of the stilbestrol birds, $382 \mathrm{MM}$ copulated on the fouth day, and 190Y' on the fifth day. 191RR was a very nervous bird and never copulated. Sexual libido normally manifested itself in the estrogen-injected capons by their frequent attempts to tread one another, which occasionally succeeded, as for example when $382 \mathrm{MM}$ raped $191 \mathrm{RR}$ on the afternoon of November 5 . When a female was released in the pen with all the capons, a veritable melee resulted from the attempts of the birds to copulate. There is a possibility that the capons becane refractive to estrogen, for some of the birds which had copulated regularly did not copulate in the last few trials at the end of the experiment.

When exposed to a normal rooster the estrogen-injected capons invariably fled. They nerer squatted lor copulation and were unreceptive and struggled whenever the rooster forced copulation.

The position of the dummy is important in the reaction of the estrogeninjected capon. If the dummy is facing him, he raises the hackle and begins to fight. If, on the other hand, it is not, he copulates. For example, on October 24, capon $170 \mathrm{Y}$ which had received $0.50 \mathrm{mg}$. a-estradiol daily for thinty-three days approached the dummy from the front, raised the hackle, and pecked the head. In walking away he happened to circle the dummy. He then approached it from the rear and copulated.

3. The Effect of Estrogen in the Rooster. The two normal roosters which received stilbestrol gradually lost their aggressireness and stopped crowing on the tenth day of injection. Nevertheless, copulations continued to the end of the experiment (47 days). The behavior pattern was complete but was performed in a lethargic, listless manner. The comb decreased practically to the castrate condition in each, and when autopsied on August 5 the testes of both were in a markedly regressed condition (macroscopically), weighing 75 and $110 \mathrm{gm}$. per bird. A third bird became sick soon after the start of the experi- 
ment and consequently injections were discontinued. Stilbestrol acts the same as $\alpha$-estradiol in producing feminization of growing feathers.

These experiments therefore indicate that androgen in the male sex induces crowing and possibly "tidbitting," and increases the frequency of or actually induces "waltzing," and that both androgens and estrogens elicit the patterns of copulation.

Summary of Data on Various Types of Injection

\begin{tabular}{|c|c|c|c|c|c|c|c|}
\hline \multirow{2}{*}{ Bird No. } & \multirow{2}{*}{ Sex* } & \multicolumn{2}{|c|}{ History } & \multirow{2}{*}{ Hormone } & \multirow{2}{*}{$\begin{array}{l}\text { Amount, } \\
\text { mg. per } \\
\text { day }\end{array}$} & \multirow{2}{*}{$\begin{array}{l}\text { Injec- } \\
\text { tions } \\
\text { days }\end{array}$} & \multirow{2}{*}{ Results } \\
\hline & & $\begin{array}{c}\text { Hatching } \\
\text { date }\end{array}$ & $\begin{array}{c}\text { Castration } \\
\text { date† }\end{array}$ & & & & \\
\hline${ }^{1} 43 \mathrm{R}$ & $\mathrm{C}$ & $5-6-40$ & $6-6-+0$ & T. P. & 1. 25 & 26 & $\begin{array}{l}\text { Imperfect copula- } \\
\text { tion; very nervous }\end{array}$ \\
\hline${ }_{4}^{4} \mathrm{M}$ & $\mathrm{C}$ & $5-6-70$ & $6-6-40$ & T. P. & 2.50 & 26 & Copulated, crowed \\
\hline${ }_{153} \mathrm{RM}$ & $\mathrm{C}$ & $5-6-40$ & $6-6-40$ & T. P. & 3.75 & 26 & Same \\
\hline $170 \mathrm{Y}$ & $\mathrm{C}$ & $5-6-40$ & $6-6-+0$ & a-Estra. & .50 & +3 & Copulated \\
\hline${ }_{4}+9 \mathrm{M}$ & $\mathrm{C}$ & $5-6-40$ & $6-4^{-}+0$ & a-Estra. & I. .0 & 43 & Same \\
\hline $153 \mathrm{RM}$ & $\mathrm{C}$ & $5^{-6-40}$ & $6-6-40$ & a-Estra. & 1. 50 & It & $\begin{array}{l}\text { Same (imperfectly; } \\
\text { sick) }\end{array}$ \\
\hline $192 Y^{Y Y}$ & $\mathrm{C}$ & $5-6-40$ & $6-4^{-40}$ & a-Estra. & $1 . \infty$ & $\mathrm{I}_{4}$ & Copulated \\
\hline${ }_{193} \mathrm{MY}$ & $\mathrm{C}$ & $5-6-40$ & $6-4^{-} 4^{\circ}$ & a-Estra. & I. 50 & $\mathrm{I}_{4}$ & Same \\
\hline $169 \mathrm{RY}$ & $\mathrm{C}$ & $5-6-40$ & $6-4^{-}+0$ & a-Estra. & 2.00 & II & Same \\
\hline $3^{82} \mathrm{RR}$ & $\mathrm{C}$ & $5-6-40$ & $6-6-40$ & Stilb. & $1 . \infty 0$ & $\mathrm{I}_{+}$ & $\begin{array}{l}\text { No copulation; very } \\
\text { nervous }\end{array}$ \\
\hline $382 \mathrm{MM}$ & $\mathrm{C}$ & $5^{-6-+0}$ & $6-6-+0$ & Stilb. & I. 50 & It & Copulated \\
\hline $382 \mathrm{YY}^{\prime}$ & $\mathrm{C}$ & $5^{-6-40}$ & $6-+40$ & Stilb. & 2.00 & It & Same \\
\hline $16{ }_{9} \mathrm{RY}$ & $\mathrm{C}$ & $5-6-40$ & $6-7-40$ & Control & & & Behavior neutral \\
\hline $170 \mathrm{Y}$ & $\mathrm{C}$ & $5-6-40$ & $6-6-40$ & Control & & & Same \\
\hline $180 \mathrm{R}$ & $\mathrm{C}$ & $5-6-40$ & $6-7-40$ & Control & & & Same \\
\hline $37^{8}$ & $\mathrm{R}$ & $5^{-6-40}$ & & Stilb. & 2.50 & 47 & $\begin{array}{l}\text { Copulated if } \text { o squat- } \\
\text { ted; stopped crow- } \\
\text { ing and "waltzing" }\end{array}$ \\
\hline${ }_{32} 3 \mathrm{PU}$ & $\mathrm{R}$ & $5-6-40$ & & Stilb. & 5.00 & +7 & Same \\
\hline $320 \mathrm{BW}$ & $\mathrm{R}$ & $5-6-40$ & & Stilb. & $7 \cdot 50$ & 25 & Sick (died of roup) \\
\hline I $8 \mathrm{PU}$ & $\mathrm{BP}$ & $6-20-3^{8}$ & $8-12-38$ & T. P. & 1.25 & 60 & $\begin{array}{l}\text { Crowed,"waltzed,"no } \\
\text { copulation }\end{array}$ \\
\hline I 32 WUR & $\mathrm{BP}$ & $6-20-38$ & $8-12-38$ & T. P. & 2.50 & 60 & Same \\
\hline I $28 \mathrm{RU}$ & $\mathrm{BP}$ & $6-20-38$ & $8-16-3^{8}$ & T. P. & $3 \cdot 75$ & 60 & Same \\
\hline I I $8 \mathrm{PU}$ & $\mathrm{BP}$ & $6-20-38$ & $8-12-38$ & $a$-Estra. & .50 & 50 & $\begin{array}{l}\text { Squatted, received } \\
\text { copulation }\end{array}$ \\
\hline I32WUR & $\mathrm{BP}$ & $6-20-38$ & $8-12-38$ & a-Estra. & 1.00 & +3 & Same \\
\hline I $28 \mathrm{RU}$ & $\mathrm{BP}$ & $6-20-38$ & $8-16-38$ & $a$-Estra. & I. 50 & 50 & Same (see text) \\
\hline
\end{tabular}


Summary of Data on Various Types of Injection (Contimued

\begin{tabular}{|c|c|c|c|c|c|c|c|}
\hline \multirow{2}{*}{ Bird No. } & \multirow{2}{*}{ Sex* } & \multicolumn{2}{|c|}{ History } & \multirow[b]{2}{*}{ Hormone } & \multirow{2}{*}{$\begin{array}{l}\text { Amount, } \\
\text { mg. per } \\
\text { day }\end{array}$} & \multirow{2}{*}{$\begin{array}{l}\text { Injec- } \\
\text { tions, } \\
\text { days } \neq\end{array}$} & \multirow[b]{2}{*}{ Results } \\
\hline & & $\begin{array}{l}\text { Hatching } \\
\text { Date }\end{array}$ & $\begin{array}{c}\text { Castration } \\
\text { Datet }\end{array}$ & & & & \\
\hline $121 \mathrm{G}$ & $\mathrm{BP}$ & $6-20-38$ & $8-16-38$ & Control & & & Behavior neutral \\
\hline${ }_{1} 35 \mathrm{~PB}$ & $\mathrm{SP}$ & $6-20-38$ & $8-2-38$ & T. P. & 1.25 & 26 & $\begin{array}{l}\text { Increased frequency of } \\
\text { crowing and "waltz- } \\
\text { ing," no copulation }\end{array}$ \\
\hline $\begin{array}{l}\mathrm{I}_{2} 2 \mathrm{M} \\
\mathrm{I}_{3} \mathrm{R}\end{array}$ & $\begin{array}{l}\text { SP } \\
\text { SP }\end{array}$ & $\begin{array}{l}6-20-38 \\
6-20-38\end{array}$ & $\begin{array}{r}7-30-38 \\
-7-00-8\end{array}$ & T. P. & 2.50 & 26 & Same \\
\hline IIIU & SP & $6-20-3^{8}$ & $7-28-38$ & Control & & & $\begin{array}{l}\text { Crowed, "tidbitted," } \\
\text { "waltzed" weakly; } \\
\text { no copulation }\end{array}$ \\
\hline $126 \mathrm{BW}$ & $\mathrm{SP}$ & $6-20-38$ & $8-1-38$ & Control & & & Same \\
\hline $127 \mathrm{Y}$ & SP & $6-20-38$ & $8-\mathrm{I}-38$ & Control & & & Same \\
\hline
\end{tabular}

* C, capon; $\mathrm{R}$, rooster: BP, bilaterally ovariectomized poulard; SP, sinistrally ovariectomized poulard. $\dagger$ Date of final operation. Except in sinistral poulards, castrations were performed in two operations.

Experiments performed from June to November 1941 .
\$ The bilaterally ovariectomized poulards used in this experiment are the same ones as were previously used in the above experiment on the effect of androgen in bilaterals. An interval of approximately one month elapsed between the two experiments.

4. The Effect of Androgen in Bilaterally Ovariectomized Poulards. A bilaterally ovariectomized poulard is one in which the left ovary has been completely removed following or preceding the complete removal or destruction of the right rudimentary gonad. Such individuals are, therefore, gonadless and resemble the capon in many important respects. Like the capon they are neutral in behavior $\left(\right.$ Domm $\left.^{5,6}\right)$.

Under the influence of androgen bilaterally orariectomized poulards became very aggressive and fought violently. The birds were first observed attempting to crow on the sixteenth day of injection. They began to crow in a perfect manner a few days later and continued to do so throughout the experiments. Within three weeks all three poulards "waltzed" at introdnced females or the dummy. The "waltzing," although not as vigorous as that of a male, was nevertheless identical in behavior pattern. These three poulards, however. did not copulate with receptive females or the dummy at any tine, even though the experiments were continued for sixty days. The poulards gave all females as well as the dummy ricious pecks about the head, even after a "waltz." Females which squatted perfectly, thereby inviting copulation, were often injured by the violence of these pecks.

5. The Effect of Androgen in Sinistrally Ovariectomized Poulards. Sinistrally ovariectomized poulards are individuals in which the left ovary only has becn removed. Following this operation the rudinentary right gonad undergoes hypertrophy, usually developing into a testis-like organ whose secretions are mixed, having both androgenic and estrogenic effects (Lillic ${ }^{7}$ ). The androgenic 
effects almost invariably appear soon after the operation and may bring about a more or less complete masculinization of sexual characters. The estrogenic effects usually become evident some time later and are chiefly manifested by the plumage (Domm $\left.{ }^{5}\right)$.

Following daily injections of testosterone, sinistrally ovariectomized poulards became noticeably more aggressive. They were observed to crow more frequently than uninjected controls and likewise displayed more interest in the female, notably evidenced by the greater frequency of "waltzing." However, like their uninjected control mates, they were never observed to copulate, but merely "waltzed" and stopped or "waltzed" and pecked. These individuals definitely became more masculine in their general reactions under the influence of testosterone but apparently they were unable to copulate, at least under the stimulus conditions prevailing in these experiments.

6. The Effect of Estrogen in Bilaterally Ovariectomized Poulards. These individuals, normally lacking aggressiveness, seemed to become more timid and even lethargic following daily injections of estrogen; they completely ignored the dummy and normal females in all tests. Bird 132 WUR, eighteen days after the beginning of injections, squatted for a normal rooster and received copulation. These experiments at this date were handicapped by the lack of a vigorous rooster, since all the males were in molt. It is possible that the injected poulards would have squatted regularly at this time for an aggressive, vigorous rooster in sexual prime. Hence, a rooster was brought into full sexual aggressiveness by daily injection of $2.0 \mathrm{mg}$. of testosterone. In the presence of this rooster, bird 132 WUR squatted regularly and $118 \mathrm{PU}$ squatted on the fortysecond day of injection. Bird $128 \mathrm{RU}$ did not squat until November 10 , after it had been severely beaten by its cage mate. Although she received copulation subsequently when exposed to the rooster it is not known whether she was receptive or merely too weak to resist.

On several occasions an estrogen injected bilaterally ovariectomized poulard squatted for an estrogen-injected capon and received copulation. These birds were all identical in plumage, lacked any vestige of gonads, and had received the same injections.

It seems apparent from these observations that androgen induced crowing and "waltzing" but did not induce copulation in the bilaterally ovariectomized poulard. These individuals became definitely more active and aggressive in the presence of the introduced female or dummy as a result of the injections. It is also evident that androgen increased the frequency of crowing and "waltzing" in sinistrally ovariectomized poulards but, as was the case in the bilaterals, it did not induce them to copulate, at least under the various stimulus situations provided.

Estrogen, on the other hand, apparently induces only the squatting pattern in the bilaterally ovariectomized poulard. It will be noted that this is in striking contrast to the effect of estrogen in the capon. One point deserves particular mention, bilaterals receiving estrogen completely ignored the dummy or 
other females. In contrast, those receiving androgen definitely noticed the dummy and reacted toward it in much the same way they reacted toward normal hens.

\section{Discussion}

The action of androgens and estrogens in the control of behavior has been studied in few species. In the domestic fowl it has been repeatedly shown that testosterone will produce crowing in both males (Benoit ${ }^{8}$ ) and females (Allec, Collias and Lutherman ${ }^{9}$; Hamilton and Golden ${ }^{10}$ ). It is important to note that these females did not copulate. In young male chicks Hamilton ${ }^{11}$ produced crowing at ten days of age although the females did not crow in fifty-five days. Later Hamilton and Dorfman ${ }^{12}$ caused male chicks to crow sixty hous after hatching. In addition, Allee, Collias and Lutherman ${ }^{2}$ observed crowing in four-month-old pullets. These authors also noted a somewhat abbreviated "waltz" or courtship pattern in two of their females. By stimulating development of gonads precociously with pituitary hebin, Domm and Van Dyke ${ }^{13,14}$ and Domm ${ }^{15}$ observed crowing in young cockerels at nine days of age and treading at thirteen days. These authors observed little if any effect on the behavior of similarly treated young pullets even though there was sufficient androgen produced, by the hypertrophied medullary component of the left ovary, to bring about masculinization of head furnishings comparable to that of treated cockerels. In female canaries Leonard ${ }^{10}$ induced singing by injection of testosterone and Shoemaker ${ }^{17}$ thus produced singing and courtship behavior as well as an increased aggressiveness, but no copulations. In nondomesticated birds Noble and Wurm ${ }^{1 s}$ found that in the black-crowned night heron testosterone will induce masculine sexual behavior in adult females and even in month-old chicks. The patterns consisted of territory defense, nest building, courtship ceremonies, and copulation on one occasion. In the laughing gull Noble and Wurm ${ }^{19}$ found that testosterone produces those behaviors common to both sexes as well as those of the male. In mammals under the influence of testosterone Ball ${ }^{20}$ found that female rats performed masculine copulatory patterns and Beach $^{21}$ observed that male rats performed female mating behavior. The latter author concluded that the stimulus situation is the selective factor that determines which type of response will be manifested under the conditions of great excitability produced by testosterone. Similarly in the lizard Anolis carolinensis, Noble and Greenberg ${ }^{22}$ found that testosterone elicits both male and female behavior. Evans, ${ }^{9,24}$ studying Anolis carolinensis, found that female lizards which had been castrated fought much more than normal individuals and that the injection of ovarian homone inhibited the fighting.

The effect of estrogen on behavior is less striking. In chickens Allee and Collias $^{25}$ found that one poulard, sinistrally ovariectomized by L. V. Domm, squatted under the influence of estrogen. Noble and $\mathbb{W}^{\top} \mathrm{Hm}^{18}$ found that no behavior of the female black-crowned night heron is due to estrogen. These authors also found ${ }^{19}$ that the injection of estrogen into either sex of the laugh- 
ing gull will induce "food-begging," a behavior pattern which is necessary for coition. In mammals Ball ${ }^{20}$ found that estrogen could produce the feminine behavior patterns in castrated male rats, but that these individuals continued to perform the masculine copulatory patterns. That there is some difference in the potentialities of the sexes is shown by the fact that more estrogen is required to produce lordosis in males than in females and that females did not show masculine tendencies under the influence of estrogen.

The evidence so far accumulated indicates that both sexes of the domestic fowl possess the potentialities for performing certain masculine behavior patterns. Crowing, "waltzing," and "tidbitting" occur in males and females under the influence of testosterone. Crowing certainly is induced by androgen, while "waltzing" and "tidbitting," if not actually induced by testosterone, are at least increased in frequency. Further research upon the stimulus situation which will induce a capon to "waltz" is necessary before a solution of this problem can be reached. Fighting and aggressiveness, although occurring in capons, is very greatly increased by the injection of testosterone. That there may be a basic quantitative difference between the sexes is indicated by the observation that capons crowed sooner than poulards under the influence of androgen.

In contrast to the ability of both sexes to perform certain behavior patterns is the observation that masculine copulatory behavior was not induced by the injection of testosterone into poulards. This is surprising because in some species of birds (Shoemaker; ${ }^{17}$ Noble and $W$ urm $^{18}$ ) the females are reported to mount, and some poultrymen say that hens sometimes tread one another. Also, there is one case on record $\left(\mathrm{Domm}^{5}\right)$ in which a sinistrally ovariectomized poulard is known to have performed the male copulatory act. Whether other stimulus situations than those employed in our experiments would elicit copulation in a testosterone-injected poulard is not known. In any case, we can confidently state that there is a sexual differential, since under the experimental procedures employed the capons copulated whereas the poulards did not. It is of further interest that both androgen and estrogen induced the copulatory behavior pattern in our capons. Apparently in this case the hormones are not specific in their action on the nervous system. These results would seem to suggest that the female chicken may not have the proper nervous patterns for the masculine copulatory behavior save in very exceptional cases.

It is worthy of note that the behavior relative to reproduction may be divided into two types. The primary patterns are related to the actual insemination. The secondary patterns (epigamic, Huxley ${ }^{20}$ ) include such actions as singing (crowing) and courtship ("waltzing"). It is perhaps more than coincidence that the typical male primary patterns appear to be sex limited but can be activated by either androgen or estrogen, while, on the other hand, the secondary patterns are induced in both sexes by androgen. Further research is necessary to determine the validity and application of this generalization.

The results of this series of injections throw some light on the problem of 
the inhibition of behavior patterns. Many female birds slow masculine behavior in the fall, such as territory holding (Michener and Michener; ${ }^{2 \pi}$ Lack ${ }^{20}$ ) or singing (Bullough and Carrick ${ }^{20}$ ), but cease these activitics in the spring. The obvious interpretation of this sequence of events is that estrogen, when it appears in the spring, inhibits the expression of masculine behavior in the same manner as it inhibits the expression of the masculine plumage in cortain species. The results of our experiments suggest the likeliluood that these masculine behavior patterns are produced in the fall by androgen and not by estrogen. However, experiments consisting of the simultanernus injection of androgen and estrogen are required to test the hypothesis of inhibition.

\section{SUMMARY}

1. In order to analyze the relation of certain endocrines to sexual behavior patterns in the domestic fowl, a series of injections was performed on capons, sinistrally and bilaterally orariectomized poulards, and normal roosters, using testosterone propionate, a-estradiol (Progynon-B), and stilbestrol. The beharior was tested by exposing the injected bird to a normal rooster, to a normal hen, or to a stuffed female dummy mounted in the pose of invitation to copulation (squatting).

2. Two out of three capons receiving testosterone copulated, crowed, "waltzed," and "tidbitted." The six capons receiving $a$-estradiol and two of the three receiving stilbestrol copulated in the masculine manner. None of them were known to crow or "tidbit." Two normal roosters receiving stilbestrol stopped crowing but continued to copulate.

3. Three bilaterally orariectomized poulards receiving testosterone crowed, "waltzed," and became aggressive, but never copulated throughout the sixty days of injections. Three sinistrally ovariectomized poulards reacted similarly. Two out of three bilaterally ovariectomized poulards receiving a-estradiol squatted for the rooster. In the stimulus situations employed in these experiments copulation was not induced in poulards by injections of testosterone.

4. Only in the male can the behavior patterns of coptation be induced by both androgen and estrogen, while the patterns of crowing, "waltzing," and "tidbitting" are under the control of androgen in both sexes.

\section{Addendum}

Since this manuscript was submitted an important report has appeared $\left(\right.$ Zitrin $\left.^{30}\right)$ describing induction of male copulatory behavior in a hen following administration of male hormone. This bird, one of two treated white Leghorn pullets, received a pellet of testosterone propionate, wcighing approximately $41 \mathrm{mg}$, when it was five months old. The bird was observed to tread a hen one hundred thirty-eight days later. Thereafter it was tested frequently with a squatting hen and observed to copulate in the typical masculine nanner. "Waltzing" was seen only occasionally and was never very rigorous. while crowing was heard but once after the bird had been readed by a male. 
Male copulatory behavior was exhibited for approximately one and a half months after which the bird began to lay fertile eggs.

In order to interpret certain phases of the experiments reported in the present paper, a new series (Domm, Davis, and Blivaiss ${ }^{31}$ ) was undertaken which closely parallels the experiment of Zitrin in certain respects. Nine brown Leghorn pullets, divided into three groups of three pullets each, received daily injections of testosterone propionate. The first group (112 days old) received $0.5^{0} \mathrm{mg}$., the second, which was the same age, received $1.00 \mathrm{mg}$. and the third (1 $3^{8}$ days old) received $1.5^{\circ} \mathrm{mg}$. daily. All birds were tested and observed daily during the first two months and usually on alternate days thereafter.

The group receiving $0.5^{\circ} \mathrm{mg}$. was injected for one hundred twenty-one days. One of these crowed, circled, and "waltzed"; another crowed but never showed any particular interest in either sex; while the third was not known to crow but began to chase, circle, and "waltz" shortly before injections were discontinued.

The other two groups of six pullets are still under observation and have now received daily injections of the amounts indicated for more than one hundred eighty days. All of these are known to crow, chase, circle, and "waltz" and several have shown weak mounting attempts. Only one of those receiving the highest dosage has actually been observed to mount. This bird grabbed and mounted a squatting female on the one hundred forty-sixth day in the typical male manner. However, copulation did not take place and a repetition has not occurred since, though several weak attempts at mounting have been observed. In all groups, crowing, chasing, circling, and "waltzing" became quite common once these reactions appeared.

In attempting to evaluate these results one is likely to raise a question concerning the relative efficacy of the two procedures employed in administering the hormone, since it is known that a constant source of hormones is necessary for the development and maintenance of many sexual characters. However, until more data are available concerning the development and maintenance of the various sexual-behavior patterns in the fowl the sporadic occurrence of treading females, whether normal or the result of various experimental procedures, must be regarded as exceptional.

\section{REFERENCES}

1. Domm, L. V., and Davis, D. E.: Proc. Soc. Exper. Biol. \&. Med. 48:665, 1941; Anat. Recrd. 81 (supp.):61, 1941 .

2. Davis, D. E., and Domm, L. V.: Proc. Soc. Exper. Biol. \& Med. 48:667, 1941; Anat. Recrd. 81 (supp.):104, 1941 .

3. Domm, L. V.: in Sex and Internal Secretions, ed. by E. Allen (2d ed.; Baltimore: 1939), 227.

4. Davis, D. E., and Domm, L. V.: In press.

5. Domm, L. V.: J1. Exper. Zoöl. 48:31, 1927.

6. Domm, L. V.: Biol. Bull. $56: 459,1929$.

7. Lillie, F. R.: J1. Exper. Zoöl. 48:175, 1927.

8. Benoit, J.: Archs. de zool. expér. et génrl. 69:217, 1929 .

9. Allee, WV. C.; Collias, N., and Lutherman, C. Z.: Physiol. Zoöl. 12:412, 1939.

10. Hamilton, J. B., and Golden, W. R. C.: Endocrinology 25:737, 1939. 
11. Hamilton, J. B.: Endocrinology 23:53, 1938.

12. Hamilton, J. B., and Dorfman, R. I.: Enclocrinolog! $24: 711,1939$.

13. Domm, L. V., and Van Dyke, H. B.: Proc. Soc. Exper. Biol. \& Med. 30:319, 1932.

14. Domm, L. V., and Van Dyke, H. B.: Science (11.s.) 77:156, 1933.

15. Domm, L. V.: Cold Spring Harbor Sympsa. Quantit. Biol. 5:2 11, 1937.

16. Leonard, S. L.: Proc. Soc. Exper. Biol. \& Med. $41: 229,1939$.

17. Shoemaker, H. H.: Proc. Soc. Exper. Biol. \& Med. f1:299, 1939.

18. Noble, G. K., and Wurm, W.: Endocrinology 26:837, 19 1\%.

19. Noble, G. K., and Wurm, W.: Anat. Recrd. 78 (supp.): $5^{0,1} 19$ $^{\circ}$.

20. Ball, J.: Jl. Compar. Psychol. 29:151, 1940.

21. Beach, F. A.: Endocrinology 29: 09,19 \{1.

22. Noble, G. K., and Greenberg, B.: Proc. Soc. Exper. Biol. \& Med. 47:32. 1941.

23. Evans, L. T.: Pedagog. Seminary \& J1. Genet. Psychol. 18:217, 1936.

2.. Evans, L. T.: Physiol. Zoöl. 10:456, 1937.

25. Allee, W. C., and Collias, N.: Endocrinology 27:87, 1940.

26. Huxley, J. S.: Proc. VIIth Internatn. Ornithol. Congr., 1930:107, 1931.

27. Michener, H., and Michener, J. R.: Condor 37:97, 1935.

28. Lack, D.: Proc. Zoöl. Soc. London, s.A. 109:169, 1939.

29. Bullough, W'. S., and Carrick, R.: Nature (London) 145:629, 19 to.

3o. Zitrin, A.: Endocrinology $31: 690,1942$.

91. Domm, L. V.; Davis, D. E., and Blivais, B.: Anat. Recrel. 8 f(supp.):31, 1912. 



\title{
PITUITARY GONADOTROPHINS
}

\author{
$B y$ \\ HEINZ FRAENKEL-CONRAT, CHOH HAO LI \\ AND MIRIAMI E. SIMPSON
}

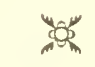

From the

I.STITLTE OF LXPERIMINTML BIOIOOG

UNIVERSITY OF CALIFORNA, BIRKILEY, C.MIFORNI 



\section{PITUITARY GONADOTROPHINS}

Within the past decade various gonadotrophic hom mones have been purified considerably. Evidence for purity of the active principles from human pregnancy urine and serum of pregnant mares has been reported. ${ }^{1-4}$ Purification of a complete gonadotrophin from pituitary extracts has not been reported, while in several laboratories fractionation of such extracts has yielded two separate gonadotrophic principles of a high degrce of al tivity ${ }^{5-17}$ The biological effects of these two principles are similar though not identical in character with those ascribed ten years ago by Fevold and his co-rorkers to their follicle-stimulating $(\mathrm{FSH})$ and luteinizing $(\mathrm{LH})$ hormone respectively. The close resemblance in the activity of the purified preparations obtained by different methods in a number of laboratories does not lend support to the assumption that these two active principles may represent antifacts or split products of a macromolecule. It is recognized, however, that the isolation of these proteins from the pituitary does not prove that they actually are secreted in this form. Evidence has been presented that the hormones liberated by intact glandular tissue are quantitatively and qualitatively superior to those extracted from such tissue. ${ }^{18}$ Howerer, the concentration of pituitary gonadotrophins in the blood stream is su low that no arrempts to purify and, possibly, fractionate these hormones, have as yet been reported. The fact that the type of gonadotrophic activity in the body fluids of nomal (nompregnant) animals may show great variations within the life cycle of the animal, primarily controlled by its gonads, tends to favor the assumption of two homones actually being secreted in varying relative amounts by the pituitary. With the study of these circulating hormones being delegated to the future, a revicw of the properties of the gonadotrophins isolated from pituitary extracts will be attempted here.

\section{Physicochenical Properties of FSH and ICSH (LH)}

(Follicle-stimulating hormone and interstitial-cell-stimulating hormone,

All gonadotrophins are glycoproteins; they can be effectively separated from inert protein and most other hormones by their stability and solubility in alcohol-water or acetone-water mixtures. Extraction of acetonc-dried sheep glands with $4^{\circ}$ per cent alcohol has proven most snccesslul. ${ }^{7 n}$ Methods of fractionation of the gonadotrophic complex are based on the fact that the FSH is more soluble in salt solutions than the ICSH. Thus, repeated precipitation of the proteins with ammonium sulfate at hall and two-thirds saturation, as well as fractionation with solium sulfate at pH f... achieves separtion of the two principles. From the lower salt fractions a pure protein was isolated which contained the ICSH activity. ${ }^{10,11,12,16,15}$ Comparison of the final products obtained from sheep ${ }^{10,11,12}$ and pig pituitaries ${ }^{16,15}$ has shown these to be quanti-

$$
[185]
$$


tatively and qualitatively similar in biological activity but quite different chemically (see table 1).

The follicle-stimulating factor has not yet been obtained in pure form. Active fractions are soluble in water and half saturated ammonium sulfate; they contain almost twice as much carbohydrate as the ICSH. ${ }^{2,18}$ Comparison of FSH from different species has to be postponed until final purification will have been achieved. At the present it can only be stated that the best sheep $\mathrm{FSH}$ is considerably more active and appears to be more stable than is pig

TABLE 1

Physicochemical Characteristics of ICSH from Sheep and Hog Pituitary Glands*

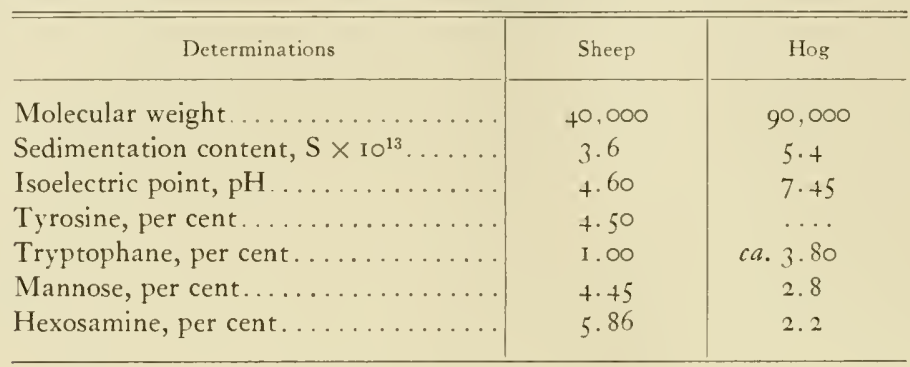

* See ref. 2, 10, I I, I2, I4, I5.

FSH. ${ }^{0,20,21}$ The latter has been claimed to be "biologically pure,"21 that is, free from all active contaminants, while the best sheep FSH fractions may contain some ICSH, but no other known hormones.

A considerable amount of work has been done to study the effect of specific reagents on the hormonal activity of the gonadotrophins. Thus, some proteolytic enzymes were found to inactivate preferentially either ICSH (LH) or FSH. Crude trypsin was shown to destroy nearly all the ICSH but not the $\mathrm{FSH}^{2,2},{ }^{23}$ while pepsin leaves intact only the ICSH $;{ }^{24}$ on the other hand, ptyalin (saliva) destroys FSH but not ICSH. ${ }^{25}$ Apparently the high carbohydrate content of the FSH is in some way, possibly only structurally, essential for its activity. Rapid inactivation by treatment with ketene $e^{26}$ and nitrous acid may be interpreted as evidence for the essentiality of free amino groups for the activity of the gonadotrophins.

Cysteine also inactivates these hormones, although not as readily as other proteins, $^{27,2 s}$ thus favoring the assumption that the integrity of some disulfide bonds which are not casily reduced is essential for hormonal activity.

\section{Biological Properties of ICSH}

As the name indicates, this hormone stimulates the interstitial tissue of the gonads of either sex. Its ability to effect repair of this tissue, which atrophies characteristically after hypophysectomy, has been used as a test method in female rats. By this method $5^{-10} \mu \mathrm{g}$. of the hormone can be detected. Other 
effects in the female become evident only in combination with ISH and will be discussed later. In male rats, stimulation of the interstitial tissue leads 10 androgen secretion, thus offering a functional test method for this hommone. It has been shown, however, that the ability of all pituitary extracts and fractions to stimulate androgen secretion is very poor compared with that of circulating hormones. ${ }^{s, 29}$ Thus, most authors (with the exception of levold and co-workers) find the seminal vesicles of immature normal or hypophysectomized rats very insensitive to stimulation by pituitary preparations. * I he observation that the rentral prostate of immature hypophysectomized rats (2 days p.o.) was much more sensitive to the secreted androgens than other parts of the accessories has supplied a reliable functional-test method for the interstitial-cell-stimulating hormone. ${ }^{29}$

Other effects of this hormone may be less specific. Thus, it increases the testis weight of normal and hypophysectomized rats and, to a greater extent, those of immature pigeons and chicks, an effect which is also produced by FSH. Recently ICSH was also found to favor placentoma formation and prolong pregnancy in normal rats, ${ }^{30}$ phenomena which are probably consequent to stimulation of the pituitary by the ICSH.

Another type of biological activity can be produced with ICSH, that is, that of antagonism. Upon intraperitoneal administration, this hormone will decrease the activity of other gonadotrophins (such as pregnant-mare serum) simultaneously administered. ${ }^{31}$

\section{Biological Properties of FSH}

As the name indicates, the primary effect of this hormone in the female is the stimulation of the development of follicles. In hypopliysectomized rats, only $2-3 \mu \mathrm{g}$. of the most active preparations from sheep pituitaries are needed for this effect. ${ }^{\circ}$ Pig FSH fractions which have been described as "biologically" pure," that is, free from other active principles, are considerably less active. The follicular growth elicited with purified FSH is associated with only limited increases in the weights of the ovaries, which rarely exceed $60 \mathrm{mg}$.

Follicles produced with FSH alone seem to secrete less estrogenic substances than those produced by unfractionated extracts, as judged by uterine development. According to Greep and his associates, "biologically pure" pig FSH was found to result in no uterine stimulation, even at very high dosage. Sheep FSH has not been obtained similarly free from cstrogenic properties. At sufficiently high levels (ten- to fiftyfold the MED) in liypophysectonized rats it produces estrus, corpora lutea, and repair of the interstitial tissue in female and ventral prostate growth in male rats. From these finclings it could be concluded that the best sheep FSH fractions still retain $10-20$ per cent ICSH. The action of FSH preparations on interstitial tissue was found to differ, however,

* ICSH maintains the accessories of adult mate rats after hypophrsecomy but does not produce, in any lype of rat, hypertrophy comparable to that cliciled wits secresed gonadotrophins. 
from that of $\mathrm{ICSH}$ in being more pronounced upon subcutaneous than intraperitoneal administration. Furthermore, it has been shown that purified FSH upon intraperitoneal administration antagonizes other gonadotrophins (even subcutaneously administered FSH). Such antagonistic phenomena can be produced with equal or even smaller amounts of FSH than are needed of ICSH. It thus appears unlikely that such antagonism is due to contamination with ICSH; antagonism probably is an inherent property of each gonadotrophin. ${ }^{31}$

These findings suggest the possibility that a limited degree of ICSH-like properties may be cliaracteristic of sheep FSH. This could be proven only by isolation of physicochemically homogeneous FSH still showing these diverse activities. Such relationships between hormones have been shown to exist in the case of the adrenal steroids, several of which may combine high activity in one respect with low activity in another direction, in which another hormone of a slightly different structure may be highly active. Furthermore, the gonadotrophin from pregnant mares appears to be a single protein while showing both FSH and ICSH properties. ${ }^{3}$

In hypophysectomized rats FSH causes increases in test is weights, which are more pronounced than those produced by similar amounts of ICSH. Histological examination indicates stimulation of the tubular development, although it appears that spermatogenesis can be furthered much more effectively if FSH is combined with ICSH. Testosterone alone has been shown to be effective in both maintaining and repairing testicular function of hypophysectomized rats; the gametrotropic effect of FSH is difficult to explain on the basis of ICSH contamination and concomitant testosterone production, in view of the atrophic condition of the accessories of rats treated with effective levels of FSH.

\section{SYNERGISM}

It has been recognized for a long time that ICSH shows pronounced activity in augmenting and modifying the action of FSH when both are given subcutaneously. A reinvestigation of these synergistic effects, using purified hormones, has led to the following conclusions: In female rats, immature normal or hypophysectomized, subcutaneously injected ICSH augments the effects of FSH on the ovaries and in particular the secondary effects on the uterus. ${ }^{8,33}$ Ovarian-weight augmentation rarely exceeds 100 per cent, in contradistinction to that produced by combined administration of FSH with "secreted" interstitial-cell-stimulating substances, such as the pregnancy urine principle. On the other hand, uterine "augmentation" becomes quite pronounced when less than 5 units of sheep FSH (alone insufficient to effect estrogen secretion) is combined with about 1 unit of ICSH. This is all the more surprising since 5 units of ICSH would be needed to produce any effect on the interstitial tissue in the same rats upon subcutaneous administration. Actually, under favorable conditions, as little as one-fifth to one-tenth of a unit of ICSH may be detected by its synergistic effect with $3-5$ units of FSH on the uterus of hypophysecto- 
mized rats. Histological study of the ovaries of such doubly treated rats reveals no indication of the presence of ICSH other than by its angunentation of the follicle stimulating action of FSH. When ICSH is combined with ligher closes of FSH, however, it may lead to luteinization of the follictes. This phenonenon led to its discovery and has prompted the nane "luteinizing hommone (LH)." "Since sheep FSH alone will cause luteinization of follicles at sufficiently high doses, it is difficult to decide whether the luteinizing action of ICSH is a specific one or is due only to its FSH augmenting action previously: discussed.* In particular, after it was shown that similar augmentation and Inteinization effects could be produced on combining FSH with inorganic salts or inert proteins, doubt was cast on the existence of this second gonadotrophin, "LH." While it appears well established that FSH can be augmented in its effect by nonspecific agents, the above described augmentation phenomena of FSH produced by ICSH are most certainly lue to a specific synergism of the two substances, for the following reasons: (1) These effects can be produced by injection at different sites of the body of the two gonadotrophins, whereas nonspecific augmentation can be produced only by administration of the mixture, and are most probably due to delayed absorption of the hormone; ${ }^{8,32}$ (2) less than $1 \mu \mathrm{g}$. of ICSH augments the effect of a few micrograms of FSH, whereas very large doses of nonspecific agents are needed to produce such augmenting effects; (3) heat inactivation of ICSH destroys also its capacity to augment FSH. It may be hoped that as a result of the purification of ICSH and with the recognition of its intrinsic effect on the interstitial tissue (which is not given by salts and inert proteins), arguments against its existence based on augmentation and luteinization phenomena will not be voiced any longer.

It has been mentioned that the ovarian weights produced by FSH (in nornial inmmature or hypophysectomized rats) rarely exceed $60 \mathrm{mg}$. after three days of treatment; and that added ICSH augments these weights to no more than double. By administering purified FSH and ICSH in the form of tannates, however, ovaries ranging from 200 to $300 \mathrm{mg}$. can be produced under the same conditions, similar to those produced with crude extracts. It thus appears possible that the inert proteins in crude extracts may exert a nonspecific angmenting action which can be replaced by the use of tannic acid.

Whereas augmentation of the effects of FSH by ICSH in females are rell recognized, augmentation of ICSH by FSH does not appear to occur; on the contrary, marked follicular stimulation may mask the action of ICSH on the interstitial tissue.

In the male rat no clear evidence for synergism between purified FSH and ICSH has been found. $\uparrow$ Interesting parabiotic experiments are reported in the

\footnotetext{
* Usually this luteinizition of follicles obtained by combining low or moderate levels of FSH with ICSH is thecal luteinization in contrast to the gramblosa luteinization chatracteristic of high levels of purified sheep FSH.

+ Nonspecific augmentation of the effect of ICSH on the vental prostate of hypophsectomized rats has been observed, using copper sullitle.
} 
literature in which a male and a female rat were subjected to the control of the same pituitary..$^{33}$ In the female, follicular and uterine stimulation were evident; in the male, testis and accessory-organ growth occurred. Duplication of these conditions and effects by treating males and females with a known FSH-ICSH mixture has shown that these cannot be interpreted as evidence for the secretion by the pituitary of a single gonadotrophin. ${ }^{34}$ The observed phenomena are better explained by the fact that, in the female, ICSH augments the action of the FSH while, in the male, only its intrinsic hormonotrophic action becomes evident.

\section{Conclusions}

An attempt has been made to summarize and coördinate briefly the results of investigations carried out in this and other laboratories within the last few years, concerning pituitary gonadotrophins. While a number of recent findings are included in this discussion, the detailed presentation of new data has been avoided.

The preparation in pure form of one of the gonadotrophins, the interstitialtissue-stimulating hormone (ICSH), has been described. Great differences in the physicochemical properties of pure ICSH obtained from sheep and hog pituitaries have been demonstrated. Nevertheless the biological activity of the two compounds was found to be similar, both qualitatively and quantitatively. Similar though less pronounced chemical species differences have been noted also for sheep and beef lactogenic hormones. Species differences have thus become a factor to be reckoned with when comparing the properties of hormones obtained from different animal species. Biological differences between follicle-stimulating hormones ( $\mathrm{FSH}$ ) from sheep and hog pituitaries may rest on chemical differences between hormones of the two sources.

Besides these species differences, there are already well-established contrasts between gonadotrophins from the pituitary and those of chorionic (or endometrial) origin. It appears possible that the hormones secreted by the pituitary resemble more those of placental origin than those extracted from the gland. However, the small amounts of pituitary hormones circulating in the blood makes their purification as yet impracticable, and gland extracts have therefore been generally used as source material for the isolation of hormones. The biological properties of FSH and ICSH prepared in this manner have been summarized. The intrinsic effects of ICSH which characterize it as a separate hormone have been considered separately from those "augmentation" effects which are evident only in the presence of FSH and may be simulated by nonspecific agents which act merely by delaying the absorption of FSH. 


\section{REFERENCES}

1. Gurin, S.; Bachman, J. M., and Wilson, D. W.: J1. Biol. Chem. 133:477, 1910.

2. Gurin. S.: Proc. Soc. Exper. Biol. \& Med, 49:48, 19.12.

3. Li, C. H.; Evans, H. M., and Wonder, D. H.: Jl. Genrl. Physiol. 23:733, 1910.

4. Lundgren. H. P.; Gurin, S.; Bachman, J. M., and Wilson, D. W.: J1. Biol. Chem. 1.f2:367, 1942 .

5. Fevold, H. L.; Hisaw, F. L., and Leonard, S. L.: Amer. Jl. Physiol. 97:291, 1931.

6. Fevold, H. L.; Lee, M.; Hisaw, F. L., and Cohn, E. J.: Endocrinology 26:999, 19 fo.

7. Fraenkel-Conrat, H.; Simpson, M. E., and Erans, H. M.: An. Fac. de med. de Monterideo 25:159.19ł0.

8. Fraenkel-Conrat, H.; Li, C. H.; Simpson, M. E., and Evans, H. M.: Endocrinology 2-:793, $194^{\circ}$.

9. Fraenkel-Conrat, H.: Simpson, M. E., and Evans, H. M.: Proc. Soc. Exper. Biol. \& Med. $45: 627,1940$.

10. Li. C. H.; Simpson, M. E., and Evans, H. M.: Endocrinology 27:803, 1940.

11. Li, C. H.; Simpson, M. E., and Erans, H. M.: Science (n.s.) 92:355, 1940.

12. Li, C. H.; Simpson, M. E., and Evans, H. M.: Jl. Amer. Chem. Soc. 64:367, 1942.

13. Chow. B. F.; Greep, R. O., and Van Dyke, H. B.: Jl. Endocrinol. 1:140, 1939.

14. Greep, R. O.; Van Dyke, H. B., and Chow, B. F.: Jl. Biol. Chem. 133:289, 1940.

15. Shedlorsky, T.; Rothen, A.; Greep, R. O.; Van Dyke, H. B., and Chow, B. F.: Science (n.s.) $92: 1,8,194^{0}$.

16. Jensen, H.; Simpson, M. E.; Tolksdorf, S., and Evans, H. M.: Endocrinology 25:57, 1939.

17. Jensen, H.; Tolksdorf, S., and Bamman, F.: J1. Biol. Chem. 135:791, 1940.

18. Fraenkel-Conrat, H.; Simpson, M. E., and Evans, H. M.: Endocrinology 27:809, 1940.

19. Evans. H. II.; Fraenkel-Conrat, H.; Simpson, M. E., and Li, C. H.: Science (r.s.) 89:249, 1939.

20. Greep, R. O.; Van Dyke, H. B., and Chow, B. F.: Anat. Recrd. $78: 88$, 1940.

21. Greep, R. O.; Van Dyke, H. B., and Chow, B. F.: Amer. Jl. Physiol. 133:303, I941.

22. Mcshan, W. H., and Meyer, R. K.: Jl. Biol. Chem. 126:361, $193^{8}$.

23. McShan, W'. H., and Meyer, R. K.: Proc. Soc. Exper. Biol. \& Med. 10:699, 1939.

24. Chen, G., and Van Dỵe, H. B.: Proc. Soc. Exper. Biol. \& Med. 10:172, 1939.

25. Abramowitz, A. A., and Hisaw, F. L.: Endocrinology 25:623, 1939.

26. Li, C. H.; Simpson, M. E., and Evans, H. M.: Jl. Biol. Chem. 131:259, 1939.

27. Fraenkel-Conrat, H.; Simpson, .I. E., and Evans, H. M.: J1. Biol. Chem. 130:243, 1939.

28. Fraenkel-Conrat, H.; Simpson, M. E., and Evans, H. M.: Science (n.s.) 91:363, 19.10 .

29. Greep, R. O.; Van Dyke, H. B., and Chow, B. F.: Proc. Soc. Exper, Biol, \& Med. \&6:6.11, $194^{1 .}$

3o. Simpson, M. E.: Li, C. H., and Evans, H. M.: Endocrinology 30:969, $19 \Perp^{2}$.

31. Fraenkel-Conrat, H.; Simpson, M. E.; Li, C. H., and Evans, H. M.: An. Fac. de med. de Montevideo $25: 169,1940$.

32. Fevold, H. L.: Endocrinology 28:33, 1911.

33. Greep, R. O.: Proc. Soc. Exper. Biol. \& Med. 44:21 4, 1940.

34. Fraenkel-Conrat, H.; Li, C. H.; Simpson, M. E., and Evans, H. M.: Proc. Soc. Exper. Biol. \& Med. $48: 723,1941$. 



\section{ESTROGEN ASSAY IN THE HUMAN}

$$
B)^{\prime}
$$

S. C. FREED

\section{策}

Froin the

DEPARTMENT OF ENDOCRINE GYNECOLOGY, LOYOLA UNIVERSITY MEDICAL SCHOOL; DEPARTMENT OF MEDICINE, MICHAEL REESE HOSPITAL, CHICAGO, ILLINOIS 



\section{ESTROGEN ASSAY IN THE HUMAN}

Number of investigators have recently expressed the opinion that the
therapeutic efficiency of an estrogen can only be judged by testing its potency in the human. Most claims for the relative therapeutic effectiveness of estrogens have been made on the basis of their activity as determined in laboratory animals, principally the rat or mouse. The assumption that data so obtained can be accepted for the human has resulted in considerable confusion in the standardization of estrogen therapy. In the first place, results obtained from assays differ widely, as indicated by the fact that the rat unit of estrone as determined in different laboratories varies as much as several thousand per cent when compared to a weighed amount of crystalline material; the same holds true for assay's in the mouse. The discrepancy in the assay of estrogens in rat or mouse cannot be entirely accounted for by technical differences in the performance of the assays, and it appears quite certain that each strain of rat or mouse has a different degree of sensitivity to any one estrogen. Similarly, comparisons of the potencies of different estrogens such as estrone and estradiol in the same laboratory cannot be judged as the true reflection of the relative therapeutic potencies of these substances, inasmuch as the ratios of activity as determined by different laboratories are far from constant. In a recent article a compilation of data on this subject reported by a number of investigators illustrates the inconsistencies in animal assays, leading to the conclusion that any statement regarding the relative therapeutic activity of estrogens on the basis of animal assays is liable to considerable error and that assay in the human is at the present time the only hope for satisfactory therapeutic standards of estrogens. ${ }^{1}$

Several attempts have been made to assay the activity of estrogens in humans. Some investigators have utilized as an index of estrogen activity the changes in the vaginal mucosa of menopausal patients following estrogen administration, much the same way as the castrate rodent is used. ${ }^{2}$ When it is recognized, however, that untreated menopausal patients have varying degrees of proliferation of the vaginal mucosa, it does not appear that this would be a satisfactory means of assay. There is a lack of evidence that the raginal epithelium of a group of menopausal women will respond to a definite amount of estrogen with a sufficient degree of uniformity. Furthermore, the reading of vaginal smears in the human for assay purposes is liable to experimental error.

An attempt has been made to utilize the changes in the menopausal endometrium following estrogen administration as a means of assay. ${ }^{3}$ Such a technique is not only cumbersome but also open to even severer criticism than that mentioned above for the use of vaginal smears, inasmuch as untreated menopausal patients may possess significant degrees of endometrial proliferation and, in fact, hyperplasia. This factor would interfere greatly with assays based on endometrial changes.

$$
[195]
$$


The author has selected as an end point in the assay of estrogens in humans the subjective response of menopausal patients. It is acknowledged that the evaluation of such a response may be obscured by numerous uncontrolled factors. Nevertheless, this method has been selected for assay for a number of reasons, not the least of which is the fact that the chief purpose in administering estrogens is to relieve the menopausal patient of her subjective symptoms. Such an assay requires no special technique and a large number of patients may be included in a study with little difficulty. In order to eliminate as many distracting factors from this study as possible, the author has established certain criteria. Patients were selected who complained of moderate or severe menopausal symptoms; those who had complaints which were of doubtful origin or might possibly be confused with psychic changes due to environmental or social complications were not included in the group tested. Patients were not included in the groups unless they had at least two to four hot flashes daily, together with other symptoms commonly found in the menopause, such as nervousness, irritability, and emotional instability. The psychic factors associated with any form of therapy involving subjective sensations were reduced to a minimum by eliminating any therapeutic suggestion, such as a promise of beneficial results or leading questions concerning therapeutic responses. In addition, the subjective changes of all patients were evaluated by the author alone in as constant a manner as possible, thus eliminating differences in interpretation of results which are prone to develop where a number of clinicians are treating the same group of patients. Furthermore, the estrogens were administered in several dosage levels in the manner which is used for assaying estrogens in laboratory animals. Two synthetic estrogens, hexestrol, and diethylstilbestrol, were thus assayed.

\section{Methods ANd Results}

Patients were given at different times one of three levels of the synthetic estrogen hexestrol-1 $\mathrm{mg}$., $2.5 \mathrm{mg}$. and $5 \mathrm{mg}$. daily. Diethylstilbestrol was administered daily in dosages of $0.5 \mathrm{mg}$. and $1 \mathrm{mg}$. Therapy was usually started by administering the highest level of hexestrol. After three weeks of treatment the therapeutic response was evaluated and listed in terms of plus signs, $3^{+}$ being considered the optimal response, $2+$ a satisfactory response, and $1+$ a slight though definite response. In the evaluation of therapeutic response, the disappearance of hot flashes was used as one of the most important criteria of relief. Changes in nervousness, irritability, etc., were also considered in this evaluation. After the first period of treatment, the dosage was dropped to the next lower level and maintained in this manner for three weeks or more. After the patient's response was evaluated at the medium level, the lowest level was then administered for three or more weeks and further response noted. The patients were then given the second estrogen, diethylstilbestrol, and their clinical course with two dosage levels followed in a similar manner. A number of patients received medication in the reverse order, first diethylstilbestrol, 
then hexestrol. Some patients were unable to undertake the entire course of assay due to such reasons as failure to follow directions satisfactorily ancl refusal to continue therapy because of unpleasant symptoms which developed. The following table contains the results of assay of both estrogens by the above-described method, together with the incidence of unpleasant symptoms.

TABLE 1

Therapeutic Response of Menopal'sal Patients following Administration of Hexestrol and Diethylestilbestrol by Mouth

\begin{tabular}{|c|c|c|c|c|c|c|c|c|c|}
\hline \multicolumn{6}{|c|}{ Hexestrol } & \multicolumn{4}{|c|}{ Diethylstilbestrol } \\
\hline \multicolumn{10}{|c|}{ Daily dose } \\
\hline \multicolumn{2}{|c|}{ I $\mathrm{mg}$. } & \multicolumn{2}{|c|}{$2.5 \mathrm{mg}$. } & \multicolumn{2}{|c|}{$5 \mathrm{mg}$. } & \multicolumn{2}{|c|}{$0.5 \mathrm{mg}$. } & \multicolumn{2}{|c|}{ I mg. } \\
\hline $\begin{array}{l}\text { No. of } \\
\text { patients }\end{array}$ & Response & $\begin{array}{l}\text { No. of } \\
\text { patients }\end{array}$ & Response & $\begin{array}{l}\text { No. of } \\
\text { patients }\end{array}$ & Response & $\begin{array}{c}\text { No. of } \\
\text { patients }\end{array}$ & Response & $\begin{array}{c}\text { No. of } \\
\text { patients }\end{array}$ & Response \\
\hline $2 \mathrm{I}$ & neg. & 7 & neg. & 15 & neg. & 9 & neg. & 5 & neg. \\
\hline IO & + & 13 & & 5 & & 17 & & 10 & + \\
\hline 6 & ++ & 29 & ++ & 22 & ++ & I 8 & ++ & 27 & ++ \\
\hline . & $\cdots$ & I I & +++ & 23 & +++ & 9 & +++ & 23 & +++ \\
\hline 37 & & 50 & & 65 & & 5.3 & & 65 & \\
\hline \multicolumn{10}{|c|}{ Incidence of toxic reactions } \\
\hline & & \multicolumn{2}{|c|}{$2 \mathrm{NHD}^{*}$} & \multicolumn{2}{|c|}{$\begin{array}{l}5 \mathrm{NHD} \\
+\mathrm{DH}\end{array}$} & \multicolumn{2}{|c|}{5 NHD } & \multicolumn{2}{|c|}{$\begin{array}{l}12 \mathrm{NHD} \\
6 \mathrm{DH}\end{array}$} \\
\hline
\end{tabular}

* NHD, nausea with or without dizziness and headache; N, nausea, H, headache; $\mathrm{D}$, dizziness.

A number of patients were questioned at certain times as to which of the two preparations they preferred. The results of this questionnaire are as follows:

TABLE 2

28 found $2.5 \mathrm{mg}$. daily hexestrol equal to $0.5 \mathrm{mg}$. daily diethylstilbestrol

14 found $2.5 \mathrm{mg}$. daily hexestrol better than $0.5 \mathrm{mg}$. daily diethylstilbestrol

4 found $2.5 \mathrm{mg}$. daily hexestrol worse than $0.5 \mathrm{mg}$. daily diethylstilbestrol

34 found $5 \mathrm{mg}$. daily hexestrol equal to I $\mathrm{mg}$. daily diethylstilbestrol

6 found $5 \mathrm{mg}$. daily hexestrol better than $1 \mathrm{mg}$. daily diethylstilbestrol

8 found $5 \mathrm{mg}$. daily hexestrol worse than I mg. daily diethylstilbestrol

It is apparent from the data contained in table 1 that a satisfactory therapeutic dose of diethylstilbestrol is $0.5^{-1.0} \mathrm{mg}$. daily, and an equivalent therapeutic dose of hexestrol is $2.5-5.0 \mathrm{mg}$. daily, the minimal effective therapeutic doses being $0.5 \mathrm{mg}$. diethylstilbestrol and $2.5 \mathrm{mg}$. hexestrol daily. It will be noted that there was a larger number of patients who failed to respond to $5 \mathrm{mg}$. daily of hexestrol than to $2.5 \mathrm{mg}$. daily of the same substance. This 
apparent paradox can be explained by the fact that the patients were first administered the higher level. Those who failed to respond did not receive the $2.5 \mathrm{mg}$. daily dose. The seven patients who failed to respond to the $2.5 \mathrm{mg}$. daily dose had received some beneficial results when they were given $5 \mathrm{mg}$. daily.

In regard to the toxic manifestations of this therapy, which is of considerable interest inasmuch as the unpleasant symptoms following oral administration of these estrogens are considered to be their greatest disadvantage, it appears that hexestrol is significantly less toxic than diethylstilbestrol, although the incidence of toxic reactions from hexestrol administration is appreciable. Additional data seem indicated on this phase of the study before definite conclusions can be drawn as to the relative toxicity of these estrogens.

\section{Discussion}

By the use of different dosage levels, a satisfactory evaluation of the therapeutic potency of estrogens can be obtained by using the relief of menopausal symptoms as an end point. Nonspecific factors are minimized by the proper selection and handling of patients. With the use of the technique described above, there is no need for control with either untreated patients or patients who receive placebo medication inasmuch as each dosage level controls the next. The psychic factor of administering some form of medication is thus reduced. In this regard, the author has observed a number of patients who responded equally well on all levels of estrogens and who when placed on placebo medication also responded satisfactorily. The data obtained from these were not included in the tables since the inclusion of this type of patient in a group for study renders results less significant statistically. With the use of multiple closage levels it is not necessary for statistical purposes to treat a large series of patients receiving a single dosage since, as can be noted from the two tables, these is some cancellation of experimental error at the different levels. Thus, in table $1,2.5 \mathrm{mg}$. hexestrol seems somewhat superior to $0.5 \mathrm{mg}$. hexestrol, but $5 \mathrm{mg}$. hexestrol is somewhat inferior to $1 \mathrm{mg}$. diethylstilbestrol. It is also expected that any new estrogen can be easily compared in potency to estrogens which have already been tested by this assay method. Furthermore, the minimal therapeutic dose can readily be determined by the use of multiple dosage levels.

The results of this study are not in accord with those of Bishop and coworkers ${ }^{5}$ regarding the relative therapeutic activity of hexestrol and diethylstilbestrol. These workers report that these compounds are almost equal in potency. My results indicate that hexestrol is one-fifth as effective as diethylstilbestrol. In addition, they claim hexestrol to be relatively free of untoward reactions. In my hands hexestrol appears to be less toxic than diethylstilbestrol in equivalent therapeutic doses, although the incidence of unpleasant symptoms is sufficiently high to warrant caution in its use. 


\section{Conclusions}

Two synthetic estrogens, diethylstilbestrol and hexestrol, have becn tested for their therapeutic efficiency by assay in humans. The subjective response of menopausal patients was used as the end point in this assay and the usual uncontrolled factors encountered in such a study were eliminated to a great extent by using multiple dosage levels of estrogens, as well as other precautions. From the results obtained, it can be concluded that hexestrol is about one-fifth as effective as diethylstilbestrol in the human. It is indicated that hexestrol is significantly less liable to induce undesirable reactions than diethylstilbestrol at equivalent therapeutic dosages.

\section{REFERENCES}

1. Freed, S. C.: Jl. Amer. Med. Assn. $117: 1175,1941$.

2. Papanicolaou, G. N., and Shorr, E.: Amer. Jl. Obstet. \& Gynecol. 31:806, 1936.

3. Werner, A. A.: Internatn. Abstr. Surg. 73:49, in Surg. Gynecol. \& Obstet., 1941.

4. Novak, E., and Richardson, E. H.: Amer. J1. Obstet. \& Gynecol. 42:564, 1941.

5. Bishop, P. M. F.; Bowes, R. K.; Boycott, M.; Kellar, R.; MacGregor, T. M., and Murless, B. C.: Lancet $238: 629,1940$. 

FUNCITIONAL INTERRELATION OF GEREBRAL CORTEX WITH BASAL

\section{GANGLIA AND GEREBELLUM}

$$
\text { By }
$$

J. F. FULTON, M.D.

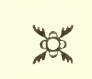

From the

LABORATORY OF PHYSIOLOGY

YALE UNIVERSITY SCHOOL OF MEDICINE

NEW HAVEN, CONNECTICUT 



\section{FUNCTIONAL INTERRELATION OF CEREBRAL CORTEX WITH BASAL GANGLIA AND GEREBELLUM*}

Tariej cushing once good-naturedly accused Herbert Evans of being "pi1 tuitary minded," and I believe that there was a prompt rejoinder from Doctor Evans to the effect that Cushing had lately transferred his "mindedness" as well as his affections to the hypothalamus. Had it been a three-cornered exchange, one might have suggested that these two seats of Cartesian turmoil are connected by silken threads of functional integration. In my mind's eye I can see Herbert racing around the sella turcica, peeping over the posterior clinoid or looking menacingly up through the diaphragm-only to meet the penetrating gaze of a diminutive Harvey Cushing seated securely on the floor of the third ventricle and exclaiming: "What, Herbert, more fractions? Stop it-I'll stir up one of them from here, and create a case of diabetes that even Jack Peters cannot control."

What other excuse can I offer for presenting the nervous system to Herbert Evans on his birthday? I fear he may not like it-but even so, he surely will be pleased by the thought that he and Cushing are still playing hide-and-seek with one another above and around the sella. And what game on the part of two men ever proved more richly rewarding to us all?

In selecting for discussion the broad theme of the physiological relation between the two great extrapyramidal systems, (i) the cortico-strio-nigral, and (ii) the cortico-ponto-cerebellar, I am aware that $I$ am taking liberties with one of the classical concepts of clinical neurology, for in common parlance the "extrapyramidal" system begins with the basal ganglia and ends somewhere in the spinal cord through the reticulo- and rubro-spinal projections. From the physiological standpoint, this is an indefensible concept, since in higher animals all subcortical motor nuclei, including the cerebellum, are under the direct control of the cerebral cortex, and it is impossible in a functional analysis to divorce the subcortical from the cortical centers of motor integration.

\section{The Cortico-strio-nigral System}

One way take for granted a knowledge of the principal subcortical nuclei of the extrapyramidal system: the neostriatum (caudate and putamen) discharging through the paleostriatum or globus pallidus, which in turn discharges by the ansa lenticularis to substantia nigra and other tegmental nuclei. In early embryological history, the paleostriatum and its motor projections were the principal motor pathways from the forebrain, but with the development of the cerebral cortex, the striate bodies became dominated by direct and in-

\footnotetext{
* Modified from an address to the Philadelphia Neurological Society, read March 28, 1941.
} 
direct projections from the cerebral cortex; indeed, they have become so intimately linked with the motor functions of the higher cortical level that in man and higher apes it is probably impossible for them to function in the organization of motor acts without the cerebral cortex itself. The interrelation between basal ganglia and the cortex has indeed become so close that they appear to function as a homogeneous unit. The basis for these generalizations comes from three lines of evidence: anatomical, electrical, and from studies involving seriatim ablations of the cerebral cortex and the striatal nuclei.

Anatomical Studies.-The anatomical evidence of interconnections between cortex and basal ganglia is less impressive than the physiological. Nearly all observers working with the Marchi technique, after ablation of areas 4 and 6 of the cerebral cortex, have found degenerating fibers passing into the caudate and putamen, and some also into the globus pallidus. But with Marchi sections there is no absolute proof that the fibers actually end in the area in which they are seen to disappear (Levin, ${ }^{1}$ Mettler $^{2}$ ). A carefully controlled study by Verhaart and Kennard, ${ }^{3}$ in which individual areas were destroyed by the thermocoagulation technique of Dusser de Barenne, indicated that fibers from areas 4 and 6, and especially from the intermediate-strip area 4 -s of Marion Hines, passed into the striatum; but as with the earlier studies, there was no certain proof that they terminated there. Ramón y Cajal ${ }^{4}$ had described corticostriatal fibers with silver preparation and he has also observed dichotomizing fibers from corticospinal projections passing into the putamen at the level of the internal capsule. These, however, were fine fibers which one could not expect to follow by Marchi degeneration.

Electrical Evidence.-Dusser de Barenne and McCulloch ${ }^{5}$ found that strychninization of certain areas in the macaque's precentral cortex evoked conspicuous electrical activity in the striate nuclei. The observation was one of challenging interest because of associated effects elsewhere in the cerebral cortex, and because of the sharply circumscribed character of the response in the striatum itself. The precentral convolution is divided into three primary areas: area 4 , area 6 , and an intermediate-strip region, first defined by

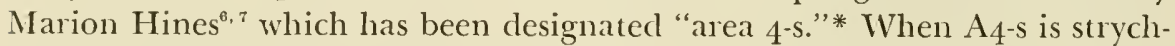
ninized, spontaneous electrical activity in $A_{4}$ disappears (see fig. 1) and its threshold for stimulation rises. Dusser de Barenne and McCulloch pointed out that this suppression of electrical activity by local strychninization is not mediated transcortically, but by a complex circuit from $\mathrm{A}_{4}$-s to the caudate nucleus, thence to the thalamus and from there back to area 4 . The caudate nucleus thus becomes specifically activated by stimulation of area 4 -s; they found furthermore that strychninization of areas 4 or 6 had no such effect on the caudate. Isolated destruction of the caudate, and of no other part of the basal ganglia, caused disappearance of the strychnine suppression from area $4^{-s .}$

* To distinguish arm, leg, and face, it has become customary to refer to the major subdivisions as $\mathrm{L}_{4}, \Lambda_{4}, \mathrm{~F}_{4}, \mathrm{~L}_{4}$-s, etc., designating the leg, arm, and face regions respectively. 
Later studies by Dusser de Barenne, Garol and McCulloch, ${ }^{8}$ reported at the meeting of the Association for Research in Nervous and Mental Discase in December, 1940, indicate that there are other suppressor areas, notably areas 8 -s and 2-s (fig. 1). On stimulation, both regions may catuse activation of the caudate nucleus in a sharply circumscribed area, 8-s activating the anterior

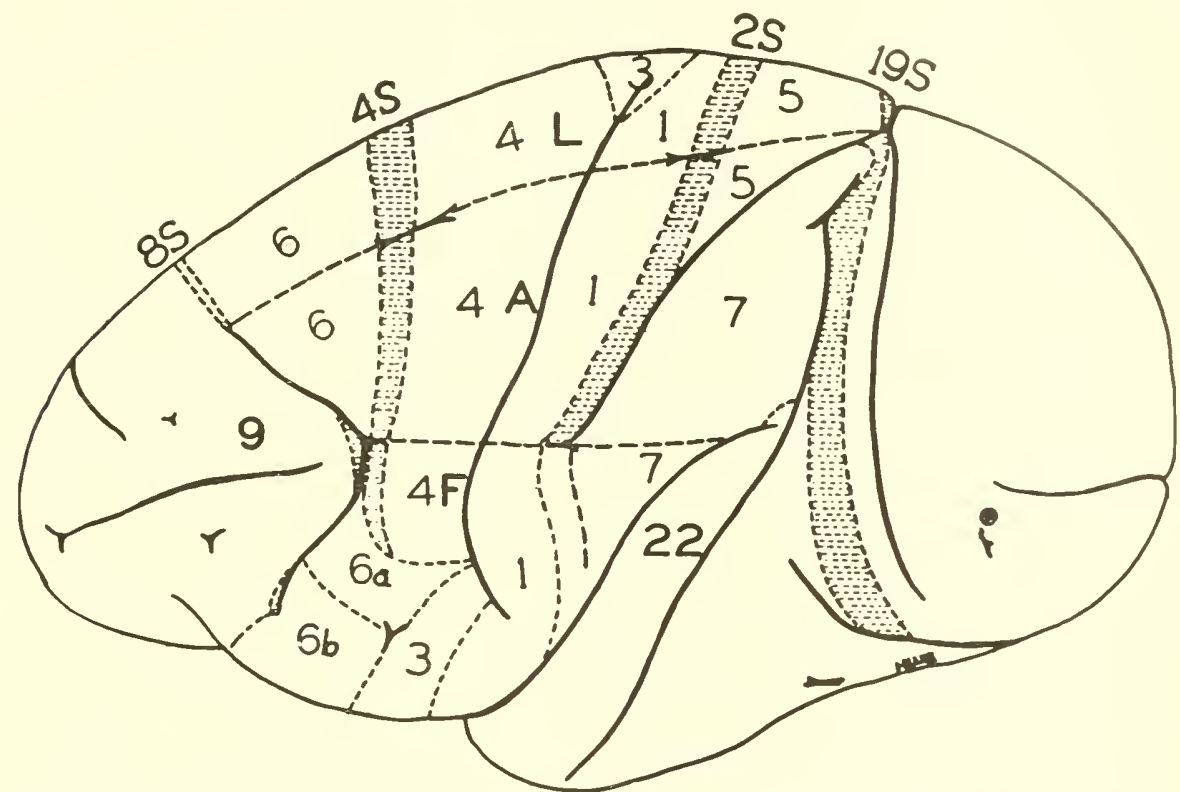

Fig. 1. A diagram of the cerebral cortex of the common Rhesus monkey (Macaca mulatta) thowing the principal suppressor areas (8-s, 4-s, 2-s, 19-s) together with the primary motor regions ${ }_{4} \mathrm{~L}(\mathrm{leg}),{ }_{4} \mathrm{~A}(\mathrm{arm}),{ }_{4} \mathbf{F}$ (face). (From Dusser de Barenne, Garol and McCulloch: Jl. Neurophysiol. 4:325, 1941.)

part of the caudate, $4^{-5}$ the medial part, and 2 -s the tail of the caudate. Thus all of the suppressor areas of the cortex converge in a spatially oriented manner upon the caudate nucleus.

With regard to the other parts of the basal ganglia, it is no doubt significant that, whereas areas 4 and 6 fail to project to the caudate, they do, when strychninized, cause strong electrical activation of the putamen, and area 6 also affects the external segment of the globus pallidus. Although the suppressor regions exhibit an anteroposterior organization of their projections, there is less precise localization within the putamen and globus pallidus. To quote Dusser de Barenne, Garol and McCulloch:

From a purely anatomical standpoint, that spatially separated areas 4 and 6 should project to one structure, the putamen, while $4^{-s}$ and 8-s project to another, the nucleus caudatus, is truly surprising, for 4 -s lies between 4 and 6 , and 6 lies between $4^{-5}$ and 8 -s. On the other hand, when one realizes that 4 and 6 are alike in giring motor responses and that 4 -s and 8 -s are alike in giving suppression, it becomes highly probably that the projections from 4 and 6 may converge somewhere else, and it ceases to be so surprising to discover these discrete convergences in the corpus striatum. 
There is also impressive evidence, based upon electrical reactiveness, pointing to a close functional interrelation between the cerebral cortex and the basal ganglia. Removal of the cerebral cortex, leaving the basal ganglia intact, does not preserve the electrical excitability of these structures, save for certain doubtful reactions in the lower vertebrate forms (Rioch and Brenner ${ }^{9}$ ). In monkeys and chimpanzees, weeks or months after the cerebral cortex has been removed the basal ganglia are quite unstimulable as far as somatic reactions are concerned (Fulton $\left.{ }^{10}\right)$.

The striking studies of Mettler, Ades, Lipman and Culler," on the other hand, in which the basal ganglia have been stimulated during concurrent stimulation of an intact cerebral cortex, indicate that from certain striatal regions suppression of cortical and motor activity may be brought about; during spontaneous phasic movements originating in the cerebral cortex, stimulation of the caudate causes suppression of these reactions-a true central inhibition. Such suppression might have been anticipated from the studies of Dusser de Barenne and McCulloch.

Seriatim Lesions of Cortex and Basal Ganglia.-The consequences of isolated regional ablations of the motor area are well known in monkeys, chimpanzees, and man. Two generalizations can be made concerning the effects of such lesions. The first is that a lesion restricted to area 4 causes motor weakness accompanied by flaccidity of the affected extremities; transient spasticity of the digits may develop in three to four wecks after an isolated area 4-lesion (Denny-Brown), but the predominant feature of corticospinal interruption is a flail paresis. If the corticospinal projections are interrupted at the level of the medullary pyramids, an enduring and purely flaccid paralysis results $\left(\right.$ Tower $^{12}$ ) without spasticity at any joint at any time. This observation entirely harmonizes with the results of area 4 -ablation. With area 4 -ablations, some extrapyramidal projections are inevitably interrupted, and these are no doubt responsible for the transient spasticity that appears in the digits after an area 4 -lesion.

The second generalization from regional ablation of the cerebral cortex is that hypertonicity and spasticity (that is, generalized increase of resistance to passive manipulation) result only when extrapyramidal projections are interrupted, either at the cortical level or, as we shall see later, at subcortical regions.

When lesions of the caudate, putamen, and globus pallidus are added to specific ablations of the cerebral cortex in adult animals-either when the striatal lesion is made simultaneously or at an interval after the cortical ablation-the motor deficit is invariably greater than with isolated removal of a given cortical area. Primary lesions of the caudate or putamen, without injury to the cortex, cause inconspicuous motor deficit. Only when combined with lesions of the cortex is the deficit grave.

Primary lesions of the globus pallidus, however, cause moderate deficit in adult animals, and if the pallidal lesions are bilateral the effects are more severe and lasting. Such animals exhibit bilateral paresis and, although able 
to climb, walk, and run, they have obvious difficulty in finer prehension novements. Spontaneous movements, moreover, are considerably slowed. Resistance to passive manipulation is increased and marked tremor develops, not seen in unilateral preparations. The tremor is definitely augmented by volitional effort and as such possibly differs from Parkinson's tremor. This I shall return to in a moment.

Further and highly impressive evidence of the intimate association between the cerebral cortex and the basal ganglia has come from Kennard's stuclies ${ }^{13}$ of the effect of ablating the cortex and basal ganglia of infant monkeys. Lesions of the motor and premotor areas, if made shortly after birth, cause no serious impairment in motor movement. At birth, motor acts are integrated largely at the subcortical level. Lesions of the basal ganglia, on the other hand, if made in infancy cause grave impairment of the motor behavior patterns, indicating that at this stage in the animal's development the cortex has not yet assumed control of basal ganglia activity. With the development of isolated movements, as Marion Hines ${ }^{14}$ and others have emphasized, the cerebral cortex assumes dominance in the regulation of motor patterns. As the animal matures, the basal ganglia no doubt remain in the background, giving support for complex adjustments; all available evidence indicates that they function more in the postural sphere than in that of phasic movement. But the two spheres of activity are so closely related that adequate separation is difficult, for, as Stanley Cobb once said: "Every phasic morement begins and ends in a posture."

Tremor and the Clinical Basal-Ganglia Syndromes.-Many attempts have been made in the past to reproduce the involuntary movements which form such a conspicuous part of the so-called basal-ganglia syndrome in men, that is, Parkinson tremor, chorea, and athetoid movements. Kennard ${ }^{15}$ has been able to induce in monkeys a tremor which often continues during rest and is greatly exaggerated by motion. This has been done by two different procedures: (i) bilateral ablation of the globus pallidus, unassociated with lesions of the cerebral cortex, and (ii) bilateral lesions of caudate and putamen accompanied by subtotal removal of the precentral convolution (either area 4 or area 6). Tremor established in this manner can be abolished if the remaining portion of the precentral convolution is removed. Integrity, therefore, of the motor projections, extrapyramidal or pyramidal, from the cortex is essential to the production of tremor associated with lesions of either the neostriatum or the paleostriatum. This observation has a bearing upon the neurosurgical procedures recently proposed for the relief of Parkinson tremor, chorea, hemiballismus, etc., and will be discussed below.

Kennard has had less success in producing athetosis and chorea. Athetoid movements have been seen in several infant monkeys following bilateral lesions of the caudate and putamen. Such movements, although unmistakable when present, are transient and difficult to reproduce from one animal to the next. A characteristic jerking chorea was induced in one chimpanzee by a 
lesion involving area 6 and the head of the caudate nucleus. It persisted for several weeks, then abruptly diminished in intensity, but was occasionally seen during a period of five or six months, whenever the animal became excited. We have been unable in two subsequent chimpanzees, with a similar lesion, to reinduce the chorea, and we are as yet unable to state what the essential lesion may have been.

In the analysis of the tremors and involuntary movement of our striatal animals, we have been frequently aware of certain similarities between the tremors of corticostriatal origin and those of corticocerebellar origin, and now I would like briefly to describe a series of recent studies on the physiology of the cerebellum which have an intimate bearing upon the problem in hand.

\section{The Cortico-Ponto-Cerebellar System}

From the cerebral cortex also arises a vast system of fibers which converge on the pontine nuclei, and from there pass their impulses to the cerebellum. The corticospinal projections, in addition, are said to send branching fibers to the pontine nuclei which directly influence cerebellar mechanisms. The cerebellar hemispheres have developed in evolutionary history pari passu with the elaboration of the cerebral cortex, and all authorities are agreed that the two organs have a close functional interrelation. It is customary to speak of the corticostrio-nigral system as being primarily concerned with postural reactions, whereas the cortico-ponto-cerebellar system is believed to be associated primarily with phasic movement. Neither generalization, however, can bear too close scrutiny.

The cerebellum has three primary divisions, two arising from the ancient brain-the posterior lobe and the anterior lobe, both midline structures-and the third, the neocerebellum, comprising the cerebellar hemispheres, which are intimately associated with the hemispheres of the cerebrum.

Posterior Lobe.-This includes two primary divisions: (a) a spinocerebellar part, consisting of pyramis and uvula, and $(b)$ the flocculonodular lobe, which is primarily vestibular in its connections. Dow ${ }^{18,17}$ has shown that ablation of the flocculonodular lobe causes disturbances of balance similar to those seen in grosser form when the vestibular nuclei are injured, and it is obvious that this ancient part of the cerebellum plays an important role in maintaining the equilibrium of the body.

Less is known concerning the pyramis and uvula, except that their ablation in conjunction with that of the flocculonodular lobe considerably exaggerates the disturbance of equilibrium caused by ablation of the flocculonodular lobe alone. Their isolated ablation, however, does not seriously affect equilibrium.

Anterior Lobe.-The anterior lobe, also called paleocerebellum, is separated from the neocerebellum by the fissura prima and is made up of three divisions: the culmen, centralis, and lingula. Stimulation of the anterior lobe, as originally shown by Miller and Banting, ${ }^{18}$ causes inhibition of decerebrate rigidity, and, in a lightly anesthetized animal with cortex intact, inhibition of extensor 
postures. Until very recently, few attempts had been made to discover whether the responsiveness of the anterior lobe is discrete, that is, whether there is separate representation of upper and lower extremities. All are agreed, however, that the homolateral side of the anterior lobe influences the homolateral extremities to a greater extent than the contralateral.

The recent studies of Gervase Connor ${ }^{19}$ indicate that, both in dogs and in monkeys, a maximal extensor release occurs when the anterior lobe is removed as an isolated entity. The positive supporting reactions of Magnus become grossly exaggerated, with head retraction and marked opisthotonos; in a pains. taking analysis Connor finds that this extensor hyperactivity persists after deafferentation of the neck muscles, after bilateral labyrinthectomy and after removal of both cerebral hemispheres, but is destroyed by a posterior root section which interrupts the proprioceptives to the extremity under examination. The exaggeration of positive supporting reaction is so intense, following anterior lobe lesions, that it has given opportunity to study the question of functional localization within the anterior lobe. Doctor Connor permits me to mention the following new disclosures.

A. Culmen.-When the culmen is removed as an isolated entity, leaving centralis and lingula intact, positive supporting reactions are found only in the hindlimbs, the forelimbs being quote unaffected. If one lateral half of the culmen is removed, positive supporting reactions are seen only in the hindlimb on the same side. From this, Connor concludes that functional representation of the hindlimbs can be demonstrated in the culmen and in the culmen alone.

B. Centralis.-Isolated removal of the posterior centralis causes positive supporting reactions elicitable only in the forelimbs, and when the lateral half of the centralis is removed the reactions are restricted to the forelimb on the side of the lesion. From this Connor concludes that the posterior centralis presides over the antigravity reactions of the upper extremity.

C. Lingula.-The lingula is peculiar in being the only portion of the anterior lobe which receives vestibular in addition to spinocerebellar fibers. When the entire anterior lobe is removed one of the striking symptoms, in addition to positive supporting reactions of the extremities, is an extreme head retraction with obvious incoördination of the neck musculature. After isolated lesions of culmen and centralis, this symptom does not occur and is only found when the lingula is included in the ablation. Owing to its anatomical position, it has been impossible as yet for Connor to remove the lingula as an isolated entity, but from the evidence just presented it would seem an entirely logical conclusion that the lingula presides over the neck musculature, and with its restibular connection stands as an integrator of the vestibular and the tonic neck-reflex mechanisms.

You will no doubt ask, how are these mechanisms related with the cerebral cortex? Their relation is less intimate than with the neocerebellum, but in Connor's analysis of the syndrome of the culmen, centralis, and lingula respectively he finds that all reactions, such as the positive supporting reflex, are 
still further released when the cerebral cortex is removed. Connor has not yet had opportunity to study the effects of isolated cortical ablations in relation to isolated ablations of the anterior lobe; but it is clear that the postural mechanisms originating in the cerebral cortex interact with those of the anterior lobe.

Neocerebellum.-It is less essential to dwell upon cortico-neocerebellar interrelations since they are more commonly recognized. Phasic movements are grossly disturbed following removal of the neocerebellar cortex. When large lesions of the neocerebellum occur, errors of rate, range, force, and direction of volitional movements commonly take place, and the discontinuities of movement which constitute the summation of these errors is generally referred to as "cerebellar tremor."

One thing frequently lost sight of in the analysis of cerebellar syndromes is that cerebellar tremor does not arise in the cerebellum, for it develops after its complete removal. It is due to action in some other part of the nervous system, and one can readily prove that cerebellar tremor, so-called, results from activity of the cerebral cortex, since the discontinuities of movement characteristic of cerebellar disease completely disappear on removal of the cerebral cortex (Fulton, Liddell and Rioch ${ }^{20}$ ) or, in monkeys, on bilateral ablation of areas 4 and 6.

Hence, cerebellar tremors and striatal tremors have this in common, namely, that they depend upon the integrity of the motor projections from the cerebral cortex; and the similarities between the two types of tremor are greater than is sometimes appreciated-or perhaps one should say, the differences are less than our textbooks would lead us to suppose. Cerebellar tremors are most conspicuous at the end of a volitional movement and are sometimes referred to as "terminal tremors." When a monkey with a neocerebellar lesion reaches for a banana, the tremor, scarcely obvious at first, becomes grossly exaggerated just as the animal reaches its objective.

A Parkinson tremor, on the other hand, tends to be more exaggerated at the beginning of movement and may be ironed out by the time the movement is completed.

I vigorously object to the distinction commonly made between striatal and cerebellar tremors, namely, that one is a tremor of rest and the other a tremor of action. The Parkinson tremor completely disappears during sleep and is present only when the subject is attempting by voluntary effort to maintain the body in a certain posture. It is in reality a tremor resulting from volitional control over postural mechanisms, whereas cerebellar tremor appears as a result of volitional control of phasic movements. Both, basically, are tremors of action.

\section{Suminary and Conclusions}

This survey of the two divisions of the extrapyramidal system leads to several general conclusions, as well as to a number of practical considerations which may be summarized as follows: 
1. Phasic morement is integrated by that part of the cortico-ponto-cerebellar system which passes to the neocerebellum. Destruction of the neocerebellum leads to tremors of action which are most conspicuous at the termination of rolitional morements. Such action tremors disappear when the precentral conrolution of the cortex is removed.

2. Postural adjustments are integrated by both systems, the cortico-strionigral and that part of the cortico-ponto-cerebellar which joins with the paleocerebellum. The antigravity and equilibritory postures are adjusted by cortical mechanisms acting in association with the anterior and posterior lobes of the cerebellum, whereas the other more complex postural adjustments, not having primarily to do with gravity or the position of the body in space, find integration through the cortico-strio-nigral system.

The cerebral cortex thus becomes the common focus of integration of the extrapyramidal systems both of the striatum and of the cerebellum, and through thus coördinating the postural with the phasic mechanisms absolute smoothness and precision of action are made possible. "Posture," it is said, "follows movement like a shadow," and this would be wholly impossible if the two wrere not integrated from a common level.

Other more practical considerations emerge from this concept of interaction of the postural and phasic mechanisms, namely, the physiological basis for surgical intervention in the cortico-striatal syndromes, and possibly, also, in the cortico-cerebellar.

The work of Bucy and Buchanan ${ }^{21}$ (see also Bucy ${ }^{22}$ ), Putnam, ${ }^{23}$ Meyers, ${ }^{24}$ and particularly that of Klemme, ${ }^{25}$ has focused attention upon the possibility of relieving patients afflicted with serere Parkinsonism, choreo-athetosis, hemiballismus, etc., through a regional cortical ablation. Similarly, Aring and Fulton $^{26}$ showed experimentally that severe cerebellar tremors could be abolished by precentral lesions, but, as far as I am aware, no one has attempted to apply this clinically-possibly for very good reasons, namely that the motor deficit would be worse than the tremor.

In the case of severe hemichorea, and in certain cases of recalcitrant Parkinson tremors, conspicuous and apparently enduring relief has followed ablation of area 4 or of area 6 from the cerebral cortex on the side opposite the affected extremity. Klemme's operation necessitated making a large lesion in the premotor region, leaving area 4 essentially intact. Bucy, on the other hand, has reported $^{22}$ several excellent results from ablation of area 4 (involving only the posterior few millimeters of area 6 ). It is not possible at present to say which is the operation of choice. I feel certain that complete ablation of areas 4 and 6 will arrest a Parkinson tremor, a hemiathetosis or hemichorea, as well as severe cerebellar tremor. Area 4 -ablation will produce much the same result, as far as cerebellar tremor is concerned, but there tends, with recovery of motor power, to be a redevelopment of the cerebellar symptoms. This has likewise proved true in certain clinical cases of hemichorea in which the symptoms have ultimately returned following small precentral lesions. From the physio- 
logical standpoint, an area 4-ablation is likely to be more effective than an ablation of area 6 ; but if, as Klemme maintains, a large ablation of area 6 gives symptomatic arrest for an indefinite period it would clearly be the operation of choice, since area 6-lesions are accompanied by far less ultimate motor deficit than in the case of lesions of area 4.

This field of work is still in its experimental stages and I believe that the solution can come only through further clinical experience. I am confident, furthermore, that in severe cases the operation is entirely justifiable and I sincerely hope that physiologically minded surgeons and neurologists will continue to encourage studies of this character, for they may bring relief in conditions which in years past have been regarded as entirely hopeless.

\section{REFERENCES}

1. Levin, P. M.: J. comp. Neurol. 63:369, 1936.

2. Mettler, F. A.: J. comp. Neurol. 61:221, 509; 62:263; 63:25, 1935.

3. Verhaart, W. J. C., and Kennard, M. A.: J. Anat. 74:239. 1940.

4. Ramón y Cajal, S.: Histologie du Système Nerveux de l'Homme et des Vertébrés (Paris: $1909-1911$ ).

5. Dusser de Barenne, J. G., and McCulloch, W. S.: J. Neurophysiol. 2:319, 1939.

6. Hines, M.: Amer. J. Physiol. 116:76, 1936.

7. Hines, M.: Johns Hopk. Hosp. Bull. 6o:313, 1937.

8. Dusser de Barenne, J. G.: Garol, H. W., and McCulloch, W. S.: Res. Publ. Ass. nerv. ment. Dis. (1940) $21: 246,1942$.

9. Rioch, D. M., and Brenner, C.: J. comp. Neurol. 68:491, $193^{8 .}$

10. Fulton, J. F.: Trans. Coll. Phys. Philad. 8:157, 1940.

11. Mettler, F. A.; Ades, H. W.; Lipman, E., and Culler, E. A.: Arch. Neurol. Psychiat. $41: 984$, 1939 .

12. Tower, S. S.: Brain $63: 36,1940$.

13. Kennard, M. A.: Arch. Neurol. Psychiat. 48:227, 1942.

14. Hines, M., and Boynton, E. P.: Contr. Embryol. Carn. Instn. 28:309, 1940.

15. Kennard, M. A., and Fulton, J. F.: Res. Publ. Ass. nerv. ment. Dis. (1940) $21: 228$, 1942.

16. Dow, R. S.: Arch. Neurol. Psychiat. 40:500, $193^{8}$.

17. Dow, R. S.: J. comp. Neurol. 68:297, $193^{8 .}$

18. Miller, F. R., and Banting, F. G.: Brain 45:104, 1922.

19. Connor, G. J., and German, W. J.: Trans. Amer. Nenrol. Ass, 1941:181.

20. Fulton, J. F.; Liddell, E. G. T., and Rioch, D. M.: Arch. Neurol. Psychiat. 28:542, 1932.

21. Bucy, P. C., and Buchanan, D. N.: Brain 55:479, 1932.

22. Bucy, P. C.: Res. Publ. Ass. nerv. ment. Dis. (1940) 21:551, 1942.

23. Putnam, T. J.: Res. Publ. Ass. nerv. ment. Dis. (1940) 21:666, $194^{2}$.

24. Meyers, P.: Res. Publ. Ass. nerv. ment. Dis. (19.10) 21:602, 1942.

25. Klemme, R. M.: Res. Publ. Ass. nerv. ment. Dis. (1940) $21: 596,1942$.

26. Aring, C. D., and Fulton, J. F.: Arch. Neurol. Psychiat. 35:439, 1936. 
THE SOLUBILITY OF PROTEINS AND THEIR SEPARATION FROM MIXTURES WITH SPECIAL REFERENCE TO SERUM

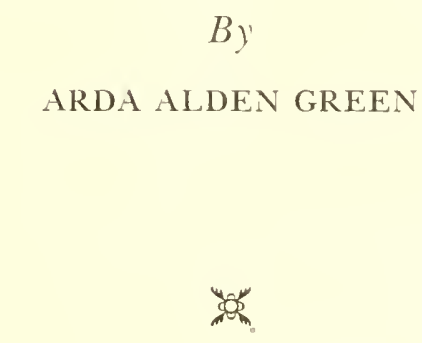

From the

DEPARTMENT OF PHARMACOIOGY WASHINGTON UNIVERSITY SCHOOL OF MEDICINE ST. LOL'IS, MISSOLRI 



\section{THE SOLUBILITY OF PROTEINS AND THEIR SEPARATION FROM MIXTURES WITH SPECIAL REFERENCE TO SERUM}

$\mathrm{T}$ HE PROCEDURES ordinarily used for the isolation of individual proteins from mixtures such are are found in plasma or in extracts of muscle, placenta, liver, kidney, or endocrine organs are relatively simple. Isolation depends upon solubility in a given medium under given conditions, and the process of finding the optimum conditions is 200 often likely to be a matter of art or of luck. The physicochemical characteristics of the molecule undoubtedly determine its solubility but the protein must be isolated before such characteristics can be determined. There are, however, certain general, more or less theoretical considerations gorerning the solubility of proteins which will be summarized here briefly.

In general, solubility depends upon the type of solvent, the presence of electrolytes, the kind and concentration of such electrolytes, the $\mathrm{pH}$, the temperature, and the presence of other organic materials, especially other proteins. These factors nutst all be considered in the extraction as well as in the purification of proteins.

To aroid confusion it may be well to define the ordinary classes of protein. Albumins are water-soluble proteins precipitated only in relatively high concentrations of neutral salts. Globulins are precipitated in lower concentrations of neutral salts and may be further divided into (1) water-insoluble globulins, true globulins or euglobulins, and (2) water-soluble or pseudoglobulins. The original definition of a globulin as a protein insoluble in water and soluble in low concentrations of salts is still applicable. The fraction of serum precipitable in one-third saturation with ammonium sulfate can no longer be termed "euglobulin" since it contains much water-soluble globulin and since waterinsoluble globulins are found also in the "albumin" fraction.

\section{Separation by Isoelectric Precipitation}

Separation of proteins from aqueous solutions of low ionic strength depends upon isoelectric precipitation. Euglobulins exhibit minimum solubility in the neighborhood of the isoelectric point and increase in solubility at either a lower or a higher $\mathrm{pH}$, where the molecule has a higher positive or negative charge. Horse hemoglobin, serum euglobulins, fibrinogen, prothrombin, pneumococcus and meningococcus antibodies, the coagulant from the placenta or lung, myosin from muscle, and certain hormones from the anterior pituitary may all be purified to varying degrees by this means. If more than one euglobulin is present in a solution, advantage may be taken of differences in isoelectric points or differences in solubility in neutral salt solutions. It should be noted that some proteins are more nearly insoluble than others at 
their isoelectric points, that small changes in electrolyte concentration may have a great effect on the $\mathrm{pH}$ of minimum solubility, and that solubility may be greatly influenced by temperature.

\section{Solubility in Concentrated Salt Solutions}

In concentrated solutions of neutral salts proteins are precipitated. The solubility of pure proteins may be described by the linear equation

$$
\log S=\beta-K_{s}{ }^{\prime} \mu
$$

where $S$ is the solubility in grams per liter, $\mu$ is the ionic strength per $1,000 \mathrm{gm}$.

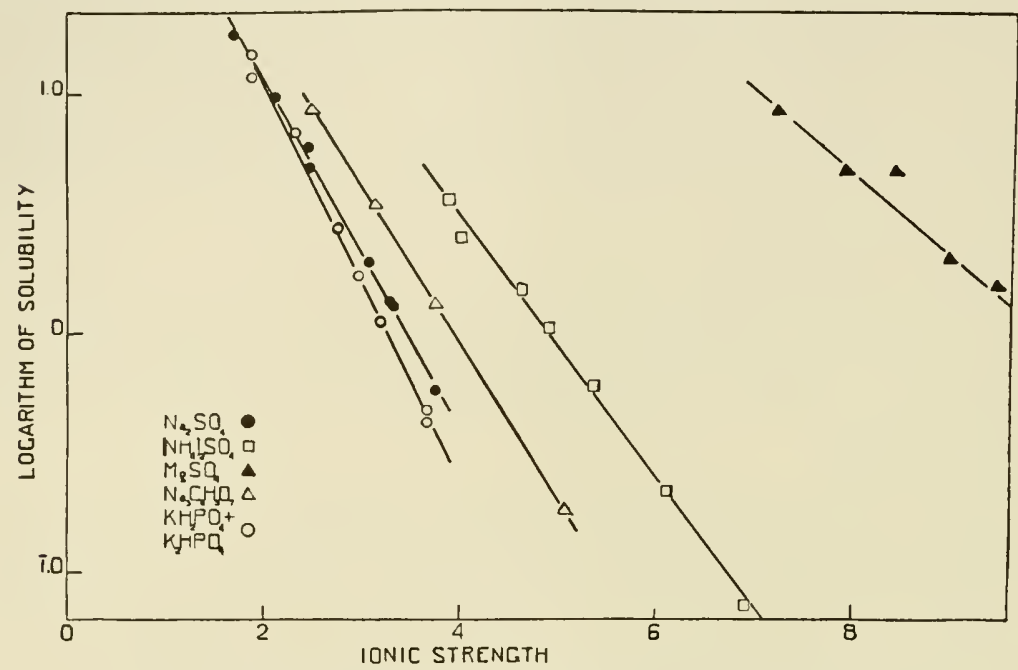

Fig. 1. The solubility of carboxyhemoglobin at $25^{\circ}$ and $\mathrm{pH} 6.6$ in concentrated solutions of various electrolytes.

(From Green, A. A.: Jl. Biol. Chem. 93:512, 1931.)

water, $\beta$ the intercept constant, and $K_{s}^{\prime}$ the "salting out" constant. If the logarithm of the solubility be plotted against the concentration of salt or against the ionic strength, a straight line results. If the quantities are expressed in terms of units per liter or in terms of mol fractions, the straight line still holds but the values of the constants are different. This form of equation was first applied to proteins by Cohn ${ }^{1}$ using the data of Sørensen and Hoyrup ${ }^{2}$ and of Chick and Martin ${ }^{3}$ for the solubility of egg albumin in ammonium sulfate, and of S $\phi$ rensen $^{4}$ for the solubility of pseudoglobulin in ammonium sulfate.

\section{a. Effect of Type of Electrolyte on Solubility}

Uni-univalent salts are relatively ineffective in precipitating proteins. Only the more insoluble proteins such as fibrinogen are precipitated by these salts even when they are used in high concentrations. Higher valent salts produce much higher ionic strengths and are much more effective as precipitating agents. 
Hemoglobin is a globulin. Its solubility is increased upon the addition of low concentrations of salt ${ }^{5}$ and it is "salted out" at higher concentrations of salt. Figure 1 represents the solubility of crystalline horse carboxyemoglobin ${ }^{\circ}$ at constant $\mathrm{pH}$ and temperature in concentrated solutions of various electrolytes.

The slopes of the lines, and therefore the $K_{s}$ ' values vary with the kind of salt used. For this protein $K_{s}^{\prime}$ decreases in the order, $\mathrm{KH}_{2} \mathrm{PO}_{4}+\mathrm{K}_{2} \mathrm{HPO}_{4}$, $\mathrm{Na}_{2} \mathrm{SO}_{4}, \mathrm{Na}_{3} \mathrm{C}_{6} \mathrm{H}_{5} \mathrm{O}_{7},\left(\mathrm{NH}_{4}\right)_{2} \mathrm{SO}_{4}$, and $\mathrm{MgSO}_{4}$. This is essentially the same

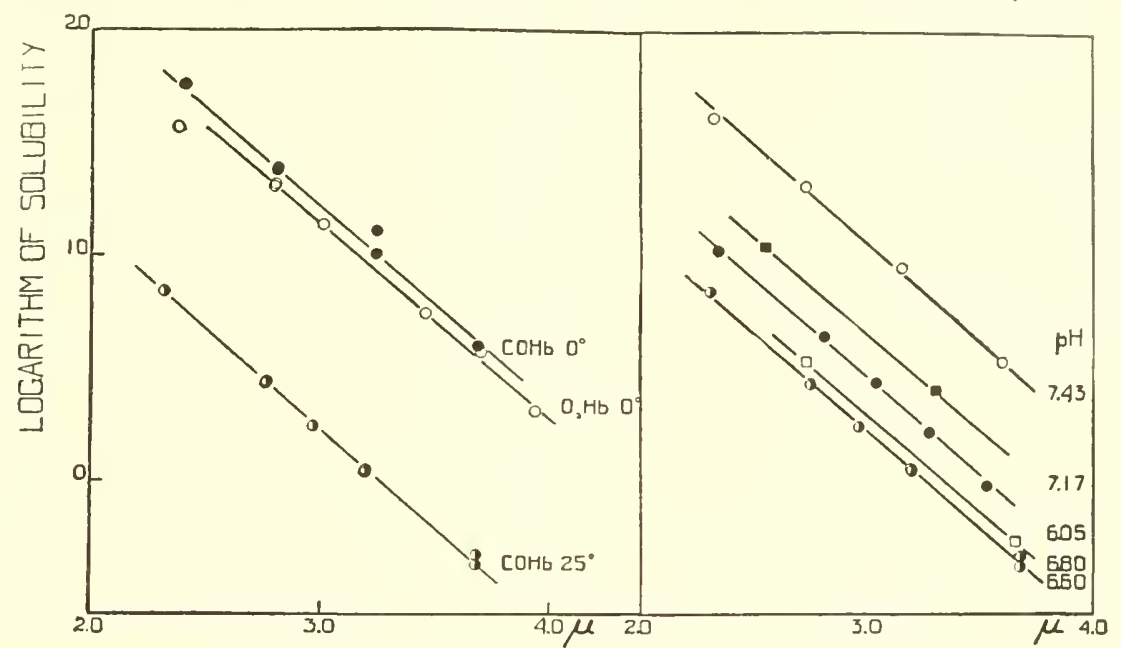

Fig. 2. The solubility of hemoglobin in concentrated phosphate buffers. of varying temperature and $\mathrm{pH}$.

(From Green, A. A.: Jl. Biol. Chem. 93:50\%, 1931.)

order as the series given by Hofmeister ${ }^{7}$ in 1888 . As is to be expected, the values of $K_{s}{ }^{\prime}$ vary from one protein to another in the same salt.

\section{b. Effect of Temperature on Solubility}

$K_{s}{ }^{\prime}$ is, however, independent of temperature and $\mathrm{pH}$. That is, curves for the logarithm of the solubility in the same salt are parallel to each other at various $\mathrm{pH}$ values as are also curves at various temperatures. This is apparent in figure $2{ }^{6}$

Hemoglobin is more soluble at $0^{\circ}$ than at $25^{\circ} \mathrm{C}$. at high salt concentrations, which is the reverse of the effect of temperature on solubility in low concentrations of salt. This phenomenon is also exhibited by other proteins, including the least soluble of the pseudoglobulins from serum. The data of Sorensen and H $\phi$ yrup $^{2}$ on the solubility of egg albumin in ammonium sulfate solutions at various temperatures again show $K_{s}$ ' to be independent of temperature, and again the solubility is greater at $0^{\circ} \mathrm{C}$. than at $20^{\circ} \mathrm{C}$., but increases at higher temperature.

Thus, for a given protein, variation in $K_{s}^{\prime}$ describes the effect of the type 
of electrolyte on the solubility, while variations in $\beta$ describe the effect of temperature and $\mathrm{pH}$ on the solubility in a given salt solution. $\beta$ is the intercept constant and therefore the logarithm of the hypothetical solubility at zero salt concentration. It is "hypothetical" because many proteins are so soluble in water that their solubility cannot be measured, and also because true globulins are insoluble in water and show increased solubility in the presence of low concentrations of salt. Variations in $\beta$ may be conveniently used to describe variation of solubility with $\mathrm{pH}$.

\section{c. Effect of $p H$ on Solubility}

Proteins become positively or negatively charged on either side of the isoelectric point and these forms are more soluble than the electrically neutral molecule. Solubility is increased by the addition of acid or base and the protein behaves as though it had a divalent charge. This is obviously only an apparent phenomenon, but it makes it possible to describe the solubility of a protein at varying hydrogen ion concentration by the equation

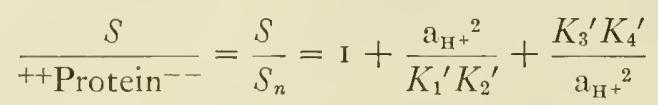

$S$ is the solubility, $S_{n}$ the solubility of the neutral molecule, $\mathrm{a}_{\mathrm{H}^{+}}$the activity of the hydrogen ions, $K_{1}{ }^{\prime} K_{2}{ }^{\prime}$ the dissociation constants in acid solution, and $K_{3}{ }^{\prime} K_{t}{ }^{\prime}$ the dissociation constants in alkaline solution. If these dissociation constants are sufficiently far apart in value, solubility in alkaline solution may be described by the equation

$$
\frac{\text { Protein }^{--}}{{ }^{++} \text {Protein }^{--}}=\frac{S}{S_{n}}=\mathrm{I}+\frac{K_{3}^{\prime \prime} K_{4}^{\prime}}{\mathrm{a}_{\mathrm{H}^{+}}{ }^{2}}
$$

and solubility in acid solution by the equation

$$
\frac{\text { Protein }^{++}}{++ \text {Protein }^{--}}=\frac{S}{S_{n}}=\mathrm{I}+\frac{\mathrm{a}_{\mathrm{H}^{+}}{ }^{2}}{K_{1} K_{2}^{\prime}}
$$

Experimental results at different ionic strengths and different reactions may be successfully analyzed in the region where equation 1 holds (since $K_{s}{ }^{\prime}$ is independent of $\mathrm{pH}$ ) by variations in $\beta$. This has been done in figure 3 , which describes the variation of solubility of both hemoglobin in phosphate buffers $^{8}$ and egg albumin in ammonium sulfate (S $\phi$ rensen and $\mathrm{H} \phi y r u p^{2}$ ), with $\mathrm{pH}$.

$\beta_{n}$ is the logarithm of the hypothetical solubility of the neutral molecule of the protein at zero salt concentration. Thus,

$$
\frac{S}{++ \text { Protein }}--=\frac{S}{S_{n}}=\frac{\operatorname{antilog} \beta}{\operatorname{antilog} \beta_{n}}
$$

The curves drawn through the points are theoretical according to equation 2. The values for $S_{n}$ or $\beta_{n}$ are not the values for minimum solubility as actually 
determined, but are corrected for slight amounts of both negatively and positively charged molecules present with the neutral molecule even at the $\mathrm{pH}$ of minimum solubility. The solubility of casein at various $\mathrm{pH}$ values may also be described by equation 2. This equation has been applied successfully to the data of Linderstrom-Lang and Kodama ${ }^{\circ}$ and of Sorensen and Sládek..$^{10}$

\section{Other Methods of Precipitation}

Temperature, $\mathrm{pH}$, isoelectric point, and concentration of solvent must also be considered when other methods of separation or precipitation of proteins

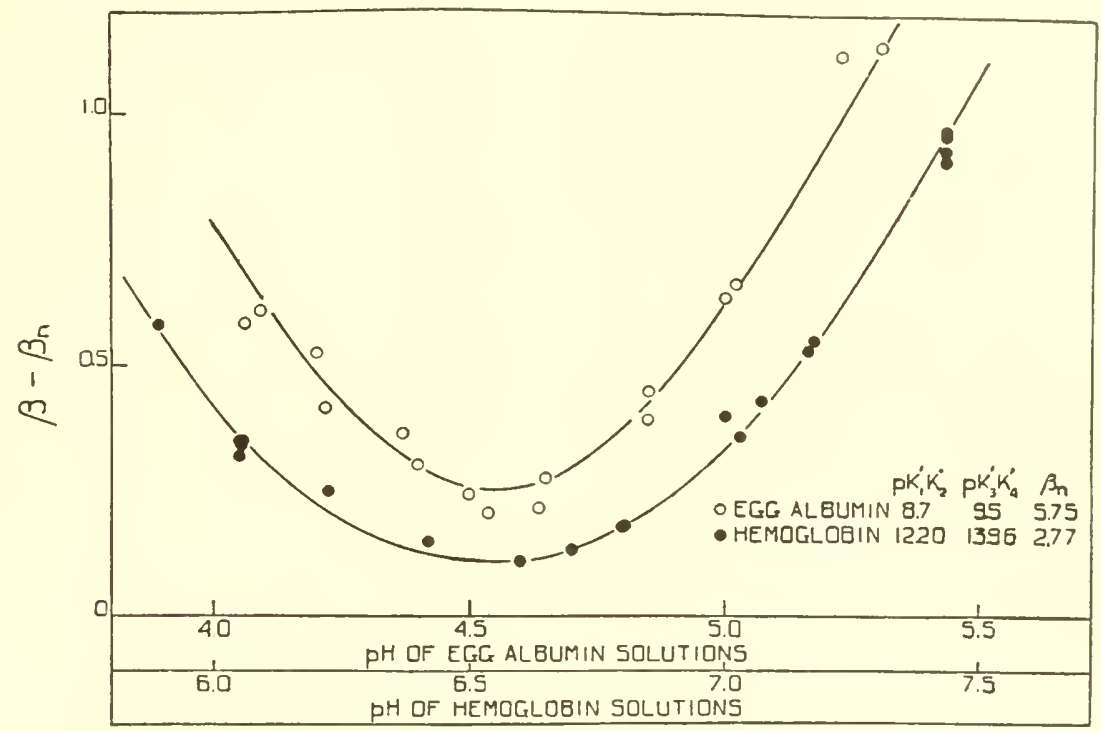

Fig. 3. The solubility of hemoglobin and of egg albumin in concentrated salt solutions of varying $\mathrm{pH}$.

(From Green, A. A.: Jl. Biol. Chen1. 93:524, 1931.)

are employed. These other methods will not be discussed here in any detail. They include colloidal adsorption; differential denaturation, especially by heat; combination with specific substances; or precipitation by such organic solvents as acetone and methyl or ethyl alcohol. Alcohol at low temperatures has been used most recently by Cohn and his co-rorkers ${ }^{\text {t1 }}$ for the separation of plasma proteins. Antibodies may be specifically precipitated by combination with the antigen. Heidelberger and Kendall ${ }^{12}$ have prepared pure pneumococcus antibody by precipitation with the type-specific carbohydrate and subsequent solution in salt solutions. Northrop ${ }^{13}$ has recently crystallized diphtheria antitoxin by digesting the toxin from the toxin-antitoxin complex with the aid of trypsin and subsequently precipitating fractionally with ammonium sulfate. All of the above-mentioned methods may be used in combination with or alternately with isoelectric or salt precipitation. 


\section{Effect of Other Proteins on Solubility}

The solubility of a given protein in a mixture of other proteins depends not only upon the factors already considered, but also upon the presence and concentration of other proteins. These differences in solubility are difficult to explain adequately but are undoubtedly due partially to the effect of the other proteins on the electrostatic characteristics of the medium or possibly to the combination of one protein with another. Whatever the reason, proteins are usually more soluble in the presence of other proteins. Thus, proteins completely precipitated in a given salt solution in the presence of other proteins and other organic molecules found in an extract may require a much lower concentration of salt for precipitation as purification proceeds.

After a protein has becn purified, the concentration of salt at which the solubility will reach a given low value will be constant, but the point at which precipitation first begins necessarily depends upon the concentration of the protein. Precipitation starts when the concentration of the protein exceeds the solubility of the protein under the given conditions, that is, when the solution is saturated with respect to the protein. If pure proteins are precipitated from a more concentrated protein solution than that found in the original extract or mixture, beginning precipitation at a lower salt concentration may be due to increased concentration of the protein itself rather than to the removal of other proteins.

One other consideration might be mentioned. Comparable proteins from different species do not necessarily have the same solubility characteristics. For instance, crystalline hemoglobin from human red cells, although having the same molecular weight and the same oxygen-combining capacity as that from the red cells of the horse, is one thousand times more soluble in phosphate buffers of the same ionic strength and $\mathrm{pH} .{ }^{14}$ Thus, it is usually not possible to employ identical purification procedures in dealing with comparable material from different species.

\section{Criteria For Purity}

Since the protein molecule is so large and since its actual chemical structure is still a mystery, the tests for the identity and purity of a given protein fraction are necessarily indirect. One of the most rigorous tests for homogeneity of a given protein fraction is constant solubility under given conditions indepeudent of the amount of saturating body. Constant chemical composition upon reprecipitation of proteins containing an inorganic constituent such as iron, copper, sulfur, or phosphorus is also an excellent indication of purity. One boundary in the electrophoresis cell and one molecular weight by diffusion and sedimentation measurements, constant mobility, dielectric constant, amphoteric properties, and viscosity all give additional information. Enzymes, hormones, antibodies, and other proteins having physiological functions which exhibit constant activity per milligram of protein tupon repeated refrac- 
tionation may be assumed to be relatively pure. L'timately the most important single factor in the isolation of a given protein is an adequate method of characterizing and identifying that protein.

\section{The Plasma Proteins}

The isolation of inchividual proteins from plasma is one of the most pressing of present-day problems in biochemistry. Proteins with peculiar physiological roles such as fibrinogen, prothrombin, the recently isolated protein constituents of complement, ${ }^{15}$ the enzymes choline esterase and phosphatase, and the antibodies to various bacteria are more easily separated, since one has the biochemical yardstick as well as the ordinary means of chemical or physicochemical characterization. It is no longer adequate to make a separation into "globulin" and "albumin" tractions.

The application of the new cataphoretic methods of Tiselius ${ }^{16}$ has divided the globulin fraction of serum into at least three components $a, \beta$, and $\gamma$, and the albumin fraction into two. ${ }^{17}$ Extensive studies have been carried out correlating ammonium sulfate and alcohol precipitation methods with electrophoretic mobility and with molecular weight as determined by ultracentrifuge and diffusion methods of both the albumin and globulin fractions. ${ }^{11,15}$ Colnn's recent review ${ }^{19}$ divides the plasma proteins into groups based on their electrophoretic mobility.

It is becoming increasingly evident that each new method of identifying or classifying serum proteins increases the number known. The simple procedure of separating the water-soluble from the water-insoluble fractions of the globulins is an example of such a procedure. Three reprochucible isoelectrically precipitable fractions of water-insoluble globulins have been separated from normal horse serum, and their amphoteric properties and viscosities studied. ${ }^{20,21}$ They have been called $P_{1}, P_{11}$ and $P_{I I I} . P_{I I}$ and $P_{I I I}$ are the more insoluble and have isoelectric points at 6.2 and 5 .o respectively. Reiner and Reiner"2 had previously found two euglobulin fractions in normal and in antipnemmococcus horse serum which correspond to $P_{I I}$ and $P_{I I I}$. Hewitt ${ }^{23}$ has describect two euglobulin fractions obtained from sera from a number of species which he calls euglobulin I and II with isoelectric points at $\mathrm{pH} 7$ and $\mathrm{pH}$ 6. Svensson ${ }^{2+}$ has prepared these various fractions and compared their electrophoretic mobility with the following results: "The fractions euglobulin I and II, described by Hewitt, were found to behave distinctly different in electrophoresis. The former contained principally $\beta$ - and $\gamma$-globulins; the latter was a rather homogeneous $\alpha$-globulin preparation. . . . The fraction $P_{I}$ of Green was shown to be identical with euglobutin II of Hewitt and with $\alpha$-euglobulin of Tischius. The results indicated that Green's fractions $P_{I I}$ and $P_{1 I I}$ correspond to $\gamma$ - and $\beta$-euglobulins respectively" (p. 824).

The blood proteins, apart from their various specific functions and their general function of maintaining the osmotic pressure, apparently combine with smaller organic molecules including phospholipids and carbohydrates. 
Chick, ${ }^{25}$ S $\phi$ rensen,${ }^{10}$ and others have studied the phosphorus content of serum proteins as a measure of the phospholipids present. The phospholipid is largely combined with the water-insoluble proteins. The phosphorus content may be higher than 0.3 per cent, which corresponds to 7.5 per cent of phospholipid. Macheboeu ${ }^{23}$ has described a protein containing a much higher percentage of phospholipid as well as cholesterol. Cholesterol has also been reported in both the euglobulin and albumin fractions. ${ }^{27,28,29}$ Kendall $^{30}$ reports the presence of a fatty acid associated with crystalline human albumin "that cannot be removed without first destroying the albumin" (p. 109).

TABLE 1

Galactose-Mannose Content of Horse Serum Globulins

\begin{tabular}{|c|c|c|}
\hline & $\begin{array}{l}\text { Per cent of } \\
\text { carbohydrate }\end{array}$ & Fraction analyzed \\
\hline 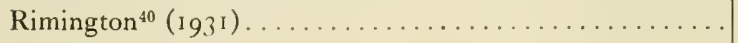 & 2.0 & Total globulins \\
\hline S $\phi r e n s e n$ and Haugaard ${ }^{41}(1933) \ldots \ldots \ldots \ldots \ldots$ & I. 8 & Total globulins \\
\hline Tiselius $^{16}$ (1 9.37).. & $\begin{array}{l}0.7 \\
2.2 \\
0.4\end{array}$ & $\begin{array}{l}\text { Gamma globulin } \\
\text { Beta globulin } \\
\text { Alpha globulin }\end{array}$ \\
\hline Hewitt $^{23}$ (1938). & $\begin{array}{l}1.4 \\
2.4 \\
5.6\end{array}$ & $\begin{array}{l}\text { Pseudoglobulin A } \\
\text { Main pseudoglobulin } \\
\text { Globoglycoid }\end{array}$ \\
\hline
\end{tabular}

The carbohydrate bound to serum proteins is reported to be probably galactose-mannose-acetylglucosamine. ${ }^{31,32}$ The only protein free from bound carbohydrate is one of the crystalline albumins; the other crystalline albumin contains about 5 per cent of carbohydrate; and Rimington ${ }^{32}$ describes the noncoagulable protein from serum, seromucoid, as containing 10.7 per cent of carbohydrate. Various authors have investigated the carbohydrate content of globulins and their results on horse serum are given in table 1 .

The most extensive survey of the carbohydrate content of serum proteins has been carried out by Hewitt, ${ }^{23,31}$ who divides the globulins from the serum of a number of species into his two euglobulin fractions and at least three pseudoglobulins, the most insoluble, $\mathrm{A}$, the main fraction, and globoglycoid which contains up to 5 per cent of carbohydrate. $\mathrm{We}^{33}$ have obtained similar results with a more extensive fractionation. The pseudoglobulin may be divided into more fractions and, as Hewitt suggests, it is possible to obtain pseudoglobulin with a somewhat lower carbolydrate content. However, none have been found to be carbohydrate free.

It is evident that proteins really combine with these smaller organic molecules as Hewitt ${ }^{31}$ says: "That the polysaccharide present in protein forms an integral part of the protein molecule and is not merely a loosely bound con- 
taminant is shown by the difficulty of removing this bound carbohydrate. Prolonged fractionation with salts, isoelectric precipitation, dialysis, heat coagulation and even specific flocculation between antigen and antibody all failed to remove the carbohydrate present in serum proteins" (p. 1502).

If one studies combination with any one substance, the proteins may be relatively easily separated into groups having a constant percentage of that constituent. If more than one compound is considered the problem is much more difficult. For instance, the number of euglobulins of serum are multiplied if one considers both phospholipid and carbohydrate content. Undoubtedly, there are also other substances combining with proteins.

Proteins combine not only with other substances but with each other. The problem of the identification of the euglobulins is further complicated by the ability of water-soluble globulins to unite and form water-insoluble globulins behaving like $\mathrm{P}_{\mathrm{I}}$. This was first recognized by Kendall, ${ }^{34}$ working on human serum. He noted a precipitate formed on the addition of the less soluble pseudoglobulin to the more soluble pseudoglobulin. He showed quantitative relationships depending upon $\mathrm{pH}$, analyzing the protein content by immunological means. Hewitt ${ }^{31}$ has since shown that his pseudoglobulin A from human serum will form a precipitate with the globoglycoid separated from the serum of different species. It is evident that $\mathrm{pH}$ is especially important in trying to separate these two proteins.

Ever since Sorensen's ${ }^{*}$ classical studies on the solubility of crystalline serum albumin it has been known that there must be more than one serum albumin, since solubility was not independent of the amount of solid crystals present. Two albumins have now been crystallized from horse serum having different electric mobility and different carbohydrate content. One is carbohydrate free and one contains 5.5 per cent of carbohydrate. ${ }^{35,36}$ The carbohydrate-free protein may also be crystallized from concentrated salt-free solutions as the sulfate. ${ }^{35}$ Although successful studies on the solubility of fibrinogen had been carried out previously, ${ }^{37}$ the carbohydrate-free albumin is the only protein so far isolated from serum exhibiting constant solubility independent of the amount of saturating body. Carbohydrate-free crystalline human serum albumin show's the same evidence of purity. ${ }^{34}$

Other proteins so far found in the albumin fraction are enzymes, including choline esterase and phosphatase, a crystalline copper containing protein, hemocuprein ${ }^{38}$ seromucoid, ${ }^{32}$ and a certain amount of euglobulin.

The solubility curves of these serum proteins necessarily overlap tremendously. Advantage must be taken of all possible variations in $\beta$ and $K_{s}$. That is, differences in variation of solubility with temperature, with $\mathrm{pH}$, with kind and concentration of electrolyte, and with type of solvent must all be utilized. Separation can be effected only after repeated fractionation, the precipitating agent being added in small increments under controlled conditions, including control of the protein concentration, and careful analysis of each fraction before pooling with other similar fractions. 
After one has succeeded in obtaining homogeneous fractions of constant chemical composition and constant physicochemical characteristics it is disheartening to remember that not only will similar fractions from another species be different, but probably fractions obtained in the same manner from serum of another animal of the same species or even from serum of the same animal under different conditions will vary considerably.

The recent work of Schoenheimer and co-workers ${ }^{39}$ on the heavy nitrogen containing amino-acid content of antibody-protein upon injection of the heavy nitrogen after the antibodies have been completely formed demonstrates the constant fluidity of the protein molecule even in regard to its amino-acid composition. In fact, it is surprising that the composite picture of serum proteins has such fundamentally stable and definite outlines that reproducible fractions can be obtained.

\section{REFERENGES}

1. Cohn, E. J.: Physiol. Rers. 5:349, 1925.

2. Sørensen, S. P. L., and Høyrup, M.: Cpts. rd. Laborat. Carlsberg 12:213, 1915-1917.

3. Chick, H., and Martin, C. J.: Biochem. Jl. 7:380, 1913.

4. Sørensen, S. P. L.: Jl. Amer. Chem. Soc. 47:457, 1925; Cpts. rd. Laborat. Carlsberg 18(5), 1930; Kolloid Ztschr. 53:102, 170, 306, 1930.

5. Green, A. A.: J1. Biol. Chem. 95:17, 1932.

6. Green, A. A.: Jl. Biol. Chem. 93:495, 1931.

7. Hofmeister, T.: Naunyn-Schmiedebergs Arch. f. exper. Pathol. u. Pharmakol. 24:247, $1887-1888$.

8. Green, A. A.: Jl. Biol. Chem. 93:517, 1931.

9. Linderstrom-Lang. K., and Kodama, S.: Cpts. rd. Laborat. Carlsberg 16(ı), 1925 .

10. Sorensen, S. P. L., and Sládek, I.: Cpts. rd. Laborat. Carlsberg 17(1.4), 1929.

11. Cohn, E. J.; Luetscher, J. A., Jr.; Oncley, J. L.; Armstrong, S. H., Jr., and Davis, B. B.: Jl. Amer. Chem. Soc. 62:3396, $194^{1}$.

12. Heidelberger, M., and Kendall, F. E.: Jl. Exper. Med. 64:161, 1936.

13. Northrop, J. H.: Jl. Genrl. Physiol. 25:465, 1942.

14. Green, A. A.; Cohn, E. J., and Blanchard, M. H.: Jl. Biol. Chem. 109:631, 1935.

15. Pillemer, L.; Ecker, E. E.; Oncley, J. L., and Colnn, E. J.: Jl. Exper. Med. 74:297, 1941.

16. Tiselius, A.: Biochem. Jl. 31:313.1464, 1937: Trns. Faraday Soc. 33:524, 1937.

17. Luetscher, J. A., Jr.: Jl. Amer. Chem. Soc. 61:2888, 1939.

18. Cohn, E. J.; McMeckin, T. L.; Oncley, J. L.; Newell, J. M., and Hughes, W. L.: Jl. Amer. Chem. Soc. $62: 33^{86,1941 .}$

19. Cohn, E. J.: Chem. Revs. 28:395, 194 1.

20. Green, A. A.: Jl. Amer. Chem. Soc. 60:1108, 1938.

21. Fahey, K. R., and Green, A. A.: Jl. Amer. Chem. Soc. 6o:3039, $193^{8 .}$

22. Reiner, H. K., and Reiner, L.: Jl. Biol. Chem. 95:345, 1932.

23. Hewitt, L. F.: Biochem. J1. 32:1540, 1938.

24. Svensson, H.: Jl. Biol. Chem. 139:805, 1941.

25. Chick, H.: Biochem. Jl. 8:jo.4, 1914.

26. Macheboeuf, M.: Bull. Soc. de chim. biol. $11: 268,485,1929$.

27. Gardiner, J. A., and Gainsborongh, H.: Biochem. Jl. $21: 141,1927$.

28. Handorsky, H.; Lohman, K., and Bosse, P.: Pflïgers Arch. f. d. gsmt. Physiol. 210:63, 1925 .

29. Kleczkowski, A.: Biochem. Ztschr. 299:311, $193^{8}$. 


\section{Arda Alden Green}

3o. Kendall, F. E.: Jl. Biol. Chem. 138:97, 1941 .

31. Hewitt, L. F.: Biochem. Jl. 33:1496, 1939.

32. Rimington, C., and Van den Ende, M.: Biochem. Jl. 3.:9.11, $19.1 \%$.

33. Green, A. A.; Fahey, K. R., and Green, S. Y.: Jl. Biol. Chem. 140:xhii, 1911.

34. Kendall, F. E.: Cold Spring Harbor Sympsa. Quantit. Biol. 6:376, $193^{8}$.

35. McMeekin, T. L.: Jl. Amer. Chem. Soc. 61:288 4, 1939.

36. McMeckin, T. L.: Jl. Amer. Chem. Soc, 62:3393, 1940.

37. Florkin, M.: Jl. Biol. Chem. 8;:629. 1930.

38. Mann, T., and Keilin, D.: Proc. Roy. Soc. London, s. B. 126:303, 1938.

39. Schoenheimer, R.; Heidelberger, M.; Rittenberg, D., and Ratner, S.: Jl. Biol. Chem. $140: c x i i, 1941$.

10. Rimington, C.: Biochem. Jl. 25:1062, 1931 .

41. Sorensen, M., and Haugaard, G.: Cpts. rd. Lahorat. Carlsberg 19(12), 1933. 



\section{GONADOTROPHIC STIMULATION}

\section{OF THE OVARIES}

\section{OF THE}

\section{ADULT RHESUS MONKEY}

$$
\text { By }
$$

CARL G. HARTMAN

\section{策}

From the

DEPARTMENT OF EMBRYOLOG

CARNEGIE INSTITUTION OF WASHINGTON

BALTIMIORE, MIARYLAND 



\section{GONADOTROPHIC STIMULATION OF THE OVARIES OF THE ADULT RHESUS MONKEY}

Cince sMITH in 1926 and Aschheim and Zondek about the same time dis$\checkmark$ covered the gonadotrophic function of the mammalian anterior pituitary gland (a logical sequence to Smith's epoch-making work, done in California, on the primacy of the anterior pituitary in the tadpole), a deluge of literature on the pituitary-gonad relation has appeared. Some iclea of the researches in this field may be gained by a perusal of volume 11 of Memoirs of the Unitiersity of California (1932) on "The Growth and Gonad-stimulating Hormones of the Anterior Lobe of the Hypophysis" by H. M. Evans and co-workers. The progress since that date may further be gauged by comparing the 1939 and the 1932 editions of E. Allen's compilation, "Sex and Internal Secretions."

When one surveys the literature on the gonadotrophic action of anterior pituitary extracts one is struck with the paucity of references to ovulation, barring, of course, studies on the Friedman test as performed on that aberrant mammal, the rabbit, which has more than once in the last hundred rears brought temporary confusion into biological studies. A review cannot be made here even of the few studies devoted to ovulation in mammals, ${ }^{1}$ but some of the more important references are given in the literature list below.

Ovulation is still too uncertain an end point to be serviceable in assaying an unknown extract for its gonadotrophic value. This is due to individual as well as strain differences of susceptibility within a species and to very wide differences between species. This is especially marked with respect to human urine of pregnancy (PU), less so with pregnant mare's serum (PMS), and least of all with follicle-stimulating hormone (FSH) made from the gland itself.

Thus far no one has been consistently successful in producing orulation in the adult rhesus monkey. Hisaw and collaborators ${ }^{2}$ brought about ovulation in young animals but the gonadotropes suitable for ovulation in adult females have, so far as the writer is aware, not yet been found. Almost without exception a diffuse overstimulation of the ovaries has been produced with gonadotropes, but never an ovulation, except for the several reported by the writer in 1938 .

After the preliminary demonstration of induced orulation in prepubertal rats by means of anterior pituitary transplants ${ }^{3}$ search was made for the active principle or principles responsible for the action of the pituitary on the gonads, notably in the laboratories of Hisaw and Fevold, of Evans, and of Van Dyke. This interesting story has often been told and will not be repeated here; suffice it to say that the dualistic theory, despite its difficulties, is still in the ascendency. By fractional precipitation it has been possible to remove from crude anterior pituitary extracts, in a highly purified state. one 
fraction which principally causes growth of the Graafian follicle, another which it is necessary to add to effect its rupture.

Since 1934 the writer has been interested in the clinical problem of increasing the incidence of ovulation in the menstrual cycles of certain hypotypical females of the Carnegie rhesus colony, for embryos were desired, ${ }^{4}$ and ovulation is a prerequisite for conception. The results of 104 experiments were published in $1938,{ }^{5}$ but they do not inspire enthusiasm. In $10_{4}$ experiments only seven ovulations were observed which could reasonably be attributed to the treatment. It is now possible to report 41 further experiments performed on 33 females in the last three years. The results were critically controlled as before by a prior study of the subjects, by palpation, by laparotomy, and by histological examination of biopsied or autopsied material. The following variations in technique were instituted: both lower and higher dosages were employed; injections were begun a week before the next expected menstrual period, so as to allow an additional week before the middle of the following menstrual interval for the slow building up of the ovaries; intravenous perfusion over a period of eight hours was tried twice; estrogens were injected concomitantly with the gonadotropes; besides Gonadogen Upjohn (PMS), good anterior pituitary extracts (AP) were made available.

One batch of FSH was prepared by Dr. H. Jensen of E. R. Squibb and Sons and used alone (with good results), or with Follutein Squibb (PU-APL) in proportion of $1: 2$ or $1: 10$. In the last proportion the combination acted like APL itself, which Engle ${ }^{6,7}$ long ago showed to be inert in the monkey.

A second potent AP extract rich in FSH was furnished by the Abbott Contpany through Dr. Hazel. The extract had been exposed briefly to tryptic digestion after the method of McShan and Meyer, presumably to increase the FSH:LH ratio by differential digestion of the LH.

It should be emphasized that in all cases subjects were selected which were (and because they were) not ovulating at the time of the experiments, hence were presumably unreactive to their own intrinsic hormones.

\section{Results}

The results of $3^{8}$ experiments done on $3^{\circ}$ animals may be tabulated as follows:

Extract

Gonadogen .

Gonadogen, I,, 00 U.U.* . . . . . .

FSH-Jensen.

FSH-Jensen + Follutein $\mathrm{I}: 2 \ldots$

FSH-Jensen + Follutein $\mathrm{I}: \mathrm{I} 0 \ldots$

FSH-Abbott

Gonadotrope + Estrogen......

\section{Ovulations}

\begin{tabular}{l}
3 \\
0 \\
2 \\
0 \\
0 \\
1 \\
0 \\
\hline 6
\end{tabular}

Overstimulation

Without effect

* Upiohn units or Cartland-Nelson units ( 0 U.U. $=100$ Cole-Saunders units): the minimum total dose which, administered to $2 \mathrm{I}$ - to 23 -day-old rats weighing $35-45 \mathrm{gm}$., in 3 equal subcutaneous injections at daily intervals, will produce at autops $y, 96$ hours after the first injection, a mean ovarian weight of $65 \mathrm{mg}$., which is $4-5$ times that of the controls (Amer. Jl. Obstet. \& Gynecol. $38: 1024,1939)$. 
Ovulations. Of the six ovulations observed and credited to the action of the hormones, one is somewhat doubtful. One case deserves special notice:

No. $5^{8} 4$ had not ovulated while in our possession up to Jan. 1910. An exploratory laparotomy was performed on Jan. 25 , day 12 of the cycle, when a $4 \times 3-\mathrm{mm}$. follicle was found in the right ovary; 10 U.U. of Gonadogen were at once injected intravenously. The next day the female was mated. On Feb. 7 a 12 -day ovum (C637) was recovered by hysterotomy.

This case raises some interesting points. It is probable that in any species ovulation may be precipitated by a correct intravenous dose of gonadotropes provided a large follicle is present in the ovary. Hence it is likely that in clinical experience some of the successes (induced ovulations) may have been merely cases of slightly hastening the ovulation. Since women cannot be laparotomized (as was monkey No. 584 before a course of treatment merely for an inspection of the ovaries), the proper control is lacking in such gynecological experiments.

The case further illustrates the spontaneous resumption of ovarian function after a period of low activity, a phenomenon which has been seen so often in the Carnegie colony that we have become extremely cautious in evaluating our results.

It is significant that but one ovulation was effected in March, the beginning of the nonbreeding (refractory) season; the others were referable to the fall and winter, the "best" season for the rhesus monkey.

In three cases 1, ooo U.U. of Gonadogen were injected subcutaneously on June $30,194^{1}$; in no case did ovulation result, but only overstimulation of the ovaries.

Diffuse Overstimulation of the Ovaries. In the event of failure to effect ovulation, if the introduced gonadotropes have any effect at all, it is to awaken an overabundance of follicles to growth, which results in excessively large glands of "cystic" appearance.

In these ovaries the liquor folliculi is very dense and, despite the large total quantity, there is evidence that generally the estrin output is very low. The Graafian follicles are like overstimulated and exhausted thyroid alveoli which are rich in colloid but poor in thyroxin. The color of the sex skin often becomes brighter and the vaginal desquamation increases as a result of the injections, but far below that expected. Removal of one ovary does not hasten the onset of the succeeding menstrual flow appreciably and removal of both does so but slightly.

One of the evident effects of the treatment with gonadotropes on the ovary is the congestion, which is in many cases visible externally as great, raw-flesh colored areas overlying dilated follicles and, in one ovulatory case, overlying the normal corpus luteum. It was at first believed that these regious were denuded of ovarian cortex; but sections showed them to be due to dilated blood ressels in the somewhat thinner cortex. Internally, this congestion is everywhere apparent in the thecal vessels of follicles which in the living ani- 
mal, as viewed directly during an exploratory laparotomy, often appear as red rings about the numerous growing follicles.

Such evidences of overstimulation are occasionally met with in untreated animals, in which the ovary grows excessively by virtue of the abnormally large number of follicles, the surface phenomena of congestion just described, and blood follicles. This condition may persist over a number of menstrual periods.

The excessive congestion inevitably leads to degeneration of the grandulosa and soon to regression of the follicles which is extremely rapid, as often determined by palpation, twice corroborated by successive exploratory laparotomies and frequently by a single laparotomy after the treatment. The rapid regression of the ovaries was reflected in the premature onset of menstruation, which frequently occurred as early as 4 to 6 days after the regression became evident, shortening the cycle to 19,20 , or 21 days. Occasionally the expected bleeding did not occur but, instead, a long period of amenorrhea set in. This, again, was neatly related to the time of year, for amenorrheic periods were likcly to follow treatment in March and rarely occurred from October to January, when recovery was generally prompt; the treated female resumed normal menstrual cycles and thereafter ovulated spontaneously.

The nonpredictability of the adult rhesus monkey may, however, be illustrated by the following bizarre case.

After a series of anovulatory cycles female No. 678 was (in March) treated with FSH-Jensen + Follutein 1:10, with little or no effect. No bleeding took place until June 10. On June 23 , which is well within the anestrum or non-breeding season of the rhesus monkey, she conceived! She carried her baby to term and nursed it normally.

Injections without Effect. As already pointed out, refractoriness of the adult rhesus monkey to gonadotropes becomes greater as the nonbreeding season characteristic of the species approaches, namely the spring of the year. Normal females which suddenly stop ovulating may become absolutely unresponsive to huge quantities of the hormone. Animals whose ovaries are unresponsive to their intrinsic hormones in the fall and winter are usually not to be stimulated by exogenous gonadotropes. But even in these one meets with the greatest surprises. In other words, the writer has not been able effectively to predict, from a prior study of the animal, what the effect of treatment might be, except, of course, in the case of obviously sick individuals.

Antihormones play no part when such small dosages are administered over so short a period of time, for it has happened that the second treatment with the same material has met with greater response than the first. ${ }^{5}$

Kind of Hormone. Gonadogen again proved itself an active stimulator of the monkey ovary and seems on the whole a very good gonadotrope. FSHJensen and FSH-Abbott made a very good showing in the small series of experiments here reported, when used without the admixture of APL (Follutein). When Follutein was added to Jensen's FSH in the proportion of 2 of Follutein to 1 of FSH, the results seem less favorable, but yet stimulation re- 
sulted; when the proportion was raised to $10: 1$ the combination became as inert as APL by itself. The reverse proportion, 10 units of FSH to 1 of Prolan (APL), as used effectively by Evans and Simpson, might have been ideal.

Combined Action of Estrin and Gonadotropes. The small series of seven experiments under this heading are, of course, not fully conclusive, but, since six out of seven trials gave completely negative results, nothing can be said in favor of the method used. Certainly congestion of the genital tract was accomplished by the estrogens in these experiments, as shown by the enlargement of the uterus in most of the subjects; hence the idea which originally prompted the experiment did not work out. The single animal (No. 2 I 7 ) which responded excessively to the combined hormones differed in no essential from two negative cases (Nos. 215 and 220) similarly treated at the same time, except that the estrogens were left out. The remarkable discovery of Pencharz," however, confinmed by Simpson, Evans and co-workers, ${ }^{10}$ of the synergisms of estrogens and gonadotropes in the hypophysectomized rat, would seem to demand further experimentation with this method in the monkey.

In the light of these findings we come back to the original method of Hisaw, Fevold, and collaborators, namely using FSH to build up the follicles, then following with an "ovulatory dose" of FSH to which LH has been added. For women and the monkey female it seems that we must argue against the use of APL (Follutein and Antuitrin S and related products) except perhaps in minimal quantity in connection with FSH which had been previously tested in hypophysectomized rats.

Thanks are due to the Squibb Institute for Medical Research and the research laboratories of the Abbott Company and the Upjohn Company for generous coöperation in these experiments.

\section{REFERENCES}

1. Hartman, C. G.: in Sex and Internal Secretions, ed. by E. Alten (2d ed.; Ballimore: 1939), 630.

2. Fevold, H. L.: in Sex and Internal Secretions, ed. by E. Allen (2d ed.; Baltimore: 1939 ), 966.

3. Smith, P. E., and Engle. E. T.: Amer. J1. Anat. $10: 159,1927$.

4. Henser, C. H., and Streeter, G. L.: Contribs. Embryol. Carnegie Instn. Washinglon 29:15, $19+1$.

5. Hartman, C. G.: Bull. Johns Hopkins Hosp. 63:351, $193^{8}$.

6. Engle, E. T.: Amer. Jl. Physiol. 108:528, 1934.

7. Engle, E. T.: Amer. J1. Physiol. 106:145, 1933.

8. Evans, H. .1., and Simpson, M. E.: Endocrinology 27:305, 1940.

9. Penchatz, R. I.: Science (11.s.) $91: 554$, 1940.

10. Simpson, M. E.; Evans, H. M.; Fraenkel-Conrat, H. L., and Li, C. H.: Endocrinolog! $28: 37,1941$.

\section{RELEVANT Literature}

Allen. E., ediror: Sex and Internal Secretions (ad ed.; Baltimore: 1939).

Burdick, H. O., and Whitney, R.: Amer. Jl. Physiol. 132: $05,1941$.

Cole, H. H.: Amer. Jl. I'hysiol. $119: 704,1937$.

Cole, H. H., and Miller, R. F.: Amer. Jl. Physiol. 10,1:165, 1933.

Engle, E. T.: in Sev and Internal Serretions, ed. by E. Illen (2d ed.; Baltimore: 1939), 1003. 
Erving, H. W.; Sears, G., and Rock, J.: Amer. Jl. Obstet. \& Gynecol. 40:695, 1940.

Frank, R. T., and Berman, R. L.: Endocrinology 28:211, 1941.

Hisaw, F. L.; Greep, R. O., and Fevold, H. L.: Anat. Recrd. 61(supp.)3:24, 1935.

Huber, C. P., and Davis, M. E.: Surg., Gynecol. \&. Obstet. 70:996, 1940.

Leathem, J. H.: Endocrinology 22:559, $193^{8}$.

Leathem, J. H., and Starky, W. F.: Proc. Pennsylvania Acad. Sci. 14:ı09, 1940.

Nelson, W. O., and Overholser, M. D.: Jl. Pharmacol. \& Exper. Therapeut. 54:378, 1935.

Pincus, G.: Anat. Recrd. 77:1, 19.10.

Smith, P. E.: Jl. Amer. Med. Assn. 88:158, $19^{27}$.

van Wagenen, G., and Morse, A. H.: Lancet 234:1220, 1938.

Windle, W. F.: Endocrinology $25: 365,1939$. 
THE PATHOLOGIG, CLINICAL AND BIOCHEMICAL CORRELATION OF TUMORS OF THE TESTIS

$$
\text { By }
$$

FRANK HINMAN, A.B., M.D., F.A.C.S.

\section{踏}

From the

DEPARTMENT OF SURGERY, DIVISION OF UROLOGY UNIVERSITY OF CALIFORNIA MEDICAL SCHOOL SAN FRANCISCO, CALIFORNIA 



\title{
THE PATHOLOGIC, CLINIGAL AND BIOCHEMICAL CORRELATION OF TUMORS OF THE TESTIS
}

\author{
INTRODUCTION
}

$\mathrm{T}$ UMORS of the testis always have presented a confusing picture. Their pathogenesis remains uncertain and they have never been classified satisfactorily. When the contemporary pathologic, clinical, and biochemical contributions, however, are brought into relation with each other, a clearer picture is presented than ever before.

As elsewhere a neoplasm may arise in the testis from any tissue cell present there and may be benign or malignant. For practical purposes, however, they are all malignant, so exceptional are the benign tumors. In earlier pathologic studies homologous or monocellular growths were distinguished from heterologous or multicellular growths and in each group certain types were defined. At first, the tumor of the one-cell pattern was identified commonly as a sarcoma. Now we know that a pure mesoblastic growth of the testis is very rare. These same monocellular tumors were next designated as seminomata or spermatocytomata, unrelated to sarcoma, and supposedly originating from sperm cells. More recently they have been called either embryonal carcinoma, with or without lymphoid stroma, or large clear-cell carcinoma, and the origin of any of them from adult sperm cells is questioned. The tumors of variegatedcell pattern, the mixed or heterologous growths called teratomata, were grouped as benign or malignant and the latter were subdivided according to the type of malignant cell. Such types, for example, as adenocarcinoma, spheroidal-cell scirrhous carcinoma, etc., and chorionepithelioma were recognized. This dual classification with its subdivisions proved most unsatisfactory. Now and then a tumor appeared which failed to fit into any part of the classification. Years ago Ewing suggested that all testicular tumors, with the obvious few exceptions, probably arose from a totipotent cell. Recent clinical observations confirm this view. Perhaps tumors of the testis may better be regarded by the clinician not only as malignant but as being one type of growth, the varieties arising from the different stages or phases of transition at which they are observed. In teratoma, groups of cells are found which are identical with the common unicellular types, and frequently careful examination of serial sections of the supposedly pure-cell type uncovers other varieties of cell, thus proving its heterogenicity. Distinction between the one-cell and the mixed-cell patterns serves no practical purpose. Rather, confusion arises in attempting such distinction. Of much more clinical value is the microscopic recognition of primitive or adult characteristics. The primitive cell is embryonal in appearance, the adult cell seems fully differentiated. Even 
this distinction is not always clear-cut. There are transitional stages. The tumor may seem to be solidly composed of fully differentiated adult cells until diligent search through serial sections discloses undifferentiated primordial cells or scattered groups of such cells which may be in different stages of transition. The most primitive form of cell is the one by which the tumor should be classified. Chorion-like cells axe the most premature. Whether this distinguishing cell occurs in a monocellular or in a mixed type of tumor is unimportant. In cither case the growth is a chorionepithelioma. The recognition of the embryonal or mature character of a tumor with transitional phases in either direction has considerable clinical value as can be demonstrated by correlation of the pathologic, clinical, and biochemical facts.

\section{Pathology}

Ewing grouped all tumors of the testis in four ways:

1. Adult embryoma or teratoma (benign)

2. Embryonal teratoid or mixed tumor (malignant)

3. Embryonal malignant tumor (embryonal carcinoma)

4. Miscellaneous (rare)

a. Adenoma

b. Fibroma

c. Myoma

d. Sarcoma

e. Interstitial-cell tumor

f. Lymphosarcoma

g. Adult multicystic adenocarcinoma (arising from adult cells of seminiferous tubules)

The tumors which can be classified under groups 1 and 4 are very rare, so rare indeed that, clinically, only groups 2 and 3 need be considered in the present correlation of facts. Disregard of the distinction between monocellular and mixed-cell tumors unites these two groups so that, except for the foregoing very rare neoplasms mentioned in groups 1 and 4 , there is only one testicular tumor. This tumor probably arises from a totipotent cell and may undergo a great variety of transitions, the nature of which can be inferred by the microscopic picture presented at the particular phase present when the tumor is examined. If the growth is allowed to develop further, however, subsequent examination may disclose an entirely different picture. For example, the primary growth found in the testis after castration may show a pure embryonal carcinoma but the metastases examined months later may disclose chorionepithelioma.

Suspecting the importance of cellular maturity as the basis of classification of testicular tumors, Dr. Jesse L. Carr, who has reviewed all our pathological material, attempted such a differentiation several years ago. Careful correlation of pathological with clinical and biochemical facts has evolved the following division, the principal distinction of which is recognition of cellular 
maturity. Any complete classification, of course, must include the rare tumors of Ewing's groups 1 and 4. All tumors in his groups 2 and 3 , however, can be listed as follows under parenchymatous tumors arising in a teratoma.
a. Embryonal carcinoma without lymphoid stroma
b. Embryonal carcinoma with lymphoid stroma
c. Large clear-cell carcinoma
d. Embryonal adenocarcinoma
e. Chorionepithelioma

The most common and probably least malignant tumor of the test is is the embryonal carcinoma, of which there are two types. Usually this is a monocellular tumor of rapid growth (the seminoma of Chevassu).

a. The embryonal carcinoma without lymphoid stroma is a tumor with well-differentiated cells resembling adult seminal epithelium. In the microscope large, pale, round or polyhedral cells of uniform size are seen lying in a light fibrous stroma containing few lymphoid cells. Occasionally an alveolar arrangement is observed. Many mitotic figures are present. This tumor is relatively rare.

b. The embryonal carcinoma with lymphoid stroma is the most common tumor of the testis. It also is made up of well-differentiated cells. By the microscope small dark-staining cells, usually in sheets. are seen lying in an abundant lymphoid stroma composed of immature fibroblasts.

c. The large clear-cell carcinoma is made up of less well-differentiated cells than those found in the foregoing tumors. It is probably more malignant. Microscopically, closely packed large cells with relatively large pale nuclei containing dark nucleoli, are grouped in a light fibrous stroma. They resemble somewhat the Langhans type of cell. This tumor is uncommon.

d. The embryonal adenocarcinoma occurs in two varieties which are not easily distinguished:

1. The adenocarcinoma, made up of primitive cells, is relatively rare. The characterizing embryonal cell is large, producing a moderate amount of cytoplasm and having a finely divided chromatin. Clinical follow-up of patients with this type of tumor, however, has shown a high degree of malignancy and in two cases particularly Carr recognized definite transitional stages between adenocarcinoma and chorionepithelioma.

2. The more differentiated type of embryonal adenocarcinoma occurs next in frequency to the embryonal carcinoma with lymphoid stroma. The microscopic appearance is similar to that seen in adenocarcinoma of other epithelial structures.

$c$. Chorionepithelioma is the most primitive and the most malignant of the testicular tumors. Microscopically it is made up of large undifferentiated types of cell and the characteristic multinuclear syncytial cells are found. Judging from the literature, this tumor is rare, but of the last forty-four cases of tumor of the testis seen here six were chorionepitheliomata. In two of these the primary tumor showed no chorionic elements, but the clinical course and the rise 
in gonadotropic homone output subsequently suggested this possibility, and this was proved at autopsy in both patients. In a third patient no nodule could be palpated in the testicle but a large retroperitoneal mass was found, as well as gynecomastia, and the urine contained 200,000 R.U. of hormone. Biopsy demonstrated chorionepithelioma.

\section{BIOCHEMISTRY}

Careful hormonal studies were made on all our patients both before and after operation. We are indebted to Dr. Herbert M. Evans, who has made all recent assays of the urine, for his interest in this subject and his help in correlating the clinical with the biochemical studies. Briefly, the routine method of testing the urine is to get a collection (for 24 hours or longer) from which the gonadotrophin is concentrated by the Levin-Tyndale method of precipitation with tannic acid. Normal immature female rats, 25 or 26 days old, are used and two groups of three animals each are utilized for the test. Over a period of four days aliquot portions of powder derived from a known amount of urine are injected into each animal and autopsy is performed on the fifth day. A positive test is one which shows follicular or uterine stimulation. Each animal of the first group is injected with a concentrated powder equivalent to $100 \mathrm{cc}$. of native urine. Rats of the second group are injected with the amount of powder derived from $4 \mathrm{cc}$. of urine. If these rats show no response there are fewer than so R.U. per liter of urine. If the animals comprising the first group show a positive reaction, while those of the second group are not stimulated, there are between 10 and $25^{\circ}$ R.U. per liter of urine. If both groups of rats react positively there are over $25^{\circ}$ R.U. per liter, and further tests are performed with varying dilutions of native urine in order to determine accurately the number of units. By this method normal men are found to excrete fewer than 20 R.U. and usually fewer than 10 R.U. per liter of urine. Table 1 gives a summary of the results obtained by the use of this test on 44 recent patients with testicular tumor. Clinically the test has proved of no diagnostic value with this exception: when it shows 10,000 R.U. or more of gonadotrophin per liter of urine, the diagnosis of chorionepithelioma is justified. So uniformly is the high output related to this type of tumor that in some localities, particularly Copenhagen, it is accepted as a fact that chorionepithelioma is the only type of tumor which causes the excretion of this hormone and that, whenever it is present in abnormal amounts, search in the growth or the metastases will disclose chorionic elements. In those patients in whom the test was positive before castration, subsequent testing of the urine has considerable value in prognosis. When the gonadotrophic output is correlated with both the pathological type of tumor and the presence or absence of mestastases a fairly accurate prognosis is possible. 


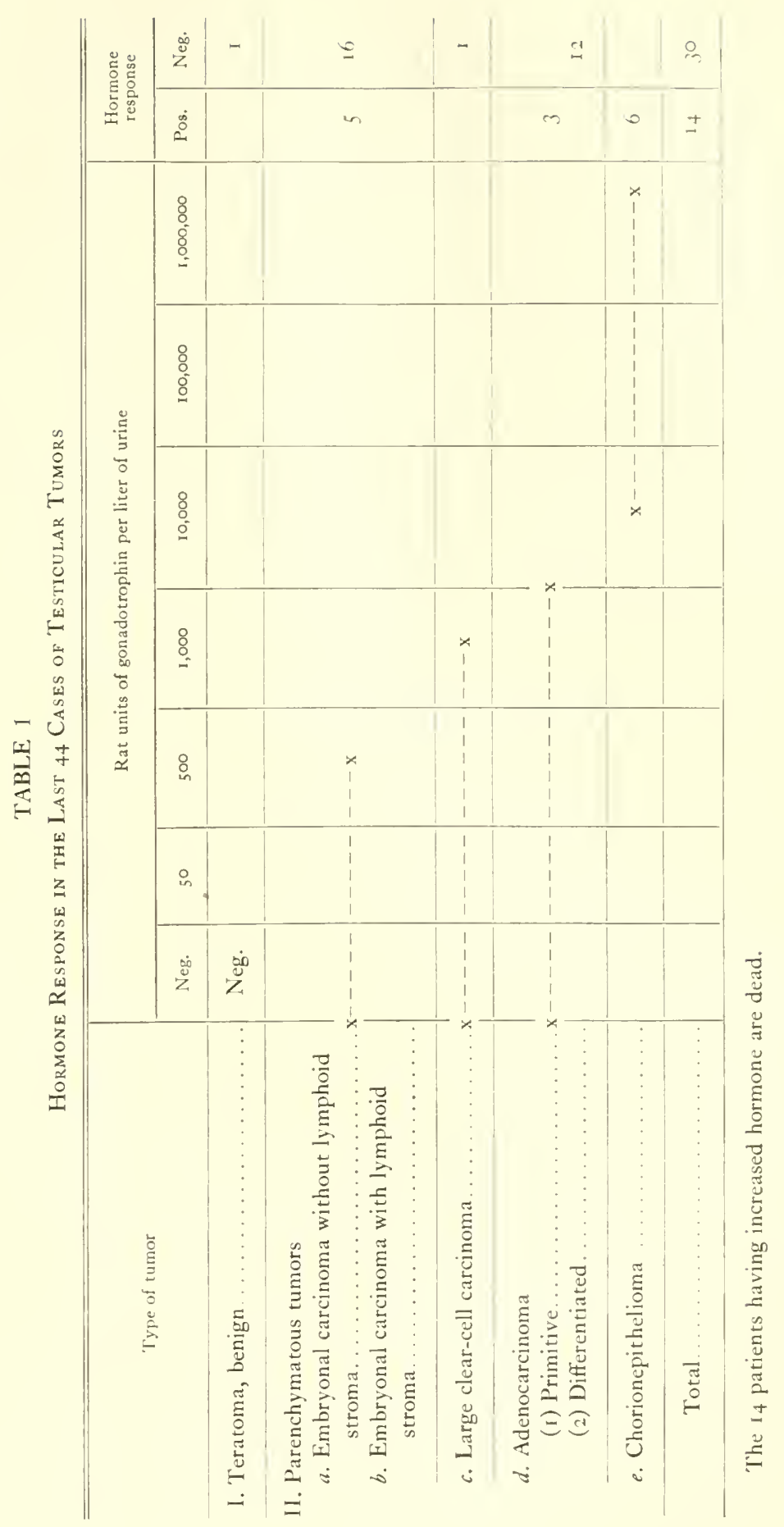




\section{Clinical}

Although found at all ages, tumors of the testis occur most frequently in early adult life, mostly between the ages of 20 and 40 years. As might be expected, most of the tumors occurring in infants and boys are of the mixedcell type (teratomata). As a rule all tumors run a rapid course and death is frequent within a year from the time of discovery. Occasionaly a malignant tumor has been present for two or three years before the patient has sought medical advice, but the accuracy of the patient's observation in respect to onset may well be questioned as thcre may have been another condition to start with and the tumor have appeared secondarily. On rare occasions the primary growth in the testis could not be discovered on physical examination before metastases appeared. Some of these patients came to autopsy and the true nature of the metastases were then discovered. In a few instances, in our own experience, biopsy of metastases disclosed the character of the growth and subsequent careful physical examination of the testis revealed a suspicious nodule, or it was found after orchidectomy. All these hidden growths were chorionepitheliomata. Clinical diagnosis is based solely on the findings made by palpation except in the rare instances of a high content of hormone in the urine with negative findings on palpation. Ordinarily the testicle and its epididymis are distinguishable. In small growths an area of induration can be made out, but in larger growths the general shape of the testicle, as a rule, is maintained as in gumma. The examiner receives the impression, however, of an increase in weight or perhaps more nearly an increase in the specific gravity of the enlarged testicle. Even in advanced growths the epididymis can still be separated from the mass and difficulties in differential diagnosis usually arise only when this becomes impossible, or when gumma is present, or when the condition is complicated by coexistant hydrocele, epididymitis, etc. Careful search for metastases should always be made. The earliest site of metastasis of tumor of the testicle is the preaortic lymph zone but the time of occurrence is so uncertain that this fact has been abandoned as an indication for radical operation (orchidectomy with complete removal of the primary lymph zone of that side). Clinically it may be found that cells have crossed to the opposite lymph zone without giving evidence of their presence in the primary one. In one patient recently a large tumor developed on the right side months after a left orchidectomy for tumor of the testis. Supraclavicular glands on the left appeared a year after the removal of this retroperitoneal metastasis, at which time no masses could be felt on the other (left) side of the aorta and vena cava. In fact, metastases to the supraclavicular group of glands called "Virchow's nodes" are not at all infrequent with tumors of the testis. Metastases also occur to the viscera by way of the blood vessels. It is of course important to determine at the time of examination the presence or absence of any of these types of metastasis as well as their extent.

The treatment of tumors of the testis has narrowed itself to simple orchidec- 
tomy and X-ray therapy. Definite diagnosis, of course, can be made only by the microscope and there is a distinct advantage therefore in carly orchidectomy. I can see no benefit to be gained by preoperative irradiation which carries a risk of sterilization even with the best of lead protection for the good test is. With high exposure of the cord at the external ring and its double ligation and division before manipulation of the tumor, orchidectomy would seem to be perfectly free from any danger of spreading metastases. Ordinarily it is advisable to have collected urine for 24 hours or more for determination of the gonadotrophic hormone. There is no advantage in waiting for the result of this test, however, before performing orchidectomy inasmuch as neither the presence nor the absence of the hormone would modify the plan of treatment. The specimen removed is sent to the pathologist for careful serial examination and this study together with the report from the biochemical laboratory gives reliable information as to prognosis. To those patients in whom metastases were not demonstrated clinically before operation, a prophylactic course of X-ray therapy to the preaortic lymph zone is given. In those patients in whom metastases were demonstrated before orchidectomy the areas of metastasis, as well as the preaortic lymph zone even if uninvolved clinically, are irradiated. Experience is not yet sufficient to permit any reliable prediction of the effect of irradiation. As a rule the more primitive types of tumor are the most radiosensitive, that is, such masses disappear most readily under irradiation so far as clinical evidence goes, yet few of these patients are cured. On the other hand, the embryonal carcinomata, which are not nearly so primitive or radiosensitive, show the most farorable results after irradiation. During the first year it has been our custom to submit for biochemical assay 24 - or $4^{8-h o u r}$ collections of urine from patients upon whom orchidectomy has been performed and followed by radiation therapy; thereafter such specimens are submitted at intervals of six months for the next two years. This has been done as a routine even on those patients who showed no increase of the hormone above normal before orchidectomy. Only on very rare occasions have abnormal amounts of the hormone appeared in these subsequent tests.

Under the foregoing plan of treatment the prognosis depends on early recognition of the tumor, the pathologic type of growth found after orchidectomy, the finding of a functioning or nonfunctioning growth, and the presence or absence of metastases as determined by clinical examination. A good prognosis may be offered for patients with an early growth and no metastases clinically, with no gonadotrophic hormone in the urine, and with a type of tumor having fairly well differentiated cells. On the other hand, in spite of early diagnosis, a poor prognosis is all that can be advanced for the patient who shows a high content of hormone in the urine and a type of tumor having primitive cells even though no clinical evidence of metastases is present. The chorionepitheliomata are the most malignant of all these tumors and, in our experience, always are fatal. Glancing back at table 1 , it is seen in fact that no patient who 
showed gonadotrophic hormone in the urine before orchidectomy survived a year afterward in spite of the most vigorous irradiation.

To summarize, patients without metastases and with no hormonal output have a good prognosis. For patients with metastases but still with no hormonal output the prognosis may be poor, fair, or even good, depending on the uncertain reaction of the particular tumor to irradiation. Finally, irrespective of metastases, paticuts who excrete gonadotrophic hormone have a very poor prognosis. 


\title{
HISTORY OF \\ HYPOPHYSIAL DIABETES
}

\author{
By
}

B. A. HOUSSAY, M.D.

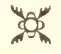

From the

INSTITLTO DE FISIOLOGIA DE LA FACULTAD DE CIENCIAS MÉDICAS DE BUENOS AIRES, ARGENTINA 



\section{HISTORY OF HYPOHPYSIAL DIABETES}

$\mathrm{T}$

HE Evolution of knowledge on the relation of the hypoplyysis to diabetes can be divided chronologically into frve periods: 1st, before 192.1, the incidence of cliabetes in acromegaly and the action of the posterior lobe; 2 d, after 1924, the hypersensitivity of hypophysectomized animals to insulin; $3 \mathrm{~d}$, alter 1929. the chiscovery of the action of the anterior lobe on diabetes; 4 th, misconceptions prevailing in 1936; $5^{\text {th }}$, permanent diabetes induced by anterohypophysial extracts.

1. Before 1924: the Incidence of Diabeles in Acromegaly and the Action of the Posterior Lobe. Since acromegaly was first studied, its coexistence with diabetic symptoms has been observed. Two papers collecting published cases may be mentioned on the subject:

\begin{tabular}{|c|c|c|c|}
\hline & \multirow{2}{*}{$\begin{array}{c}\text { Number of } \\
\text { cases }\end{array}$} & \multicolumn{2}{|c|}{ Glycosuria } \\
\hline & & Cases & Per cent \\
\hline Borchard $t^{-1}$ & 176 & 71 & 40 \\
\hline Atkinson ${ }^{2}$. & 817 & 268 & 32.8 \\
\hline
\end{tabular}

The high incidence of diabetes in acromegaly prompted Borchardt ${ }^{1}$ to inject pituitary extracts: he found that they produced glycosuria and blood sugar increase of short duration. This effect is due to the posterior lobe and has been extensively studied by Houssay and Di Benedetto. ${ }^{3}$ In that paper many references to previous work are mentioned, besides the authors' experiments.

In 1929 Burn $^{+}$discovered the antagonistic action on blood sugar of posteriorlobe extracts and insulin in the rabbit. This effect was also found in the dog by Magenta and Biasott $\mathrm{i}^{5}$ as were several other antagonistic actions of these substances (Houssay $y^{\circ}$ ). From then until 1929 the prevailing idea was that if the hypophysis had any action on carbohydrate metabolism and on the diabetes in acromegaly it was due to its posterior lobe.

Cushing and his associates since 1911 have insistently studied the role of the hypophysis in carbohydrate metabolism. In the papers of Goetsch, Cushing and Jacobson ${ }^{\tau}$ and of Weed, Cushing and Jacobson ${ }^{5}$ it is mentioned that in hypophysectomized dogs there occurs an increase in tolerance to sugar, since in these dogs the ingestion of large amounts of saccharose was not followed by glycosuria.* They also observed an increase in tolerance in hypophysectomized dogs in which a large part of the pancreas had been remored but did not experiment with totally pancreatectomized animals. These changes were attrib-

* These results might be due to the slow absorption of sngar, as has been found in hypophyectomiced rats, and do not prove that more sugar is consumed. On the contrary, the injection of glucose into the reins of hypophysectomized dogs produces a blood sugar increase which lasts longer than in normal dogs (Biasotti; ${ }^{9}$ Foglia and Potick ${ }^{10}$ ).

$$
[217]
$$


uted to the abscnce of the posterior lobe because it was observed that they appeared in dogs in which that lobe had been removed and because the injection of postcrior-lobe extracts decreases the sugar tolerance of normal and hypophysectomized dogs.

Weed, Cushing and Jacobson ${ }^{8}$ assumed that the hypophysis secreted a glycogenolytic and glycosuric hormone which was liberated by the action of nervous stimuli sent by the superior cervical ganglion. But in 1930 Cushing ${ }^{11}$ was inclined to attribute these cffects to the action of the hypothalamus: "Our findings may be capable of other interpretations now that attention has been drawn to the importance of the hypothalamic region whence possibly our glycogenolytic responses originated rather than in the hypophysis itself."

2. After 1924, the Hypersensitivity of Hypophysectomized Animals to Insulin. After the discovery of insulin in 1922 it was prepared in Buenos Aires early in 1923 by Dr. Sordelli and we formed a team for studying its metabolic action and also its effects on the chemistry of blood and milk in different species, its antagonistic or coadjuvant action with different substances, and especially the influence of removing endocrine glands as well as the role of the nervous system, etc. A review on the latter subjects was published in Endocrinology in 1925 by Houssay. ${ }^{12}$

In 1923 the action of insulin in thyroidectomized (Ducheneau ${ }^{13}$ ) and adrenalectomized (Lewis and Magenta ${ }^{14}$ ) animals was studied in our Institute.

Houssay and Magenta ${ }^{15}$ published in 1924 experiments showing the striking hypersensitivity of hypophysectomized dogs to insulin. These studies were extended in $1927^{16}$ and in $1929 .{ }^{17}$ In 1924 the great sensitivity to insulin was found in the toad after removal of the entire hypophysis or of the anterior lobe (Houssay, Mazzocco and Rietti ${ }^{18}$ ). Three years afterwards (1927) Geiling, Campbell and Ishikawa, ${ }^{19}$ confirmed our findings that hypophysectomized dogs are more sensitive to insulin but wrongly attributed the hypersensitivity to the absence of the posterior lobe.

In 1927 Davidoff and Cushing ${ }^{20}$ wrote: "An experimentally induced hyperglycemia, brought on by removal of a large portion of the pancreas, tended to subside when a partial hypophysectomy was subsequently performed." "If loss or diminution of the internal secretion of the pancreas robs the tissues of their power of metabolizing carbohydrates, certainly loss or diminution of the secretion of the hypophysial posterior lobe [sic] greatly enhances their power in this respect." Two important points are mentioned in this paragraph: 1st, the attenuation of pancreatic diabetes by hypophysectomy; $2 \mathrm{~d}$, the possibility that the part played by the hypophysis might not belong to its posterior lobe. Unfortunately the authors published no experimental details, such as the amount of pancreas removed, etc. It is well known that the changes produced by partial hypophysectomy or partial pancreatectomy are not permanent and often subside spontaneously and completely. Moreover these studies were not properly completed by their authors and this is why they did not carry a general conviction. 
In 1927 Davidoff and Cushing ${ }^{20}$ observed that insulin alcts on the diabetes of acromegaly but that larger anounts are needed to obtain normal blood sugan than in other types of diabetes. "They attributed the insulin resistance to a pituitary hyperactivity which would partially suppress the action of insulin and found that after removing a part of the adenoma the insulin resistance disappeared. They seemed inclined to assign some role to the anterior lobe: "Whether in acromegaly the melituria is due to an excess of posterior lobe extract, as the countereffect on insulin would appear experimentally to indicate, or to an overactivity of the acidophilic cells of the anterior lobe as we are inclined to believe, or possibly to a combination of both, for we know little of the source of the active substance of the posterior lobe, time will surely tell.'

In 1927 Johns, O'Mulvenny, Potts and Laughton ${ }^{21}$ observed that extracts of anterior lobe produced slight hyperglycemia and glycosuria. The preparation of the extracts was not published in detail but it was stated that they were free from protein. They may have erred in the last point, because according to our experiments the diabetogenic activity is contained in the protein fraction of the extracts.

3. After 1929, the Discovery of the Action of the Anterior Lobe on Diabetes. Extending their studies on the hypersensitivity of hypophysectomized animals to insulin, Houssay and Potick ${ }^{22}$ in 1929 confirmed the fact that the hypersensitivity appears in toads with no anterior lobe just as in those where the whole hypophysis had been removed. They also discovered that the implantation of anterior lobe from toads or mammals (ox) protects hypophysectomized toads against the action of insulin. This finding led us to study with Dr. Biasotti the influence of hypophysectomy in pancreatectomized dogs and toads. I clearly recall the impression we received when we found that our furst hypophysectomized dog did not excrete glucose in the urine during the three days following total pancreatectomy. These results were first published in 1929 by Houssay ${ }^{6}$ in a footnote of a paper in the jubilee volume dedicated to Prof. G. Aráoz Alfaro.

In 1930 Houssay and Biasott $\mathrm{i}^{23-25}$ published their experiments in detail in three papers. The total removal of the pituitary in $\operatorname{dogs}^{24}$ or toads ${ }^{23}$ or of the anterior lobe in the toad ${ }^{23}$ produced a great decrease in the intensity of pancreatic diabetes, also of phlorizin diabetes in the dog. ${ }^{25}$ Implantation or injection of anterior lobe (posterior lobe was much less active) to hypophysectomizedpancreatectomized toads produced severe diabetes. ${ }^{23}$

These experiments allowed us to deduce the following conclusions: (1) the anterior hypophysis has a diabetogenic action; (2) its action on carbohydrate metabolism is physiologic and constant; (3) there exists a certain physiologic antagonism between the anterior hypophysis and the endocrine pancreas

* In the extensive literature this resistance has been found present in some cases of acromegaly but lacking in others. In the light of our present knowledge is may be assumed that in the insulin-resistant cases there actually exists an increased secretion of the autcrior hypophysis, whereas in the nonresistant cases the pancreas had been damatged by an increased secretion of the anterior hypophysis which afterwards had subsided and had become normat. 
(attenuation of pancreatic diabetes by hypophysectomy, hypersensitivity to insulin of hypophysectomized animals with or without pancreas, intense diabetogenic action of the anterior lobe in absence of the pancreas); (4) fasting produces marked changes in hypophysectomized animals (rapid hypoglycemia and death in animals with or without pancreas, great decrease in glycosuria and in blood-sugar level of hypophysectomized-pancreatectomized dogs); ${ }^{24,20}$ (5) hypophysectomized dogs utilize food protein well but the endogenous catabolism is decreased during fasting or in pancreatic and phlorizin diabetes; $;{ }^{28},{ }^{28}$ (6) hypophysectomized-pancreatectomized dogs utilize glucose, excreting only a part of the amount injected; hypoglycemia can appear during fasting, recovery following rapidly on administration of ghucose; ${ }^{20,28}(7)$ hypophysectomy clecreases the ketonuria of pancreatic or phlorizin diabetes, as Rietti ${ }^{20}$ found in 1931 ; (8) the removal of the posterior lobe* does not alleviate the symptoms of pancreatic or phlorizin diabetes and does not increase the sensitivity to insulin in the dog.

In the following years we found $\mathrm{d}^{31-40}$ that: 1 st, the diabetogenic action is specific for the liypophysis, other organs being inactive; $2 \mathrm{~d}$, the anterior lobe of vertebrates (fishes, batrachians, reptiles, birds, and mammals) is active when injected into batrachians or mammals; $3 \mathrm{~d}$, removal of the hypophysis decreases the intensity of pancreatic diabetes in mammals, reptiles, batrachians, and fishes, and of phlorizin diabetes in mammals and batrachians.

Our work remained unnoticed from 1929 to 1931 and therefore we sent a summary of it to two of the leading American medical journals. The paper was not accepted by either of these journals but was finally published in Endocrinology. ${ }^{26}$ After the appearance of this paper two workers in the Physiological Institute of Chicago, Barnes and Regan, ${ }^{41}$ confirmed and extended our experiments. Since 1934 Long and Lukens ${ }^{42.43}$ in important papers confirmed our results, using cats.

In 1932 the diabetogenic action of the anterior hypophysis in mammals was observed. The three papers which appeared were in chronological order: 1, Evans, Meyer, Simpson and Reichert; ${ }^{44.45}$ 2, Bauman and Marine; ${ }^{46} 3$, Houssay, Biasotti and Rietti (with Di Benedetto). ${ }^{37}$ Confirmatory experiments were published in 1933 by Barnes and Regan, ${ }^{41}$ and E. I. Evans. ${ }^{47}$

H. M. Evans and his co-workers ${ }^{44,45}$ in their studies on the growth hormone of the hypophysis injected anterior-lobe extracts free from gonadotrophic substances. They observed that a male dog after about eight mon ths of continuous injection "developed marked skin infections and abscesses, became emaciated in spite of a large appetite, was easily exhausted, drank great amounts of water, and excreted great amounts of urine. This led to investigation of the urine of the injected male for the presence of sugar. It was present in large amounts. Fasting blood sugar was also high $(232 \mathrm{mg}$. per $100 \mathrm{cc}$.). The animal was obviously failing and injections were stopped to prevent its death. Four months

* The alterations produced by diencephalic lesions and total removal of the neurohypophysis are still not clearly understood (see Davis and co-workers, ${ }^{30}$ and Houssay ${ }^{28}$ ). 
after cessation of treatment, the urine still gave a positive Fchling test. The amount of sugar excreted had decreased and the mine volume was less. The animal was more active and had gained weight." In the other group, one female dog injected for nine months had infection on the skin. hyperglycemia (228 mg. per $100 \mathrm{cc}$.) and glycosuria; when the injections were interrupted the bitch remained glycosuric for two months and no abnormalities werc found in its Langerhans islets. One female of the first group and a brother of the female of the second group which were treated likewise did not show disturbances of carbohydrate metabolism (blood and urine) even a year after being injected. Prof. Evans wrote to me about his experiments before publishing them and I mentioned this letter in my paper of 1932 (see Houssay ${ }^{39}$ ).

In the same year, Bauman and Marine ${ }^{46}$ injected four rabbits during six or more days with a saline extract of fresh bovine anterior lobe. The animals presented glycosuria, polyuria and an increase in blood sugar. The body weight did not decrease. Using the growth extract "Phyone," glycosuria appeared in one out of four rabbits. From 1932 up to now we have confirmed the Evans phenomenon several times, dogs injected daily with anterior lobe developing diabetes for some weeks during the treatment, remaining diabetic for one to four weeks after the injections were stopped, and then gradually becoming normal. The return of the blood sugar to normal is probably due to the disappearance of the lesions of the beta cells of the Langerhans islands.

In 1930 Houssay and Biasotti $i^{23}$ had discorered the diabetogenic action of the anterior lobe by injecting toads deprived of hypophysis and pancreas. In 1932 it was confrrmed in dogs without hypophysis and pancreas by Houssay, Biasotti and Rietti ${ }^{38-40}$ who published three notes about it, one of them with Di Benedetto. ${ }^{38}$ In these notes is also described the diabetogenic action of the anterohypophysial extract in: 1st, dogs with pancreatic mass reduced but normoglycemic (this particular point was later studied by Houssay, Foglia and Smyth $^{48}$ in 1941); 2d, dogs with Sandmeyer diabetes; 3 d, normal dogs. In the same year (1932) it was proved in our Institute that the anterohypophysial extract aggravates the phlorizin diabetes in toads ${ }^{40}$ and dogs. ${ }^{33,37}$ Finally in 1937, Foglia, Gerschman, Marenzi, Muñoz and Rietti ${ }^{50}$ showed that when injected into totally pancreatectomized dogs it aggravated the diabetes, increased especially the ketonemia and ketonuria, decreased the alkaline reserve, and killed them in coma within one to three days.

In 1933 Houssay, Biasotti and Rietti ${ }^{40}$ compared the sensitivity of several animal species to the diabetogenic anterohypophysial action. They studied several chemical properties of the extract and demonstrated that its action can be observed in dogs without gonads, thyroid, adrenal medulla, sympathetic chains, and splanchnic nerves. In the hypophysectomized and pancreatectomized toad Houssay and Biasotti $i^{31,32}$ had shown from 1931 to 1933 diabetogenic action in absence of the digestive apparatus, lungs, kidneys, testicles, ovaries, thyroid, or forebrain, interbrain and nidbrain.

The diabetogenic action is not observed in absence of the liver in the pan- 
createctomized and hypophysectomized toad, as shown by Campos, Curutchet and Lanari ${ }^{51}$ in 1933 and Foglia. ${ }^{52}$ By progressively reducing the amount of liver left it was shown that when the loss was over 55 per cent the diabetogenic action diminishes $\left(\right.$ Foglia $\left.{ }^{52}\right)$. In dogs with full anterohypophysial diabetes, hepatectomy produces a quick fall of the glucemia and within a few hours they show serious hypoglycenic reactions, which disappear momentarily with glucose. According to Soskin ${ }^{53}$ the anterohypophysial diabetogenic action is due to an overproduction of glucose in the liver.

From 1934 to $193^{6}$ appeared the important works of Long and Lukens ${ }^{42,43}$ and in 1937 one by Long, ${ }^{54}$ studying the influence of hypophysectomy on pancreatic cliabetes and the action of anterohypophysial extract in animals with both operations. The above studies led them to investigate the influence of adrenalectomy on pancreatic diabetes. In this field they did splendid work; their last paper (Long, Katzin and Fry ${ }^{55}$ ) was in 1940.

4. Misconceptions Prevailing in 1936. During my trip to the United States in 1936 I realized that two false notions were held: 1 st, it was not possible to observe the diabetogenic action in intact animals; 2d, the anterohypophysis had no intrinsic action on the metabolism of the carbohydrates, its action being exerted by way of the corticoadrenal hormones.

Bennett, as well as Collip, and also Long and Lukens, had observed diagetogenic action in animals without hypophysis and pancreas, but not in normals. In reporting further work done in Evans's laboratory, Russell ${ }^{56}$ in $193^{8}$ stated: "In our own laboratory, in spite of initial successes, more extensive trials in normal dogs and rabbits were unsuccessful also, except in a few instances which were considered doubtful because of attendant protein reactions in the animals."

In spite of this general incredulity, our Institute went on continuously obtaining and studying this diabetogenic action, which we have by now observed in hundreds of dogs. The reason for our success was explained to all the abovementioned investigators and to Young (November, 1935) on the basis of the following procedure used in preparing our extracts; immediately after the slaughtering of the animals the hypophyses were placed in carbon-dioxide snow and the dissection and subsequent preparation of the extracts was always carried out near $0^{\circ} \mathrm{C}$.; the glands were kept frozen from then on; we realized that at room temperature the glands and the extracts lose their action in a few hours. Among all these investigators only Young followed our advice; that is why he was able to accomplish the outstanding investigations well known to all of us.

When Young ${ }^{57,58}$ in 1937 and $193^{8}$ published his results the doubts vanished; it explains why many believe he discovered the diabetogenic action of anterohypophysial extract, which really has been well known since 1930 and 1932.

The idea that the diabetogenic action is mediated exclusively through the adrenals comes from the work of Long. However, Long himself was always rather cautious in his conclusions, and in the paper by Long, Katzin and Fry ${ }^{55}$ 
(in 19.0) it was stated that "not all the diabetogenic effect of the anterior pituitary is mediated by the adrenal cortex, but rather that a synergism exists between these two hormones." The proof of the diabetogenic action of anterohypophysial extracts in animals without adrenals was presented in the toad by Houssay and Biasotti ${ }^{32,35}$ in 1933 and $193^{6}$ and by Houssay and Leloin ${ }^{58}$ in 1935, and in adrenalectomized dogs with reduced pancreas, kept alive with adrenal extract (Houssay and Biasott ${ }^{36}$ in $393^{8}$ ) or with desoxycorticosterone or only with sodium chloride (umpublished experiments ${ }^{60}$ ). While we do not discard the possible existence of the synergism between anterohypophysis and corticoadrenal hormones, in the latter experiments no such synergism was detectable. Concerning participation of the adrenals in antcrohypophysial action we shall publish some other experimental results later.

5. Permanent Diabetes Induced by Anterohypophysial Extracts. In 1932 Houssay, Biasotti and Rietti $i^{34,34}$ proved that the in jection of anterohypophysial extract into normoglycemic dogs with reduced pancreatic mass produces a diabetogenic action. After the interruption of the injection the majority of the animals returned to a nomoglycemic state, but some remained permanently diabetic until death. This was the first demonstration of permanent diabetes due to the action of anterohypophysial extract.

In 1937 Young $^{5 \pi}$ reported the very important verification, namely, that this particular permanent diabetes can be produced in normal dogs. His remarkable work was duly appreciated and the doubts of some concerning the anterohypophysial diabetogenic action definitely subsided. Summaries of these works were published by Young ${ }^{61-63}$ in 1939 and 1940.

A year before, in $193^{6}$, Houssay and Foglia ${ }^{64}$ demonstrated that the pancreas of dogs with hypophysial diabetes showed a decrease in its capacity to secrete insulin. This was confurmed in 1941 by Houssay, Foglia, Smyth, Rietti and Houssay $y^{a 5}$ who also showed that if the dog resists the diabetogenic action and remains normogtycemic, or in case his diabetes subsides, the pancreas in many instances has a normal (and sometimes supernormal) secretion of insulin.

Richardson $^{66}$ and Young ${ }^{62}$ have shown that during anterohypophysial diabetes the beta cells show a disappearance of granules, vacuolization and pyknosis; in case the animal remains with a permanent diabetes the islets are found atrophic, hyalinized, with few or no beta cells. If the animal resists the extract or if his hyperglycemia subsides, recuperation of the beta cells can be observed, as shown by Porto. ${ }^{.7}$

Actually the anterohypophysial extract produces two kinds of diabetes: (1) the appropriately designated anterohypophysial diabetes observed during the injection of the extract; its origin is due first to extrapancreatic factors for only afterwards are the islets injured and the secretion of insulin diminished. There is in these animals characteristic increase in resistance to insulin; (2) permanent diabetes, which is pancreatic and should be called metahypophysial diabetes, being due to the lack of active Langerhans islets; the antero- 
hypophysial extract damages the islets, but its continued action is unnecessary during the permanent diabetic state.

This history of anterohypophysial diabetes stops at this point without discussing the important contributions of Long, Chambers, Collip, Young, Soskin, and other investigators, because they are more recent and the exact chronology is better known.

The discoveries made by Professor Herbert M. Evans in several fields of the biological sciences, among them in the physiology of the hypophysis, are many and fundamental. I am happy to associate myself in the homage now dedicated to him by writing this exposition of some fundamental points in the history of anterohypophysial diabetes, which I know as actor or coeval. Professor Evans was the first to demonstrate the anterohypophysial diabetogenic action in mammals, and discovered that this effect may persist for several weeks after the treatment is ended. Later his pupils, Bennett and Russell, made other valuable contributions. I take this opportunity to express to Professor Evans my greatest admiration and sincere friendship.

\section{REFERENGES}

1. Borchardt, L.: Ztschr. f. klin. Med. 66:332, 1908.

2. Atkinson, F. R. B.: Endokrinologie 20:245, 1938.

3. Houssay, B. A., and Di Benedetto, E.: Rev. Soc. argentin. de biol. 9:300, 310, 1933; Cpts. rd. Soc. de biol. 114:793, 795, 1933 .

4. Burn, J. H.: Jl. Physiol. 57:318, 1923.

5. Magenta, M. A., and Biasotti, A.: Rev. Asn. méd. argentin, 36:60, 1923; Cpts. rd. Soc. de biol. 89:1125, 1923.

6. Houssay, 'B. A.: Endokrinologie 5:103, 1929; Libro de oro en homenaje al Dr. Gregorio Araoz Alfaro (Buenos Aires: 1929).

7. Goetsch, E.; Cushing, H., and Jacobson, C.: Johns Hopkins Hosp. Bull. 22:165, 1911.

8. Weed, L. H.; Cushing, H., and Jacobson, C.: Johns Hopkins Hosp. Bull. 24:40, 1913.

9. Biasotti, A.: Rev. Soc. argentin. de biol. 10:124, 1934; Cpts. rd. Soc. de biol. $117: 54,1934$.

10. Foglia, V. G., and Potick, D.: Rev. Soc. argentin. de biol. 17:289, 1941.

11. Cushing, H.: Lancet $219: 119,175,1930$.

12. Houssay, B. A.: Endocrinology 9:456, 1925 .

13. Ducheneau, L.: Rev. Asn. méd. argentin. 36:944, 1923; Cpts. rd. Soc. de biol. 9o:248, 1924.

14. Lewis, J. T., and Magenta, M. A.: Rev. Asn. méd. argentin. 37:37o, 1924; Cpts. rd. Soc. de biol. $92: 821,1925$.

15. Houssay, B. A., and Magenta, M. A.: Rev. Asn. méd. argentin. 37:389, 1924; Cpts. rd. Soc. de biol. 92:822, 1925.

16. Houssay, B. A., and Magenta, M. A.: Rev. Soc. argentin. de biol. 3:217, 1927; Cpts. rd. Soc. de biol. $97: 596,1927$.

17. Houssay, B. A., and Magenta, M. A.: Rev. Soc. argentin. de biol. 5:99, 1929; Cpts. rd. Soc. de biol. 102:429, 1929.

18. Houssay, B. A.; Mazzocco, P., and Rietti, C. T.: Rev. Soc. argentin. de biol. 1:231, 1925; Cpts. rd. Soc. de biol. 93:968, 1925.

19. Geiling, E. M. K.; Campbell, D., and Ishikawa, J.: Jl. Pharmacol. \& Exper. Therapeut. $31: 247,1927$.

20. Davidoff, L. M., and Cushing, H.: Archs. Internal Med. 39:751, 1927.

2. Johns, W. S.; O’Mulvenny, T. O.; Potts, E. B., and Laughton, N. B.: Amer. Jl. Physiol. $80: 100,1927$. 
22. Houssay, B. A., and Potick, D.: Rev. Soc. argentin. de biol. 5:66, 1929; Cpts. rd. Soc. de biol. 101:940, 1929.

23. Houssay, B. A., and Biasotti, A.: Rev. Soc. argentin. de biol. 6:8, 1930; Cpts. rd. Soc. de biol. 10.:107, 1930; Pflügers Arch. f. d. gsmt. Physiol. 227:239, 1931.

24. Houssay, B. A., and Biasotti, A.: Rev. Soc. argentin. de biol. 6:251, 1930; Gpts. rd. Soc. de biol. 105:121, 1930; Pflügers Arch. f. d. gsmt. Physiol. 227:664, 1931.

25. Houssay, B. A., and Biasotti, A.: Rev. Soc. argentin. de biol. 6:326, 1930; Cpts. rd. Soc. de biol. 105:126, 1930; Pflïgers Arch. f. d. gsmt. Physiol. 227:657, 1931.

26. Houssay, B. A., and Biasotti, A.: Endocrinology 15:511, 1931.

27. Biasotti, A., and Houssay, B. A.: Jl. P'hysiol. 77:81, 1932.

28. Houssay, B. A.: New England Jl. Med. $214: 913$, 1936; Bol. Acad. nacn. de med. de Buenos Aires 1936:183.

29. Rietti, C. T.: Archs. Soc. de biol. de Montevideo supp. 2:322, 1931; Jl. Physiol. 77:92, 1932; Rev. Soc, argentin. de biol. 10:136, 1934; Cpts. rd. Soc. de biol. 117:57, 1934.

3o. Davis, L.; Cleveland, D., and Ingram, W. R.: Archs. Neurol. \& Psychiat. 33:592, 1935.

31. Houssay, B. A., and Biasotti, A.: Rev. Soc. argentin. de biol. 7:3, 1931; Cpts. rd. Soc. de biol. 107:733, 1931.

32. Houssay, B. A., and Biasotti, A.: Rev. Soc. argentin. de biol. 9:29, 1933; Cpts. rd. Soc. de biol. $113: 469,1933$.

33. Houssay, B. A., and Biasotti, A.: Bol. Acad, nacn, de med. de Buenos Aires 1933:6.1.

34. Houssay, B. A., and Biasotti, A.: Rev. Soc. argentin. de biol. 12:104, 1936; Cpts. rd. Soc. de biol. $123: 497,1936$.

35. Houssay, B. A., and Biasotti, A.: Rev. Soc. argentin. de biol, 12:185, 1936; Cpts. rd. Soc. de biol. $123: 82.4,1936$.

36. Houssay, B. A., and Biasotti, A.: Rev. Soc. argentin. de biol. 1.4:308, 1938; Cpts. rd. Soc. de biol. 129:1261, 1938.

37. Houssay, B. A.; Biasotti, A.; Di Benedetto, E., and Rietti, C. T.: Rev. Soc. argentin. de biol. 8:570, 1932; Cpts. rd. Soc. de biol. 112:497, 1933 .

38. Houssay, B. A.; Biasotti, A.; Di Benedetto, E., and Rietti, C. T.: Rev. Soc. argentin. de biol. 8:563, 1932; Cpts. rd. Soc. de biol. 112:494, 1933.

39. Houssay, B. A.; Biasotti, A., and Rietti, C. T.: Bol. Acal. nacn. de med. de Buenos Aires 1932:171; Rev. Soc. argentin. de biol. 8:469, 1932; Cpts. rd. Soc. de biol. $111: 479,1932$.

10. Houssay, B. A.; Biasotti, A., and Rietti, C. T.: Rev. Soc. argentin. de biol. 9:489, 1933; Cpts. rd. Soc. de biol. $115: 323,325,327,1934$.

41. Barnes, B. O., and Regan, J. F.: Endocrinology 22:193, 1933.

42. Long, C. N. H., and Lukens, F. D. W.: Science (n.s.) 79:569, 1934; Proc. Soc. Exper. Biol. \& Med. 32:326, 1934; Proc. Soc. Exper. Biol. \& Med. 32:743, 1935.

43. Long, C. N. H., and Lukens, F. D. W': J1. Exper. Med. 63:465, 1936.

44. Evans, H. M.; Meyer, K.; Simpson, M. E., and Reichert, F. L.: Proc. Soc. Exper. Biol. \& Med. $29: 85 \bar{\gamma}, 1931$.

45. Evans, H. M.; Simpson, M. E.; Meyer, K., and Reichert, F. L.: Mems. Univ. California $11: 425,1933$.

46. Bauman, E., and Marine, D.: Proc. Soc. Exper. Biol. \& Mcd. 29:1220, 1932.

47. Evans, E. I.: Proc. Soc. Exper. Biol. \& Med. 30:1370, 1933.

48. Houssay, B. A.; Foglia, V. G., and Smyth, F. S.: Jl. Exper. Med. 74:283, 1941.

49. Di Benedetto, E.: Rev. Soc. argentin. de biol. 7:196, 1931; Cpts. rd. Soc. de biol. 107:1193, 1931.

5o. Foglia, V. G.; Gerschman, R.; Marenzi, A. D.; Muñoz, J. M., and Rietti, C. T.: Rev. Soc. argentin. de biol. 13:83, 1937; Cpts. rd. Soc. de biol. 126:152, 1937.

51. Campos, C. A.; Curutchet, J. L., and Lanari, A.: Rev. Soc. argentin. de biol. 9:11, 1933; Cpts. red. Soc, de biol. $113: 467,1933$.

52. Foglia, V. G.: Unpublished data.

53. Soskin. S.: Physiol. Rers. 21:140, 1941. 
54. Long, C. N. H.: Harvey Lects. 32:194, 1937 .

55. Long, C. N. H.; Katzin, B., and Fry, E. G.: Endocrinology 26:309, 1940.

56. Russell, J. A.: Physiol. Revs. 18:1, $193^{8}$.

57. Young, F. G.: Lancet 233:372, 1937 .

58. Young, F. G.: Biochem. J1. 32:524, $1521,193^{8 .}$

59. Houssay, B. A., and Leloir, L. F.: Rev. Soc. argentin. de biol. 11:464, 1935; Cpts. rd. Soc. de biol. 120:670, 1935.

6o. Houssay, B. A., and Foglia, V. G.: Unpublished data.

61. Young, F. G.: J1. Endocrinol. 1:339, 1939 .

62. Young, F. G.: New England J1. Med. 221:635, 1940.

63. loung, F. G.: Endocrinology 26:315, 1940.

6. Houssay, B. A., and Foglia, V. G.: Rev. Soc. argentin. de biol. 12:237, 1936; Cpts. rd. Soc. de biol. $123: 82.4,193^{6 .}$

65. Houssay, B. A.; Foglia, V. G.; Smyth, F. S.; Rietti, C. T., and Houssay, A. B.: Acts. y trabs., I1 Congr. pan-amer. de endocrinol. 1:222, 1941; Rev. Soc. argentin. de biol. 17:301, 19.1; Fl. exper. med. $75: 5.17,1942$.

66. Richardson, K. C.: Proc. Roy. Soc. London, S.B 128:153, 1940.

67. Porto, J.: Rev. Soc. argentin. de biol. 17:351, 367, 1941 . 
THE SYMBALLOPHONE:

A DOUBLE STETHOSCOPE FOR THE COMPARISON AND

\title{
LATERALIZATION OF SOUND
}

\author{
By
}

WM. J. KERR

\section{临}

From the

DIVISION OF MEDICINE

UNIVERSITY OF CALIFORNIA MEDICAL SCHOOL

SAN FRANCISCO, CAIIFORNIA 



\section{THE SYMBALLOPHONE: \\ A DOUBLE STETHOSCOPE FOR THE COMPARISON AND LATERALIZATION OF SOUND}

$\mathrm{P}$ AIRED ORGANS of hearing are a convenience and almost a necessity in the forms of animal life in which they are found. In the primitive sense, these animals are able to locate sources of sound which may indicate danger or a supply of food. The eyes are then directed to the point of origin of the sound and the identity of the agent may be determined. The hunter, whether animal or man, is greatly aided by the sounds produced by game in motion. Conversely, the hunted instinctively recognizes the safety value of a fixed position with respect to both sound and sight. In our highly mechanistic age the man on the street is at a great disadvantage if he cannot locate an onrushing vehicle.

The localizing functions of the paired organs of hearing are extremely sensitive. Psychologically, sounds arising from a point in the midline or in the plane of projection of the long ax is of the head reach the tympanic membranes of both ears simultaneously and are of equal intensity. Unless the subject moves his head, he is unable to locate the origin of the sound in this plane which is perpendicular to the axis between the two ears. If, however, the sound arises from one side of the midline, the point of its origin may be lateralized with remarkable accuracy chiefly by means of the difference in the time of arrival and in intensity of the sound waves that reach the tympanic membranes of the two ears. The difference in the time of arrival of the sound waves is determined by the difference in distance between the source of the sound and the two ears; the difference in intensity is determined by the reduction in intensity caused by deflection of the sound waves which pass around the head to reach the ear on the side more remote from the source of the sound (fig. 1).

The simple device shown in figure 2 readily demonstrates that a normal person's cars are capable of detecting differences in time of 0.000003 sec. This function may be tested by connecting a rigid hollow metal or glass tube of convenient bore with flexible rubber tubing of equal bore and length, to the headand earpieces of an ordinary binaural stethoscope. Small holes are drilled into the rigid tube, one exactly in the center, one on each side $5 \mathrm{~mm}$. from the central aperture, and others equiclistant from the central aperture but at variable distances from the center. The subject inserts the earpieces into his external auditory canals in the manner ordinarily employed by the physician and closes his eyes. Sounds are produced by blowing or by vibrating a tuning fork over the apertures. In normal subjects the sounds that enter the central aperture are not lateralized but those that enter either aperture $5 \mathrm{~mm}$. from the center are readily lateralized to the side on which they originated. Sounds

$$
[259]
$$


that enter the apertures more remote from the center appear to arise at a greater distance from the midline. But when the difference in distance becomes as great as 15 to $18 \mathrm{~cm}$., the sounds appear to arise almost opposite one ear.

Sound travels in air at the rate of $330 \mathrm{~m}$. per sec. If the ears are able to lateralize the sound that arises only $5 \mathrm{~mm}$. from the midline (which under

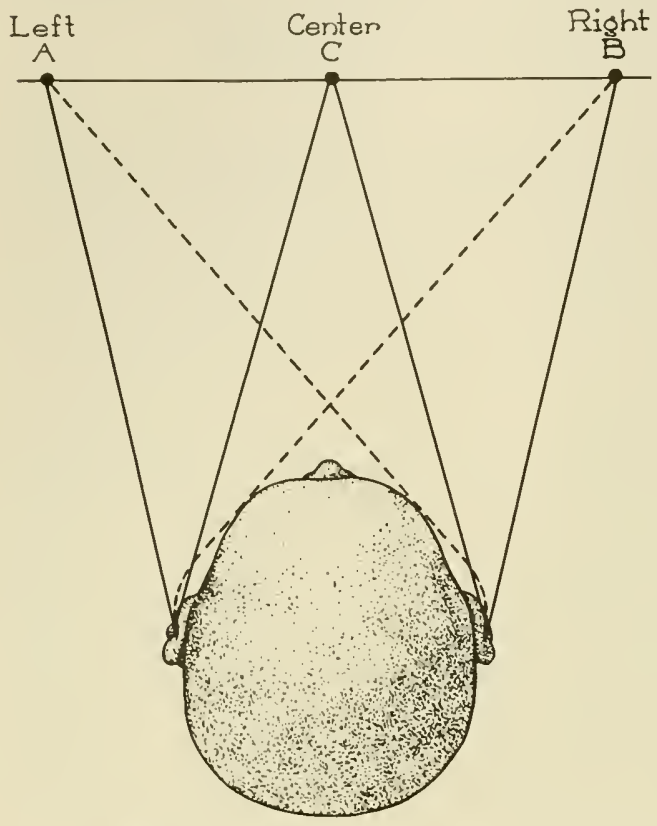

Fig. 1. When sounds arise from a point $C$ which lies in the longitudinal plane of the head and is equidistant from the two ears, the sound waves reach the auditory nerves simultaneously. When sounds arise from any points to either side of point $\mathrm{C}$, they arrive at the two ears after different intervals of time and always later in the ear more distant from the source of the sound, as shown by the broken lines. Likewise, the sound waves which travel through the greater distance are deflected in their course around the head and the intensity of the deflected sound is reduced. The differences in timing and intensity of the sounds that reach the two ears are the two most important conditions in determining the perception of lateralization. Sounds of different qualities from different external sources may be located simultaneously because of the highly selective functions of the organ of Corli. experimental conditions would mean a difference in distance of $10 \mathrm{~mm}$., or $1 \mathrm{~cm}$., between the two ears) they must be capable of detecting differences in time of only 0.000003 sec.the time required for sound to travel $1 \mathrm{~cm}$. in air. This time factor may be shown by the following analysis: sound travels in air at the rate of $330 \mathrm{~m}$. per sec., or $0.33^{\circ} \mathrm{m}$. (330 $\mathrm{cm}$.) in $0.001 \mathrm{sec}$, $0.0003 \mathrm{~m}$. (0.3 cm.) in $0.000001 \mathrm{sec}$, and $1 \mathrm{~cm}$. in $0.000003 \mathrm{sec}$. Some years ago, while we were studying the lateralizing and differentiating functions of the ears, one of my associates (Dr. A. M. Bassett) and I were paying the usual tribute to a Middle Western city between trains at a moving-picture theater. During the interlude a trumpeter with three trumpets of different keys appeared on the stage. The trumpets were arranged as shown in figure 3 . We were sitting in the balcony approximately $30 \mathrm{~m}$. from the trumpeter. When the trumpets were blown separately or in unison, we could differentiate accurately the sound produced by each instrument. Anyone with normal hearing can readily lateralize the sounds produced by instruments in an orchestra or a band or by voices of certain pitch or quality in a chorus. Furthermore, sounds such as voices may be differentiated and located accurately, for instance around the dinnes table, at a tea or at a cocktail party. The organ of Corti is remarkably selective 
in detecting differences in quality of sounds and in lateralizing them through differences in timing, intensity, and other less important factors. When the hearing in one ear is defective, the ability to lateralize extraneous sounds may not be lost entirely if any sounds can be heard by the affected ear, since the ability to detect differences in timing may be retained.

The stethoscope first described by Laennec in 1819 still is used by many European physicians. It consisted of a hollow wooden tube for mediate auscultation. It was interposed between the ear of the physician and the body of the

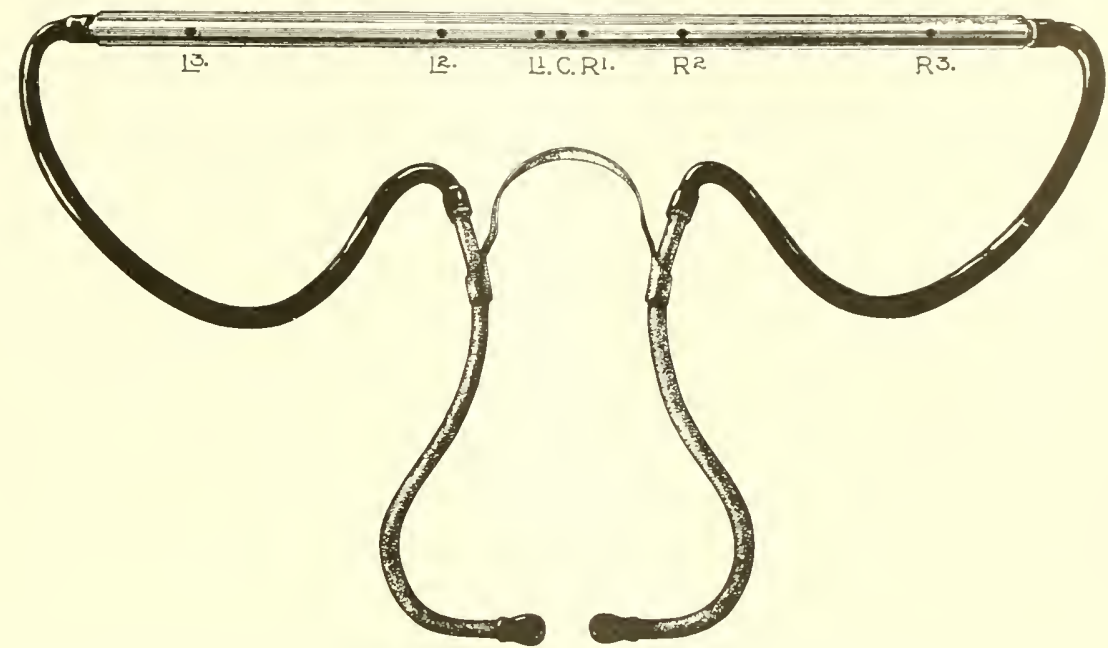

Fig. 2. A simple device to demonstrate the remarkably sensitive capacity of the ears to detect differences of time of 0.000003 (one three-millionth) sec. consists of a rigid hollow tube connected by rubber tubing of equal length and bore with the familiar headset of a stethoscope. Apertures are made in the hollow tube at the central point $\mathrm{C}$ and at points $\mathrm{R}^{1}$ and $\mathrm{L}^{1}$ $5 \mathrm{~mm}$. to the right and to the left of the central aperture. Other apertures may be made at any points $\mathrm{R}^{2}$ and $\mathrm{L}^{2}$ and $\mathrm{R}^{3}$ and $\mathrm{L}^{3}$ to the right and left of the central aperture. To test the lateralizing sensitivity of the two ears through function of timing, sounds are made directly over one of the apertures. When the normal subject listens while sounds are produced over the central aperture, he hears the sounds simultaneously in both ears; hence there is no lateralizing effect. When sounds are produced over apertures $\mathrm{R}^{1}$ or $\mathrm{L}^{\mathrm{T}}$ they will appear to arise at points to the right or left of the midline. Since these points are only $5 \mathrm{~mm}$. remored from the center and the difference in distance to the two ears is $10 \mathrm{~mm}$. or $1 \mathrm{~cm}$., it is demonstrated that differences of $0.000003 \mathrm{sec}$. can be detected. If sound waves in air travel at the rate of $330 \mathrm{~m}$. ( $1,080 \mathrm{ft}$.) per sec., thes would travel $1 \mathrm{~cm}$. in $0.000003 \mathrm{sec}$. Sounds that enter the device at points $R^{2}$ and $L^{2}$ and $R^{3}$ and $L^{3}$ appear to arise at points progressively more remote from the midline. The greatest differences in distance from the point of origin of sound to the two ears necessary to give complete lateralization would be about 15 to $18 \mathrm{~cm}$., or onefourth the circumference of the head.

patient, and enhanced the accuracy of observations of sounds produced in the body, notably in the lungs and heart. Incidentally it protected as well the sensibilities of both the patient and the physician. Williams, in 1829, developed the binaural stethoscope fitted with two earpieces and with two semirigid tubes joined to a device for application to the body of the patient. This 
instrument was improved by Camman in 1855 and by Alison and many others in subsequent years. In use the original Lacnnec stethoscope was clumsy and the sounds heard through it appeared to arise directly in the ear. The binaural stethoscope constructed with connecting tubes of equal length and bore projected the sound by illusion to a point directly in front of the physician. He instinctively turned his head toward the point to which the chest piece had been applied in order to ascertain the location of certain sounds. In making studies

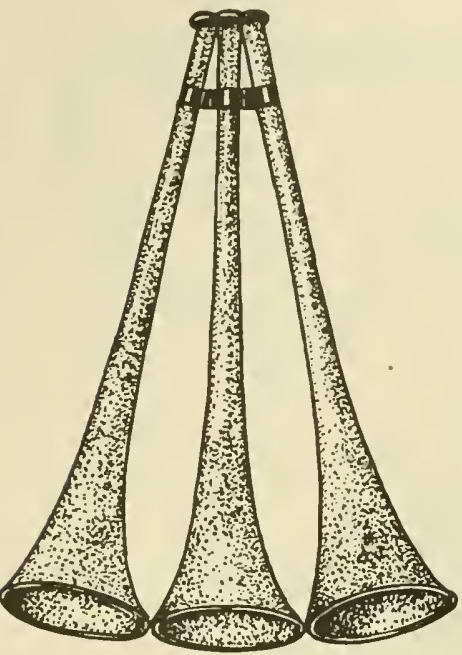

Fig. 3. Arrangement of the three trumpets described in the text. of homologous areas on the surface of the body, he had to move the chest piece between the two points to be compared. He could compare the qualities of different sounds but he could not perceive the finer variations. By this auscultatory method differences in timing of events in two areas that produced sound could not be detected, although when it was combined with palpation the movements of the thoracic cage and the events in the cardiac cycle could be correlated in some measure with the auditory evidence of motion at nearby or remote points.

During the century since the invention of the stethoscope, many improvements have been made in the chest pieces. Multiple stethoscopes have been devised that permit several auditors to listen simultaneously to a given sound. Audio-amplification has been adapted for use in large halls or by special wiring of individual receivers attached to the ordinary binaural stethoscope. A system of electrical filters has been introduced to permit study of the bands of frequency of sounds produced in the body. In recent years several types of double stethoscopes have been described. Muralt ${ }^{1}$ in 1910 devised a stethoscope which permitted the physician to listen simultaneously to two areas over the lungs. This double stethoscope consisted of two chest pieces or acoustic bells each of which could be connected to one ear by a rubber tube. It is apparent from his illustrations that the length of the crossed tubes to the opposite ears was equal to that of the tubes passing directly from a chest piece to the ear on the same side. Sounds originating in either chest piece reached both ears simultancously. More recently Fröschels ${ }^{2}$ suggested the use of a "differential stethoscope," which is essentially a pair of chest pieces connected to the ears by an X- (or four-way) connection to permit either an ipsolateral or a contralateral course of the sound to each ear. This instrument was devised to study the sounds produced in the vocal cords during phonation in cases of paralysis of the laryngeal nerves. Nicolai ${ }^{3}$ devised a "stereostethoscope" to observe differences in sounds originating in the two tempero-mandibular joints, and suggested its use in 
other fields of clinical medicine. This instrument consisted of two chest pieces connected by two separate rubber tubes to their respective earpieces. Hantschmann and Nicolai ${ }^{4}$ reported that this instrument was of value in the study of cardiac and pulmonary disease. In 1935 Hawthorne $^{5}$ described a differential (double) stethoscope similar to that devised by Nicolai. Alison ${ }^{6}$ had described this type of instrument in $185^{8}$ and had given a report on its use in 1859 .

My personal interest in the possible value of a comparing stethoscope was aroused in 1936 when before a meeting of the journal club of the Division of Medicine one of my colleagues, Dr. T. L. Althausen, gave a report on Nicolai's paper. ${ }^{3}$ During the discussion I pointed out that, in nature, sounds which are lateralized or compared are heard in both ears and that differences in timing and intensity are factors which aid in locating and comparing sounds. In Nicolai's instrument the sounds to be compared could not be heard in both ears under the conditions existing in nature. During the afternoon following this discussion, rubber tubing, four Ypieces, two similar chest pieces, and a headset from an ordinary binaural stethoscope were assembled into a clumsy but working model of the symballophone. The crossed tubes passing from the two chest pieces to the contralateral ears were made longer than the direct tubes, that is, those passing
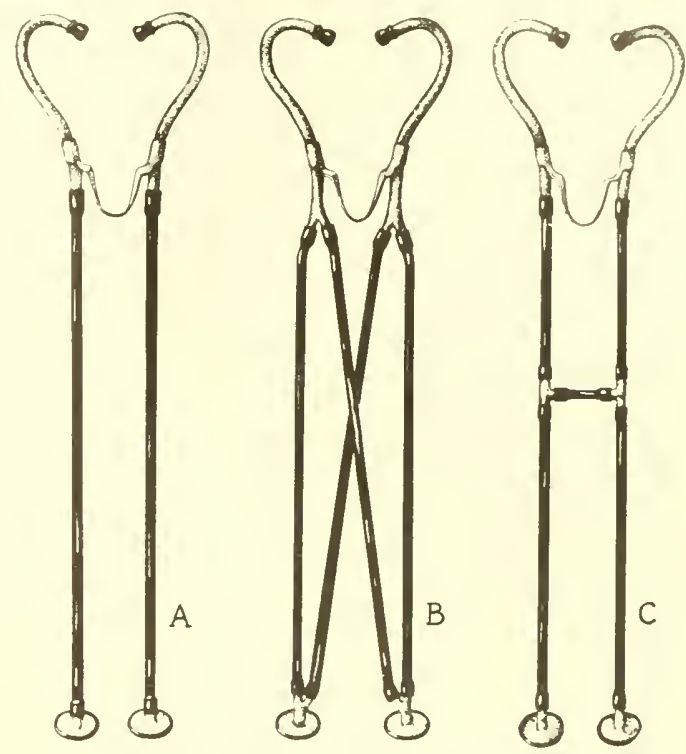

Fig. 4. (A) Nicolai's comparing stethoscope. (B) The original symballophone showing the arrangement of tubing. The diagonal tubes are longer than the lateral tubes, and the bore of the crossed tubes is reduced. The sounds to be compared are heard in both ears as would be the case with sounds heard in nature. (C) A possible variation of (B) but impractical because the connections would permit sound waves to pass freely in either direction from the transverse connecting tube.

from the chest pieces to the ipsolateral ears. Subsequently the bore of the crossed tubes was reduced (fig. 4). This crude working model was capable of giving information not readily obtainable by the binaural stethoscope. Homologous areas in the two lungs could be compared by a method that employed the normal functions of the ears for comparing sounds. Sounds produced in the circulatory system by contraction of the heart and by the movements of the pulse wave could be readily compared. In disease, murmurs propagated on the pulse wave beyond the heart were heard as sounds in motion, in contrast to the isolated sounds heard with the binaural stetho- 
scope. While clinical observations were being made, experimental studies were begun to determine the most effective device for enhancing the illusion produced by the use of tubes of varying length and bore.

Through the coöperation of Professor C. W. Brown of the Department of Psychology, University of California, the studies which will be described were made. By means of a gravity-pressure system, water was caused to flow through rubber tubing arranged in such a way that the flow could be impeded by metal

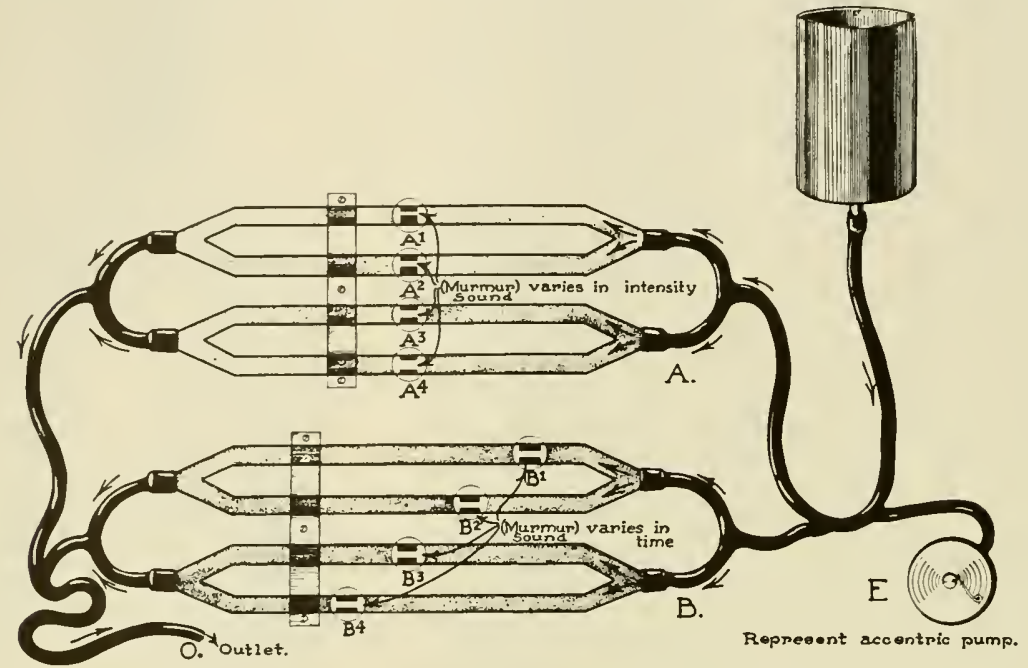

Fig. 5.-A device for the study of the capacity of the two ears to detect differences in intensity and timing of sounds with the symballophone. Water under hydrostatic pressure was allowed to flow through the system of tubing at A or $\mathbf{B}$. An eccentric pump E gave an impetus to the current to represent the pulse wave and to accentuate the sounds produced by fauls in streamlining at points $A,{ }^{1,2,3,4}$ and $B .^{1,2,3,4}$ Metal cylinders of different bore were placed in the rubber tubing at points $A^{1,2,3,4}$ equidistant from the point of inflow, and metal cylinders of equal bore were placed at points $B^{1,2,3,4}$ at varying distances from the point of inflow. For comparison of sounds the two chest pieces of the symballophone were placed over the two obstructions where sounds were to be compared. In this manner differences in intensity of sound were studied over $A^{1,2,3,4}$ and differences of timing over $\mathrm{B}^{1,2,3,4}$

cylinders with bores (1) of varying diameters or (2) of equal diameter but so placed that they were at unequal distances from the point of inflow. The vibrations caused by the water passing through these narrowed apertures, which could be heard as sounds (murmurs), were studied with the aid of the symballophone. An eccentric pump was inserted in the pressure system above the obstructions to simulate the pulse wave and to enhance the sounds (murmurs). Figure 5 shows the details of the arrangement.*

Soon it was apparent that the ears are so sensitive that extremely small differences in intensity or time could be readily detected by untrained persons

* Throughout this study I had the assistance of two able senior medical students, A. M. Bassett and M. J. Goldman, to whom I am greatly indebted. 
as well as by those experienced in the use of the symballoplone. I)iflerences of 1 per cent in the flow through any two obstructing cylinders conld be differentiated by observing differences in intensity of the sounds produced. It was almost impossible to arrange obstructions of equal bore, so that the smallest differences in time could not be noted. However, by varying the bore and length of the crossed sections of tubing, the differences in length and bore which gave the most satisfactory results were obtained. When the crossed tubes were approximately $15 \mathrm{~cm}$. longer than the direct tubes, the optimal difference in timing to the two ears was secured. When the crossed tubes had an internal diameter approximately threefourths that of the direct tubes, the differences in intensity of the sound which reached the two ears could be made to supplement the illusion of lateralization.

A number of models with exchangeable mctallic parts of varying length and bore were constructed. By practical experience in normal and abnormal subjects. it was found that the length and bore of the tubes previously described were the most satisfactory. The final model ${ }^{\circ}$ (fig. 6) differed from model $\mathrm{B}$ shown in figure + in that the crossed and direct tubes were made of rigid metal tubing to insure permanency of

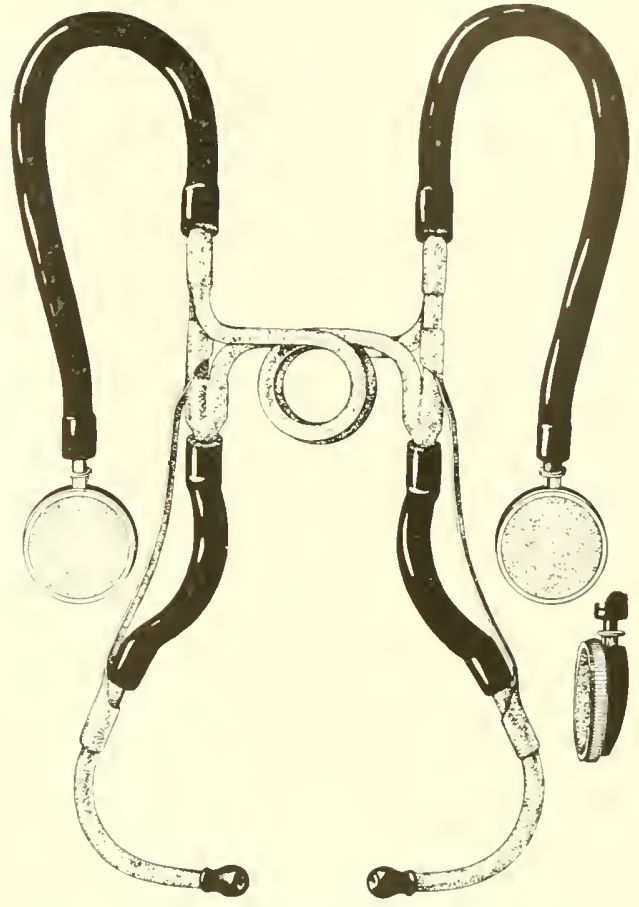

Fig. 6. The smballophone as finalls constructed after experimental and clinical studies.

the essential functioning parts. The tubes from the chest pieces to the central unit were made of rubber tubing of equal length and bore to permit flexibility in use. Rubber tubes of equal length and bore were inserted to connect the central unit to the earpieces. Strong lateral steel-band springs were fixed to exert equal pressure on the earpieces in the extemal auditory canals.*

\section{Clinical Observations}

Lungs. In examining the sounds produced in the lungs during respiration (auscultation), the physician who uses the ordinary binaural stethoscope usually moves the chest piece from one point to another in order to compare

* The symballophone has been patented, and in order to protect it from exploitation, the rights under patent No. 2,209.164 have been assigned to the Regents of the University of Califormia. The instrument is made and sold at of near cost with the moderstanding that any profit which may accme from its mannfacture and sale will be used for medical research. 
homologous areas for differences in cluration, pitch and intensity of sound and to discover and localize abnormal sounds. By this method he is unable to detect a lag or delay in motion on one side or in one area although the palpatory method may be used to detect gross changes in timing. In comparing the qualities of the sounds in different areas, he must remember the sounds heard at one area while he is listening over another. By use of the symballo-
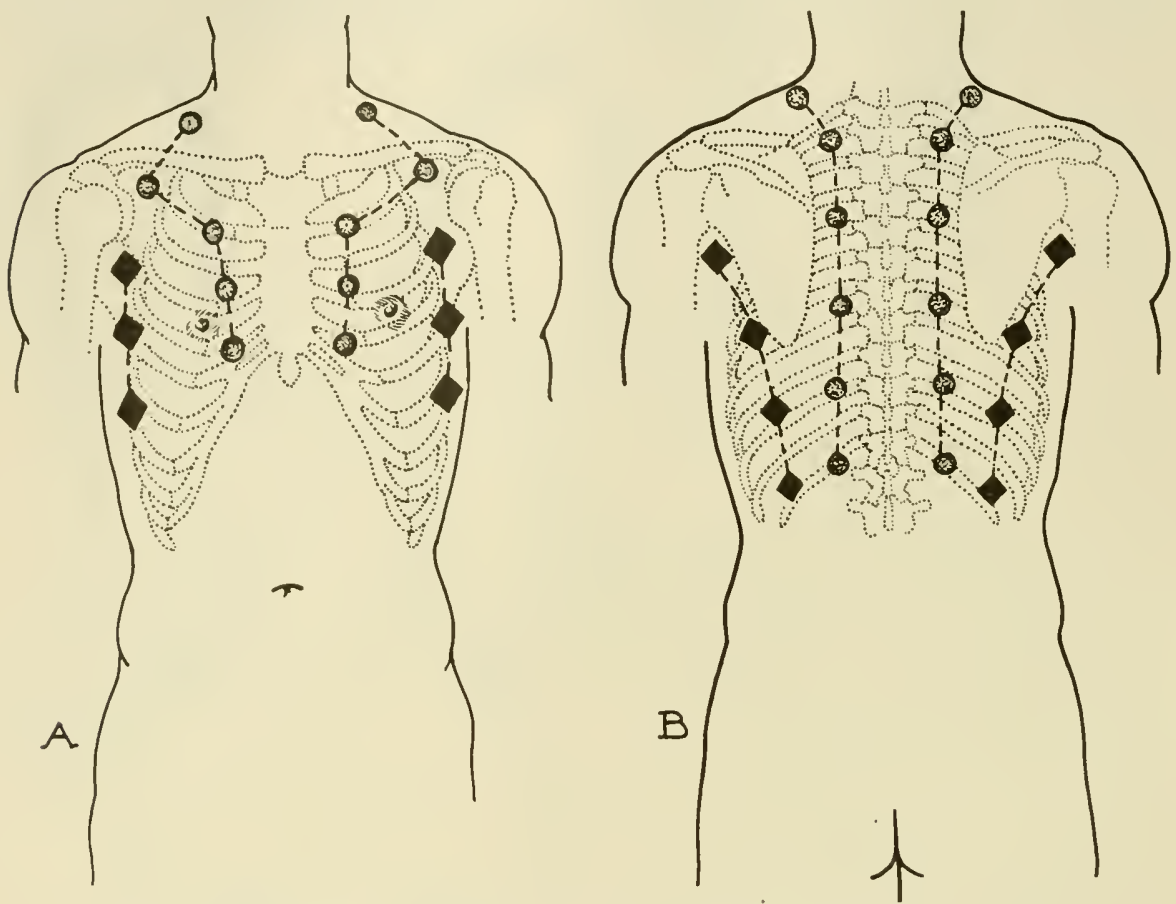

Fig. 7. Points on the chest at which the two chest pieces of the symballoplone may be applied to compare homologous areas. In this manner the respiratory sounds may be compared more accurately on the two sides of the chest. The examination may be completed in approximately one-third the time required when the ordinary stethoscope is employed. Two areas over either lung may be similarly compared. $A$, ventral view; $B$, dorsal view of chest.

phone (fig. 6) two areas may be compared simultaneously. The auscultatory signs in the chest may be examined more quickly and accurately than by the use of the ordinary stethoscope. As shown in the diagram (fig. 7), homologous points may be explored uniformly. Differences in timing of the respiratory movements and differences in pitch and intensity can be readily noted. Localization of abnormal sounds (ronchi, rales) can be determined through lateralization. Sounds of different quality may be differentiated in the two areas under observation. The physician with some training may observe a number of differences in respiratory sounds during a single complete respiratory cycle.

It is well known that the respiratory sounds over the right apex of the lung dorsally are harsh, but it is not so well known that the sounds over the left apex ventrally are harsher. These differences probably are due to the relative 
differences in volume of the pulmonary tissue through which air is moving on the two sides, which are determined by the position of the aorta. The ascending aorta encroaches on the right lung ventrad and the descending aorta on the left lung dorsad.

By the use of the symballophone, areas of consolidation, collections of fluid or air, and other clinical conditions can be localized more accurately than by any other auscultatory method. Medical students and physicians alike have little difficulty in locating areas of abnormality in the chest because the device makes use of the normal functions of the ears for the comparison and lateralization of sound. The physician need not understand the details of construction.* He becomes concerned with the explanation of the causes for the differences he observes in the areas of the chest. However, he must give some thought to the functions of the membranes and the airways of the lungs in which the sounds are produced if he is to interpret the significance of the abnormal sounds he hears.

Heart and Blood Vessels. In early life the closure of the semilunar valves is accompanied by a sound which is of greater intensity or louder in the second left than in the right intercostal space equidistant from and adjacent to the costal margin. During and beyond middle life the intensity of the sounds over these two areas is reversed. In the first instance we say that the pulmonary closure (second) sound exceeds or is greater than the aortic closure (second) sound, and in the second instance, that the aortic closure (second) sound exceeds or is greater than the pulmonary closure (second) sound. Many physicians carelessly place the single chest piece of a binaural stethoscope over the right and left second or third intercostal spaces and merely record the relative intensity of the second sounds. With the symballophone the classical differences in the second intercostal space can be readily demonstrated. In the third intercostal spaces the second sounds over the pulmonary valve are almost always louder than over the aortic valve even when aortic hypertension exists. A great increase in the pulmonary second sound is observed in patients who have the clinical condition known as cor pulmonale.

The second or closure sounds of the semilunar valves can readily be compared in intensity with the first or systolic sound heard at the apex which accompanies contraction of the ventricles. In myocardial failure this systolic sound at the apex frequently is diminished in intensity although it may be heard faintly in other conditions such as pumonary emphysema, pleural effusion, pneumothorax, or pericardial disease with an accumulation of fluid or air in the pericardium.

Murmurs that arise in connection with defects in the valves travel with the pulse wave. Diastolic murmurs are not propagated beyond the heart since they are associated with the flow of blood into the cardiac chambers. Systolic murmurs that arise in the heart, however, are of two types and may be de-

\footnotetext{
* An analogous situation exists when a person with normal stereoscopic vision uses Oliver Wendell Holmes's stereoscope. He perceives a sensation of depth without being required to know how the derice is constutucted.
} 
scribed as (1) those which are propagated on the pulse wave and leave the leatrt through the aortic or pulmonary valve, and (2) those which are propagated through the tricuspid or mitral valve into the auricles. The former travel widely on the pulse wave along the course of the aorta or pulmonary artery and frequently are accompanied by a palpable thrill because of the proximity of these vessels to the surface of the chest. Those propagated along the pulmonary artery are not transmitted widely, in no case beyond the chest. Systolic murmurs associated with backflow through the tricuspid valve are heard over the lower portion of the sternum which is nearest to the right auricle. The systolic murmur of mitral insufficiency is heard best at the apex

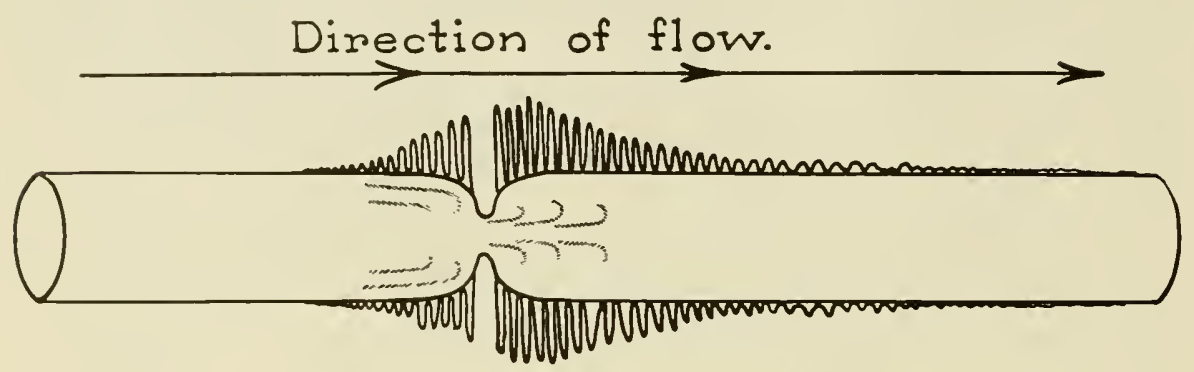

Murmurs Produced by Faults in Streamlining,

Murmurs travel both ways from point of constriction, but for a greater distance in the direction the liquid is flowing.

Fig. 8. A simple elastic tube such as a garden hose through which liquid is flowing may be used to illustrate the effects of compression that cause faults in streamlining. Obstructions in the hearl at the orifices of the valves, or variations in the size of the lumina of vessels, cause fauls in streamlining which produce vibrations that may be heard as murmurs.

and is transmitted toward the left axilla and left subscapular region which is nearest to the left ventricle and auricle. The intense systolic pressure in the left ventricle drives the blood backward through the aperture in the defective mitral valve with such force that the sounds produced are louder and more widely propagated. The proximity of the contracted left ventricular muscle in systole to the wall of the chest permits more direct propagation of the vibrations which produce the murnur. The vibrations travel in both directions from the point of origin but for a greater distance in the direction of the blood flow, as will be described.

If a simple compressible elastic tube, for example, a garden hose, through which liquid is flowing (figs. 8 and 9 ) is compressed, vibrations are produced in the walls of the tube and eddies form in the liquid. If the tube is palpated in front of and beyond the point of constriction, the vibrations are felt as thrills. With the stethoscope, sounds are heard which may be designated as murmurs. These sounds may be heard for some distance in both directions from the point of compression but always for a greater distance in the direction of the flow of the liquid. Let us now apply these observations to the heart and blood vessels. Two good clinical examples of this kind are aortic stenosis and pulmonary stenosis in which the diseased valves provide the partial obstructions, 
and the ventricles, aorta, and puhmonary artery provide the channel through which the blood is flowing during systole. The pulse wave travels through the aorta at the rate of about $15 \mathrm{~m}$. per sec. If the carotid ressels or the aorta are palpated in the neck or through the chest over the upper sternum, a systolic thrill appears on the crest of the pulse wave. If one chest piece of the symballophone is applied over the aortic area (second right intercostal space near the sternum) and the other above the course of the carotid artery or even

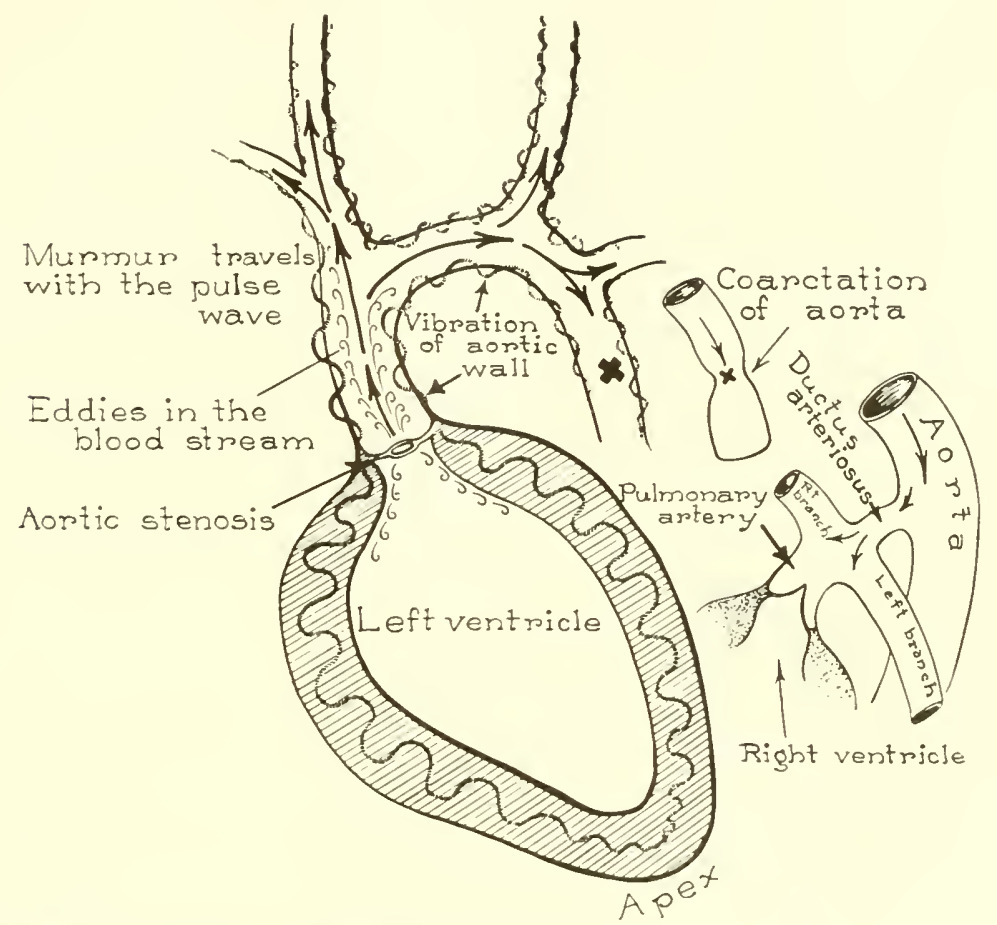

Fin. 9. I he transmission of the "rtolic nummur forward in the direction of the blood flow from the stenosed aortic valve and backward along the walls of the left ventricle is shown diagrammatically. At the point $\mathrm{X}$ in the descending aorta two types of congenital lesion are encountered. In each instance the timing of events depends upon the arrival of the pulse wave at this point between $1 / 20$ and 1,10 sec. following the first or srstolic sound at the apex. In coarctation of the aorta a systolic murmur is heard over the left upper chest dorsad, and in patent ductus arteriosus (Botalli) the svstolic accentuation of a continuous murmur is heard orer the pulmonary artery rentrad, chiefly to the left of the sternum and below the clavicle in the second and third intercostal spaces.

over the sternum at a point cephelad to the other chest piece, the systolic murmur heard appears first at the point nearer the aortic valve and later at the more distant point. After a simple auditory demonstration of the sensory effect of blowing across the two chest pieces, the natural perception of a sound in motion can quickly be recognized. The sounds heard appear to be "alive" in contrast to the rushing noise heard with the ordinary stethoscope. The systolic murmur over the carotid arteries appears about $0.0_{5}$ sec. after the first sound 
at the apex which accompanics the systolic contraction of the ventricles. Differences in time of this magnitude are readily determined by the use of the symballophone in which the crossed tubes are $15 \mathrm{~cm}$. longer than the direct tubes, since with it differences in time of only $0.000003 \mathrm{sec}$. can be detected. Furthermore, patients with aortic stenosis may present a systolic murmur at the apex as well as at the base of the heart. With the symballophone it may be demonstrated that the murmur appears at the apex after it has been heard at the base. Apparently this murmur is propagated along the muscle of the left ventricle when it is in a contracted state. With the ordinary stethoscope this systolic murmur sometimes is diagnosed as a midsystolic murmur. If the aortic valve is calcified and the murmur is very loud, the demonstration is easy even for the novice. See figure 9 .

In patients with lesions of the pulmonary valve, congenital or acquired, conditions similar to those described for the aortic valve exist. The systolic murmur is not widely propagated; it is heard best in the region of the pulmonary valve moving outward and upward toward the left clavicle; it is heard faintly in the second right intercostal space adjacent to the sternum where the right pulmonary artery passes behind the ascending aorta. This murmur is not propagated beyond the larger branches of the pulmonary artery. In patients who have had long-standing pulmonary stenosis, the systolic murmur is prolonged, probably because the thin-walled pulmonary artery beyond the obstruction is widely dilated. The time of maximum intensity appears to be during or soon after the first or systolic cardiac sound.

Two and possibly three types of congenital heart disease lend themselves to analysis by means of the symballophone (fig. 9). In patent ductus arteriosus (Botalli) the murmur which usually is present is heard best in the region of the puImonary artery beneath the left clavicle. Frequently it is a loud continuous murmur with a churning or rushing sound in the systolic phase. If one chest piece of the symballophone is applied over the apex of the heart and the other over the pulmonary artery, it will be readily noted that the time of the systolic accentuation of the murmur is much later than the time of the first apical sound. This observation indicates that the pulse wave has traveled over a prolonged route which in this case is via the aorta to the ductus and thence to the pulmonary artery. In my experience these conditions have been met in no other clinical state. Recently, in a patient with a patent ductus arteriosus (Botalli) the character of the murmur changed after the ductus was tied off. The delay noted in the time of appearance of the systolic murmur over the pulmonary artery could be explained by the great dilatation of this thin-walled vessel after many years of strain from increased arterial pressure transmitted from the aorta through the ductus arteriosus (Botalli). Theoretically, in a patient with patent interventricular septum the pulmonary artery may become similarly dilated and thus cause a systolic murmur from relative pulmonary stenosis through dilatation of the pulmonary artery after longcontinued hypertension in the lesser circulation. 
In coarctation of the aorta a systolic murmur frequently is heard over the upper thoracic spine and betreen this area and the left scapula. If one chest piece of the symballophone is placed over the apex and the other over the area in which the murmur is heard, it will be readily noted that the murmur appears appreciably later than the first or systolic sound at the apex. The reasons are that the area of coarctation usually is found in the descending limb of the thoracic aorta and that the pulse wave arrives in the aorta at that point about $0.0_{5}$ sec. after the systolic contraction of the heart. Arteriovenous aneurysms in the orbit, cranium, and extremities lend themselves to more accurate study with the symballophone than with the ordinary stethoscopes. Blood-

Foetal heart rate: 160 per minute, 16 beats per 6 seconds.

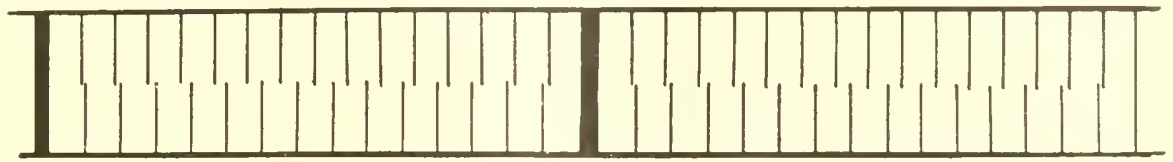

Foetal heart uate: 150 per minute, 15 beats per 6 seconds.

Fig. 10. Schematic representation of the auditory effects produced by two rhythmic sounds of different rates as heard over the symballophone. When the rates are almost identical they may be easily differentiated by the cyclic returu of synchronous and asynchronous phases. Foetal heart sounds in twin pregnancy in which the heart of each foetus has its own cardiac rate may be taken as a clinical example. The foetal and maternal cardiac rates may be similarly compared.

pressure measurements by the auscultatory method may be made by applying either chest piece of the symballophone over the artery distal to the point of compression.

With the symballophone foetal heart sounds may be compared with maternal heart sounds. Such observations are of importance when the maternal cardiac rate is high and the question of a viable foetus arises. Differences of a single heartbeat per minute may be readily detected. Twin pregnancies may be diagnosed if the two chest pieces are placed over the areas in which distmct foetal sounds are heard. As the physician listens to the sounds, he will observe that at times the two sounds are asynchronous, then they gradually approach each other and finally they coincide. Thereafter they gradually move apart and again approach each other in the next cycle, as shown in figure 10. Unless this pattern of sound is kept in mind, the obstetrician will not be able to make an accurate comparison when there is little difference in the foetal heart rates.

Vocal Cords. Vibrations of the vocal cords produce a variety of sounds through variations in length and in tension of the membranes. If one of the paired cords is diseased or contracts imperfectly because of weakness of the controlling muscles, abnormal vocal sounds are produced. In clinical medicine it frequently is important to know whether hoarseness is due to local disease or to paralysis of the muscles of phonation. If the physician stands directly behind the patient and applies the chest pieces of the symballophone 


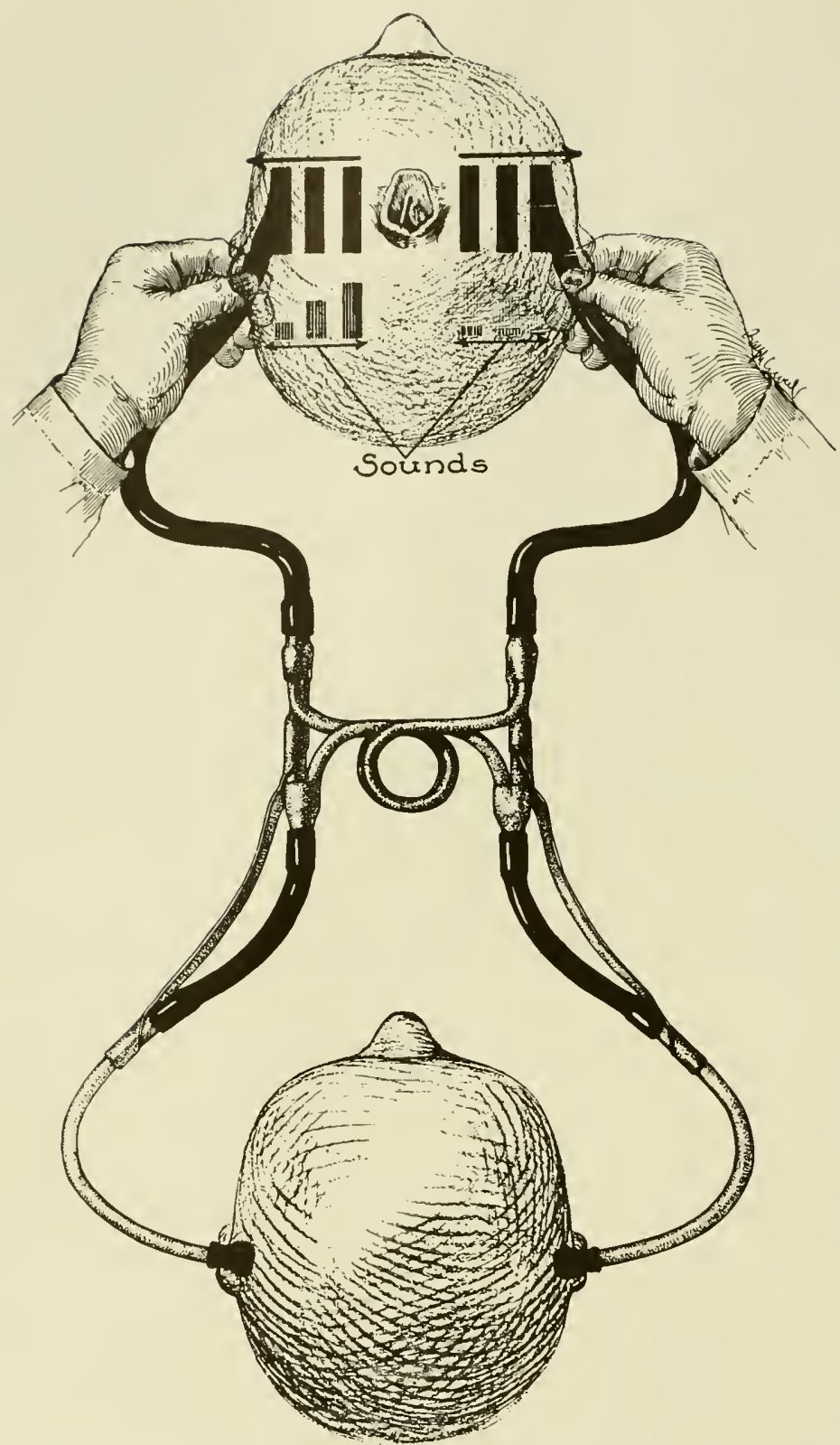

Fig. 11. Position of the examiner while the sounds produced by the vocal cords are being compared. The drawing illustrates the method of placing the two chest pieces equidistant from the larynx. The right vocal cord in this example is paralyzed and does not vibrate normally. The normal (left) cord produces a more intense sound than the defective (right) cord and the sound is lateralized to the normal (left) side. The examiner places himself in a similar position directly behind the patient when he examines the antra. The louder sounds are lateralized to the normal or unaffected side. 
evenly to the sides of the larynx and at other points equidistant from the larynx, as shown in figure 11 , the paralyzed rocal cord can be readily determined. The sounds are of greater intensity on the side on which the vocal cord is intact while the paralyzed cord is incapable of producing a normal sound. The sound used for the determination is repetition of a high-pitchec tone and may be produced by having the subject pronounce the long letters $\mathrm{E}$ or $\mathrm{A}$. In a large number of patients who had paralysis of one vocal cord due to goiter with associated injury of the laryngeal nerves or due to aneurysm of the aorta with associated injury of the left recurrent laryngeal nerve, we have been able to discover the site of the paralysis. In some of these patients direct laryngeal examination of the rocal cords had given doubtful evidence of the paralysis.

Antrum of Highmore. If one antrum of Highmore is filled with fluid, the nasal tones do not reverberate over it as well as they do over the unaffected sinus. The symballophone is useful in detecting this abnormal state. The physician stands directly behind the patient and while he applies the chest pieces evenly over the antra the patient repeats "ninety-nine," "nine unknown men," or some other combination of nasal tones. The louder sound is lateralized to the side of the normal antrum.

Malingerers of Hearing may be discovered by use of the symballophone. In this instance the earpieces are inserted in the patient's ears. After he has been blindfolded, sounds are made by the physician over either chest piece. If the hearing in one ear is very defective, the sounds that arise in either chest piece are referred to the ear with normal hearing. By alternately clamping the rubber tubing in the headset of the instrument, sounds may be deflected to either ear. Thus it is impossible for the malingerer to escape detection.

Joints and Muscles. By means of the symballophone, sounds in paired joints in motion may be compared. This method is particularly useful in the study of the tempero-mandibular joint. Uneven mastication may result in injury to one joint. Faulty or uneven movements and abnormal sounds may be noted and lateralized. Differences in the time when events occur in the joint can be readily determined. In studying paired muscles with the symballophone, the impaired sound may be detected on the affected side by comparing the purring sounds produced when the muscles are stretched or contracted. This observation may be important when slight differences occur in the muscles of the two sides of the body, as in minor degrees of paralysis or in residual weakness on one side following hemiplegia or monoplegia which is too slight to be detected by ordinary means.

Stomach and Intestine. Peristaltic sounds in the stomach and large bowel may be studied by the use of the symballophone. It may be important to determine whether peristaltic sounds in the epigastrium are moving from left to right or from right to left. The former would suggest that the sounds arose in the stomach; the latter, that they arose in the transverse colon.

The symballophone is of no value to persons whose hearing is defective in 
one ear. Among medical students, about 10 per cent have auditory defects which preclude any practical use of the symballophone. To some of them the binaural stethoscope is of no more value than the original monaural stethoscope would be. Older physicians whose auditory functions are failing do not derive additional information from the use of the symballophone.

\section{SUMMARY}

The symballophone, an improved double stethoscope for lateralization and comparison of sounds, has been described. A brief historical sketch has been given of the evolution of the stethoscope, and previous types of lateralizing stethoscopes have been mentioned. The psychological and clinical studies which led to the perfection of the symballophone have been discussed. The application of the symballophone to medical practice has advanced our interest in the art of auscultation and our knowledge of the fundamental principles involved in the moving structures in which sounds are produced. The symballophone should replace the ordinary binaural stethoscope for all clinical purposes.

\section{REFERENCES}

1. Muralt, L. V.: Btrge. z. Klin. d. Tuberk. 16:121, 1910.

2. Fröschels, E.: Med. Klin. 30:1099, 1934.

3. Nicolai, L.: Klin. Wchnschr. 15:91, 1936.

4. Hantschmann, L., and Nicolai, L.: Klin Wchnschr. 15:92, 1936.

5. Hawthorne, C. O.: Irish Jl. Med. Sci. (7[i.e., 6]) 1935:49.

6. Alison, S. S.: Med. Times \& Gaz. (n.s.) 19:7, 28, 1859 .

7. Kerr, W. J.; Althausen, T. L.; Bassett, A. M., and Goldman, M. J.: Amer. Heart Jl. $14: 594$, 1937.

8. Kerr, W. J.; Althausen, T. L.; Bassett, A. M., and Goldman, M. J.: Trns. Assn. Amer-Physns. $52: 92,1937$.

9. Kerr, W. J.: West. Jl. Surg., Obstet. \&. Gynecol. 49:632, 1941. 
ON THE SIGNIFICANCE OF THE FORGOTTEN THERMODYNAMIC

THEOREMS OF CARNOT

By

F. O. KOENIG

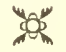

From the

DEPARTMENT OF CHEMISTRY

STANFORD UNIVERSITY, CALIFORNIA 



\title{
ON THE SIGNIFICANGE OF THE FORGOTTEN THERMODYNAMIG THEOREMS OF CARNOT
}

\author{
I. INTRODUCTION
}

$\mathrm{E}^{\mathrm{N}}$ Xamination of the famous memoir by Nicolas-Léonard-Sadi Carnot ( 796 1892) entitled Réflexions sur la Puissance Motrice du Feu et sur lés Machines propres à Dézelopper celle Puissance (A Paris, che Bachelier, libraire. Quai des Augustins, No. 55, 189.4 * shows that this work, although in the form of a single chapter without subheadings, falls naturally into three distinct parts.

In the first part $(C a \mathrm{pp} .1-38,4 a \mathrm{pp} .3-21)$ Carnot describes the cycle and demonstrates the theorem which have both come to bear his name. As is well known, Carnot's demonstration consists of a logically correct argument from two premises, one of which is true and the other false: the true premise is the impossibility of perpetual motion, and the false one the caloric theory of heat. according to which heat is a weightless indestructible substance. Carnot theorem is thus an outstinding example of a physically true statement which is rigorously deducible from premises which are at least partly false.

In the second part (Ca Pp. 39-88, Ma PP. 21-46) of the Réflexions, Carnot decluces seven further theorens relating mostly to the thermal behavior of gases, and illustrates these theorems to some extent by numerical data and calculations. It is these seren theorems that we here refer to as "the forgotten thermodrnamic theorems of Carnot." The arguments by which Carnot arrives at these theorems are again logically correct and again based upon two premises, one of which is true and the other false: the true premise here is Carnot's theorem and the false one again the caloric theory of heat. In the light of modern knowledge it is obvious that any theorem deduced in this way must belong to one of the following three classes: class $A$, theorems based on Cirrnot's theorem alone and therefore true; class B, true theorems based either on the caloric theory alone or on the caloric theory and Carnot's theorem simultaneously; class C, false theorems based either on the caloric theory alone or on the caloric theory and Carnot's theorem simultaneously. Class B would evidently furnish further examples of true statements rigorously deducilole from premises at least partly false.

In the third pait (Ca Pp. 89-118, Ma PP. 47-61) of his memoir Camot compares in the light of the two preceding parts the practical advantages of differ-

* The first edition of this work will here be referred to by the abberiation Ca. An English tramslation with a few notes by $W^{T}$. F. Magie is included, together with writings by Clamsius and by William Thomson, in volmme VI of "Harper's Scientific Mentois" (ed. by J. S. Ames: New York and London: 1899); this volume, which is entilled The Second Law of Thermodynamics, will here be referred to by the abbreviation Ma. An anmolated German translation of the Réflexions by Wilhelm Ostwald, containing further bibliographic information on Carnot, constitutes Nr. 37 of "Ostwald's Klassiker del kxaklen Wissenschafen" (Leiprig: 1892). 
ent types of working substances and points out how far the efficiency of steam engines actually in operation in his day falls short of the theoretical maximum.

Of these three parts of the Réflexions, the third is a contribution primarily to technology, while the first and second contain Carnot's contributions to science. Of these contributions to science, in turn, by far the most important are contained in the first part of the Réflexions: Carnot's cycle and Carnot's theorem on reversible engines are the ideas which in the minds of Clausius $\left(185^{\circ}\right)$ and of William Thomson (1851) gave birth to the second law of thermodynamics. It is moreover only this outstanding part of his achievement by virtue of which Carnot lives in the consciousness of scholars today; the existence of the second part of the Réflexions appears to have been completely forgotten.

Our object in this article is to show that Carnot's forgotten theorems deserve some attention both from historians of science and from scientists of the present.

\section{Critical Summary of the Forgotten Thermodynamig Theorems}

These theorems, quoted from $M a$ in the order of their enunciation and numbered by us in that order, are as follows:

1. When a gas passes without change of temperature from one definite volume and pressure to another, the quantity of caloric absorbed or emitted is always the same, irrespective of the nature of the gas chosen as the subject of the experiment.

2. [At a given pressure] the difference between the specific heat [referred to unit volume] under constant pressure and the specific heat at constant volume is the same for all gases.

3. When a gas changes in volume without change of temperature the quantities of heat which it absorbs or gives up are in arithmetical progression when the increments or reductions of volume are in geometrical progression.

4. When the volume of a gas increases in geometrical progression its specific heat [referred to unit weight] increases in arithmetical progression.

5 . [For a given gas at a given temperature] the difference between the specific heat under constant pressure and that at constant volume is always the same, whatever the density of the gas, provided the quantity of gas by weight remains the same.

6. The quantity of heat due to the change in volume of a gas [at constant temperature] becomes greater as its temperature is raised.

7. The descent of caloric produces more motive power at lower degrees of temperature than at higher.

Comments. (1) Gases are assumed throughout to obey the laws of Boyle and Gay-Lussac, that is, to be perfect. (2) All the proofs given in the text proper are of the synthetic quasi-Eucliclean type, but in a long footnote (beginning on $\mathrm{Ca}$ p. 73, $M a$ p. 39) Carnot gives alternative analytic proofs of theorems 
$1,3,4,7$. (3) Scrutiny of Carnot's proofs in the light of our present knowledge reveals the fact that the distribution of the theorems among the three necessary classes mentioned above is as follows:

Class A: theorems 1, 3 Class B: theorems 2, 5, 6,7 Class C: theorem 4. The proof of this distribution would of course require extensive quotation from the Réflexions and must be omitted here for lack of space.

\section{SIGNIFIGANGE FOR THE HIS IORY OF SCIENGE}

The forgotten theorems of Carnot are the first examples in thermodynamics of special results of physical interest obtained by deduction from general principles which are in turn derived from phenomena. It follows that Carnot is the founder not only of the second law of thermodynamics but also of thermodynamic deduction. In the former and fully recognized role Carnot is the first member of the trio which includes Clausius (1850) and William Thomson (1851); in the latter and at present unrecognized role he is the first member of a highly ramified hierarchy which culminates in Gibbs and among whose chief additional figures are: Clapeyron (1834), Helmholtz $\left(18_{47}, 1877 \mathrm{ff}\right.$.), William Thomson (1848 ff.), Clausius (1850), Kirchhoff (1858), Guldberg (1867 ff.), Massieu (1877), Boltzmann (1884), Van't Hoff (1884 ff.), Nernst (1888 ff.), Lewis $(1907,1923)$. That in brief is the significance of the forgotten theorems of Carnot for the history of science.

This view of Carnot's role in the history of thermodynamic deduction might be criticized on the grounds that a majority of the forgotten theorems, although correct, were deduced by Carnot from the erroneous caloric theory (class $\mathrm{B})$. The answer to this criticism is that the famous theorem on reversible engines was likewise so deduced by Carnot, and that therefore, as long as we regard Carnot as the founder of the second law of thermodynamics, we can hardly escape from regarding him also as the founder of thermodynamic deduction.

The implications of this duality become clearer in the light of some familiar facts concerning the structure of theoretical physics. Any of the major subdivisions of theoretical physics-for example, classical mechanics, relativity theory, statistical mechanics, thermodynamics, etc.-has two parts: the first consists of the erection of general principles through expeditions discussion of selected phenomena; the second, of the systematic deductive exploitation of these general principles. This is often expressed by the statement that in theoretical physics we have induction followed by deduction. Actually, however, the arguments leading to the general principles are more complex than mere induction in the strict sense: they seem to consist in general of expedicnt combinations of induction, deduction, and plausible assumption. Thus the argument leading to the second law of thermodynamics in the form $Q \leqq T d S$ contains all three of these elements, and in any system of statistical mechanics there is always at least one general principle, for instance, that of equal a priori probabilities, which is frankly an assumption. We therefore prefer 
to say that in the sciences making up theoretical physics we have construction followed by deduction. Turning now to consider the evolution of any of these sciences, we are not surprised to find that the early stages are given over largely to construction and that, as the science matures, deduction becomes increasingly important and eventually predominates. In some cases there has been reached a relatively final stage of high perfection, characterized by cxpositions from which constructive argument is entirely omitted and the general principles are treated solely as axioms sufficiently verified by their consequences; examples are the exposition of classical mechanics starting from Hamilton's principle and that of thermodynamics starting from the axioms of Carathéodory.* In such cases the constructive arguments have, however, not been banished completely, but have simply been relegated to the elementary textbooks.

Within this general evolutionary pattern the position of Carnot is now clear: he stands at the beginning of thermodynamics with a constructive contribution of the first magnitude, supplemented by a deductive achievement noteworthy for its prescience.

\section{Significance for Thermonynamics at Present}

Needless to say, of the forgotten theorems of Carnot the true ones-those belonging to classes $\mathrm{A}$ and $\mathrm{B}$-have not been forgotten in the sense that their content has become unfamiliar. What has been forgotten is the existence of knowledge deducible from Carnot's theorem on reversible engines without the help of the first law of thermodynamics. Carnot's theorems of class $\mathrm{A}$ are examples of such knowledge and therefore have a special significance which is permanent, though neglected by contemporary authors. In order fully to reveal this significance we shall give below a summary of the consequences deducible from Camnot's theorem without benefit of the first law.

The existence of such consequences was well known to the pioneers of thermodynamics, and most of the formulas in our summary can be found, more or less mingled with consequences of the caloric theory or of the first law of thermodynamics, in the writings of Clapeyron, Clausius, and above all William Thomson. We shall, however, be able to make only passing reference to the history of some of the individual formulas.

The neglect of results of the type here summarized has probably been due to haste to obtain the more inclusive results that follow from the first and second laws combined, or, in the case of perfect gases, from the first law alone. But the need for such haste is now long past and a time has arrived in which writers on thermodynamics might profit from an awareness of the consequences that follow from Carnot's theorem without the first law.

\footnotetext{
* See A. Landé: “Axiomatische Begründung der Thermodynamik durch Caralhéodory," in Handbuch der Physik, ed. by H. Geiger and K. Scheel, IX (Berlin: 1926), 28I.
} 
SUMMARY OF THF CONSHQUFNCFS OF CARNOT'S THFOREM AI.ONE

1. The Existence of Absolute Temperature. Let the different possible empirical temperature scales be numbered $1,2, \ldots, i, \ldots$ and let the values of a given temperature on these scales be denoted by $\theta_{1}, \theta_{2}, \ldots, \theta_{i}, \ldots$ respectively. Then Carnot's theorem can be expressed in the form

$$
\frac{W}{Q}=\Phi_{i}\left(\theta_{i}{ }^{\prime}, \theta_{i}{ }^{\prime \prime}\right)
$$

in which $W$ is the work of a Carnot cycle whose higher and lower temperatures are $\theta_{i}{ }^{\prime}$ and $\theta_{i}{ }^{\prime \prime}$ respectively, $Q$ is the heat absorbed at the higher temperature, and $\Phi_{i}$ denotes a function of $\theta_{i}{ }^{\prime}$ and $\theta_{i}{ }^{\prime \prime}$ which is inclependent of the working substance. Since $I^{\top} Q$ is independent of the selection of temperature scales, it is furthermore clear that the value of $\Phi_{i}$ for a given pair of temperatures is the same for all scales and that therefore the form $\Phi_{i}$ must vary from scale to scale, which is the reason for attaching the subscript $i$ to the $\Phi$. If we introduce the physically obvious assumption implicit in the work of Carnot and his successors, that as $\theta_{i}{ }^{\prime}-\theta_{i}{ }^{\prime \prime}$ approaches zero, $I T$ becomes an infunitesimal, $\delta \mathbf{l} \boldsymbol{l}^{\prime}$, of the same order as $\theta_{i}{ }^{\prime}-\theta_{i}{ }^{\prime \prime}$, eq. (1) yields, for a Camot cycle working over the infmitesimal temperature interval $d \theta_{i}$ which includes the temperature $\theta_{i}$

$$
\frac{\delta W}{Q}=\mu_{i}\left(\theta_{i}\right) d \theta_{i}
$$

in which the function $\mu_{i}\left(\theta_{i}\right)$, named Carnot's function by Thomson, is independent of the working substance. Furthermore, while both the form of $\mu_{i}$ and its value at a given temperature depend on the choice of the scale $i$, the value of the infinitesimal, $\mu_{i}\left(\theta_{i}\right) d \theta_{i}$, for a given temperature and a given infinitesimal temperature interval, is an invariant of all scales $i$. Hence the value of

$$
\int_{\theta_{i}{ }^{\prime \prime}}^{\theta_{i}{ }^{\prime}} \mu_{i}\left(\theta_{i}\right) d \theta_{i}=\varphi_{i}\left(\theta_{i}{ }^{\prime}\right)-\varphi_{i}\left(\theta_{i}{ }^{\prime \prime}\right)
$$

for a given temperature interval is also an invariant of all scales $i$. Now consider the functions $T=\Psi_{i}\left(\theta_{i}\right)$ defined by the differential equations

$$
M(T) d T=\mu_{i}\left(\theta_{i}\right) d \theta_{i}
$$

in which the form of $M$ is arbitrary but the same for all scales $i$. Integrattion gives

$$
F\left(T^{\prime}\right)-F\left(T^{\prime \prime}\right)=\varphi_{i}\left(\theta_{i}{ }^{\prime}\right)-\varphi_{i}\left(\theta_{i}{ }^{\prime \prime}\right)
$$

whence it appears that $F\left(T^{\prime}\right)-F\left(T^{\prime \prime}\right)$ is invariant under $i$ with respect both to its value for a given temperature interval and to the form of $F$. But the 
form of $F$ is arbitrary because the form of its derivative, $M$, is arbitrary. Hence the value of $T^{\prime}-T^{\prime \prime}$ is an invariant of all scales $i$. The functions $T=\Psi_{i}\left(\theta_{i}\right)$ thus have the properties required by an absolute temperature. Hence eq. (3) may be taken as a general definition of an infinity of absolute temperature scales depending on the choice of $M$. The scale universally used is defined by the choice $M=I / T$.

Thomson's original and unsatisfactory definition of absolute temperature (1848) was based upon Carnot's theorem and the caloric theory, while his later definition (1854), which continues to enjoy general use, follows only from the combination of Carnot's theorem with the first law. In the present paper the contribution of Carnot's theorem alone to the definition of absolute temperature is explicitly set forth for the first time to our knowledge.

It is very instructive to note-we must omit proof for lack of space-that Carnot's theorem alone yields no information as to the form of the function $\Phi_{i}\left(\theta_{i}{ }^{\prime}, \theta_{i}{ }^{\prime \prime}\right)$ in eq. (1), and that it is only with the help of the first law that we can prove this function to be of the form

$$
\Phi_{i}\left(\theta_{i}{ }^{\prime}, \theta_{i}{ }^{\prime \prime}\right)=\frac{e^{\varphi_{i}\left(\theta_{i}{ }^{\prime}\right)}-e^{\varphi_{i}\left(\theta_{i}{ }^{\prime \prime}\right)}}{e^{\varphi_{i}\left(\theta^{\prime} i\right)}}
$$

2. Formulas for Heat of Isothermal Change of State. Consider an infinitesimal Carnot cycle; let $d \theta_{i}$ denote the temperature interval and $d V$ and $d P$ the changes of volume and pressure respectively along the higher isothermal. Let the working substance be a single phase. The area of the corresponding infinitesimal parallelogram in the $P-V$ plane is seen on inspection to be given by

$$
\delta W=\left(\frac{\partial P}{\partial \theta_{i}}\right)_{V} d \theta_{i} d V^{Y}
$$

By an obvious transformation we may replace $V$ by $P$ as an independent varia-. ble and obtain the alternative expression

$$
\delta V=-\left(\frac{\partial V}{\partial \theta_{i}}\right)_{P} d \theta_{i} d P
$$

Corresponding to these two expressions for $\delta W$ we may write the heat $\delta Q$ absorbed along the higher isothermal in the alternative forms

$$
\delta Q=l d V=h d P
$$

where $l$ and $h$ are both definite functions of the state of the working substance. Carnot's theorem then gives

$$
\frac{\delta W}{\delta Q}=\frac{\left(\frac{\partial P}{\partial \theta_{i}}\right)_{V} d \theta_{i} d V}{l d V}=\frac{-\left(\frac{\partial V}{\partial \theta_{i}}\right)_{P} d \theta_{i} d P}{h d P}=\mu_{i}\left(\theta_{i}\right) d \theta_{i}
$$


whence

$$
\begin{aligned}
& l=\frac{1}{\mu_{i}\left(\theta_{i}\right)}\left(\frac{\partial P}{\theta_{i}}\right)_{V^{V}}, \quad h=-\frac{1}{\mu_{i}\left(\theta_{i}\right)}\left(\frac{\partial V}{\partial \theta_{i}}\right)_{P} \\
& Q=\frac{1}{\mu_{i}\left(\theta_{i}\right)} \int_{V_{1}}^{V_{2}}\left(\frac{\partial P}{\partial \theta_{i}}\right)_{V} d V=-\frac{1}{\mu_{i}\left(\theta_{i}\right)} \int_{P_{1}}^{P_{2}}\left(\frac{\partial V}{i \theta_{i}}\right)_{P} d P
\end{aligned}
$$

in which $Q$ now denotes the heat absorbed in the reversible expansion of any uniform substance at the temperature $\theta_{i}$ from $P_{1}$ and $V_{1}$ to $P_{2}$ and $V_{2}$. Eq. $(5.1)(5 \cdot 2)(6)$ are the most general thermodynamic formulas declucible from Carnot's theorem without the first law. We may in particular take $\theta_{i}$ to be the temperature measured on the perfect gas scale; denoting this temperature by $t$ and the corresponding Carnot's function by $\mu(t)$ we obtain of course

$$
l=\frac{1}{\mu(t)}\left(\frac{\partial P}{\partial t}\right)_{V}, \quad h=-\frac{1}{\mu(t)}\left(\frac{\partial V}{\partial t}\right)_{P}
$$

with corresponding formulas for $Q . \mathrm{Eq} \cdot(7 \cdot 1)(7.2)$ were first obtained by Clapeyron (1834). If on the other hand we introduce the customary absolute temperature defined, as explained above, by

$$
M(T) d T=\frac{1}{T} d T=\mu_{i}\left(\theta_{i}\right) d \theta_{i}
$$

we obtain

$$
l=\frac{1}{T}\left(\frac{\partial P}{\partial T}\right)_{V}, \quad h=-\frac{1}{T}\left(\frac{\partial V}{\partial T}\right)_{P}
$$

with corresponding formulas for $Q$.

Application of these results in the form of eq. $(7.1)(7.2)$ to a perfect gas defined by

$$
P I^{Y}=n R t
$$

where $n$ is the number of moles of gas in the sample and $R$ is the gas constant, yields

$$
\begin{aligned}
l=\frac{n R}{V \mu(t)}, \quad h=-\frac{n R}{P \mu(t)} \\
Q=\frac{n R}{\mu(t)} \log \frac{V_{2}}{V_{1}}=\frac{n R}{\mu(t)} \log \frac{P_{1}}{P_{2}}
\end{aligned}
$$

Eq. (9) expresses Carnot's forgotten theorems 1 and 3 in mathematical form. The fact that $\mu(t)=I, t$ (and therefore the further fact that $t=T$ ) cannot be deduced from Carnot's theorem alone but follows only from comparison of eq. (9) with the cquation

$$
Q=n R t \log \frac{V_{2}}{I_{1}}
$$


which is a consequence of the frist law and of the fact that the energy of a gas is a function of temperature alone.

Finally, if one takes as a working substance a system of a single component in two phases, $\alpha$ and $\beta$, in equilibrimm, one obtains, corresponding to eq. $(5 \cdot 1)$ $(7 \cdot 1)(8.1)$, for $l$

$$
l=\frac{1}{\mu_{i}\left(\theta_{i}\right)} \frac{d P}{d \theta_{i}}=\frac{1}{\mu(t)} \frac{d P}{d t}=\frac{1}{T} \frac{d P}{d T}
$$

while equations corresponding to $(5.2)(7.2)(8.2)$ for $h$ do not exist. In this casc however eq. (4.1) can be integrated directly to give for $l$

$$
l=\frac{Q}{l^{\gamma \beta}-V^{a}}
$$

where $V^{a}$ and $V^{\prime} \beta$ are the molar volumes of the component in the phases $\alpha$ and $\beta$ respectively, and $Q$ is the heat absorbed per mole by the isothermal transition $a \rightarrow \beta$. One accordingly obtains

$$
\frac{1}{\mu_{i}\left(\theta_{i}\right)} \frac{d P}{d \theta_{i}}=\frac{1}{\mu(t)} \frac{d P}{d t}=\frac{1}{T} \frac{d P}{d T}=\frac{Q}{V^{\beta}-V^{\alpha a}}
$$

of which the equation in $t$ was first cleduced, in slightly different form, and for the special case of a liquid in equilibrium with its vapor, by Clapeyron (1834). 


\section{JOHN BANISTER}

AND THE

\section{PULMONARY GIRGULATION}

$$
\text { By }
$$

SANFORD Y. IARKEY AND OWSEI TEMKIN

\section{x}

\section{From}

THE WELCH MEDICAL LIBRARY AND THE INSTITUTE OF THF HISTORY OF MEDICINE OF THE JOHNS HOPKINS UNIYRSIIY BALTIMORE, MARYLAND 



\section{JOHN BANISTER AND THE PULMONARY GIRCULATION}

I

W

HuLe Much has been written about the background of William Harvey's discovery of the circulation of the blood, very little attention has been paid to an earlier Englishman, John Banister, who brought to the notice of his countrymen, in their own language, one of the important steps leading to this discovery, the idea of the pulmonary circulation. In 1578 Banister pulblished an anatomical text, The Historie of Man sucked from the sappe of the most approved Anathomistes, which was based largely on the works of Vesalius and of Realdus Columbus, and which contained in detail the views of Columbus on the passage of blood through the lungs.

Except for Sir D'Arcy Power, who was particularly interested in Banister's influence on the teaching of anatomy and surgery, most historians of anatomy and those who have written on the history of the discovery of the circulation of the blood have passed over Banister's work, either not mentioning it at all, or saying that it was based entirely on classical authorities, or was of no interest. In some instances these statements lead to completely erroneous views as to the anatomical ideas of the period.

There have been two fairly recent articles which refer to Banister, by R. F. Jones and by Goldwin Smith, ${ }^{1}$ which should be mentioned. Both of these authors speak depreciatingly of Elizabethan medicine, including anatomy, and yet both seem unaware of the important works in the field of anatomy which led to the rapid dissemination of the ideas of Vesalius and of the other great Renaissance anatomists. While there was little original investigation in anatomy in sixteenth-century England, it is important that the latest ideas were made known to English anatomists and surgeons very soon after their appearance on the Continent. Yet Smith says: "The influence of the Renaissance in the field of medicine in England was not significant. The ferment caused upon the Continent by Vesalius's 'De Humani Corporis Fabrica' raised but feeble echoes, even in Oxford, Cambridge and London ... Considerable and varied evidence indicates that England took no active part in the medical Renaissance of the Continent until the appearance of Harvey's 'de Motu Cordis' in $1628 . "$

They both seem to think of Thomas Vicary's A profitable Treatise of the Anatomie of mans body, published in 1577 , although presumably based on an earlier edition of 1548 not now extant, as the typical anatomical work of the period. Jones speaks of Vicary as "the author of the first English treatise on anatomy, published four years after Vesalius had laid the foundations for modern anatomy in a book not drawn from Galen but basect upon actual dissection and observation," while Smith says: "Even the great Vicary, physi- 
cian to Henry VIII and Elizabeth, in his 'Treatise of the Anatomy of a Man's Body' (1548, 1577 , etc.) made no reference to European medical science or to his own experience. The reason for the omissions was an excellent one. Vicary liad copied, without acknowledgment, a fourteenth-century manuscript. No changes seemed necessary and none were made." However, neither of them mentions the Vesalian compendium published by Thomas Geminus in $\mathbf{1 5 4 5}$, two years after Vesalius' book, or the English translation in 1559. ${ }^{2}$ This work of Geminus and that of Banister were largely responsible for the spread of Renaissance anatomy in England. Both Jones and Smith refer to Banister, but neither gives a true account of his sources or of the purpose of his book. Jones cites him as example of the "extreme worship of authority," giving as evidence "the innumerable references to Galen" in Banister's Treatise of Chirurgerie, 1575. There is no mention of Banister's sources from Vesalius and Columbus in his anatomical book. Smith speaks slightingly of the work of Banister as typical of Tudor medical literature and says: "Banister delighted in compilations. One of these embraced nine volumes and bore the title "The History of Man Sucked from the Sap of the Most Approved Anatomists' (1578)." The significant point is that neither of these authors has mentioned the fact that Banister drew upon the most modern writers available to him and brought their ideas to the young English students of anatomy and surgery.

It is our purpose to treat in detail only one phase of this newer anatomical learning, the pulmonary circulation, and to show how, in regard to this, Banister dealt with his sources. The idea of the passage of blood through the lungs is certainly one of the most important developments prior to Harvey, and Banister's treatment of it should give a clue to his general attitude toward the modern ideas of his time. We know that he used the De Re Anatomica of Columbus in his lectures on anatomy, for Sir D'Arcy Power has shown ${ }^{3}$ that in the picture of Banister giving the "visceral" lecture at the Barber Surgeons' Hall in 1581 the book on the lectern is that of Columbus, and he has identified the passage to which it is opened.

The best descriptions of the life of Banister are given in these articles by Sir D'Arcy Power and in the Dictionary of National Biography. According to the DNB. John Banister, or Banester, was born in 1540 . However, Sir D'Arcy Power shows that the picture mentioned above gives his age as 48 in ${ }_{1} 5^{81}$, making his date of birth therefore 1533 . He died in 3610 . He had a long career as a surgeon, and on two occasions served with the military forces, with the Earl of Warwick in $15^{6} 3$ and with the Earl of Leicester's expedition to the Lowlands in 1588 . He was admitted to the Barber Surgeons' Company in 1572 , was granted a license to practice physic by the University of Oxford in 1573 , and in 1593 , upon royal recommendation, he was granted a license by the College of Physicians. He was on close terms with the leading surgeons of the time, particularly William Clowes, and John Read, who married his daughter. Stephen Bradwell says in one of his works that he is the grandson of Banister, while Richard Banister, the oculist, was a near kinsman and was educated 
under the older surgeon. The trio-Banister, Read, and Clowes-were the leading lights in the advance of English surgery in their time, and in the works of each of them will be found letters and poems front the others, showing their very close friendship. Thus, in William Clowes: A short and profitable treatise touching the cure of the morbus gallicus by unctions, there is an epilogue by John Banister on quicksilver. Banister lived both in Nottingham and in London.

Aside from the Historie of Mam, Banister's other works are entirely surgical and are translations of or treatises based on continental writers. The details of these have been given by Sir D'Arcy Power. The Historie of Man was printed by John Daye, London, ${ }_{1578}$. It is a small folio of about 224 pages divided into nine books, beginning with the first book on the bones and continuing through the body, following a systemic arrangement. There are five woodcut illustrations copied from Vesalius but reduced. Two of these are of skeleton figures, two of muscle figures, and one the illustration of the instruments used in dissection.

The work is dedicated in the usual fulsome style to Sir Francis Willoughby, but has a much more forthright epistle to the "Fraternitie of Chirurgians in London." In this he tells his readers that he has decided to write this book in English for those that do not understand Latin, and was resolved to bring to these readers the best authors, explaining particularly why he had chosen Columbus. "But to returne to my first determination when I had wholly given my consent to this end, I might see first a farre of, what sondry and great mutations nature hath used in the body of man since Galen wrote in anathomy: and omitting divers old writers, whose workes had not all equall successe, I came at length to Vesalizus, whose whole work seemed as tedious as his Epitome overculled and short. But when I saw Fuchsius to have extract a notable Epitome out of Vesalius and Galen, I had thought to look no further till Collumbus appeared in my sight: whose labours then revolvyng, and seyng him in some thynges use sufficient prolixitie, as in his Bookes of Bones and Muscles. and in other causes to be somewhat brief (because l'esalius had sufficiently handled them) as in the nutritive parts, immediately I refused to bynde myselfe to any peculiar translation, chusing rather to picke a posie of the chicfest flowers from all their Gardens, the opinion of Fernelius and others not beyng utterly refused, as throughout the History is diligently noted."*

Around the middle of the thirteenth century an Arabic physician, Ibn anNafīs, described the pulmonary circulation. This is the earliest description we know, and its rediscovery has put an end to the claims for priority of either Michael Servetus (1553) or Realdus Columbus (1559). Howerer, it is not prob-

* In this and in the following quotations the original spelling and puncuation have been retained. except for lengthening of contractions, and mokernizing of certain typographical featmres (s; $\mathrm{v}$ and $\mathrm{u}$; i and $\mathrm{j}$ ). 
able that Servetus knew of his Arabic predecessor, ${ }^{4}$ nor has any historical link been established between Ibn an-Nafis and Columbus. Whether, on the other liand, any connection existed between Servetus and Columbus is a question still open for debate.

No such difficult questions of historical priority confront us when we read the paragraphs in Banister's Historie of Man that deal with pulmonary circulation. Not only does he quote his authority, Columbus, but most of the latter's passages concerning circulation can be found in literal translation in Banister's text. Yet Banister's arrangement is somewhat different; and in order to understand the task he had to solve, we must briefly review Columbus' argument.

What we now call the pulmonary circulation (neither Columbus nor Banister knew that all the blood had to pass through the lungs) is described by Columbus in two different parts of his De Re Anatomica and under slightly different points of view. In book VII, "On the Heart and Arteries," he develops his thesis in refutation of the traditional theory, while in the chapter "On the Lung" (book XI, ch. 2) he gives full emphasis to his claim of having discovered a new "use" of the lung.

The traditional theory which Columbus attacked presented itself about as follows: From the right ventricle of the heart, blood passed through the septum into the left ventricle. On this passage it became thin on account of the generation of vital spirits which the arteries carried through all parts of the body. The pulmonary artery (the "arterial vein" in Galenic terminology) carried blood to the lungs for their nourishment. In the pulmonary vein ("venous artery") fumes were carried from the left ventricle to the lung. This is not a complete picture of the original Galenic theory, but it gives the points which Columbus attacked. "For the blood," he says, "is carried through the arterial vein to the lung and is there made thin; then, together with air it is carried through the venous artery to the left ventricle of the heart: which nobody has hitherto noticed or left in writing: although greatest attention should be paid to it by everybody." "The size of the pulmonary artery suggests that the blood which it carries is not only for the nourishment of the lung, but also for alteration. Dissection and vivisection, moreover, prove that the pulmonary vein contains blood, not fumes.

According to the traditional theory, the use of the lung was twofold. Through inspiration and expiration the vocal organs received the necessary air; and by carrying air to the heart, the lung served the latter, the seat of the "innate heat." Columbus acknowledges these views as correct. But he claims to have discovered an additional "use" of which no anatomist before had even dreamt. This new use is the elaboration of the vital spirit in the lung; and though he variously alludes to it in the part dealing with the heart and arteries, the doctrine is fully stated in the chapter "On the Lung." In this chapter, then, we find another and more comprehensive formulation of the pulmonary circulation and we may quote it in Banister's almost literal translation. 
For it [that is, the newly discovered "use"] is . . the preparation, yca almost the generation of vitall spirites, which after are perfected in the hart. That is to say, the inspired ayre it receiveth, through the mouth, and nostreles, it beyng brought, by the conreiance of the rough arterie through the substaunce of the lunges: the which instrument ccasseth not to mixe the same arre, with that bloud, which is brought unto it, by the arteriall vevne, from the right ventricle of the hart. For this same arteriall veyne, besides that it bringeth bloud, for nourishment, is so large, as that it may scrve for other use also. And this bloud by styrring, through the continuall movyng of the lunges, is made thinne, and together with the ayre mixed, which thus, by the same refraction, and beatyng together, is prepared: so that, the ayre, and bloud, together mixed, are received by the braunches of the veniall Arterie, and at length, by the trunke of the same veyne, sent into the left ventricle of the hart: but so wel mixed, and attenuated together, as that to the hart, small labour at all is left: after which small elaboration, the hart (as it were) laying to the last hand, to the makyng of the vitall spirites, that, by meanes of the great arterie, they might be distributed to all the partes of the body it was most requisite. ${ }^{6}$

In faror of this extended theory Columbus cites additional arguments. The lung could not exist without "vital blood." But since neither the pulmonary artery nor vein are really "arteries," the lung (as he thought) is not supplied by any artery at all and it must, therefore, be assumed that the vital blood originated in the lung itself. Besides, every physician judges blood to be expectorated from the lungs by its having the same characteristics as arterial blood. ${ }^{7}$

As said before, most of Columbus' passages touching upon pulmonary circulation are taken over by Banister. But instead of being spread over two different parts, they are incorporated into one book (book VII) which treats "of the makyng of the hart, and of the Instrumentes ministryng to his function: commonly called, The Vitall or Spirituall partes." Banister succeeded in presenting such a smooth text that the reader is not always aware whether he or Columbus is speaking. For instance, having reported about the coronary arteries and the subtle inferences which according to Columbus might be drawn from their functions, Banister continues: "Albeit he [that is, Columbus] referreth the case to the more sapient Philosophers to discusse. And so it shal be sufficient, here, truly to describe the partes of the body, how they are, and to what use created, least I meddle over farre in such misteries."s Without comparing the texts, the reader will not easily realize that the whole last sentence with the exception of the last clause is still a literal translation of Columbus!

Yet the different arrangement leads to a slight difference of emphasis. The passage on the function of the lungs comes early in Banister's context so that the reader is immediately confronted with the full scope of the theory. For Banister, the discovery of the path the blood travels and of the function of the lungs belong together. He makes this clear by the formulation in which at the outset of book VII he contrasts Columbus' opinion with that of the Galenists. "Contrariwise Realdus Collumbus sayth, that the bloud, sent from the right ventricle of the hart, by the arteriall Veyne, into the lunges, there takyng the mixture of ayre, is drawne, by the veniall arterie, into the left ventricle of the hart, whereas, beyng almost made before, it is now perfected vitall spirite." 
Which side did Banister himself choose? As if the conflicting theories of the Galenists and Columbus were not enough, Leonardus Botallus had lately contradicted both and claimed the discovery of the right path. He had found a (probably open) foramen ovale and believed this to be the source of the arteries and vital spirits. ${ }^{10}$ No wonder that Banister at the beginning of book VII found himself "amased, and as one plunged in the depth of contrary streames." 1 It in interesting to compare his attitude with that of Ambroise Paré as expressed in the latter's Anatomy of $1575 .{ }^{12}$ Paré, too, quotes Columbus and Botallus. He sketches the former's doctrine briefly and adds: "This opinion is very probable." ${ }^{\prime 3}$ Regarding Botallus' discovery, he doubts its originality. Banister does not definitely reject the Galenists or Botallus, although he criticizes the latter for the inaccuracy of his description. Nor does he commit himself definitely to Columbus. He simply chooses Columbus as his guide without prejuclice to others. "I have thought good," he says, "to describe the partes after the best approved, and that in such wise, as there shall appeare therein great perspicuitie, and likehode of truth." ${ }^{14}$ The final judgment he leaves to the reader.

\section{REFERENCES}

1. Jones, Richard Foster: Ancients and Moderns: a study of the background of the Battle of the Books (St. Louis: 1936); "Washington Univ. Studies" n.s.-Lang. \& Lit. 11o. 6; Smith, Goldwin: "The practice of medicine in Tudor England" Sci. Month. 50:65, $194^{\circ}$.

2. Larkey, Sanford V.: "The Vesalian compendium of Geminus and Nicholas Udall's translation; their relation to Vesalius, Caius, Vicary and de Mondeville" The Library (4)13: 367,1933 .

3. Power, Sir D'Arcy: "Notes on early portraits of John Banister, of William Harvey, and the Barber Surgeons' Visceral Lecture in 1581" Proc. Roy. Soc. Med. 6:18, 1913; "John Banester, 1533-1610" Brit. J1. Surg. 5:8, 1917-18; "The education of a surgeon under Thomas Vicary" Brit. Jl. Surg. 8:240, 1920-1921. Also in his Selected IVritings, $1877-1930$ (Oxford: 1931), 67-94.

4. See Temkin, Owsei: "Was Servetus influenced by Ibn an Nafis?” Bull. Histor. Med. 8:731, $194^{\circ}$.

5. Columbus Cremonensis, Realdus: De Re Anatomica Libri XV (V'enetiis: 1559), 177.

6. Banister: Historie of Man, fol. $91^{\mathrm{r}}$.

7. An English translation of most of the passages from Columbus relevant to the pulmonary circulation can be found in Dalton, J. C.: Doctrines of the Circulation (Philadelphia: 1884).

8. Banister, as cited, fol. $92^{\mathrm{v}}$.

9. Same, fol. $89^{r}$.

10. Sce Franklin, K. J.: "Ductus Venosus [Arantii] and Ductus Arteriosus [Botalli]" Bull. Histor. Med. 9:581, 1941 .

11. Banister, as cited, fol. $89^{\mathrm{r}}$.

12. See Bayon, H. P.: "William Harvey, physician and biologist; his precursors, opponents and successors" Ann. Sci. 4:347, 1939.

13. Oeuvres Complètes d'Ambroise Paré, ed. by J.-F. Malgaigne. I (Paris: $18 \_0$ ), 19.1.

14. Banister, as cited, fol. $89^{\text {r }}$. 
COMPARISON OF THE CONDITIONS

UNDER WHICH ESTROGENS AND

CARCINOGENIC HYDROCARBONS

ARE TUMORIGENIC

$$
B y
$$

PROFESSOR ALEXANDER LIPSCHÜTZ

\section{糈}

From the

DEPARTMENT OF EXPERINENTAL MEDICINE, NATIONAL HEALTH SERIICE OF THE REPUBLIC OF CHILE, SANTIAGO 

Knowledge on regulation and stinulation of normal boty growth by prehypophysial hormones will forever be bound with the name of H. M. Evans. I have thought that a good way to express my sincere appreciation for the tremendous rork done by Evans and his school in this field would be to show how atypical or tumoral growth may depend upon orarian hormones and indirectly also upon those of the anterior bolse of the hypophyis. 



\title{
COMPARISON OF THE CONDITIONS UNDER WHICH ESTROGENSAND CARCINOGENIC HYDROCARBONS ARE TUMORIGENIC**
}

\author{
I. Atypical Epithelial and Connective-tissue Growth Iniduch \\ BY ESTROGENS
}

\begin{abstract}
TY pical cellular proliferation with metaplasia or production of new growth A has been elicited with estrogens in numerous instances. In the case of epithelial tissues one might mention the work of Loeb ${ }^{1}$ and of Lacassagne ${ }^{2,3,4}$ in the production of mammary adenocarcinoma in certain strains of mice, and that of Hofbauer, ${ }^{5,6}$ of Allen, Hisaw and Gardner, ${ }^{7}$ Del Castillo and Sammartino, also Korenchevsky and $\mathrm{Hall}^{\circ}$ with the uterine mucosa. Adenomatous polyps of the uterus descending into the vagina (Lipschütz, Vargas, Jedlicky and Bellolio; ${ }^{10}$ Bellolio ${ }^{11}$ ), and precancerous transformation of the portio (Loeb, Suntzeff and Burns; ${ }^{12}$ Suntzeff and co-workers; ${ }^{13}$ McEnen; ${ }^{14}$ Lipschütz and coworkers $\left.^{1 "}\right)$, have been induced in the mouse, rat, and guinea pig. As to connective tissue, sarcomata of spindle-shaped type have been elicited in mice at the site of injection or elsewhere and lymphosarcomata have been reported in the thymus and lymphatic glands (Gardner, Smith, Strong and Allen; ${ }^{10}$ Gardner; ${ }^{17}$ Burns and co-workers; $;^{18}$ Lacassagne $\left.{ }^{19}\right)$. Subserous uterine fibroids also have been elicited in the guinea pig (Nelson; ; ${ }^{20}{ }^{21}$ Moricard and Cauchoix; ${ }^{22}$ Lipschütz and Iglesias $\left.{ }^{23}\right)$. The latter authors ${ }^{23}$ established the fact that extragenital subserous fibroids can be induced also by estrogens in most of the abdominal organs, as stomach, intestine, spleen, pancreas, liver, kidneys, etc. Iglesias $^{24}$ ). Localization, incidence, and microscopical structure of these extragenital abdominal fibroids have been studied extensively by Lipschütz and his associates (Lipschütz, Iglesias and Vargas; ${ }^{15}$ Lipschütz and Vargas; ${ }^{25}$ V'argas and Lipschütz: ${ }^{26}$ Murillo ${ }^{27}$ ). They are to be found in both sexes, but the female is more susceptible than the male (work of Koref, Jedlicky, Vargas, Chaume. Szabó, and others in this department; see Patma ${ }^{25}$ ). Sammartino and GandolfoHerrera $^{29}$ have fully corroborated our findings.
\end{abstract}

\section{Are these Atypical Growths Real Tumors:}

One must question whether the atypical proliferations induced by estrogens should be classified as neoplasms or real tumors. The answer fully depends on one's definition of tumoral growth. Tumoral growth or proliferation may be defined as cellular proliferation which is localized or insular; and which is atypical not only as to intensity (number of mitoses) but also as to cellular structure and tissue organization, that is, is metaplastic; and which

* This work was aided by The Jane Coffin Childs Ifemorial fiund tol Medical Researh and b The Rockefeller Foundation.

$$
[297]
$$


is autonomous and thus persists even though the extracellular stimulus which may have been responsible for the atypical proliferation is no longer active. So arbitrary is such a definition that it does not apply to the fibromyomata in women which stop growing and begin to regress when the ovary ceases its endocrine activity. Nevertheless we must adhere to this definition and must work with it, as will be recognized by all trained in human pathology.

There is scarcely any doubt that our definition applies to the experimental epithelial growths elicited by estrogens. The atypical metaplastic proliferation of the endometrium in rats with pluristratification and cornification may be "more or les complete" (Selye, Thomson and Collip ${ }^{30}$ ). But according to our findings, complete metaplasia with cornification is a rare phenomenon in the rat (pl. 1, fig. 1); in general the metaplastic proliferation is strictly insular (pl. 1, figs. 2 and 3). The data relative to its autonomy are scarce but existent. On one occasion, a guinca pig having been injected for eight months with estradiol benzoate was found three months later to have a precancerous transformation of the endometrium in the upper third of the uterine horn (pl. 1, figs. 4 and 5). Gardner, Allen, Smith and Strong ${ }^{31}$ have reported an invasive epithelial tumor of the cervix in a mouse treated for eighteen months with estrogens; this growth, having a cancerous aspect, proved to be transplantable. The same investigators showed that the mammary adenocarcinoma induced by estrogens is capable of growth without continued treatment and that it can be successfully grafted into normal or castrated animals of either sex (Gardner, Allen, Strong and Smith, see Allen and co-workers, ${ }^{7}$ p. $5^{6} 7-5^{68)}$.

Our definition also fully applies to the atypical connective-tissue growth elicited by estrogens; both the subcutaneous sarcoma and the lymphosarcoma of the thymus are transplantable (Allen, Hisaw and Gardner ${ }^{7}$ ).

In the case of abdominal fibroids the situation is more complicated. It is certain that under the influence of prolonged treatment with estrogens the connective tissue throughout the whole body will react with proliferation. Illustrative of this is the reaction in the prostate $\left(\right.$ Zuckerman $\left.^{32}\right)$ or in the genital tract of the female (Loeb, Suntzeff and Burns; ${ }^{33}$ Burack, Wolfe, Lansing and Wright $\left.^{3 i}\right)$. In the guinea pig, fibrous strands and diffuse fibrosis can be seen in the mesentery and in the parietal peritoneum at certain typical places (Vargas). Thickenings are found in the renal capsule, and also in the uterine subserosa (Lipschütz and Vargas ${ }^{25}$ ). For these reasons uterine and extragenital fibroids induced by estrogens are to be considered as intensified local manifestations of a generalized fibrous reaction (Lipschüt $\mathrm{z}^{35}$ ). These local manifestations are, however, typical as to their site (Lipschütz, Iglesias and Vargas ${ }^{15}$ ); that is, they obey certain laws as to localization not yet known to us-laws which apply to tumors in general in men and animals. One should not forget that extragenital abdominal fibroids have also been reported in men and women, and it is remarkable that their gastric and intestinal localizations are 
coincident with those in our experimental guinea pigs (pl. 2, fig. 6).* The microscopical structure of the experimental fibroid, though different from that of the spontancous fibroid of the woman or of the guinea pig itself (where spontaneous fibroids are extremely rare: Lipschütz $z^{30}$ ), differs atlso from ordinary connective tissue in its abundance of cells, in the new for mation of smooth muscle fibers, and in the disorderly disposition of the collagen fibers.

It might be argued that the definition of neoplasm or tumor which we have given above does not cover our experimental abdominal fibroids. Indeed, the experimental fibroid has no autonomous growth since when estrogens are withdrawn, the fibroid begins to regress and when grafted beneath the skin or into the abclominal cavity, the fibroid may resist for a certain time, but eventually becomes absorbed. But if this precludes classification of the experimental fibroid as a neoplasm, then neither is the uterine fibroid in women a neoplasm.

\section{ili. Comparison of Estrogens and Carcinogenic Hyurocarbons}

The neoplasms produced by carcinogenic hydrocarbons in mice are unanimously recognized as comparable to spontaneous sarcoma and carcinoma in man. This is appropriate, for they are structurally similar to spontaneous neoplasms and the induced sarcoma is transplantable. It has been reported that, in the chicken, the induced sarcoma is even filtrable and leads to serological changes similar to those reported with spontaneously occurring filtrable tumors $\left(\right.$ Foulds $^{37}$ ). Can estrogens compete with these hydrocarbons as to their tumorigenic powers? This is a delicate question which it would be vain to discuss at the moment. But we shall show below that there are similarities in the conditions necessary for tumorigenesis from these two substances.

1. The Tumorigenic Minimum Quantity. The quantity of the carcinogenic hydrocarbons which is still able to elicit a tumor (subsequently designated as "tumorigenic minimum quantity") is certainly very small. Though experimental data arailable are still insufficient, certain experiments show that a single subcutancous injection of $5 \mu \mathrm{g}$. (or less) of dibenzanthracene is sufficient to elicit sarcoma in mice (Dobrovolskaja-Zavadskaja ${ }^{38}$ ). The same will probably apply to other highly active carcinogenic hydrocarbons. It is generally assumed that the tumorigenic minimum for estrogens is very great. Our own work has, however, shorw that this assumption is erroneous. It is true that considerable quantities of the free hormone (estradiol or estrone) must be injected in the course of a certain time to clicit utcrine metaplasia; but when esterified estradiol is used, the minimum quantity is much less. It has been shown (Lipschütz, Vargas, Jedlicky and Bellolio;: Bellolio ${ }^{12}$ ) that

* Sammartino and Gandolfo-Herrera ${ }^{29}$ observed two cases of thoracic fibroids in 27 animals with abdominal tumors induced by estrogens. Lately a similat case was oberved in this department. It is the first among more than a thousand cases. I This ditterential incidence of thoracie fibroids in our laboratory and in that of the Irgentine workers nar depend on the strains used

t The ideas here expressed were first prescnted in an addsess given to the second Pan American Congress of Endocrinologs held in Mareh, [y l1, in Monterideo. 
pluristratified insular metaplasia of the endometrium can be produced in the guinea pig with less than forty injections of $1 \mu \mathrm{g}$. of estradiol when it is given as an ester. Certain esters, especially the 17 -caprylate, are more active than others; with the 17 -caprylate or the 17 -benzoate-3-n-butyric ester of estradiol one may sometimes observe beginning metaplasia with one-tenth these quantities.

The threshold for fibromatogenic action seems to be higher than that for the beginning proliferation or metaplasia of the uterine epithelium. Snall parametrial fibroids sometimes appear, however, when only forty injections of $1 \mu \mathrm{g}$. of esterified estradiol have been given; some animals will show abdominal fibroids with less than forty injections of $2 \mu \mathrm{g}$. of estradiol given as 17 -caprylate (Lipschütz, Vargas, Baeza-Rosales and Baeza-Herrera ${ }^{30}$ ). The first signs of a fibrous tumorigenic reaction on the spleen, or what we called the "tumoral seed" (Vargas and Lipschüit $z^{26}$ ), may become evident with as little as ten injections of $1 \mu \mathrm{g}$. of estradiol given as the 17 -caprylate in the course of twenty-one days.

When similar quantities of free and esterified estradiol are administered under similar timing conditions (three injections weekly in the course of three months), differences become evident: esterification with caprylic acid in position 17 , for example, enhances the fibromatogenic action of estradiol one hundred to two hundred times; a dose of 2 to $5 \mu \mathrm{g}$. of the caprylate is enormously superior to 200 to $400 \mu \mathrm{g}$. of free alpha-estradiol. The fibromatogenic minimum of the 17 -caprylate of estradiol is, in fact, greater than the sarcomatogenic minimum of certain hydrocarbons, but the enhancement of the power of an estrogen to induce tumors by simple esterification has an analogy in the carcinogenic hydrocarbons, where methylation, for instance, may confer the highest carcinogenic capacity; 1:2-benzanthracene is almost devoid of carcinogenic action, whereas its 5:10-dimethyl derivative is highly active (Bachmann and coworkers $\left.{ }^{40}\right)$.

2. The Tumorigenic Timing Conditions. Why is the tumorigenic capacity of estrogens so consiclerably enhanced by esterification? At the beginning of our work the assumption was tentatively made that a certain threshold, or tumorigenic level, of folliculinemia must be attained and continuously maintained for tumorigenesis to occur (Lipschütz ${ }^{41}$ ). The free hormone is rapidly absorbed and inactivated in the body so that the concentration of the hormone in the blood is subject to considerable fluctuation when injections are given thrice weekly. Under these conditions, great quantities of the hormone would be necessary to maintain the concentration of hormone in the blood at the tumorigenic level. On the other hand, absorption of the esterified hormone is generally considered to be slow, a circumstance favoring the maintenance of folliculinemia at the tumorigenic level, even when smaller quantities are injected. Later we found that differences in the tumorigenic faculty of the free hormone and the esterified one did not always parallel differences in the rate of absorption. The dipropionate of estradiol is much more tumorigenic than the 


\section{Alexander Lipschütz}

free hormone (Lipschuitz, Bellolio, Chatume and Vargas ${ }^{42}$ ); nevertheless, its rate of absorption is not less and is probably greater than that of the free hormone (Lipschütz and Vargas; ${ }^{42 a}$ Emmens ${ }^{43}$ ). It remains truc, however, in accordance with our conception of the importance attributable to the continuous maintenance of a tumorigenic threshold-level of folliculinemia, that the timing conditions are fundamental for tumorigenesis eliciled by estrogens. If a continuous flow of estrogen is established in the body from a subcutaneously or intraperitoneally implanted tablet of free estrogen, fibromatogenesis is produced in the course of several weeks, the quantitics absorbed being several times smaller than those which are necessary when three injections are given per week for a period of several months (Lipschütz and Vargas; Chaume and $\left.\operatorname{Vargas}^{45}\right)$. This is true also for other estrogens, such as free estriol $\left(\right.$ Szabó $\left.^{46}\right)$, and especially estrone (Thibaut ${ }^{47}$ ). Tumorigenesis can be elicited with a total of $3^{00}$ to $400 \mu \mathrm{g}$. of estrone absorbed in the course of three months from a subcutaneously implanted pellet (pl. 2, fig. 7). On the other hand, thirty-eight injections of $300 \mu \mathrm{g}$. of estrone given in oily solution in the course of three months, or a total of $11,400 \mu \mathrm{g}$., thirty times that absorbed from a pellet, are not sufficient to produce abdominal fibroids (Lipschütz, Rodríguez and Vargas: ${ }^{48}$ Rodriguez $\left.{ }^{40}\right)$. On the other hand treatment with a highly tumorigenic ester such as estradiol benzoate fails to elicit fibroids if each injectionweek is followed by wo weeks free from injections; similar treatment may be prolonged for a whole year without appearance of fibroids (Lipschütz, Rodríguez and Vargas $^{50}$ ) (pl. 2, fig. 8).

Carcinogenic hydrocarbons have been studied only sporadically as yet with reference to the necessity of continuous administration. The few data available rather favor the assumption that here also continuity of the tumorigenic stimulus is important. When studying the timing conditions for the carcinogenic action of benzpyrene in mice, Peacock and Beck $k^{51}$ found that epitheliomas appeared when painting with a solution of 0.3 per cent was repeated twice weekly for a period of two to three months. If the painting during the three-month period is, however, intermittent, no applications being made during alternate months, then the incidence of tumors diminishes. It will probably be possible to demonstrate the importance of continuity of application of the carcinogenic hydrocarbons in a more striking manner when more suitable concentrations and intervals are devised. Further proof of the importance of the timing factor in tumorigenesis elicited by hydrocarbons will be mentioned in the next paragraph.

3. Reversibility and Irrezersibility of the Tumoral Reaction. As already mentioned, atypical proliferation in the uterine mucosa induced by estrogens rarely persists after the withdrawal of estrogens. The situation is the same in the case of connective tissue tumors induced by estrogens. This reversibility of the condition is in general considered as fundamentally different from what would have been expected if the proliferation were a real tumor. The epithelioma induced by painting with carcinogenic hydrocarbons may on the 
other hand become cancerous, and, as already mentioned, is transplantable. Important clata are available, howcver, indicating that things are not so clearcut as originally supposed with reference to the autonomous growth of these tumors induced by hydrocarbons. Mider and Morton ${ }^{62}$ reported regression of cutaneous papillomas elicited in mice by a single painting with 0.5 per cent of methylcolanthrene. Rous and Kidd ${ }^{53}$ have recently described at length the transient condition of many of the new growths induced in the skin by tarring of the ear of the rabbit. They not only disappear when tarring is stopped, but they can even do so while tarring is continued. Similar statements were recently made by Flory $y^{54}$ regarding papillomas elicited by tobacco tars. Our own observations with the guinea pig (unpublished results) give evidence of regression of hyperkeratosis of the skin induced by painting with benzpyrene, though the painting was maintained. This has recently been corroborated by Miss Moreira in this laboratory. Exaniples of regression of papillomas or "carcinomatoids," to use the terminology of Rous and Kidd, are found in the original work of Yamagawa and Ichikawa as early as 1915-1918 (quoted from Rous and $\mathrm{Kidd}^{53}$ ). In regard to sarcoma due to carcinogenic hydrocarbons it may be noted that Des Ligneris ${ }^{55}$ observed that the new growths started as simple granulation tissue and became sarcomatous only subsequently.

Such results with tumors induced by tarring or painting with carcinogenic hydrocarbons remind us that not too much stress can be laid on regression of newgrowth elicited by estrogens. One must suppose rather that there are two different phases in experimental production of tumors: the first one is that of active, atypical proliferation of cells which are as yet physiologically normal; the second phase is that of transformation into cells capable of autonomous growth. In the case of carcinogenic hydrocarbons the first phase is in general, though not always, succeeded by the second. With estrogens the first phase is in general not succeeded by the second; but this depends apparently upon experimental conditions,-all the more so as under certain experimental conditions even the second phase can become independent from the first one, as shown by Rous and Kidd ${ }^{53}$ with tar warts, where newly acquired "neoplastic potentialities" may remain in abeyance or dormant.

4. Differential Behavior of Homologous Territories in Different Species. When one compares the response of the skin in mice and guinea pigs toward carcinogenic hydrocarbons it is evident that the same, or homologous, territories react differently in different species. This is true also for tumorigenesis resulting from estrogens. Comparative results with prolonged treatment with estrogens in guinea pigs and rats are given in table 1.

Pluristratified metaplasia and subsequent cornification of the endometrium may be seen in the rat treated for three months with estrogens. In contrast to this, cornification was never seen under similar experimental conditions in the guinea pig. This was true even when treatment with great quantities was prolonged for a year (see pl. 1, fig. 1 and pl. 3, fig. 9) and even though pluristratified metaplasia of the endometrium was easily established in the guinea 


\section{Alexander Lipschütz}

pig with small quantities of estrogens and the cervical mucosa had undergone cornification. It follows from our comparative work in rats and guinea pigs that the metaplastic pluristratified epithelium of the endometrium in the guinea pig is unable to undergo keratinization as in the rat. Neither were there (in the guinea pig) the great increase in size and the tumoral transformation of the anterior lobe of the hypophysis which so readily appears in the rat (McEucn, Selye and Collip; ${ }^{56}$ Zondek $^{57}$ ). The mammary gland, which in the guinea pig greatly increases when treated with estrogens, never became adenocarcinomatous, while this is characteristic for certain strains of mice. In guinc'a

TABLE 1

\begin{tabular}{|c|c|c|}
\hline \multirow{2}{*}{ Territories } & \multicolumn{2}{|c|}{ Type of reaction in } \\
\hline & Guinea pigs & Rats \\
\hline Endometrium & $\begin{array}{c}\text { Pluristratified metaplasia } \\
\text { without cornification }\end{array}$ & $\begin{array}{l}\text { Pluristratified metaplasia } \\
\text { with cornification }\end{array}$ \\
\hline Anterior lobe of the hypophysis & Never great increase in size & $\begin{array}{l}\text { Enormous increase in size, } \\
\text { sometimes abnormal and } \\
\text { tumoral. }\end{array}$ \\
\hline Visceral and parietal serosa.... & Abdominal fibroids & No abdominal fibroids. \\
\hline Mammary gland. & $\begin{array}{l}\text { Rarely adenofibroma; never } \\
\text { adenocarcinoma }\end{array}$ & [Mice: adenocarcinoma] \\
\hline
\end{tabular}

pigs we found adenofibroma on two occasions and slight metaplastic changes also in two cases. As to the abdominal serosa, the difference between guinea pigs and rats is very marked. Quantities forty times greater than those which induce fibroids in almost every guinea pig fail to elicit any macroscopically visible reaction in the visceral or parietal serosa of the rat (Lipschütz, Egaña, Sıabó and Lecanellier ${ }^{58}$ ).

The above statements give full evidence that homologous territories respond to the tumorigenic stimulus of estrogens in a different manner according to the species, as is also the case with carcinogenic hydrocarbons. The organism may be considered tentatively as a mosaic of territories each of which obeys its own laws in development of experimental tumors. It is very likely that similar conditions prevail also with respect to spontaneous tumors. According to Locb" it is probable "that each type of tumor is hereditarily transmitted without regard to other types of tumors."

\section{Experinental Tumorigensis Elicited by Endogenous Hormones}

It has been shown by our former work (Lipschütz ${ }^{80-83}$ ) that atypical proliferation of the epithelium of the uterine mucosa may be seen in the guinea pig when protracted follicular phases are produced by experimental intervention 
with the ovary, such as fragmentation or transplantation. Frequent proliferation of uterine glands occured, with formation of polyps and penetration of glinds between the muscle layers of the myometrium, and on one occasion a papilloma of precancerous aspect with pearl formation and cornification in the cervix appeared. Similar observations have been reported for the rat by Pfeiffer. ${ }^{64}$ Schmidt ${ }^{65}$ has reported induction of uterine fibroids by ovarian irradiation in guinea pigs; here also a protracted action of follicular hormones seemingly plays a role.

Gonadal fragmentation or transplantation is likely to produce a disturbance of the ovarian-prehypophysial relationship which manifests itself in an increase of gonadotrophic substances in the anterior lobe $\left(\right.$ Lipchütz $z^{66}$ ). It is in this way that the protracted follicular phases which establish themselves under these experimental conditions can be explained. And it is probably by the increased gonadotrophic activity of the anterior lobe that some phenomena of atypical epithelial proliferation in the gonadal fragment or graft itself must be explained. When ovarian fragments or grafts are made, proliferation of epithelial cords in the hilum of the ovary have been reported, though rarely (Lipschüt $z^{37,68}$ ). Nodular proliferation of interstitial cells* as observed years ago in testicular fragments (pl. 3, figs. 10 and 11 ) may be explained today on similar lines (Lipschüt ${ }^{69,70,71}$ ). This may also apply to the metastasizing interstitialcell tumor of the testis produced in mice subjected to a prolonged treatment with estrogens (Hooker, Gardner and Pfeiffer ${ }^{\tau^{2}}$ ).

\section{SUMMARY}

The question is discussed whether the atypical proliferations induced by estrogens are to be considered as true neoplasms.

According to the author and his associates, atypical proliferation of epithelial and connective tissue elicited by estrogens in the guinea pig affords characteristic signs of neoplastic or tumoral growth. Endometrial proliferation with production of squamous epithelium in the uterine mucosa is strictly insular. Adenomatous polyps, with occasional precancerous changes, are procluced. Finally, uterine and extragenital abdominal fibroids of typical localization are formed which infiltrate neighboring tissues.

There is also a far-reaching similarily between conditions for tumor formation from estrogens and carcinogenic hydrocarbons: (1) The tumorigenic minimum quantity of estrogens is minute under certain experimental conditions, especially when the estrogen is enhanced by esterification or when it is absorbed from subcutaneous pellets, though the quantity is still greater than that required of carcinogenic hydrocarbons. (2) The fundamental tining condition for the tumorigenic action of estrogens is continuous application of a minimum stimulus. The same seens to be true for carcinogenic hydrocarbons.

* Twenty years ago this behavior of the interstitial tissue in testicular fragments was explained as due to local conditions, especially those of blood supply (Lipschütz, ${ }^{69}$ p. 135). The veering of opinion in this minor case reflects the fundamental change which has taken place in the last two decades in interpretation of physiological and pathological processes. 


\section{Alexander Lipschütz}

(3) The epithelial new growth elicited by carcinogenic hydrocarbons under certain timing conditions is reversible as is the rule with estrogens. (4) The tumorigenic effect of estrogens, as with carcinogenic hydrocarbons, is dependent on the species, each organism being a mosaic of territories in which a homologous territory may react toward estrogen in a different way according to the specics.

\section{REFERENCES}

1. Loeh, L.: J1. Med. Resrch. fo:4177, 1919.

2. Lacassagne, A.: Cpts. rd. Acac. d. scis. (Paris) 195:630, 1932.

3. Lacassagne, A.: Erghne, d. Vitamin- u. Hormonforsch. 2:258, 1939.

1. Lacassagne, A.: Amer. J1. Canc. 37:114, 1939.

5. Hofbauer, J.: Surg., Gynecol. \& Obstet. 52:222, 1931.

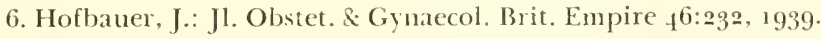

7. Allen, E.; Hisaw. F. I., and Gardner, W. U.: in Sex and Intermat Secretions, ed. by E. Allen (2d ed.; Baltimore: 1939), 564 .

8. Del Castillo, E. B., and Sammartino, R.: Rev. Soc, argentin. de biol. 13:455, 1937 .

9. Korenchersky, V., and Hall, K.: Jl. Obstet. \& Gynaecol. Brit. Empire 45:22, 1938.

10. Lipschïtz, A.; Vargas, L., Jr.; Jedlicky, A., and Bellolio, P.: Amer. Jl. Canc. 39:18丂, 1940. 11. Bellolio, P.: Publns. Depmt. de med. exper., Chile no. 2, 1939.

12. Loeb, L.; Suntzeff, V., and Burns, E. L.: Amer. Jl. Canc. 3.1:113, 1938.

13. Suntzeff, V.; Burns, E. L.; Moskop, M., and Loeb, L.: Amer. Jl. Canc. 32:256, $193^{8}$.

1 t. McEnen, C. S.: Amer. J1. Canc. 31:18.4, 1939.

15. Lipschütz, A.; Iglesias, R., and Vargas. L.. Jr.: Proc. Soc. Exper. Biol, \& Med. 45:788, 1940. 16. Gardner, W. U.; Smith, G. M.; Strong, L. C., and Allen, E.: Jl. Amer. Med. Assn. 107:656, 1936.

17. Gardner, W. U.: Occas. Publns. Amer. Assn. Advancmt. Sci. 4:67, 1937.

18. Burns, E. L.; Suntzeff, V., and Loeb, L.: Amer. J1. Canc. 32:534, 1938.

19. Lacassagne, A.: Bull. Assn. franc. p. l'etude du canc. 27:96, $193^{8}$.

20. Nelson, W. O.: Anat. Recrd. 68:99, 1937.

21. Velson, W. O.: Endocrinology 24:5o, 1939.

2. Noricard, R., and Cauchoix, J.: Cpts. rd. Soc. de biol. 129:556, 1938.

23. Lipschütz, A., and Iglesias, R.: Cpts. rd. Soc. de biol. 129:519, 1938.

24. Iglesias, R.: Publns. Depmt. de med. exper., Chile, no. 1, 1938.

25. Lipschütz, A., and Vargas, L., Jr.: Canc. Resrch. 1:236, $194^{1 .}$

26. Vargas, L., Jr., and Lipschütz, A.: Cpts. rd. Soc. de biol. 129:810, $193^{8 .}$

27. Murillo, R.: Publns. Depmt. de med. exper., Chile, no. 4, 1940.

28. Palma, J.: Publns. Depmt. de med. exper., Chile, no. 6, 1940.

29. Sammartino, R., and Gandolfo-Herrera, R.: Rev. méd. latino-amer. 25:976, 19 ło.

30. Selye, H.; Thomson, D. L., and Collip, J. B.: Nature (London) 135:65, 1935 .

31. Gardner, W. U.; Allen, E.; Smith. G. M.. and Strong, L. C.: J1. Amer. Med. Asin. 110: $1182,1938$.

32. Luckerman, S.: Biol. Rers. 15:291, $191 \%$.

33. Loeb. L.; Suntzelf, V., and Burns, E. L.: Amer. J1. Canc. 35:159. 1939.

34. Burack, E.; Wolfe, J. M.; Lansing, W.. and Wright, A. W.: Canc. Resuch. 1:22\%, 19 1.

3.5. Lipschütz, A.: Trns, $1^{\circ}$. Congr. chilen. y aner, de cir. 252, 1939.

36. Lipschiitz, A.: Archs. P'athol. 31:702, 1941.

37. Foulds, L.: Amex. J1. Canc. 31:.10 1, 1937.

38. Dobrovolskaja-Zaradskaja, N.: Cpts. rd. Soc, de biol, $129: 105,5,193^{5}$.

39. Lipschütz, A.; Vargas, L.. Jr.; Baeza-Rosales, H... and Baeı-Herrera. H.: Proc. Soc. Exper. Biol. \& Med. $4^{6: 76,1941 .}$

fo. Bachmann, W. E.; Cook, J. W.: Dansi, A.; de Worms, G. G. M.. and Robinson, . . M.: Proc. Roy. Soc. London, s.13 123:343, 1937. 
41. Lipschüty, A.: in "Liuro de homenagem" aos Professores Alvaro e Miguel Ozorio de Almeida (Rio de Janciro: 1939), 413 .

42. Lipschiitz, A.; Bcllolio, P.; Chaume, J., and Vargas, L.., Jr.: Proc. Soc. Fxper. Biol. \& Med. $4^{6: 16} 1,1911$.

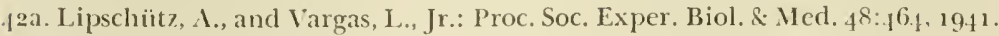

13. Emmens, C. W': Endocrinology $28: 633,1941$.

14. Lipschütz, A., and Vargas, L.., Jr.: Lancet 236:1313, 1939.

45. Chatume, J., and Vargas, L.. Jr.: Rev. chilen. de hig. y med. prevent. 3:83, 194\%.

16. Szabó, I.: Rev. chilen. de hig. y med. prevent. 3:127, 1940.

47. Thibaut, R.: Publus. Depmt. de med. exper., Chile, no. $7,1941$.

48. Lipschiitz, A.; Rorlriguez, F., and Vargas, L., J1.: Cpts. rd. Soc. de biol. 130:939. 1939.

49. Rodriguez, F.: Publns. Depmt. de med. exper., Chile, no. 5, 19.10.

5o. Lipschiit\%, A.; Rodriguez, F., and Vargas, L., Jr.: Endocrinolog! 28:664, 19/1

51. Peacock, P. R., and Beck, S.: Brit. Jl. Exper. Pathol. 21:227, 1940.

52. Mider, C. B., and Morton, J. J.: Jl. Natn. Canc. Inste. 1: $11,1940$.

.73. Rous, P., and Kidd. J. G.: Jl. Exper. Med. 73:365, 1941.

5. Flory, C. M.: Canc. Resrch. 1:262, $194^{1 .}$

55. Des Ligneris, M. J. A.: Amer. Jl. Canc. 40:1, 1940.

56. McEuen, C. S.; Selye, H., and Collip. J. B.: Lancet 230:775, 1936.

57. Zondek, B.: Lancet 230:776, 1936.

58. Lipschütz, A.; Egaña, E.; Szabó, I., and Lecannelier, S.: Proc. Soc. Exper. Biol. \& Mecl. $4^{6}$ : 161,1941 .

59 . Loeb, L.: Act. Union internatn. ctr. canc. 2:148, 1937.

6o. Lipschütz, A.: Cpts. rd. Acad. d. scis. (Paris) 203:1025, $193^{6}$.

61. Lipschütz, A.: Bull. Acad. de med. (Paris) 117:654, 1937 .

62. Lipschütz, A.: Gynécol. ct obstét. 36:407, 481, 1937.

63. Lipschütz, A.: Gynćcol. et obstét. 37:17, 1938.

64. Pfeiffer, C. A.: Anat. Recrd. $75: 465,1939$.

65. Schmidt, 1. G.: Endocrinology 24:69, 1939.

66. Lipschütz, A.: Archs. de biol. 47:181, 1936 .

67. Lipschütz, A.: Virchows Arch. f. pathol. Anat. u. Physiol. 285:35, 1932.

68. Lipschiitz, A.: Cpts. rd. Soc. de biol. $112: 1272,1933$.

6. Lipschütz, A.: Proc. Roy. Soc. London, s.B 93:132; $91: 83,1922$.

7o. Lipschütz, A.: The Internal Secretions of the Sex Glands (Cambridge Engl.], Baltimore: 1924).

71. Lipschütz, A.: in Handbuch der Biologischen Arbeitsmethoden, ed. by E. Abderhalden, Abtl. V, Tl. 3B, 1. Hlft. (Berlin, Wien: 1926), 357 .

72. Hooker, C. W.; Gardner, W. U., and Pfeiffer, C. A.: Jl. Amer. Medl. Assn. $115: 443,1940$. 
EXPLANATION OF PLATES 
Fig. 1. Squamous epithelium and connification in the uterine hom of the rat. $3^{8}$ injections of $80 \mu \mathrm{g}$. of estradiol given as 17 -caprylate in the course of 94 days. $\times$ 33. (XIV, R. 12: from a series of experiments marle in collaboration with $\mathrm{E}$. Egaña and others.)

Figs. 2 and 3. Fig. 2. Insular metaplasia of the uterus in the rat. 37 injections of $10 \mu \mathrm{g}$. of estradiol given as 17 -caprylate in the course of 91 days. Hypertrophied cpithelial cells of the cndometrium (uterine "body") surrounding the metaplastic island. Flattened epithelial cells of the endomctrinm covering the metaplastic island. $\times 8$. . (XIV, R. 6.) Fig. 3. Cylindric epithelial masses in the stroma of the mucosa of the uterine horn of the rat. $3^{8}$ injections of $80 \mu \mathrm{g}$. of estradiol given as 17 -caprylate in the course of 94 days. Proliferation is probably at the expense of uterine glands. Flattened epithelial cells of the edometrium cover the cylindrical epithelial masses. $\times 67$. (XIV, R. 15 ; same series as fig. 1.)

Figs. 7 and 5. Epithelial proliferation of "precancerous" aspect in the endometrium of the upper third of uterine horn in the guinea pig. 100 injections of $20 \mu \mathrm{g}$. of estradiol given as 3 -benzoate in the course of 245 days; sacrificed 114 days after stopping injections. Fig. 4. At the top: glandular cysts; at the bottom: extensive epithelial proliferative masses in the stroma beneath the endometrium; scattered glands in the stroma. Fig. 5. Part of the epithelial masses at higher magnification (1, 14; from a series of experiments made in collaboration with R. Iglesias). 

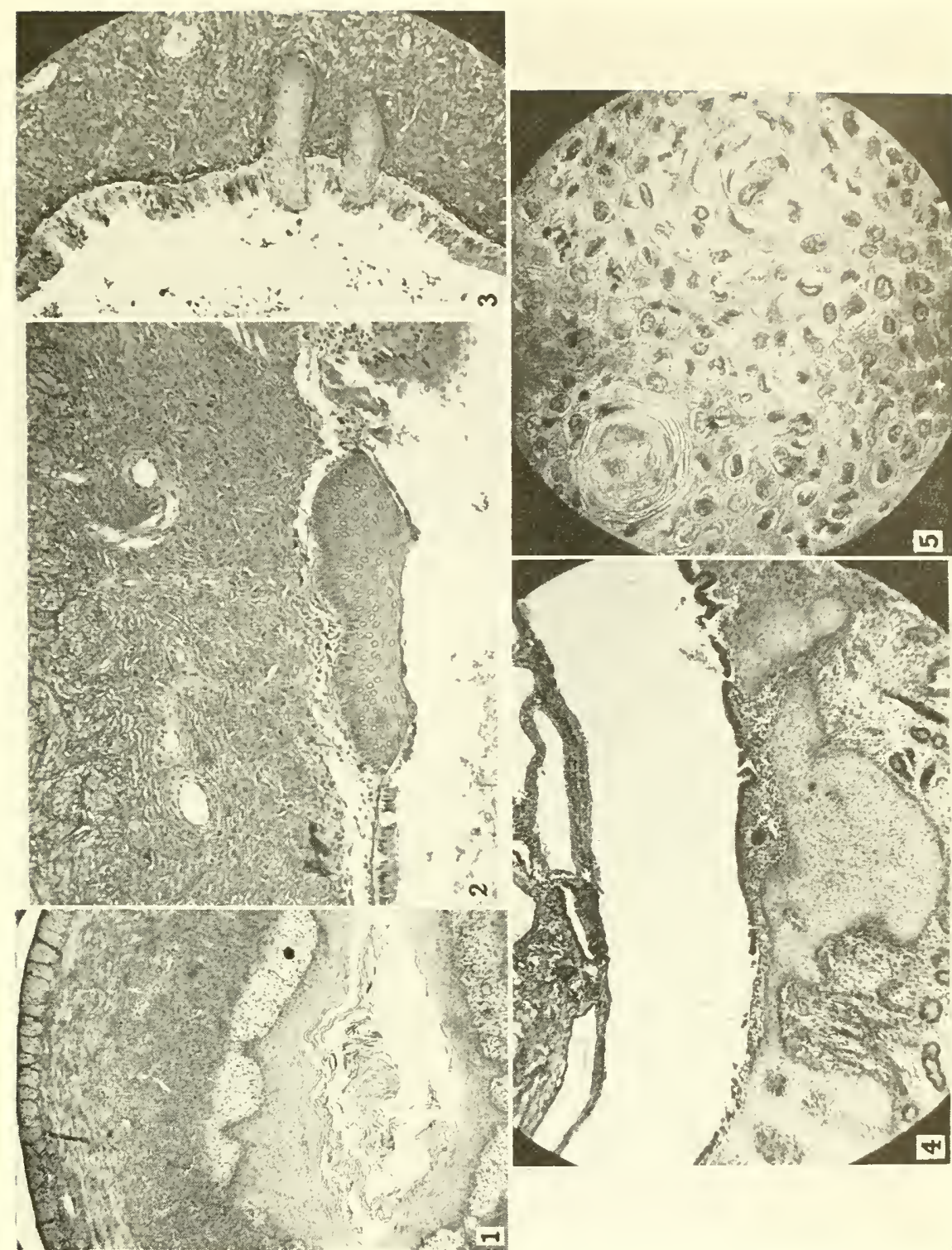

3

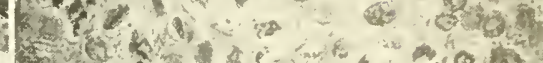
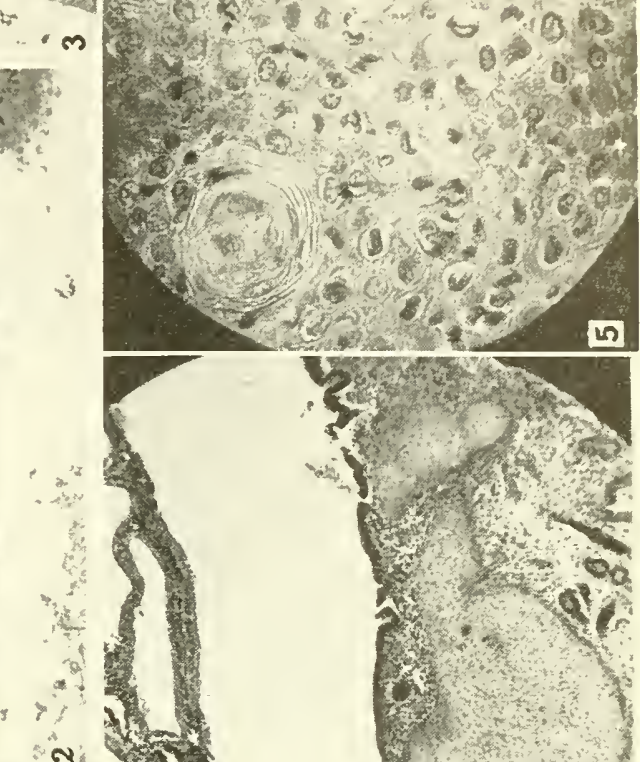

xis
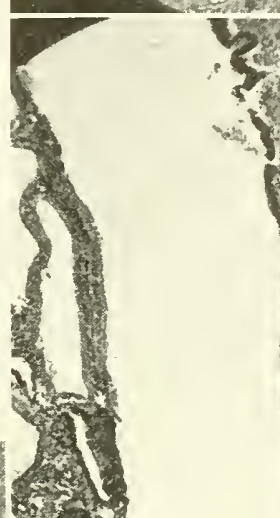

\section{$\stackrel{3}{\stackrel{3}{=}}$}

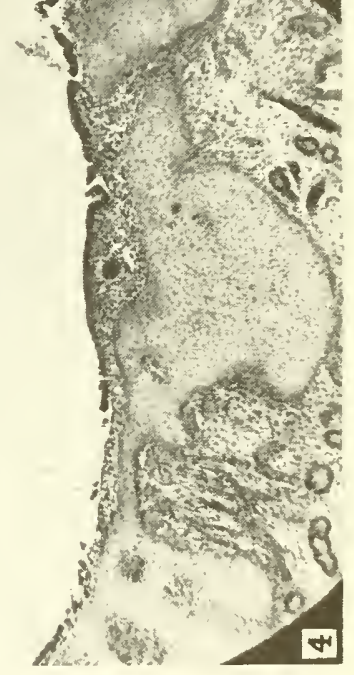


Fig. 6. Various experinental intestinal and mesenteric fibroids in the female guinca pig. At the top, two fibroids of the parietal serosa near the cliaphragm. Subcutancously implanted pellet of estradiol of $2.2 \mathrm{mg}$. from which $1.2 \mathrm{mg}$. have been alssorbed in the eonrse of 80 days (XXVIII, 96; from a scries of experiments in collaboration with R. 'Thibaut and L. Vargas, Jr.).

Fig. 7. Experimental intestinal, mesenteric and "apical" fibroids elicited in the fcmale guinea pig by estrone. The apical tumor (of the mesosalpinx) displaces the left kidney to the right. Subcutaneously implanted pellet of estrone of $52 \mathrm{mg}$. from which $0.4 \mathrm{mg}$. have been absorbed in the course of 80 days (XXVIII, 6o; same series as fig. 4).

Fig. 8. Influence of timing conditions on the tumorigenic action of estrogens. One $\mathbf{m m}$. of the scale corresponds to 2 days. Each mark indicates an injection given on that day. Upper line: one week of injections is followed by two to three weeks free from injections; a total of $3,760 \mu \mathrm{g}$. of estradiol given as 3 -benzoate in the coursc of $3^{6} 5$ days is unable to elicit fibroids and the uterine weight is not far from normal. Under line: injections are given thrice weekly without intervals free from injections; $940 \mu \mathrm{g}$. given in the course of only 113 days elicit uterine subserous, mesometrial and apical fibroids and extragcnital ones; the uterus is enormously increased. Macroscopical figures reduced to the same scale, microscopical figures of the same magnification. (From a series of expcriments published in conjunction with Rodríguez and V'argas. ${ }^{50}$ ) 


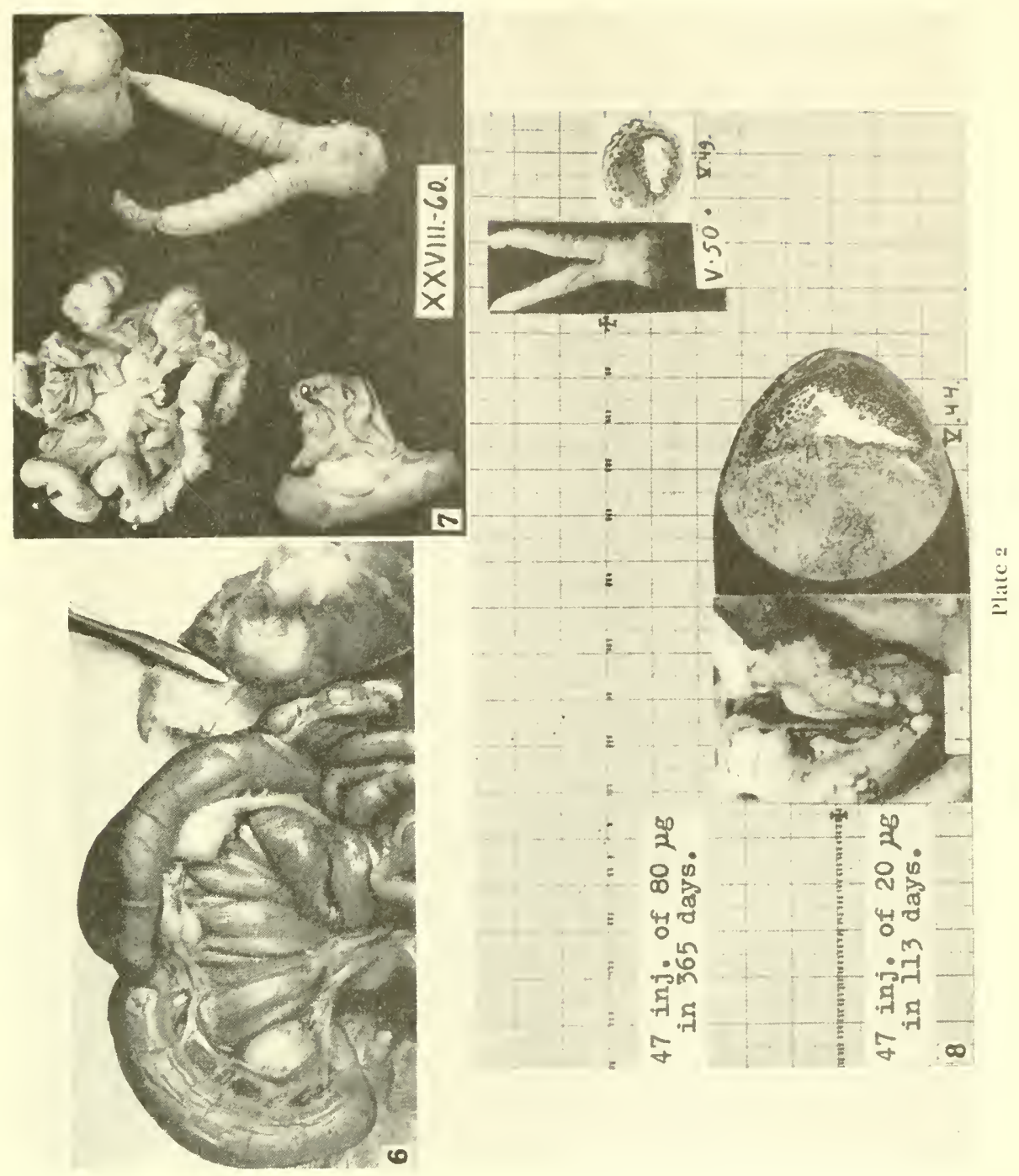




\section{PLATE 3}

Fig. 9. Pluristratified epithelimm of the endometrium of the uterine horn of at guinea pig which has receired 129 injections of $20 \mu \mathrm{g}$. of estradiol given as 3 -benzoate in the course of 335 days. Note absence of cornification. To be compared with frgure $1 . \times 145$. (I, 21; same series as fig. 3.)

Figs. 10 and 11. Nodular local increase of interstitial tissue in a testicular fragment. Fig. 10. Fragment of the upper pole of the right testicle of the guinea pig 130 days after removal of the left end of the greater part of the right testicle, the fragment of the latter being shown. The fragment is surrounded by the fatty body of the testicle. Parts of the head of the epididymis and plexus pampiniformis are also visible. The fragment weighed about $20 \mathrm{mg}$. or 5 per cent of the normal weight of the two testicles. Seminiferous tubules in a state of far-going degeneration. $\times 14$. Fig. 11. Part of interstitial-tissue nodule at higher magnification. Note the variation of nuclear size of interstitial cells which are mostly hypertrophied. $\times 176$. (D. 30 .) 

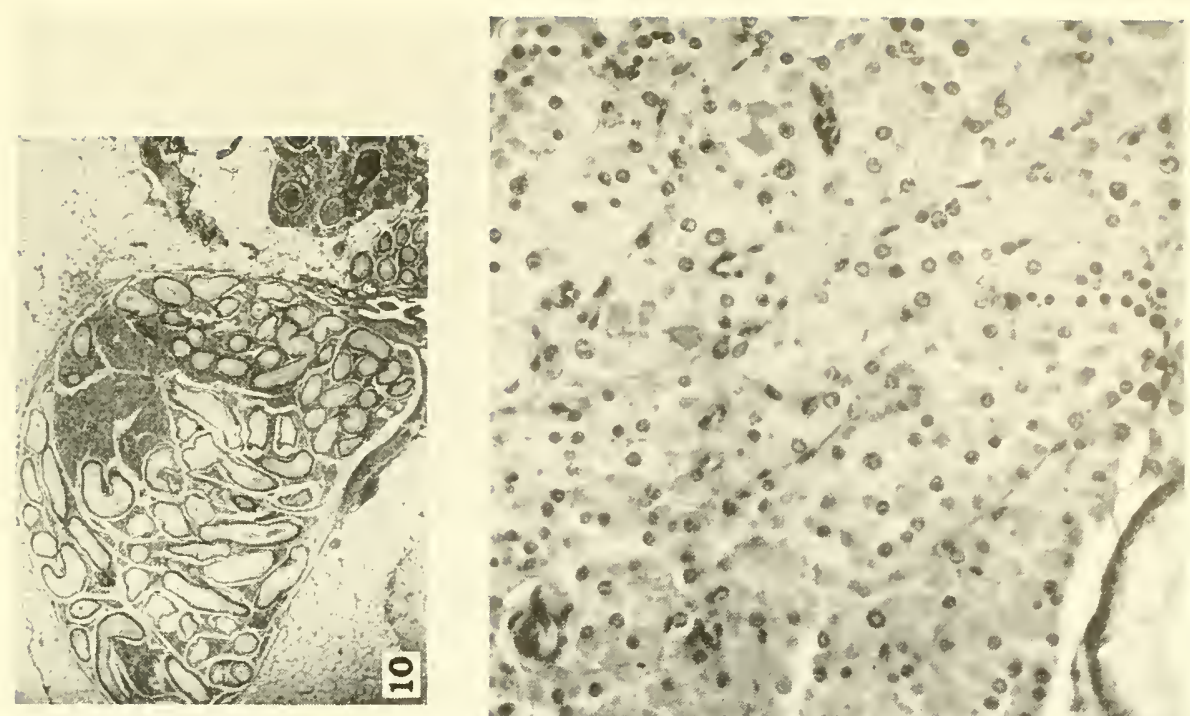

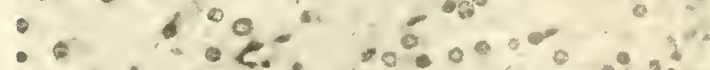

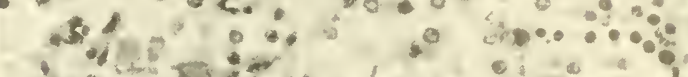

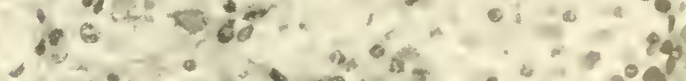

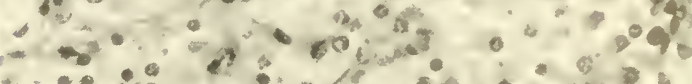

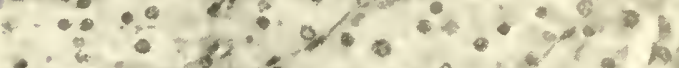

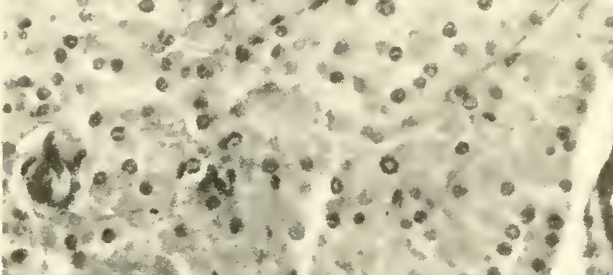

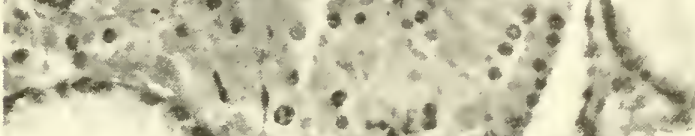
$y-2.1 \geq$

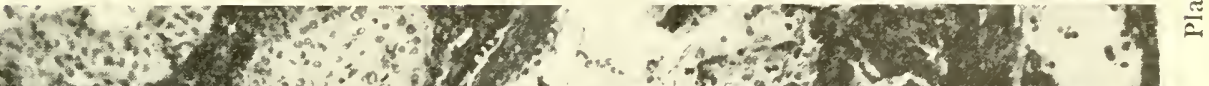

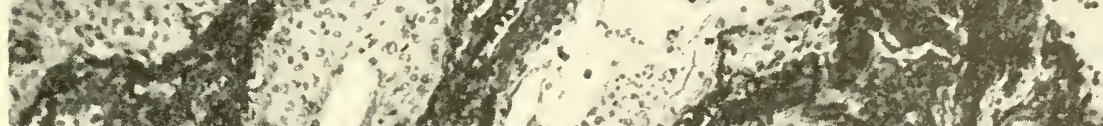

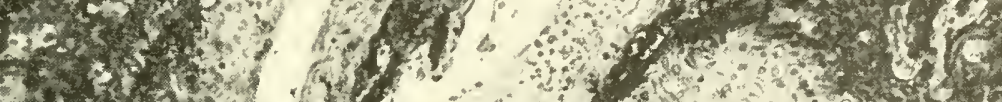

E.

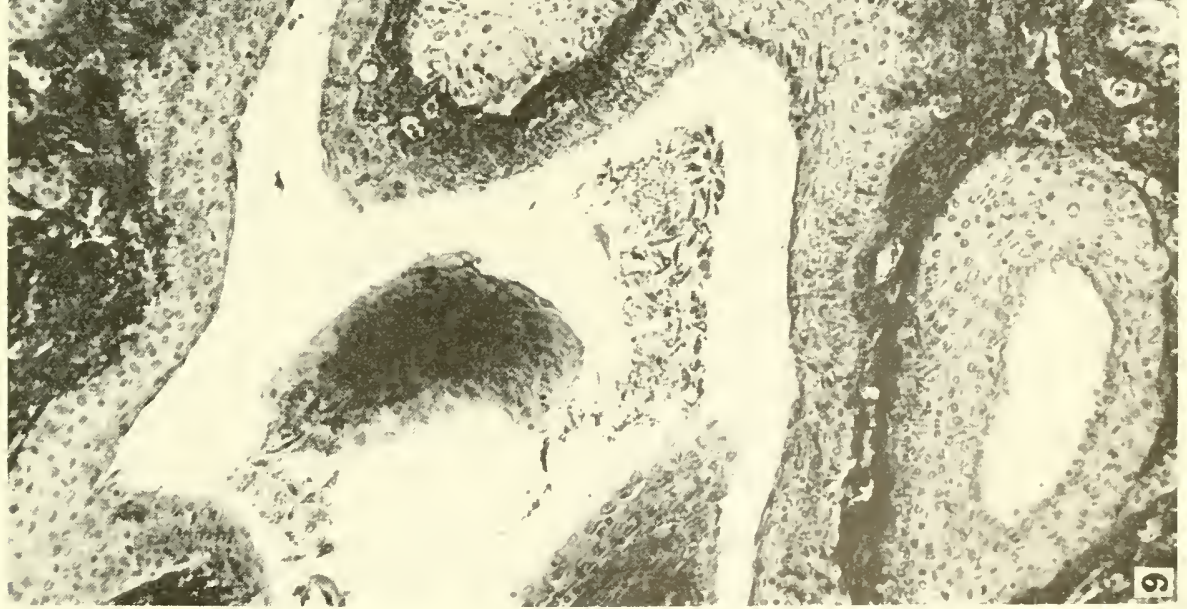



LOBULO-ALVEOLAR MAMMARY GROWTH INDUCED IN HYPOPHYSEGTOMIZED RATS BY INJEGTIONS OF OVARIAN AND HYPOPHYSIAL HORMONES

\author{
By
}

WM. R. LYONS

\title{
策
}

From the

DIVISION OF ANATOMY

UNIVERSITY OF CALIFORNIA MEDICAL SCHOOL

BERKELEY, CALIFORNIA 



\section{LOBULO-ALVEOLAR MAMMARY GROWTH INDUCED IN HYPOPHYSECTOMIZED RATS BY INJEGTIONS OF OVARIAN AND HYPOPHYSIAL HORMONES}

$\mathrm{T}$ WENTY YEARS AGO, adrenotrophic, thyrotrophic, gonadotrophic and somatotrophic functions had atready been proven for the pituitary gland by Evans and co-workers. And from these same investigators came the first evidence of a corpus luteum-activating or luteotrophic function, now identified with the mammotrophic or lactogenic hormone of the anterior lobe (see Evans' Harvey Lecture ${ }^{1}$ for review of early work). Mammary-stimulating activity was demonstrable in crude pituitary extracts by Evans and Simpson ${ }^{2}$ and at that time was thought to be due to pituitary gonadotrophic hormone causing the ovaries to secrete the mammary-stimulating female sex hormones, estrin and progestin. Recent experiments from this laboratory ${ }^{3}$ have shown that the lobulo-alveolar growth induced in intact rats by Evans and Simpson with crude pituitary extracts may be duplicated with purified lactogenic hormone. Here, as in earlier work, ${ }^{4}$ the inclusion of the lactogenic hormone in a gonadotrophic triad along with follicle-stimulating hormone (FSH) and interstitial cell stimulating hormone (ICSH) has seemed advisable since it is capable of causing functional hypertrophy of luteal cells already formed in the ovary. Lactogenic hormone injected into normal rats induces a condition comparable to pseudopregnancy, in which $(a)$ a single crop of corpora lutea become hypertrophic and secrete progestin, $(b)$ follicles do not develop to maturity and therfore ovulation is inhibited, $(c)$ the vagina shows a high degree of mucification, $(d)$ the uterus shows progestational changes and will nidate threads, and $(e)$ the mammary glands show lobulo-alveolar development. Since Nelson ${ }^{5,6}$ and others have shown that estrone will bring about these same changes it might be assumed that this hormone causes an increased secretion of lactogenic hormone by the pituitary. Granted that the pseudopregnant rat is under the influence of an increased secretion of lactogenic hormone, it might be expected that after removal of the pituitary the injection of that hormone would provide adequate substitution therapy in maintaining the set of conditions just listed. As far as the genital tract is concerned that may be true, but the manmary gland fails to grow to the same degree as in the intact animal. This result was foreshadowed in the earlier experiments of Evans and co-workers mentioned by Lyons and Pencharz in 1936, in which gonadotrophic preparations stimulated the ovaries and indirectly the genital tract in hypophysectomized rats, but left the mammary glands atrophic.

The majority of the many experiments of the past seven years in which at- 
tempts have been made to cause mammary growths in hypophysectomized rats with the sex hormones have yiclded negative results (sce Folley, ${ }^{8}$ Turner, ${ }^{8}$ and Petersen ${ }^{10}$ for reviews of this subject). In 1935 Selye and Collip ${ }^{11}$ reported that estrone did not prevent the rapid involution of the hypophysectomized rat's mammary gland. Later ${ }^{12}$ they tried substitution therapy with crude pituitary extracts and estrone, but apparently produced too little mammary development to be considered significant. They concluded that the pituitary extracts given with estrone produced no more development than estrone alone in hypophysectomized rats, but postulated that the ovarian hormones act upon the mammary gland indirectly by way of their pituitary-stimulating effect. Gomez, Turner and co-workers ${ }^{n, 13}$ believe that estrin and progestin do not act directly upon the mammary gland as was formerly thought (estrin causing duct growth and estrin combined with progestin causing lobulo-alveolar growth), but that a pituitary hormone (mammogen I) stimulated to increased secretion by estrin causes duct growth and a second (mammogen II) stimulated to secretion by progestin plus estrin causes lobulo-alveolar growth. Lewis and co-workers ${ }^{14}$ obtained duct growth in hypophysectomized female rats $(25-40$ days old) by injecting for ten days what they claim to be a lipid-soluble mammogen I extracted from cattle pituitaries. Their illustrations show that they restored the glands from the regressed condition observed after hypophysectomy. Greep and Stavely ${ }^{15}$ were able to demonstrate mammary-duct growth in hypophysectomized immature female rats injected with pituitary dry powders suspended in saline, but not with ether-alcohol extracts of dried or wet pituitaries. Mixner and Turner ${ }^{18}$ induced comparable lobulo-alveolar mammary growth in spayed virgin mice by injecting either $400 \mathrm{mg}$. of pituitary suspension which contained mammogen II, or $0.5^{-1.5} \mathrm{mg}$. of progesterone plus 133 I.U. of estrone.

Other investigators believe that duct and alveolar growth of the mammary gland may still depend upon the ovarian hormones (as is suggested by the fact that the proper dose of estrin applied locally to a mammary gland causes only that and no other gland to grow), ${ }^{17}$ but that these hormones will not stimulate mammary growth in the hypophysectomized animal unless some of its multiple deficiencies are corrected. Astwood and co-workers ${ }^{18}$ showed that intact rats restricted to a food intake equal to that of hypophysectomized animals failed as did the latter to show mammary growth when injected with estrin. Samuels and co-workers ${ }^{\text {to }}$ attempted to correct some of the deficiencies of the hypophysectomized rat by force-feeding a diet supplemented by $\mathrm{NaCl}$, adrenocortical extract, and thyroid. Their animals gained in weight, but failed to show mammary growth in response to injections of 1,ooo I.U. of estradiol benzoate every other day for twenty-eight days. Nelson and Tobin ${ }^{20}$ injected their hypophysectomized rats with crude anterior-lobe extract plus estrin and obtained lobular mammary growth. Purified lactogenic hormone plus estrin had "little effect." Uyldert and co-workers ${ }^{21}$ obtained mammary growth when estrin and progestin and a pituitary extract were injected into hypophysecto- 
mized rats. Nathanson and co-workers, ${ }^{22}$ by giving hypophysectonized rats estradiol benzoate plus a "growth complex" containing growtl, lactogenic, and adrenotrophic hormones, were able to maintain the manmary glands in cight of twenty-four animals. Reece and Leonard ${ }^{23}$ obtained mammary-duct growth in hypophysectomized rats injected with estrin plus a "growill" preparation which apparently was a mixture of anterior-lobe hormones. They claim that slight growth was produced in such animals by injecting the "growth" preparation alone, and because of this announced an alternative hypothesis to that of Turner and co-workers, namely that "either estrogen facilitited the mammogenic effect of the growth hormone or that growth hormone facilitated and was responsible for the effect of estrogen." As cuoted by Petersen "Samuels et al. using a more highly purified growth hormone corroborate the findings of Reece and Leonard, but contend other pituitary hormones are also needed." Gardner and White ${ }^{24}$ by giving estrone plus pure prolactin induced mammary growth in hypophysectomized mice comparable to that previously reported in hypophysectomized mice injected with estradiol dipropionate and progesterone; $;^{25}$ apparently no lobulo-alveolar growth was induced in these investigations. Gardner and White suggest "that prolactin may either sensitize the mammary tissue of hypophysectomized mice to estrogen or improve the general condition of these animals so that mammary proliferation may occur."

The literature cited has to do for the most part with the roles played by the ovary and the pituitary in duct and alveolar development of the mammary gland, since in the report to follow only that type of mammary growth (prolactational) and not functional (or lactational) growth is considered. The latter deserves separate treatment and seems to require a different set of synergizing hormones. It is difficult to agree with Uyldert, David and Frend ${ }^{21}$ that "a study of the literature with reference to the problem of the mammary gland and lactation gives one the impression that there is no endocrinological problem to mammary evolution left unsolved." However, these authors admirably sum up the true situation when they write that "various parts of these [developmental] processes can be artificially reproduced with the aid of hormones, but the whole complex eludes attempts to induce it artificially." Progress will have been made when we learn what combination of purified hormones simultancously maintains pregnancy and causes nonlactating lobuloalveolar mammary growth, and what combination subsequently maintains a mammary apparatus adequate in every respect for the suckling of the offspring. In 1938 it was shown that postpartum lactation could be induced and maintained in hypophysectomized rats by injecting extremely high doses of a lactogenic-adrenotrophic hormone combination, but the mothers seemed unable to eject their milk, possibly due to a posterior-pituitaly deficiency. More recently, because of the availability of purified hormones, it has seemed advisable to retun to a study of the homonal factors necessary for prolatiational or lobulo-alveolar growth. During the past year with the constant helpand advice 
of Drs. H. M. Evans and M. E. Simpson and the coöperation of the members of the Institute of Experimental Biology that investigation has been begun and forms the subject of this paper.*

\section{Procedure}

In all of the experiments reported here, female rats of the Long-Evans strain, 6o-7o days of age, were used. Hypophysectomy was done by the parapharyngeal approach on the day following vaginal cornification, and oöphorectomy when performed was carried out immediately after hypophysectomy. At necropsy the completeness of pituitary removal was determined. Injection of the various hormonal combinations was begın immediately after operation. The operated rats received thyroxin subcutaneously, usually in a dose calculated to bring the animals' oxygen consumption back to normal (10 $\mu \mathrm{g}$. daily) and glucose in doses of $200 \mathrm{mg}$. given intraperitoneally four times weekly. All other hormones were administered subcutaneously, the sex hormones in $0.1 \mathrm{cc}$. of sesame oil and the pituitary fractions in $0.5 \mathrm{cc}$. of 2 per cent butanol in water. Injections were made daily for ten days with necropsy twenty-four hours after the last injection. The first inguinal mammary gland was taken from each rat, spread on filter paper, fixed in 10 per cent formol, stained with alum-carmine and cleared in methyl-salicylate.

The mammary glands were judged with the aid of a binocular dissecting microscope and placed in one of six different classes depending upon the type and degree of development shown. D refers to glands showing a duct system either completely devoid of alveoli or alveolar buds, or else having only a negligible number of these (pl. 1, fig. 1). Such a gland in 6o-7o-day-old rats is indicative of regression since rats of this age normally show sparsely distributed alveoli or alveolar buds on a well-developed duct system, for which the designation $\mathrm{DAB}$ is used. The gland shown in plate 1 , figure 2 may be considered representative of the upper limits of $\mathrm{DAB}$ development and when compared with plate 1, figure 1, gives one some idea of the rate at which regression occurs in the ten days following hypophysectomy. Since most of the normal rats showed duct and alveolar mammary development equal to or only slightly less than is shown in plate $\mathbf{t}$, figure 2 , the hormonal combinations used have been judged active on the basis of whether they were able in the first place to maintain this amount of development, and in the second place to cause prolactational or lobular growth. Plate 1 , figures $3-6$, represent a purely arbitrary scale ranging from 1 to $4+$, depending upon the degree of lobulo-alveolar growth (LA) obtained, and may be used in judging the efficacy of the various forms of treatment. Since it is probable that lobulo-alveolar mammary growth may be due to more than one hormone, it has been deemed unnecessary at this time to attempt any estimates of unitage of a lobulo-alveolar growth-

* My sincere thanks go to Miss F. Carter and Mrs. A. McKnight for hypophysectomizing all of the rats, to Dr. M. E. Simpson for the FSH, to Dr. Oliver Kamm of Parke. Davis and Company, for the estrone and progesterone used in this experiment, and to Dr. H. M. Evans for the use of all of the facilities of his Institute. 
TABLE 1

Observations on the Mammary Glands of Normal (N), Hypophysectomized (H), or HYPOPHYSECTOMIZED-Ö̈PHORECTOMIZED (HO) RATS INJECTED

With Various Hormones

\begin{tabular}{|c|c|c|c|c|c|c|}
\hline $\begin{array}{c}\text { Experi- } \\
\text { ment }\end{array}$ & Type & $\begin{array}{l}\text { No. of } \\
\text { rats }\end{array}$ & Ilormone injected* & $\begin{array}{l}\text { Daily } \\
\text { dose }\end{array}$ & $\begin{array}{l}\text { Body } \\
\text { weight } \\
\text { change, } \\
\text { gm. }\end{array}$ & Mammary gland $t$ \\
\hline 1 & $\mathrm{~N}$ & 3 & $\mathrm{~L}_{3} 66 \mathrm{~B} \ldots \ldots \ldots \ldots$ & $2 \mathrm{mg}$ & +38 & $\mathrm{IA}+++$ \\
\hline I & $\mathrm{N}$ & 5 & $\ldots \ldots \ldots \ldots$ & $\cdots \cdots$ & +24 & D.AB \\
\hline 2 & $\mathrm{H}$ & 3 & Estrone........... & $\mathrm{I} \mu \mathrm{g}$. & -15 & $\mathrm{D}$ \\
\hline 2 & $\mathrm{H}$ & 3 & Estrone. . . . . . . . . . . . & $10 \mu \mathrm{g}$ & -21 & $\mathrm{D}$ \\
\hline 2 & $\mathrm{H}$ & 3 & $\left\{\begin{array}{l}\text { Estrone ....................... } \\
\text { Progesterone ... }\end{array}\right.$ & $\begin{array}{l}\text { I } \mu \mathrm{g} \text {. } \\
1 \mathrm{mg} \text {. }\end{array}$ & -16 & $\mathrm{D}$ \\
\hline 2 & $\mathrm{H}$ & 3 & $\left\{\begin{array}{l}\text { Estrone............. } \\
\text { Progesterone . . . }\end{array}\right.$ & $\begin{array}{l}10 \mu \mathrm{g} . \\
\mathrm{I} \mathrm{mg} .\end{array}$ & -21 & $\mathrm{D}$ \\
\hline 2 & $\mathrm{H}$ & 3 & Progesterone. & I mg. & -25 & $\mathrm{D}$ \\
\hline 2 & $\mathrm{H}$ & IO & $\ldots \ldots \ldots \ldots \ldots$ & $\ldots \ldots$ & -11 & $\mathrm{D}$ \\
\hline 3 & $\mathrm{H}$ & 3 & FSH . . & $0.12 \mathrm{mg}$. & -16 & $\mathrm{D}$ \\
\hline+ & $\mathrm{H}$ & 5 & $\mathrm{~L}_{341} \mathrm{~S}$ & $2 \mathrm{mg}$ & -1 & $\mathrm{DAB}$ \\
\hline 4 & $\mathrm{H}$ & 3 & $\mathrm{~L}_{3} 66 \mathrm{~B} \ldots \ldots \ldots$ & $+\mathrm{mg}$ & $\circ$ & $\mathrm{DAB}$ \\
\hline 5 & $\mathrm{H}$ & 5 & $\left\{\begin{array}{l}\mathrm{L}_{3} 66 \mathrm{~B} \ldots \ldots \ldots \ldots \\
\text { Estrone . . . . }\end{array}\right.$ & $\begin{array}{l}2 \mathrm{mg} . \\
\text { I } \mu \mathrm{g} .\end{array}$ & +2 & $\begin{array}{l}\mathrm{LA}+(4) \\
\mathrm{D}(\mathrm{I})\end{array}$ \\
\hline 6 & $\mathrm{H}$ & 3 & $\left\{\begin{array}{l}\mathrm{L}, 366 \mathrm{~B} \ldots \ldots \\
\mathrm{FSH} \ldots \ldots\end{array}\right.$ & $\begin{array}{l}2 \mathrm{mg} \text {. } \\
0.12 \mathrm{mg} \text {. }\end{array}$ & $-I_{4}$ & $\mathrm{LA}+$ \\
\hline 7 & $\mathrm{H}$ & 3 & $\mathrm{~L}_{35} \times \mathrm{B}$. & $5 \mathrm{mg}$. & +20 & $\begin{array}{l}\mathrm{LA}+(2) \\
\mathrm{DAB}(\mathrm{I})\end{array}$ \\
\hline 7 & $\mathrm{H}$ & 3 & $\mathrm{~L}_{351} \mathrm{~B}$ & $10 \mathrm{mg}$. & +27 & $\mathrm{I} . \mathrm{A}+$ \\
\hline 8 & $\mathrm{H}$ & 3 & $\left\{\begin{array}{l}\mathrm{L}_{35 \mathrm{IB}} \mathrm{B} \\
\text { Estrone }\end{array}\right.$ & $\begin{array}{l}1.2 \mathrm{mg} \text {. } \\
\text { I } \mu \mathrm{g} \text {. }\end{array}$ & +19 & $\mathrm{DAB}$ \\
\hline 8 & $\mathrm{H}$ & 3 & $\left\{\begin{array}{l}\text { L35 I B } \\
\text { Estrone }\end{array}\right.$ & $\begin{array}{l}2.5 \mathrm{mg} \text {. } \\
\text { I } \mu \mathrm{g} \text {. }\end{array}$ & +3 I & $D+B$ \\
\hline 8 & $\mathrm{H}$ & 6 & $\left\{\begin{array}{l}\text { L35I B... } \\
\text { Estrone. }\end{array}\right.$ & $\begin{array}{l}5 \mathrm{mg} . \\
\mathrm{I} \mu \mathrm{g} .\end{array}$ & +21 & $\begin{array}{l}\mathrm{LA}+++(5) \\
\mathrm{LA}++(\mathrm{I})\end{array}$ \\
\hline 9 & $\mathrm{H}$ & .3 & $\begin{array}{l}\mathrm{L}_{35 \mathrm{I}} \mathrm{B} \\
\mathrm{FSH}\end{array}$ & $\begin{array}{l}5 \mathrm{mg} . \\
0.12 \mathrm{mg} \text {. }\end{array}$ & +10 & $\begin{array}{l}\mathrm{LA}+++(2) \\
\mathrm{LA}++(\mathrm{I})\end{array}$ \\
\hline 10 & $\mathrm{HO}$ & 3 & $\begin{array}{l}\mathrm{L}_{351 \mathrm{~B}} \mathrm{~B} \\
\text { Estrone.... }\end{array}$ & $\begin{array}{l}5 \mathrm{mg} . \\
1 \mu \mathrm{g} .\end{array}$ & +11 & $D A B$ \\
\hline II & $\mathrm{HO}$ & 3 & $\begin{array}{l}\mathrm{L}_{351} \mathrm{~B} \ldots \ldots \\
\mathrm{FSH}\end{array}$ & $\begin{array}{l}5 \mathrm{mg} . \\
0.12 \mathrm{mg} .\end{array}$ & +24 & D.AB \\
\hline 12 & $\mathrm{HO}$ & 3 & $\begin{array}{l}\text { L } 35 \text { I B . . . } \\
\text { Estrone.... } \\
\text { Progesterone }\end{array}$ & $\begin{array}{l}5 \mathrm{mg} . \\
1 \mu \mathrm{g} . \\
2 \mathrm{mg} \text {. }\end{array}$ & +16 & $\begin{array}{l}\mathrm{LA}++(1) \\
\mathrm{LA}+(2)\end{array}$ \\
\hline I3 & $\mathrm{HO}$ & 3 & $\begin{array}{l}\mathrm{L}_{38} 8_{4} \mathrm{~S} \\
\text { Estrone } \\
\text { Progesterone }\end{array}$ & $\begin{array}{l}2 \mathrm{mg} \text {. } \\
\mathrm{I} \mathrm{\mu g} \text {. } \\
\mathrm{I} \mathrm{mg} .\end{array}$ & -3 & $\begin{array}{l}1 \mathrm{~A}+(2) \\
\mathrm{DAB}(\mathrm{I})\end{array}$ \\
\hline
\end{tabular}

* $\mathrm{L}_{34} \mathrm{IS}, \mathrm{L}_{366 \mathrm{~B}}$, and $\mathrm{L}_{3,84} \mathrm{~S}=$ purified lactogenic hormone; $\mathrm{L}_{351}=\mathrm{a}$ crude lactngenic preparation.

$+\mathrm{D}=$ regression, $\mathrm{DAB}=$ maintenance, $\mathrm{LA}=$ lobulo-alveolar growth: number of rats in parentheses: plus signs indicate grade of LA development. 
promoting factor. Rather, it has seemed important to determine the hormonal factors necessary to build as complete a mammary tree as is found in the antepartum rat $(\mathrm{LA}++$ or ++++$)$.

\section{Experiments and Results (Table 1)}

Experiment I.-Purified lactogenic hormone (2 $\mathrm{mg}$. or 60 I.U. daily) was injected subcutaneously for to days into 3 normal female rats. The estrous cycles were inhibited, and at necropsy on day it the raginae showed mucification, a single crop of large corpora lutea and small Graafian follicles were found in the ovaries, and the manmary glands showed complete lobulo-alveolar growth (pl. 1, fig. 5). Normal control rats sacrificed at 70 days of age showed a DAB condition in the mammary glands comparable to plate 1, figure 2 .

Experiment 2.-Estrone alone (10 I.U. and 100 I.U. daily), estrone (1o I.U. and 100 I.U.) plus I I.U. of progesterone daily, and progesterone alone (1.o I.U. daily) were injected for 10 days into groups of 3 hypophysectomized female rats. Except for the group injected with progesterone alone, the rats showed estrous vaginae, but the mammary glands in every case showed regressive changes similar to those of hypophysectomized controls (pl. 1, fig. 1). Alt of the rats lost weight.

Experiment 3.-A preparation of partially purified pituitary follicle-stimulating hormone (FSH) was injected subcutaneously into 3 rats at a daily dose of 5 R.U. for 10 days. This dose produced large follicles in the ovaries and kept the rats in estrus, but as with estrone the mammary glands showed regression. The animals lost weight.

Experiment 4.-Purified shecp lactogenic hormone was injected at the $2 \mathrm{mg}$. (6o I.U.) level for 10 days into 5 hypophysectomized female rats and purified beef lactogenic hormone at the 4 mg. level (120 I.U.) for a similar period into 3 hypophysectomized rats. The mammary glands of all but one of these rats showed maintenance (DAB, pl. 1, fig. 2). One animal on the 2-mg. dose showed regressing glands. On an average the rats maintained their preoperative weight in this experiment.

Experiment 5.-Five hypophysectomized female rats were injected daily for 10 days with the same beef lactogenic hormone used in Experiment $f(2 \mathrm{mg}$.) plus to I.U. estrone. Slight but definite lobulo-alveolar growth (LA+, pl. 1, fig. 3) was found in the mammary glands of all but one rat which showed regressive glands. This rat lost $10 \mathrm{gm}$., although the group showed a slight average gain.

Experiment 6.-Three hypophysectomized female rats were injected daily for 10 days with $2 \mathrm{mg}$. of the same pure beef lactogenic hormone plus 5 R.U. of FSH. The mammary glands of all animals showed slight lobulo-alveolar growth (LAt, pl, 1, fig. 3). There was an average weight loss of $14 \mathrm{gm}$. in this group.

Experiment 7.-Two groups of 3 hypophysectomized female rats were injected daily for 10 days with 5 and $10 \mathrm{mg}$. respectively of a crude lactogenic preparation containing approximately 10 I.U. of lactogenic hormone per mg., a Moon unit (normal immature male rat test) of adrenotrophin in about $60 \mathrm{mg}$. and a unit of somatotrophin ("growth hormone") in about $1 \mathrm{mg}$. Slight lobulo-alveolar growth $(\mathrm{LA}+)$ was observed in the mammary glands of five rats while the sixth animal ( 5 -mg. dose) showed D.AB.

Experiment S.-Six hypophysectomized female rats were injected daily for to days with $10 \mathrm{I}$.U. of estrone plus $5 \mathrm{mg}$. of crude lactogenic hormone. Excellent lobulo-alveolar growth (LA+1+, fig. 5) was observed in 5 animals and good growth (LA+t, pl. 1, fig. 4) in the sixth. The rats showed an average gain of $2 \mathrm{gm}$. per day. Other experiments in which 1.2 and $2.5 \mathrm{mg}$. of the crude lactogenic extract were injected with to I.U. of estrone merely resulted in mammary gland maintenance (DAB) although the rats gained from 1 to $2 \mathrm{gm}$. per day in body weight.

Experiment 9.-Three hypophysectomized female rats were injected claily for 10 days with $5 \mathrm{mg}$. of the same crude lactogenic preparation plus 5 R.U. of FSH. The results were similar to 
those of Experiment $\mathcal{S}$, two of thee rats showing mammary growth rated ats L. Itrme and one showing LAH growth.

Experiment 10.-Three hypophysectomized-ö̈phorectomized rats were injected daily for 10 days with 10 I.U. of estrone plus $5 \mathrm{mg}$. of the crude lactogenic cxtract. No growth was induced in the mammary glands, but regression was prevented. The rats gained about 1 gun. per day in weight.

Experiment II.-Three hypophysectomized-oöphorectomized rats were injected daily fol 10 days with 5 R.U. of FSH plus $5 \mathrm{mg}$. of crude lactogenic extract. The results were similar to those of Experiment io.

Experiment I2.-Thrce hypophyscctomized-oöphorectomized rats were injected daily for 10 days with 10 I.U. of estrone, a I.U. of progesterone, and $5 \mathrm{mg}$. of culde lactogenic hormone. The mammary growth induced was rated as $\mathrm{LA}+$ in one animal (pl. 1, fig. 4) and L. $1+i n t w o$. In another experiment in which I instead of 2 I.U. of progesterone was used, all three rats showed LAt growth. The rats gained 1-2 gm. per day in body weight.

Experiment 13.--Three hypophysectomized-oöphorectomizcd rats were injected daily for io days with 10 I.U. of estrone, 1 I.U. of progesterone, and 6o I.U. of pure lactogenic hormone. The mammary growth indiced was rated as barely positive lobulo-alveolar growth in two while in the third rat, the gland was merely maintained. These rats lost 1-5 gm. in body weight.

\section{Discussion}

The doses of estrone and progesterone (alone or in combination) used in these experiments failed to stimulate any further growth of the hypophysectomized rats' mammary glands; and they were ineffective in even maintaining the slight alveolar development always present in these rats before hypophysectomy. This was also found to be true in similar animals treated with a pituitary FSH capable of stimulating the secretion of estrin by the ovary. These findings are in accord with the results obtained by the majority of workers who have attempted to stimulate hypophysectomized rats' mammary glands with the sex steroids. Higher doses of the sex hormones in different ratios should be tried before concluding that they are completely ineffective in stimulating mammary growth in the hypophysectomized rat. It has been reported that these hormones do stimulate lobulo-alveolar mammary growth in the hypophysectomized rabbit. ${ }^{2 \bar{T}}$

Purified lactogenic hormone injected into normal rats $(2 \mathrm{mg}$. or 60 I.U. daily) caused excellent lobulo-alveolar mammary growth, but doses of 60-1 20 I.U. daily given to hypophysectomized rats were only capable of preventing or delaying postoperative mammary regression. It is known that lactogenic hormone stimulates the luteal cells to secrete progestin even in the hypophysectomized rat, but apparently in these animals the amount of estrin secreted is negligible or insufficient to act with the progestin to cause mammary growth. This deduction is made from the fact that when $15^{-60}$ I.U of purified lactogenic homone were given daily to hypophyectomized rats along with either 10 I.U. of estrone, or a pituitary FSH which caused estrin secretion, slight lobulo-alveolar growth was induced. The success of this type of treatment was undoubtedly partly due to the secretion of progestin by the activated corpora lutea, but it is also necessary to point out that hypophysectomized rats injected with lactogenic homone consume more food than 
uninjected hypophysectomized controls and maintain (on an average) their preoperative weight, in contrast to a loss of about $17 \mathrm{gm}$. by the latter. Nevertheless, it was noted that minimal lobulo-alveolar growth was induced by lactogenic hormone and FSH in some hypophysectomized rats which had lost as much weight as the controls and showed atrophic thyroids and adrenals at necropsy. In this same connection it has been noted that hypophysectomized rats injected with somatotrophic hormone may sometimes show bone growth even though they experience a loss of body weight.

It was possible to obtain complete lobulo-alveolar mammary growth in hypophysectomized rats given 10 I.U. of estrone (or 5 R.U. of FSH) with $5 \mathrm{mg}$. of a crude acid-acetone beef anterior-lobe extract, $\mathrm{L}_{35} \mathrm{~B}$, containing approximately $10 \mathrm{I}$.U. of lactogenic hormone per $\mathrm{mg}$. Since a considerably higher unitage of lactogenic hormone given in the pure form with estrone was quite incapable of stimulating this degree of lobulo-alveolar development it would appear that another pituitary hormone (or hormones) important for mammary growth and not identified with the lactogenic is present in the crude preparation. It should be recalled that in Astwood's experiments, ${ }^{28}$ luteotrophic and mammary-stimulating activities were not always found together in the same extracts. Enough somatotrophin was present in our crude extract to cause the hypophysectomized rats to grow at the rate of about $2 \mathrm{gm}$. per day even at a $1-\mathrm{mg}$. daily dose, while the $5 \mathrm{mg}$. daily dose maintained the adrenals at about two-thirds of their normal weight.

Further evidence for an unidentified pituitary factor or combination important for mammary growth was found in the doubly operated rats. Estrone and progesterone caused slight lobulo-alveolar growth in hypophysectomizedoöphorectomized rats when given with lactogenic hormone, and good lobuloalveolar growth when given with the crude extract. The crude lactogenic preparation caused no lobulo-alveolar growth when given to the doubly operated animals with estrone or FSH. It is not possible to say, as yet, whether a new hormone or the proper combination of lactogenic, adrenotrophic, and somatotrophic hormones known to be present in the crude extract is capable of rendering the hypophysectomized rat's mammary gland responsive to estrone and progesterone. A few experiments have already been carried out which show that no one of the three mentioned hormones injected with estrone will cause in the hypophysectomized rat the complete lobulo-alveolar growth induced with estrone and the crude combination.

Apparently the mammogen theory of mammary growth is not supported by the data presented. A degree of lobulo-alveolar growth comparable to that consiclered adequate for assaying mammogen $\mathrm{II}^{16}$ was incuced in $(a)$ hypophysectomized rats injected with estrone and a pure protein* (the lactogenic hormone) and (b) hypophysectomized-oöphorectomized rats injected with estrone,

\footnotetext{
* The pure lactogenic hormone used was made by essentially the same method as reported in $1937 .{ }^{29}$ We have shown that the homone isolated by this method may be proven chemically pure by solubility tests. ${ }^{30}$ The acid-acetone extract obtained before the $\mathrm{NH}_{\text {: }}$ step was used as the crude lactogenic preparation.
} 
progesterone, and the same protein. In all our experiments the importance of the two ovarian hormones in stimulating prolactational mammary growth has been demonstrated. None of the well-identified pituitary hormones is at present suspected of being able to stimulate directly the growth of the mammary gland except the lactogenic. We have been able to stimulate "local" lactational growth in individual mammary glands (or sectors) in rablits injected intraductally with pure lactogenic hormone. But it seems likely, judging by the experience of most investigators, that the direct mammotrophic action of the lactogenic hormone is only possible in the hypophysectomized animal restored toward normalcy by certain of the depleted "target-organ" hormones, as for example, adrenocortical hormone.

\section{Conclusions}

I. In female rats hypophysectomized at 60-70 days of age and treated immediately thereafter, the following types of mammary development were observed after daily injections for ten days of the hormones listed:

A. Regression to a gland showing bare ducts after:

(1) 5-10 I.U. of estrone

(2) 1 I.U. of progesterone

(3) 10 I.U. of estrone plus 1-2 I.U. of progesterone

(4) A pituitary FSH which stimulated the ovaries and produced estrous uteri and vaginae

B. Maintenance of an apparently normal duct system bearing sparsely distributed alveoli and alveolar buds after:

( 1) 6o-1 20 I.U. of purified lactogenic hormone

C. Incomplete lobulo-alveolar growth after:

(1) 60 I.U. of purified Iactogenic hormone plus 10 I.U. of estrone

(2) 60 I.U. of purified lactogenic hormone plus 5 R.U. of FSH

(3) 5 and $10 \mathrm{mg}$. of a crude lactogenic hormone (also containing adrenotrophin and somatotrophin)

D. Complete lobulo-alveolar growth after:

(1) $5 \mathrm{mg}$. of a crude lactogenic extract also containing adrenotrophic and somatotrophic hormones, plus 10 I.U. of estrone

(2) $5 \mathrm{mg}$. of the same crude lactogenic extract plus 5 R.U. of FSH

II. In female rats hypophysectomized and oöphorectomized at 6o-7o days of age and treated immediately thereafter, the following types of mammary development were observed after daily injections for ten days of the hormones listed:

A. Maintenance of an apparently nomal duct system, bearing sparsely distributed alveoli and alveolar buds after:

(1) $5 \mathrm{mg}$. of the above-mentioned crude lactogenic extract plus io I.U. of estrone

(2) $5 \mathrm{mg}$. of the same crude lactogenic extract plus 5 R.U. of FSH 
B. Incomplete lobulo-alveolar growth after:

(1) 6 o I.U. of purified lactogenic hormone plus ı I.U. of estrone and 1-2 I.U. of progesterone (barely positive)

(2) $5 \mathrm{mg}$. of the crude lactogenic extract plus 10 I.U. of estrone and 1-2 I.U. of progesterone (definitely positive)

III. Normal 6o-7o-day-old female rats injected for ten days with 6o I.U. of purified lactogenic hormone daily showed complete lobulo-alveolar mammary development.

\section{REFERENCES}

1. Evans, H. Mf.: Harver Lects. (1923) 19:212, 1925.

2. Evans, H. M., and Simpson, M. E.: Aner. Jl. Physiol. 89:511, 1931.

3. Lyons, W. R.; Simpson, M. E., and Evans, H. M.: Proc. Soc. Exper. Biol. \& Med. 48:634, 1941.

4. Evans, H. M.; Simpson, M. E.; Lyons, W. R., and Turpeinin, K.: Endocrinology 28:933, $194^{1}$.

5. Nelson, W. O.: Anat. Recrd. 64(supp. 1):52, 1935 .

6. Merckel, C., and Nelson, W. O.: Anat. Recrd. 76:391, 1940.

7. Lyons, W. R., and Pencharz, R. I.: Proc. Soc. Exper. Biol. \& Med. 33:589, 1936.

8. Folley, S. J.: Biol. Revs. 15:421, 1940.

9. Tumer, C. W.: in Sex and Internal Secretions, ed. by E. Allen (2d ed.; Baltimore: 1939), $74^{\circ}$.

1o. Petersen, W. E.: Jl. Dair. Sci. 25:71, 1942.

11. Selye, H., and Collip, J. B.: Proc. Soc. Exper. Biol. \&. Med. 32:1377, 1935.

12. Selye, H., and Collip, J. B.: Endocrinology 20:667, $193^{6 .}$

13. Gomez, E. T., and Turner, C. W.: Proc. Soc. Exper. Biol. \& Med. 37:607, $193^{8}$.

14. Lewis, A. A.; Gomez, E. T., and Turner, C. W.: Endocrinology 30:36, $194^{2}$.

15. Greep, R. O., and Stavely, H. E.: Endocrinology 29:18, 1941.

16. Mixner, J. P., and Turner, C. W.: Endocrinology 29:324, 1941.

17. Lyons, W. R., and Sako, Y': Proc. Soc. Exper. Biol. \& Med. $44: 398,1940$.

18. Astwood, E. B.; Geschickter, C. F., and Rausch, E. O.: Amer. Jl. Anat. 61:373, 1937.

19. Samuels, L. T.; Reinecke, R. M., and Petersen, IV. E.: Proc. Soc. Exper. Biol. \& Med. $4^{6:}$ $379.19+1$.

20. Nelson, W. O., and Tobin, C. E.: Anat. Recid. 67(supp. 1):111, 1936.

21. Uyldert, I. E.; David, K. G., and Freud, J.: Act. brev. Neerland. physiol. 10:105, 1940.

22. Nathanson, I. T.; Shaw, D. T., and Franseen, C. C.: Proc. Soc. Exper. Biol. \&. Med. 12:652. 1939.

23. Reece, R. P., and Leonard, S. L.: Endocrinology 29:297, 1941.

24. Gardner, W. U., and White, A.: Proc. Soc. Exper. Biol. \& Med. 48:590, 1941.

25. Gardner, W. U.: Proc. Soc. Exper. Biol. \& Med. 45:835, $194^{\circ}$.

26. Pencharz, R. I., and Lyons, WV. R.: Proc. Soc. Exper. Biol. \& Med. $3^{8: 388, ~} 193^{8}$.

27. Asdell, S. A., and Seidenstein, H. R.: Proc. Soc. Exper. Biol. \& Med. 32:931, 1935.

28. Astwood. E. B.: Endocrinology 28:309, 1941.

29. Lyons, W. R.: Proc. Soc. Exper. Biol. \& Med. 35:645, 1937.

30. Li, C. H.; Lyons, W. R., and Evans, H. M.: Jl. Genrl. Physiol. 24:303, 1941. 
EXPLANATION OF PLATE 
Figs. 1-6 represent one-half to two-thirds of the first right inguinal mammary gland removed from female rats after various treatments as listed below. Fixed in 10 per cent formol, stained with alum-carmine, cleared in methyl salicylate, photographed at $\times 1.25$.

Hypophysectomy and oöphorectomy were performed on the same day when the rats were 6o-7o days of age; treatment begun immediately and continued for to days with necropsy on day 11 .

Fig. 1. From a hypophysectomized rat injected with FSH, ghucose, and thyroxin. This is the state of mammary development referred to in the text and table as D, signifying that little or no parenchyma beyond bare ducts is present. It is representative of the slow regression that occurs following hypophysectomy in the rat used, whether uninjected or injected with certain levels of estrin, progestin, or FSH.

Fig. 2. From a hypophysectomized-oöphorectomized rat injected with crude lactogenic hormone, FSH, thyroxin, and glucose. Referred to as DAB = ducts, and a few scattered alveoli which are mostly in the so-called "bud" form and not aggregated into lobules. The development shown here represents the upper limit of what may be found in normal 6o-7o-day-old rats.

Fig. 3. From a hypophysectomized rat injected with purified lactogenic hormone, FSH, thyroxin, and glucose. Referred to as LAt $=$ minimal lobuloalveolar growth which may also be induced with pure lactogenic hormone and estrone.

Fig. 4. From a hypophysectomized-oöphorectomized rat injected with estrone, progesterone, crude lactogenic hormone, thyroxin, and glucose. Referred to as LA+t, signifying an intermediate degree of lobulation.

Fig. 5. From a normal rat injected with purified lactogenic hormone. Referred to as LAH+1. This gland and that in figure 6 represent the variation seen in the pregnant rat from day 16 to term. The degree of development shown here has been attained in hypophysectomized rats injected with crude lactogenic hormone plus either FSH or estrone.

Fig. 6. From a normal rat injected with crude lactogenic hormone. Referred to as $\mathrm{LA}+\mathrm{HH}=$ complete lobulo-alveolar growth. Enlargement of individual alveoli suggests that the early secretory phase had begun in this gland. 

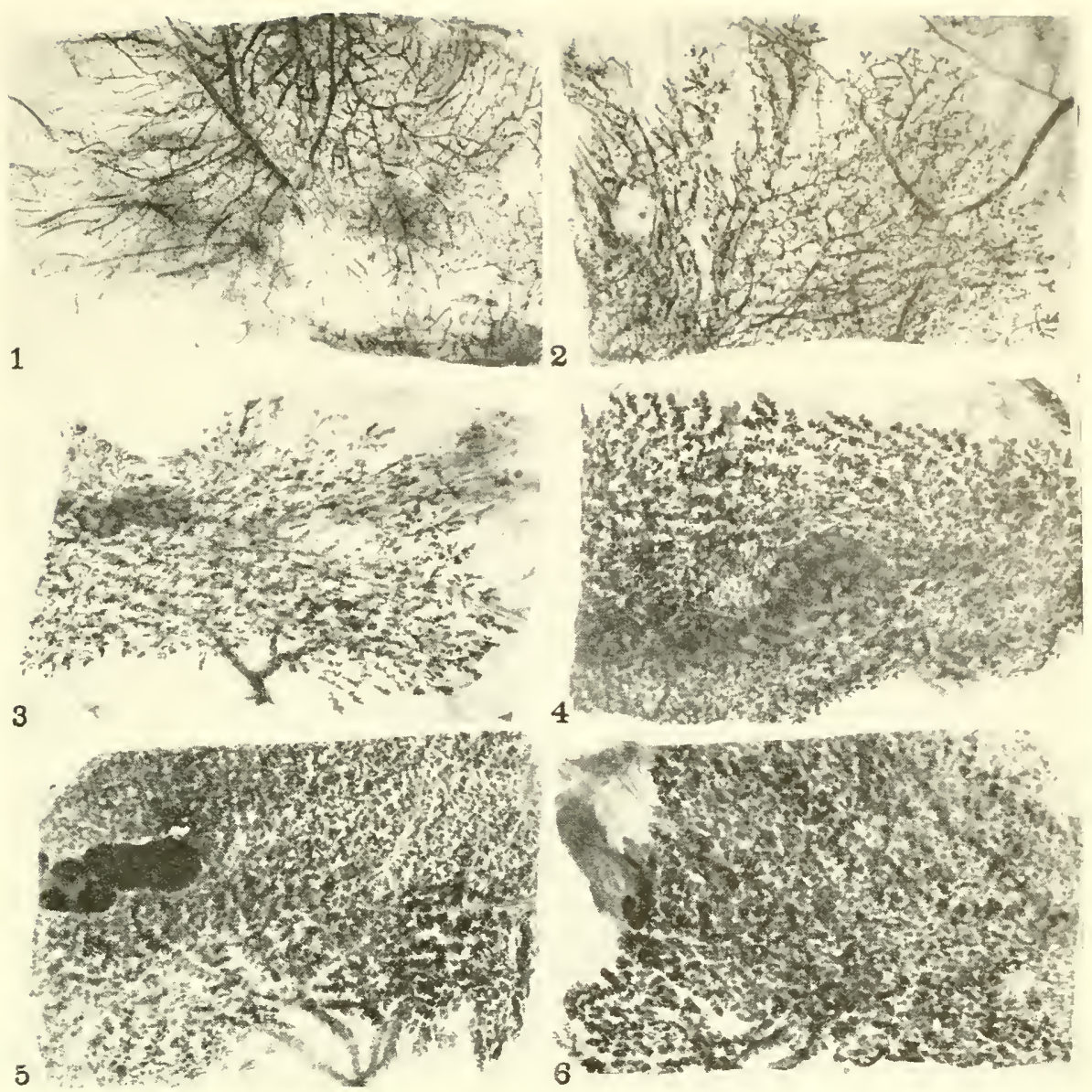

Plate 1 



\section{PULMONIC INTERSTITIAL}

EMPHYSEMA AND ITS SEQUELAE: AN ANATOMICAL INTERPRETATION

$$
\text { By }
$$

CHARLES C. MACKIIN AND MADGE T. MACKLIN

\section{稰}

From the

LNIVERSITY OF WESTERN ONTARIO MEDICAL SCHOOL LONDON, CANADA 

The authors regard it as a great honor to be invited to contribute to this testimonial to Professor Herbert McLean Evans who has done so much to advance functional anatomy, and to apply his discoveries to the solution of problems in scientific medicine. In this way he has materially aided the luman race. We look back with pleasure to the days when we were all working together in the great anatomical department of the Johns Hopkins Medical School under that master of anatomical research and development, the late Professor Franklin Paine Mall. We join in wishing for Professor Evans the continued possession of all factors requisite to the prolongation for many years of his outstanding work. 



\section{TABLE OF GONTENTS}

Introduction . . . . . . . . . . . . . . . . . . . . 337

Pulmonic Comnective Tissuc and Its Pneumatization . . . . . . 337

Human Pulmonic Interstitial Emphysema (PIE). Pneumomediastinum, etc. . . . . . . . . . . . . . . . . . . 339

Movement of Air Bubbles Toward the Mediastinum . . . . . . . $34^{\circ}$

Airblock and Its Effects . . . . . . . . . . . . . . . . 340

The "Splinting" of the Lung by Incarcerated Air . . . . . . . . 342

Natural Relief of PIE . . . . . . . . . . . . . . 342

Mediastinal Emphysema and Its Alleviation . . . . . . . . . . . 343

Animal Experiments . . . . . . . . . . . . . . . . . . 341

Forcible Orerinflation of Part of a Living Animal's Lung

Forcible Overinflation of Entire Fresh Lungs

Analogies in Human Chest Pathology . . . . . . . . . . . $34^{6}$

Atelectasis

Contributory Causes

Survey of the Literature for PIE and Its Sequelae . . . . . . . $34^{8}$

Chest Conditions Probably Showing PIE and Sequelae, from Local Alveolar Overstrain . . . . . . . . . . . . . 348

Atelectasis Neonatorum

Autoresorption of Aberrant Air

Why Aberrant Air Escapes Attention

Interalveolar Pores

Hereditary Predisposition

Local Alveolar Overstrain

PIE from General Alveolar Overstrain . . . . . . . . . . 352

Natural Overstrain Cases

Abrupt Decompression

Artificial Overstrain Cases

Lung Blast

Intratracheal Anesthesia and Artificial Respiration PIE Cases

Miscellaneous Cases of PIE . . . . . . . . . . . . . . $35^{8}$

Rupture Sites . . . . . . . . . . . . . . . . . . . . 359

Prevention, Diagnosis and Treatment . . . . . . . . . . . . 360

Summary . . . . . . . . . . . . . . . . . 361

Final Note . . . . . . . . . . . . . . . . . 36 5

References . . . . . . . . . . . . . . . 366 



\section{PULMONIC INTERSTITIAL EMPHYSEMA AND ITS SEQUELAE: AN ANATOMICAL INTERPRETATION*}

\section{INTRODUCTION}

$\mathrm{T}$ HE BETTER the understanding of the functional anatomy of an organ the better the comprehension of its fundamental pathology. The newer knowledge, for instance, of the way the various parts of the lung work together to subserve its function has helped materially in the interpretation of its discases, such as senile emphysema. ${ }^{1}$ In a more restricted application of this principle, the functional conception of the connective-tissue formations of the lung has given us the means of grasping the nature and significance of pulmonic interstitial cmphysema and its sequelae. In the development of this proposition we shall discuss the following anong other points: how pulmonic interstitial emphysema (referred to hereinafter for brevity as PIE) originates and spreads, as revealed particularly by animal experimentation; some of the many clinical conditions with which it is associated; and the mode of action in producing its ill effects, known as "airblock," which may have serious and even fatal consequences. Although airblock is only now beginning to be diagnosed, its physical basis, the aberrant air in the connective tissues of the lung, mediastinum and beyond, has been revealed at autopsy, and is now being demonstrated by roentgenography. From a study of pertinent clinical and pathological reports in the light of our laboratory experience we believe that airblock is present in serious degree more often than is realized, and hope that this emphasis on its widespread occurrence will lead to its more general discorery and alleviation. Suggestions for its diagnosis and relief are given. First, let us say a word on the dynamics of pulmonic connective tissue.

\section{Pulmonic Connective Tissue and Its Pneumatization}

The subdivisions of the pulmonic connective tissue are named from their relation to various lung structures; as subserous, inter- or perilobular (or septal), hilar, peribronchial, and perivascular. They are confluent, and the mass extends directly, through the lung root, into the mediastinum and beyond. Viewed in toto, this tissue is a continum of soft succulent material, readily dissectible by air which may gain entry into it. Most important of these subdivisions in its bearing on PIE is the sheath of the pulmonary arterial and venous trees. This, in microsections, is seen as a layer betreen the vasculat

* In part as given by Charles C. Macklin on the invitation program of the American Association of Anatomists on April $11,19 f 1$, at the Lniversity of Chicago, ander the title "Some features of the functional anatoms of the lung," and also before the Gilson . Inamical Society of the University of Buffalo Medical School, on March 31, 1912, on "Pulmonic Interstitial Emphysema, interpreted by an Anatomist." Neither lecture has been published. 
wall within and the ring of pulmonic alveoli without. Specifically, the outer boundary of this vascular sheath is made up of the contiguous bases of the perivascular alveoli which, collectively, form a mosaic or pavementlike layer. This extremely thin membrane is all that intervenes between the air of the lung and the fluid-filled connective tissue of the underlying vascular sheath.

Now the interesting thing, functionally, about this perivascular ring of alveoli (or rather branched tunnel system, for the alveolar layer is continuous around the pulmonary blood vessels from the smaller branches to the larger trunks) is that it widens with inspiration. This action has the effect of increasing the caliber of the pulmonary arteries and veins during inspiration, and thus of lowering the resistance of the pulmonary circulatory system. In other words, the inspiratory enlargement of this distensible perivascular envelope of alveoli steepens the down-gradient from right ventricle to left atrium. It is of less importance, at this juncture, to remark that this widening of the arterial and venous streambeds of the pulmonary system is accomplished by the stroma pull of the lung, which is motivated by the pressure of the incoming air, which, in turn, is permitted to act thus because of the muscular action of the inspiratory mechanism; that, through this functional anatonical conception, further light is shed on the fortunate natural arrangement whereby the operation which brings air into the lungs synchronously brings more blood into them; and that this explanation of an inspiratory "swelling action" on the pulmonary blood vessels makes less puzzling, perhaps, such cryptic terms as "negative pressure" and "suction." Rather for us, now, the important thing to note is that this perivascular tunnel system of alveoli does widen during inspiration with, consequentially, a certain amount of stretching of each and every alveolar base which separates the air from the underlying connective tissue of the vascular sheath; and that this stretching due to widening of the tunnel is augmented by that due to its lengthening, for inspiratory lengthening of the pulmonary blood vessels and their environmental structures is just as much a part of inflational adjustment as is the lengthening of the bronchial tree during the same respiratory phase. ${ }^{1}$ This much is physiology.

As long as the swelling of the blood vessel keeps pace with the enlargement of the surrounding zone of alveoli there is no disturbance of the pressure relations between the alveolar air and the underlying connective tissue; or, more explicitly, there is no tendency for air to break through the thin alveolar bases and invade the vascular sheath. All that happens in the sheath is a passive enlargement in diameter in accommodation with the similar enlargements of its neighbors. But if the alveolar zone becomes overdistended without there being a simultaneous and equivalent swelling of the blood vessel, then a downward pressure gradient is set up between air and connective tissue, and in consequence minute ruptures may be formed in the thin alveolar bases, weakened through divarication of their network of fibers, through which air enters the sheath. The same imbalance may occur if the blood ressel shrinks (as it does 
when, for any reason, the normal volume of blood is not receivect from the right ventricle) without there being an equivalent narrowing of the alveolat envelope. These leakage-favoring factors are spoken of, respectively, as " $\mathrm{A}$ " and "B." When they act together there is even more tendency for air to leak into the vascular sheaths than when either is acting alone.

Much could be said as to the efficiency of the lung as an air container, and the safeguards against leakage of air into the pulmonic connective tissues usually obtaining, but this is not the place to say it. The air holder is not alwaty impervions. We admit, too, that air may break out from the hing at other points than the perivascular alveolar bases, under abnormal conditions, as into the interlobular septa, or eren through the pleura. We feel confident, however, that the perivascular zone is an important one from the point of view of leakage of air and are convinced that a knowledge of the functional anatomy of these parts has done much to explain the mode of origin of PIE. From the vascular sheaths the air can spread into the other parts of the lung connective tissue. It is through pressure upon the blood vessels by air bubbles, and through interference by air incarcerated in the connective tissues with the ventilational action of the lungs that PIE exerts its damaging influence on the vital functions of circulation and respiration.

Human Pulamonic Interstitial Emphysema, Pneunomediastinum, Etc.

This is just what happens in the human subject when air, in damaging quantity, enters the interstitial tissue of the lung. It is an "accident" of surprisingty frequent occursence, and is found under a wide variety of clinical conditions. The initial step, pulmonary interstitial emphysema, is seldom recognized clinically, and not always at autopsy. Even emphysema of the mediastinum. the next point of invasion by the air, is only now beginning to be diagnosed clinically with any degree of frequency. ${ }^{2-9}$ The further extension of air into the subcutaneous tissues of the neck, face, chest, etc., has been recognized, of course, although the source of the air has not been well understood. It has usually been thought to be a laceration in the mucosa of the upper airway, in those cases in which intratracheal anesthesia has been used or in which some instrument has been introduced into the trachea. Unexplained entry of air into the pleural cavities has long been known as "spontaneous" or "idiopathic" pneumothorax, although here, again, the source and route of the air have not been correctly visualized in the majority of instances. Spontaneous pneumothorax has often been regarded as arising through rupture of subpleural blebs, ${ }^{10}$ the origin of which has been variously interpreted, rather than as occurring from the rupture of an air-distended mediastinum ${ }^{11}$ which has received its air by extension from a PIE. Berkley and Coffen, ${ }^{12}$ however, recognized that subcutaneous emphysema and pneumothorax, arising in patients with influenza, had a common source of origin, namely air in the mediastinum. Pneumoretroperitoneum has been looked upon as due to the extension of ail from the mediastinum, although PIE as the origin of the mediastinal air hat 
often been overlooked. Pncumoprecordium has been diagnosed occasionally, but PIE as its source has not often becn suspected. This condition is not infrequently called pncumopericardium, we think, erroncously, for the most part. When the air has worked its way forward over the heart, a "crunching" sound, audible several fect away from the patient, and synchronous with the heart beat, may be hcard., ${ }^{4,13}$ This is pathognomonic of air in the anterior mediastinum, but absence of this sign does not rule out the presence of air in other parts of the mediastinum.

\section{Movement of Air Bubbles toward the Mediastinum}

Once rupture openings have been formed, the tendency is for leakage of air into the interstitial tissue to continue until conditions arise to prevent it. The air does not accumulate near the vascular-sheath invasion sites but tends to move toward the mediastinum, in which it may develop a pressure greater than that of the atmosphere. The ordinary plus pressure of expiration would seem insufficient to account for the impulsion of the bubbles against such opposition, and elevation of the pressure head in the leaking alveoli, as by coughing and straining with the glottis closed, must be postulated in explanation. Newly entered bubbles push on those already in the connective tissue.

Another factor in moving the bubbles along would seem to be a sort of "pumping" or "milking" action on the part of the broncho-vascular rays. One of the most interesting features of the functional anatomy of the lung is the way all structures radiating out from the hilum, such as bronchi and blood vessels, elongate in inspiration and shorten in expiration. ${ }^{14-17}$ Without this accommodational length change, inflation and deflation of the lung would be impossible. ${ }^{118-21}$ Yet this perpetual lengthening and shortening, particularly of the pulmonary arteries and veins, is not an unmixed blessing when once air has entered the sheaths, for it seems to have the effect of moving along the train of air bubbles toward the lung root until stopped by the mass of packed bubbles, and thus of augmenting the same propensity arising from their being pushed from behind by new bubbles leaking in under the raised pressure head. The stream does not seem to become easily dammed up; not, perhaps, at times, until the pressure in the mediastinum rises to a prohibitive degree, in cases where escape from that space is not readily provided. The path of least resistance is toward the root. The way is thus constantly open for more air to enter from the leakage points. The air bubbles increase in size through coalescence and the degree of their pressure damage increases as they move along, for they constantly impinge on larger and larger trunks. Here, again, a knowledge of the functional anatomy of the lung aids in the understanding of PIE.

\section{Airblock and Its Effects}

Airblock is primarily a malady of the chest, but since the aberrant air may extend through the superior and inferior thoracic apertures, a field beyond the mediastinum may develop in addition to the pulmonic and mediastinal 
ones. Clinically the effect is general. Airblock strikes at two vital functions, circulation and respiration. More thought might well be given to the physical nature of the air bubbles which do the damage. Their surface tension derives from the nature of the connective-tissue fluid. The bubbles, as they emerge from the alveoli, and press upon the terminal pulmonic vascular branches, must be very tiny. Their tendency to merge is irresistible. In the mediastinum they are large and conspicuous, and in the retroperitoneum may be inches across. It may take some hours for any given case of airblock to develop. With conditions favorable for the continuance of air leakage the air tends to move on into the mediastinum.

The air accumulates in the mediastinum and the curious condition may arise in which its pressure there is even greater than that of the atmosphere. Situated thus it is in the position of a strong invading army in a vital center. It is placed where it can do the greatest possible damage. All the mediastinal contents are pressed upon. The filling of the ventricular, and particularly the atrial, chambers would be hampered, and, in extreme cases, actually prevented. The great vessels, too, would be pressed upon. Systemic venous return would be slowed and even halted. Generation of pressure in the mediastinum rrould reflect back on the lung, and the aberrant air pressure there would also rise. Relief would be instantly afforded by air breaking out of the mediastinum, so that. in some ways, such things as subcutaneous emphysema and retroperitoneum are favorable signs in that they indicate at least a temporary surcease for the oppressed mediastinal contents. Pneumothorax is of the same order, and, in addition, if on the affected side, it tends to stop the leakage. The progressively weakened circulation is less and less able to take care of the task of absorbing the air, so that there is little or no assuagement from that quarter. The importance of a serious case of pneumomediastinum can hardly be overemphasized. It constitutes a dramatic crisis. Yet until recently many physicians have been blind to a realization of what was going on, and how the condition might be relieved. It has, no doubt, been occurring for ages, in the dark.

It may be that there are many relatively slight cases of PIE which clear up without producing serious airblock, but there are undoubtedly many cases where the interstitial emphysema rapidly advances from local to general as the bubbles, swarming toward the lung root, hamper the circulation in the entire lung rather than in a part; then, invading the mediastinum ${ }^{22-25}$ they proceed to eroke the circulatory crisis there, already described. Physicians are urged to visualize the effects on the mediastinal contents when the pressure of mediastinal air rises above atmospheric pressure. Doubtless many of these cases were thought by the attending physicians to be hopeless, when but a needle prick would have saved their lives! Many were probably set down to a failing myocardium. In view of the hidden nature of the malady it is not surprising that there has been failure in diagnosis. Some have been mistaken for angina pectoris, ${ }^{28,27}$ and the symptoms were presumably due to pressure upon the great vessels, heart, or perhaps specifically upon the coronaries themselves. Here is 
a condition which, like syphilis, acting behind a mask, may simulate other diseases. Backing up from the mediastinum, a PIE may be established in the opposite lung, and the distress of the patient become even more aggravated. The imagination should be called into play to envisage serious cases with pulmonary and systemic ressels impeded by the indentations of the air bubbles, and the action of the heart itself embarrassed or completely throttled by the mass of froth around it, as well as by the encroachment upon it of the bloated and stiffened lungs. Airblock should be regarded as a disease in itself. The "air sickness" of aviation medicine is not the only pneumapathy; here is one which is widespread and may be deadly. The condition may-indeed often doesclear up of itself, but this should not lead us to view it lightly. The hopeful side of the matter is that so many progressive physicians are studying PIE and mediastinal emphysema scientifically and arriving at useful means of diagnosis and treatment.

\section{The "Splinting" of the Lung by Incarcerated Air}

In functional anatomy, the arrangement of the bronchial and vascular trees, with their connective-tissue envelopes, has been likened to a mechanical framework which opens up in inspiration and closes in expiration. The aforementioned lengthening and shortening of these structures are an integral part of this action,,$^{21}$ without which no respiration could occur. For it to take place it is essential that there be complete freedom of inlet and outlet of air. When air is trapped in the vascular sheaths, interlobular septa, or other parts of the connective tissue, this opening and closing action is interfered with. The normal amount of air intake is reduced, the requisite collapse is prevented, and the ventilational process hampered; in short, the lung is more or less seriously fixed or locked in a state of bulk comparable to partial or full inspiration..$^{25}$ The enlargement of its mass is, in man, more notable in the central and radicular than in the peripheral regions. The greater the accumulation of air, the more the patient strives by forced breathing, to overcome the handicap, but too often succeeds only in making the condition worse. So a vicious circle is set up. In extreme cases the chest is fixed in hyperinspiration, and the tidal flow of air is practically nil. Much of the baneful influence of PIE is due to the immobilization of the lung from these air bubbles, which interdict the normal operation of the aforementioned pulmonic framework or "skeleton." Once again functional anatony has assisted in the interpretation of a pathological condition. This air locking or splinting effect on the ling is an important fraction of the basis of airblock.

\section{Natural Relief of PIE}

In the ordinary course of events there are but two means of mitigating PIEby absorption into the blood stream, and by mass escape. It does not seem that diffusion into the airway plays any part. With the circulatory embarrassment ineritably caused by PIE there is diminished power of absorbing aberrant 
air. The mass escape may be through a rupture in the viscelal pleura, but we have found no evidence of this mode except under drastic experimental conditions not comparable to clinical ones. In our expericnce it is via the lung root into the mediastinum, so widening the airblock ficld. It is certain that air bubbles are forced in to the mediastinum, traveling thence along the slucatlis of the great pulmonary blood vessels. Unfortunately, there is a considerable amount of air which cannot be so evacuated, because, as we have just secn, it is trapped in regions of the connective tissuc of the lung such as the inter lobular septa. If the pulmonic airblock involves one lung only, its prognosis is less serious than when both lungs are implicated. No artifice has been suggested for removing the air from the lung interstitium.

\section{Mediastinil Enphysema and Its Alleviation}

Mediastinal emphysema, or pnemmonediastinum as it is often called, is seen to be the result of invasion of air, ria the lung root, from an initial PIE. The tendency is for alveolar-base air leakage to go on, once it gets started, until a counterbalancing condition obtains. Air-bubble columns continue to move along lines of least resistance toward the lung root, and so a mediastinal emphysema is likely to grow in severity. The pressure rises, and cardiac and rascular functions are handicapped." Easement may be naturally afforded to the compressed contents by efflux of air through perivascular channels which it dissects for itself into the root of the neck and retroperitoneum. The holding strength of the mediastinal walls may be taxed to the breaking point. In rabbits a rupure of the lateral mediastinal wall, giving rise to a pneumothorax. has been demonstrated. ${ }^{-9}$ Instant and dramatic cleliverance of the stressed mediastinal contents is effected by such a sudden breakout of air. A pneumothorax. too. on the side of an increasing PIE, has the effect of stopping the leakage, and hence artificial pneumothorax, at least partial, has been suggested as is therapeutic measure. ${ }^{.2-24}$ Lateral roentgenograms are useful in revealing precordial air pockets, which may be evacuated by means of a hollow needle. ${ }^{3}$ The anterior mediastinum is the place of election for direct attack upon the cause of airblock. An understanding of the morphodynamics of airblock has led to suggestions, ${ }^{22-24}$ already successfur ${ }^{3,7}$ for its alleviation. It seems probable that lives have already been saved by recourse to intervention. Again, functional anatomy has aicled pathology and also practical medicine.

Hyperatmospheric Mediastinal Pressure.-Ordinarily the pressure in the mediastinum is lower than that of the atmosphere. ${ }^{30}$ In some cases of pnenmomediastinum it becomes higher. For instance, in Gumbiner and Cutler's $\operatorname{case}^{3}$ the plunger of the syringe shot out when they tapped the substernal pocket of air, and this was in a newborn babe. How can we account for this dramatic elevation? The mechanism seems analogous to that in the so-called "pressure pneumothorax." The motive power, in nonexperimental cases, must ultimately be in the individual's own respiratory musculature, regular and accessory. Normally the interstitial tissue of the lung and mediastinum is pro- 
tected against air invasion, the alveolar bases being competent to hold the air in the alveoli against not only the normal hyperatmospheric pressures of expiration, but the still higher ones of coughing, straining, forcible expiration, etc. But we have seen that when these bases are ruptured the tendency is for air to continue to leak in to the interstitial tissue and for pressure to rise in the accumulated air pools. Once in the interstitial tissue the air apparently cannot go back into the alveoli. There is a sort of valve action here, and bubbles move toward the mediastinum in natural course. The augmented pressure head in the alveoli during coughing, straining, etc., is carried over into the bubbles and, in part, held therein. The effect is cumulative. It extends along the train of bubbles into the mediastinum. The potential raised in the elastic tissue of the broncho-vascular rays and other parts of the lung in inspiration, particularly when forced, is expended in the expiratory phase to pack the bubbles and move them onward, as we have seen in the discussion of the mechanism of transpulmonic air-bubble movement. It seems that air can in this way get into the mediastinum more easily than it can break out. It is thus compressed by the recoil of the chest, particularly after the inspiratory movements are forced, as in dyspnea. We have here something analogous to the intake and compression strokes of the internal combustion engine. The greater the airblock the greater the dyspnea; and the severer the dyspnea becomes, the more likely is the tension in the mediastinum to increase. It is to be noted that, as with tension pneumothorax, aberrant air can enter the mediastinum only during the expiratory phase, once the pressure in it has reached that of the atmosphere, for only at that period is a pressure in excess of atmospheric generated in the lung; and not (as most authors erroneously state for tension pneumothorax) during inspiration. Therefore, when a patient, in whom atelectasis may be present, is making or has just made forced expiratory efforts of any kind, as in coughing, the clinician should be alive to the ever-present menace of PIE and particularly of its sequel-air in the mediastinum under pressure-which will certainly establish an airblock. If the leakage continues under such conditions, rupture from the mediastinum into the pleural cavity is likely to set up a tension pneumothorax.

\section{Animal Experinients}

The interpretation of PIE and its sequels just given has a broad foundation of data from animal experiments. Without the information gained from these we should not understand how air breaks out from the lungs; is moved in a definite way to distant points, and exerts its pernicious, even lethal, effects; nor should we be able to visualize the tissue mechanics of inspiratory swelling of the pulmonic blood vessels. Functional anatomy and, through it, pathology and clinical medicine are incalculably indebted to the experimental method. Through it the connective tissue of the lung is seen in a new light. As has so often happened in research work, the experiments were started with quite another objective-information on the nature of the pulmonic alveolar walls- 
and the discovery of the origin and ramifications of PIE was at first incidental; but the leads were quickly followed up, and what was initially a by-product became one of importance. There were two series: $(a)$ local and $(b)$ general overinflation of the lungs.

Forcible Overinflation of Part of a Living Animal's Lung.-Some thirty-five animals were used, mostly cats. A flexible male urethral catheter, with the end cut off, was passed down the trachea of the anesthetized animal and as far as it would go without effort into the bronchus of the right lower lobe, which it entered naturally. The lung tissue about the tip of the catheter was then insufflated with pure air blown into it from the mains of the building. In the first cats used, the air contained the fumes of osmium tetroxide, but this made no essential difference. The pressure varied from 1 to $22 \mathrm{~mm}$. of mercury as read on a manometer, but must have been somewhat higher than that to which the alveoli were subjected. In most cases the abdomen and thorax becamc swollen, and also the neck, axillae and chest if the insufflation was continued. The effect was very striking. It was usual to find a double pneumothorax. Large air blebs were conspicuous in the axillae and retroperitoneum. ${ }^{29}$ The heart was surrounded by bubbles. In the fresh condition bubbles could be seen in the lung roots, and, by probing from the heart it was found that these were in the sheaths of the pulmonary blood vessels. Examination of gross slices and microscopic sections of the lungs, fixed by intratracheal injection, disclosed air bubbles along the sheaths of the pulmonic blood vessels and in the tissue extending out from these. The bubbles were small at the periphery of the lung, where the vessels were small, and increased in size toward the hilum. The appearance of the pulmonic vessels was indeed striking. The walls were collapsed, and might even be folded inward upon themselves until in many cases there was no discernible lumen. Between this collapsed tube and the surrounding lung alveoli was a large space occupied by air (or by a space which had formerly contained air when this had been given up in the technical manipulations), and this space was crisscrossed by delicate cobweblike strands, the remains of the connective-tissue sheath of the vessel. Looked at lengthwise in gross pieces, with a low-power lens, the vessels often appeared as mere crumpled tubes swung by tenuous guy ropes attaching in all directions, and surrounded by bubbles. A glance would convince anyone that little or no circulation could go on in such vessels. In one such case from an overinflated excised calf lung, fluid could not be forced through at a pressure of three feet of water. One could readily see why cyanosis should be a prominent feature of airblock. A similar occlusion of pulmonic blood vessels was found in the lungs of two children, one of whom had died after aspirating peanut fragments, ${ }^{31}$ and the other of atelectasis of the newborn. ${ }^{32}$

The alveolar-base rupture points are invisible in ordinary histological sections, made from immersion-fixed blocks, but in certain of these animals their sites were located by a method of injection of the previously overinflated lobe, through the same bronchus, with hot gelatin containing minute carmine par- 
ticles. $^{33}{ }^{34}$ The alveolar bases about the finer pulmonary blood vessels of the overinflated region were implicated. The role of the pulmonic connective tissue as an air conduit to the nediastinum was clearly demonstrated.

Conditions here are not, of course, identical with those in the human subject. The air pressure was sometimes much higher, for instance, than that under natural conditions, and the inflow was sudden and continuous. The overdistended region, however, was comparable to a region of compensatory emphysema such as frequently occurs in human lungs and where leakage of air into the interstitium is known to happen at times. ${ }^{31}$

Forcible Overinflation of Entire Fresh Lungs.-The fresh excised lungs of calves were overinflated in toto ${ }^{25}$ by blowing air into the tightly cannulated trachea until the alveoli ruptured. As the pleura became taut and the air escaped into the connective tissue and opened up rumways therein, a striking noise of coarse crepitation was heard. Soon air began to bubble out from around the stumps of the great pulmonary vessels in the lung roots. It was a dramatic sight to watch it emerging thus continuously as long as it was forced into the trachea, and was an unforgettable lesson in the way air invades the mediastinum from the lung tissue. When the trachea was again opened, part of the air escaped through it, but the lungs did not resume their original size, and their enlargement was due to retained air in the interstitial tissues. In the lungs of cattle the partitions between lobule groups are very obvious, and these became infiltrated with air, giving a characteristic pavement appearance not only to the surface but to sections of the interior cut from intrabronchially fixed material. It was easy to see why a patient in whom such a condition had arisen should show a chest fixed in a state of inspiration, with little tidal flow of air, and also why dyspnea and cyanosis should be prominent features of the airblock syndrome. Splinting of the lung and clamping down upon the blood vessels combine to vitiate the patient's circulatory and respiratory systems. In this material a few actual ruptures in alveolar bases not only of the vascular sheaths but of the interlobular septa were demonstrated in microsections.

\section{Analogies in Human Chest Pathology}

The lessons learned from the animal experiments go far to explain how air breaks into the pulmonic connective tissue, moves toward the mediastinum, and exerts its evil influence in airblock. A number of common factors underlie the animal and human phenomena. The human cases may be classified broadly in accordance with the two experimental subdivisions, namely, as local and general overstrain of the air-container system.

Thus there is a large group which shows the result of local overstrain arising as a consequence of definite pathological change. There is a limit beyond which the pleural cavity may not normally be reduced in capacity, and the lung has to adapt itself to this minimal volume. Hence, if any part of the lung is abnormally reduced in bulk, as it is in atelectasis, then other parts have to overexpand to fill up the space. This overfilling of a part with air is known 
technically as "compensatory emphysema." * In this condition the individual air spaces are overdistended; and this means that the bases of alreoli lying against connective tissue, particularly that of the sheaths of the blood ressels, as we have seen, are strained and may become ruptured, allowing air to leak into the interstitium. Factor "A," with its downgradient from alveolus to vascular sheath, is then operative.

Atelectasis.-It is, then, quite possible for PIE to originate in any local, or alveolar, emphysematous area; and this brings strongly to the fore the importance of atelectasis as an initiatory cause of PlE. Atelectasis, as is well known, is found under a variety of conditions, but obstruction of the bronchus supplying the atelectatic region is a generally recognized immediate cause. An obstruction can arise suddenly, as by impaction of a foreign body in the bronchus; or gradually, in the course of disease, as in bronchopneumonia, when it results from inflammatory tumefaction and exudate. The last ype is usually multiple in locale. Thus, atelectasis may be in one or many regions of the lung: it may involve a large area of lung substance or a small one. We feel that, if all human PIE cases could be searched through to their origin, it would be found that atelectasis, by inducing compensatory alveolar emphysema, is at the bottom of many, if not most. of them.

Contributory Causes.-Now it is, perhaps, too much to say that all cases of local overstrain of the air container are followed by PIE, even in minute degree, and it would seem that something more than simple alveolar ectasia is usually necessary to induce a leakage of air into the interstitium. It is probable that the strain upon the alveolar bases is severe when the extent of the stretching is great, and particularly when it is accompanied by elevation of pressure, as in coughing and intense muscular effort. Where there is inflammation the alveolar bases may be presumed to be weakened from this state, and so may be more easily ruptured. In some individuals the bases are apparently naturally weaker, and so confer a predisposition to what may be termed "idiopathic" PIE. Then, too, Factor "B" must be kept in mind. It operates when, for any reason, the volume of blood in the pulnonary ressels is reduced, for then the internal buttress of the vascular sheath gives way, creating a further downward gradient from alveolus to sheath. It seems quite likely that if these vessels are overswollen the tendency to PIE resulting from alveolar ectasia may be warded off. Such a protection may be operating when, for instance, a lobe, or even one entire lung, is removed, for then the blood vessels of the remaining parts are carrying not only their own quota of blood but that from the parts which have been removed, and are thus engorged. Augmented in size in this way they encroach upon the space of their surrounding sheaths and so tend to make up for the outward pull of the surrounding

\footnotetext{
* It is unfortunate that pathologists and clinicians ne the same term, "enplusema," for wo different entities: (1) alveolar ectasia and (2) incerstial (mphyscma. Emphysema meams to blow up or inflate. By using qualifying adjectives and specaking of "alicolar" emphysemas on the one hand and "interstitial" emphysema on the ofluct, we can do much to avoid confusion.
} 
ring of alveoli, which arises inevitably with the compensatory alveolar emphysema occurring by reason of the fact that the surviving lung substance has to enlarge to fill the space vacated by the ablated part. PIE has not so far been presented as an important postoperative problem in lobectomies and pneumonectomies. So, pulmonic local overstrain, arising in an atelectasis-engendered alveolar ectasia, when augmented by contributory factors, conditions PIE. In this light, atelectasis is a menace. All possible means should be taken to diagnose it and be on the watch for its offspring, PIE, which makes itself known clinically by the airblock syndrome, and in other ways.

\section{Survey of the Literature for PIE and Its Sequelae}

A survey of pathological and clinical literature shows that there is reason to conclude that PIE was present in many cases where, to the attending physicians, it was occult; and, indeed, to believe that it is much more prevalent than is supposed. The evidence is direct and indirect. The direct, or pathological, evidence is obtained at autopsy when bubbles of air are disclosed in the interstitial tissues of the lung. The indirect, or clinical, evidence is of several sorts. Important is the roentgenographic display of the effect of air in the mediastinum, which must have originated from a PIE; and also of the result of air in the pleural cavity, for this may ultimately have come from a PIE. Actual proof that there was air in the anterior mediastinum would be afforded by withdrawing it from the location with a hollow needle. The presence of subcutaneous emphysema would probably implicate the mediastinum as the source, and ultimately the lung interstitium. The symptoms and signs pointing to the existence of airblock would be important indicators of PIE and its sequelae. The following résumé of published clinical reports was prepared by one of us (M.T.M.) We shall first take up cases in which it seems reasonable to believe that local overstrain was the important causal factor, and where the air-pervious region probably arose as a consequence of an atelectatic condition. The survey makes no pretension to completeness. It is impossible here to mention all the clinical instances of this kind in the literature, and the references given will be only a few of the many that might be cited.

We feel that this study brings home strongly the great usefulness of reporting clinical and pathological observations, even though their significance is not immediately apparent. A number of interesting reports came from American army camps during the first World War when those who made them were doubtless hard pressed to find the necessary time for this work. These writers are to be warmly commended for their enterprise.

\section{Chest Conditions Probably Showing PIE and Sequels from Local}

\section{Alveolar Overstrain}

Influenza is an outstanding example of diseases in this class. Torrey and Grosh $^{35}$ reported patients in the epidemic of 1918-1919 who had dyspnea, cyanosis, fixation of the chest in a position of maximal inspiration, with 
scarcely any tidal flow of air, and retrostemal pain. W'hen these patients clied, as was usually the case, there was not enough involvement of the lung to explain the marked respiratory clistress. There were areas of consolidation, with other areas of compensatory hyperinllation. ${ }^{36}$ The lungs did not collapse as readily or as fulty as did normal lungs when the thorax was opened, and there were often numerous blebs, usually unruptured, beneath the pleura.; Sonctimes these moribund patients showed sudden intprovement, the cyanosis lessened, the breathing became much easier and of fuller excursion, and the patient usually went on to recovery. The condtition which always accompanied, and seemed to explain, this sudden improvement was the appearance of subcutaneous emphysema of the neck and face. The implications of this were not realized, and no attempt was made to remove the air from the mediastinum, thus relieving the pressure which was causing the symptoms. It seems to ut likely, howerer, that had such a procedure been followed, many of those dring could have been saved. These various authors reported over 1,100 such patients, thus demonstrating that this condition is not uncommon.

A very interesting finding was that of "air streaks" along the course of the pulmonary blood ressels in roentgenograms taken of influenza patients. ${ }^{12}$ This, in our view, is the first $\mathrm{X}$-ray demonstration of perirascular PIE. Air bubbles along the ressels of the hand were reported as haring been seen in such patients. ${ }^{37}$ Again, the importance of these findings was not generally recognized. The simultaneous appearance of pneumothorax and subcutaneous emphysema in some of the patients was interpreted by Berkley and Coffen ${ }^{12}$ as being dependent upon a single cause, namely, air in the mediastinum which had reached that region from the pulmonic "air streaks" already mentioned. We feel that these authors should be credited not only with the first X-ray demonstration of PIE but with the discovery that PIE causes mediastinal emphysema and, through this, subcutaneous emphysema and pneumothorax. This important research came out of an American army camp during the first World War.

Apart from epidemic influenza, there are reports of other infectious diseases involving bronchopneumonitis with probable atelectasis which provide evidence of some variety that PIE was present. Among such may be mentioned measles, ${ }^{38}$ pneumonia, ${ }^{39}$ bronchopneumonia ${ }^{40}$ including the postoperative type, and diphtheria. ${ }^{41}+2$ This great group of bronchopnemonic inflammaton y conditions is most important, and careful watch for symptoms and signs of airblock should be kept so that immediate steps may be taken to relieve it.

There are also conditions which, though not infectious in themselves, yet nevertheless lead to atelectasis through the mechanical disturbance they occasion or throngh inflammatory reactions they set up in the bronchi; and so, because of the area or areas of compensatory emphysema which ensue, they result in PIE and its sequelae. In this category are the foreign body impactions, ${ }^{43,4}$ occlusion of a bronchus by tuberculous lymph nodes, ${ }^{45}$ or possibly cancer, scarring of the lung tissue by silicosis, ${ }^{40}$ or tuberculosis. ${ }^{47}$ Particularly in the cases of atelectasis which occur suddenly is there danger of leakage. 
Atelectasis Neonatorum.-Atclectasis of the newborn is a special condition which has recently come in for some intelligent investigation and operative interference. ${ }^{3,78}$ It is evident that airblock is quite prevalent in this class. One might well speak of "PIE nconatorum." Certain progressive physicians who have beconie aware of the common occurrence and scrious nature of this condition have examined, particularly by $\mathrm{X}$ ray, newborn infants who were showing signs of respiratory distress, for the presence of air in the mediastinum. The lateral roentgenograms have been particularly useful in revealing the signs of air in the precordial region, from whence it was withdrawn with a hollow needle. ${ }^{3}$ The dyspnea and cyanosis have in this way been strikingly relieved, and children who have appeared moribund have recovered..$^{3,7}$ Not only has the air in the mediastinum been thus withdrawn, but it would appear from roentgenograms ${ }^{7}$ that air that has been in the connective tissues of the lung, particularly in the vascular sheaths splinting it and holding it in a position of inspiration, has to some extent been allowed to escape into the mediastinum, whence it, also, could be withdrawn. This method of treatment would seem best adapted for immediate and substantial relief of airblock, draining off some of the air even from the interstitial tissues of the lungs, and so relieving the disastrous effects of pressure on the intrapulmonary blood vessels as well as on mediastinal structures. Doubtless also some air escapes in time from pulmonic connective tissue apart from that of the vascular sheaths, such as the interlobular septa.

Autoresorption of Aberrant Air.-It has been averred by a number of work$\mathrm{ers}^{4,5}$ that pneumomediastinum (and inferentially PIE) is a benign condition, requiring no special treatment, as the air is resorbed in a few days or at most weeks. This is doubtless true in some of the cases, but sometimes the patient. does not live long enough to resorb the air, but dies of asphyxia before his unaided efforts can accomplish this desideratum. In the presence of such tragedies it seems more than possible that many physicians have not realized what was the real cause of death. Assistance in the form of prompt and adequate withdrawal of the air from the anterior mediastinum may tide the patient over an illness not necessarily in itself fatal in that patient at that particular time, but in the course of which he may succumb because, unaided by surgical intervention, his circulation and respiration are too markedly impeded by the aberrant air.

Why Aberrant Air Escapes Attention.-It might be asked at this point why PIE and its sequelae have not been more often demonstrated in persons dying of airblock. There are several reasons why it may have been overlooked, among which may be mentioned the following: (1) autopsies, in proportion to the total number dying, are not often done; (2) the autopsy is usually long delayed, so that a considerable amount of the air has diffused away after death; (3) the air bubbles are obscured by blood and serum; (4) the operation of cutting the lung bursts the bubbles and dissipates the air; (5) the pathologist was not actually seeking air in the pulmonic vascular sheaths and other parts of 
the lung comnective tissue, and so overlooked what was mot to him olyvious; (6) the lung was not fixed by intratracheal injection, but by immersion of small blocks of tissue, and the air was squeezed ont of these or diffused anvay in the various technical manipulations. We feel that intratracheal fixation is very important in the demonstration of air bubbles and the impressions made by these in the pulmonic connective tissue. The lung, however, should not be overdistended with fixative, for then the vascular sheaths are dilated, giving rise to an appearance simulating air in the sheaths. ${ }^{2}$ Fisher's ${ }^{32}$ case, atutopsied within an hour or so after death, revealed the air in the mediastinum and along the vessels very clearly. The case of Fisher and Macklin ${ }^{3 x}$ is another good example of the value of prompt postmortem examination and intrabronchial fixation.

Interalveolar Pores.--Recent investigations in functional anatomy have shown that interalveolar pores are an actmality..$^{n-51}$ It has been suggested that they allow air to diffuse into a region of lung whose bronchus has become occluded and that thus they tend to prevent atelectasis. It may be that they have some influence of this kind, but, if so, it is undeniable that atelectasis occurs in spite of them. This may be, in small areas, because the pores have become stopped up from the effect of inflammation; or in large areas because the pores do not occur in the connective-tissue septa lying between secondary lobules of lung substance. It is possible, too, that, when atelectasis does occur, the consequent compensatory emphysema involves less alveolar overstrain since, due to the free diffusion of air through the lung tissue on account of the pores. the area of alveolar ectasia is spread out more and so the alveoli in any local area are not subjected to a breaking strain. Be that as it may, it is possible that the presence of pores explains the freedom of some individuals from PIE and its sequels when showing the leakage-predisposing conditions mentioned in the paragraphs immediately preceding. We would certainly not say that every person who develops these conditions will as a consequence have a PIE. There is, however, no reason to think that pores are more abundant in the lungs of some people than in others of the same age, so there seems to be no somnd explanation for immunity to PIE, if so it may be called, on the part of a certain class of patient, on the basis purely of pore equipment.

Hereditary Predisposition.-On the other hand, it may be that susceptibility to air leakage may rest, to some extent at least, on hereditary gronnd. This applies not only to the cases already discussed, but to those which are to follow. There may be an inherent weakness in the alveolar walls of some persons. leading them to rupture more easily than normal, as evidenced by the numerous records of recurrent pnemothorax ${ }^{52}$ and of fanilial pnemmothorax. ${ }^{53}$

Local Alveolar Overstrain.-From these reports and many others that could be cited, it appears reasonable to conclude that PIE is a concomitant of many disease conditions and bronchial accidents that involve local alveolar overstrain. We may affirm that any condition which induces atelectasis may precipitate compensatory overinfation, and this, in lum. particulatly when aided 
by accessory causes, may lead to PIE and its sequelae. The accessory causes already outlined are regarded as important. They may, indeed, be the determining factors in the precipitation of any given case of PIE, in the presence of alveolar-base overstrain. Thus cough, straining at stool, etc., by raising the intra-alveolar pressure in a region of alveolar ectasia, particularly if the bases of the alveoli are weakened by an inflammatory process, may produce a rupturing of the alveolar bases and leakage of air into the interstitium. Increased pressure in the alveoli is of great moment in this connection. Can it alone cause PIE? That seems possible, as will appear from the discussion of later cases. Certainly the combination of increased alveolar pressure and overdistention of alveoli is a dangerous one.

Again it is brought home that the functional anatony of the lung is necessary to an understanding of the response of the parts of the organ to abnormal conditions. Aided by the data from experimental work we are enabled to understand the origin and course of PIE, and even to predict in what type of disease condition PIE may be expected. The testimony of recorded clinical experience sustains our predictions.

\section{PIE from General Alveolar Overstrain}

So far we have dealt with clinical reports of human cases in which there may be presumed to have been a PIE resulting from some local overstrain of the alveolar bases, with complications. Even in these there may have been some general overstrain as well as the predominating local one. In them elevation of alveolar pressure, even though momentary, was regarded as very important. We now wish to consider cases in which it is reasonable to assume that there has been a general overstrain of alveolar bases on account of elevated pressure. It is convenient to divide these into two categories: (1) Natural, and (2) Artificial.

Natural Overstrain Cases.-The natural overstrain cases all show a severe muscular effort characteristically for a short period, but one which may be repeated; and when presumably the glottis is closed, so that the intrathoracic pressure is raised and blood is prevented from entering the thorax, so that the blood volume of the pulmonary vascular system is lowered and Factor "B" is produced. Manifestations of PIE have been found in individuals who have held their breath while lifting heavy weights, ${ }^{54}$ or tugging at heavy objects. ${ }^{55}$ If strong expiratory efforts are made while the breath is being held the intraalveolar pressure is augmented; we have evidence of PIE occurring in women during childbirth, ${ }^{56,57}$ or in persons straining violently at stool. ${ }^{58}$ Closely analogous are the cases which occur even if the glottis is not completely closed yet where there is sufficient obstruction in the airway to raise the intra-alveolar pressure as expiratory efforts are made; then this pressure, combined with the recluction in caliber of the pulmonary blood vessels arising through the prolonged interruption of venous return to the heart, will cause PIE. Thus we find that PIE has been reported in patients with asthma; ${ }^{69}$ with congenital 
stenosis of the larynx, or in obstruction to the outflow of air from the bronchial tree of any variety whatever; ${ }^{80}$ with violent cough whatever its origin; ${ }^{82,02,83}$ and also in patients who have been blowing against an olstruction, as into a wind instrument or a blow gun. ${ }^{8 *}$ In all of these, elevated intra-alveolar pressure associated with Factor "B" may be postulated. The possibility of ateleclasis with compensatory emphysema exists in some of these cases with lung disease, as indeed it does in any of these cases; but it seems reasonable to assume that such simple conditions as weightlifting, childbirth, etc., would be unassociated with it as a general rule.

The cases of prolonged muscular exertion, but without the holding of the breath or any obvious elevation of the intra-alveolar pressure, should be mentioned here. Scott ${ }^{2 \pi}$ found pneumomediastinum, or pneumothorax, in athletes who had run a long hard race, some hours after the race was over, and here, we feel, PIE must have been the precursor. Failing heart, with supervening Factor "B," can hardly be ruled out here. The lungs had been ventilated to the full for a long period. There was no suggestion of atelectasis, though we think this a possibility.

Abrupt Decompression.-On the borderline between the natural and artificial overstrain cases are those which show PIE from too abrupt a decompression, as in leaving caissons ${ }^{95}$ or escaping from submarines. The latter is of particular naval importance at the moment of writing, and is an accident which occurs in men being trained in the technique of ascending from deep levels of water, when they fail to obey orders. ${ }^{6,67}$ The recruits are taught to release themselves from diving bells at various levels, and to ascend with relative slowness to the surface, pausing at different depths, and all the while to breathe in and out of a bag attached to the mouth. The nose is held by a clip, and the bag has a flutter-valve attachment which permits adjustment of pressure within the bag and thus within the lungs as the person ascends. This prevents the overexpansion of the air in the alveoli as the pressure on the outside of the chest lessens during the ascent, as would be the case if the man held his breath. Now this impulsion to hold the breath during the ascent is said to be overmastering in some men, and when this is done during rapid ascent the air in the lungs expands, causing generalized increase in pressure and such overinflation as is possible in the confines of the thorax. At the same time the pulmonary blood-vessel caliber is reduced on account of the obstruction to inlet of blood into the thorax. Factor "B" would thus be in operation, as well as Factor "A" to some extent. In these cases, not only does air make its way into the interstitial connective tissue of the lungs (PIE) but also into the pulmonary capillaries in the form of fine bubbles, ${ }^{67}$ so that cerebral gas embolisn results. Blood likewise makes its escape into the alveoli, and bloody frothy sputum may emerge from the mouth and nostrils. If the amount of air escaping into the pulmonary blood ressels is large it gets churned into a frothy mass in the left side of the heart and the victim succumbs rapidly.

The important thing for us is that PIE is present, and that it is produced 
very rapidly. We must assume alveolar-base rupture, since that is the only way air can possibly leak from the lung air spaces into the connective tissue unless it be through the walls of the bronchi and bronchioles, and there is no evidence of that. It should be frankly admitted that we do not know the details of the morphological changes going on in the interior of the lungs in any of these natural overstrain cases; and it may well be that, under these abnormal conditions, certain areas of the lung are likely to expand unduly and thus to suffer alveolar-base rupture. Accordingly, there may be, even here, local areas of overinflation. If this is so then the mechanics of PIE production would be comparable to those obtaining in the local alveolar-base overstrain cases.

The literature on submarine escape and analogous events is growing, and only a little of it has been here referred to. We may confidently look for more enlightenment on obscure points in the near future and, as knowledge unfolcls, the role of functional anatomy in facilitating progress in pathological science will be increasingly useful. The important practical point is that air should be diagnosed whenever present and released by aspiration whenever it is causing airblock.

Artificial Overstrain Cases.-It is always difficult to classify the items in a new subject like the pneumonopathies herein dealt with, and it is quite possible that the PIE resulting from sudden and unorthodox submarine escape should appear under the heading of the artificially induced cases rather than those arising from "natural" living conditions. However that may be, it is certain that the lung-blast cases belong in the artificial group.

Lung Blast.-Although people have been experiencing serious injury and death from explosions for a long time, yet it is only recently that attention has been given to the changes in the lung shown by these catastrophies. There are already many articles on the subject to be found in the literature, but here we shall be able to refer to only a few of them. Although the effect of bomb explosions on the lung (as on the body as a whole) varies from total disintegration to relatively slight injury, we are most of all concerned with those cases which survive and in which there is a chance of doing something to aid recovery from PIE and its sequelae. That PIE is caused by lung blast there is no doubt, ${ }^{68}$ for autopsy findings in the victims show it. There are, too, clinical observational signs in human subjects and X-ray pictures in experimental animals which point to its existence, and syndromic recordings typical of airblock are already to be found in the literature.

Lung blast is a special phenomenon composed of two phases, compression and decompression. The time of each phase is very brief, and in this respect the etiology differs from other cases of PIE that we have been reviewing. The severity of the injury varies, of course, with the violence of the explosion and its proximity. For an analysis of its physics, etc., reference must be made to other sources. The effect of the compression wave is like that of a sudden, sharp, but nonpenetrating and diffuse blow struck against the chest wall. ${ }^{60}$ It does not enter via the trachea. ${ }^{70}$ The ribs are not usually fractured. The intra- 
alveolar pressure would be raised during this phase. The action is so rapid that there would not seem to be time for local inequalities of distention of alveoli to develop, nor could Factor "B" gain head for the same reason. The effect of the decompression wave, which follows immediately after, would tend to convert the hyperatmospheric intrapulmonic pressure to hypoatmospheric, with distention of the alveoli; but it is impossible to visualize the inert lung substance in its reactions to these almost instantaneous happenings. Most of the reports have featured numerous areas of hemorrhage, not only on the surface but also in the depths of the lung, as the salient pathological picture. In some ways this suggests a bruise of the lung. We have found no reports on such lungs which have been specially fixed by injection of the preserving fluid into the bronchial tree and which have been studied both grossly and microscopically in an effort to find the exact points where the hemorrhages occurred. It seems clear, however, that the hemorrhagic points were multiple. There has naturally been considerable discussion as to whether it is the compression on decompression phase which is responsible for this clamage, with Zuckerman," faroring the former.

When reports of lung blast first began to appear in this present war we read the descriptions very carefully to ascertain whether PIE was occurring in the victims who lived for some hours or days after, and our expectations were realized by such reports as those of Dean and his co-workers ${ }^{\mathrm{r}}$ and of O'Reilly and Gloyne. ${ }^{72}$ We had felt, from our study of the functional anatomy of the lung, that PIE might be predicted in these cases. Although it was not likely that much air would be driven into the interstitial tissues of the lung during the actual blast waves, yet ruptures would probably then occur through which air would continue to leak into the interstitim and possibly set up an airblock. The accounts which finally confirmed our belief that PIE would occur in some of these lung-blast patients gave the clinical picture as follows, although not all of the symptoms might be present in any one case exhibiting any of them: cyanosis of marked degree; extreme dyspnea, the chest being fixed in a position of maximal inspiration; substernal pain; acute abolominal pain for which no explanation could be found at exploratory laparotomy: extreme restlessness requiring opiates; diplopia; and occasional pnemmothorax. At autopsy, air was found in the mediastinum and pleural cavity, and there was extravasated blood in the carotid sheaths and mediastinum for which no bleeding point could be found, in addition to the numerous areas of hemorrhage throughout the depths of the lungs.

We think it reasonable to postulate that PIE and its sequelae account for these findings. The cyanosis, dyspnea, and chest fixation we have already explained as indicative of airblock. The substemal pain might well be caused by the pressure of trapped air on the mediastinal contents, as in Hamman's cases. The abdominal pain might justifiably be attributed to extreme abdominal distention with tension on the ureters and presiture on the intestines by retroperitoneal air. Cases have been reportecl in which acute abdominal 
symptoms calling for surgical interference have occurred in patients with pneumothorax. ${ }^{55}, 73$ The air might have ruptured into the abdominal cavity in these lung-blast victims, to escape at the time of operation, leaving little or no trace of its former presence. The extreme restlessness and diplopia could be accounted for by cerebral air cmbolism, which may accompany PIE in severe cases and which originates from air invasion of the pulmonic capillaries clue to augmented intra-alveolar pressure. The blood in the mediastinum may have entered with air from the connective tissue of the lung, and the blood in the carotid sheaths may have similarly invaded them along with air from the mediastinum in an extension of the mediastinal emphysema. It has been found in experimental animals ${ }^{29}$ that blood, as well as air, could enter the vascular sheaths of the ling when intra-alveolar pressure was high, and this pointed to an actual fracture of the capillaries of the alveolar bases. Continuing to enter the interstitial tissue with the air, it would soon find its way to the mediastinum, although this last was not actually observed in the experimental animals. From the mediastinum, blood, as well as air, could rupture into the pleural cavity. Numerous clinical reports of hemopneumothorax, in which no point of escape for either air or blood could be found, relate to patients in whom there was every possibility of there being a PIE. ${ }^{74,75}$ When pulmonary capillaries rupture, the blood is likely not only to escape into the vascular sheaths and other parts of the interstitium, but also into the alveoli, thus explaining the numerous areas of hemorrhage into the lungs without there being any evidence of external hemorrhage.

The presence of blood in the alveoli and in the extrapulmonary vascular sheaths, and of air bubbles within the blood vessels and heart, occurs, obviously, only in cases in which the pressure gradient has been high, and in this respect there is an analogy between the victims of lung blast and those of submarine-escape accidents. The decompression phase of lung blast has some similarity in plysical conditions with the submarine decompression; but in the latter the time interval is much longer and there is opportunity for Factor " $\mathrm{B}$ " to develop. Where pressure variations are less marked, and particularly where they occur less suddenly, although air may escape into the connective tissue, the pneumarrhage is not complicated by hemorrhage.

We feel ${ }^{8 s}$ that the lateral roentgenograms of the chest of a cat which had been subjected to lung blast ${ }^{76}$ give assumptive evidence of air in the anterior mediastinum, as well as of splinting of the lungs, as shown by elevation of the ribs. Others of the roentgenograms and illustrations in this article of Zuckerman's $^{\text {i6 }}$ support, for us, the idea of PIE being present in the experimental lung-blast victim.

The possibilities of airblock and its operative relief in these lung-blast cases has recently been raised, ${ }^{68}$ and $\mathrm{X}$-ray examination, particularly with lateral and oblique projections, enjoined.

The perhaps more familiar crush injuries of the chest, ${ }^{69}$ while not so spectacular as lung blast, may also show PIE. While these are likely to occur at any 
time, they are particularly prevalent in time of total war like the present when people are, for instance, buried beneath the debris of bombed buildings. Even if the air has entered from a wound, rather than from an alveolar-base leakage, it may nevertheless be expedient to remove it; and in any event the physician should be aware of its existence whenever present.

We feel that the discussion of this subject of lung blast should not be closed without favorable comment upon the work which anatomical laboratories, like that of the University of Oxford in England, are doing to advance our knowledge. Zuckerman's ${ }^{78}$ experimental findings made there have been verv helpful. As modern war injures humanity, medical science alleviates and heals. We hope to learn much more about lung-blast lesions in the near future.

Intratracheal Anesthesia and Artificial Respiration PIE Cases.-Less violent in mode of origin, and more widely distributed, are the PIE cases occurring from artificial alveolar overstrain during the administration of an anesthetic by insufflation, or the induction of artificial respiration, where the pressure within the pulmonic alveoli is too high. This hazard from intratracheal anesthesia is probably not as great as formerly on account of the safeguards now in use in the improved types of anesthesia machine. The lung must have a considerable amount of resistance to alveolar air pressure, otherwise this method of anesthesia could not be used at all. The literature contains accounts of air in the mediastinum or subcutaneous tissues under these circumstances, ${ }^{77-81}$ which point indubitably to an initiatory PIE; and of similar meaning is the report of large postrenal blebs of air found in an operation on the kidney. ${ }^{77}$ It is not unusual to see descriptions of subcutaneous emphysema following operations in the neck region, ${ }^{82}$ such as thyroidectomy, ${ }^{2}$ tracheotomy, or tonsillectomy. ${ }^{\text {s.st }}$ The presence of air is usually ascribed (we think, erroneously, on the whole) to laceration of the airway in the course of the operation, or to nicking the dome of the pleura if the operation was in that region, or to the sucking of air into the wound with inspiration if the operation area involved the mediastinum. It would seem probable that the reason for the frequency of the manifestations of PIE sequelae in operations in the neck region and kidney ${ }^{85}$ is that insufflation anesthesia is then often employed. Any complicating discase, such as bronchopneumonia, with atelectasis, would, we think, increase the probability of PIE.

Operations on the open thorax, when artificial respiration and insufflation anesthesia are used, would secm specially liable to set up an air leak. Marcotte and his co-workers ${ }^{86}$ have recently pointed out the danger of "positive-pressure" anesthesia in such operations, saying that when the chest has been opened and the pressure within the bronchial tree is raised emphysema occurs more readily; and that when emphysema has once made its appearance the pressure required for its further development is somewhat less than that needed to start it in the first place. They issue the warning that such anesthesia may result in serious complications and even death. The results of experimental overinflation of the fresh lungs of calves help to explatin these finclings. 
Closely analogous are the resuscitation cases, when air or oxygen is forced into the lung under pressurc. There is always danger of PIE in such induction of artificial respiration. The pulmotor examples will readily come to mind. Cases such as near-drowning, clectric shock, gas asphyxia, and asphyxia neonatorum are so often in extremis that desperate measures may be warranted. The airblock syndrome is not manifest, since breathing is almost, or quite, suspended. Factor "B" would be a likely contributor to PIE production in these cases.

Withdrawal of the air should be done in all of these cases whenever it is deleterious; indeed the idea should be considered by physicians, surgeons, and anesthetists of inserting a hollow needle routinely into the anterior mediastinum to draw off any air which might happen to have invaded that region during the emergency. In this way we could be fairly sure that the circulatory and respiratory systems would not be incommoded by the treatment.

\section{Miscellaneous Cases of PIE}

There is a group of cases in which air was found in the mediastinum, pleural cavity, subcutaneous tissues, etc., but in which no cause of PIE is obvious. Signs of aberrant air are found, for instance, after the person awakes from sleep, or following a quiet walk, or while sitting in a car, or during shaving, etc. The relatively quiescent nature of the bodily state at the time of the first symptoms has been stressed. Superficially, it would appear that none of the predisposing circumstances were present. When it is recalled, however, that little appreciation exists of the wide variety of the factors which might precipitate PIE, and that considerable time may elapse between the initial causal event and the accumulation of enough air in the mediastinum to be diagnosed. it will be admitted, we think, that in some of these patients an initiatory event might have been found had the physician known what to inquire for and made an honest effort to find it.

W' have referred to the gravity of atelectasis ${ }^{29}$ as a predisposing cause in such cases. This is commoner than many physicians think. More frequent and better $\mathrm{X}$-ray examinations in all such cases will, we feel certain, disclose it oftener. Associated infections may well contribute to the likelihood of air rupturing from the compensatorily overinflated regions of lung. An atelectasis, too small to be diagnosed in the usual course, might be large enough to do the damage. We know little or nothing about the relative degree of distention, at any one time, of the various regions of even the normal lung, and it is very diffcult to go about finding whether the lung tissue is always uniformly expanded or whether the various parts are always more or less unequally expanded with respect to one another. Many aspects of the related pathology of the lung are no clearer. There is still plenty of opportunity for functional anatomy to aid pathology in the lung.

Then, too, the history of these individuals in the period prior to the first appearance of evidence of PIE should be searched by the attending physician. 
The patient, for instance, might have been lifting a heary weight, or straining at stool, or violently coughing, even some hours before the first symptoms appeared. It takes time for the air to work its way up the sheaths of the ressels to the hilum of the lung, and more time for it to gather in the mediastinum in sufficient quantity and under sufficient pressure to produce symptoms. Igain, prolonged pressure upon one area of the thorax may induce relative collapse of the lung, as in lying on one side too long, or in sitting crouched over the wheel of a car in a long drive, with possible loss of thoracic-muscle tone. ${ }^{\text {si }}$ Thus in every such case the stage may have been set for local or general alveolar overstrain and a resulting PIE. As physicians become more cognizant of the conditions which usher in PIE they will inquire more fully into the happenings of the preceding 24 or more hours, and will, we feel confident, find more often a satisfactory explanation for PIE. Things like PIE never "just happen"; there is always a cause. Factor "B" should not be forgotten. There may be doubt that it alone could induce PIE, but in combination with Factor " $A$ " and elevated intra-alveolar pressure it is looked upon as an adjuvant. There is a report of pneumothorax in a patient with a pulmonary enbolus, and it is possible that Factor " $\mathrm{B}$ " was here one of the causes of a PIE.

\section{Rupture Sites}

A final word is in order on the sites of air leakage and the nature of the tissue in which the ruptures occur. The lung has been referred to as an air "container" which is efficient under ordinary circumstances. It may be regarded as a special part of the organism built around a little of the gaseous environment, from which it appropriates energizing material, and into which it eliminates certain catabolites. By means of its bellows action the lnng is enabled to take in portions of this oxygenated gas as needed, and through its specialized structure to subdivide these into minute parcels in order that the surface may be greatly increased. The inner surface of the container, to which this air surface is applied, is similarly widespread, and is essentially a great capillary net or curtain, enormously reduplicated. The ultimate functional anatomical units are the alveoli, which are small contiguous diverticulac from the terminals of the respiratory part of the airway, known as the alveolar sacs. Each alveolus is like a little box with one side left out. Opposite to this opening, or "mouth," is the base.

Now there are two categories of base. Many bases are partitions between the alveoli of two separate but approximated sacs. Their capillaries function on each of their two sides. Air, in breaking through such a "partitional" base, would merely pass into an adjoining alveolus. An analogous transit of air apparently occurs normally, through the pores. The other type of base does not act as a partition between alveoli; on the contrary, it rests on connective tissue, as already pointed out. Such bases unite to form tubes around blood and air vessels, and layers flanking interlobular septa or underlying the pleura, as already described. Their capillaries, of course, as far as external respiration 
is concerned, are functional on only one side. It is these "one-sided," "nonpartitional," "sessile," or "marginal" bases that concern us, for air, in breaking through them, passes, not innocuously into neighboring alveoli, but dangerously into the underlying connective tissue.

The nature of the lining of the alveoli has long been a moot problem, and it is important for us here, for it is in this lining that the rupture openings occur. A basic layer of fibers and ground substance is admitted by all. One modern view ${ }^{1}$ recognizes in the lining a few surviving epithelial cells or "epicytes" in the capillary meshes, but in ordinary histological sections no epithelium is visible on the "bare areas" which make up most of the total area of the alveolar wall and which overlie the capillaries. Both epicytes and bare areas have been marked out by silver lines, the former more clearly. The final point at issue is the nature of the air-protoplasmic interface in these bare areas. There are some who hold that it is a thin, ordinarily invisible derivative or extension from epithelium; and there are others who think that it is a specialization of mesoderm. It is through this thin film that diffusion of oxygen and carbon dioxide takes place, so that it may be regarded as a vital tissue. It seems to be through this film that minute bubbles of air pass into the capillaries to form emboli when the intra-alveolar pressure is too high. Ordinarily, of course, no leakage of air occurs in it. More work is needed as to the exact situation, in the marginal alveolar bases, of the rupture sites through which minute air freshets pass to cause PIE. It is clear that, if such a base be abnormally spread out, then the fibers of connective tissue in it are separated and the ground substance thinned so that it will be weakened and may become air-pervious. These bases are not built to stand air pressures much above that of the atmosphere. More experimental work needs to be done on pressures required to rupture these bases in the different laboratory animals. The breaking strain seems to be less in young children than in adult human subjects. In the experiments the break-through made itself apparent suddenly, as though many alveolar ruptures had occurred simultaneously; we are dealing with Factor "B" here, as well as Factor "A." Once the ruptures are formed the air continues to leak into the connective tissue through them and increase the PIE. When the intra-alveolar pressure is high the capillaries of the base may apparently become torn.

\section{Prevention, Diagnosis, and Treatment}

At first blush it would seem futile to seek to prevent PIE, for it arises so frequently under natural circumstances; but a survey of possibilities indicates that something can be done. As with any other ailment, we should try to remove the causes. The artificially induced overstrain cases would seem preventible, and the avoidance of overly high intra-alveolar pressures, for instance in intratracheal anesthesia and artificial respiration, will suggest itself. The dangers underlying the various predisposing activities, such as heavy lifting, straining at stool, and violent and continuous coughing, should be pointed out to patients by clinicians wherever possible, particularly if there is a history 
of a previous attack of any pneumonopathy engendered by PIE, such as pneumothorax. It is likely, too, that at least some of the pulmonic diseases favoring PIE can be sidestepped, or their dangers lessened, by proper health mcasures. The prompt removal of foreign bodies and exudate plugs from the bronchial tree, where possible, is particularly enjoined. But, after all this has been said and done, many cases will still occur. What then?

It is most important that the physician should become airblock "conscious." Since such signs and symptoms as dyspnea and cyanosis are so frequently associated with primary cardiac incompetence, it is but natural for the physician who finds them present to make his diagnosis "heart disease" of some kind, and let it go at that. When he does this, all opportunity to relieve an existing airblock by depneumatization goes by the board. The physician should always think of the possibility of airblock whenever his patients have such things as dyspnea, cyanosis, inspiratory thoracic fixation, subcutaneous emphysema, tympanites, pneumothorax, anginoid pains, or the peculiar "crunching" sound in the precordium-or, indeed, whenever any predisposing condition is present, particularly atelectasis. An X-ray examination, especially by the lateral projection, should be done as soon as possible to reveal air-pockets,-above all, those of the substernal region. PIE and mediastinal emphysema may be present, however, when no air has yet reached the anterior mediastinum.

Air is most conveniently attacked when it is trapped in the anterior mediastinum. The technic, by aspiration through a hollow needle, has been made clear by Gumbiner and Cutler, ${ }^{3}$ and has been particularly successful in the very young infant. For air in the posterior mediastinum the method which Tiegel employed, of suction applied to an incision in the root of the neck, may be used. ${ }^{22}$ Withdrawal of air from this site by way of a catheter insinuated into the mediastinum might also be done when indicated.

\section{SUMIMARY}

A knowledge of the functional anatomy of the lung and connected parts, gained by the experimental method, has enabled us to understand many salient features of pulmonic interstitial emphysema and its sequelae occurring in the course of disease and adverse physical conditions. W'e have found that the anatomical weak spots of the air-container system are the "non-partitional" alveolar bases which lie upon connective tissue. Particularly important as potential air-leakage points are those bases which enclose the terminals of the pulmonary arteries and reins. Under adrerse conditions these bases are orerstrained and are ruptured when the alreolar air pressure rises beyond their powers of resistance. The leak-promoting overstretching of the perivascular bases is seen as an exaggeration of a normal change in them during inspiration, in the course of which the caliber of these ressels is increased to facilitate blood flow through the lungs. We feel that this conception of the usefulness of inspiratory stroma-pull has not been sufficiently appreciated by physiologists whose attention seems to have been focused on the capillaries rather than the 
arteries and veins. Ruptues may also occur in the paraseptal and subpleural alveolar bases, but have never becn found in those around the airway. Various features of these ruptures have been discussed. Atelectasis, by inducing compensatory alvcolar ectasia, predisposes to air leakage. Interalveolar pores tend to prevent atelectasis by allowing air to diffuse into threatened parts whose bronchus is plugged, and also to minimize the degree of stretching of the affected alveolar bases by wiclening the areas of periatelectatic alveolar ectasia, and so appear to have some influence, though often ineffective, in warding off PIE.

Once these multiple minute rupture openings have been made, the likelihood is that air will continue to leak into the pulmonic interstitium. The bubbles become larger through coalescence, and most of them move on to the mediastinum, but some remain in various parts of the connective tissue where they interfere with normal lung movements. The conception of the opening and closing action of the extensible pulmonary broncho-vascular "framework" or "skeleton," essential to lung inflation and deflation, enables us to see how, when this action is interdicted by filling of the interstitium with air bubbles, the lung is splinted or locked. Until this happens, the lengthening, and especially the shortening, movements of the broncho-vascular rays may assist in the migration of the bubbles, which are impelled by more recently invading bubbles continuing to be driven through the ruptures by augmented pressure heads in the affected alveoli, as in coughing. The pulmonic connective tissue is seen as a funnel that gathers in air bubbles from the periphery and leads them to the root, from which they debouch into the mediastinum. The histological character of the connective tissue explains the preferred courses of the air burrows. A most serious blocking of the pulmonary arteries and veins, by impingement of air bubbles in their sheaths, is indicated in microscopic sections made by approved methods.

Pneumomediastinum, or mediastinal emphysema, is a direct consequence of PIE. The biomechanics of pressure elevation beyond that of the atmosphere are considered, and emphasis is laid on the pernicious effect of the air bubbles here on the circulatory mechanism. The syndrome may simulate that of angina pectoris. The aerogenous escape channels are traced, through which pneumatization of the subcutaneous tissues of the neck, head, upper extremity and chest, the opposite lung, and the pleural cavity is effected. The panemphysema field has been surveyed. It is noted that in this air canalization the vascular sheaths are followed by preference not only in the lung, but also in the mediastinum and adnexa, the hiatus aorticus being freely used by air invading the abdomen. In all of this, a knowledge of the anatomy of working parts is invaluable. The pool of air in the anterior mediastinum gathers from increments following lines of least resistance from the posterior mediastinum. The selection of these lines, traversing the loose connective tissue between the parietal layers of the pleura and pericardium, is explained by the embryology of the parts. This precorclial pool is of particular importance clinically for 
it may be well demonstrated by lateral X-ray films; the effect of its presence may be listened to with a stethoscope, and it may be operatively remored.

Airblock is localized mainly, and frequently altogether, in the mediastinum and lung, and involves the pulmonary circulation primarily. It is the combined effect of the interference of aberrant air with the circulation of the blood and the respiratory movements of the lung. It results (a) from impingement of bubbles of air on the pulmonary arteries and veins, and upon the heart and great vessels in the mediastinum, which is particularly serious when the pressure in that space rises above that of the atmosphere; and (b) from immobilization of large areas of the lung by air bubbles locked in the connective tissue. It is relieved naturally, to some extent at least, by escape of air from the mediastinum into adjoining regions, including the pleural cavity. When the pressure of the extravasated air in the metamediastinal parts, as the root of the neck, or retroperitoneal region, becomes raised, there is interference with the blood flow in these regions, and the airblock field is thus extended. This field may be, therefore, in its most expansive form, subdivided into three parts: pulmonic, mediastinal, and metamediastinal. Airblock is clinically sensed by the airblock syndrome, which includes dyspnea, cyanosis, and inspiratory thoracic fixation. It may be confused with heart disease. There may be accompanying signs of spread of air beyond the confines of the mediastinum. Retroperitoneal air may cause abdominal pain, simulating abdominal disease. Airblock may be overcome by the bodily defense powers, the air being absorbed into the blood stream, but, on the other hand, it may weight the scales in favor of death.

A special survey of the literature has revealed a multitude of human cases of different kinds which show evidence of PIE and sequelae, with airblock. All of these are regarded as arising from orerstrained nonpartitional alveolar bases which are subjected to unbearable pressure. Alveolar ectasia (usually called alveolar "emphysema") is a very potent exciting cause, since it produces attenuation and weakening of these ruhnerable bases. Sudden overstrain is regarded as more important than gradual, as in the latter sort there is time for protective circulatory and other compensatory adjustments to be made. Local alveolar ectasia is regarded as more serious than general, as there is, in the lormer, more scope for excessive stretching of the nompartitional bases to take place. Increased intra-alveolar air pressure is also an important exciting cause, and may be set up in a number of ways, all, excepting those of environmental induction, coming under the heading of strong expiratory effort, particularly when the glottis is closed. The important predisposing cause is diminution in volume of part of the lung, as the remaining part must then become overexpanded, with overstretching of the nonpartitional bases. Atelectasis is the most common volume-reducing condition, and may be single or multiple, large or comparatively small. It may follow occlusion of the bronchi from within or from without. The type due to impaction of foreign bodies is serious because of its sudden production. Atelectasis is frequent in diseases 
involving the bronchi, such as bronchopneumonia, where the bronchi are plugged by exudate or by swelling of the walls. Certain allergic conditions belong here. Spasmodic contraction of the bronchial musculature predisposes. The important thing is that compensatory emphysema is thus set up. Inflammatory changes involving the stretched nonpartitional bases may still further weaken them and make them more easily ruptured; and additional impetus in this direction is provided by acts which raise the intra-alveolar pressure, as coughing. Influenza has been found to be very important in inducing PIE. Whooping cough is serious. Such cases of PIE are regarded as being due primarily to overstretching of the nonpartitional bases, often having deteriorated protoplasm, combined with intermittent elevation of intra-alveolar pressure.

An effect similar to atelectasis is produced by diminution of lung volume from the ablation of a lobe or an entire lung, for the remaining part, without thoracoplasty, has to become overexpanded. There is here, however, a compensatory feature in the increased blood volume in the surviving parts, which acts thus oppositely to what we have termed "Factor 'B," " and which would in this way tend to offset the action of Factor "A." Occlusion of the bronchi from without may also induce collapse, but this, being gradual in onset in most cases, is not regarded as so provocative of air leakage from the associated compensatory alveolar ectasia as is the case when the onset is sudden. In this class we have pressure from new growths, particularly primary cancer, or from scars, as in tuberculosis, silicosis, etc. Reduction of volume, too, may occur from continuous pressure on the chest wall, as in lying on the side for a long time, with sudden release, setting up an overstrain in presumably overdistended areas of the lung. There are some cases which support this assumption. The noninflation cases occurring soon after birth make a special class, where leakage has taken place on account of the relative overexpansion of aerated parts of the lung. This group is notable for the brilliant progress already made in diagnosis and treatment. In some cases, considered under the heading "miscellaneous," it is difficult to do more than speculate as to exactly how the PIE is brought about; but here, as in all others, the nonpartitional bases must be involved, and the fundamental features of etiology are doubtless the same as elsewhere.

There are other types of case showing PIE and its effects in which the primary factor in bringing about the multiple rupture of the nonpartitional bases seems to be a raised intra-alveolar pressure, though there is nothing to rule out coincidental overstretching of these bases, at least in some areas. Prominent in this class, at the monent, is lung blast, during the compression phase; and we have given consideration to this condition and made suggestions for its relief. Here there is sudden violent pressure on the chest. Crush injuries of the chest by impaction of solid masses are somewhat analogous. An interesting type of PIE formation occurs in apparently healthy individuals in which the only obvious cause is increased intra-alveolar pressure from violent expira- 
tory efforts, particularly against obstruction. In the discussion, an effort has been made to visualize the rascular sheaths under the influence of what we have termed "Factors 'A' and 'B.' "Factor "B"' is important wherever it exists, and seems to be particularly so in those cases of PIE arising alter prolonged muscular effort, as in young men who have just run a "marathon."

There is a type of case where the chest is suddenly decompressed, causing air in the alveoli to assume a plus pressure relative to that of the environment. Faulty submarine escape is listed here. The decompression phase of bomb blast may also produce overstrain from this cause, but authorities tend to regard the compression phase as the more important.

We have attempted to divide the cases of PIE into two groups depending on whether the nonpartitional bases show local or general overstrain, but it is difficult to draw a sharp line here. The important cases arising from overstrain from too high pressure in intratracheal anesthesia and in artificial respiration may be more general than local in base involvement. Heredity seems undoubtedly to predispose to PIE.

We have found in the literature so much evidence of unsuspected PIE and its sequelae, with airblock, that we are impelled to believe that the condition is much more prevalent than is realized by the medical profession. W'e therefore urge that clinicians be on the lookout for evidences of airblock, that they take all possible means to diagnose it, particularly by $\mathrm{X}$ ray, and that they relieve it by surgical intervention whenerer it is deleterious to the patient. It seems more than possible, too, that preventive medicine can do something to lower the incidence of PIE. We feel that our predictions of the widespread occurrence of PIE and the types of disease in which it was to be found, made on the basis of our knowledge of the functional anatomy of the parts concerned. have been fulfilled, and that the light shed on the condition has already enabled clinicians to see their way more clearly and helpfully. Much remains to be done, but we feel that the anatomical approach to such problems will in the future, as in the past, lead to valuable knowledge.

\section{Final Note}

Anent our emphasis on atelectasis as a cause of PIE, the paper of $\mathrm{W}^{\top}$ yatt, ${ }^{\text {s9 }}$ just published, is of great interest. He finds, in a series of 135 cases of pneumonia in children, that no less than 26 , or 19 per cent, had atelectasis demonstrated roentgenographically. Although he does not mention PIE, nor pneumomediastinum, as being present in his atelectasis cases, four of the lateral roentgenograms which he reproduces in his article are, in our opinion, suggestive of air in the mediastinum, and, inferentially, of PIE.

A letter has also just appeared in the Lancet by E. Montuschion on the subject of airblock in lung blast, in which he refers to the technique of L. Condorelli ${ }^{91}$ for entering the anterior mediastinum to remove air. "The approach." he says, "is from the suprasternal notch, downward, with a curved needle sliding behind the posterior aspect of the manubrium sterni." Montuschi states 
that he has given a more detailed account of the technique in another place, ${ }^{02}$ and further that "This route was devised for the purpose of inducing an artificial anterior pneumomediastinum, which permits in selected cases a more precise diagnosis of conditions arising in this region and of pericardial and pericardio-sternal adhesions. It is evident that when air under tension is collected in the anterior mediastinum it should be easy to relieve the pressure through this route, as there is no difficulty in penetrating into this region in the normal individual."

Much has been written on the entry of air into the mediastinum and pleural cavity from wounds of the neck and chest. One of the most recent of these discussions is that of Neffson ${ }^{83}$ who analyzed a series of cases of tension pneumothorax and mediastinal emphysema occurring after tracheotomy. He admits, however, that the mediast inal emphysema may arise in some of these cases from a PIE originating as described in this paper, from rupture of alveoli into the pulmonary interstitial tissue.

\section{REFERENCES}

1. Macklin, C. C.: in Problems of Ageing, ed. by E. V. Cowdry (2d ed.; Baltimore: 19\{2), ch. 9 .

2. Barrie, H. J.: Lancet 238:996, $191^{\circ}$.

3. Gumbiner, B., and Cutler, M. M.: Amer. Jl. Discases Childr. 61:65o, 1911; also Jl. Amer.

Med. Assn. $117: 2050,1941$.

4. Hamman, L.: Trns. Assn. Amer. Physns. 52:311, 1937.

5. Hamman, L.: Bull. Jolnns Hopkins Hosp. 6 f:1, 1939.

6. NcGuire, J., and Bean, W. B.: Amer. Jl. Med. Scis. 197:502, 1939.

7. Smith, A. B., and Bowser, J. F.: Racliology 38:314, $194^{2}$.

8. Styron, C. W.: New England Med. Jl. 225:908, $194^{1 .}$

9. Wolff, B. P.: Ann. Internal Med. 13:1250, 1940.

10. Ehrlich, D. E., and Schomer, A.: Radiology $30: 471,193^{8}$.

11. Macklin, C. C.: Brit. Med. Jl. II:994, 1937.

12. Berkley, H. K., and Coffen, T. H.: J1. Amer. Med. Assn. 72:535, 1919.

13. Lister, W. A.: Lancet $214: 1225,1928$.

14. Macklin, C. C.: Anat. Recrd. 24:119, 1922.

15. Macklin, C. C.: Amer. Jl. Anat. 35:303, 1925.

16. Macklin, C. C.: Med. Recrd. $143: 89,1936$.

17. Macklin, C. C., and Andrus, P. M.: Anat. Recrd. 45:231, 1930.

18. Macklin, C. C.: Physiol. Rers. 9:1, 1929.

19. Macklin, C. C.: Archs. Surg. 19:1212, 1929.

20. Macklin, C. C.: Amer. Rev. Tuberc. 25:393, 1932.

21. Macklin, C. C.: Tubercle $14 \cdot 16,69,1932$.

22. Macklin, C. C.: Archs. Internal Med. 64:913, 1939.

23. Macklin, C. C.: Mecl. Recrd. 150:5, 1939.

21. Macklin, C. C.: Jl. Michigan State Med. Soc. 39:756, $194^{\circ}$.

25. Macklin, C. C.: Proc. \& Trns. Roy. Soc. Canada (s.3:sect.V) 34:69, $194^{\circ}$.

26. Bourne, G.: Brit. Med. JI. II:313, 19410.

27. Scott, A. M.: Lancet 232:1327, 1937.

28. Jessup, P. M.: Archs. Surg. 23:760, 1931.

29. Macklin, C. C.: Canad. Med. Assn. Jl. 36:414, 1937.

30. Ballon, H. C., and Francis, B. F.: Archs. Surg. 19:1627, 1929.

31. Fisher, J. H., and Macklin, C. C.: Amer. J1. Diseases Childr. 6o: 102, 1940. 


\section{Macklin and Macklin}

32. Fisher, J. H.: Canat. Medl. Assir. J1. 41:27, 19-1.

33. Macklin. C. C.: Anat. Anzgr. 85 (Ergzgshft.): $78,1937$.

3. Macklin, C. C.: Canad. Med. Assn. Jl. 38:ן01, $193^{8 .}$

35. Torrey, R. G., and Grosh, L. C.: Amer. Jl. Med. Scis. 157:170, 1919.

36. Bullowa, J. G. M.: Med. Recrd. 95:346, 1919.

37. Clark, E., and Synnott, M. J.: Amer. Jl. Med. Scis. 157:219. 1919.

$3^{8 .}$ Massey, .1., and Oldershaw, H. L.: Brit. Med. JI. I:61, 1933.

39. Benjamin, B., and Childs, A. E.: Jl. P'ediat. 15:621, 1939.

fo. Hurzumache, E., and Pineles, S.: Amer. Jl. Diseases Childr. 62:661, 1941.

41. Dolgopol, V. B., and Stern, M. E.: Archs. Otolaryngol. 31:14,0, 19.0.

42. Ewart, W., and Roderick, H. B.: Lancet $77: 1808,1899$.

13. Clerf, L. H.: Ann. Otol., Rhinol. \& Laryngol. 41:364, 1935.

44. Imperatori, C. J.: Ann. Otol., Rhinol. \& Laryngol. 42:923, 1933.

45. Gumbiner, B.: Personal communication.

46. Moorman, L. J.: Amer. Rev. Tuberc. 42:412, 1940.

47. Hurrell, G.: Brit. Med. JI. II:16, 1941 .

18. Elkin, W. P.: Sonth. Med. Jl. 31:929, 1941.

19. Macklin, C. C.: Proc. \& Trns. Roy. Soc. Canada (s.3:sect. V') 28:37, 1934.

50. Macklin, C. C.: Jl. Anat. 69:188, 1935.

51. Macklin, C. C.: Archs. Pathol. 21:202, 1936.

52. Hawes, J. B.: Boston Merl. \& Surg. Jl. 186:528, 1922.

53. Gøtzsche, C.: Ugeskr. f. Lacg. 95:765, 1933.

5. Wälinder, B. E.: Act. tuberc Scandinar. เo:66, 1936.

55. Hurxthal, L. M.: New England J1. Med. 198:687, 1928.

56. Nussbaum, F. H.: Brit. Med. Jl. II:1169, 1937.

57. Phillips, P.: Brit. Med. J1. I:54, 1938.

58. Young, R. A.: Brit. Med. Jl. I1:699, 1936.

59. Calverley, E. J. G.: Brit. Med. Jl. II: $1899,1902$.

6o. Graebner, H.: Archs. Otolaryngol. 29:446, 1939.

61. Blumberg, N., and Latowsky, L. W.: Diseases Chest 6:211, 1940.

62. Caldwell, H. W.: J1. Amer. Med. Assn. 116:301, 1941.

63. Worden, E. M., and Chaisson, A. F.: Canad. Med. Assn. J1. 41:237, 1939.

64. Turnley, W. H.: Jl. Connecticut State Med. Soc. 2:357, 1938.

65. Polak, I. B., and Tibbals, C. L.: U. S. Nav. Med. Bull. 28:862, 1930.

66. Brown, E. W.: U. S. Nav. Med. Bull. 29:366, 1931.

67. Polak, B., and Adams, H.: U. S. Nav. Med. Bull. 30:165, 1932.

68. Macklin, C. C., and Macklin, M. T.: Lancet $24^{2}: 602,194^{2}$.

69. Cooke, W. E.: Brit. Med. J1. I:461, 1936.

7o. Zuckerman, S.: Proc. Roy. Soc. Medl. $34: 171,1941$.

71. Dean, D. M.; Thomas, A. R., and Allison, R. S.: Lancet 239:221, 1940.

72. O'Reilly, J. N., and Gloyne, S. R.: Lancet $241: 423,1941$.

73. Steigmann, F, and Singer, H. A.: Amer. Jl. Med. Scis. 192:67, 1936.

74. Hopkins, H. U.: Amer. Jl. Med. Scis. 193:763, 1937.

75. Perry, K. M. A.: Lancet $211: 829,1938$.

76 . Zuckerman, S.: Lancet 239:219. $194^{\circ}$.

77. Ehrlich, S. D.: Med, Recrd. 86:926, 1914 .

78. Eisen, D.: Radiolog! 31:629.1938.

79. Heidrick, A. F.: Aulams, W. E., and Livingstone, H. M.: Archr. Surg. 11:61, 19 fo. $^{\circ}$

8o. Lilienthal. H.: Thoracic Surgery, I (Philadelphia: 192.5), 2.50 .

sı. Stephens, H. B.: Jl. Thorac. Surg. 5:471, 1936.

82. Ackerman, L. V... and Bricker. E. M.: Archs. Surg. 13:145. 19.1.

83. del Chicca, S.: lllinois Medl. Jl. 73:414, 1938.

8. Keen, J. A.: Jl. Laryngol. \&. Otol. 47:1, 1932. 
85. Mathé, C. P., and Faulkner, W. B.: Jl. Urol. 46:601, 1941 .

86. Marcotte, R. J.; Phillips, F. J.; Adans, W. E., and Livingstone, H.: Jl. Thorac. Surg. $9: 34^{6,1940 .}$

87. Henderson, Y.: Lancet 229:178, 1935.

88. Daniels, L. P.: Nederland. tdschr. v. geneesk. 8o:1455, 1936.

89. Wyatt, G. M.: Amer. Jl. Roentgenol. 47:86.4, 1942.

9o. Montuschi, E.: Lancet 242:722, 1942.

91. Condorelli, L.: Minerva med. 27:81, $193^{6 .}$

92. Montuschi, E.: Post-Grad. Med. J1. 14:216, 1938.

93. Neffson, A. H.: Archs. Otolaryngol. 37:23, 1943. 


\title{
CHARLES EDWARD BROWN-SÉQUARD
}

\author{
By \\ RALPH H. MAJOR, M.D.
}

\section{䟢}

From the

DEPARTMIENT OF INTERNAL MEDICINE

THE UNIVERSITY OF KANSAS SCHOOL OF MEDICINE

KANSAS CITY, KANSAS 


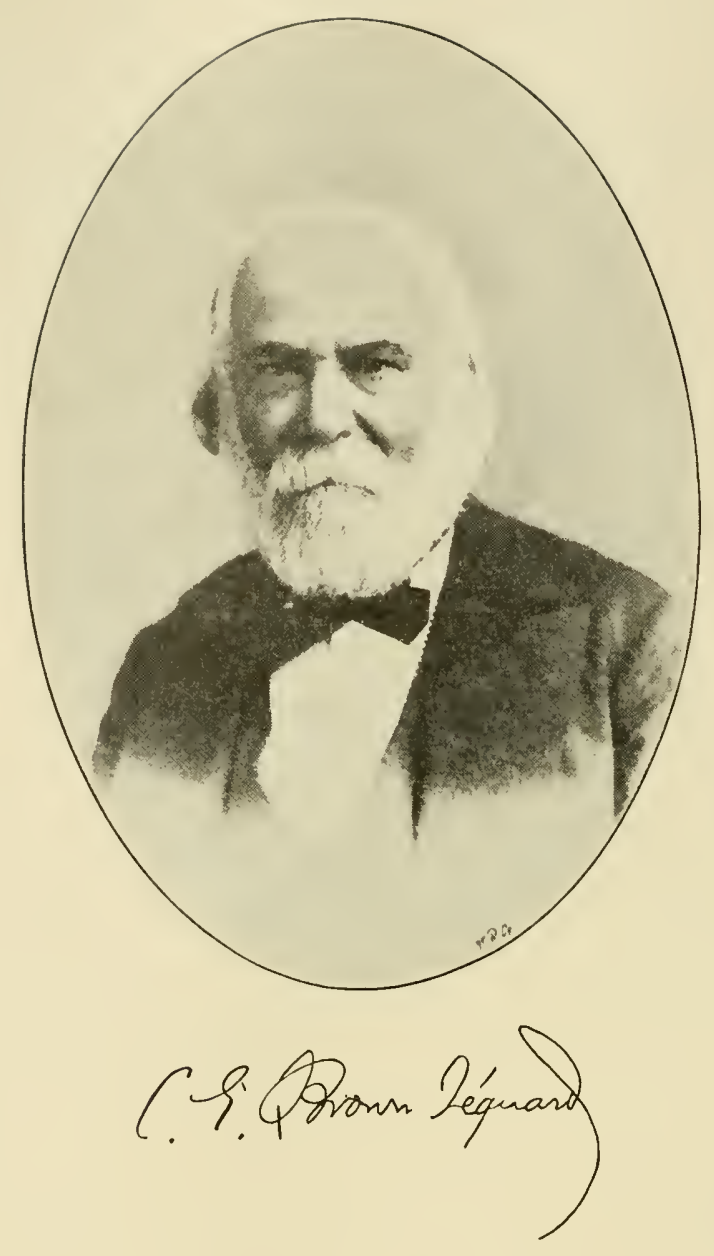




\section{CHARLES EDWARD BROWN'SÉQUARI)}

$\mathrm{B}$ ROWN-SÉQUARD was once described by Harrey Cushing as "the l'once de Leon of our predecessors," who "thought he had in reality found the fountain of perpetual youth." While Ponce de Leon failed in his attempt to discorer the fabled fountain, he did succeed in conquering the island of Puen(o) Rico and was appointed by the King of Spain to the office of gorernor of "I the Island of Florida." Brown-Séquard had his disappointments in endocrinological discovery, yet he made many important observations in the virgin ficld of endocrinology and left an honored record in medical history as a gilted and indefatigable explorer. It would seem fitting in this volume, which honors one who has found time from his studies in anatomy and in nutrition to carry on epochal work in endocrinology, to sketch briefly the career of this pioneer of an earlier generation. Brown-Séquard did not have at his disposal the wellequipped laboratories of the wentieth century with their wealth of accumulated chemical and physical knowledge. Much of his work was done in hours snatched from long days of arduous medical practice, frequently interrupted by revolutions, coups d'état and profound political and social uphearals. Yet, like our colleague and friend, he was gifted with a rivid imagination, an interest in many fields of medical research and a most remarkable industry. energy, and persererance.

Charles Edward Brown-Séquard was born in 1817 on the island of Mauritius in the Indian Ocean, some $55^{\circ}$ miles east of Madagascar. This island of Maturitius was discovered by the Portuguese, but settled and then abandoned by the Dutch. It was subsequently under French rule from 1715 until 1810 , when it was captured by the British. The British still rule the island, although to this day the majority of the population speak French. According to some authorities, Brown-Séquard's father, Edward Brown, was an Irishman from county Galway, but other biographers state that he was a sea captain from Philadelphia. There is general agreement that his mother, Mlle. Séquard, was a native of Mauritius and of French extraction. His father, the hardy sea captain, died on a cruise before the birth of his son, and his widow presently brought the child to the United States, where he received his early education. From his earliest childhood, he apparently had not one, but two mother tongues, for he wrote and spoke both English and French with cqual facility. While most of his scientific work was done in France and he died as a prolessor in the Collège de France in Paris, according to his obituary in the Lancet, "he never lost an opportunity of expressing his desire that he should be looked upon as a British subject." He was, however, in many respects, a true cosmopolitan and, in the course of his life, practiced medicine in Paris, London, Mauritius, Boston, and New York.

Brown-Séquard emigrated to France at the age of trenty-one, and began the study of medicine at Paris. At that time Paris was, anquestionably, the

$$
[3,1]
$$


medical center of the world. The tradition of Bichat, Corvisart, and Laënnec was very much alive and molded the thought of both instructors and students. Bouillaud was still active, and Louis, Gruveilheir, Trousseau, Magendie and Orfila were attracting enthusiastic students from all parts of the world. Young Brown-Séquard was thrown into the stimulating atmosphere of a medical center which had only recently produced a revolution in medical thought and was impatient to extend still further the boundaries of human knowledge.

In 1846 , Brown-Séquard received the degree of doctor of medicine from the Faculty of Medicine of Paris. His doctor's thesis was on the "Vital Properties and Functions of the Spinal Cord," a subject which continued to interest him throughout his medical career. In this thesis, Brown-Séquard reported studies on the motor power of the legs of a frog following section of the spinal cord. He found that immediately after section the motor force was zero, or at most, one-quarter or one-third that before the operation, while one hour later it was greatly increased, often twice the preoperative value. Twenty-four hours later, the motor power showed its maximum increase after which there was usually a gradual decline. He also noted that section of one-half of the cord did not destroy sensation in the areas receiving their nerve supply from the lower portion of the cord.

Brown-Séquard continued to study the nervous system, carrying out numerous experiments and studying patients suffering from nervous diseases. In 1849, three years after his graduation, he published in the Comptes Rendus des Séances et Mémoires de la Société de Biologie an observation that brought him instant recognition and fame-the demonstration of sensory decussation in the spinal cord. This phenomenon, since known as Brown-Séquard's syndrome or paralysis and described in almost every textbook of neurology published since that date, is described by Dorland as "paralysis of motion on one side and of sensation on the other side after hemisection of the spinal cord." This subject continued the object of Brown-Séquard's study for years, and fourteen years later he summarized twenty-four cases showing this phenomenon, some the result of wounds, others the result of disease of the spinal cord.

Brown-Séquard practised medicine in Paris a few years, devoting his attention mainly to diseases of the nervous system, assembling data on his patients, and carrying out physiological experiments. While he was always primarily interested in the nervous system, his restless spirit refused to be confined in this cadre, so that his interests wandered over the general field of medicine. His restlessness of spirit is also reflected in his peregrinations to various parts of the world. His free expression of radical political views is said to have forced him to flee France in 1852 and to find refuge in New York, where he supported himself by the practice of obstetrics, charging five dollars per case for his services. In 1854 we find him practicing medicine in his native Mauritius, but not for long. The following year he is once more in America, teaching the institutes of medicine in the Virginia Medical College. The next year, however, he was back again in his old haunts in Paris. 
One of his experiments, reported in the Medical Examiner of Philadel phia, August, $185^{2}$, was of especial interest:

"My friend, Dr. Claude Bernard, has recently discovered the curious fact, that after the section of the sympathetic nerve in the neck, the face on the same side and more particularly the ear, becomes wamer and more sensible than the other side. The blood ressels are nuch enlarged and a great many are visible which were not so before the operation ...

"If galvanism is applied to the superior portion of the sympathetic after it has been cut in the neck, the ressels of the face and of the ear after a certitin time, begin to contract; their contraction increases slowly, but at last it is evident that they resume their nomal condition, if they are not eren smaller. Then the temperature and the sensibility diminish in the face and the car, and they become in the palsied side the same as in the sound side.

"When the galvanic current ceases to act, the ressels begin to dilate again and all the phenomena discovered by Dr. Bernard reappear."

This experiment was subsequently carried out and published by Claude Bernard. who was apparently not aware of Brown-Séquard's experiments. Since, however, this observation of Brown-Séquard was a natural corollary of Bernard's work, no controversy over priority developed.

In 1856 Brown-Séquard published one of his earliest excursions in to the field of endocrinology, an article with the title, "Recherches expérimentales sur la physiologie des capsules surrénales." In this paper, he describes removal of the suprarenals in dogs, cats, rabbits, and guinea pigs, and concludes that "death is due to the absence of the suprarenal capsules" and that "the functions of the suprarenal capsules are essential to life." The importance of this work apparently did not impress his colleagues, for, some ten years later, when Claude Bernard read his "Report on the Progress and Achievements of General Physiology in France," a report praising the contributions of France to the science of physiology, he made no mention of this work. "It is curious," Olmsted remarks, "that he seems to have missed the significance of BrownSéquard's work on the adrenal glands in $18_{5}^{6-58}$, choosing to mention his very much less important work on transfusion."

In 1858 , Brown-Séquard accepted an invitation to deliver a series of lectures before the Royal College of Surgeons in London. This event was one of the landmarks in his career. He discussed in great detail the anatomy, physiology, and pathology of the nervous system. These lectures were published in the Lancet. Their success wats phenomenal and established the fame of BrownSéquard in English-speaking countries. The Lancet of March 12, $18_{59}$, notes:

"We are gratified to be able to say that our prophecy concerning Dr. BrownSéquard will be fulfilled. We maintained that his course of lectures 'On the Physiology and Pathology of the Central Nervous System' which lately appeared in these columns, was calculated to produce a greater effect in a very large portion of the wide field of medical practice than any course of prelections we had ever before published ... It has happened as we prophesied, for 
we now hear that, through the exertions of Dr. Hughes Bennett, Dr. BrownSéquard is to be secured to give a course of lectures at the northern capital, whilst Dr. G. H. B. Macleod has been farourably interceding also for a course at Glasgow. But the infection has likewise spread to Dublin, where the eminent physiologist is afterwards to appear, in consequence of the invitation conveycd to him through Dr. Robert McDonnell. The College of Surgeons of London, then, will not be allowed to have had all the harvest to itself, although. to be just, wc must give it credit for taking the first steps to gather it in."

Brown-Séquard also reaped a certain harvest. Encouraged by the success of his lectures, he migrated to London, and was at once appointed physician to the recently established National Hospital for the Paralysed and Epileptic. Here he availed himself of the splendid opportunity to study various types of nervous disease, but unlike many of his colleagues in positions of similar prominence, he did not garner any golden harvest. This was doubtless due not to lack of opportunity, but to lack of interest. On one occasion he was asked to come from London to Liverpool to see a patient, the fee being 200 pounds. Brown-Séquart replied calmly that he would be in Liverpool in a few days en route for New York, that the patient could see him then, and the fee would be five guineas. On another occasion he was offered by a wealth! American a fee of 10,000 pouncls to go to Italy to treat his ailing son. BrownSéquard refused on the ground that he was not the right person to treat the patient. However little pecuniary affairs interested him, he seems to have been happy with his patients and his studies, and was much pleased when, in 1861 , he was invited to deliver the Goulstonian Lectures at the Royal College of Physicians. Meanwhile, in 1858 , just subsequent to his first lectures in London, he became editor of the Journal de la Physiologie de l'Homme et des Animaux, and continued to write for this periodical during his sojourn in London. The index of this journal from the year 1856 to 1867 lists fifty articles on physiological subjects, the majority treating of the physiology of the nervous system.

Brown-Séquard's activity in various political movements has been cited by some biographers as the cause of his frequent departures from France, with his inevitable return. His life in Paris did coincide with several abrupt changes in the government-the collapse of the monarchy of Louis Philippe, the establishment of the Second Republic, and then the foundation of the Second Empire of Napoleon III. Brown-Séquard, however, practiced and worked in Paris on five different occasions and the dates of departure from Paris do not coincide, in the main, with any political upheavals. He seems to have been deeply infected with the wanderlust, possibly an inheritance from his seafaring father. In 1864, he was appointed Professor of the Physiology and Pathology of the Nervous System at Harvard College, and once more emigrated to the New W'orld.

Two years later, to quote Samuel W. Francis in an article in The Medical and Surgical Reporter, August 25, 1866, describing eminent American physicians, "Dr. Brown-Séquard, having settled in New York with the specific pur- 
pose of practising in this metropolis, is not only welcomed by the lovers of science, but may, with the strictest propriety, be included in the present series." Dr. Francis relates that he sought Brown-Séquard's views on smoking to which the doctor replied, "I never smoke, and have seen the most evident proofs of the injurious effects of tobacco on the nervous system." When asked what specialty in medicine interested him most, Brown-Séquard answered, "I an chiefly consulted for nerrous affections, both functional and organic, but I am not a specialist; and have studied, and continue to study every branch of medicine."

Dr. Francis continues: “Dr. Brown-Séquard's general health has been very good, being exempt from many of the affections that flesh is heir to. But at desire to investigate the contents of his own stomach, under different circumstances, by means of which he could examine the gastric juice, or partially digested food, has brought on a rare affection, which is sometimes seen in man, namely, a persistent merycism, or rumination, when one is forced to chew a scond time what has been swallowed. This has existed since $\mathbf{1} 8.4$, in consequence of his having often performed on himself experiments, consisting in swallowing sponges, to which were at tached threads; by drawing upon which the sponges were withdrawn from the stomach, containing gastric juice and liquid or liquified food, which he wished to study."

Brown-Séquard, however, did not "settle in New York." In 1867, he returned to Paris and the next year became Professor of Experimental Pathology in the School of Medicine. Claude Bernard was one of the first to welcome him and made a point of attending his opening lecture. Brown-Séquard did not remain long in Paris as Professor of Experimental Pathology. In 1873 he was again in New York. Finally, however, in 1878 , following the death of Claude Bernard, he was named as his successor. He returned to Paris in 1878 and this time he apparently ceased his wanderings once and for all. He remained in Paris until his death in 1894 .

These years which Brown-Séquard spent in Paris were marked by his usual experimental activity, as reflected in the numerous articles which continued to flow from his pen. He presently devoted most of his time to the functions of the endocrine glands, a subject which had interested him for many years. As far back as 1869 , in a series of lectures of the Faculty of Medicine in Paris, he advanced the idea, to quote his own words, "that the glands have internal secretions and furnish to the blood useful if not essential principles." These inrestigations of Brown-Séquard presently focused upon him the attention of the medical and lay world, causing him to be an object of reneration to some and an object of derision to others. In an article published in 189 , he emphasized the proof that had been advanced to support his statement in 1869 that the internal secretions of the various glands played an important role in physiology. He reviewed the work which proved that the throid, athenals, and pancreas all produced internal secretions necessary for health, pointing out that removal of the adrenals caused death, removal of the thyroid produced 
hypothyroidism, and the removal of the pancreas produced diabetes mellitus. About this time Brown-Séquard began his own work on the internal secretions of the testes, work which was to cause such a furor in the scientific world.

In one of his early publications he points out that the sexual glands have three important roles: one, that of generation; another, their effect upon the nervous centers "which give to man and to woman their physical, moral and intellectual characteristics"; and thirdly, a special tonic action upon the spinal cord and the brain. He expresses, on numerous occasions, his conviction that the weakness of old men depends, in part, on the diminution of the activity of the sperm glands. Having boldly advanced his theories, Brown-Séquard immediately plunged into the fray to prove the correctness of his conceptions. Some of his case reports are remarkable in the extreme. He frequently saw examples of the striking results obtained from injection of testicular extract or even of semen itself.

"Young man, tubercular leprosy. After the first injection he noticed a great increase in strength. He walked many miles on foot, in spite of the heat of summer (in the tropics). He could do his work as a worker because, he declared, of these injections. The hair returned in parts where it had long since fallen."

"Young man, age 30 , confined to his bed with nodular rheumatism, obliged to rest on his back for several months, ankylosed. After two or three injections he turned himself in his bed and put himself at will on one or the other side. He could bend his right leg up until the middle of the sole of his foot was flat on the bed."

"A young doctor in Paris injected, with rapid and complete success, his own sperm under the skin of his wife. She had been in bed in a state of extreme weakness caused by hemorrhage. Her strength returned very rapidly. On four occasions at different times the same weakness, due to the same cause, was relieved by dynamogenic action of sperm injected under the skin."

A skeptical world refused to be impressed. Dr. Brown-Séquard was deterred, however, neither by criticism, nor abuse, nor by the sarcastic description of the testicular extract, as "Brown-Séquard's Elixir." He continued his work and spent more than 10,000 francs distributing gratis samples of his testicular extract for clinical use.

Reviewing this period of Brown-Séquard's activity, we are impressed by his lack of discrimination in assaying the value of the clinical trials. However crude and uncontrolled as much of his work was, we realize that BrownSéquard's premise that the sexual glands had other functions than those of generation stamps him as possessed of a very keen and observant mind. During this period Brown-Séquard also experimented with extracts of other organs. He employed an extract of the thyroid gland in myxedema with great success, recorded prolongation of life in adrenalectomized animals following injections of a suprarenal extract, and described experiments with aqueous extracts of the pancreas. He also studied the physiological effects of extracts of the thymus, spleen, liver, and kidneys, and advanced the opinion that extracts of the 
pituitary gland will be of great value in the treatment of hypopituitarism as soon as we can "build up the malady constituted by the special symptoms showing the absence of secretion of the pituitary gland"-a service rendered several years later by Fröhlich and others. Since the protocols of these experiments contain no records of the blood chemistry or of the blood pressure, it is impossible to tell whether he was working with active extracts. There is certainly no evidence that he had an extract of the pancreas which contained insulin, afthough, judging from his previous communications, he was obviously seeking for some such substance in the pancreas.

If Brown-Séquard had had at his disposal the fine procedures of the modern chemist, he would have been able to control his own imaginative thinking and also to avoid the derision of many of his colleagues. Fundamentally, many of his ideas were sound, but he had tackled his work without the tools to fashion it, since these tools were, at that time, undiscovered.

Brown-Séquard died in 1894, at the age of seventy-seven, having served medicine faithfully for fifty-six years. His contributions, as we have seen, were numerous and varied. The actual number of his publications exceeds five hundred, and, while the majority of them relate to the physiology and pathology of the nervous system and to endocrinology, a review of his bibliography shows numerous articles also on the subjects of hematology, hypnosis, anesthesia, laryngology, experimental emphysema, vitiated air, and antiseptics. His greatest contributions, however, were his demonstration of the Brown-Séquard syndrome, which was anticipated in his doctor's thesis, and his work on the glands of internal secretion, which, while faulty in certain respects, had the most desirable effect of turning the attention of medicine to this much neglected field. We can imagine his great enthusiasm if he were among us today and could view the enormous strides that endocrinology has made since his time. 



\section{THE UNDISCHARGED OVARIAN FOLLICLE}

$$
\text { By }
$$

F. H. A. MARSHALL,

\section{ख}

From the

SCHOOL OF AGRICULTI'RE, CAMIBRIDGF, ENGIAND 



\section{THE UNDISCHARGED OVARIAN FOLLICLE}

$\mathrm{A}^{\mathrm{s}}$ Is well known in the matter of ovulation, there are two main categories of nammal, first those in which the mature ovarian follicles discharge spontaneously, usually at or about the periods of estrus, and secondly those in which the follicles rupture nomally only as a result of coition or some other sexual stimulus producing an orgasm. The common domestic animals such as the bitch, the mare, the cow, the ewe, and the sow are examples of the first group; the rabbit, the ferret, and the American ground squirrel are examples of the second group. The cat appears to belong to both groups, individuals orulating spontaneously or only in response to sexual stimulation in about equal proportions. Among the lower vertebrate classes the same physiological division occurs, but, whereas among birds ovulation generally appears to depend upon the presence of the male, in reptiles, amphibians, and fishes spontancous ovulation is the rule, though there are some noteworthy exceptions $\left(\right.$ Marshall $\left.{ }^{1}\right)$. With those species of mammal which do not usually ovulate except as a result of coition there are further marked differences in the behavior of the nonovulating follicles. In the domestic rabbit two types of follicular atrophy are clistinguishable. In the commoner type, which with various minor differences is normal for most animals, the liquor folliculi is absorbed, the epithelium is broken down, the orum becomes flattened and shriveled, and the cavity eventually becomes filled in by a loose ingrowth of connective tissue from the thecal wall. In the second type, which was described by Heape $^{2}$ and Hammond, ${ }^{3}$ there is a large extravasation into the cavity of blood which clots so as to form a red or black spot; this can be seen on the surface, and in the later stages resembles a blood blister in the skin, whereas the other type is visible only microscopically. A newly formed blood follicle is bright red and becomes dark and eventually black only some time after it has been formed.

I am indebted to Dr. John Hammond for allowing me to examine microscopically a large series of blood follicles; these show that in the process of formation the loose tissue of the theca interna has broken down in many places, the previously engorged blood vessels having undergone rupture. The rush of blood into the cavity may result in much of the follicular epithelium, together with the orum being swept aside and chisintegrated, the ortum becoming shrunken. The latter may, however, remain surrouncled at a little distance by a reduced number of epithelial cells. The theca interna may become completely or ahmost completely stripped away from the theca externa, or parts of it may remain lined internally by follicular epithelial walls, some of which are hypertrophied as though in an attempt to form luteal cells. The sections show also various transitional stages between mature follicles and disintegrated atrophic follicles. In the later stages as described by Hammond ${ }^{3}$ the orum has lisappeared as well as the epithelial cells, and the blood follicle is

$$
\left[3^{8} 1\right]
$$


gradually absorbed. Granules of black or brown pigment may be detected in the thecal wall and these are probably derived from the blood pigment in process of absorption.

Blood follicles are only very rarely found in other species of mammal and are normal in none of them under any conditions. Blood spots, however, are found in the ovaries of the immature mouse as a result of injecting gonadotrophic hormone (in pregnancy urine); these spots occur in the ovarian stroma and, though some may be large and easily seen, others are very minute (Robson $\left.{ }^{4}\right)$; moreover, it is not always clear that they are associated directly with follicles.

It used to be supposed that hemorrhagic follicles in the rabbit represented follicles which failed to undergo ovulation owing to the buck being withheld and that such was probably the normal fate of mature follicles after an estrous period had been going on for a prolonged time. This conclusion, however, is now known to be incorrect, in view particularly of two considerations. First, it is now realized that the formation of blood follicles is the result of a sexual stimulus of the nature of an orgasm and may be produced artificially by the injection of anterior pituitary secretion or pituitarylike substances or by electrical or other stimuli which act on the pituitary through the intermediation of the central nervous system. Secondly, it has been shown through the work of Evans and Swezy ${ }^{5}$ that in the rat, guinea pig, dog, cat, and mouse oögenesis occurs rhythmically throughout the whole period of sexual life and in relation to the ovulation cycle. It had already been ascertained, contrary to what was usually supposed, that in the rabbit (Lane-Claypon') and other animals new ova were produced after sexual maturity, and the earlier literature is reviewed by Evans and Swezy. Moreover, Hill and White, ${ }^{7}$ and Smelser, Walton and Whetham ${ }^{s}$ independently discovered that the mature follicle does not persist in the estrous rabbit but is rather short-lived, so that during the prolonged heat periods numbers of follicles appear and disappear, the series overlapping in such a way that at any one time there are approximately the same number of mature follicles on the ovarian surface and estrus and potential fertility are continuous. From what has been said it is clear that the formation of hemorrhagic follicles in the rabbit is of the nature of an attempted ovulation and probably occurs normally as a result of a sexual stimulus of some kind (for instance, when two female rabbits are kept together) which is, however, insufficient to produce ovulation.

In other species of mammals which are known to ovulate only after coition, hemorrhagic follicles are not formed, or at any rate have not been described except rarely or as occurring abnormally. In the American ground squirrel Foster $^{\ominus}$ has given an account of follicular atrophy of the more usual type in which there is no hemorrhage, and such atrophy appears to be the fate of the mature follicles which do not discharge. The ovum, however, is stated to degenerate before the surrounding epithelial cells, whereas in most mammals the reverse is usually the case. 
The ferret also differs from most mammals in that it ovulates only after coition $\left(\right.$ Marshall $^{10}$ ) and it differs from the rabbit in that no known exceptions to this causal relation have been recorded or observed. The atrophic follicle first figured in 1904 has recently been fully described by Hanilton and Gould. ${ }^{11}$ Atresia may set in at all stages of follicular growth and at all times in the cycle. The earliest indications are degeneration of the epithelium and loss of shape. Hamilton and Gould suggest that the interstitial tissue contributes towards the collapse of the follicle by slow cellular proliferation and the pressure which it exerts. The theca becomes fibrotic and constitutes the scars found later in the ovaries. Unlike that of the ground squirrel mentioned above, the zona pellucicla of the ovum may persist for a long time along with some leucocytes which remain in the cavity. This description is in general agreement with my own earlier but less detailed observations. Hamilton and Gould state further that the scars of the atrophic follicles of the ferret differ from those of the sow, goat, and mouse in which there is proliferation of the theca that comes to fill the collapsed cavity with fibrous ingrowth, whereas in the ferret there is comparatively little active proliferation of the theca. There is often, however, a loose ingrowth of connective tissue, which may be seen while the ovum is still visible in the cavity $\left(\right.$ Marshall $\left.^{10}\right)$. No hemorrhage from the theca or any part of the wall of the follicle was ever observed, and this may be interpreted as due to the greater density of the tissue as compared with that of the rabbit.

Unruptured follicles of a somewhat different type have also been observed in the ferret in some cases where the animals had been on heat for an exceptionally long time. These show a retention with lutealization of some of the epithelial cells not unlike those of the rabbits described above. The ova in various stages of degeneration could also sometimes be seen within such follicles.

An attempt was made to cliscover if there were differences in the histological appearance of the ovary at different times in the prolonged héat periods. For this purpose ferrets were killed after they had been continuously on heat under natural conditions (that is, without artificial stimulation by light or electricity) for five, six, eight, and twelve weeks. It may be stated at once, however, that there was general resemblance in the ovarian histology at all those stages. Each stage showed large follicles, some apparently ready to rupture, but there were no discharged follicles or typical corpora lutea. There were also follicles in process of degeneration, but in the five- and six-week stages these were small ones which apparently had never grown. In the ferret which had been on heat for eight weeks the ovaries contained some medium-sized atrophic follicles with the degenerate ova surrounded by unenlarged or only slightly enlarged epithelial cells. Big degenerate follicles with lutealization of some or most of the epithelial cells as described above were found only in the twelve-week stage. The observations made were not numerous enough to warrant any very definite conclusions, but they suggest that degeneration of large follicles is 
more characteristic of animals which have been on heat for a prolonged period than that it occurs normally in all estrous ferrets. Such a view is consistent with what was found in a ferret subjected to ultraviolet light for thirty-eight weeks, but it is to be noted that in this case no degenerate ova were found in the follicles (Marshall ${ }^{12}$ ). These observations suggest that in the ferret, as in the rabbit, ripe follicles develop in relays and then degenerate if ovulation cannot occur, as described for the rabbit by Smelser, Walton and Whetham, ${ }^{8}$ but that the process does not go on so rapidly in the ferret.

Attempts were made to induce ovulation in the ferret by electrical stimulation through the head by the method which produced ovulation or the formation of hemorrhagic follicles in the rabbit (Marshall and Verney ${ }^{13}$ ). With ferrets, however, no reaction on the ovaries was obtained. These negative results may have been due to the stimulation not being applied for a sufficiently long period, since ferrets in copulating normally take a very long time over the process, and if the male is withdrawn after a quarter of an hour ovulation may not follow. Or they may have been due to the fact that the electrical resistance of the bones of the ferret's skull is greater than that of the rabbit's, and since the electrodes were external to the cranium less current would pass through to the hypothalamus and pituitary $\left(\right.$ Harris $\left.^{14}\right)$. With these considerations in mind Harris stimulated the hypothalamus directly with an electrode inserted into the posterior region. As a result at post-mortem 102 hours after stimulation three cystic follicles with extensive lutealization were found in the ovaries, but no blood follicles.

\section{SUMMARY}

(1) Among all the mammals in which the reproductive processes have been investigated the rabbit appears to be unique in having ovarian blood follicles as a frequent phenomenon.

(2) Ferrets do not ovulate or develop blood follicles (as do rabbits) when experimentally stimulated, possibly on account of the denseness of the tissue surrounding the follicles.

(3) Histological study of ferrets' ovaries suggests that in this animal, as in the rabbit, ripe follicles develop in relays in the ovaries during estrus, but that in the ferret the process is more marked towards the later stages of the prolonged heat periods.

(4) Appearances suggest also that especially in the later stages of estrus the ripe follicles become atrophic, some of the epithelial cells at first becoming hypertrophied while the ovum remains in the cavity of the follicle.

\section{REFERENCES}

1. Marshall, F. H. A.: Biol. Revs. $17: 68,1942$.

2. Heape, W.: Proc. Roy. Soc. London, s.B 76:260, 1905.

3. Hammond, J.: Reproduction in the Rabbit (Edinburgh: 1935).

4. Robson, J. M.: Recent Adrances in Sex and Reproductize Physiology (2d ed.; London: $1910)$. 


\section{F. H. A. Marshall}

5. Evans, H. M., and Swezy, O.: Mems. Univ. California 9:119, 1931.

6. Lane-Claypon, J. E.: Proc. Roy. Soc. London, s.B 77:32, 1905.

7. Hill, M., and White, W. E.: Jl. Physiol. 80:174, 1934.

8. Smelser, G. K.; Walton, A., and Whetham, E. O.: Jl. Exper. Biol. 11:325, 193 1.

9. Foster, M. A.: Amer. J1. Anat. 5.1:48, 1934.

10. Marshall, F. H. A.: Quart. Jl. Microscop. Sci. 48:323, 1904.

11. Hamilton, W. J., and Gould, J. H.: Trns. Roy. Soc. Edinburgh 60:87, 1940.

12. Marshall, F. H. A.: Jl. Exper. Biol. 17:1 39, 1940.

13. Marshall, F. H. A., and Verney, E. B.: Jl. Physiol. 86:327, $193^{6 .}$

11. Harris, G. W.: Proc. Roy. Soc. London, s.B 122:374, 1937. 



\section{MECHANISM OF THE DESGENT OF THE TESTIGLE \\ UNDER THE AGTION OF \\ SEX HORMONES}

$$
\text { By }
$$

THALES MARTINS

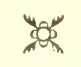

From the

INSIITL TO OSWALDO CRLZ, RIO DE JANEIRO, BRA7IL 



\section{MECHANISM OF THE DESCENT OF THE TESTICLE UNDER THE ACTION OF SEX HORMONES}

$\mathrm{T}$ IHE ELUCidation of the mechanism of testicular descent in the postnatal period has lately made real progress. The use of active hormones has demonstrated that the migration of the organ into its scrotal seat is unquestionably controlled by endocrine factors.

Engle $^{1}$ has shown that after treatment of preadolescent rhesus monkeys with gonadotrophic extracts testicular migration is hastened, a fact that has been corroborated by a number of later papers, which report the use of both hypophysial and pregnancy-urine extracts and extend the application to other zoölogical groups, man included.

Hamilton," using testosterone esters, was able to induce identical effects in rhesus monkeys. Walsh, Cuyler and McCullagh ${ }^{3}$ and also Nelson and Gallagher ${ }^{4}$ showed that in hypophysectomized rats androgenic substances are able to prevent testicular changes for some time as well as keep the organ in its normal position. In squirrels, androgenic substances may induce spermatogenesis in seasons of sex inactivity (Wells and Moore ${ }^{5}$ ).

These results do not allow one to exclude a direct action of the hormones upon the testicle. There is left open for discussion the participation of the gonad in the phenomenon, regarding both the modification of its consistency, dimensions, etc., as well as the influence on its own endocrine activity.

In order to eliminate these factors, that is, to solve the paradox of the descent of the testicles in a castrated animal, we performed experiments with small paraffin pellets as substitutes for the testicular parenchyma. In such a way a mechanical "testicle" is maintained with exclusion of every endocrine function of the organ. Hamilton, ${ }^{6}$ in a study directed toward another end, used the technique of placing loose small paraffin spheres in the scrotum in order to discover whether they exert any influence on the development of the cremaster. Our technique and experimental purposes are, however, quite different from those of this author. In the present paper, we report further experiments on extirpation of the scrotum and the results with regard to the position of the testicle. A preliminary note on the subject has already been published. ${ }^{7}$

\section{Methods}

Animals: The operation was performed on 17 rats weighing from 180 to $250 \mathrm{gm}$., and on 4 rhesus monkeys weighing from 3.5 to $9 \mathrm{~kg}$.

Operation: In the rats we always used the abdominal method in order to avoid irritation of the scrotal and cremasteric region. The testicles were exposed by a small suprapubic incision, from 1.0 to $1.5 \mathrm{~cm}$. in length. Another 
longitudinal incision was made in the tunica albuginea, measuring about $1 / 3$ of the length of the organ so as to enable the removal of the entire parenchyma, care being taken to clean up the remnants of the testicular pulp which possibly might have remained adherent. A small ovoid paraffin mass of shape and size nearly cqual to that of the testicle was then introduced into the cavity of the albuginea; at last the incision was then sutured with extra fine catgut. The operation was always performed on both sides. On the first days after the operation the substituted organ was pushed back and forth towards the abdomen in order to avoid adhesions which might easily be formed as a result of the irritation caused by such a foreign body and which, in case of fixing the "testicle," would invalidate the experiment.

In the rhesus monkey operation by the abdominal route, in order to spare the inguino-scrotal region, is not possible. In one preadolescent animal with testes still in the canal the operation was performed through an incision of the inguinal wall; in the other three it was performed by way of the scrotum.

Extirpation of the Scrotal Pouch: In 5 rats weighing from 150 to $200 \mathrm{gm}$., of course not subjected to the operation with paraffin pellets, the whole skin of the scrotum was extirpated, including the entire region which normally covers the testicles. In 2 of them the cremaster was also extirpated.

Treatment: In 4 rats, injection was begun 3 to 11 months after the operation; $5 \mathrm{mg}$. of testosterone prepionate* in 0.5 to $1.0 \mathrm{cc}$. of sesame oil were given every 3 to 5 days; in rhesus monkeys, starting from 2 to 4 months after the operation, $10 \mathrm{mg}$. doses were given at the same intervals.

\section{Results}

Of the 17 rats operated and with artificial testes substituted 11 were impaired for experimental purposes by local inflammatory reactions, ulcerations, and irremovable adhesions. In the other 6 the result was favorable, the "testicles" being fairly movable, remaining in the scrotal pouch during the first days, and subject to the same mobility as that which is observed in normal animals. For instance, they responded very well to mechanical and thermic stimulants, ascending to the abdomen when the rats were placed at $6^{\circ}$ to $10^{\circ} \mathrm{C}$., and descending again when the temperature of the environment rose to $25^{\circ}$ to $30^{\circ} \mathrm{C}$.

From 2 to 5 weeks later, as the endocrine secretion of the gonad was lacking, the false "testes" ascended to the canal and abdomen, remaining there indefinitely in the animals not subjected to hormonal treatment.

Four rats, operated from 3 to 11 months before, were employed for experiments on the action of injected androgenic products. The effects were relatively rapid; even 5 to 10 days after the beginning of the treatment the "testicles" were seen to have moved towards the scrotal pouch being engaged in the canal or in the upper third of the scrotum. Within 15 days descent was completely achieved, the "testicles" remaining thereafter consistently in

\footnotetext{
* We are grateful to the Schering Corporation for the donation of the hormonal material.
} 
the scrotal pouch (pl. 1, figs. 1 to 3); after cessation of treatment, they returned to their intra-abdominal position.

In the rhesus monkeys the results were not so readily demonstrable. After the operation the "testicles" ascended to the upper region of the scrotum or into the canal. After 2 to 3 weeks of testosterone treatment, the beginning of descent was detected; the cord became longer, the organ approached the pouch. In one case there was quite a complete descent, the "testicles" occupying the middle region of the scrotum. In the 3 other animals, they descended 2 to 3 $\mathrm{cm}$., lodging in the lower end of the canal or in the upper third of the pouch. A hanging position, like that observed in the rat, was not attained in the rhesus monkey; but the reasons for this may, perhaps, be merely the results of surgical complications. By digital examination we had the impression of the existence of connective bands which prevented complete descent; in one case post-mortem examination showed in fact the presence of adhesions. The differences in the surgical procedures in the two species must also be remembered; in the rat it was possible to make a suprapubic approach, all the tracts and adnexa of the testicle remaining untouched; in the rhesus monkey it was necessary to make the incision in the scrotum or the canal which favored the formation of adhesions which were further aggravated by the presence of the foreign body. Nevertheless, we are enabled to conclude that there was a visible effect of the hormonal treatment, although not so positive as in rats.

Extirpation of the Scrotum: In normal rats, that is to say in those not subjected to the experiment of substituting the testicular parenchyma with paraffin, we observed that the operation of scrotal extirpation was no hindrance to the maintenance of practically normal position of the gonads, which distended the adjacent nongenital skin (pl. 1, fig. 4).

\section{Discussion}

The results here reported show clearly that in rats, and very probably in rhesus monkeys, testosterone is able to induce the descent of artificial paraffin testicles. The action of the homone is, therefore, extragonadic, independent of any functional or morphological modification and of the dimensions or consistency of the testicles. What then are the extragonadic conditions that are necessary for the descent of the testicles?

It seems that the most important are the following:

permeability of the inguinal rings and canal;

length and extensibility of the vas deferens, vessels, and smooth fibers of the spermatic cord;

development and relaxation of cremaster and dar tos nuscles; good development of scrotal pouch;

sufficient abdominal pressure.

When we look for an active motile agent that might cause displacenent in the process of descent, we meet with difficulties. There is no muscular organ which has its insertion on the testicle and another fixed extratesticular at- 
tachment which by contraction should induce the descent of the organ. The gubernaculum testis with two moving insertions seems to play no active role in the descent, in the postnatal period at least. Its Latin name means "helm of the testicle," a denomination which we deem very adequate, as we agree with Deming in his statement that the gubernaculum "is either a guide or rudder, but not a tractor for the testicle." On the other hand, the experiments here recorded on scrotum extirpation show that even in its absence the agents that impel the testicle can force the extragenital skin to distend.

Spiral or circular contractions of the musculature of the canal comparable to those which induce the progression of intestinal contents are a conjectural matter, and not yet proved true.

It seems that the most important impelling force to be taken into consideration, mainly in animals with a lifelong permeable inguinal canal, is the abdominal pressure; in certain cases, gravity may also be a facilitating agent.

The most relevant role of the testicular hormone would be to annul the resistances and forces that oppose descent; in other words, to develop the vas deferens, spermatic cord, cremaster, and scrotum, while maintaining the genital musculature at a certain degree of relaxation.

If the endocrine secretion of the testes is insufficient or absent, the shortening through atrophy associated with greater contractility or tonus of the accessory muscular organs will necessarily lead to ascent of the testicle. Recent work in our laboratory shows that testosterone exerts an inhibitory action on the contractility "in vitro" of the vasa deferentia, epididymides, seminal vesicles, and prostate glands of rats and rhesus monkeys and the vasa deferentia of cats. ${ }^{9-15}$ The organs of castrated animals or of those treated with estradiol become more responsive to pharmacologic agents and exhibit spontaneous or automatic contractions. In normal or castrated animals treated with testosterone, there is no attomatism and their reactivity to drugs is much less. Experiments "in vivo" corroborate these results (Martins and Valle ${ }^{18,17}$ ); moreover, studies of the excitability of the cremaster, as investigated with chronaxy methods, seem to demonstrate that, in rats, the contractility of this muscle is also under the control of testosterone (Martins and Cavalcanti $\mathrm{i}^{\mathrm{is}}$ ).

All these results agree well with the conditions necessary for testicular descent, namely the checking of muscle actions which would work against the forces that are intended to draw down the testicle. For these reasons, in our preceding work we have pointed out that descent through hormonal treatment, either experimental or clinical, should result from effects, not only morphological but also functional. In certain cases, particularly when the effects are very rapid, we can suppose that the dominant action is the functional one, namely that which modifies the contractility of the musculature in question. Moreover, in the papers quoted above we were able to verify the fact that the latency period for testosterone treatment to exert influence upon the contractility of the vas deferens and seminal vesicles is relatively short, in rats 42 to 72 hours. 
In the clinical case published by various auliors, references are made to surprisingly quick results from hormones in the treatment of test icular ectopy; although they rouse a certain skepticism, it is not impossible that the result really derives from the therapy, as the functional action of testosterone can be manifested within a matter of hours, as experimentally demonstrated by ur.

In cases of pseudocryptorchidism, as Hamilton calls such spastic retentions, the influence of the hor mone must be primarily lunctional; in fact, Hamilton and Hubert ${ }^{19}$ were able to induce in 12 patients a permanent descent of the testicles, using doses of androgens insufficient to provoke erections and scrotal growth. Such clinical results may be regarded as hamonizing with the physiologic data discussed in the present paper.

\section{SUMMTARY}

Experiments were performed in rats and rhesus monkeys in which the testicular parenchyma was replaced by paraffin pellets inserted into the tunica albuginea cavity. In rats, some days after the opcration, the "artificial testicles" ascend towards the inguinal canal or the abdomen, remaining there; but after injections of testosterone propionate they completely descend to the scrotal pouch at the end of 10 to $y_{5}$ days of treatment. In rhesus monkeys there also was an appreciable but less pronounced descent, due perhaps to the fact that in this species postoperative adhesions are formed with greater frequency.

In a group of rats which was not subjected to the experiment with paraffun pellets but in which the scrotal pouch was completely extirpated, we verified the fact that the testes remained in their descended position thanks to the distension of the extragenital skin. Thus it becomes evident that, in rats at least, the scrotum is not an active factor in inducing testicular descent.

The results of testosterone propionate in rats with paraffin pellets show that the action of this hormone can appear without any modification of the consistency, size, or endocrine activity of the gonads, as the animals, though having a "mechanical testicle" are castrated. The action of the hormone is, consequently, extragonadal, controlling the growth and contractility of the testicular adnexa.

\section{REFERENCES}

1. Engle, E. T.: Endocrinology 16:513, 1932.

2. Hamilton. J. B.: Amer. Jl. Playsiol. 119:325, 1937.

3. Walsh, E. L.; Cuyler, W. K., and McCullagh, D. R.: Imer. Jl. Plıs aiol. 107:508, 1934.

4. Nelson, W. O., and Gallagher, T. F.: Science (n.s.) 8ł:230, 1936.

5. Wells, L. J.. and Moore, C. R.: Inat. Recrd. 66:181, 1936.

6. Hamilton, J. B.: Proc. Soc. Exper. Biol. \&. Med. $35: 386,1936$.

7. Martins, T :: Cpls, rd. Soc de Biol. 131:299, 1939.

8. I)eming, C. I..: J]. E ${ }^{\top}$ rol. .36:274, $193^{6}$.

9. Martins, 1... and do Valle, J.: Cpess. 16. Soc. de biol. 127:16.1. 1938.

10. Martins. T., and Valle, J. R.: Cpts. rd. Soc. de biol. 127:1381, $193^{8}$.

11. Matiun, I., and Vialle, J. R.: Fudocrinolog! 25:5o. 1939).

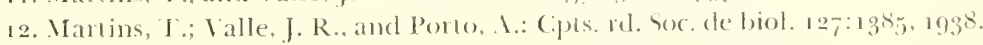

13. Martius, Г.. and Porto. 1.: Cpes. rel. sor. de biol. 127:1389, 1938. 
1.4. Martins, T.; Valle, J. R., and Porto, A.: Pflügers Arch. f. d. gsmt. Physiol. 242:155, 1939. 15. Martins, T., and Valle, J. R.: Cpts. rd. Soc. de biol. 130:189, 1939.

16. Martins, T., and Valle, J. R.: Pflügers Arch. f. d. gsmt. Physiol. 243:243, 1940.

17. Martins, T., and Valle, J. P.: Mems. Insto. de Butantan 14:109, 1940.

18. Martins, T., and Cavalcanti, T.: Unpublished data.

19. Hamilton, J. B., and Hubert, G.: Proc. Soc. Exper. Biol.\&. Med. 39:4, $193^{8}$. 
EXPLANATION OF PLATE 
PLATE 1

Figs. 1 and 2. Genital region of rat $D_{5}, 11$ months after substitution of the testicular parenchyma by paraffin pellets.

In 1: the intra-abdominal position of the "testicles" before treatment is marked with ink.

In 2: after 15 days' treatment with testosterone propionate; prominence of the descended testicles is scen in the well-developed scrotal pouch.

Fig. 3. Reproductive system of rat, 6 months after implantation of paraffin pellets, well tolerated by the albuginea, which appears smooth and vascularized.

Fig. 4 . Rat 9,70 days after extirpation of the scrotal pouch. Testicles fairly descended, distending the extragenital skin. 


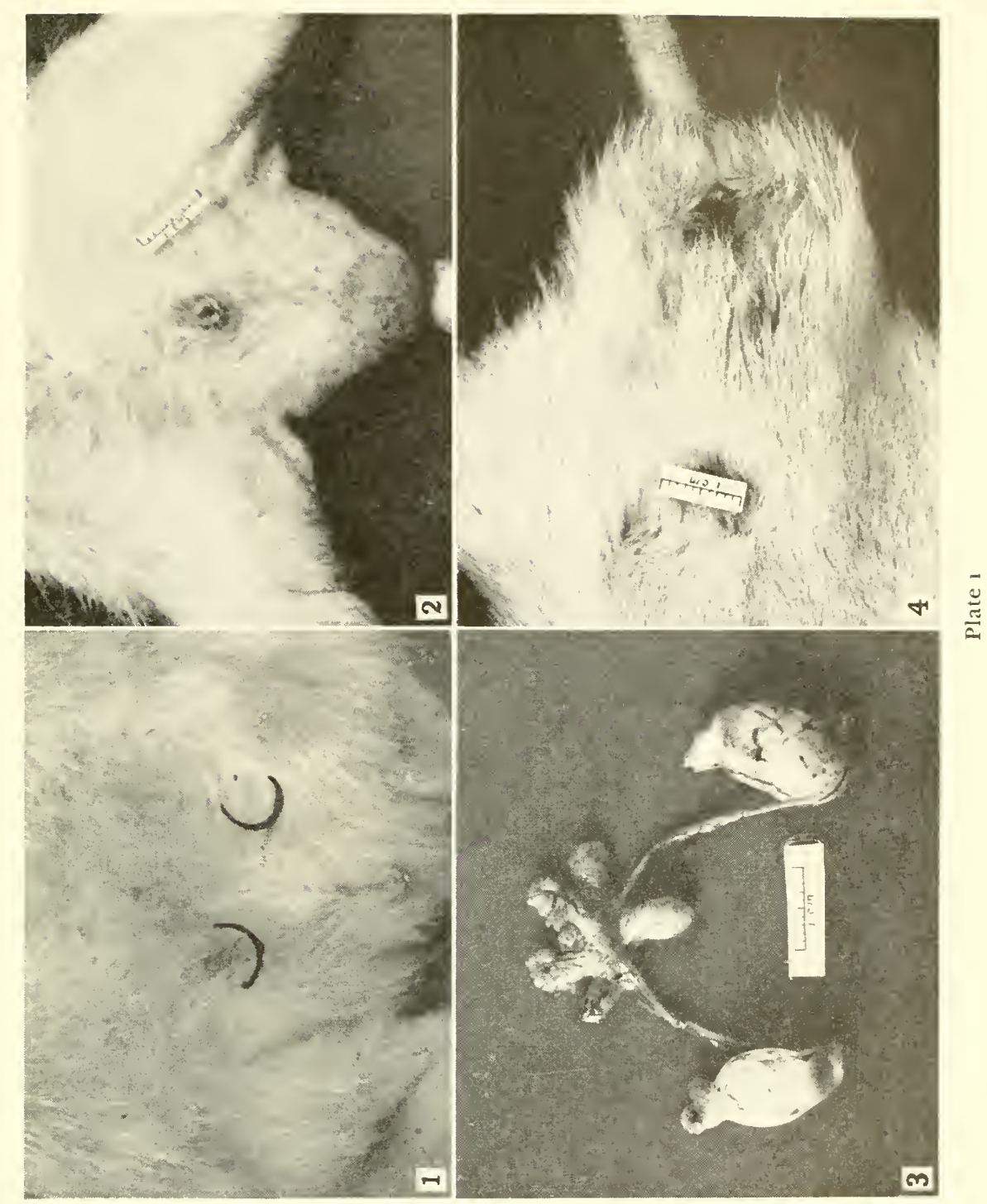





\title{
A HEMORRHAGIC STATE
}

IN THE

\section{VITAMIN E-DEFICIENT FETUS}

\section{OF THE RAT}

\author{
By
}

KARL E. MASON

\section{稰}

\section{From the}

DEPARTMENTS OF ANATOMY, VANDERBILT UNIVERSITY SCHOOI, OF MEDICINE, NASHVILLE, TENN., AND UNIVERSITY OF ROCHESTER SCHOOL OF MEDICINE AND DENTISTRY, ROCHESTER, N. Y. 



\section{A HEMORRHAGIC STATE \\ IN THE VITAMIN E-DEFICIENT FETUS \\ OF THE RAT**}

$\mathrm{D}^{\prime}$ EFICIENCY of vitamin $\mathrm{E}$ in female rats is characterized by death and autoly sis of the implanted embryo during the second week of gestation, usually between the ninth and thirteenth days. The maternal decidua is at first unaffected but some days later shows regressive changes secondary to the loss of fetal elements. It has been generally accepted that the early fetus succumbs to starvation and asphyxiation, which in turn are secondary to retarded development and rarefaction of mesenchymal derivatives, especially those related to the hematopoietic system (Evans and Burr, ${ }^{1}$ Urner $^{2}$ ). The resorptive process can be prevented by administration of adequate vitamin $\mathrm{E}$ during the first week or ten days of pregnancy.

However, when sterile rats are given borderline doses of vitamin $\mathrm{E}$, as in routine bio-assay tests, variable numbers of early resorptions, dead fetuses in different stages of autolysis, and viable fetuses may be observed in uteri examined at laparotomy or at autopsy during the last third of pregnancy $\left(\right.$ Mason $\left.^{3,4}\right)$. It appears that fetuses at certain implantation sites escape the early process of resorption but eventually succumb at different periods during the latter part of gestation. Since there exist all gradations between early resorption and viable fetuses, it seemed that an investigation of the nature and causes of fetal death during later stages of pregnancy might afford a better understanding of the role of vitamin $\mathrm{E}$ in fetal development. These studies have revealed the existence of hitherto undescribed abnormalities of the rascular system, associated with late fetal death, the gross characteristics of which are discussed in the present report.

\section{Fetal Death at the Sixteenth Day of Pregnancy}

Although fetal death has been observed at all stages of late pregnancy, an extensive series of studies concerned with the establishment of new criteriat of bio-assay response based upon examination of the uterus at the sixteenth day of gestation (Mason ${ }^{4}$ ), and the subsequent application of this procedure

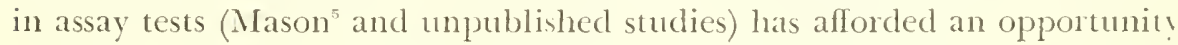
to examine large numbers of dead fetusest and associated living fetuses it

* These studies were begun in the Departnent of Anatomy of Vanderbilt Lniversity School of Medicine, aided by a grant from the Division of Medical Sciences of the Rockerfeller loundation, and have been continued at the Department of Anatomy, Universits of Rochenter School of Medicine and Dentistry. 1 wish to acknowledge my indebtedness to Mr. Roger Terry and to Mr. Robert Pfaff, Student Fellows in Anatomy, University of Rocheser School of Medicine and Dentistry, for their valuable assistance and collaboration in these stulies.

† Since all transitions exist between typicat resorption sites and sites in which death has just occurred, the term "dead feus" has been arbitrarily applicel only to those implantation 
this particular stage of development. In more than 1600 rats autopsied or laparotomized at the sixteenth day in routine bio-assay tests, approximately 22 per cent have possessed one or more dead fetuses in utero. As many as four or five such fetuses were sometimes encountered in a single uterus.

A preliminary study demonstrated that administration of small amounts of vitamin $\mathrm{E}$ as late as the twelfth day readily prevents the occurrence of fetal death at the sixteentl day of pregnancy, and also improves the bio-assay response (table 1 ).

Histologically, many viable fetuses removed from uteri containing dead fetuses and resorption sites were normal in every respect. Other live fetuses,

TABLE 1

Effect of Additional Vitamin E, Administered on the Tenth and on the Twelfth Days of Pregnancy, upon the Incidence of Dead Fetuses at the

Sixteenth Day of Gestation

\begin{tabular}{|c|c|c|c|c|c|c|c|c|c|}
\hline \multirow{2}{*}{$\begin{array}{l}\text { No. of } \\
\text { rats }\end{array}$} & \multicolumn{3}{|c|}{$\begin{array}{l}\text { Vitamin } \mathrm{E} \text { concentrate } \\
\text { fed on }\end{array}$} & \multicolumn{3}{|c|}{$\begin{array}{l}\text { Implantation sites at } 16 \text { th } \\
\text { day of pregnancy }\end{array}$} & \multirow{2}{*}{$\begin{array}{c}\text { Positive } \\
\text { assay } \\
\text { responses, } \\
\text { per cent }\end{array}$} & \multicolumn{2}{|c|}{$\begin{array}{l}\text { Aver. wt. of implan- } \\
\text { tation sites }\end{array}$} \\
\hline & $\begin{array}{l}5^{\text {th }} \text { day, } \\
\text { mg. }\end{array}$ & $\begin{array}{l}\text { Ioth day, } \\
\text { mg. }\end{array}$ & $\begin{array}{l}\text { reth day. } \\
\text { mg. }\end{array}$ & Live & Dead & Res. & & $\begin{array}{l}\text { Live, } \\
\text { gm. }\end{array}$ & $\begin{array}{l}\text { Dead, } \\
\text { gm. }\end{array}$ \\
\hline 12 & 50 & . & . & $3^{8}$ & I 5 & 49 & $5^{8}$ & I. O4 & $0.7^{8}$ \\
\hline 10 & 50 & 50 & . & 72 & 0 & 23 & 90 & I. 09 & $\ldots$ \\
\hline 10 & 50 & . & 50 & 76 & 0 & $2 \mathrm{I}$ & 100 & I. 12 & $\ldots$ \\
\hline
\end{tabular}

and dead fetuses in which early stages of autolysis were apparent, usually showed a paucity of blood cells in the vessels of the fetus, yolk sac, and fetal placenta, resembling thę conditions noted in earlier fetuses by Evans and Burr. There were certain exceptions, however, which suggested that fetal death might be attributable to causes other than decreased hematopoiesis. Furthermore, a study of stained smears of the liver and blood of low-E fetuses revealed no qualitative disturbances of hematopoietic activity. Other organs and tissues appeared normal histologically and showed considerable mitotic activity up to the time of death, following which autolysis of the fetal tissues was rapid. On the other hand, certain blood vessels of the fetus were frequently distended with blood cells whose staining reactions suggested stasis, while other vessels appeared normal in size but relatively empty. Occasionally there was evidence of hemorrhage into the adjacent tissues, even in embryos which showed no evidence of autolysis.

These findings called to mind hemorrhagic areas previously noted in many fetuses removed from uteri when interest was centered upon establishing criteria of response to assay dose based upon the weight of the uterine contents at the sixteenth day $\left(\mathrm{Mason}^{4}\right)$. These areas, attributed at that time to trauma

sites in which the total weight of the placenta, fetus, and intact fetal membranes exceeds 0.4 gin. The usual weight of dead fetuses and their adnexa varied from 0.70 to $1.2 \mathrm{gm}$., that of associated living fetuses from 0.92 to $1.34 \mathrm{gm}$. 
induced during the removal and rupture of implantation sites, on closer examination proved to be associated invariably with fetuses which had just died or with those whose continued survival could be considered questionable. In all subsequent bio-assay tests for vitamin $\mathrm{E}$ (in which positive responses are based upon the presence of two or more viable fetuses at the sixteenth day of pregnancy) implantation sites containing dead or living fetuses have been routinely examined with the aid of a dissecting microscope. The intact sites were placed in warm physiological saline, the state of circulation in the yolk sac noted, the fetal membranes carefully removed, and the fetus with its attached umbilical vessels and placenta examined grossly. The location and extent of vascular injury in each fetus, and the relative position of the latter

TABLE 2

The Frequency of Vascular Changes in Dead and Live Fetuses at the Sixteenth Day

\begin{tabular}{|c|c|c|c|c|c|c|}
\hline \multirow{2}{*}{ No. of assay rats } & \multicolumn{3}{|c|}{ No. of liv fetuses } & \multicolumn{3}{|c|}{ No. of dead fetuses } \\
\hline & $\begin{array}{l}\text { Total } \\
\text { examined }\end{array}$ & $\begin{array}{c}\text { With vascular } \\
\text { injury }\end{array}$ & Per cent & $\begin{array}{c}\text { Total } \\
\text { examined }\end{array}$ & $\begin{array}{c}\text { With yascular } \\
\text { injury }\end{array}$ & Per cent \\
\hline $210^{*}$ & 1228 & +3.32 & 15 & 186 & 95 & $22 \dagger$ \\
\hline
\end{tabular}

* This number includes only rats in which one or more of the living fetuses showed vascular changes.

$\dagger$ Autolysis was so far advanced in many of the dead fetuses that no evidence of the vascular damage remained.

in the uterine horns, were recorded. The data of table 2 present the incidence of vascular changes observed in 210 rats possessing one or more viable and affected fetuses at autopsy on the sixteenth day.

\section{Vascular Changes in Fetuses at the Sixteenth Day}

The earliest changes obscrved consisted of dilation and congestion in superficial blood ressels. Vascular plexuses in the region of the cranial vault. external ear, shoulder, and dorsolateral portions of the trunk were most frequently involved. In the capillary bed related to these plexuses there often were petechia-like areas of variable size and shape which, under high magnification, appeared to represent localized areas of extensive capillary dilation and stasis. The gross appearance of normal fetuses is shown in plate 1 . figure 1. The injected specimen shown in plate 1 , figure 2 , illustrates the character of this vascular congestion in supcrficial plexuses of the supraorbital, posterior atrricular, and shoulder regions, and in more localized areas on the limbs and lateral body wall. The dark color of the latter is due to retained blood, for the ink suspension usually failed to penetrate these larger areas of rascular stasis.

The plexiform dilations and petechiae usually appeared in the renous channels, whereas the more extensive areas of hemorrhage to be described later. involved also the arterial trunks and their capillary bed. However, it was often impossible to determine which division of the vascular system was concerned. Although normal circulation could be observed in vessels immediately adjacent to the affected areas, as well as elsewhere, the volume of blood was 
often reduced to such an extent that the fetus appeared distinctly pale. This pallor and the areas of vascular injury could be noted before removal of the fetal membranes.

Fetuses in which death was imminent, or had recently occurred, showed more striking and irregular distention of superficial vessels, associated with marked dilation of deeper vessels in the immediately vicinity. Most frequently involved were the large vascular trunks at the root of the neck and their more superficial branches in the lateral thoracic wall near the base of the forelimb (pl. 1, fig. 3). These latter changes were almost universally accompanied by prominent areas of hemorrhage in the lateral wall and floor of the cerebral vesicles. Histological examination revealed extensive extravasation of blood into the substance of the corpus striatum and adjacent regions of the cerebral hemispheres. Similar but less extensive areas of hemorrhage were sometimes encountered in other regions of the brain and in the spinal cord, tail, extremities, and liver. Fetuses such as depicted in plate 1, figure 3, if viable, showed an almost imperceptible circulation in the vessels of the yolk sac and in the superficial capillaries of the fetus proper, while that of the umbilical vessels was diminished to a variable degree. Yet, on histological examination, the fetal tissues involved by vascular congestion or hemorrhage as well as those not so affected appeared normal and sometimes showed considerable mitotic activity.

Occasionally the terminal stages of fetal life were characterized by more diffuse areas of hemorrhage in the superficial tissues of the head and body wall (pl. 1, fig. 4), in addition to certain of the vascular changes described above. Sometimes large areas of superficial edema in the body wall and a bloody tinge to the amniotic fluid were noted. It seemed incredible that fetuses with such extensive vascular injury and edema could still be viable. The striking pallor and vascular changes of fetuses such as pictured in plate 1 , figures 3 and 4 , could be noted before the uterine wall was opened. Although similar changes were found in fetuses which proved to be dead on examination, they were soon obliterated by autolytic changes in the fetus.

A single protocol will serve to illustrate the diverse conditions observed in fetuses at autopsy on the sixteenth day of pregnancy.

\section{Protocol}

Rat 3697 received $1.75 \mathrm{mg}$. of synthetic beta-tocopherol, distributed over the first ten days of pregnancy; a dosage level which gave a positive response in six of eleven rats tested. At autopsy there were eleven viable fetuses, six in the right horn and five in the left horn of the uterus. The finding in individual fetuses, beginning at the cephalic end of the uterine horns, was as follows:

$\mathrm{R}_{1}$ - Normal

$\mathrm{R} 2$-Congestion in superficial vessels of shoulder region

$\mathrm{R}_{3}$-Superficial congestion near ear, shoulder, and lateral body wall

$\mathrm{R}_{4}$-Superficial congestion in extensive plexus lateral to lumbar and sacral vertebrae

$\mathrm{R} 5$-Moderate congestion over shoulder and hip region; deep hemorrhage in right cerebrum

R6-Congestion in deep vessels overlying spinal cord in upper lumbar and thoracic region, and in superficial vessels around eye 
$L_{1}$ - Superficial congestion around right shoulder and over both parietal regions

L2- Normal

L3-superficial congestion in posterior anricular and left parictal regions

L. - Superficial congestion in right shoulder and orer lumbar vestebrac

1,5-Exensive congested plexuses over dorsum of trunk and Inead. Multiple perechiae orerlying cervical and thoracic spinal cord, with distention of vertelual vessels on each sicle; other petechial spots over cerchrum and corebellım

The vascular changes described are unquestionably pathognomonic for vitamin $\mathrm{E}$ deficiency. Their incidence, and that of late fetal death, have consistently proved to be inversely proportional to the magnitude of borderline levels of graded dosage in bio-assays of the various natural and synthetic forms of vitamin $\mathrm{E}$. It has been conclusively demonstrated that the daily administration of relatively large amounts of ascorbic acid or vitamin $\mathrm{K}$ (2-methylnapthoquinone) during the first sixteen days of pregnancy does not influence citlice the occurrence or the character of the vascular injury. Furthermore, vitamin E-deficient fetuses have been found to contain a normal content of vitamin $\mathrm{C}$ as measured by the silver nitrate technique, and rats suffering from prolonged deficiency of vitanin E have shown no alteration in blood-clotting time.*

\section{Disclission}

The ultimate cause of fetal death in the vitamin E-deficient fetus at the sixteenth day of gestation is undoubtedly the same as that operative at earlier stages of development, namely, diminution of the circulating blood to a level inadequate for continued survival of fetal tissues. The question of paramount importance is whether this ischemic state is brought about by a suppression of hematopoiesis, as suggested by Evans and Burr in their study of younger fetuses, or by a defect in the vascular wall leading to congestion, stasis, and cxtravasation of blood into the tissues. Acceptance of the first explanation implies that the vascular injury is the natural result of decreased blood rolume. Acceptance of the second alternative implies that the evidence suggestive of impaired hematopoiesis is really an artifact caused by vascular dilation and congestion associated with hemorrhage into the soft tissues. It cannot be denied, however, that both processes might be operative at different period, of the development or even simultaneously.

The observations presented here afford some evidence that the hematopoietic activity of the liver at the sixteenth day of development may not be appreciably depressed in fetuses exhibiting early vascular lesions. Howerer. the variable picture encountered in different fetuses and the rapid telescoping of the terminal events have so far made it impossible to state with certainty whether phenomena suggestive of hematopoictic dysfunction are the cause of, or the result of, the vascular lesions.

Little can be said at present concerning the exact cause or nature of the

* I am indebted to Dr. C. P. Leblond for analysis of the fetal tissues by silver nitrate precipitation, to Dr. Sarah Hooker and Mr. R. A. Bruce for determinations on the blood-clottiug time. 
vascular changes. Since frank hemorrhage occurs most frequently in areas such as the cerebral wall, where the tissues are relatively more compact than those in which the vascular channels are usually dilated and thrombosed, reakness of the extravascular supporting tissues does not appear to be a factor. The occurrence of demonstrable edema only in advanced stages of the disorder suggests that altered permeability of the vascular wall is a secondary phenomenon. Undoubtedly, the varying incidence and gross characteristics of the vascular changes in different regions of the fetus constitute factors whose significance cannot be fully appreciated at the present stage of these investigations.

There is need for a reinvestigation of the early resorptive process in order to determine whether there exist abnormalities of the vascular system comparable to those described above. Should such prove to be the case, the histopathology of vitamin $\mathrm{E}$ deficiency in the female rat would have much in common with spontaneous hemorrhage observed in vitamin E-deficient chick embryos (Adamstone ${ }^{6,7}$ ), together with the capillary thrombi in cerebellar and cerebral vessels (Pappenheimer and Goettsch ${ }^{8}$ ) and the exudative diathesis (Dam and Glavind ${ }^{\circ}$ ) observed in young and adult chicks deprived of ritamin E. It should be mentioned, however, that the present state of our knowledge does not permit an explanation of the various histopathological manifestations of vitamin $\mathrm{E}$ deficiency on the basis of either a structural or physiological defect of the vascular wall or a suppression of hematopoiesis. These can be regarded only as a manifestation of underlying metabolic disturbances which, when finally understood, will afford the real answer concerning the physiological role and function of vitamin E. A more extensive discussion of these vascular phenomena and their correlation with other lesions of vitamin $\mathrm{E}$ deficiency in laboratory animals has been presented elsewhere. ${ }^{10}$

\section{Summary And Conclusions}

Fetal death is of frequent occurrence in sterile vitamin E-deficient rats given borderline doses of vitamin $\mathrm{E}$ and autopsied at the sixteenth day of pregnancy.

Prior to exitus there appear abnormalities in the vascular system characterized by variable degrees of dilation and thrombosis of peripheral and deeper vascular channels and by either localized or diffuse areas of hemorrhage which are sometimes associated with edema, together with a paucity of blood in other vessels of the fetus and in those of the fetal membranes. The fetus succumbs to generalized ischemia. Although suppressed hematopoiesis in the liver and yolk sac, characteristic of earlier fetal death and resorption (Evans and Burr ${ }^{1}$ ), cannot be excluded as a contributory factor, vascular injury is regarded as the primary cause of late fetal death.

These vascular changes, which can be directly correlated with the level of vitamin $\mathrm{E}$ dosage and are not influenced by separate administration of vitamin $\mathrm{C}$ or vitamin $\mathrm{K}$, are undoubtedly pathognomonic for vitamin $\mathrm{E}$ deficiency and resemble in many respects the capillary thrombi and exudative diathesis observed in the vitamin E-deficient chick by other investigators. 


\section{REFERENCES}

1. Evans, H. M., and Burr, G. O.: Mems. Univ. California v.8, 192\%.

2. Urner, J. A.: Anat. Recrd. 50:175, 1931.

3. Mason, K. E.: in Vitamin E: a symposium (Cambridge (Engl.): 1939 . 31.

4. Mason, K. E.: Jl. Nutrit. 23:59, 1942.

5. Mason, K. E.: Jl. Nutrit. 23:71, 1942.

6. Adamstone, F. B.: J1. Morphol. \& Physiol. 52:47, 1931.

7. Adamstone, F. B.: Archs. Pathol. 31:622, 1941.

8. Pappenheimer, A. M., and Goettsch, M.: Jl. Exper. Med. 53:11, 1931.

9. Dam, H., and Glavind, J.: Skandinav. Arch. f. Physiol. 82:299, 1939.

1o. Mason, K. E.: Vale Jl. Biol. \& Med. 1 f:605, 19.2 . 


\section{EXPLANATION OF PLATE}

PLATE 1

Photographs of rat fetuses at the sixteenth day of pregnancy, with fetal membranes removed but umbilical circulation intact. $\times 5$.

Fig. 1. Normal rat fetus showing appearance of vascular system.

Fig. 2. Vitamin E-deficient fet us (fixed in formalin) injected with a suspension of India ink before death, showing dilated vascular channels in supraorbital, posterior auricular, and lateral trunk regions. The ink suspension penetrated the small petechial spots on the extremities and dorsal midline, but failed to enter the larger areas along the lateral body wall which are still filled with blood. The fetal heart continued to pulsate after injection was discontinued.

Fig. 3. Vitamin E-deficient fetus showing marked dilation and congestion of vascular plexuses just caudad to forelimb, marked distention of deeper vessels just cephalad to forelimb, and extensive bilateral hemorrhage in the floor and lateral wall of the cerebral vesicles. This fetus was living but showed meager circulation in peripheral capillaries and a marked reduction in blood flow through the umbilical vessels.

Fig. 4. Vitamin E-deficient fetus in which faint circulation was demonstrable in vitelline and umbilical vessels despite the extensive localized congestion in certain vessels and the diffuse areas of hemorrhage in other regions. 

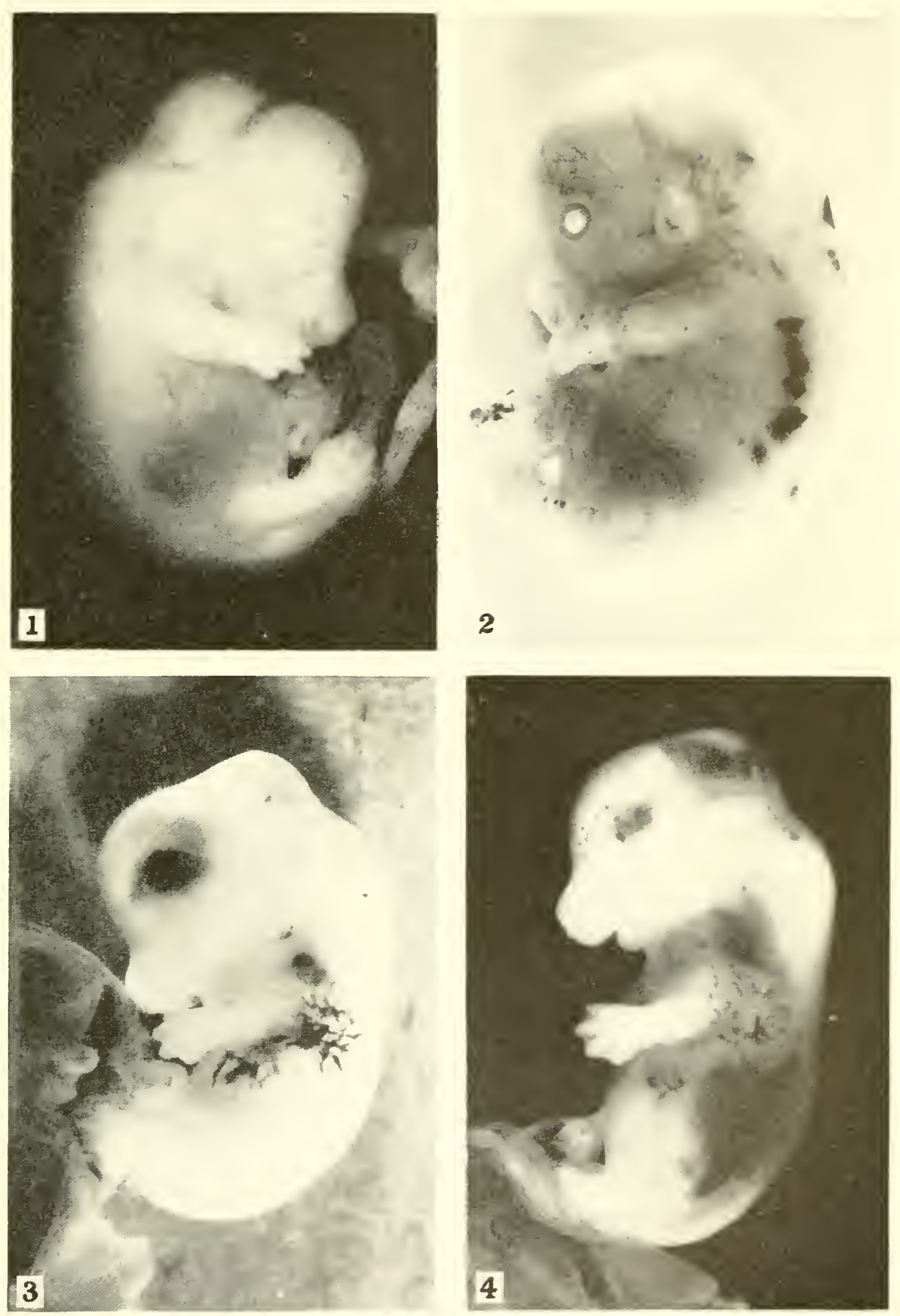

Plate 1

[409] 



\section{RELATIONSHIPS OF \\ SODIUM AND POTASSIUM \\ TO}

CARBOHYDRATE METABOLISM

$$
\text { B)' }
$$

IRVINE MaQUARRIE, Ph.D., M.D.

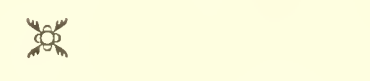

From the

DEPARTMENT OF PEDIATRICS, UNIVERSITY OF MINNESOTA MINNEAPOLIS, MINNESOTA 



\section{RELATIONSHIPS OF SODIUM AND POTASSIUM TO CARBOHYDRATE METABOLISM}

$\mathrm{D}$

URING the past few years an increasing rumber of investigator have called attention to the possibility of interrelationships between the monovalent elements, sodium and potassium, and carbohydrate metabolism. However, no effort has as yet been made to correlate the results of experiments carried out from many different angles and no place has been given to the subject even in the latest monographs or textbooks on physiology. The present review represents an attempt to summarize and cvaluate pertinent data from widely scattered sources, special reference being made to reports concerning the antagonistic effects of sodium and potassium on carbohydrate metabolism in diabetes mellitus.

\section{Relationship of Sodium to Carbohydrate Metabolism}

The first suggestion that mammalian carbohydrate metabolism might be influenced by the administration of sodium salts was the observation by Murlin and Kramer ${ }^{1}$ that sodium hydroxide and sodium carbonate increased the utilization of glucose by depancreatized dogs. Murlin and Craver ${ }^{2}$ and Underhill $^{3}$ subsequently reported marked decreases in glycosuria in diabetic patients following administration of these alkaline salts in liberal amounts. The effects observed were attributed to induced changes in the acid-base equilibrium of the body toward the alkaline side.

Subsequent studies on the effects of changes in the acid-base balance on carbohydrate metabolism, however, have been somewhat contradictory. For instance, Beard ${ }^{4}$ reported finding little or no effect from giving moderate amounts of sodium bicarbonate to diabetics but incidentally recorded the fact that two of his patients, who voluntarily took increased amounts of sodium chloride and water, showed increases in their carbohydrate tolerance. He drew no conclusions from these observations. Thompson, Mitchell and Kolb found in normal subjects that acid administration was followed by diminution of carbohydrate tolerance as indicated by blood-sugar curves, while alkalosis had little effect. In a series of acute experiments on normal children, Johnston and Maroney ${ }^{6}$ found the oxidation of dextrose to be accelerated by a slight shift toward the acid side of neutrality but depressed by marked acidosis. It was inhibited on the alkaline side. They also found that the oxidation of dextrose was at first depressed but later accelerated by ingestion of $\mathrm{NaCl}$ and water. It would appear from these conflicting results that acid-base balance per se plays little or no direct role in carbohydrate metabolism.

Schenk, ${ }^{7}$ who investigated the effects of intravenous administration of various electrolytes on blood sugar, found that the latter was decreased signifi- 
cantly by injection of a 10 per cent solution of $\mathrm{NaCl}$. This change was attributed entirely to blood dilution, resulting from the hypertonic infusion. In an attempt to determine the influcnce of various electrolytes on the action of insulin, Abelin and Goldener ${ }^{8}$ at about the same time found that $2 \mathrm{gm}$. of $\mathrm{NaH}_{2} \mathrm{PO}_{4}$ or $2 \mathrm{gm}$. of a mixture of $\mathrm{NaCl}, \mathrm{NaHCO}_{3}$ and $\mathrm{Na}_{2} \mathrm{SO}_{4}$ given by mouth to a rabbit produccd marked augmentation of the hypoglycemic effect of 4 to 6 units of insulin injected simultaneously. Semler ${ }^{8}$ reported finding no cliange in the blood sugar of two diabetic men following the injection of 5 gm. of $\mathrm{NaCl}$ without insulin. Because of the finding of low blood chloride in diabetics and high blood sugar in various conditions accompanied by hypochloremia, such as intestinal obstruction or histamine poisoning, Glass and Bcilcss ${ }^{10}$ reinvestigated the effects of injecting hypertonic $\mathrm{NaCl}$ solutions in diabetic subjects. In ten such patients they found that a single injection of 3 or $4 \mathrm{gm}$. of chemically pure $\mathrm{NaCl}$ in a 15 to 20 per cent solution caused a decrease in blood sugar of from 12 to 43 per cent with great regularity. A 12 gram dose of $\mathrm{NaCl}$ given by mouth had a similar effect. In explanation of their results, these authors claimed to have excluded the possibility of blood dilution or of spontaneous fluctuation in blood-sugar concentration. They attributed the blood-sugar-lowering effect to the $\mathrm{Cl}$ ion rather than to the $\mathrm{Na}$ ion and suggested that the salt exerted a vagotonic action.

\section{Relationship of Potassium to Carbohydrate Metabolism}

No reference is made to a possible relationship between $\mathrm{K}$ and carbohydrate metabolism in any of the foregoing papers, in spite of the fact that the possibility of such a relationship was first suggested shortly after insulin was discovered. Briggs and co-workers ${ }^{11}$ found an average decrease of 24 per cent in the serum $\mathrm{K}$ of fasting dogs following the injection of insulin in large doses. Shortly thereafter Harrop and Benedict ${ }^{12}$ independently observed in both normal and diabetic subjects that a fall in $\mathrm{K}$ accompanied the well-known decreases in blood glucose and inorganic phosphorus, which result from administration of insulin. They suggested that $\mathrm{K}$ may enter into the intermediary metabolism of carbohydrate in association with the phosphoruscarbohydrate combination. Many other investigators (Wigglesworth and co-workers; ${ }^{13}$ Häusler and Heesch; ${ }^{14}$ Kerr; ${ }^{15}$ Cori and Cori $;{ }^{16}$ Ellsworth and Weinstein; ${ }^{17}$ Keys; ${ }^{18}$ McQuarrie and co-workers ${ }^{19}$ ) have likewise found insulin hypoglycemia to be accompanied by a simultaneous fall of plasma $\mathrm{K}$ and $\mathrm{PO}_{4}$.

Data obtained subsequently from many other sources have strengthened the hypothesis that $\mathrm{K}$ participates in some essential manner in the synthesis and breakdown of complex polysaccharides both in plant life and in the animal body. Plant cells behave in a general way like the liver cells in animals as regards the movements of $\mathrm{K}$ and sugar. Pulver and Verzar ${ }^{20}$ showed that $\mathrm{K}$ and sugar absorption and output are paralleled in yeast metabolism. Day and Comboni ${ }^{21}$ studied the role of $\mathrm{K}$ in starch synthesis by plants (Pisum sativum) grown from seeds in sand cultures with complete nutrient solution 
containing potassium phosphate. When the starch content of plants grown in this medium was compared with that of similar plants grown under identical conditions, except for substitution of the $\mathrm{NH}_{4}$ ion for the $\mathrm{K}$ ion, it was found that the plants raised in the K-deficient solution produced but half as much starch. Lasnitski and Szörenyi $i^{22}$ reported that the anaerobic fermentation of glucose by baker's yeast increased on the average by about 150 per cent if $\mathrm{K}$ (0.01 M KCI) was added to the medium which contained as other cations $\mathrm{NH}_{4}$ and $\mathrm{Mg}$.

Lasnitski ${ }^{23,24}$ earlier found that anaerobic fermentation of glucose by tumor tissue or normal tissue, especially brain cortex, was markedly greater in a medium containing both $\mathrm{K}$ and $\mathrm{Na}$ in physiological concentrations than in a medium containing $\mathrm{Na}$ alone. Ashford and Dixon ${ }^{25}$ and Dickens and Greville $e^{28}$ found that the aerobic fermentation and oxidation of glucose by brain cortex could be increased considerably by the addition of a surplus of $K$ to the medium. That is, $\mathrm{K}$ appeared to activate the enzymatic breakdown of glucose.

Excepting in conditions like adrenal insufficiency (serum K elevated, sugar low) and hypercorticoadrenalism (serum $\mathrm{K}$ at times decreased, sugar increased), it is true in general that glucose, inorganic $\mathrm{PO}_{4}$, and $\mathrm{K}$ appear to move out of or into the blood together. Fenn ${ }^{2 t}$ showed that deposition of glycogen in the liver was necessarily accompanied by the deposition of $\mathrm{K}$ and water. The quantity of $\mathrm{K}$ so deposited, however, was far less than the quantity of glycogen (measured in equivalents), whereas the blood changes would suggest equivalent amounts. Flock and $\mathrm{co}^{- \text {workers }}{ }^{28}$ found that intravenous administration of glucose or levulose at a constant rate produced a decrease of serum $\mathrm{K}$ in normal dogs. The decrease in $\mathrm{K}$, expressed in percentage of original concentration in the serum was not so large as that simultaneously produced in the concentration of inorganic P. Sodium lactate and sodium pyruvate produced similar results, but their effect was attributed to the $\mathrm{Na}$ ion because $\mathrm{NaHCO}_{3}$ and $\mathrm{NaCl}$ were found to be equally effective. In depancreatized dogs, not receiving insulin. injection of glucose had variable effects on the level of serum $\mathrm{K}$. In a later investigation ${ }^{29}$ the same authors found that injection of 10 per cent glucose solution, with or without cortin, or o.9 per cent $\mathrm{NaCl}$ solution, causęd a decrease in serum $\mathrm{K}$ in adrenalectomized dogs. They observed that $\mathrm{NaCl}$, like cortin, when given with glucose solution to adrenalectomized dogs, prevented the rise in $\mathrm{K}$ which occurred if glucose solution alone was administered. $\mathrm{NaCl}$ appeared to be the full equivalent of cortin in respect to the excretion of $\mathbf{K}$ and the response of the adrenalectomized dog to an injection of glucose. The disposal of injected glucose occurred to the same extent, and the same changes in $\mathrm{K}$ and inorganic $\mathrm{P}$ of the serum were seen in the adrenalectomized dog as in normal dogs. They concluded that "the probable influence of inorganic ions, such as $\mathrm{Na}$ and $\mathrm{CI}$, is through osmosis, ion antagonism and changes in the permeability of membranes." Long and coworkers ${ }^{30}$ likewise reported that the essential chenical changes associated with carbohydrate metabolism could proceed in adrenalectonized dogs without 
the "salt and water" hormone of the adrenal cortex, provided an adequate supply of $\mathrm{Na}$ and $\mathrm{Cl}$ ions were available. In partially depancreatized rats $\mathrm{NaCl}$ did not produce glycosuria as the hormone did.

Pulver and Verzar ${ }^{20}$ offer in support of the theory-that $\mathrm{K}$ is involved in the phosphorylation process leading to the formation of a polysaccharide-the observation that substances which retard phosphorylation inhibit the uptake of both glucose and K. "From this point of view," says Lasnitzki," "there appear to be at least two main possibilities regarding the explanation of the effect of $\mathrm{K}$ on fermentation and oxidation of glucose. Either $\mathrm{K}$ activates phosphorylation and thereby the subsequent formation of the supposed polysaccharide, or it activates the breakdown of the latter. In the former case, $\mathrm{K}$ might be bound chemically, while in the latter case it might be adsorbed by the polysaccharide (probably having colloidal properties). In either case $\mathrm{K}$ would be liberated with breakdown of the polysaccharide." Verzar and Somogyi $i^{32,33,34}$ suggested that $K$ is organically bound in phosphorylation of sugar. The latter process they regard as being under the control of the adrenals in mammals. The disturbance in glycogenesis resulting from adrenalectomy accounts for there being no increase in output of $\mathrm{K}$ to the blood from muscle stimulation in the adrenalectomized animal, comparable to that shown by Fenn $^{35}$ to occur in the normal animal.

As first shown by $\mathrm{D}^{\prime}$ Silva, ${ }^{38,37}$ the concentration of $\mathrm{K}$ in the serum of animals is regularly increased for a few minutes after the intravenous injection of adrenalin. Posterior pituitary extract (pitressin, P.D.) had a similar effect, but the rise was more delayed. Both agents are known to increase blood sugar, also. The rise in serum $\mathrm{K}$ after adrenalin was shown to be followed by a more prolonged fall, which was attributed to stimulation of insulin production by the hyperglycemia. This "after fall" of $\mathrm{K}$ was practically absent in depancreatized animals. Paralysis of the parasympathetic system with atropine likewise prevented the fall. The temporary rise in serum $\mathrm{K}$ after adrenalin injections has been confirmed by subsequent work (Marenzi and Gerschman;;39 Schwartz; ${ }^{40}$ Houssay and co-workers ${ }^{41}$ ). In the human subject, Keys ${ }^{18}$ found a more transient increase in serum $\mathrm{K}$ than reported for lower animals. Houssay, Marenzi and Gerschman ${ }^{41}$ showed that the $\mathrm{K}$ entering the blood, following injection of adrenaline or direct stimulation of the sympathetic nerves to the liver, comes from the liver. Snyder and Johnson ${ }^{42}$ demonstrated that the output of both $\mathrm{K}$ and glucose from the perfused liver of the turtle was decreased by vagal stimulation.

Fenn $^{43}$ points out that $\mathrm{K}$ and lactic acid appear to move together in relationship to muscular activity just as $\mathrm{K}$ and glucose rise and fall together under certain conditions apparently concerned with the movement of glucose into or out of the liver. Lactic acid and $\mathrm{K}$ increase together in the venous blood plasma when muscles contract as they do in asphyxia, after hemorrhage and in histamine shock. In the light of these observations, Fenn states: "It is tempting to suggest that $\mathrm{K}$ leaves the liver or enters muscle in company with glucose 
while it leaves the muscle or enters the liver along with lactic acid. Some sup)port for such a tentative hypothesis is found in the observation that after muscular activity there is a consistent increase in the $\mathrm{K}$ content of the liver." The existence of a $\mathrm{K}$ cycle from muscle to liver and other viscera, and back again, comparable to the lactic acid cycle of Soskin ${ }^{44}$ and Cori ${ }^{45}$ is suggested.

In this connection it is interesting to refer briefly to studies on the $\mathrm{K}$ and carbohydrate metabolism in the clinical condition known as famitial periodic paralysis. In this disorder serum $\mathrm{K}$ is found to be very low during periodic attacks of muscular paralysis ( $\mathrm{Walker}^{46}$ ). Attacks are brought on by excessive carbohydrate intake. Administration of $\mathrm{K}$ salts raises the serum $\mathrm{K}$ and causes prompt relief of the paralysis (Aitken and co-workers ${ }^{47}$ ). Aitken and co-workers ${ }^{47}$ showed that paralytic attacks could be induced at will in such patients by any procedure that lowers serum K. The K-lowering effect of glucose or levulose by mouth or by vein was found to be more marked than in the normal subject. Allott and McArdle ${ }^{4 s}$ found by balance studies that $K$ is retained by the body during an attack. Phosphate was the only other inorganic substance found to be altered in attacks. It tended to parallel changes in $\mathrm{K}$. The disease, therefore, appears to involve the hexosephosphate mechanism in some manner.

\section{Antagonistic Effects of Na and K on Carbohydrate Metabolism}

The attention of the author and his associates (McQuarrie and co-workers ${ }^{42}$, ) was first directed to the possibility of an interrelationship between the $\mathrm{Na}$ and K economy and carbohydrate metabolism in 1930, when they observed freakish variations in the degree of glycosuria shown by an 8-year-old diabetic girl, who manifested an abnormal craving for salt. Although the patient was maintained on a uniform diet, it was found that the total amount of sugar in the urine for a given period tended to vary inversely with the quantity of $\mathrm{NaCl}$ which she was allowed to consume. Unfortumately, an attempt to carry out a more complete investigation of the observed phenomenon in that patient was frustrated by her premature discharge from the hospital to move with her parents to another community.

Three years later, however, a second diabetic child, complaining of an almost insatiable craving for salt, was subjected to a series of metabolic studies originally designed primarily to determine the nature of the physiological disturbance responsible for this bizarre symptom. This patient, a 15 -year-old boy, was found to require between 80 and $90 \mathrm{gm}$. of table salt daily to satisfy his craving. Since he had been on an ordinary diabetic diet (naturally high in k) for a long period of time. had partially depleted his reserve of fixed base as a result of a mild degree of diabetic acidosis and had romited an undetermined number of times just prior to his admission to the hospital (thereby losing a considerable amount of chloricle), the inordinate craving for salt was at first presumed to be explainable on the simple basis of temporary plysiological need for both $\mathrm{Na}$ and $\mathrm{Cl}$. That such an explanation was quite inadequate soon became apparent, however, when the craving was observed to 
continue long after all eviclence of ketosis had disappeared and after a simplified diet with a low K content had been substituted for the ordinary diabetic diet. The possibility that adrenal insufficiency might account for the salt craving was entertained, but no supporting clinical evidence for this complication was obtained.

After a preliminary period of observation had demonstrated that the degree of glycosuria in this case, as in the previous one, tended to be inversely proportional to the quantity of $\mathrm{NaCl}$ ingested, this plase of the problem was investigated more extensively under well-controlled conditions. For the sake of comparison, similar studies were also made on four other juvenile diabetics, who manifested no abnormal taste for salt.

Studies were carried out on but two patients at a time. The latter were kept in a small metabolic ward under the constant supervision of special nurses, who collected the urine quantitatively and made certain that meals, salt allowances, and insulin were received by the experimental subjects every six hours precisely as ordered. For the sake of uniformity and accuracy, the basic diet with low $\mathrm{Na}$ and $\mathrm{K}$ content was made up from powdered whole milk, egg white, egg yolk, unsalted butter, cane sugar, fresh lemon juice (for vitamin C), powdered yeast (for vitamins of the B complex), and water. The mineral constituents of a typical day's diet, containing protein 64, fat $9^{6}$ and carbohydrate $132 \mathrm{gm}$. were as follows: $\mathrm{Na}, 1.03 ; \mathrm{K}, 1.34 ; \mathrm{Ca}, 0.68 ; \mathrm{Mg}, 0.16 ; \mathrm{Cl}, 1.8_{3}$; $\mathrm{P}, 0.93$ and $\mathrm{S}, 0.76 \mathrm{gm}$.

When used, insulin was given at 6-hour intervals in doses sufficiently small to permit some degre of glycosuria in each subdivision of the day, when the patient was on the basic diet. A significant change in the amount of sugar excreted in the urine during an experiment was then regarded as a reliable criterion of an effect produced by the extra salt ingested. The latter was given with or immediately after each of the four meals every day in the form of a 1 per cent solution or in gelatin capsules. Water was given ad libitum.

The results of this study may be summarized briefly as follows: Ingestion of excessive amounts (1 to $2 \mathrm{gm}$. per kilogram of body weight) of $\mathrm{NaCl}$ or other sodium salts repeatedly reduced the total output of sugar in the urine of all five patients. As illustrated in figure 1, glycosuria was at times reduced to as little as one-fifth of what it was during control periods. Such an effect was either not apparent or was much less marked, however, when but small amounts of $\mathrm{NaCl}$ were ingested or when the ordinary diabetic diet was substituted for the basic experimental diet (low in $\mathrm{K}$ ). The fasting blood-sugar level was distinctly lower and the respiratory quotient was somewhat higher during periods of excessive $\mathrm{Na}$ intake. In the severely diabetic patients, ketosis was found to develop earlier after withdrawal of insulin therapy during periods of extremely low $\mathrm{NaCl}$ intake than during periods of excessively high intake. Glycosuria increased rapidly in severe diabetics upon withdrawal of insulin in spite of the high intake of sodium. However, unless the insulin dosage was adjusted to a level to allow hyperglycemia when the low-Na basic diet was 
given, administration of 2 gm. of $\mathrm{NaCl}$ per kilogram of body weight per day not infrequently resulted in the patient's having typical hypoglycemic reactions. The level of serum $\mathrm{K}$ tended to fall and the wrinary cxcretion of $\mathrm{K}$ was increased slightly by excessive ingestion of NaCl. Both the systolic and the diastolic blood-pressure readings were gradually clevated to lerels between 30 and $5^{\circ}$ per cent above their base lines, as a result of the increased $\mathrm{NaCl}$ intake. In the case of one patient, showing the hypercorticoadrenal syndrome with an atypical form of diabetes mellitus, arterial hypertension, and a disturbance

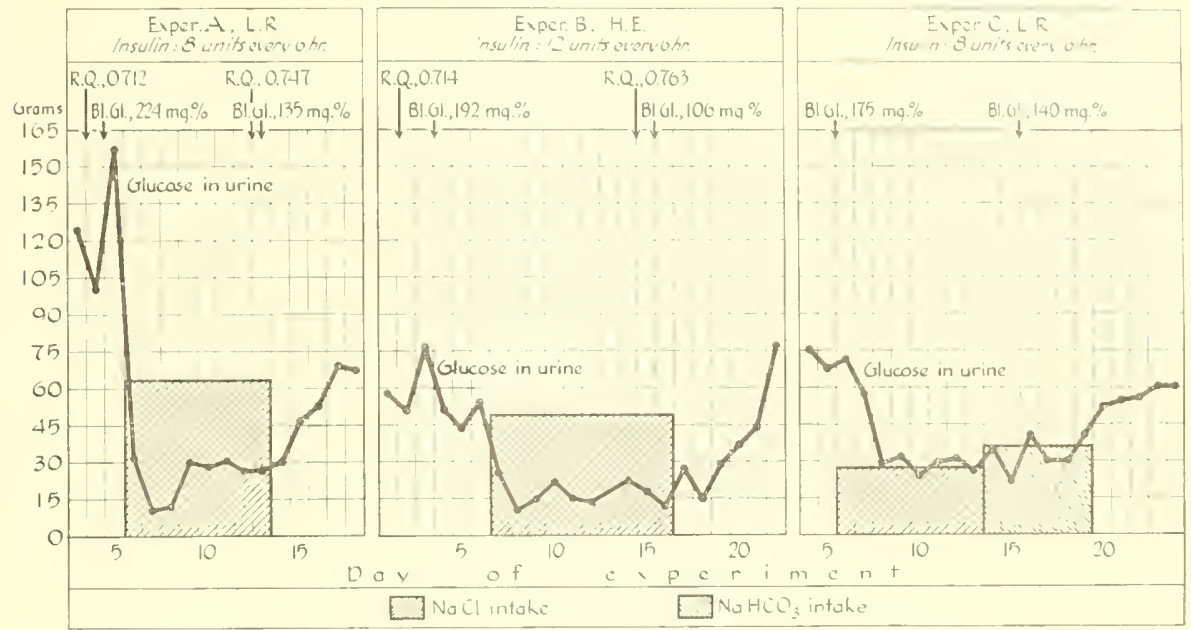

Fig. 1. Effects of high-Na, low-k regimen on glycosuria, fasting blood sugar (Bl. Gl.) and respiratory quotient (R.Q.) in severe diabetics. L.R., age $1_{5}$ years, a salt craver, was more responsive to Na than other diabetics tested.

in electrolyte metabolism (increased $\mathrm{Na}$ and reduced $\mathrm{K}$ in the scrum), ingestion of extra $\mathrm{NaCl}$ appeared from a single short test to have a deleterious rather than a beneficial effect (McQuarrie and co-workers ${ }^{51}$ ).

In an attempt to learn which, if either, of the two ions, $\mathrm{Na}$ or $\mathrm{Cl}$, was the more important in producing these changes, $\mathrm{KCl}$ was substituted for, or was given in addition to, $\mathrm{NaCl}$ in approximately one-third chemically equivalent amounts in a number of separate experiments. As illustrated by the three experiments represented in figure 2, which is largely self-explanatory, the effects of the $\mathrm{K}$ salt were found to be diametrically opposite to those produced by Na salts. Glycosuria and fasting blood-sugar levels rere gradually increased, while the blood pressure was reduced. In a small series of umpublished observations on ordinary juvenile diabetics, Thompson so subsequently found that the dosage of insulin required for adequate treatment could be reduced significantly by selecting a diet with a very low $\mathrm{K}$ content, other factors remaining unchanged. In an unusually severe case of spontaneous hypoglycemia is an adult patient showing a low concentration of $\mathrm{K}$ in the serum, the fasting blood sugar rose from a level around $12 \mathrm{mg}$. per cent to rahes varying between 53 
and $90 \mathrm{mg}$. per cent and hypoglycemic convulsions ceased, when he was placed on a low-Na high-K regimen ( 24 to $48 \mathrm{gm}$. KCl daily) for a few days only. When the $\mathrm{KCl}$ was finally refused by the patient because it produced gastric distress, the hypoglycemia and convulsions promptly recurred (McQuarrie and coworkers $^{50}$ ).

Attempts by the author and his associates to investigate the influence of varying the oral intake of $\mathrm{Na}$ and $\mathrm{K}$ on carbohydrate metabolism in depancreatized and in adrenalectomized dogs did not meet with a high degree of

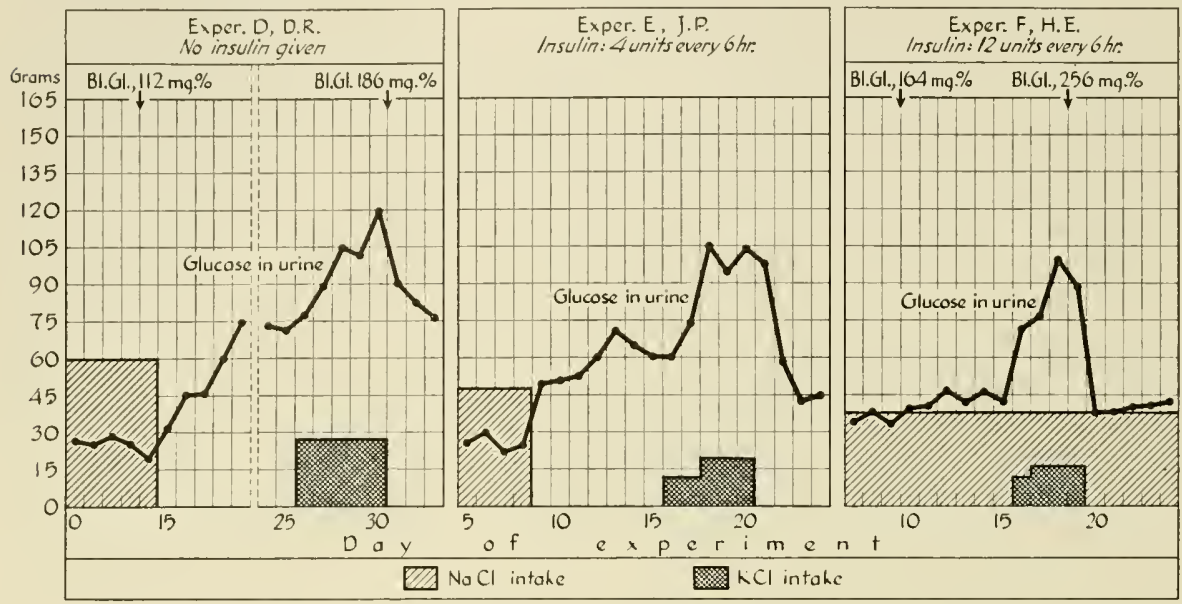

Fig. 2. Antagonistic effects of $\mathrm{Na}$ and $\mathrm{K}$ on glycosuria and on blood sugar (Bl. Gl.) in diabetics. Note effectiveness of $\mathrm{NaCl}$ in mild diabetic (D.R. exper. D) without insulin. $\mathrm{NaCl}$ and $\mathrm{KCl}$ were fed during different periods in experiments D and E. When given simultaneously with $\mathrm{NaCl}$ (exper. F), KCl abolished effects of the Na salt.

success because of difficulties involved in making such animals eat the experimental diet with the extra salt added or in making them retain the same when given by stomach tube. Ziegler and the author ${ }^{53}$ studied the effects of $\mathrm{Na}$ and $\mathrm{K}$ salts in moderate amounts on the glycosuria and hypoglycemia of phloridzin poisoning in four normal adult dogs. No significant effects were demonstrated. In the normal fasting dog, however, continuous administration of $\mathrm{KCl}$ was found to impede the development of insulin hypoglycemia (McQuarrie and co-workers ${ }^{54}$ ).

Since the foregoing studies concerning the antagonistic effects of $\mathrm{Na}$ and $\mathrm{K}$ on carbohydrate metabolism in diabetes were first reported, a number of publications bearing on some phase of the subject have appeared in the literature. Although a few workers have obtained somewhat equivocal results, most of them have directly or indirectly supported the conclusion that a high-Na low-K regimen increases carbohydrate utilization. McLean ${ }^{55}$ and Wilder ${ }^{58}$ confirmed the beneficial effects in adult diabetics. The former gave a patient with relative insensitivity to insulin (attributable to infected gangrene of the foot) $40 \mathrm{gm}$. of $\mathrm{NaCl}$ after each of three meals daily. As a result the patient experi- 
enced a severe insulin reaction and his requincuneut lor iusulin steadily declined thereafter from 115 to 55 units per day while the cxtra salt was being given. Wilder's experience led him to believe that smaller doses of $\mathrm{NaCl}$ were effective in some cases of diabetes. He concluded that the special usefuluess of the procedure would be found principally in the management of patients with relative insensitivity to insulin. Insulin requirements were reduced significantly in a number of his cases so treated. Sanstead ${ }^{57}$ reported lowering of the fasting blood sugar in all of eight adult male diabetics to whom he gave from 1o to $90 \mathrm{gm}$. of $\mathrm{NaCl}$ daily. Ingestion of the added salt made it possible to either reduce the insulin dosage or increase the diet of these patients.

In a more recent therapeutic trial of the procedure, Strouse and Co-workers ${ }^{54}$ reported very variable results when they gave twelve adult diabetics 20 to 30 gm. of NaGl daily supplementary to their ordinary diabetic diets (presumably with high $\mathrm{K}$ content). They reported that in any one patient administration of $\mathrm{NaCl}$ was followed at one time by decreased glucose excretion and at another by increased excretion. One juvenile diabetic given a special diet with fairly low $\mathrm{K}$ content for 5 days showed no significant decrease in glycosuria. Because their patients complained of nausea, however, these authors gave much smaller amounts of $\mathrm{NaCl}$ than those given by most of the previous workers. Similar variability in results followed administration of $\mathrm{KCl}$. One depancreatized dog showed a decrease in glucose excretion from $26.2 \mathrm{gm}$. (arerage for 5 control days) to $12.4 \mathrm{gm}$. per day (average for 7 experimental days), when the Na intake was increased by $3.96 \mathrm{gm}$. daily. In a second depancreatized dog, showing spontaneous decreases in glucose excretion during the course of the experiment, extra $\mathrm{NaCl}$ appeared to decrease glycosuria in one experiment and to increase it in another. Experiments on a depancreatized goat fed a diet of sucrose and alfalfa, containing 7.8 to $10 \mathrm{gm}$. of $\mathrm{K}$ daily, showed no effect when 2.5 to $3 \mathrm{gm}$. of $\mathrm{Na}$ was given daily. Glycosuria remained fairly marked and the blood sugar was high. This negative effect of $\mathrm{NaCl}$ in the presence of so much $\mathrm{K}$ in the diet would be expected in view of data presented above. From their variable results these observers concluded that "changes in carbohyclratc metabolism which follow ingestion of $\mathrm{Na}$ or $\mathrm{K}$ chloride cannot be explained as a result of the mere addition of these salts to the dietary intake."

Further light has been thrown on the role of $\mathrm{NaCl}$ in carbohydrate metabolism by experimental studies concerned with the effects of deficiency of this salt on carbohydrate tolerance. Michelson ${ }^{59}$ reported that high blood-sugar values accompanied the $\mathrm{NaCl}$ deficiency produced by diuretin. McCance ${ }^{60}$ later found that five normal human subjects, maintained on NaCl-deficient diets and exposed to profuse sweating, exhibited impaired glucose tolerance. The fasting blood samples, as well as those taken at 30, 60, 90, and 120 minutes after ingestion of $5^{\circ} \mathrm{gm}$. of glucose, showed consistently ligher glucose values than did normal control subjects. Aldersberg and Wachstein ${ }^{61}$ observed a profound sweeping out of $\mathrm{NaCl}$ in experimental animals after complete pancreatectomy and concluded that the pancreas normally controls $\mathrm{Cl}$ metabolisin. 
They found that this loss of $\mathrm{NaCl}$ intensified the diabetes caused by removal of the pancreas. Glycosuria and the fasting blood sugar were significantly reduced, however, if $\mathrm{NaCl}$ was administered either with or without insulin therapy. In several human diabetics tested by these authors, giving of extra $\mathrm{NaCl}$ by mouth in moderate amounts (without regard to the $\mathrm{K}$ content of the diet) did not appear to modify carbohydrate tolerance so definitely.

Calculations based upon carbohydrate intake, decrease in glucose lost in the urine, alterations in blood-sugar level and changes in volume of body fluids, indicated clearly that the diabetic patients studied by the author and his associates (McQuarrie and co-workers ${ }^{50}$ ) stored glycogen while ingesting large amounts of $\mathrm{NaCl}$. Direct proof that this type of regimen has such an effect, at least in normal animals, was later furnished by the experiments of Crabtree and Longwell. ${ }^{62}$ These authors demonstrated a marked increase in the amount of glycogen in the livers of young rats following ingestion by the latter of excessive quantities of $\mathrm{NaCl}$. Anderson, Herring and Joseph, ${ }^{63}$ in a study of the carbohydrate stores in adrenalectomized rats given various amounts of $\mathrm{NaCl}$, found that such rats given $65^{\circ}$ to $940 \mathrm{mg}$. $\mathrm{NaCl}$ daily for a period of 176 days after operation were able to store fed glucose almost as well as the normal rat subjected to "sham adrenalectomy." However, animals fed amounts of $\mathrm{NaCl}$ distinctly above or below this level were not able to do so. Glycogen stores were lessened in animals given tap water instead of I per cent $\mathrm{NaCl}$. Excessive amounts of $\mathrm{NaCl}$ (1 $234 \mathrm{mg}$. per day) prevented high glycogen storage.

As regards the specific effects of intravenous $\mathrm{KCl}$ on the carbohydrate metabolism of normal animals, results of various investigators have differed somewhat. Semler ${ }^{-8}$ early reported finding a sustained hyperglycemia after injection of 3 to $5 \mathrm{gm}$. of this salt in diabetics. Kiyohara and co-workers ${ }^{64}$ obtained similar results from intravenous administration of $\mathrm{KCl}$ solution. Kylin and Engel $^{65}$ reported a slight initial decrease in blood sugar, but did not follow the changes beyond one hour. In the rabbit, Odashima ${ }^{66}$ found blood sugar to be lowered and lactic acid to be increased. More recently Silvette and Brit$\operatorname{ton}^{87,68}$ reported the production of prolonged hyperglycemia and marked reduction in liver glycogen in normal rats following injection of $\mathrm{KCl}$ solution.

Lewis $^{89}$ found that excessive ingestion of $\mathrm{NaCl}$ increased, while $\mathrm{KCl}$ decreased, the sensitivity of normal rats to insulin. Animals with a high KCl intake stored less glycogen following dextrose administration than control rats. Those with an excessive intake of $\mathrm{NaCl}$ stored more glycogen but oxidized less than control animals. Fasting blood-sugar levels and the carbohydrate tolerance of normal rats were not found to be altered significantly by these salts. In partially depancreatized, diabetic rats and in rats of the Yale strain with hereditary diabetes, Orten and Devlin ${ }^{70,71}$ demonstrated that carbohydrate tolerance could be restored to essentially normal levels by the administration of $\mathrm{NaCl}$ in large amounts without insulin. Sayers and Orten $^{72}$ found an increased storage of glycogen in the livers of such diabetic rats after periods of high $\mathrm{NaCl}$ intake. 
Scrum $\mathrm{K}$ is characteristically elevated in severe, inadequately controlled diabetes mellitus. Rathéry and Bertoliatti ${ }^{72}$ found $\mathrm{K}$ values to average 35 per cent above normal in seven cases of diabetes not on insulin therapy and 22 per cent above nomal in seven insulin-treated cases. In a comprehensire study of the serum electrolytes and acid-base equilibrium in four cases of severe diabetes, Guest ${ }^{\pi 4}$ found the $\mathrm{Na}$ and $\mathrm{Cl}$ to be abnormally low and the $\mathrm{K}$ and inorganic $\mathrm{P}$ to be greatly elevated, when the patients were out of control. 'I' him these changes appeared to be more closely related to prolonged duration of the accompanying acidosis and to temporary impairment of renal function than to the intensity of the acidosis, as indicated by the $\mathrm{pH}$ and the $\mathrm{CO}_{2}$ content of the plasma. Insulin therapy caused a specific reversal of all of these alterations, the serum $\mathrm{K}$ and inorganic $\mathrm{P}$ declining to subnormal levels.

\section{Comment}

It is evident, from the miscellaneous data presented here, that sodium and potassium play important roles in carbohydrate metabolism. While there is obviously a lack of complete agreement between the results of various workers concerned with the problem of such interrelationships, differences in experimental conditions apparently account for most of the discrepancies reported. The mechanisms by which the $\mathrm{Na}$ and $\mathrm{K}$ ions influence carbohydrate economy and those by which their exchanges in the body are in turn influenced by it are not known.

The roles of the two elements are obviously different and are in the main antagonistic to each other. Potassium would appear to have the better claim to an essential role in the intermediary metabolism. Its movements into and out of the blood in company with glucose and inorganic $\mathrm{PO}_{\ddagger}$ or with lactic acid under various conditions, have suggested that it may be organically bound with some hexosephosphate compound or may be adsorbed to the surface of the latter. The fact that the quantity of $\mathrm{K}$ involved in the deposition of glycogen or released with its breakdorn is far less than the glycogen (measured in equivalents), argues against the assumption that it enters into direct chemical combination with the carbohydrate as $\mathrm{PO}_{4}$ does in the process of phosphorylation. At present it would appear more likely that $\mathrm{K}$ plays the role of accelerating certain enzymatic reactions involved in carbohydrate metabolism, just as magnesium, nanganese and cobalt have been shown by Cori ${ }^{\text {is }}$ to do in the case of the enzyme, phosphoglucomutase. It has already been shown to accelerate the fermentative and oxidative breakclown of glucose in yeast cultures and in fresh tissuc slices. The suggestion that its physical relationship to the complex carbohydrate molecule is one of adsorption becomes more likely in the light of this latter role.

Sodium does not move into or out of the blood or other media with glucose and inorganic $\mathrm{PO}_{4}\left(\mathrm{Ziegler}^{\pi /}\right)$. Nor is it known to activate enzymatic reactions under simple experimental conditions similar to those in which the accelerating effect of $\mathrm{K}$ has been demonstrated. Its influence on carbohydrate metabo- 
lism appears to be an "over-all" action in the animal body. While the possibility of its acting directly on certain enzyme systems has not been entirely excluded, its effects appear at present to be related to endocrine or autonomic nervous functions. When administered in large amounts, Na salts have been shown to increase the deposition of glycogen in the liver of normal, diabetic and adrenalectomized (glucose-fed) rats. There is some evidence to indicate that the rate of oxidation of glucose is simultaneously diminished. In these respects $\mathrm{NaCl}$ behaves very much like certain adrenal cortical hormones. Long and his co-workers ${ }^{77}$ have demonstrated that the latter slow up glucose oxidation while accelerating the deposition of glycogen in the liver. Since this glycogen-conserving action of $\mathrm{Na}$ salts is effective even in totally adrenalectomized animals, when they are supplied with glucose, it is obvious that the $\mathrm{Na}$ effect is not dependent entirely upon the adrenal gland. Recent experiments by Grollman, ${ }^{78}$ however, emphasize the interdependence between the function of the adrenal cortex and the action of sodium salts. The results of studies by Richter ${ }^{79}, 80$ on the appetites of adrenalectomized rats for $\mathrm{NaCl}$ and dextrose likewise indicate the essential interdependence of $\mathrm{Na}$ and carbohydrate metabolism in relationship to adrenal function.

Data reported by various workers from experiments on normal and diabetic animals, as well as on diabetic human subjects, indicate that $\mathrm{Na}$ increases sensitivity to administered insulin. In the intact animal, it may act directly on the insulin-producing mechanism or, on the other hand, it may serve to inhibit the so-called "anti-insulin" or "diabetogenic" mechanisms. Whether or not the production of glycogen is increased at the expense of protein, when $\mathrm{Na}$ salts are given in excessive amounts, has not as yet been ascertained; nor has the significance of differences in the effects of $\mathrm{Na}$ and $\mathrm{K}$ on water balance been fully determined.

In addition to its supposed roles in the intermediary metabolism of carbohydrates, $\mathrm{K}$ also appears to act on the intact animal in an "over-all" way with effects antagonistic to those of $\mathrm{Na}$. When administered in comparatively large amounts to normal or diabetic subjects, it inhibits the formation of glycogen or actively promotes glycogenolysis with resulting hyperglycemia and glycosuria (in diabetics). Whether or not these effects are mediated through neuroendocrine mechanisms or are due to direct influence on the combined action of the phosphorylase and phosphatase systems, considered by Cori ${ }^{75}$ to govern the formation of blood sugar from liver glycogen, cannot at present be said.

\section{SumMary}

Miscellaneous data pertaining to the interrelationships between the exchanges of sodium and potassium and carbohydrate metabolism have been assembled from widely scattered sources. A critical evaluation of the fairly imposing array of evidence thereby made available indicates that these interrelations are of profound significance in both animal and plant economy.

The "over-all" effects of these two monovalent bases in the animal body have 
been shown to be antagonistic to each other in the main. Sodium tends to retard the oxidation of glucose and to increase the deposition of glycogen in the liver. On the other hand, potassium inhibits glycogenesis in the liver and tends to increase blood sugar and glycosuria at the expense of liver glycogen. Under certain conditions it apparently activates the enzymatic breakdown of glucose.

The clinical significance of these interrelationships is apparent in such conditions as diabetes mellitus, hyperinsulinism, Addison's disease and familial periodic paralysis.

\section{REFERENCES}

1. Murlin, J. R., and Kramer, B.: J1. Biol. Chem. 27:.181, 517, 1916.

2. Murlin, J. R., and Craver, J. A.: Jl. Biol. Chem. 28:289, 1916.

3. Underhill, F. P.: Jl. Amer. Med. Assn. 68:197, 1917.

4. Beard, A. H.: Archs. Internal Med. 21:־16, 1918.

5. Thompson, G. D.; Nitchell, M., and Koll, L. C.: Biochem. Jl. 27:1253, 1933.

6. Johnston, J. A., and Maroney, J. W.: Amer. Jl. Diseases Childr. 49:12.40, 1935 .

7. Schenk, H.: Ztschr. f. d. gsmt. exper. Med. 12:269. 1921.

8. Abelin, J., and Goldener, E.: Klin. Wchnschr. $4: 2466,1925$.

9. Semler, R.: Klin. Wichnschr. $4: 697 \cdot 1925$.

10. Glass, E., and Beiless, I.: Ztschr. f. d. gsmt exper. Med. 73:801, 1930.

11. Briggs, A. P.; Koechig, I.; Doisy, E. A., and Weber, C. J.: Jl. Biol. Chem. 58:721, 1923.

12. Harrop, G. A., and Benedict, E. M.: J1. Biol. Chem. $59: 68_{3}, 1924$.

13. Wigglesworth, V. E.; Woodrow, C. E.: Smith, Wr, and Winter, L. B.: Jl. Physiol. 57 it7, 1922.

14. Hïusler, H., and Heesch, O.: Pflügers Arch. f. d. gsmt. Pbysiol. 210:545, 1925.

15. Kerr, S. E.: Jl. Biol, Chem. 78:35, 1928.

16. Cori, C. F., and Cori, G. T.: Naunyn-Schmiedebergs Arch. f. exper. Pathol. u. Pharmakol. $172: 2+9 \cdot 1933$.

17. Ellsworth, R., and Weinstein, A.: BuH. Johns Hopkins Hosp. 53:21, 1933 .

18. Keys, A.: Amer. Jl. Physiol. 123:608, $193^{8}$.

19. McQuarrie, I., and Ziegler, M. R.: Proc. Soc. Exper. Biol. \& Med. 39:523, 1938.

20. Pulver, R., and Verzir, F.: Nature (London) $145: 829$, $194^{\circ}$.

21. Day, D., and Comboni, S.: Amer. Jl. Bot. 24:591, 1937.

22. Lasnitski, A., and szörenyi, E.: Biochem. J1. 29:580, 1935.

23. Lasnitski, A.: Biochem. Ztschr. 264:285, 1933.

24. Lasnitski, A.: Protoplasma 22:271, 1931.

25. Ashford, C. A., and Dixon, K. C.: Biochem. J1. 29:157, 1935 .

26. Dickens, F.. and Greville, G. D.: Biochem. J1. $29: 1468$, 1935.

27. Fenn, W. O.: Jl. Biol. Chem. 128:297, 1939.

28. Flock, E.: Bollman, J. L.; Mann, F. C., and Kendall, E. C.: J1. Biol. Chem. 125:57, 1938.

29. Kendall, E. C.; Flock, E. V.; Bollman, J. L., and Mann, F. C.: Jl. Biol. Chem. 126:697, 1938.

30. Long, C. N. H.; Fry, E. G., and Thompson, K. W.: Amer. Jl. Physiol, 123:130, 1938.

31. Lasnitzki, . .: Nature (London) 1 46:99, $191^{0 .}$

32. Verzar, F., and romog) i, J. C.: Nature (Londons) 114:101 1. 1999.

33. Verzar, F.. and Somog! i. J. C.: Helvet. med. act. 23:118

34. Verzar, F., and somogyi, J. C.: Archs. intematn. de pharmacodsu. et de therapie $65,5 \%$ $194^{1 .}$

35. Fenn, W. O.: Physiol. Rers. 16:150, 1936.

36. D'silva, J. L.: Jl. Physiol. 82:393, 193t.

37. D silva, J. L.: Jl. Phrsiol. 90:303, 1937.

38. Marenzi. 1. D., and (ierschman, R.: Rer, boc. argentin. de biol. 12:121. $193^{6}$ 
39. Marenzi, A. D., and Gerschman, R.: Cpts. rd. Soc. de biol. 124:382, 1937.

40. Schwartz, H.: Naunyn-Schmiedebergs Arch. f. exper. Pathol. u. Pharmakol. 177:628, 1935 .

11. Houssay, B. A.; Marenzi, A. D., and Gerschman, R.: Cpts. rd. Soc. de biol. 124:383, 1937 .

42. Snyder, C. D., and Johnson, R. E.: Johns Hopkins Hosp. Bull. 62:110, $193^{8}$.

43. Fenn, W. O.: Physiol. Revs. 20:377, 1940.

44. Soskin, S.: Amer. Jl. Physiol. 81:382, 1927.

45. Cori, C. F.: Physiol. Revs. 11:143, 1931.

46. Walker, M.: Lancet 229:47, 1935 .

47. Aitken, R. S.; Allott, E. N.; Castleden, L. I. M., and Walker, M.: Clin. Sci. 3:47, 1937.

48. Allott, E. N., and McArdle, B.: Clin. Sci. 3:229, 1938.

49. McQuarrie, I., and Thompson, W. H.: Proc. Soc. Exper. Biol. \& Med. 31 :907, 1934.

5o. McQuarrie, I.; Thompson, W. H., and Anderson, J. A.: Jl. Nutrit. 11:77, 1936.

51. McQuarrie, I.; Ziegler, M. R., and Johnson, R. M.: Endocrinology 21:762, 1937.

52. Thompson, WV. H.: Unpublished data.

53. Ziegler, M. R., and McQuarrie, I.: Proc. Soc. Exper. Biol. \& Med. 39:142, $193^{8}$.

54. McQuarrie, I.; Ziegler, M. R., and Stone, W. E.: Chin. Med. Jl. 58:1, 1940.

55. McLean, A. R.: Proc. Staff Meetgs. Mayo Clin. 10:321, 1935.

56. Wilder, R. M.: Archs. Internal Med. 57:422, 1936.

57. Sanstead, H. R.: Hosp. News 21:1, 1936.

58. Strouse, S.; Buel, F.; Kay, R., and Drury, D.: Jl. Nutrit. 21:599, $194^{1}$.

59. Michelson, H.: Naunyn-Schmiedebergs Arch. f. exper. Pathol. u. Pharmakol. 173:750, 1933.

6o. McCance, K. A.: Biochem. Jl. $31: 1276,1937$.

61. Aldersberg, D., and Wachstein, M.: Klin. Wchnschr. 16:85, 1937.

62. Crabtree, D. G., and Longwell, B. B.: Proc. Soc. Exper. Biol. \& Med. 34: 705.1936.

63. Anderson, E.; Herring, V., and Joseph, M.: Proc. Soc. Exper. Biol. \& Med. 45:488, 1940.

64. Kiyohara, K.; Morita, M., and Muta, S.: Cpts. rd. Soc. de biol. 120:101 1, 1935.

65. Kylin, E., and Engel, A.: Klin. Wchnschr. 4:653, 1925.

66. Odashima, G.: Tohoku Jl. Exper. Med. 18:250, 1932.

67. Silvette, H., and Britton, S. W.: Proc. Soc. Exper. Biol. \& Med. 37:252, 1937.

68. Silvette, H.; Britton, S. W., and Kline, A.: Amer. Jl. Physiol. 122:446, 524, 1938.

69. Lewis, R. C.: Univ. Colorado Studies, genrl. s. (A) 26(3):73. 1940.

7o. Orten, J. M., and Devlin, H. B.: Proc. Soc. Exper. Biol. \& Med. 42:632, 1939.

71. Orten, J. M., and Devlin, H. B.: Jl. Biol. Chem. 136:461, 1940.

72. Sayers, G., and Orten, J. M.: Proc. Soc. Exper. Biol. \&. Med. 46:287, 1941 .

73. Rathéry, F., and Bertoliatti, J.: Cpts. rd. Soc. de biol. 116:1346, 1934.

74. Guest, G. M.: Personal communication.

75. Cori, C. F.: Endocrinology 26:285, 1940.

76. Ziegler, M. R.: Proc. Soc. Exper. Biol. \& Med. 43:165, 19.4 .

77. Long, C. N. H.; Katzin, B., and Fry, E. G.: Endocrinology 26:309, 1940.

78. Grollman, A.: Endocrinology 29:862, 1941 .

79. Richter, C. P., and Eckert, J. F.: Endocrinology 22:214, 1938.

8o. Richter, C. P.: Endocrinology 29:111, 1941. 
HARVEY'S IDEAS OF EMBRYONIC

NUTRITION

By

A. W. MEYER

蕬

From the

DEPARTMENT OF ANATOMY

STANFORD UNIVERSITY, CALIFORNIA 



\section{HARVEY'S IDEAS OF EMBRYONIC NUTRITION*}

$\mathrm{I}$ N HiS LETTER of April 28, 1652 , to R. Morison, M.D., of Paris, Harvey regarded it as ". . . a most certain fact ... that the embryos of all red-blooded animals are nourished by means of the umbilical vessels from the mother, and this in virtue of the circulation of the blood. They are not nourished, howeter, immediately by the blood, as many have imagined, but after the manner of the chick in ovo, which is first nourished by the albumen, and then by the vitellus..."' (p. 6o8).

After considering conception in the deer in the month of December, Harvey had concluded that: "From all of what precedes it is manifest that in both the classes of viviparous animals alluded to, those, namely, that are provided with carunculae or cotyledons, and those that want them, and perhaps in viviparous animals generally, the foetus in utero is not nourished otherwise than the chick in ovo; the nutritive matter, the albumen, being of the same identical kind in all. ... And this is further obvious from the fact of the extremities of the umbilical ressels, when they are drawn out of the afore-mentioned mucor, looking completely white; a certain proof that they absorb this mucilage liquefied only, and not blood. The same arrangement may very readily be observed to obtain in the egg.

"The human placenta is rendered uneven on its convex surface, and where it adheres to the uterus, by a number of tuberous projections, and it seems indeed to adhere to the uterus by means of these; it is not consequently attached at every point, but at those places only where the vessels pierce it in search of nourishment, and at those where, in consequence of this arrangement, an appearance as if of vessels broken short off is perceived. But whether the extremities of these vessels suck up blood from the uterus, or rather a certain concocted matter of the nature of albumen, as I have described the thing in the hind and doe, I have not yet ascertained" (p. 497).

"It seems manifest, therefore, that the foetus in utero is not nourished by its mother's blood, but by this albuminous fuid duly elaborated. It may even be, perhaps, that the adult animal is not nourished immediately by the blood. but rather by something mixed with the blood, which serves as the ultimate aliment; as may perhaps be more particularly shown in our Physiologyt and particular treatise on the Blood" (p. 498).

In his letter of July 19, 1655 (old style), to "John Dan. Horst," he likewise declared, "I only say (keeping silence as to any other channels), that the nutri-

* All quotations not separately identified are from Willis" edition (Iondon: 1847) of Harvers works. The italics and words in brackets were intuoluced by the compiler. More annotations and comments were precluded by the unavoidable limits set.

+ Harvey is not known to have written such a treatise. 
tive juice might be as readily transported by the uterine arteries, and distilled into the uterus, as watery fluid is carricd by the emulgent arteries to the kidneys ... What you say of the excrements of new-born infants differing from those of the child that has once tasted milk I do not admit..." (p. 614-615).

Harvey began his discussion "of the nutrition of the chick in ovo," in "Exercise the Fifty-eighth" of the De Generatione, by recalling that Democritus, Epicurus, and Hippocrates supported the idea that the mammalian foetus sucks in utero. He said that his teacher, Fabricius, had rejected this idea "as a delusion," but that he nevertheless believed it because his observations on generation make that opinion not "merely probable" but necessary. In support of his opinion Harvey further called attention to the "fact" that the amniotic fluid ". . . has a pleasant taste, like that of watery milk, so that almost all viviparous animals lap it up, ... greedily swallowing" it (p. 435).* "To me, therefore, the opinion of Hippocrates appears more probable than that of Fabricius and other anatomists, who look on this liquid as sweat, and believe that it must prove detrimental to the foetus. I am disposed, I say, to believe that the fluid with which the foetus is surrounded may serve it for nourishment; that the thinner and purer portions of it, taken up by the umbilical veins, may serve for the constitution and increase of the first formed parts of the embryo; and that from the remainder or the milk, $\dagger$ taken into the mouth by suction, passed on to the stomach by the act of deglutition, and there digested or chylified, and finally absorbed by the mesenteric veins, the new being continues to grow and be nourished. I am the more disposed to take this view from certain not impertinent arguments, which $I$ shall proceed to state.

"As soon as the embryo acquires a certain degree of perfection it moves its extremities, and begins to prove the actions of the organs destined to locomotion. Now I have seen the chick in ovo, surrounded with liquid, opening its mouth, and any fluid that thus gained access to the fauces must needs have been swallowed; for it is certain that whatever passes the root of the tongue and gains the top of the oesophagus, cannot be rejected by any animal with a less effort than that of vomiting. ... If the embryo swimming in the fluid in question, then, do but open his mouth, it is absolutely necessary that the fluid must reach the fauces; and if the creature then move other muscles, wherefore should we not believe that he also uses his throat in its appropriate office and swallows the fluid?

* Even as late as 1815 , Béclard, on the basis of experimental evidence, concluded that the fetuses of mammals swallow amniotic fluid because hairs were present in the meconium of fetuses whose necks had been constricted by a tourniquet. Béclard also had found hairs in a still born proximal to the site of an intestinal obstruction, and had noticed that the increase in the rapidity of fetal respiratory movements was proportional to the extent of placental detachment. Moreover, pigment injected into the amniotic fluid, after ligation of the fetal neck, was found up to the ligature.

†The word milk was then used to designate the fluids surrounding the fetus instead of those within the uterus, but Harvey also spoke of milk in the thymus and lymph glands. 
"It is further quite certain that in the crop of the chick,-and the same thing occurs in reference to the stomach of other cmbryos-there is a certain matter having a colour, taste, and consistence, very similar to that of the liquid mentioned, and some of it in the stomach digested to a certain extent, like coagulated milk; and further, whilst we discorcr a kind of chyle in the upper intestines, we find the lower bowels full of stercoraceous cxcrencnts. In like manner we perceive the large intestines of the foetuses of viviparous aninuals to contain excrements of the same description as those that distend them when they feed on milk. In the sheep and other bistilcated animals we even find scybala" (pp. 438-439). This he said was observed by "Volcher Coiter, a careful and experienced dissector." Harvey concluded that "The embryo, therefore seeks for and sucks in nourishment by the mouth: and you will readily believe that he does so if you rip him from his mother's womb and instantly put a finger in his mouth; which Hippocrates thinks he would not seize harl he not previously sucked whilst in the womb" (p. 440).

"In the stomach of the foetus there is a watery fluid contained, not unlike that in which it swims, but somewhat more turbid or less transparent. It resembles the milk that begins to be secreted in the breasts of pregnant women about the fourth or fifth month of pregnancy, and may be pressed out of the nipples, or it is like the drink which we call white posset.

"In the small intestines there is an abundance of chyle concocted from the same matter; in the colon greenish faeces and scybala begin to appear" (pp. $493-494)$.

"Just as the colliquament found in the crop of the chick is a kind of crude milk, whilst the same fluid discovered in the stomach is concocted, white, and curclled; so in viviparous animals, before the milk is concocted in the mammae, a kind of dew and colliquament makes its appearance there, and the colliquament only puts on the semblance of milk after it has undergone concoction in the stomach. And so it happens, in Aristotle's opinion, that the first and most essential parts are formed out of the purer and thimner portion of the colliquament, and are increased by the remaining more indifferent portion after it has undergone elaboration by a new digestion in the stomach. In the same way are the other less important parts developed and maintained. Thus has nature, like a fond and indulgent mother, been sedulous rather to provide superfluity, than to suffer any scarcity of things necessary. Or it might be said to be in conformity with reason to suppose that the foetus, now grown more perfect, should also be nourished in a more perfect manner, by the mouth, to wit, and be a more perfect kind of aliment, rendered purer by having undergone the two antecedent digestions and been thereby freed from the two kinds of excrementitious matter. In the beginning and early stages, nourished by the ramifications of the umbilical veins, it leads in some sort the life of a plant: the body is then crude, white, and imperfect; like plants, too, it is motionless and impassive. As soon, however, as it begins by the mouth to partake of the 
same aliment farther elaborated, as if feeling a diviner influence, boasting a higher grade of vegetative existence, the gelatinous mass of the body is changed into flesh, the organs of motion are distinguished, the spirits are perfected, and motion begins; nor is it any longer nourished like a vegetable, by the roots, but, living the life of an animal, it is supported by the mouth" (p. 441-442).

"These and other observations of the same kind [upon prenatal deglutition, suckling, and intestinal contents] make it extremely probable that the chick in ovo is nourished in a twofold manner, namely, by the umbilical and by the mesenteric veins. By the former he imbibes a nourishment that is well nigh perfectly prepared, whence the first-formed parts are engendered and augmented; by the latter he receives chyle for the structure and growth of the other remaining parts" (p. 440).

"All admit this distinction of fluids. But I, as I have already said, distinguish two albumens in the egg, kept separate by an interposed membrane, the more cxternal of which embraces the other within it, in the same way as the yolk is surrounded by the albumen in general. I have also insisted on the diverse nature of these albumens; distinguished both by situation and their surrounding membranes, they seem in like manner calculated for different uses. Both, however, are there for ends of nutrition, the outermost, as that to which the branches of the umbilical veins are earliest distributed, being first consumed, and then the inner and thicker portion; last of all the vitellus is attacked, and by it is the chick nourished, not only till it escapes from the shell but for some time afterwards.

"But upon this point we shall have more to say below, when we come to speak of the manner in which the foetuses of viviparous animals are developed, and at the same time demonstrate that these all derive their origin from eggs, and live by a twofold albuminous food in the womb. One of these is thinner, and contained within the ovum or conception; the other is obtained by the umbilical vessels from the placenta and uterine cotyledons. The fluid of the ovum resembles a dilute albumen in colour and consistence; it is a sluggish, pellucid liquid, in all respects similar to that which we have called the colliquament of the egg, in which the embryo swims, and on which it feeds by the mouth. The fluid which the foctus obtains from the uterine placenta by the aid of the umbilical vessels is more dense and mucaginous, like the inspissated albumen. Whence it clearly appears that the foetus in utero is no more nourished by its parent's blood than is the suckling afterwards, or the chick in ovo; but that it is nourished by an albuminous matter concocted in the placenta, and not unlike white of egg" (p. 447-448).

The placenta "in like manner [as the liver], prepares for the foetus alimentary matters which have come from the mother ..." and ". . so, too, the placenta ... abounds in an albuminous fluid, and is only to be found at the period of pregnancy" (p. $56_{3}$ ).

Harvey did not hold these views because he rightly believed that the blood 
of the mother does not circulate in the fetus, but because he held that in prenatal life the placenta plays the nutritional role that the mother plays in postnatal life, and when discussing the role of the "humours"*-or uterine and embryonic fluids-he declared, “. . I nevertheless most confidently assert my belief that these humours are at the commencement destined for the nourishment of the foetus, just as the colliquament and albumen are in the case of the chick; but that, in course of time, when the thinner and purer portions are absorbed, the remainder takes on the character of excrementitious matter, but still has its uses, and in some animals especially conduces to the safety of the foetus, and also greatly facilitates birth. For just as wine becomes poor and tasteless when the spirit has evaporated; and as all excreted matters owe their origin for the most part to what has been previously food; so, after all the nutrient portions of the fluid contained in the chorion have been taken up by the foetus, the remainder becomes excrementitious, and is applied to the above-mentioned uses. But all the fuid of the amnion is usually consumed by the time of birth; so that it is probable the foetus seeks its exit on account of deficiency of nutriment" (p. 559).

Although he thought of the conceptus as becoming attached to the uterus for the purpose of taking up nutriment, Harvey emphasized that "At the commencement the 'conception' (like an egg placed within the uterus) is found in contact with every part of the uterus, yet at no point is it adherent; but produces and nourishes the embryo out of the humours contained within it, as I have explained in the instance of the hen's egg. This adhesion, or growing together, first takes place, and the fleshy mass (constituting the bond of union between the 'conception' and the uterus) is first produced, when the foctus becomes perfectly formed, and, through want either of different or more abundant nourishment, dispatches the extremities of the umbilical vessels to the uterus, that from hence (as plants do from the earth by their radicles), it may absorb the nutrient juices. For in the beginning, as I have said, when the 'punctum saliens' and the blood can alone be seen, the ramifications of the umbilical vessels are only visible in the colliquament and amnion. When, howerer, the fabric of the body is completely formed, the ramifications extend further, and are distributed in vast numbers throughout the chorion, that from the albuminous fluid which there exists, they may obtain nourishment for the foetus.

"Hence it is manifest that the young of viviparous animals are at the beginning nourished in exactly the sane manner as the chick in the cgg; and that they are detained within the uterus in order that (when they can no longer supply themselves with nutriment from their own stores) they may form arthesions to it by means of this fleshy substance, and receiving nore abundant supplies of food from the mother, may be nourished and made to grow.

\footnotetext{
* By humours, as here used, Harver understood both uterine and felal fluids but he also thought of the ormm or primordinm of the new being, as "formed out of the humours of the merus."
} 
"Wherefore Fabricius has rightly observed, that in some animals the "conception' is scarcely attached to the uterus at all. Thus the sow and the mare have no such fleshy mode of union,-but in them the ovum or 'conception,' as in the beginning it is formed out of the humours of the uterus, so it is nourished subsequently by the same means; just as the ovum of the hen is supplied with aliment at the expense of the albuminous matter without any connexion whatever with the uterus: and thus the foetus is furnished with aliment by the 'conception' in which it is contained, and is nourished as the chick is from the fluids of the egg. This is a strong argument that the foetus of viviparous animals is no more nourished by the blood of the mother than the chick in the egg; and moreover, that the fluid within the chorion is neither urine nor any other excrementitious matter; but serves for the support of the foetus. Although as I have before remarked, it is possible when all the nutrient portions have been taken up, the remainder may degenerate into excrementitious matter resembling urine. This is also clear from what I formerly observed of the cotyledons in the deer, viz., that in these animals the fleshy mass was of a spongy character, and constituted, like a honeycomb, of innumerable shallow pits filled with a muco-albuminous fluid (a circumstance already observed by Galen); and that from this source the ramifications of the umbilical vessels absorbed the nutriment and carried it to the foetus: just as, in animals after their birth, the extremities of the mesenteric vessels are spread over the coats of the intestines and thence take up chyle" (p. 561-562).

In regard to the role of the so-called "spirits" in nutrition, he asserted that "They who advocate incorporeal spirits have no ground of experience to stand upon; their spirits indeed are synonymous with powers or faculties, such as a concoctive spirit, a chylopoietic spirit, a procreative spirit, etc.-they admit as many spirits, in short, as there are faculties or organs" (p. 116).

"For if the spirits exhaling from the blood, like the vapour of water attenuated by heat, exist in a state of constant flow and succession as the pabulum of the tissues, it necessarily follows that they are not distinct from this pabulum, but are incessantly disappearing; whereby it seems that they can neither have influx nor reflux, nor passage, nor yet remain at rest without the influx, the reflux, the passage (or stasis) of the blood, which is the fluid that serves as their vehicle or pabulum" (p. 118).

He remained skeptical regarding the role of the lacteals and lymphatics in nutrition for he held that "Even as the umbilical reins absorb the nutritive juices from the fluids of the egg and transport them for the nutrition and growth of the chick, in its embryo state, so do the meseraic veins suck up the chyle from the intestines and transfer it to the liver; and why should we not maintain that they perform the same office in the adult?" (p. 95). In his first letter to Riolan, written in 1649 , Harvey further declared, "I shall elsewhere state my views of the lacteal veins when I treat of the milk found in different parts of new-born animals, especially of the human subject; for it is met with 
in the mesentery and all its glands, in the thymus, in the axillac, also in the breasts of infants" (p. 95). He spoke of this also in his letter of April 28, 16.52, to "R. Morison, M.D., of Paris," in which he wrote:

"But for various reasons, and led by several experiments, I could never be brought to believe that that milky fluid [in the lacteals] was chyle conducted hither from the intestines, and distributed to all parts of the body for their nourishment: but that it was rather met with occasionally and by acciclent, and proceeded from too ample a supply of nourishment and a peculiar vigour of concoction; in rirtue of the same law of nature, in short, as that by which fat, marrow, semen, hair, etc., are produced; even as in the due digestion of ulcers pus is formed, which the nearer it approaches to the consistency of milk, viz., as it is whiter, smoother, and more homogeneous, is held more laudable, so that some of the ancients thought pus and milk were of the same nature, or nearly allied. Wherefore, although there can be no question of the existence of the ressels themselves, still I can by no means agree with Aselli in considering them as chyliferous vesseIs, and this especially for the reasons about to be given, which lead me to a different conclusion. For the fluid contained in the lacteal veins appears to me to be pure milk, such as is found in the lacteal veins [the milk ducts] of the mammae. Now it does not seem to me very probable (and more than it does to Auzotius in his letter to Pecquet) that the milk is chyle, and thus that the whole body is nourished by means of milk. The reasons which lead to a contrary conclusion, viz., that it is chyle, are not of such force as to compel my assent. I should first desire to have it demonstrated to me by the clearest reasonings, and the guarantee of experiments, that the fluid contained in these ressels was chyle, which, brought hither from the intestines, supplies nourishment to the whole body. For unless we are agreed upon the first point, any ulterior, any more operose, cliscussion of their nature, is in vain. But how can these ressels serve as conduits for the whole of the chyle, or the nourishment of the body, when we see that they are different in clifferent animals? In some they proceed to the liver, in others to the porta only, and in others still to neither of these. In some creatures they are seen to be extremely numerous in the pancreas; in others the thymus is crowded with them; in a third class, again, nothing can be seen of them in either of these organs. In some animals, indeed, such chyliferous canals are nowhere to be discovered (vide Liceti Epist. xiii, tit. ii, p. $8_{3}$, et Sennerti Praxeos, lib. v, tit. 2, par. 3. cap. 1); neither do they exist in any at all times. But the ressels which serve for nutrition must neccsarily both exist in all animals, and present themselres at all times; inasnuch as the waste incurred by the ceaseless efflux of the spirits, and the rear and tear of the parts of the body, can only be supplied by as ceaseless a restoration or untrition. And then, their very slender calibre seems to render them not less inadequate to this duty than their structure seems to unfit them for its performance: the smaller channels ought plainly to end in larger ones, these in their turn in channels larger still, and the whole to concentrate in one great trunk, which 
should correspond in its dimensions to the aggregate capacity of all the branches; just such an arrangement as may be seen to exist in the vena portae and its tributaries, and farther in the trunk of the tree, which is equal to its roots. Wherefore, if the efferent canals of a fluid must be equal in dimensions to the afferent canals of the same fluid, the chyliferous ducts which Pecquet discovers in the thorax, ought at least to equal the two ureters in dimensions; otherwise they who drink a gallon or more of one of the acidulous waters could not pass off all this fluid in so short a space of time by these vessels into the bladder. And truly, when we see the matter of the urine passing thus copiously through the appropriate channels, I do not see how these veins could preserve their milky colour, and the urine all the while remain without a tinge of whiteness" (pp. 605-606).

Almost wholly unencumbered by personal comments, the above words of one of the immortals of science are offered in cordial tribute to a valued friend and fruitful seeker who not only has garnered and treasured many precious volumes from seekers of days long passed but has generously entrusted them to others.-May Time deal gently with him and ease the burden of passing years. 


\section{OBSERVATIONS ON THE \\ PATHOGENESIS OF UNDULANT \\ FEVER}

By

K. F. MEYER

\section{知}

From the

GEORGE WILIIAMS HOOPER IOLNDATION

UNIVERSITY OF CALIFORNIA

SAN FRANCISCO, CALIFORNIA 



\section{OBSERVATIONS ON THE PATHOGENESIS OF UNDULANT FEVER}

Contrncous perusal of the many papers which have appeared during the 1 past fifteen years on human brucellosis, induced by the abortus and suis types of Brucella, makes it appear that this discase still remains an inadequately understood and consequently an intriguing subject. Despite the vast amount of research and the collection of case histories, relatively little is known concerning the genesis and pathology of the infection. In fact, what has been reported is frequently contradictory and little agreement has as yet been reached. In order to elucidate certain phases of the morbid processes, the pathological and bacteriological findings made on a laboratory-animal caretaker, who succumbed to a fulminating $B r$. suis septicemia within eleven days after he was observed to be ill, are herewith reported.

The history of the patient presents the following essential data: White male, D.S., age 24 , laboratory technician with a strongly positive phagocytic index test of 6.88 for Br.abortus and a positive allergic skin test indicative of a passed latent Brucella infection, complained on November $2_{t}$ of discomfort in the abdomen, nausea, vomiting after a weck of malaise, marked spells of perspiration, and occipital headache. The examination disclosed a purplish lue of the skin over his back, face and anterior thorax, a temperature of $101^{\circ} \mathrm{F}$, tachycardia (128), vesicular breathing, a soft large splecn; he was decidedly restless and irritable, occasionally irrational. R.B.C. $4,640,000$; W.B.C. 33,200; 91 per cent P.M.N. and 4 per cent monocytes; urine: albumen $+H$, small hyaline and granular casts. A quantitative blood culture yielded 1,750 colonies of $\mathrm{Br}$. suis per cc. On November 27 , a slight icteric tinge of the sclera was noted and the urine was positive for urobilinogen. He developed a progressive jaundice (icterus index 13o. van den Bergh direct and indirect); the serum gave a positive agglutination test with Br.abortus 1:40. On December 2, extensive consolidation at the base of the right lung was recorded: he became comatose and expired on December 4 , despite repeated transfusion and glucose administrattion by chysis and supportive treatment.

A utopsy: The autopsy was performed 7 hours after death by W. T. Partch, M.D., and the author. Only the significant findings as dictated are recordect.

The body of a well-nourished male about 30 years of age shows marked icteric tinge to the skin and post-mortem lividity. On incision in the abdominal cavity and in the right pleural cavity approximately $50 \mathrm{cc}$. of slightly blood-tinged fluid are found. No exudate is seen in the left cavity while the pericardial cavity contains $50 \mathrm{cc}$, of clcar straw-colorch fluid.

The weight of the heart is $370 \mathrm{gm}$. The valves and the myocardium are esscntialty normal.

Left Lung: A slight amount of fibrinous exudate is present over the visceral plenra of the left lower lobe. In cut section the entire lobe is scen to be markedly reddened and edematous (hemorrhagic edema). No consolidation is present; mediastinal lymph nodes are reddened, soft, and markedly enlarged.

Right Lung: On palpation of the upper lobe and the posterior aspect of the right lower lobe many areas of consolidation are felt; the middlc lobe crepitates normally throughout. The upper lobe on section is red in appcarance, and practically consolidated. There is contral consolictation in the base. From numerous nodules along the posterior aspect of the lower lobe droplets of pus exude from the cut surface. There is a very iccent fibrinons cxudate over the viscerai pleura of the right lung.

The spleen weighs $420 \mathrm{gm}$; it is moderately firm on palpation and dark bhuish in color. 
On section the Malpighian bodies are not always visible and the splenic substance is quite pulpy in character.

The Intestines show a slight superficial injection throughout the entire tract. The mesenteric blands are not enlarged. The mucosa of the terminal end of the small intestine shows hemorrhagic injection, and some old free blood is found in the jejunum.

The Stomach is distended and contains about 500 cc. of dark bile-stained fluid. The wall is deeply injected, particularly in the cardiac portion. The wall of the duodenum is also injected. The enlargement of the lymphoid follicles in the duodenum is quite marked.

The Liver weighs $3,030 \mathrm{gm}$. The surface is smooth throughout. On section the normal markings are not easily distinguished and the surface appears yellowish. The gall bladder is distended with about $100 \mathrm{cc}$. of rather thin bile. There are numerous enlarged lymph nodes along the common duct.

Both Adrenal Glands appear on gross examination to be normal.

The Right Kidney is markedly enlarged and of a soft rubbery consistency; the capsule strips with ease, exposing scattered small abscesses. On section the normal markings are only partially seen and there are numerous small (metastatic) abscesses in the pyramids and a few in the cortex.

Left Kidney: The left kidney weighs 360 gm., shows just under the capsule a number of small subcapsular and cortical abscesses. Otherwise, it is similar to the right.

Permission for an examination of the Central Nervous System was unfortunately not granted.

The significant gross findings therefore were the enlargement and softening of the spleen and liver. The latter organs showed diffuse acute parenchymatous changes. The enlargement of the lymph follicles throughout the duodenum and swelling of the portal lymph nodes was noteworthy. A fresh fibrinous pleurisy on the left and right lung was associated with the red and gray hepatization and multiple-abscess formation in the right lung. Of particular interest was the bilateral metastatic descending nephritis.

Microscopic examination of sections stained according to the method of Wolbach with Giemsa's stain, hematoxylin-eosin, and Sudan III revealed the following significant findings:

Lungs: The portions of the left lobe lying beneath the pleura covered with partially organized fibrin nets show marked filling of the alveolar capillaries with red cells. Similarly the blood vessels of the bronchioles are affected. Few alveoli are empty. Directly under the pleura the cell linings of the air sacs are desquamated and imbedded in amorphous material. Below this layer the majority of the abcoli are filled either with red cells or with masses of polymorphonuclear leucocytes and some monocytes. Occasionally an air sac contains a network of delicate fibrin threads and a few leucocytes, while others reveal clusters of "dust cells." In the bronchioles and bronchi either red cells or amorphous pink-staining detritus without leucocytes cover the normal mucous lining. In the deeper sections large areas of the parenchyma consist of alveoli gorged with red-cell masses or a transuclate. A similar picture is presented by the right lobe, although alveoli with polymorphonuclear exudate enclosing pneumococci predominate. Located directly under the pleura or adjacent to it many alveoli form a confluent mass consisting of mononucleated cells with very few polymorphonuclear cells and some nuclear detritus. The remains of the alveolar septa are hyalinized and necrotic. In the center of these areas dense deeply stained chumps of gram-negative coccoid bacteria are present (pl. 2, fig. 3). Morphologically the organisms resemble Brucella. However, in some alveoli clumps of gram-positive diplococei and aggregates of single cocci embedded in a meshwork of long gram-positive and gram-negative rods are seen. The exudate surrounding the bacterial masses is relatively small and consists of polymorphonuclear cells which have phagocytized a great many of the cocci. The alveolar sacs surrounding these various types of abscess are engorged with red cells, not infrequently forming a confluent hemorrhagic pneumonic consolidation. There are no cellular reactions in the bronchioles, although pinkstaining loosely arranged material is present in the lumen.

The exact origin of the abscesses induced by the Brucella organism is not definitely dis- 
cernible, but in some sections clumps of bacili are noted in the capillaries of the interlobular vessels. It is reasonable to suspect that they are the seeds for the metastic-embolic origin of the abscesses. On the other hand, the bacterial aggregates in the alveoli of the right lower lobe represent early stages of microbial localization which would ultimately have led to small focal or even a lobular aspiration pneumonia. The extensive red and gray hepatization is unquestionably induced by pneumococci.

Mediastinal and Bronchial Lymph Nodes: The general engorgement of the capillaries and the looseness of the follicles separated by dilated sinuses explains the ectematous state of the organ. Cortical as well as medullary sinuses are filled with amorphous material, a few leucocytes, monocytes, and red cells. Pneumococci are readily demonstrable.

Spleen: Engorgement of the venous sinuses with red-cell masses predominates to such an extent that wide areas of the spleen resemble large hemorrhages. Although polyblasts and lymphocytes are present, monocytes are numerous and predominate in the sinuses locaterl under the capsule. The Malpighian bodies without germinal centers are of a loose structure; they are slightly enlarged and completely submerged in the masses of red cells. In a great many areas of the spleen nucleated cells are only noted along the trabeculae and the penicilli.

Intestinal Canal: Numerous hemorrhages are present in the villi of the duodenal and jejunal mucosa. The lymphoid-tissue follicles show a loose arrangement and lack distinct germinal centers.

Liver: The mosaic of the liver lobules is frequently indistinct; the sinusoids are distended and filled partly with amorphous material, red cells, occasional polyblasts, and monocytes (pl. 2, fig. 4). In the periphery of the lobule many of the hepatic cells contain fine and large fat droplets, some show nuclear necrobiotic changes while others are acidophilic and in a state of dissolution. Throughout the columns the hepatic cells show a coarsely granular or even a flaky cytoplasm; those adjacent to the central vein are in part studded with irregular coarse particles of bile pigment. The Kupffer's cells contain hemosiderin. Bacteria are not recognized despite carcful search. The gall-bladder wall is slightly edematous; the mucosa is normal.

Portal Lymph Nodes: The capillaries are markedly distended and filled with red cells. In the cortical and subcapsular sinuses masses of red cells, polymorphonuclear leucocites, and monocytes are present. The secondary nodules of the lymph follicles are faintly visible (pl. 2, figs. 5 and 6). Several of the medullary sinuses contain nests of epithelioid hyperplasia furst described by Fabyan ${ }^{1}$ in connection with his studies on the pathogenesis of abortus infections in guinea pigs. An occasional cell contains one of two gram-negative coccoid rods.

Kidneys: Both organs show in general the identical involvement, although the areas with abscesses are more evident in the right kidney. Aside from an engorgement of the blood vessels in the pyramids, the tubules are markedly dilated, filled with albuminous content and occasional amorphous clumps of pigment. As a rule, the glomerular tufts are normal in size, in part filled with blood, in part collapsed, but the subcapsular space contains albuminous detritus. In several renal corpuscles of many sections examined, the capsular epithelium reveals a number of decply stained cells protruding into the lumen of Bowman's capsule (pl. 2, figs. 7 and 8). Under high magnification these cells contain clusters or morulalike masses of gram-negative bacteria. These abnormal renal corpuscles are in the vicinity of extensive areas of cellular infiltration which may be locaterl directly bencath the capsule in the center of the cortex or even in the medullary substance (pl. 3 , figs. 9 and 10 ). As a rule. the center of such a zone contains one or several transverse sections of proxinnal convoluted tubules with dark bluish or acidophilic cells attached to the basement membrane. These cells are also seen in the lumen of the excretory ducts.

Close examination of the bluish cells reveats that they have cuclosed in their cytoplasm irregular masses and nests of bacteria indistinguishable from typical Brucella organisms. Many of these cells have a darkly stained round nucleus while in others various stages of karyolysis attest to necrobiotic changes which have apparently taken place. The bacterial 
clusters neatly arranged in discs or spheres are intracellular colonies of Brucella which developed in the living epithelium of the proximal convoluted tubules and the capsule (pl. 3 , figs. 11 and 12). Surrounding these abnormal tubules, massive infiltrations of the stroma by monocytes, lymphocytes, plasma cells, and an occasional polyblast give the lesion a pattern which distinguishes it from the common renal abscesses induced by pyogenic cocci. Moreover, the arrangencut of the epithelioid cells indicates a focal growth incited and maintained by the activity of the bacteria ( $\mathrm{pl} .3$, fig. 13). As a whole, the lesions resemble those described by Fabyan for the kidneys of guinea pigs infected with $\mathrm{Br}$. abortus. The infiltration extends along and between the collecting system and compresses other tubules. On the outer zones of these areas the capillaries are greatly dilated and filled with red cells.

Throughout the tubular system one encounters single or small clusters of bacteria as free masses or embedded in albuminous material and desquamated cells within the lumen. In the medullary zone an occasional collecting tubule with completely necrotic epithelial cells encloses a solid plug of gram-negative bacilli (pl. 3, fig. 14). The reactive inflammatory process surrounding these tubules consists predominantly of monocytes or histiocytes and a few polyblasts, and extends rootlike between the uriniferous structures deep into the pyramids. These cells are imbedded in a mesh of slightly thickened reticular fibers. Some of the cells harbor phagocytized fragments of nuclear material in the broad cytoplasm. The epithelium of the convoluted tubules not involved contains small fat droplets, and occasional single cells or groups of cells are acidophilic and necrotic.

\section{Bacteriological Examination of Body Fluids and Tissues Recoverfo at Autopsy}

The specimens were cultured by impressing freshly cut surfaces of the organs over several blood- or liver-agar-plates or by streaking $0.1 \mathrm{cc}$. of the fluid-triturated organs ( $1 \mathrm{gm}$. in $10 \mathrm{cc}$. of broth) over the media.

Heart Blood: Pneumococcus Type 2 and Type IV (?); E. coli and Staphylococcus aurens.

Right Lung: Metastatic abscesses: Brucclla suis (about 80 per cent), pneumococci, Staphylococcus aurcus, very few $E$. coli.

Consolidated area: Pneumococci, hemolytic cocci and few E. coli.

Mediastinal Lymph Node: Pneumococci, E. coli and stapliylococci, about 4 Brucella colonies.

Liver: 18-25 colonics of Brucella suis, a few E. coli (2 tỵpes not identified).

Bile: 0.1 cc. of dilution 1:10 yields approximately 300 Brucella colonies or approximately 30.000 bacilli per cc. of bile and 400 E. coli.

Portal Lymph Nodes: Second dilution plate: 14 colonies of Br. suis, 9 E. coli and a few colonies of staphylococcus.

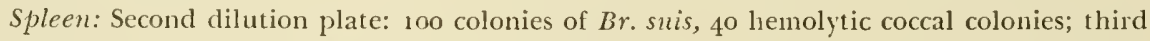
dilution plate: 20 colonies of $B r$. suis, few coccal colonies.

One gm. of splenic tissue was emulsified in to cc. of broth; o.1 cc. of the organ suspension yielded 36 colonies of Brucclla suis or 3,60o organisms per gm. of splenic pulp.

Left Kidney: Innumerable colonies of Br. suis.

Right Kidney: Innumerable colonies of Br. suis and $4-5$ of $E$. coli.

Ileum: (hemorrhagic segment); principally E. coli but a few Br. suis.

The Brucella strain isolated from the blood culture taken on Novmber 26 and at least 10 other strains grown from organs and selected at random, grew freely aerobically, formed abundant $\mathrm{H}_{2} \mathrm{~S}$, dereloped readily in the presence of thionin and moderately heavily in basic fuchsin $(1: 50,000)$, and were identified with the laboratory strain $\mathrm{Br}$. suis No. 80 (Meyer and Zobel12). It was specifically agglutinated by an absorbed abortus serum and it infected guinea pigs with trpical granulomas which presented central aggregates of polymorphouuclear leucocytes. 
Pure Brucella abortus infections with a duration of less than three wecks have not as yet been reported. Therefore, it is indeed a rare experience to be able to study an overwhelming Brucella sepsis during its rapid clinical couse as well as post mortem. Unfortunately, the Brucella discase was complicaled by a lobar and lobular pneumonia in part induced by pneumococci, staphyls. cocci, and streptococci. In consequence, the lesions in the lungs were partly obscured by the supervening microbian invasion, which was in all probability of the type of an aspiration pneumonia with relatively little involvement of the bronchial tree. On the other hand, there is definite proof that the abscesses in the right lobes were at least in part of hematogenous origin, and represented metastatic-embolic localization of the Brucella which circulated in very large numbers in the blood stream early in the course of the infection. Both the bacterioscopic and cultural examinations proved the predominance of the Brucella organisms in the purulent monocytic exudate. Old (Sharp ${ }^{3}$ ) and new (v. Albertini and Lieberherr, ${ }^{4}$ and Rabson ${ }^{5}$ ) analyses of the pathology of undulant fever mention pulmonary localizations as a complication of the disease. Hardy, Jordan, Borts and Hardy (case 40) describe a pulmoniny abscess in a patient who was infected with both suis and boris varieties, but they were unable to cletermine whether it was caused by one or both of the primary infectious agents or to some secondary invasion. In all probability, the same difficulties would have arisen had the patient, D.S., survived for a slightly longer period of time. The presence of clusters of a great variety of bacteria within many of the air sacs filled with an inflammatory exudate amply attest to such a possibility.

The extensive icterus, the increased weight, and the mottled appearance of the liver suggested extensive lesions in form of widespread necroses, which were readily recognized both in the periphery of the lobule and occasionally in the center of the columns of the hepatic cells. Necrobiotic processes around the central vein, as clescribed by Lillie (see Hardy and associates, ${ }^{6}$ fatal case ${ }_{1} \mathrm{D}$ and $\left.2 \mathrm{D}, \mathrm{P} .7_{7}-79\right)$, Wohlwill, and others were relatively rare. Focalized necroses or typical "granulomas," as observed by a number of pathologists (for detailed refercnces see Rabson ${ }^{5}$ ) in livers derived from human or guinca pig Brucella infections, were strikingly absent. To be sure, the extent of the liver damage hardly accounts for the icterus. This complication seems to be rare. The analysis of 125 cases (1929) and subsequently 300 cases by Hardy and his associates, ${ }^{6,8}$ also Hardy's summary in Huddleson, ${ }^{\circ}$ and the review by Sharp ${ }^{3}$ make no mention of jaundice as a symptom of abortus-undulant fever. It is stated that a subicteric tinge is common and that in all severe cases there is urobilinogenuria. Ebskov and Harpoth ${ }^{10}$ in describing a case of febris undulans with jaundice interpreted the complication as a hemolytic icterus induced by the infection. Schittenheln ${ }^{11}$ observed icterus in one case of a series of sixty. Urobilinogen is present in the urine of one-lialf of the cases observed; but, since localized pain in the regiom of the gall bladder arouses 
the suspicion of cholecystitis, it infrequently remains undecided as to whether the icterus is caused by increased bilirubin formation or insufficiency of the liver cclls. Schlierbach and $W^{\top}$ urm $^{12}$ mention a Bang infection which appeared with the symptoms of a "catarrhal jaundice."

Both the direct and indirect van den Bergh reactions were positive in the blood plasma of D.S. An excess of urobilinogen in the urine would suggest that the jaundice resulted from overproduction of bile pigment. As essential factors, one night suspect the fever associated with anoxemia which depresses the function of the hepatic cells. On the other hand, the direct-reacting plasinabilirubin was demonstrable in the blood. Thus the widespread necrosis of liver cells was followed by leakage of bilirubin from the canaliculi into the blood. Overproduction led to retention and later to hepatic damage with subsequent regurgitation.

In the future the faintly marked jaundice-which may be observed in the course of a Brucella infection-should be carefully analyzed in order that the etiology and pathogenesis may be clarified. It is becoming increasingly evident that the term "catarrhal jaundice" has been applied to a mixture of different etiologies. From the facts thus far available, it is clear that a moderate retention jaundice due to overproduction of bilirubin is a common symptom of brucellosis.

The bile contained in the gall bladder at autopsy yielded $3^{0,00 o}$ Brucella organisms per cubic centimeter. It is not unlikely that, just as may be the case in typhoid fever, this viscus becomes the seat of prolonged harborage and proliferation of the Brucella organisms (Kennedy, ${ }^{13}$ Eyre, ${ }^{14}$ and others). In fact, in quite a few instances it has bcome necessary to remove the gall bladder to relieve the patient and to accelerate recovery (Bull and Gram; ${ }^{15}$ Simpson; ${ }^{16}$ Hardy and associates; ${ }^{6}$ Leavell and Amoss; $;^{17}$ Amoss; $;^{18}$ Mettier and Kerr; $;^{19}$ Menefee and Poston $;^{20}$ and others). Unpublished experiments on rabbits and on guinea pigs indicate that intravenously inoculated Brucella organisms promptly appear in the bile. The larger the inoculum the greater the shedding of bacteria in the bile of the common duct or the accumulations in the cystic bile. Thus the hemato-hepatic route is the usual one in the animal and in all probability also in man. From what is known concerning the pathogenesis of cholecystitis, it would indeed have been a miracle if this organ had escaped invasion in the presence of a blood-stream infection of over 1,70o organisms per cubic centimeter. A careful search for embolic-metastatic foci throughout the mucosa of the gall bladder was entirely negative. However, it should be remembered that with the progress of the inflammatory reactions in the liver, the biliary appendices may become involved. The persistence of the Brucella bile-carrier state in all probability depends on the degree of the inflammation of the gallbladder wall.

It was noted that the portal lymph nodes were definitely enlarged and hyperemic. Significant lesions in the form of a desquamative process in the cortical sinuses and the early aggregations of mononuclear cells and a few 
polyblasts in the medullary sinuses appear to be attributable to the action of the Brucella organism. Through culture and through bacterioscopic examination the heavy invasion of the nodes was definitely proved. Just as in typhoid fever, so in brucellosis a definite relationship exists between these cellular elements and the bacteria. Perhaps the phagocytic activity of these cells is important in the immunity mechanisms. Von Alberini and Licberherr ${ }^{4}$ have noted the frequent involvement of the portal and retroperitoneal lymph nodes in Bang's disease, and although the furation of the disease was approximately five months in one of their cases the lesions were clute similas to those seen in the organs of D.S. Definite epithelioid nodules, which replace the lymphoid structures, are missing, but the aggregates of monocytes interspersed by lymphocytes and a few polyblasts are unquestionably precursors of the focal or diffuse structures found in the lymph nodes, liver, spleen, bonc marrow, etc., of human brucellosis. These nodular reactions, with which erery pathologist is familiar, since they were described by Smith and Fabyan, ${ }^{21}$ by Fabyan, ${ }^{22}$ and by $\operatorname{Smith}^{23}$ were first recorded by Löfler and v. Albertini ${ }^{24}$ and shortly thereafter by Wohlwill in a human autopsy specimen from proved Bang infections. Subsequently, their presence has been amply confurmed by many investigators (see Rabson ${ }^{5}$ ). However, not every fatal Bang infection exhibits this nodular reaction. In fact, as autopsy reports and microscopic tissue examinations accumulate, it becomes apparent that these focal inflammatory or proliferative processes, although characteristic, and in their later stages diagnostically significant for Brucella infections, are the exception rather than the rule. That they are the resultants of reactions which take place in the reticulo-endothelial system in response to the phagocytosis of bacilli in the blood or lymph streams, there is little doubt, but the immunobiological factors responsible for their formation are entirely unknown. Rössle ${ }^{25,96}$ interprets these cellular aggregates as an expression of allergic reactions. Until the mechanism of the immunity in Brucella infection is really understood, it is advisable to abstain from premature attempts to explain these nodular lesions. While their genesis remains a fascinating study subject to experimental analysis, it is apparent that these structures contribute an important share to the well-known latency and chonicity of undulant ferer. In this connection. it should be recalled that dead brucellas or their protein may produce similar lesions in the sensitized hosts; consequently one may encounter nodules which are bacteriologically sterile.

It is reported with increasing frequency that the hepato-lienal syndrome governs a Bang infection. Aside from the pathology in the liver, the most obvious and general gross changes, particularly in cases of long standing, is the enlargement of the spleen. On account of the rapid course of the infection in the patient, D.S., the splenic organ showed merely the early stages of an inflammatory reaction, accompanied by hemorrhagic engorgenent which submerged the follicles. The diffuse reticulo-endothelial hyperplasia might possibly be interpreted as early stages ol the "uberculoid reaction" so frequently 
observed in the spleen in the latter stages of undulant fever. As a sequel of the inflammatory process, a Bantilike disease, accompanied by atrophic liver, cirrhosis with ascites, and sub-icterus, has been noted (Habs, ${ }^{27}$ Bürger, ${ }^{28,20}$ Löffler, ${ }^{30}$ Schottmüller $\left.{ }^{31}\right)$.

The gross lesions in the intestinal tube suggested, aside from the few extravasations in the villi, some involvement of the lymphatic apparatus. Despite the examination of many sections, definite hyperplasia of the reticuloendothelium of the follicles was not discorered. Just as in the spleen, the germinal centers were lacking.

Of all the changes, those noted in the kidneys are the most interesting. Localized infiltrations involving the interstitial tissue between the tubules have been described by v. Albertini and Lieberherr, ${ }^{4}$ Cortese, ${ }^{32}$ de Giorgi, ${ }^{33}$ and Gregersen and Lund..$^{34}$ Equally, necroses of the tubular epithelium Ieading to nephroses are on record (Bruce; $;^{35}$ De la Chapelle; ${ }^{36}$ Hardy and associates, ${ }^{6}$ case $\left.1 \mathrm{D}\right)$. Clinical data furthermore attest to the occasional involvement of the kidneys. Albuminuria with hyaline and occasionally granular casts, even leucocytes and red blood cells, indicate either toxic effects or localization of the specific infection in the urinary tract. The Brucella organism may be isolated from the urine up to 12 months after the onset of a melitensis infection, or the continuous discharge of $\mathrm{Br}$. suis in the bladder of a specifically allergic individual may give rise to a hemorrhagic cystitis without significant cystoscopic and pyelographic findings (personal observations). As a whole, the participation of the kidneys in the course of melitensis undulant fever infection may involve at least 10 per cent of the patients (Duncan and Whitby $\left.{ }^{3 \pi}\right)$; on the other hand, a mere dozen of a series of 200 patients with melitensis brucellosis seen by Cantaloube ${ }^{35}$ yielded albumin in any significant amounts, while Simpson ${ }^{16}$ states that only traces of albumin are found in abortus infections. It will be shown below that the absence of chemical or physical damage does not preclude a bacilluria.

The students of the experimental disease in guinea pigs frequently found the kidneys of the animals injected with $\mathrm{Br}$. bovis diseased. According to Fabyan, ${ }^{1} 29$ per cent of these animals showed whitish to gray nodules in the cortex. Radiation toward the medulla was not observed, although the colorless appearance of the renal structures indicated a diffuse process. Microscopically, the focal areas were composed of epithelioid and lymploid elements, compressing and destroying the convoluted tubules near the glomeruli. In other instances, these "granulomas" were in the vicinity of blood vessels. As far as published records indicate, no attempt has been made to explain the genesis of these lesions, although the examinations of chick embryos infected with $\mathrm{Br}$. suis reveals granulomatous foci consisting of proliferations of endothelial cells remarkably similar to those noted in human kidneys. The findings made on the sections of the kidneys removed at autopsy from the body of D.S. may shed some light on the evolution of the renal pathology in brucellosis. 
First and foremost is the intracytoplasmic multiplication of the bacteria in the epithelium of Bowman's capsule and the convoluted tubules. It was thought that the propagation took place in necrotic cells, but, on closer scrutiny of many sections, invasions and viability were equally present in cells with intact vesicular or dense nuclei. In fact, the peculiar intracellular growth differs in no way from that first described by Theobald Smith in the chorionic epithelium of the calf. or of the goat $\left(\right.$ Meyer $\left.^{40}\right)$, and more recently by Goodpasture and Anderson ${ }^{41}$ and by Buddingh and Wromack ${ }^{42}$ in the vascular endothelium and cells of mesodermal origin of the growing chick. These authors justly concluded that the ectodermal epithelium and mesodermal cells serve as suitable host cells and media for invasion and propagation for Br. abortus and Br. suis. Experiments of a similar nature conducted with the $B r$ suis strain isolated from D.S., and two years before the paper of Buddingh and Wronack had appeared, amply confirmed the observations of Goodpasture and Anderson, but revealed the important fact that the endothelial cells lining the columns of hepatic cells and the glomeruli of the nephros in the embryos sacrificed on the fourth day were frequently crowded with specific bacteria as intracytoplasmic inclusions. The microscopic pictures were indistinguishable from those seen in the human renal cells. This selective intracellular parasitism in mesenchime cells of various organs is doubtless of greatest significance in the pathogenesis of Brucella infections.

Up to the present time, the available observations on undulant fever have indicated neither the portal of entry of the Brucella organisms into the tissues of the animal or human host, nor the sites of multiplication of these organisnus after invasion has taken place. There is no proof that brucellas multiply in the blood stream, although they will grow freely in necrotic tissue (chickchorion allantoic nembrane; abscesses in lymph nodes and epididymis of guinea pigs). Their presence in macrophages and polymorphonuclear lencocrtes is justly attributed to phagocytosis, there being some indications that under certain conditions even the cytoplasms of these cells may serve as a medium for propagation. Little attention has been paid to the possibility that the epithelial cells of the proximal convoluted tubules of Bowman's capsule, and of the chorionic epithelium may possess phagocytic power. For the localization in the latter, Theobald Smith believes that the bacilli pass from the blood ressels into the uterine carity where they are rubbed into the substance of the cell by pressure. Once in the cytoplasma, they find conditions farorable for multiplication and protection against plagocytosis. As far as the renal localization is concerned, two possibilities may be envisioned: (a) the bacilli, which pass the glomerulus without causing visible damage, naly be pressed by the urinary filtrate into the epithelial cells, or $(b)$ since a peculiar group of renal cells-the lining of Bowman's capsule and the proxinnal end of the convoluted tubes-are involved, the possibility of an end result of an excretory function should not be overlooked. The visible phenomenon of intracytoplasmic parasitism in the epithelium may be the result of "resorption" or 
"secretion." Knowledge concerning the physiology of these groups of cells is largely speculative. The localization, however, is probably not a mere coincidence, since it is well-known that Sporozoa of the character of coccidia not infrequently are present in the same cellular elements as the Brucella organism. Apparently, the nutritional conditions in the epithelia are suitable for a diversity of parasites, which somehow enter the cytoplasm through motility of their own or through other physical forces as yet poorly understood. As a sequel to intracytoplasmic proliferation, the majority of epithelial cells undergo necrosis. The bacterial masses are discharged into the collective tubules where they form casts, and in turn cause death of the tubular lining. A reactive inflammation extends along the uriniferous tubules deep into the medulla and even into the calyces. The cells forming the infiltrative reaction are mostly mononuclear histiocytes and lymphocytes; some with broad cytoplasmic margins have ingested nuclear detritus and some bacilli. This type of medullary localization is merely a part of the metastic elimination nephritis.

The possibility exists that renal abscesses or inflammatory infiltrations may be the sequel of hematogenic embolic processes, which are so commonly seen in coccic infections, and described for lesions observed in guinea pigs infected with $\mathrm{Br}$. abortus or Br. suis. A careful scrutiny of many sections from ten separate portions of the kidneys of D.S. failed to demonstrate connections with emboli. The entire process is confined to the uriniferous tubules, and ultimately to the intracytoplasmic growth and necrosis of the epithelial cells. What the outcome of these lesions may be is well illustrated by v. Albertini and Lieberherr, ${ }^{4}$ who found in the fifth month of a Bang's infection massive interstitial granulation tissue composed of large phagocytic granuloma cells. Unfortunately, no information relative to the bacteriology of the urine of this particular case has been published; it is noted that the diazo reaction was strongly positive. It would have been of interest to know whether the focal lesions in the kidneys were closed or whether they discharged Brucella occasionally or intermittently. According to Huddleson, Brucella abortus has been cultured very few times from the urine of infected human beings. On the other hand, Horrocks ${ }^{43}$ succeeded in culturing Br. melitensis 39 times from the urine of 13 different patients. He reports that the organism has not been isolated from the urine earlier than the fifteenth day or later than the eighty-second day of disease. The actual number passed varied between 4 to $59^{6}$ organisms per cubic centimeter. Occasionally, a trace of albumin was noticed, but no physical or chemical changes common to all the urines and indicative of the passage of $\mathrm{Br}$. melitensis has been observed. As a rule, the discharge of the bacilli was intermittent and occasional, while in very few cases it was contimuous over a period of two weeks. The observations were made on cases of the undulant, intermittent, and irregular types of melitensis fever. Renewed interest in the bacteriological examination of the urine in brucellosis infections due to $\mathrm{Br}$. abortus and $\mathrm{Br}$. suis might indicate that the discharge of the specific bacteria is not so rare as published statements would imply. 
Fortuitous circumstances permitted an cxhaustive bacteriological examination of the organs of D.S. at the time of autopsy. The quantitative estimations reveal more definitely than any other evidence the septicemic-metastatic character of the infection. Every organ, in fact every tissue fragment, yielded Br. suis, sometimes in such numbers that accurate counting was impossible. The absence of Brucella in the heart blood must be ascribed to the orergrowth by the pneumococcus in the rich culture afforded by the clot in the right ventricle. Attention must be directed to the estimation of 3,600 organisms per gram of spleen or approximately 1,512,ooo bacteria for the entire organ which, in all probability, is due to the presence here of the main reticuloendothelial system and its "filteration" of the Brucella from the blood stream. Such a limited storehouse of bacteria could not have served as the seedbed for the blood stream. In all probability the distributions of the organisms is uneven and the number of bacteria calculated for the entire organ is probably too low. However, it should be remembered that in typhoid ferer the contimuous bacteremia is, as a rule, maintained by the focal lesions in the bone marrow. The same is suspected for a Brucella infection. Unfortunately, the possibility had not been considered and therefore no cultures were prepared from the marrow of D.S. It certainly should not be missed in future autopsies.

The literature on undulant fever due to Brabortus or suis contain 4.1 reports on supposedly fatal infections attributable to the specific organisms. In $1 f$ of the reports no microscopic-anatomical data are presented. The histories of 15 cases together with 8 observations of their own have been analyzed by v. Albertini and Lieberherr. ${ }^{4}$ In addition, data on 7 cases of Bang's infection (one by De la Chapelle ${ }^{36}$ was caused by Br. melitensis) are detailed in the American literature $\left(\right.$ Rabson $\left.^{5}\right)$. A condensed analysis definitely indicates that Brucella infections due to the boris or suis types are very rarely fatal. Of the total number of 44 only 7 were uncomplicated deaths directly attributable to the specific organisms. In the remaining 37 , death was due to some complication such as embolism, uremia, tuberculosis, hemorrhages, rupture of the spleen, hepatic cirrhosis, pneumonia, recurent endocarditis, etc. Invariably in typical Brucella suis or abortus deaths, a definite sepsis was demonstrable. To attribute i death to a Brucella infection because the patient's serum gave immunological reactions suggestive of undulant fever, without an autopsy lollowed by nicroscopic study of the tissues and detailed bacteriological cxamination of the organs, is not justifiable in the light of available experience. No effort should be spared to secure autopsies on supposedly fatal cases of buncellonis.

Knowledge relative to the pathogenesis of the Brucella infections in the aberrant host-man-is entircly inadequate. The pathways of infection are supposedly proved. One suspects the intestinal and the percutaneous routes. The clinical course manifests itself in the form of an intermittent or undulant fever. By analogy with malaria, spirochetosis, and cndocarditis, the bouts of fever presuppose repeated invasions of the bacteria into the blood stream. These seedings come, according to Wholwill, from an! one of the reticulo- 
endothelial beds in the organs. Löffler and v. Albertini ${ }^{24}$ specifically place the focal processes in the spleen and liver. This interpretation of the pathogenesis is largely based on the fact that the characteristic "tuberculoid, nodular" lesions or "granulomas" are principally noted in these organs and the cultivation of the organism from these tissues is frequently successful. Their presence in the lymph nodes is believed to be sccondary and not the resultant of hematogenic invasion. The explanation by Löfler ${ }^{24}$ has a great deal of plausibility. In uncomplicated Brucella deaths the spleen is regularly enlarged; furtlermore, the majority of clinicians have found the spleen palpable in varying degrees. The German data mention this sign in 80 per cent of the cases; on the other hand, Simpson, ${ }^{18}$ and Hardy and associates ${ }^{6}$ found a splenic tumor in only 30 per cent of their observations. Thus, there is no justification for considering the splenic tumor as an obligatory sign of brucellosis. The liver is enlarged even less frequently (German data 20 per cent; 4 per cent in Simpson's cases). No correlations between the enlargement of these organs and the blood-culture findings are available.

Nothing is known concerning focal seedbeds in the bone marrow; both Wohlwill ${ }^{7}$ and Wegener $^{44}$ have found epithelioid nodules and even necroses. Even the best culture methods used repeatedly and by experienced workers have yielded negative blood cultures. It is, therefore, not unlikely that other factors than the bacteremia are responsible for the febrile reactions. Since true toxins of the Brucella organism have not as yet been demonstrated, one has to think of the proteolytic degradation of the harmless albuminoid body substances to poisons or the formation of febrigenic substances to poisons from the tissues of the infected host through autolysis. These poisons in turn generate new foci of inflammation, and thus fever-inducing factors are created without the actual proliferation and dissemination of the specific bacteria which initiated the disease. A series of febrile elevations of the body temperature may not be accompanied by or induced by a bacteremia.

Finally, there is the possibility that the symptoms are manifestations of the allergic state which always develops in the course of a brucellosis. The parenteral presence of the bacterial elements as antigens stimulates the production of antibodies in the tissues, and these in turn come in contact with the bacterial protein which is liberated during the disintegration of the bacteria in the various pliagocytes. Through interaction of these two components a diseaseproducing agent may be formed. Obviously, it is subject to discussion as to how these substances are formed: the combination may produce the poison, the disintegration of the bacterial protein may liberate an injurious substance, or the evolution of the antibody per se may represent the noxis. In Brucella infection, just as in tuberculosis or in fungus disease, the allergy factor plays an important role in the mechanism of immunity, and a fair portion of the symptomatology may be conditioned by this altered state of reactivity.

All these attempts to explain the pathogenesis of a Brucella infection leave out of consideration the primary question: Does the organism lead an intra- 
cytoplasmic existence during its parasitism and, if so, in what cells? Comparative studies of infection of the goat udder, the chick embryo, and now of the tissues of man strongly suggest that the mesenchymal and possibly the ectodermal layers are host cells for the brucellas. Very acute infections lend them. selves to a demonstration of this stage of the parasitism. With the progress of the disease, the phagocytic activities in the reticulo-endothclial beds, the inflammatory reaction to the necroses in the organs damaged by the bacteria, or the split products of the allergic inflammation create microscopic pictures in which the early phases are either not discernible or so widely scattered that it is impossible to find them without examining serial sections.

In the interest of a clearer understanding of the pathogenesis, it is obviously desirable to study acute Brucella infections exhaustively. In the subacute or protracted disease stages one finds either no lesions (ccrtain questionable autopsy reports indicate absence of organ changes while a few show specific evidence of invasion) or the "tuberculoid nodules" or "granulomas," which may be interpreted as characteristic. The factors which guide the formation of these lesions are unknown. They have all the markings of a defensive cellular mechanism and raise the following questions: Is it possible that the polymorphonuclear leucocytes ingest the free bacteria under the influence of the opsonins and then become impotent, their place being taken by the monocytes, which rapidly arrange themselves into nodules in order to destroy the bacteria? Do the brucellas, in part changed by the antibodies, lose their invasiveness and merely act to incite specific gramulomas as a foreign-body reaction? Are these structures in some way connected with allergy? And finally in what manner are the capsules of the brucellas related to these processes? (See Mickle. ${ }^{45}$ )

The microscopic findings in the kidneys and the lymph nodes of D.S. have shown that in the vicinity of the bacterial proliferation, either in the living tubular epithelium or the necrotic cellular detritus, an intense proliferation of the reticulo-endothelial cells took place. In the kiclney this has occurred in the intertubular connective tissue. The cellular types, which possess all the properties of phagocytes, resembled the elements one finds in typhomas; they are monoblasts-mono- or histiocytes-intermingled with lymphocytes. The reasonableness is great that these lesions represent the early stages of the granulomas, which through necrobiotic processes finally reach the structural appearance seen and clescribed in the majority of fatal Bang infections subjected to autopsy within the first to the sixth month. When the infiluation is very large and the necrobiotic colliquation is extensive, typical purulent metastases in a diversity of organs may be encountered.

Indulant fever due to $B$ r. abortus or suis is, in the majority of inutances. a relapsing bacteremia which may be interworen with allergic manifestations. Although the principal place of proliferation nay be the splecn, it is apparent that the bone marrow deserves consideration. In a small percentage of infections, metastatic foci are formed in the spleen, liver, the lymph nodes, kidneys, sex organs, bones, and central nervous system. Necrobionic processes in these 
metastases may lead to suppurative processes. Fatal septicemic infections are exceptionally rare.

Finally, it is not out of place to reflect briefly on the significance of the intracytoplasmic parasitism of Brucella. If this phenomenon can be proved to be as common as is indicated in the growing chick and in the few observations here recorded, the concepts of the immunity mechanism, which places the entire weight on the antibodies, may require a fundamental revision. In fact, the well-known realization that it is impossible to create any noteworthy degree of acquired resistance with killed vaccines might possibly receive proper explanation. Just as in tuberculosis, the degree of protection afforded is proportional to the extent of the primary lesion or lesions. Only a true infection can produce extensive lesions in which a great many cells of the reticuloendothelial system participate. Furthermore, these cellular elements may have had intimate contact with the Brucella organism. But what is more important is the antigenic structure. There is every reason to suspect that the antigens, which develop as a result of the intracellular parasitism, may in some respect be different from those generated in artificial media. A true infection will, in contrast with the injection of culture antigen, produce immunity. Moreover, it is equally probable that the susceptible mesenchyme cells and their descendants may be rendered immune only through infection or temporary intracytoplasmic parasitism and not through mere exposure to soluble antigens. There is no doubt that the viability and in particular the latency-one of the most important manifestations of a Brucella infection in cattle, goats, and hogs-is intimately connected with the intracellular development cycles. Viewed from these angles the Brucella problem, so hopelessly bewildering, deserves renewed critical inquiries and experiments.

\section{SUMMARY}

(i) The pathological and bacteriological findings made on an acute malignant infection due to $\mathrm{Br}$. suis No. 80 in a laboratory-animal caretaker is reported. The circumstances surrounding the infection strongly indicate the ingestion of a very heavy suspension of the specific bacteria. According to the positive allergic skin reaction and the strong opsono-cytophagic response (index 6:88) the patient had been considered immune to brucellosis.

(2) The metastatic lesions in the kidneys were not embolic but due to the elimination of brucellas through the glomerulus. The bacteria developed in the epithelium of Bowman's capsule and the proximal end of the convoluted tubules. The significance of the intracytoplasmic parasitism is discussed.

(3) The genesis of Brucella infections is critically analyzed and suggestions for further studies are presented.

\section{REFERENCES}

1. Fabyan, M.: J1. Med. Resrch. 28:81, 1913.

2. Meyer, K. F., and Zobell, C. E.: Jl. Infect. Diseases $5^{1: 72,1932 .}$

3. Sharp, W. B.: Archs. Pathol. 18:72, 1934. 
4. I. Albertini, A., and Lieberherr, W.: liankfurt. Ztschr. f. Pathol. 51:69, 1937.

5. Rabson, S. M.: Amer. J1. Clin. Pathol. 9:601. 1939.

6. Hardy, A. B.; Jordan, C. F.; Borts, I. H., and Hardy, G. C.: Natn. Inste. Hith. Bu11. 110. 158, 1930.

7. Wohlwill, F.: Virchows Arch. f. pathol. Anat. u. Physiol, 286:141, 1932.

8. Hardy, A. V.: J1. Amer. Med. Assn. 92:853, 1929.

9. Huddleson, I. F.: Brucellosis in Man and Animals (New York: 1939).

10. Ebskov, C., and Harpoth, H.: Ugeskr. f. Laeg. 37:8 $, 2,1930$.

11. Schittenhelm, A.: in Handbuch der Inneren Medizin, ed, by L. Moln and R. Staehelin, I (3d ed.; Berlin: 1934), 985 .

12. Schlierbach, P., and Wurm, K.: Deutsch. med. Wchnschr. 62:888, 1936.

13. Kennedy, J. C.: J1. Roy. Army Corps 6:623, 1906.

14. Eyre, J. W. H.: in Handbuch der Pathogenen Microorganismen, al. by W. Kolle and . von Wassermann, IV (2d ed.; Jena: 1912), 421.

15. Bull, P., and Gram, H. M.: Norsk mag. [. laegridnskpn. 9:1026, 19ı.

16. Simpson, W. M.: Amer. Jl. Surg. 7:597, 1929.

17. Leavel1, H. R., and Amoss, H. L.: Amer. J1. Med. Scis. 181:96, 1931.

18. Amoss, H. L.: Internatn. Chins. 4:93, 1931.

19. Mettier, S. R., and Kerr, W. J.: Archs. Internal Med. 5 f: 702, 193 .

20. Menefee, E. E., and Poston, M. A.: South. Med. J1. 31:1061, $193^{8}$.

2ı. Smith, T. and Fabyan, M.: Cntrlblt. f. Bakteriol., Parasitnk. u. Infektnskrankhn., I. Abtl. $61: 5+9,1912$.

22. Fabyan, M.: J1. Med. Resrch. 26:141, 1912.

23. Smith, T.: Jl. Exper. Med. 49:671, 1929.

21. Löfles, W., and v. Albertini, A.: Krankheitsforschung 8:1, 1930.

25. Rössle, R.: München. med. Wchnschr. 80:5, 1939.

26. Rössle, R.: Wien. klin. Wchnschr. 45:609, 648, 1932.

27. Habs, H.: Klin. Wchnschr. $7: 153,1928$.

28. Bürger, M.: München. med. Wchmschr. $75: 754,1928$.

29. Bürger, M.: Zntrlblt. f. inner. Med. $49:-8,1928$.

3o. Löffler, W.: Würzburg. Abhdln. a. d. Cismtgbt. d. Med. no. 11, 1930.

31. Schottmïller, H.: Klin. Wchuschr. 11:905, 1932.

32. Cortese, F.: Clin. med. ital. 66:77.1, 1935.

33. de Giorgi, L.: Gior. di clin. med. 18:565, 1937.

31. Gregersen, F., and Lund, T. M.: Hospitalstidende 74:349, 1931.

35. Bruce, D.: Ann. Inst. Pasteu (Paris) 7:289, 1893 .

36. De la Chapelle, C. E.: Amer. Heart J1. 4:732, 1929.

37. Duncan, J. T., and Whitby, L. E. H.: in A System of Bacteriology in Relation to Medicine, issued by the Medical Research Council [of Great Britain], V (London: 1930; 388-426), 39 S.

38. Cantaloube, P.: La Fiève de Malte en France (Paris: 1911).

39. Smith, T.: Jl. Exper. Med. 29:451, 1919.

fo. Meyer, K. F.: Jl. Amer. Veterin. Med. Assn. 39:286, 1995; and supplementary unpublished observations.

41. Goodpasture, E. W'. and Anderson, K.: Amer. J1. Pathol. 13:16.4, 1937.

12. Buddingh, G. J., and Womack, F. C.: Jl. Exper. Med. 71:213,1941.

43. Horrocks, W. H.: in Reports of the Commission appointed by the Admiralty, the If ar Office and the Civil Government of Malta for the Investigation of Mediterranean Feter, I (London: 1905), 21.

41. Wegener, T.: Cntrlblt, f. allgm. Pathol. u. pathol. Anat. 64:33, 1935-36.

f.) Mickle, W. A.: Jl. Infect. Diseases 66:271, $194^{\circ}$ 


\section{EXILANATION OF PLATES}

\section{PLATE}

l'hotographic records of blood plates seeded with (fig. 1) $0.01 \mathrm{cc}$. of bile and (fig. 2) $0.01 \mathrm{cc}$. of $1 \mathrm{gm}$. of triturated right kidney in $10 \mathrm{cc}$. of broth. Specimen obtained at autopsi of D.S. 


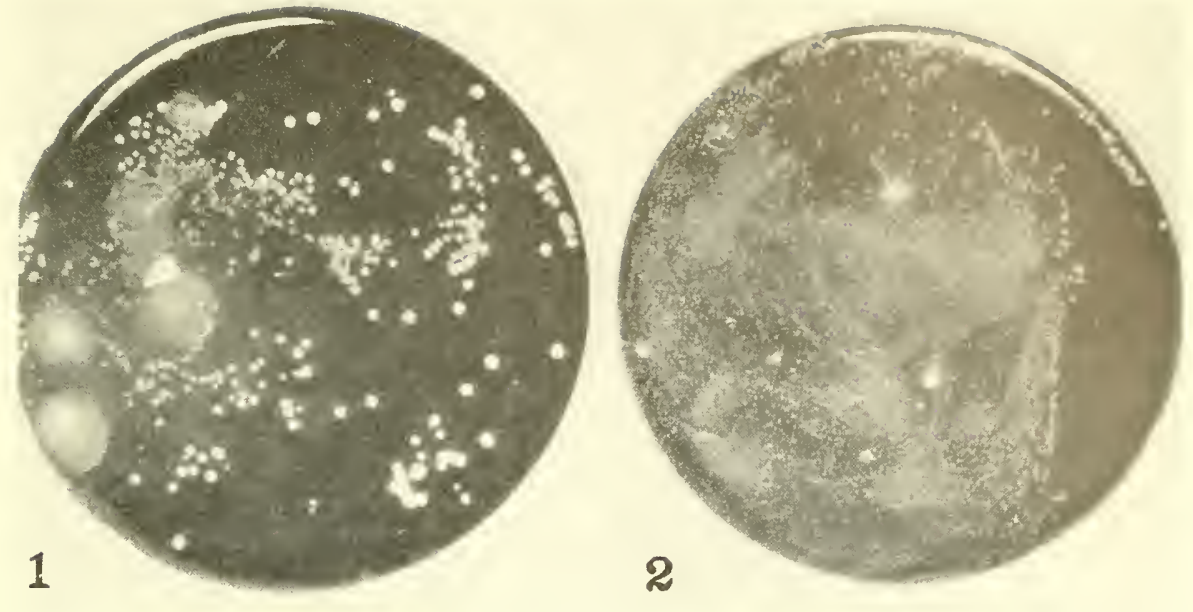

Plate I

[455] 


\section{PLATE 2}

Fig. 3. Section of right lung lobe. Small abscess due to Brucella surrounded by hemorrhagic pneumonic consolidation. Zenker fixation and Giemsa stain. $\times 74$.

Fig. 4. Section of liver with distended sinusoids filled with amorphous material and necrobiotic changes in the hepatic cells. Formalin fixation and hematoxylin-eosin stain. $\times 74$.

Fig. 5 . Section of portal lymph node with medullary sinus filled with monocytes. Zenker fixation and Giemsa stain. $\times 74$.

Fig. 6 . The same section; medullary sinus. $\times 388$.

Fig. 7. Section of right kidney. Glomerulus with deeply stained capsular epithelium protruding into the lumen of Bowman's capsule. Zenker fixation and Giemsa stain. $\times 98$.

Fig. 8. Section of the capsular epithelium; intracytoplasmic growth of brucellas. Zenker fixation and Giemsa stain. $\times 388$. 


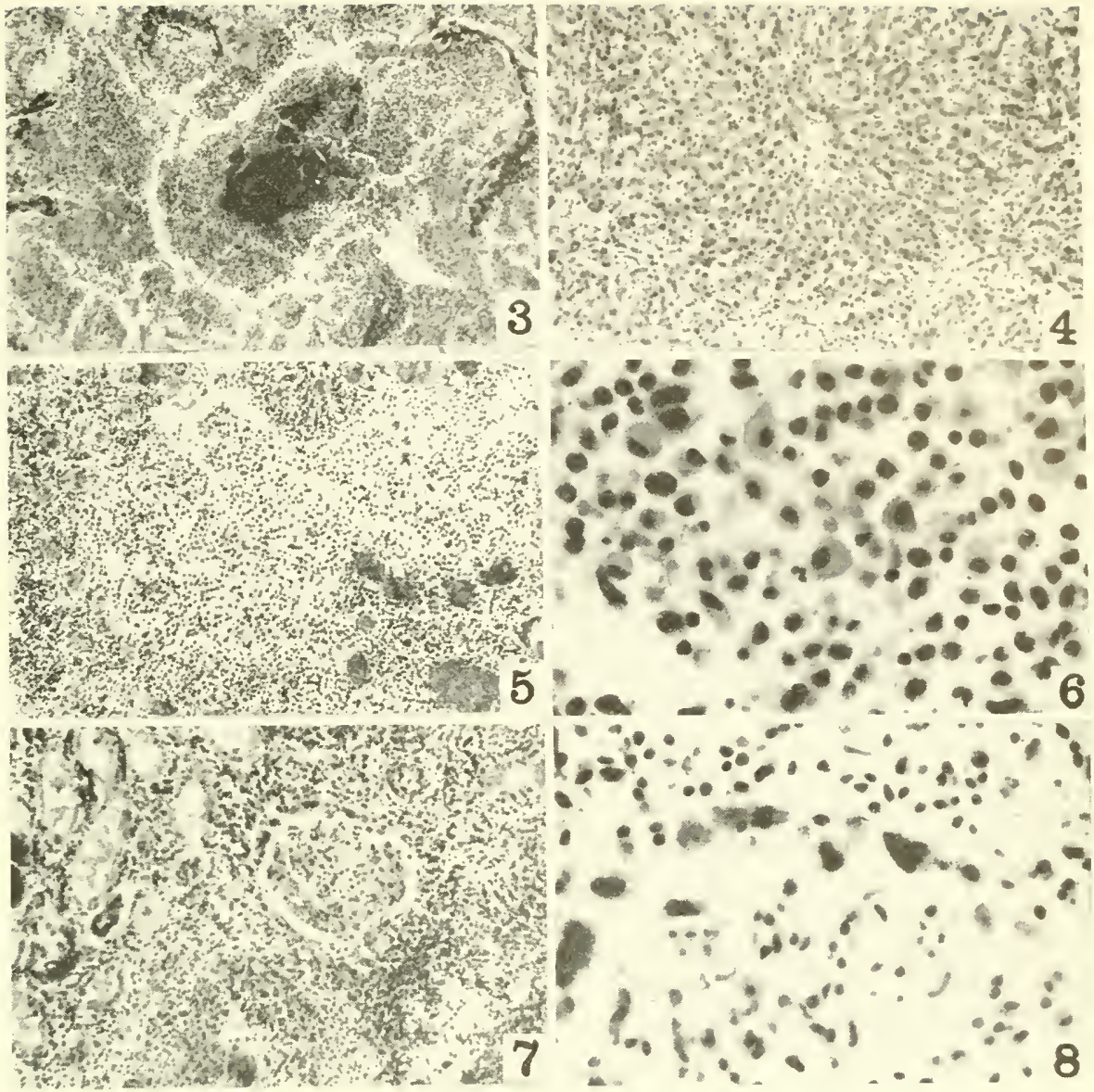

Plate 
PI.ATE 3

Fig. 9. Section of right kidney. Proximal convoluted tubnles with deeply stained cells; the abnormal tubules are surrounded by massive infiltration of stroma by monocytes, plasma cells, lymphocytes, and polyblasts. Zenker fixation and Giemsa stain. $\times 9^{8}$.

Figs. 10, 1.4. Epithelial cells of the tubules filled with intracytoplasmic colonies of brucellas. Some of the cells are still normal, others necrobiotic. $\times 777$.

Fig. 11. Section through renal tubule with epithelia serving as host cells for brucellas. $\times 388$.

Fig. 12. Necrotic collective tubule plugged with masses of Brucella. Zenker fixation-hematoxylin stain. $\times 388$.

Fig. 13. Focal arrangement of monocytes surrounding tubule with cells containing brucellas. Zenker fixation and Giemsa stain. $\times 510$. 


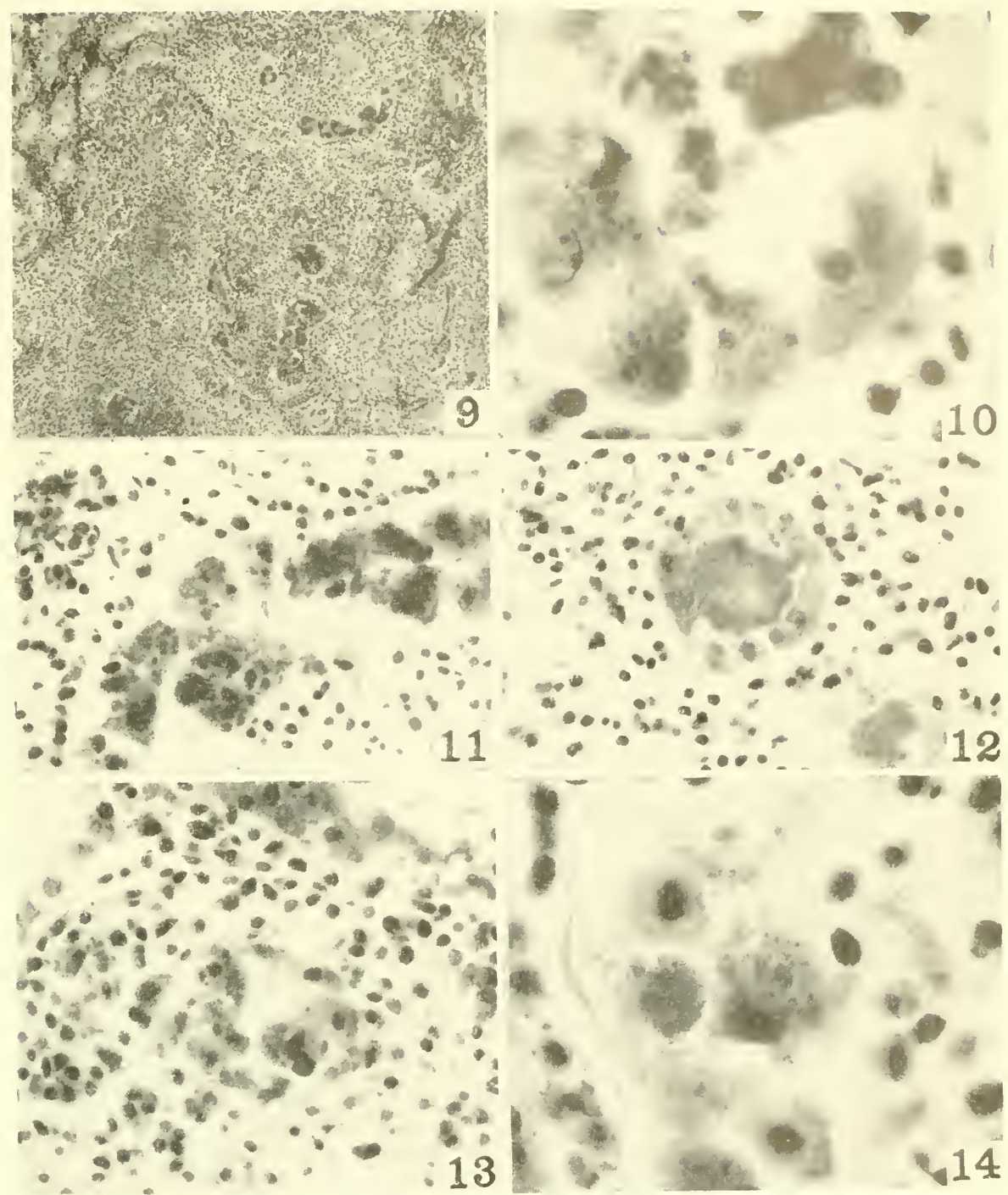

Plate 3 

FRENCH MEDICAL EDUCATION AS A LEGACY FROM THE REVOLUTION

$$
B !
$$

J. M. D. OLMSTED

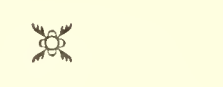

From the

DIVISION OF PHYSIOLOGY, UNIVERSITY OF CALIFORNIA BERKELEY, CALIFORNIA 


\section{PLAN GÉNÉRAL}

D E

\section{L'ENSEIGNEMENT \\ DANS L'ECOLE DE SANTE \\ D E P A R I S.}

Imprimé par ordre du Comité d'Instruction publique de la Convention Nationale.

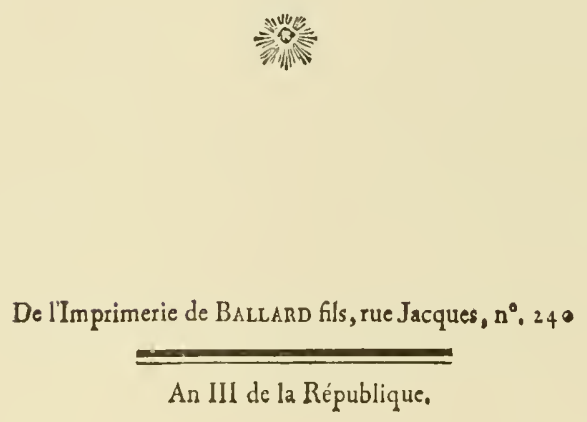

Photograph of the title page of the pamphlet of 1794 . 


\section{FRENCH MEDICAL EDUCATION AS A LEGACY FROM THE REVOLUTION}

$\mathrm{T}$

HE LEADERS of the French Revolution were nothing if not thorough in their attempts to root out all evidences of the ancien régime. Before the Revolution medical education in France had been in the hands of facultics and colleges of medicine in various cities throughout the country from Rennes in Brittany to Orange in Provence. The medical school having the best organization for teaching was not, as one might have imagined, located in the capital, but in Montpellier. Nevertheless, Paris was undoubtedly the great center for medical practice in France, and the provincial cities followed its lead. The Paris Faculty of Medicine included all the physicians of the city, and each year they elected certain of their number to give the public lectures. It was perhaps because the lecturer felt this to be only a temporary task, soon over, that official medical instruction had come to be perfunctory, often consisting in nothing more than a reading from out-of-date textbooks like that of Haller in physiology, of Boerhave in medicine or of Hévin in pathology. Students, therefore, generally preferred to attach themselves to some private teacher who could give a more interesting exposition of the subject, or to one who had made a name for himself in the practice of medicine. Surgery was an entirely separate profession from that of medicine, and in Paris was officially taught by the College of Surgery independently of the Faculty of Medicine. In spite of the fact that the courses in anatomy, physiology, therapeutics, and even operative procedure might last a scant three months for students of surgery, it is claimed that these students were better taught from the point of view of practical instruction than students attending the more protracted series of lectures on the same subjects at the Faculty of Medicine. In both cases official instruction in the art of healing still proceeded along the lines laid down in the sixtcenth century and had become lax and ineffective. The lawmakers of the Revolution changed all this with a stroke of the pen.

The Convention, in decrees of March 8 and September 15, 1793, abolished all schools, colleges, and universities, ordered all their possessions sold and their endowments confiscated. This drastic purge included the Faculties of Medicine and Colleges of Surgery, and seals were put on the closed cloors of the buildings formerly occupied by them. The idea was to make education free. This was in itself a laudable enough intent, but the means adopted to bring about the desired result led merely to license and confusion. The historian Guizot, commenting some twenty years later on the effects of these measures, said, "Ignorance and disorder gained the upper hand." Of the whole French system of education the primary school alone survived, and this in spite of Jean Jacques Rousseau's advice to give a child no instruction whatsoever until he reached the age of twelve years, when the clean, unsullied page of the young

$$
\left[4^{6} 3\right]
$$


mind would all the more readily take the imprint of directions for conduct worthy of republican citizenship.

It was the needs of the army which first brought home the necessity for systematic instruction beyond the primary-school age, and the first institutions of higher learning to be thought of by the Revolutionaries were schools for training engineers and officers. The Central School for Public Works was decreed March 11 and the School of Mars on June 6, 1794. Teachers were also needed, and on October 30 came a decree establishing a Normal School, a center for instruction "in the art of teaching morals and forming the minds of young republicans in the practice of public and private virtues." Finally, on December 4 ( 14 frimaire an 3 . according to the Revolutionary calendar) the Convention made provision for three Schools of Health, one in Paris, one in Montpellier, and one in Strasbourg. The School of Mars and the Normal School were very short-lived, their existence being only a matter of a few months, but the School of Public Works became the well-known Paris École Polytechnique, and the three Schools of Health became the leading medical schools in France, although one of them has been forced to change its nationality three times.

To Antoine François Fourcroy belongs the honor of setting in motion the legislation which gave rise to present-day French medical education. He himself had obtained his medical degree in 1780 with great difficulty because of poverty. The 6,ooo livres necessary for the diploma had been contributed by friends of the celebrated anatomist, Vicq d'Azyr, who boarded with young Fourcroy's family. Fourcroy had welcomed the Revolutionary movement and the reforms it promised, but he was averse to entering the wild arena of practical politics and at first refused to accept any office. In spite of his protests he was elected a member of the Convention-one of the few physicians in this body-and here he devoted himself almost entirely to questions concerning education. Convinced of the necessity of a supply of physicians, chiefly for the army, he consulted Prieur, the member of the Committee on Public Safety in charge of the teaching of sciences and arts, asking him to recommend someone capable of collaborating in mapping out a scheme of organization for medical education. The name of François Chaussier was suggested.

Chaussier was not a Parisian, but had been prominent in medical circles in the provincial city of Dijon, holding appointments there not only as Surgeon of the Prisons and Physician of the Hospitals but also as Professor of Chemistry, and giving courses in anatomy and legal medicine. Because he sympathized with the idea of the Jacobins regarding the centralization of all power in Paris he proposed the establishment in that city of a single Central School of Health. Jacobin principles, however, had just passed into disfavor, and members of the Convention agreed that similar schools should be established at Montpellier and Strasbourg. Fourcroy concurred and the decree was so worded. It is curious to note that when the government came to publish the text of the decree it prefaced it by a copy of Chaussier's report advocating a 
single Central School of Health in Paris. A few footnotes were added to the effect that the recommendations contained in the report were applicable to three schools as well as to a single one.

The telling argument in this report was, of course, the need for "health officers in military hospitals and camps," for it was stated that "six hundred such officers have perished in the last eighteen months. If it is a glory for them, since they died serving their country, it is a necessity for the republic to replace this loss." Chaussier went on to point out that opportunity was at the same time afforded to organize a complete system of the art of healing in a way never before attempted. To remedy one of the most glaring defects of preRevolutionary medical instruction, namely, the mere reading of obsolete texts, he proposed a startling innovation-lectures were to be supplemented by "exercises on the part of the students, chemical experiments, anatomical dissections, surgical operations, use of apparatus. Little to read, much to see, much to do, such shall be the basis of the new teaching ... Observation at the bedside of patients shall become one of the chief principles of this teaching." A second recommendation of equal importance for medical education was to be found in his suggestion that "medicine and surgery are two branches of the same science," and should therefore be taught together to all prospective health officers.*

The decree as passed by the Convention embodied Chaussier's recommendations, which had been transmitted through Fourcroy. Article 1 stated the purpose of the measure: "There shall be established a School of Health at Paris, at Montpellier, and at Strasbourg; these three schools shall be destined to produce officers of health for the service of the hospitals." Article 3 outlined the general subject matter to be taught, such as "the signs and symptoms of disease," etc., and Article 4 contained the important rider, "Besides this first part of the teaching, students shall practise anatomical, surgical, and chemical operations; they shall observe the nature of diseases at the bedside of patients, and shall follow their treatment in the hospitals near the schools." Article 5 provided eight professorships at Montpellier, six at Strasbourg, and twelve at Paris, together with an equal number of associates. Permanent professorships would ensure continuity in the mode of teaching, lack of which had been one of the wreaknesses of pre-Revolutionary days. Article 13 showed that Fourcroy

* The idea that surger should be coequal with medicine did not originate with Chausicr, but had gradually been taking shape for several years. In 1790 , that is, shortly after the down. fall of the monarchy and the establishment of the National Assembly, but before the dissolution of the Faculties of Medicine and Colleges of Surgery, all learned societies were required to make a report to the Assembly on changes in their constitutions necessitated by the new order of society. The Royal Society of Medicine was one of the group and in their report to the Assembly they devoted several pages to a plea that surgeons be required wo stan their profesional training with as good a preliminary education, and that their profenional studies be as extensive, as those demancled of physicians. Surgery mould thus be placed on a par with medicine. This point of view was clearly stated in the following sentence: "We bro thone who are still astonished at this conclusion to reflect that since the division of discase into internal and external is vicious, the separation of melicine and surgery, which depends on weh a dis sion, can no longer be maintianed." 
remembered his own difficulties in obtaining a medical education, for there was provided a yearly allowance of 1,200 livres to each of the three hundred chosen students for a period of three years, this being the length of time allotted for a complete course of instruction.

Two months later the Committee on Public Instruction, headed by Fourcroy, authorized the printing of a second small pamphlet entitled "General Plan of Teaching in the Paris School of Health." 'This pamphlet proved to be virtually an announcement of courses, with a schedule of class hours. It contains, however, a much fuller description of the contents of the courses and their aims than is usually to be found in the modern university catalogue.

Instruction was classified under two headings, "Permanent courses" and "Non-permanent courses or semesters." The former were to include the clinical instruction in the hospitals which each student must attend daily from the very beginning of his student days to their end; the latter were to include twelve courses in special subjects taught by the twelve newly appointed professors and their twelve associates. An academic year lasted a full calendar year. The students' hours were arranged as follows: up to 10 a.m. (hospital rounds began at 7 o'clock) and during his spare hours, he must spend his time in one or other of the hospitals the year round. Three hospitals had been selected for teaching, and students were to be assigned to each one for a period of four months, thus going the entire round in a year's time. In the winter semester, beginning September 24, first-year students at 1 o'clock daily, "except on the tenth day consecrated to rest," listened to lectures in anatomy-physiology. These two subjects were taught as one, and Chaussier very appropriately had been given this chair in the Paris School of Health. His associate was Antoine Dubois, who was destined later to become one of the great deans of the Paris medical faculty. At noon on alternate days came lectures on medical chemistry and pharmacy by Deyeux (who seems to have had no associate). The remainder of the afternoon was devoted to practical exercises in the laboratories. In the summer semester, beginning the last of March, at 10 a.m. on odd days, came lectures in materia medica and botany by Peyrilhe and Richard, and on even days, lectures in medical physics and hygiene by Hallé and Pinel; with no definite assignments in the afternoons.

Second-year students in the winter semester again listened to lectures and performed practical exercises in anatomy-physiology and medical chemistry and pharmacy, but at noon on alternate days there were in addition lectures in operative medicine by Sabatier and Boyer. In the summer semester the student again listened to lectures in materia medica and botany but added at noon daily lectures in pathology, external pathology on even days by Choppart and Percy, internal pathology on odd days by Doublet and Bourdier, the afternoons being devoted to a course in obstetrics by Alphonse Leroy and Baudeloque.

Third-year students in the winter semester again attended lectures in anatomy, pathology, chemistry, pharmacy, and operative medicine, but they might 
devote their afternoons either to practical exercises or to study; in the summes semester they listened again in the mornings to the professors of materia medica and of pathology; and in the aftemoons they followed the course in obstetrics on odd days only, and on even days at 4 p.m. attencied lectures on legal medicine and the history of medicine by Lassus and Mahon. From the wording of the text it would seem that there might be a great deal of duplication, since there is nothing to show, for example, that the lectures in anatomy-physiology occurring at the same hour for students in each of their three years were not the same in subject matter. If, however, the instructors rotated subjects so that they were different each year, it would seem that the instruction adapted for first-year students would not be suitable for thirdyears students, and vice versa. Perhaps duplication or even triplication was not considered undesirable. In any case, the inauguration of an official series of examinations, in which the various subjects were disposed of in a definite order, must have brought about a corresponding reorganization of the curriculum just nine years later.

It was not long after the passing of the decree of 1794 establishing the three Schools of Health that Napoleon took over the reins of government and at the same time began his active military campaigns. The original provision for 300 students at Paris, 150 at Montpellier and 100 at Strasbourg did not suffice to supply his armies, and on May 1, 1802, a further decree under the Consulate permitted the creation of three additional "Schools of Medicine," as they were now called, "one of which must be especially devoted to the study of diseases of land and sea troops." It was not until Jume 9 of the following year that the provisions of this decree were carried out in part by the creation of medical schools at Turin and Nayence. The year 1802 also saw the inauguration of the system of competitive examinations for externships and internships so characteristic of modern French medical education. Arrangements were made for two such competitions yearly for externships, and a single one for the highest prize of a medical student's career, the internship. The first interns receired their promotion September 13, 1802 .

Another consular decree regarding medical schools, of equal importance with the original Revolutionary decree of 1794 , was passed on March 10, 1803 . Its object was to require any person adopting the professions of medicine or surgery, or wishing to serve as a health officer, to undergo an examination and be duly accepted by examining boards under government control. Until now no diplomas had been issued by the medical schools established under the Revolution, but from this time on candidates who successfully passed their examinations were to bear through the authority of the Minister of the Interior the title of doctor of medicine, or doctor of surgery, or health officer. Since all practitioners must hold a diploma, the claims of those who had obtained degrees from pre-Revolutionary Faculties of Mcdicine and Colleges of Surgery were recognized and provision was made for giving diplomas to those who had studied the art of healing between 1793 and 1809 . Bichat, who 
had exercised a greater influence upon medicine than any other teacher, had died without either a degree or a diploma, and Paris was treated to the spectacle of the famous Dupuytren defending the thesis which he had written for his degree, and even the great Boyer himself, although nearly fifty at the time, had to submit to an examination by his less illustrious colleagues and pay for his diploma. The decree of 1803 also increased the length of the course in medical schools to a minimum of four years, established a system of five examinations (two of which had to be in Latin) and required the writing of a thesis (either in Latin or in French). The five examinations were to be passed in the following order: (1) anatomy and physiology; (2) pathology and nosology; (3) materia medica, chemistry, and pharmacy; (4) hygiene and legal medicine; (5) internal or external clinical practice, depending on whether the candidate wished the doctorate in medicine or surgery.

Although the three schools had originally been founded to train health officers, this clecree put the health officers in a separate and inferior class by themselves. In preparation for their examinations they might apprentice themselves to a physician for six years, or follow hospital service for five years, or spend three consecutive years in one of the medical schools. The number of their examinations was limited to three: (1) anatomy; (2) elements of medicine; (3) surgery and ordinary practices of pharmacy.

That the student was held to the rigid system of examination is shown in the old diplomas still in existence. We may take that of François Magendie as an example, since it has been examined by the present writer in the Musée Gilbert of the Paris Medical School where it was to be found, at least until 1939, along with other personal papers carefully preserved by Magendie. We find that he passed his examinations in "anatomy and physiology" on " 0 frimaire an XIII" (December, 1804). The date for the passing of pathology and nosology is obscured by worm holes in the parchment, only the month, "messidor," being decipherable. Presumably the year was 1806 , since among his papers is preserved a certificate exempting him from military service in 1805 on the grounds of "visceral obstruction," and there is no record of his attendance at the hospitals during that year. This makes it probable that he did not attend medical school during 1805 because of illness. Examinations in materia medica, chemistry, and pharmacy were completed " 26 vendémiaire an XIV" (September, 1806). The date for examination in hygiene and legal medicine is no longer written according to the Revolutionary calendar, but reads "May 20, 1807 ." On February 22, 1808 , he satisfied his examiners as to his proficiency in "internal clinics." His thesis having been approved and his fees paid, the diploma was awarded March 24, 1808 .

The final step in the evolution of the external forms of French medical education was taken by Napoleon in his imperial decree of March 17, 1808 , which recreated the University of Paris and placed all public instruction throughout the Empire under its authority. This brought the present-day Paris Faculty of Medicine into existence as one of the five faculties of the 
University, the others being science, law, theology and, als alonecsion, ants. Article 12 of this decree states that "the existing five schools of medicine* shall form five faculties of the same name. They shall preserve the organization deternined by the law of 19 rentose an XI" (March 10, ISog). "The die of French medical schools had, therefore, already been cast in 1803 , and with the awarding of the doctorate as the certificate of the attainment of at superior medical education beyond that of an officer of health, the modern scheme of organization of medical instruction had already been entered upon. The later decree merely brought the medical schools into the same systcm as other departments of public instruction, and the title of doctor of medicine or doctor of surgery was now conferred under the authority of the University.

A study of the 1938-1939 announcement of courses given by the Faculiy of Medicine at the Sorbonne (the last to come to the Library of the University of California) shows that there is still a close parallel between its provisions and the scheme outlined in 1803 , which was, after all, merely an cxtension of the plan proposed by Chaussier in 1794 . Mornings for all students of medicine are to be spent in the hospitals. For the M.D. degree there are five sets of exam inations in theoretical subjects, three clinical examinations, and a thesis. The five examinations in theoretical subjects come at the end of the different years in the following order: (1) mainly anatomy with some histology, physiology, medical physics, and medical chemistry; (2) mainly physiology with some anatomy, histology, medical physics, and chemistry; (3) pathology, experimental medicine, parasitology, and bacteriology; (4) obstetrics, medical and surgical pathology; (5) general pathology, hygiene, legal medicine, therapeutics, and pharmacology. Aside from the inclusion of those sciences which were developed chiefly by the aid of the microscope in the nineteenth century, such as histology and bacteriology, the scheme is essentially the same as the original one, although naturally the content of the various courses has kept pace with advance in the medical sciences.

The idea is to produce practitioners, hence the emphasis on hospital training from the first day the student enters medical school to his last. The bad features of the system have been emphasized in the report (1932) of the Commission on Medical Education under the chairmanship of A. Lawrence Lowell. A single quoted sentence will convey the main objection: "The students are preoccupied and quite overwhelmed with clinical problems, for the understanding of which they have had no preparation." In spite of this overattention to the clinic, the Commission claimed that because of the competitive appointments of externs and interns, "5o per cent of medical students in France do not receive adequate clinical experience before graduation. About 4o per cent (those who have succeeded in becoming externs) obtain a good preliminary experience... while about 10 per cent (the interns) recoive what is probably the largest and most varied clinical experience provided for medical students anywhere in the world."

* Paris, Montpellier. Sumbourg, Turin, and Mainz. 
The sick in Paris may therefore bless or curse the legacy of the Revolution according to whether or not they are attencled by one of the favored 10 per cent-which seems an odd result of at least one of the three principles of Liberty, Equality, and Fraternity.

\section{Relevant Literature}

Busquet, P.: "Chanssier (François)," in Les Biographies .Médicales, I'(Paris: 1927), 37.

Carpentier, A., and Du Saint, G. F.: Répertoire Générale Alphabétique du Droit Français (Paris: 1896$)$.

De l'Enseignement Actuel de la Médecine et de la Chirurgie (Paris: 1815?).

Durergier, J. B.: Collection Complète des Lois, Ordonnances, Règlemens, Avis du Conseil d'Etat (Paris: 1836 ).

Final Report of the Commission on Medical Education (New York: 1932).

Guizot, F.: Essai sur l'Histoire et sur l'Etat Actuel de l'Instruction Publique en France (Paris: $1816)$.

Mémoire en Réponse à un Ecrit Anonyme, intitulé Observations Présentées au Roi, sur la Faculté de Médecine (Paris: 1815 ?).

Plan Général de l'Enseignement dans l'Ecole de Santé de Paris. Imprimé par ordre du Comité d'Instruction Publique de la Convention Nationale (Paris: An III de la République).

Rapport et Décret de la Convention Nationale, sur les Ecoles de Santé de Paris, IIontpellier et Strasbourg (Paris: An 3 de la République).

Réflexions sur l'Etablissement d'une Société Royale de llédecine et de Chirurgie (Paris: 1815?).

Richerand, A. B.: "Séance publique de l'Ecole de Médecine, le 24 nov., 1808 " Gaz. natn., ou Le Monit. miv. p. 1431 , Dec. 29, 1808. 


\section{GYTOLOGICAL DIFFERENGES}

\section{BETWEEN CASTRATION}

AND THYROIDEGTOMY BASOPHILS

IN THE RAT HYPOPHYSIS

$$
\text { By }
$$

J. D. REESE, A. A. KONEFF, AND P. WAINMAN

\section{䉿}

\section{From the}

IMISION OF ANATOMY, MEDICAL SCHOOT AND THF IXSTITLTE OF EXPERIMENTAL BIOLOGY, UNIVERSITY OF CALIFORNIA BERKELEY, CALIFORNIA 



\section{GYTOLOGICAL DIFFERENCES BETWEEN CASTRATION AND THYROIDECTOMY BASOPHILS IN THE RAT HYPOPHYSIS}

\section{INTRODUCTION}

$I^{1}$ $\mathrm{N}$ viEw of the voluminous literature which has accumulated on the pituitary of the rat, it seems remarkable that there is no agreement on the identity or lack of identity of castration and thyroidectomy basophils. The question still exists whether they differ morphologically to such a degree that they may be considered different entities. Furthermore it is not settled whether these cells arise from the same or different stem cells or whether they are the same or different physiologically. In this paper it is our purpose to deal only with the morphological aspect of the problem. In a later communication, we shall state the results of experiments dealing with certain aspects of the physiology of these cells.

\section{Historical Review}

The effect of castration upon the anterior lobe of the rat has been discussed in such admirable treatises as those of Severinghaus. ${ }^{1-4}$ Studies dealing with the anterior-lobe changes after thyroidectomy have also been reviewed in recent years by Severinghaus ${ }^{3,5}$ and by Zeckwer and co-workers. ${ }^{6}$

Agreement exists regarding some points of similarity and difference in the histology of the anterior lobe after the two operations. The granulated acidophils of the rat pituitary disappear after thyroidectomy, according to Hohlweg and Junkmann; ${ }^{7}$ Severinghaus; ${ }^{5}$ Zeckwer; ${ }^{6}$ and Guyer and Claus. ${ }^{8}$ It is also true that, in the rat, after both thyroidectomy and castration, there is an increase in the number and size of the basophils. In both conditions, basophil vacuolation is sooner or later a prominent feature. That these changes in the basophil are consequences of castration was established by the work of Addison, Schleidt, ${ }^{10}$ Lehmann, ${ }^{11}$ Nukariya, ${ }^{12}$ and others. That such transitions in basophils followed thyroidectomy was established by Kojima; ${ }^{13}$ Hohlweg and Junkmann; ${ }^{7}$ Severinghaus, Smelser and Clark; ${ }^{5}$ Zeckwer and co-workers; ${ }^{6}$ and Guyer and Claus. ${ }^{8}$

In 1934 Severinghaus, Smelser and Clark, ${ }^{5}$ describing the basophils after thyroidectomy, reported the following: "The basophils are increased in 11 unber, are of maximum size, and give to the pituitary the castrate appearance. Many have deeply chromatic elongated nuclei. Large numbers of ypical castration cells are present." In several later publications Sereringhaus has expressed the opinion that, except for the rapidity with which the changes in the basophils take place, they are essentially the same after castration and thyroidectomy. 
Zeckwer and her co-workers ${ }^{\circ}$ state: "Morphologically there are distinct differences between the changes in the pituitary resulting from thyroidectomy and those resulting from castration. It is only at long intervals after thyroidectomy that the cells are somewhat similar to castration cells. The intracellular globules of 'castration cells' are large, smooth, well defined, and appear to be composed of dense secretion, hyaline in appearance when fixed and stained, and push to one side the basophilic granules in the cell, but in thyroidectomy cells the secretory accumulation has a less regular contour. We have not seen in early stages of 'castration cells' the characteristics observed in early stages of 'thryoidectomy cells.' In both cases, thyroidectomy and castration, there is preliminary to the formation of vacuoles, a distinct increase in large solid basophilic cells." Guyer and Claus ${ }^{8}$ agree there are significant morphological differences between castration and thyroidectomy basophils and point out a number of criteria which they believe serve to differentiate the two cell types.

\section{Materials And Methods}

The present studies on the pituitaries of castrated and thyroidectomized rats have extended over a period of years-since 1930. The material consists of pituitaries of adult male rats which were castrated and sacrificed at periods varying from 10 days to 18 months after operation; also the glands of similar animals thyroidectomized and autopsied 10 to 162 days after thyroidectomy. Completeness of thyroidectomy was checked at autopsy by examination of the region under the binocular microscope.

The following technical methods were employed for this study of the pituitary: Mallory-Azan technique of staining was the routine method for general histological study; this method was supplemented by cytological techniques similar to those used by Severinghaus; the Nassonov-Kolatchev method of osmic-acid impregnation was used to demonstrate the Golgi apparatus; some of such osmicated preparations were counterstained with the Mallory-Azan technique; the Altmann-Masson method of staining, following Champy fixation, has also proved very helpful in demonstrating the mitochondria. Details of the histological and cytological methods as adapted here have been previously published-Koneff; ${ }^{14}$ and Reese, Koneff and Akimoto. ${ }^{15}$

\section{Observations}

Insufficient attention has been given to the importance of the differences in the manner in which vacuoles form in thyroidectomy and castration cells. It is true, fallacious conclusions may be drawn from constructing a series of changes based upon a study of various stages in a process. However, if the intracellular phenomena are so marked as to result in reduction of the entire cytoplasm to a vacuolated mass, it does seem that a trained observer should not encounter any difficulty in identifying the various stages in the process. This is particularly cogent since the examination of preparations made at 
varying postoperative times can be correlated with the changes in individual cells in preparations representing a single postoperative period.

It has been pointed out by Guyer and Claus, ${ }^{8}$ by Zeckwer and co-rworkers, and others that more vacuoles are present in thyroidectomy than in castration basophils. In our preparations the basophils seen soon after thyroidectomy show an enlargement of fine atveolar subdivisions which may normally be present in the cytoplasm. These multiple vacuoles in the process of development occupy a considerable part of the circumference of the cell. The altered areas of cytoplasm have a smooth hyaline appearance, their content is basophilic. They are at first quite small (pl. 1, figs. 1 and 2), vary in shape, being often polygonal, and are separated from one another by areas of cytoplasm. normal in appearance. The partitions at first may be of considerable thickness. but ultimately become mere strands between the enlarging vacuoles (pl. 1, figs. 4 and 5 ). Examination of a series of cells shows not only that these vacuoles are formed first on the periphery of the cell, but that progressive vacuolation of the cytoplasm approaches more and more closely the nucleus as time gocs on (pl. 1, figs. 4, 5 , and 6).

Accompanying this reduction in the amount of normal cytoplasm there is a redistribution of mitocinondria, and certain changes in the position of the Golgi apparatus. Early in the process, certainly as soon as changes in the peripheral cytoplasm are discernible, the majority of the mitochondria become concentrated in the region surrounding the nucleus. They are to be found either in the zone of perinuclear cytoplasm or they may be strung out along the intervacuolar partitions where they may give the appearance of strings of beads. As in castration basophils they are never found in the vacuole itself. The Golgi apparatus assumes a position early in this process quite at variance with its usual situation in the cytoplasm. It is found in the nonvacuolated portion of the cytoplasm, hence near the nucleus (pl. 1, figs. 7 and 8 ).

In more advanced stages of the thyroidectomy basophil evolution, the vacuoles tend gradually to become fewer and larger. It is not an unwarranted assumption that this reduction in number and increase in size is due to coalescence. This coalescence is usually noted first where the vacuoles are first formed, namely at the periphery of the cell. When coalescence of the vacuoles becomes moderately advanced, the zone of cytoplasm nucleus and Golgi apparatus remains connected to the periphery of the cell by strands of cytoplasm. Such partitions become progressively fewer and fewer in more advanced stages of the process.

Often the entire cytoplasm of a thyroidectomy basophil is riddled by vacuoles, except for a small portion containing the nucleus, Golgi apparatus, and mitochondria. This segment of cytoplasm extends from the region of the nucleus to the nearest adjacent portion of the cell membrane. Since the 11ucleus is typically eccentric this cytoplasmic mass may be quite small, and as the vacuoles coalesce, the granular material and the cell organelles come to 
occupy a small area of cytoplasm at or near the cell membrane. In the end, one or two vacuoles may be present, and the nucleus, remains of Golgi apparatus, and mitochondria are at the periphery of the cell. The cell as a whole presents true degenerative changes.

When this type of vacuole formation is compared with that seen in the so-called castration cell, it may be seen here also that in early stages the cytoplasm has a finely alveolar appearance. Especially is this evident in Champyfixed material. The vacuolation as it appears, however, has the form of a single (or at most double or triple) vacuole which has no perceptible relation to these cytoplasmic subdivisions. The vacuole appears as a small round or oval area of altered cytoplasm, hyaline in nature (pl. 1, fig. 10). Its colloidal content stains less deeply than the surrounding cytoplasm, but is typically more basophilic than the colloidal material in the thyroidectomy cell. We concur in the opinion expressed by Severinghaus that vacuole formation in the castration cell is preceded by liquefaction of the granular material of the cytoplasm. The most outstanding characteristic of vacuole formation in the castration basophil is that the precursor of the vacuole is not a subdivision of the normal cytoplasm as it is in the case of the thyroidectomy basophil but begins as a separate vacuole in the cytoplasm which enlarges and distorts the cell.

The gradual enlargement of the vacuole produces its effect upon the cytoplasm itself and its contents. The nucleus usually retains its shape until the pressure of the vacuole forces it toward the cell membrane; it then accommodates itself to the remaining available space. It becomes elongated in many instances, and finally it may become intensely hyperchromatic and compact. The Golgi apparatus also adapts itself to the free cytoplasm, which in the castration cell forms a rim of varying width about the entire circumference of the cell. The Golgi apparatus, just as the nucleus, becomes elongated and fits itself between the vacuole and the cell membrane. It may lie close to the nucleus or may be separated from it by a considerable distance. Schleidt ${ }^{10}$ had a very good reason for applying the term "signet ring" to these cells. The signet part of the ring consists of that portion where nucleus and Golgi apparatus lie and the normal cytoplasm forms a continuous, albeit in highly distended cells very thin, rim about the entire circumference of the cell (pl. 1, figs. 11, 12,13 , and 14 ).

It is true that the Golgi apparatus and nucleus, in the majority of both thyroidectomy and castration basophils, come to occupy a position near the cell periphery, but, as has already been demonstrated, the processes which lead to this final disposition are entirely different in the two cases. It should be adcled that clear vesicles are to be found in the hyaline vacuolar material of both castration and thyroidectomy basophils. The size finally attained during vacuolation in thyroidectomy cells is greater than that in the "signet ring" cells of castration. 
There are other differences in the cytoplasm distinguishable in the early stages of development which enable one to differentiate the two types of basophil. The cytoplasm of the thyroidectomy basophil is usually nore basophilic than that of the castration cell. The cytoplasm of these cells contains coarse floccular basophilic material which becomes more and more apparent as the vacuoles increase in size and is subsequently forced into a smill space near the nucleus.

The cytoplasm of young castration basophils, though it may be alveolan in structure, is more uniform than the thyroidectomy basophil and is more fincly granular. In the Nassonov-Kalotcher preparations, the cytoplasm of the castration basophil is generally less osmiophitic than is that of the thyroidectomy cell.

There are noteworthy changes in the Golgi apparatus in the two groups of basophils other than the changes in position aheady mentioned. These are the changes in size, shape, and internal structure of the Golgi apparatus. The Golgi apparatus is a satisfactory indicator in the normal rat hypophysis of the strain to which any individual cell belongs. Sereringhaus ${ }^{1}$ first stressed the inportance of this fact, and results from this laboratory are in agreement with his findings. This does not, however, mean that the position of the Golgi apparatus has equivalent value as an indicator of cell type after physiological or pathological changes. Such conditions may alter the relation of the Golgi apparatus to the nucleus and even the fmer morphology of the apparatus. Under such circunstances, if the Golgi apparatus only were used as the single criterion, great difficulty might be experienced in determining whether a cell belonged to the acidophil or basophil strain. In the thyroidectomy basophil, the Golgi apparatus is so altered that it may bear little resemblance to the classic description which Severinghaus has given of that organelle in normal basophil. At least some of these modifications which the Golgi apparatu undergoes are coincident with changes in the cytoplasm, and cloubtless result from such changes. As the Golgi apparatus is crowched toward the nucleus, the originally rounded apparatus comes to lie as a cap against the muclens (pl. 1, figs. 7 and 8). That we are dealing here with a thyroidectomy basophil and not an enlarged acidophil is easily proved by the application of a suitable counterstain, such as the Mallory-Azan to positive impregnations of the Golgi apparatus.

It will be remembered that in the castration basophil the relation of the Golgi apparatus to the nucleus is quite different from that in the thyroidectony basophil. As Guyer and Claus noted, the Golgi apparatus not uncommonly lies between the nucleus and the enlarging vacuole (pl. 1, fig. 13). This relationship is, however, far from invariable, the Golgi bocly very frequently coming to lie side by side with the nucleus, both bordering the vacuole (pl. 1, figs. 11, 12. and 14); in other words, the vacuole often begins in a portion of the cytoplasm quite distant from the nucleus and Golgi ap- 
paratus, and the enlargement of the vacuole probably determines the ultimate position of both of the other cell structures.

The ease with which the Golgi apparatus is clemonstrable in the thyroidectomy and castration cell differs markedly. Even a short time after thyroidectomy, the Golgi apparatus bccomes more difficult to demonstrate than in the normal or castrate basophil. This is probably related to the increased osmiophilia of the cytoplasm of these cells.

Early enlargement of the Golgi apparatus is seen in both the thyroidectomy and castration basophils. The shape and internal structure of the apparatus, however, is markedly different. The enlargement in the castration cell is such that it does not disturb the fundamental pattern of the double-ralled sphere. It is true that at a time when the Golgi body has reached maximum size (somewhat before vacuolation occurs) its outer surface may be somewhat crenated, but the whole structure remains rounded or oval (pl. 1, figs. 15 and 16). However lightly such an apparatus is impregnated, it always has a sharp outline and the component parts of its net are shown with clarity.

The Golgi apparatus of the basophil also enlarges after thyroidectomy, but assumes peculiar shapes conforming to the contour of the limited cytoplasm in which it is forced by the multiple vacuoles. The apparatus in such cells has a very tenuous character; long filaments or strands are formed which are interrupted by areas which are relatively osmiophobic. Though the shape of the Golgi apparatus is distorted by pressure effects, it does not need to be considered degenerate in early stages.

Guyer and Claus ${ }^{8}$ have described the Golgi apparatus in thyroidectomy as "commonly granular or diffuse." This is true and this granularity or diffuseness is seen in many cells which show only early thyroidectomy changes as far as racuole formation is concerned. Later during vacuolation there may be complete fragmentation and the remains of the Golgi body are then manifested only as a granular osmiophilic area. In some cells, parts of the apparatus may remain intact while the remainder is undergoing fragmentation. Disintegration of the apparatus is the rule in later periods after thyroidectomy. The enlargement of the apparatus in thyroidectomy cells is temporary; the final effect is destruction.

Granular distintegration of the Golgi body is not seen in castration cells. In these cells the apparatus is first enlarged, later becomes smaller. The enlarging vacuole compresses the apparatus into a very small space at the cell periphery and the shape of the apparatus is changed, but the integrity of the net remains undisturbed. Even in the largest castration cells after the apparatus itself is decreased in size there is no evidence of a dissolution such as is scen in thyroidectomy cells.

The mitochondria also differentiate the processes occurring in the basophils after the two operations, both by their changes in size, shape, and distribution. The differences in these structures in the two cells are sufficiently marked so 
that they are discernible, not only in preparations specifically stained, but in those stained by the Mallory-Azan technique in which the mitochondria are stained by azo-carmine.

No experimental conditions have been encountered, aside from cstrini $/$ tion, which produce mitochondria of such large size as have becn observed in thyroidectomy basophils. These mitochondria are almost all oval or spherical in shape, filaments and rods being very rare. In almost 6 to 10 per cent of the cells they are unusually coarse and numerous. The mitochondria are situated close to the nucleus or are strung like beads along the thin strands of cytoplasm which form the thin partitions between the numerous vacuoles in these cells (pl. 1. fig. 9).

After castration, the basophil mitochondria, while very numerous, are in general smaller, and are more dispersed thronghout the cell; short rods and eren filaments are present as well as granules. During the period of enlargement of the castration basophil, the mitochondrial distribution usually follows the normal pattern. They are definitely concentrated in the region of the Golgi apparatus (pl. 1, figs. 15 and 17), from which they radiate into the surrounding cytoplasm. It is true that this distribution is disturbed by the appearance of the vacuole, but the fundamental arrangement of mitochondria, as well as other intracellttlar inclusions, is not markedly affected until late in the process.

A comparison such as has been undertaken here would be incomplete without some statement regarding differences in general cell size and shape at various periods after the two types of operation. These criteria alone allow the observer to differentiate at a glance the earlier phases of the two processes. Zeckwer and co-workers ${ }^{8}$ have stated that in both instances there is "preliminary to the formation of vacuoles a distinct increase in large solid basophilic cells." The contour, however, of these large basophilic cells differs remarkably and assists in the differentiation. In discussing this point it is necessary to stress the difference between the basophils of normal female and male rats. By this criterion we believe one can differentiate pituitaries from the two sexes. The predominant type of basophil in the normal pituitary of the male is an oval or rounded cell which stains comparatively lightly; in the female the predominating basophil is polygonal in shape and more basophilic, and in this cell the mitochondria are large and usually spherical. In the early response to thyroidectomy of either sex, a marked increase in number of basophils occurs, the cells closely approximating the type of cell just described for the normal female. They are irregular in shape, often polyhedral and have a distinctly increased basophilia. As Guyer and Claus ${ }^{8}$ have stated, thyroidectomy basophils show a marked tendency toward grouping. Castration basophils, on the other hand, in early stages of formation are compact cells which are oval or round. The granules are evenly distributed and the cell stains as a rule more lightly with aniline blue than young thyroidectomy basophils. In a 
pituitary studicd about thirty-five days after castration, these cells are found to be exccedingly numerous and are scattered throughout the anterior lobe. They show no tendency toward grouping as after thyroidectomy.

There are similarities between the late thyroidcctomy and castration basophils, but these similarities are superficial. In the first place, the castration basophil distencled by a castration vacuole never reaches the size characteristic of the basophil after thyroidectomy. The other criteria which differentiate the cells in these late stages are as follows: Castration basophils undergoing vacuolation are always accompanied by a crop of young basophils. These young basophils have been described as typical of the early castration reaction, but they are always present in appreciable numbers regardless of the period which may elapse after castration. Development of new basophils in such numbers does not take place after thyroidectomy. In fact after a relatively long postoperative period (62 days) very few young basophils are present; practically all the basophils show some degree of vacuolation. After $16_{5}$ days all recognizable basophils are markedly diminished in number. The vacuolated cells by this time are sometimes recognizable only as irregular masses of basophilic cytoplasm and one must trace these in serial sections in order to identify the remains of the nucleus. The young basophils present are negligible in number and there is no evidence that the gland is making an effort to replace the vacuolated basophils. This diminution in the total number of basophils is therefore undoubtedly due to two factors-first, the vacuolated cells undergo complete degeneration, and secondly, a new crop of the basophils does not develop from the stem cell.

Certain differences in the nuclei also serve to differentiate the basophils after thyroidectomy and castration. Guyer and Claus ${ }^{8}$ have made the point that vacuolation of the nucleus is common in basophils after thyroidectomy, but does not occur in the same cells after castration. That this cannot be considered an important differential point will be seen from observations on the nucleus changes. In the period following thyroidectomy, from 10 to 63 days, the following changes in the nucleus have been observed: Prior to the development of vacuolation, the nuclei of the polyhedral darkly staining basophils arc often compact and polychromatic. In the initial periods of vacuole development the nucleus of the enlarged thyroidectomy basophil is round, lightly staining and vesicular; there is a notable scarcity of basichromatin. The size of the nuclei is often greatly increased, in fact may reach twice the size of the nucleus of the normal basophil. The nucleoli also are greatly enlarged, sometimes threefold the size of those in the normal basophil (pl. 1, fig. 2). Later the nucleus shows definite evidence of degeneration and finally becomes pyknotic. This process continues until the nucleus is an irregular compact mass lying at or near the periphery of the cell (pl. 1, fig. 6).

Changes in the nucleus of the basophils after castration are different. Often one sces elongation of the nucleus, due doubtless to the pressure exerted by 
the enlarging vacuole. Such a change in the contour of the nucleus is rare in the thyroidectomy basophil. On the other hand, enlargement of the nucleus and nucleolus described in the basophil after thyroidectony are very uncommon for the cells affected by castration. Although pyknosis may be the ultimate fate of the nucleus in both cell types, it is not so common a phenomenon after castration as after thyroidectomy.

No difficulty was encountered in detecting the vacuolation of the nucleus found by Guyer and Claus in the basophils after thyroidectomy. These single vacuoles contained a homogeneous colloidlike material reacting like mucin with methyl green.* Later such vacuoles sometimes had increased in size so that they filled the nucleus. The nucleoli in such cases were pushed toward the nuclear membrane (pl. 1, figs. 18 and 19). In the colloidal material of the nuclear vacuole, round or oval colorless spaces were sometimes present, possibly due in part to solution of the material in reagents used in histological preparation. The growth of such intranuclear vacuoles may proceed to the point at which the vacuole itself is larger than the entire nucleus of a nomal basophil, the nuclear membrane and nucleoli still being intact. Although vacuolation of the nucleus of the basophil is less common after castration than after thyroidectomy, it has nevertheless been observed in certain pituitaries from rats sacrificed at long periods after castration. These racuolar changes did not differ in any essential way from those seen after thyroidectomy (pl. 1, fig. 20).

Vacuolation of the nucleus cannot therefore be considered to constitute a reliable criterion for differentiating the two types of basophil (as suggested by Guyer and Claus ${ }^{9}$ ). Nevertheless there are differences in the nuclei which aid in the differentiation. The increase in size of the nucleus after thyroidectomy is more marked than after castration. The pressure of the castration-cell vacuoles often causes an elongation of the nucleus which is highly characteristic. Finally, the marked enlargement of the nucleoli seen after thyroidectomy is not present after castration.

In discussing differences or similarities of castration and thyroidectomy basophils one should alrays bear in mind that "castrationlike" or "thyroidectomylike" basophils may occasionally be found in other types of hypophyses. including normal ones. The authors do not consider, however, that cells identical with those of castration occur in significant numbers after remoral of the thyroid. The crux of the entire problem is whether any competent observer can distinguish the pituitary of a thyroidectomized animal from one which has been castrated if the decision is based only upon changes in the basophils. Using the criteria described in this paper it is considered that one should not encounter difficulty in distinguishing the two types of pituitaries regardless of the postoperative period.

* Unpublished data of 1 . Koneff show the effectivenes of methyl green in staining mucoid substances. 


\section{Conclusions}

The thyroidectomy and castration basophils of the anterior hypophyses of the rat differ morphologically to such an extent that they may be used to differentiate the pituitaries after these two types of operation. These differences are manifested in the size, shape, and distribution of the cells, also in the mode of vacuole formation and in the distribution and fate of cytoplasm, Golgi apparatus, and mitochondria.

\section{REFERENGES}

1. Severinghaus, A. E.: Anat. Recrd. 57:149, 1933 .

2. Severinghaus, A. E.: Proc. Assn. Resrch. Nerv. \& Ment. Disease 17:69, 1936.

3. Severinghaus, A. E.: Physiol. Revs. 17:556, 1937.

4. Severinghaus, A. E.: in Sex and Internal Secretions, ed. by E. Allen (2d ed.; Baltimore: 1939), 10.45.

5. Severinghaus, A. E.; Smelser, G. K., and Clark, H. M.: Proc. Soc. Exper, Biol. \& Med. 31 : 1127,1934 .

6. Zeckwer, I. T.; Davidson, L. W.; Thomas, B. K., and Livingood, C. S.: Amer. Jl. Med. Scis. 190:145, 1935.

7. Hohlweg. W., and Junkmann, K.: Pflügers Arch. f. d. gsmt. Physiol. 232:148, 1933.

8. Guyer, M. F., and Claus, P. E.: Anat. Recrd. 67:145, 1937.

9. Addison, W. H. F.: Jl. Compar. Neurol. 28:441, 1917 .

10. Schleidt, J.: Zentrlblt, f. Physiol. 27:1170, 1914.

11. Lehmann, J.: Pflügers Arch. f. d. gsmt. Physiol. $216: 729,1927$.

12. Nukariya, S.: Pflügers Arch. f. d. gsmt. Physiol. 214:697, 1926.

13. Kojima, M.: Quart. J1. Exper. Physiol, 11:319, 1917.

14. Koneff, A. A.: Stain Technol. 13:49, $193^{8}$.

15. Reese, J. D.; Koneff, A. A., and Akimoto, M. B.: Anat. Recrd. 75:373, 1939. 
EXPLANATION OF PLATE

(Reduced 1/6) 
All photographs were taken with a $2 \mathrm{~mm}$. oil immersion objective; magnification $\times 900$.

Figs. 1, 2, 4, 5, 9, 17 were taken from Altmann-Masson preparations; figs. 3, 7, $8,12,13,16$ from Nassonov-Kolatcher preparations; figs. $6,10,11,14,15,18,19$, 20 from section stained by Mallory-Azan method.

Figs. 1 to 6 represent the sequence of changes observed in basophils after thyroidectomy.

Figs. 10 to 14 represent the sequence of changes observed in basophils after castration.

Figs. 7 and 8. Highly reticular and diffuse Golgi apparatus found in the basophil of thyroidectomy.

Fig. 9. Thyroidectomy basophil.

Note the distribution of mitochondria in the remaining part of the cytoplasm near the nucleus and between vacuoles.

Figs. 15 and 16 . Negative image and a positively impregnated Golgi apparatus of the young castration basophil without the vacuole.

Fig. 17 . Note the general distribution and concentration of mitochondria in the Golgi region of a young castration basophil.

Figs. 18 and 19. Small early and adranced nuclear vacuolation found in the basophil after thyroidectomy:

Fig. 20. Castration basophil showing racuolation of the nucleus morphologically identical with that seen in the thyroidectomy basophil (fig. 18). 


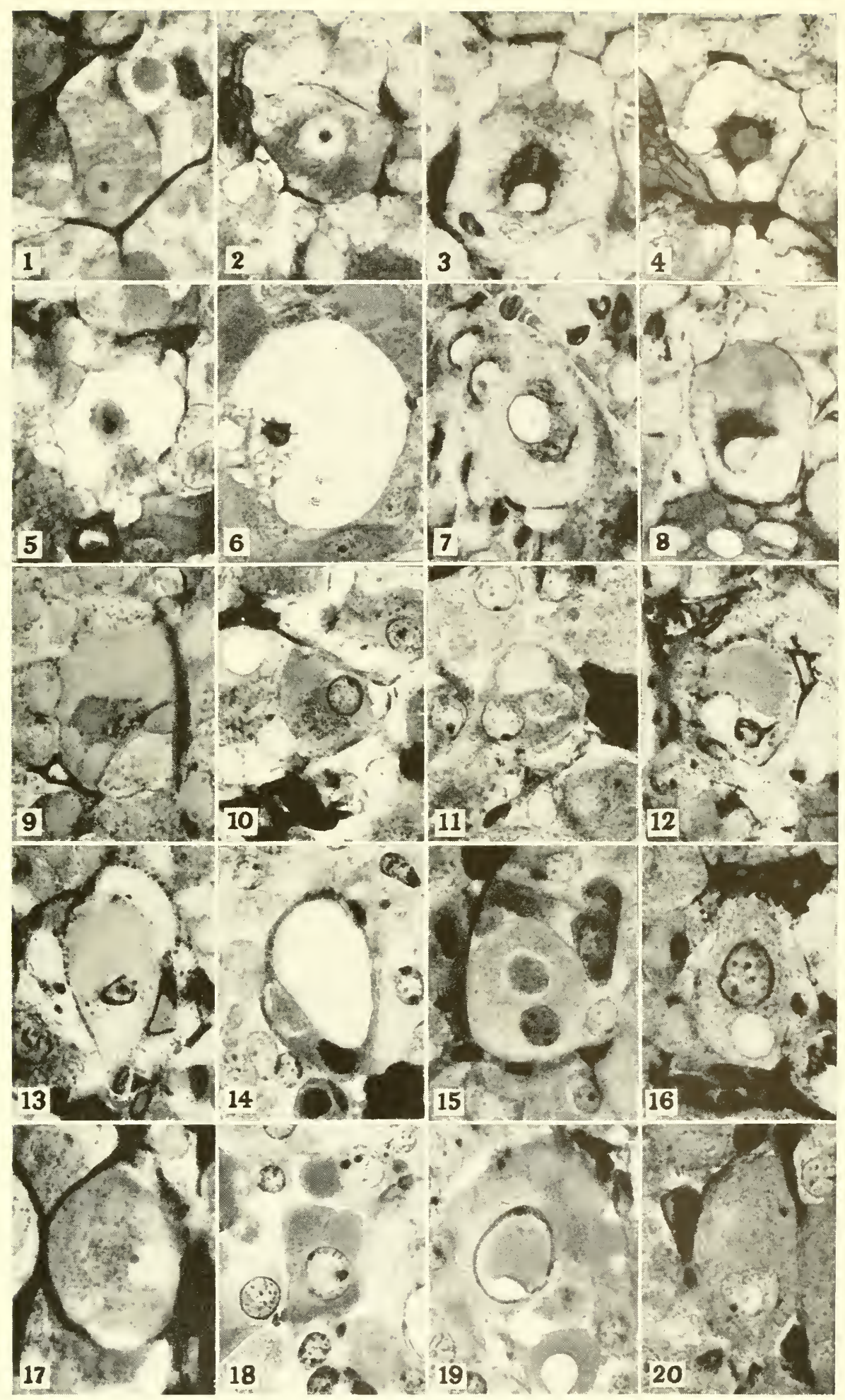

Plate 1 



\section{STUDIES ON THE GROWTH OF LYMPH NODES, THYMUS,}

\section{AND SPLEEN IN THE RAT}

$$
\text { By }
$$

W'ILLIAN O. REINHARDT

\section{糈}

\section{From the}

DIVISION OF ANATOMY AND THE INSTITUTE OF EXPERIMENTAL

BIOLOGY, UNIVERSITY OF CALIFORNIA

BERKELEY, CALIFORNIA 



\section{STUDIES ON THE GROWTH OF LYMPH NODES, THYMUS, AND SPLEEN IN THE RAT}

\section{INTRODUCTION}

E XPERIENTAL and clinical observations on changes in size of the lymph nodes, thymus, and spleen in various pathological conditions have suggested the possibility of making comparative quantitative studies on the growth and reaction of these structures to disturbances of an endocrine or nutritional nature.

In order to lay a foundation for studies of a quantitative nature on lymph modes, spleen, and thymus, it was thought advisable to follow the development of these organs over a considerable part of the life span of the rat in order that their behavior in distubed physiological states might be more intelligently interpreted. The form of the growth curves for thymus and spleen have been studied elsewhere in other strains of rats than the Long-Evans strain (Donaldson, ${ }^{1}$ Chiodi, ${ }^{2,3}$ Plagge $\left.{ }^{4}\right)$. The present study is devoted to a comparison of the growth in weight of thymus and spleen with that of the lymph nodes in the Long-Evans strain. The growth in weight of these organs is followed in groups of rats born at approximately the same time and autopsied at intervals over a period of seven months. In addition, the reactions (in terms of weight changes) of these structures to such stimuli as fasting. exposure to low temperature, and endocrine imbalances are indicated to show the extent of weight loss which may orcur in these structures. Histological studies are not included in this report.

The studies of $\mathrm{Job}^{5}$ have been of value in elucidating the location of the various groups of lymph nodes in the rat. It was demonstrated by Job, and is confirmed by the present worker, that the lymph nodes in the rat are relatively constant in position and number. On the basis of umpublished experiments, the cervical and mesenteric nodes have been selected as representative of the lymph node tissue in the body. It is, of course, realized that the behavior of these groups of nodes may not be representative of all lymph nodes as a whole; generalizations may be applied only in a limited way to the other lymph nodes of the body.

\section{MATlRials ANd Methods}

Rats of the Long-Evans strain born in the last week of June and the first week of July, 1941, were maintained under comparable envirommental conditions to the age of seven months. The animals received a regular ration (Diet XIV) ad libitum, supplemented twice weekly with fresh lettuce. At varying intervals chung this time, groups of each sex were weighed and sacrificed under chloroform ancsthesia followed by bleeding from the heart. Animals from the same litters were sacrificed in different age groups to avoid peculiarities due to litter groupings. The age at autopsy and the number of animals in each group are indicated in the tables. The animals were then dissected, the tissues being 
removed in a definite order by the same person to avoid variation in technique. Upon removal from the animal, the tissues were placed in moist-atmosphere weighing dishes and were weighed to the nearest milligram in a closed balance. Care was taken to avoid drying of the tissues before and during weighing. The technique remained the same for the entire series of autopsies. The data obtained were analyzed to show means and standard errors of the means. These data are presented in the form of tables, and further in the form of curves, showing changes in organ weight for each age group. The body-weight averages included in the tables are not corrected for intestinal and bladder contents, nor were the animals fasted preliminary to autopsy.

A brief clescription is in order as to the technique of dissection of spleen, thymus, and lymph nodes. The spleen was removed immediately after the death of the animal in order to eliminate variation in weight due to changes in the blood content of this organ. The spleen and thymus were dissected out by simple severance of their connective tissue and vascular pedicles. Care was taken in the case of the thymus to dissect away the associated lymph nodes. Dissection of the cervical lymph nodes was carried out in the following manner: a midline incision from the tip of the mandible to the sternum was carried down through skin and superficial connective tissue. Reflection of the skin flaps allowed exposure of the lymph nodes where they lie lateral to the submandibular salivary glands along the line of the external jugular vein. Incision of the overlying connective tissue allowed the enucleation of the wellencapsulated nodes. The pedicles of the nodes were severed along the line of the external jugular vein and the nodes were cleanly excised. There were usually three separate and discrete nodes in the position mentioned. Included in the nodes dissected was one deep cervical node from each side of the neck (located dorsal and lateral to the omohyoid muscle where the latter crosses the vascular sheath of the neck). The mesenteric nodes required relatively more care in dissection. The procedure employed was to remove the entire gastro-enteric tract and associated viscera from the abdomen by simple section of the mesenteries at the points of reflection upon the abdominal wall. The liver was removed from the excised group of organs, and the entire mesentery was carefully stripped away from the stonach and the large and small intestines. Remaining was the mesentery (of the intestines and stomach) with the associated vessels, fat, nerves, and lymph nodes. The mesenteric nodes were found lying in a row along the root of the mesentery. By simple incision of the overlying peritoneum the nodes were removed and freed from connective tissue and fat. The nodes of the cervical and mesenteric regions were solid structures, the cut surfaces appearing rather dry, there being little fluid accumulated within the nodes. The dissection of the mesenteric nodes included groups which may be designated as hepatic, gastric, intestinal, pancreatic, and cecal.

The animals autopsied were examined for the presence of pathological conditions. Animals suffering from gross evidence of respiratory or enteric disturbances were excluded from the study. 


\section{Results}

The data obtained in this study of the growth of thymus, spleen, and lymph nodes are summarized in tables 1 and 2. A total of 284 animals were cmployed, divided equally between males and females. Seven age groups were studied, consisting of about 20 animals of each sex. The lymph nodes were not dissected in the newborn animals because of practical difficulties. Study of

TABLE 1

Mean Weights of Thymus, Lymph Nodes, and Spleen of Male Rats

\begin{tabular}{|c|c|c|c|c|c|c|}
\hline $\begin{array}{l}\text { Age in } \\
\text { days }\end{array}$ & $\begin{array}{l}\text { No. of } \\
\text { animais }\end{array}$ & $\begin{array}{c}\text { Body weight, } \\
\text { gm. }\end{array}$ & Thymus & Spleen & $\begin{array}{l}\text { Cervical } \\
\text { nodes }\end{array}$ & $\begin{array}{l}\text { Mesenteric } \\
\text { nodes }\end{array}$ \\
\hline I & 20 & $8.5 \pm 0.2$ & II. $5 \pm 0.5^{*}$ & $33.5 \pm=2$ & $\ldots \ldots \ldots$ & \\
\hline 22 & 22 & $47 \pm 1.3$ & $128 \pm 7.5$ & $224 \pm 12$ & $25 \pm 1.5^{*}$ & $4^{6} \pm 2.2^{*}$ \\
\hline 42 & 21 & I $28 \pm 3$ & $356 \pm 19$ & $593 \pm 56$ & I 28 土 2 & $228 \pm 17$ \\
\hline 65 & I 6 & $23.3 \pm 8$ & $3 t^{2} \pm 20$ & I $35 \pm 122$ & $2 \mathrm{I} 8 \pm \mathrm{I} 4$ & $295 \pm \mathrm{I}_{4}$ \\
\hline 100 & I 8 & $306 \pm 10$ & $260 \pm 13$ & $1350 \pm 56$ & $351 \pm 18$ & $296 \pm 12$ \\
\hline 176 & 20 & $394 \pm \mathrm{I} 5$ & I9I \pm I 8 & $\mathrm{I} 203 \pm 4^{8}$ & $257 \pm 15$ & $289 \pm 15$ \\
\hline 223 & 20 & $430 \pm 11$ & $171 \pm 12$ & $\mathrm{I} 204 \pm 53$ & $275 \pm 16$ & $299 \pm 15$ \\
\hline
\end{tabular}

* Mean weights in milligrams \pm standard error of the mean $\left(\frac{\text { S.D. }}{\sqrt{X-1}}\right)$. All figures expressed to the nearest
integer.

TABLE 2

Mean Weights of Thymus, Lymph Nodes, and Spleen of Female Rats

\begin{tabular}{|c|c|c|c|c|c|c|}
\hline $\begin{array}{c}\text { Age in } \\
\text { days }\end{array}$ & $\begin{array}{l}\text { No. of } \\
\text { animals }\end{array}$ & $\begin{array}{c}\text { Body weight, } \\
\text { gm. }\end{array}$ & Thymus & Spleen & $\begin{array}{c}\text { Cervical } \\
\text { nodes }\end{array}$ & $\begin{array}{l}\text { Mesenteric } \\
\text { nodes }\end{array}$ \\
\hline I & 25 & $6.7 \pm 0.2$ & $8.9 \pm 0.4^{*}$ & $19.7 \pm 1.3$ & $\ldots \ldots$ & $\ldots \ldots$ \\
\hline $2 I$ & 20 & $49 \pm 1.5$ & $150 \pm 12$ & $334 \pm 16$ & $29 \pm 1.4$ & $57 \pm 3.7$ \\
\hline+2 & 21 & II $5 \pm 3$ & $308 \pm 13$ & $625 \pm 73$ & $125 \pm 10$ & $2 I_{5} \pm I_{4}$ \\
\hline 70 & $2 I$ & $166 \pm 4$ & $306 \pm 13$ & $832 \pm 72$ & $\mathrm{I} 9 \mathrm{I} \pm \mathrm{II}$ & $265 \pm 9$ \\
\hline 95 & 20 & $210 \pm 5$ & $235 \pm I_{4}$ & $878 \pm 64$ & $271 \pm 16$ & $273 \pm 11$ \\
\hline 176 & 20 & $2+5 \pm 8$ & $156 \pm 10$ & $78 \mathrm{I} \pm 53$ & $212 \pm 15$ & $275 \pm 15$ \\
\hline 223 & 20 & $25+ \pm 6$ & $I_{42} \pm 9$ & $747 \pm+5$ & $166 \pm 9$ & $2+4 \pm 14$ \\
\hline
\end{tabular}

* As in Table 8 .

the standard errors in relation to the number of samples and the size of the means provides an estimate of the amount of variation in these tissues. Such analyses, however, are not to be considered as standards in application to other experiments. They are included here for the purpose of indicating the extent of observed variation in this series of animals and under the conditions employed.

Figure 1 shows the growth in weight of the thymus gland in both males and females in this series of animals. Each of the points on the curves represents, on the average, the mean of the thymus weights of 20 animals at the various ages indicated. 
Examination of these curves shows the absolute-weight maximum of the thymus to occur between the ages of 40 to 60 days. This is supported by studies of the thymus weight of some six hundred other animals of various ages in this colony. After the attainment of maximum absolute-weight there is a

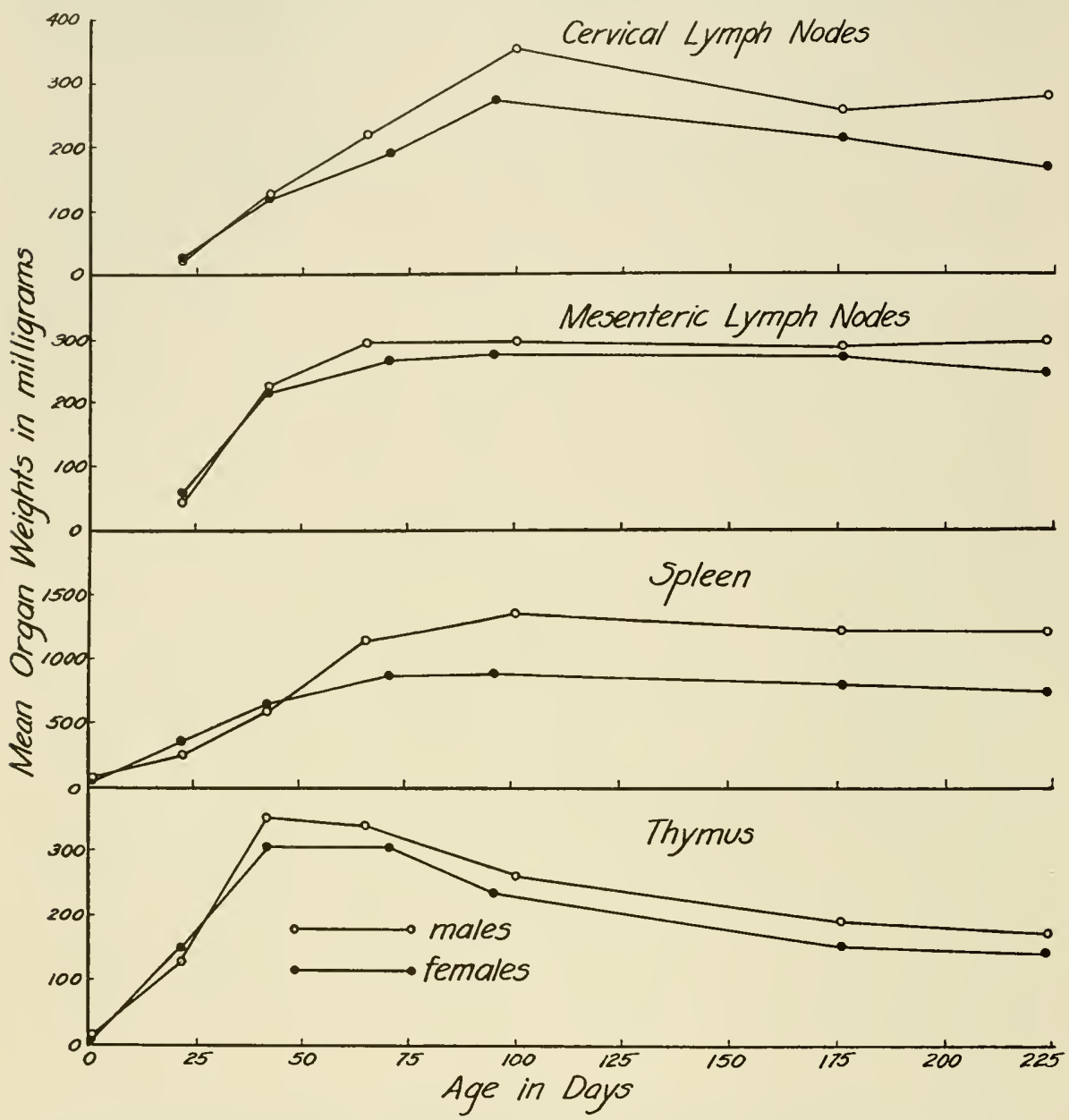

Fig. 1. Growth in weight of thymus, spleen, and lymph nodes in male and female rats.

gradual decline. Studies of the relative-weight curves (not included here) show the maximum relative weight to be attained between the ages of 25 to 45 days. The relative weight is high at birth, rises rapidly, and falls off proportionately as involution of the gland gains momentum. On the basis of these studies, one may consider the thymus as the most labile of the structures studied in that its growth and involution are the most pronounced. The form of the curve obtained for the growth of the thymus is similar to that obtained for other colonies, differing chiefly in the time of attainment of maximum absolute- 


\section{William O. Reinhardt}

weight. This may be related to colony differences, environmental conditions, or differences in the onset of puberty.

Figure 1 also presents the curves for the growth in absolute weight of the spleen. No correction has been made in the means for the variation in weight of the spleen which occurs within the groups and which is evidenced by the large standard crrors. It is realized that weight studies of the spleen must take into account the relation between the blood and lymphoid elements of that organ. An attempt was made to standardize the technique of autopsy and dissection in order to render this relationship as nearly constant as possible, although other factors may complicate this problem. The average values for the weight of the spleen are greater for the male than for the female after the age of $5^{0}$ days. There is a gradual leveling off in the absolute weight of the spleen in each sex, but studies of the relative weights show that there is a comparable decline for each sex after 100 days of age. The reason for the greater absolute weight of the spleen in the male is not apparent. Donaldson ${ }^{1}$ states that there was no apparent difference between male and female spleen weights in material employed by him in his studies.

The form of the growth curve for the cervical lymph nodes is similar in males and females. There is an increase in weight to the age of roo days and then a gradual decline, but not as marked as in the case of the thymus. A study of relative-weight curves shows the same phenomenon as is the case for the absolute weights. One may speak of growth and involution in weight of the cervical lymph nodes on the basis of these curves. The form of growth curves for the cervical lymph nodes is generally similar to those of Hellman ${ }^{6}$ for the rabbit, and those of $\mathrm{Chiodi}^{3}$ for the rat. These investigators employed the same technique as here utilized, but they have examined other groups of nodes in smaller numbers of animals.

Growth of the mesenteric lymph nodes in absolute values is the same for males and females. Maximum weights in both sexes are attained at about the age of 60 days, after which time the weights remain fairly constant. Relative to body weight, the weights of the mesenteric lymph nodes show a slow decline (after the age of $4^{0}$ days). Since the absolute weights of the mesenteric nodes remain constant for the various age periods after the age of 60 days, there is relatively more mesenteric node tissue in the female because the latter does not attain the same body weight as the male. This contrasts with the case of the cervical lymph nodes in which the form of the absolute- and relative-weight curves for male and female are more nearly the same. Since the mesenteric nodes apparently have a different function from that of the cervical nodes, particularly in relation to the absorption of food from the intestine, it is possible that the growth and maintenance of the former may depend on other factors, such as food absorption.

Aside from interest in a comparison of the growth curves of the thymus. spleen, and lymph nodes, the value of these studies lies in their application to experiments devoted to elucidation of the function of these structures in the 
animal economy. The relationship may be made clearer by comparative studies of the effects, on lymph nodes and spleen, of endocrine imbalances and dietary disturbances which are already known to affect the thymus gland.

\section{The Effect of Fasting and Exposure to Cold on the Weights of Thymus, Lymph Nodes, and Spleen}

The following experiments are included to show the extent to which disturbed nutrition will influence the weights of the structures under consideration. Fasting is well known as a stimulus which will cause rapid weight involution

TABLE 3

Efrect of Fasting on the Weights of Thymus, Lymph Nodes and Spleen in Male Rats

\begin{tabular}{|c|c|c|c|c|c|c|}
\hline Treatment & $\begin{array}{c}\text { No. of } \\
\text { animals }\end{array} \mid$ & $\begin{array}{c}\text { Final } \\
\text { Body weight, } \\
\text { gm. }\end{array}$ & Thymus & Lymph nodes & Mesenteric nodes & Spleen \\
\hline $\begin{array}{l}\text { Fed } \\
\text { controls }\end{array}$ & 3 & $\begin{array}{c}317 \\
(310-332)\end{array}$ & $\begin{array}{c}306^{*} \\
(292-320)\end{array}$ & $\begin{array}{c}453 \\
(329-568)\end{array}$ & $\begin{array}{c}328 \\
(263-404)\end{array}$ & $\begin{array}{c}695 \\
(560-862)\end{array}$ \\
\hline $\begin{array}{l}\text { Fasted } \\
\text { controls }\end{array}$ & 3 & $\begin{array}{c}179 \\
\left(162-20_{4}\right)\end{array}$ & $\begin{array}{c}66 \\
(36-95)\end{array}$ & $\begin{array}{c}224 \\
(\mathrm{I} 42-267)\end{array}$ & $\begin{array}{c}89 \\
(46-117)\end{array}$ & $\begin{array}{c}30 \mathrm{I} \\
(\mathrm{I} 88-38 \mathrm{I})\end{array}$ \\
\hline $\begin{array}{l}\text { Fasted } 5 \\
\text { days, refed } \\
3 \text { days }\end{array}$ & 3 & $\begin{array}{c}243 \\
\left(20_{4}-3 \circ 5\right)\end{array}$ & $\begin{array}{c}\text { I37 } \\
(\text { (19-17I) }\end{array}$ & $\begin{array}{c}35 \mathrm{I} \\
(308-405)\end{array}$ & $\begin{array}{c}4^{10} \\
\left(234^{-678)}\right.\end{array}$ & $\begin{array}{c}74 I \\
\left(57^{6}-923\right)\end{array}$ \\
\hline
\end{tabular}

* Weight of the tissues in milligrams. Figures in parentheses indicate ranges.

of the thymus gland. It was thought probable that the lymph nodes might be affected in a similar manner. Normal male rats of this colony, 80 days of age, were subjected to fasting for a period of five days. The animals had access only to tap water for drinking purposes. At the end of this time, normal control fed animals of the same age were autopsied at the same time as the experimental animals. A further group was fasted for five days and then refed the regular diet for three days. Data are given in table 3. The findings have been confirmed in subsequent experiments. The lymph nodes dissected included the combined cervical, axillary, mediastinal, and retroperitoneal abdominal nodes, and the mesenteric nodes which are noted separately.

Thymus, lymph nodes, and spleen, as can be seen by examination of this table, undergo a marked diminution in weight subsequent to a period of fasting. Refeeding restores these structures to an approximately normal weight even though the animals have not regained their original body weight. This contributes direct evidence that not only thymus but also lymph nodes and spleen respond to the withdrawal of food by marked decrease in weight.

A further experiment to demonstrate the gross reaction of these organs to sudden and profound changes in environment was carried out by exposure of 
animals to a cold atmosphere. Female rats averaging $210 \mathrm{gm}$. in body weight were subjected to exposure in the cold room for a period of 63 hours to a temperature of $36-38^{\circ} \mathrm{F}$. and a further exposure to a temperature of $25^{\circ} \mathrm{F}$. for a period of three hours. The animals were placed in individual wire-bottom metabolism cages and allowed free access to 1 per cent sodium chloride solution as a source of drinking water. The groups employed consisted of normal fasted animals maintained at room temperature, a group exposed to cold and fasted, and a third group which was allowed food ad libitum in the cold. The

TABLE 4

Weights of Thymus, Spleen, and Lymph Nodes in Rats Exposed to the Cold

\begin{tabular}{|c|c|c|c|c|c|}
\hline Treatment & $\begin{array}{l}\text { No. of } \\
\text { animals }\end{array}$ & Thymus & Spleen & Cervical nodes & Mesenteric nomes \\
\hline Normal fasted & + & $\begin{array}{c}178^{*} \\
\left(134^{-262)}\right.\end{array}$ & $\begin{array}{c}804 \\
(660-1089)\end{array}$ & $\begin{array}{c}234 \\
(16+-368)\end{array}$ & $\begin{array}{c}325 \\
(278-391)\end{array}$ \\
\hline $\begin{array}{l}\text { Exposed to cold } \\
\text { and fasted }\end{array}$ & 5 & $\begin{array}{c}89 \\
(6 I-117)\end{array}$ & $\begin{array}{c}3^{6} 3 \\
(202-583)\end{array}$ & $\begin{array}{c}\text { II } 6 \\
(72-164)\end{array}$ & $\begin{array}{c}126 \\
(105-150)\end{array}$ \\
\hline $\begin{array}{l}\text { Exposed to cold } \\
\text { and fed }\end{array}$ & + & $\begin{array}{c}14+4 \\
(102-190)\end{array}$ & $\begin{array}{c}+72 \\
(39+-6 \times 5)\end{array}$ & $\begin{array}{c}182 \\
(150-231)\end{array}$ & $\begin{array}{c}228 \\
(198-263)\end{array}$ \\
\hline
\end{tabular}

* Organ weights in milligrams. Figures in parentheses represent ranges within each group.

thymus, spleen, cervical, and mesenteric nodes were weighed. The data obtained are presented in table 4.

It would seem reasonable and in agreement with Selye $\mathrm{e}^{7}$ to conclude that exposure to cold constitutes a stimulus which will cause a significant absoluteweight reduction in the organs studied and that this weight reduction may be partially prevented by the administration of food.

\section{Relationships betivenn Endocrines and the Thymus, Spleen, AND LYMPH NODES}

Experiments involving the effect of certain hormonal treatments or deficiencies on the thymus have in turn led to a consideration of the role of certain endocrine glands in affecting the gross amount of 1 ymph-node tissue in the body.

In this laboratory, studies have been made of the effect of adrenalectomy, castration, and hypophysectomy. The adrenalectomized animal maintained on 1 per cent $\mathrm{NaCl}$ solution has shown significant increases in certain of the lymph-node groups (Reinhardt and Holmes ${ }^{8}$ ). Castration causes a significant enlargement of thymus, spleen, and lymph nodes (Reinhardt and Wainman ${ }^{9}$ ). These findings are in accord with those of Chiodi ${ }^{3}$ and of Houssay and coworkers. ${ }^{10}$ Preliminary studies show that hypophysectomy causes a decrease in the weight of thymus, spleen, and cervical lymph nodes, but not of the mesenteric lymph nodes. Administration of desiccated thyroid gland orally to nor- 
mal rats causcs a marked weight increase in lymph nodes and spleen, but not in the thymus. Testosterone propionate and estradiol dipropionate have only moderate reducing effects on the weight of the lymph nodes as contrasted with the usual marked involuting effects on the thymus gland. Interesting is the fact, however, that testosterone propionate will prevent the increase in the weight of lyniph nodes which follows castration of the male rat (Reinhardt and Wainman ${ }^{9}$. Other preliminary experiments indicate that anterior pituitary grow th hormone will cause increase in weight of thymus and lymph nodes in both normal and hypophysectomized animals, but will not produce enlargement of lymph nodes of the hypophysectomized rat when the food intake is restricted to the level of untreated hypophysectomized animals. This places further emphasis on the role of nutritive substances in the maintenance of the normal amounts of lymph-node tissue in the body. Further experiments are planned to show the role of certain vitamins in this respect.

\section{SUMMARY}

(1) Normal Growth and Involution. Studies of the weights of thymus, spleen, cervical and mesenteric lymph nodes in a series of $28_{4}$ rats of both sexes and of various ages (birth to 7 months) have been used as the basis for the construction and comparison of the curves for growth in weight of these organs. The cervical and mesenteric nodes have a period of growth and involution in weight which is comparable to that of the thymus and spleen with certain exceptions which are discussed. The absolute-growth curves for male and female animals for the thymus, cervical and mesenteric nodes are generally the same in form. The maximum absolute weight of the thymus is reached at about the age of 40 days, of the spleen, cervical and mesenteric nodes between the ages of 60-10o days. After the attainment of maximum absolute weight there is a decline in weight which is most rapid for the thymus and least for the mesenteric nodes. Maximum relative weights are attained for the thymus, spleen, and mesenteric nodes at about 35 days of age $\left(25^{-} 50\right)$, whereas the cervical nodes attain their maximum at about 100 days. There is a rapid decline in the relative weight of the thymus and a less rapid decline in the relative weights of the spleen, cervical and mesenteric lymph nodes. One may speak of a weight increase and a weight involution, of a greater or lesser degree, depending on the organ concerned, over the period of the life span of the rat here studied.

(2) Reaction of Lymph Nodes, Thymus, and Spleen to Fasting, and Exposure to Cold and Certain Hormonal Stimuli. Employment of quantitative measurements of changes in weight of the above structures demonstrates that the rapid weight involution which characterizes the reaction of the thymus to fasting and cold is also found to occur in the case of the spleen and lymph nodes. Certain hormonal stimuli which are known to enlarge or decrease the size of the thymus are cliscussed as exerting a generally comparable effect on lymph nodes and spleen. 


\section{REFERENCES}

1. Donaldson, H. H.: Mems. Wistar Inst. Anat. \& Biol. no. 6, 192.4.

2. Chiodi, H.: El Timo en Relación con el Crecimiento y la Función Sexual (Thesis; Buenos Aires: 1938).

3. Chiodi, H.: Rev. Soc. argentin. de biol. 14:74, 1938.

4. Plagge, J. C.: Jl. Morphol. 68:519, 1941.

5. Job, T.: Anat. Record. $9: 447,1915$.

6. Hellman, T. J.: Upsala läkareförengs. förhdlr. (n.f.) 19 (supp.), $19^{1} 4$.

7. Selye, H.: Endocrinology 21:169, 1937 .

8. Reinhardt, W. O., and Holmes, R. O.: Proc. Soc. Exper. Biol, \& Med. 45:267, 1940.

9. Reinhardt, W. O., and Wainman, P.: Proc. Soc. Exper. Biol. \&. Med. 49:257, 1942.

10. Houssay, B. A.; del Castillo, E. B., and Pinto, A.: Rev. Soc. argentin de biol. 17:26, 1941. 



\title{
THE SELF-SELEGTION OF DIETS
}

\author{
By
}

CURT P. RICHTER

篦

From the

PSYCHOBIOLOGICAL LABORATORY, PHIPPS CLINIC

JOHNS HOPKINS HOSPITAL

BALTIMIORE, MARYLAND 



\section{THE SELF-SELEGTION OF DIETS}

D RING the last three decades workers in agricultural stations and in nutrition laboratories have made sporadic attempts to test the ability of animals to select their own diets. Evvard ${ }^{1,2}$ reported the first observations on farm animals. He found that hogs which had access to a number of different foodstuffs-whole meal, meat meal (6o per cent protein), whole oats, linseed-oil meal, wheat middlings, charcoal, limestone, salt, water, all offered in separate containers-showed excellent growth. One hog was the largest that had been raised at the Iowa Agricultural Station. Pearl and Fairchild ${ }^{3}$ reported that chickens which had access to a variety of natural foods grew better than those that were given the regular diet. Dovet also found that chickens thrived on

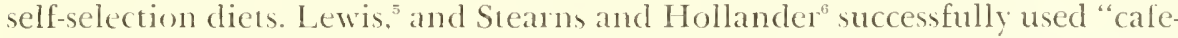
teria" feeding systems for pigeons. The latter authors found that choices made from corn, peas, wheat, and kaffir corn, offered in separate compartments, greatly speeded up egg production and spillage and wastage of food were reduced. Godden ${ }^{\top}$ found that animals grazing on uncultivated pastures selected grass from parts of the pastures which had a higher mineral content. Orr ${ }^{8}$ has reported numerous instances of self-selection of diets in cattle. One of the most common observations is that animals that graze in pastures with a low phosphorus content manilest a craving for foods with a high phosphorus content. The observations made by Theiler, Green and Viljoen on cattle in South Africa constitute a classical example of reactions of animals to a phosphorus-deficient diet. Osborn and Mendel ${ }^{10}$ made the first self-selection studies on rats under laboratory conditions. They found that when rats were offered pairs of diets, one inferior, the other superior, the rats regularly selected the latter. Mitchell and Mendel ${ }^{11}$ later made similar observations. Studies have also been made on human beings, most notably by Davis, ${ }^{12,13}$ who found that very young children given a free choice of a great variety of natural foods grew and thrived. Sometimes for several days a child ate scarcely anything but eggs, or large amounts of fats, and the intake of the different foods fluctuated markedly from day to day, or week to week. Sweet ${ }^{14}$ has also reported favorable results of free-choice methods of feeding children.

In most instances workers interested in self-selection studies have based their studies on the belief that animals or human beings could make beneficial selections only from so-called natural foods, that is, foods which were natural to animals of a given species. More recent experiments, in which it was shown that rats are able to make beneficial selections from purified substances, have opened up a new attack on the problems concerned with the self-selection of diets. From these studies, made chiefly on rats, we have learned the following principles:

1. Normal rats make beneficial selections from purified substances: carbohydrates, fats, proteins, minerals, vitamins. Rats have been kept several hundred days on a choice of sixteen purified substances offered in separate 
containers, using dextrose or sucrose as a source of carbohydrate, casein (autoclaved and purified) for protein, and olive oil for fat; crystalline thiamin chloride, riboflavin, nicotinic acid, pyridoxin, pantothenic acid, and choline chloride as representatives of the vitamin B complex; cod liver oil for vitamins A and D; and solutions of sodium phosphate, sodium chloride, calcium lactate, magnesium chloride, and potassium chloride for the minerals. Some of these rats grew at a normal rate and showed regular vaginal smear cycles (Richter and Hawkes ${ }^{15}$ ).

2. Rats kept on a vitamin-deficient diet will seek vitamins or substances which help to replace vitamins. Thus, rats kept on this self-selection diet without any of the vitamin B factors will eat large amounts of yeast or liver when these substances are offered to them and as a result quickly correct their deficiency. If not given access to a source of the $B$ complex the rats will eat almost no carbohydrate, but take large amounts of fat, which apparently can be at least partially metabolized under these circumstances (Richter, Holt, Barelare and Hawkes ${ }^{16}$ ).

3. The appetite for carbohydrate and fat always shows an inverse relationship. When rats have a marked craving for fat, they refuse carbohydrate and vice versa. Many instances of this relationship have been observed. Thus, vitamin B-deficient rats stop eating carbohydrate and eat large amounts of fats. Almost at once after they have access to vitamin B in the form of yeast, they reverse their appetites, stop eating fat and eat large amounts of carbohydrate. Rats made diabetic by pancreatectomy stop eating carbohydrate and start eating fat, then when treated with insulin reverse their appetite. After ligature of the bile duct, rats stop eating fat and start eating carbohydrate. Spontaneous changes in appetite for fat are always accompanied by inverse changes in the carbohydrate appetite.

4. The appetites for carbohydrate, fat, and protein, are dependent to a large extent on the amount of the various components of the vitamin $B$ complex present in the diet. By varying the combination of vitamin $\mathrm{B}$ components made accessible to the rats we are able almost at will to make a rat manifest a marked appetite or a marked aversion for either carbohydrate, fat, or protein. In the absence of all vitamin $B$, rats eat large amounts of fat, little or no carbohydrate, and no protein. When thiamin chloride is made available as the sole representative of the vitamin B complex they eat carbohydrate, little fat, and still completely avoid protein. Progressively, as the other components are made available they eat more carbohydrate, less fat, more protein. When thiamin chloride, riboflavin, nicotinic acid, pyridoxin, pantothenic acid, choline chloride, and biotin are made available they thrive on a diet of very little fat, high carbohydrate, and moderately high protein.

5. Bulk apparently is not necessary. On the self-selection diets in which only purified substances were used, bulk was reduced to a minimum. The animals passed only a few small feces. The good health of the rats showed that bulk was unnecessary. 
6. Diets self-selected from purified or nearly purified substances are more cfficient than regular syntinetic stock diets or diets composed of natural foods. Rats which selected their diets from sucrose, olive oil, cascin, frve mineral solutions, cod liver oil, and yeast ate approximately 35 per cent less food per day as measured in grams, than rats of the same age and weight on the stock diet. However, owing to the higher fat content of the self-selection diet, the caloric intake on the latter was only 18.7 per cent less than that of the animals on the stock food (Richter, Holt and Barelare ${ }^{17}$ ). Experiments on dietary selections of pregnant and lactating rats offered the same choice of substances gave the most striking evidence for the efficiency of the self-selected diets. They showed a greatly increased appetite for protein (casein), fat (olive oil), calcium and phosphorus. At the height of lactation, rats on the self-selection diet nursing the same number of young ingested only about half as much food as measured in grams as rats on the stock diet. Despite the much lower food intake, the mother and voung remained in excellent shape and the young were normal in size. Presumably the lowered food intake of the rats on self-selection diets is directly due to the ability to obtain the needed calcium, phosphorus, etc., without being forced to take increased amounts of the other unneeded components of the mixed diet (Richter and Barelare ${ }^{18}$ ).

7. Rats deprived of endocrine secretions which regulate metabolism of carbohydrates, fats, proteins, or electrolytes, will when given the opportunity, select substances which compensate for the loss of the secretions. Thus, adrenalectomized rats compensate for the increased excretion of sodium by ingesting large amounts of sodium solutions and as a result keep themselves alive and free from symptoms of insufficiency. Likewise, parathyroiclectomized rats manifest a greatly increased appetite for solutions of calcium, or for the closely related metals, magnesium and strontium (Richter and Eckert ${ }^{19}$ ). By virtue of the increased intake of these metals they not only survive but remain free from symptoms of tetany. Rats made diabetic by removal of the pancreas select substances, chiefly fat, which help to alleviate or even eliminate diabetic symptoms. They actually gain weight, lose their polydipsia, polyphagia, and hyperglycemia (Richter and Schmidt ${ }^{20}$ ).

8. The self-selection activities of rats may be used to determine functions of various glands and may serve to short-circuit prolonged biochemical investigation. For example, it took biochemists many decades to determine that the adrenal glands play an important part in the regulation of sodium metabolism. Endless studies of the mineral content of the blood, urine, and feces were made before this result was achieved. With the self-selection technique, by offering adrenalectomized rats access to a variety of substances in purified form, we could have determined within a few days, and long before the advent of modern biochemical methods, that the adrenal glands are concerned with the regulation of sodium metabolism. In the same way we could have determined that the parathyroids are concerned with the regulation of calcium metabolism. Thus far this method has indicated that riboflavin is concerned with the 
metabolism of fat. Mannering, Lipton and Elvehjem ${ }^{21}$ have recently arrived at this conclusion on the basis of their biochemical studies. Our results have also indicated that protein metabolism is largely dependent on the vitamin $B$ complex.

9. The self-selection technique may be used to bio-assay hormone and vitamin preparations. Thus, the increased calcium lactate appetite of parathyroidectomized rats has been used to bio-assay vitamins which affect calcium metabolism. It was found that the calcium lactate intake could be reduced to approximately its normal level by 3,730 irradiated vitamin $\mathrm{D}$ units per kilogram body weight of vitamin $\mathrm{D}_{2}$ (crystalline); 8,880 units of irradiated ergosterol; 3,380 units of vitamin $\mathrm{D}_{3}$ (crystalline); or by 3,770 units of irradiated cholesterol. Daily doses of dihydrotachysterol (A.T. 10) in minute amounts, $35 \mu$ g. suffice to decrease the daily calcium lactate intake to its normal level. Parathyroid extract injected daily did not reduce the calcium lactate intake to its normal level until doses of 100 units per day were administered. This dosage was definitely toxic (Richter and Birmingham ${ }^{22}$ ). Similar assays have been made on the sodium regulatory functions of desoxycorticosterone using the sodium chloride appetite of adrenalectomized rats as a measure.

10. The maintenance of the total caloric intake at its normal level prevents the appearance of deficiency and other disturbances. It was found that when rats are forced to consume added calories with their drinking water they will reduce the caloric intake from their food in direct proportion to that taken from the other source. Thus, rats given a 16 per cent solution of alcolol as the sole source of water reduced their food intake directly in proportion to the caloric value of the ingested alcohol. This meant that the total caloric intake remained the same. That this actually was a beneficial selection is shown by the fact that rats which have been forced for over one hundred days to take

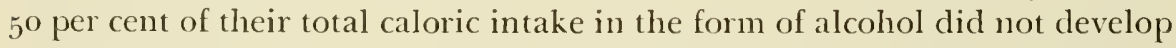
any deficiency symptoms. It may be that in human beings similar effects from the use of alcohol depend on the fact that the caloric intake from the food added to that from the alcohol gives a total caloric intake which far surpasses the normal caloric requirements. If forced to take sugar in the same way, rats will reduce their food intake so that the total does not surpass the normal level (Richter ${ }^{23}$ ).

11. Solutions preferred in any concentration to water by the rats are apt to have mutritional value, while those which are not preferred to water in any concentration are apt to have no nutritional value or to be toxic. Thus, rats were found to prefer solutions of the following substances to water: dextrose, maltose, levulose, sucrose, galactose, sodium chloride, potassium chloride, calcium lactate, alcohol-all of which are known to have a nutritional value. On the other hand, they were found to prefer water to solutions of the following substances: mercuric chloride, morphine sulphate, arsenic trioxide, phenylthiocarbamide-all of which are known to be poisonous (Richter and Campbell $\left.{ }^{24}\right)$. 
12. Taste thresholds may vary with internal needs. Taste-threshold tests showed that normal rats were able to distinguish sodium chloride solution from water in concentrations of 1:2,000, while adrenalectomized rats, which have much lower blood-sodium values, due to the increased excretion of sodium from the body, made the distinction in solutions of 1:33,000 (Richter and McLean ${ }^{25}$ ).

13. Rats and human beings have almost identically the same taste thresholds. Thus, the taste thresholds were practically the same for sodium chloride 0.055 per cent for rats, 0.087 per cent for human beings); for sucrose ( 0.5 and 0.41 per cent respectively); for phenylthiocarbamide 0.0003 and 0.0003 per cent respectively) (Richter and Clisby ${ }^{26}$ ).

14. The ability to make beneficial selections apparently depends upon taste, not on experience or the effects produced by the substances. After section of taste nerves, adrenalectomized rats no longer selected salt. The lower taste threshold of adrenalectomized rats also brings evidence to support this view. Rats showed an increased appetite for salt solution in concentrations which could not possibly have had any physiological effect.

15. Inability to make beneficial selections may depend on inherited taste defects, that is, on the inability to taste certain substances. Salmon and Blakeslee $^{2 \tau}$ and Blakeslee $e^{2 s}$ showed that a small percentage of people are unable to taste the bitter phenylthiocarbamide. We have found many individuals who are unable to taste sucrose in concentrations as high as 16 per cent, or riboflavin in crystalline form. Blakeslee and Fox $^{20}$ and Snyder ${ }^{30}$ reported that inability to taste phenylthiocarbamide is inherited as a Mendelian recessive. Some of our observations indicate that the inability to taste riboflavin and alcohol may also be inherited.

16. All of the various types of self-selection behavior form part of Claude Bernard's concept of the constancy of the internal environment. Bernard ${ }^{31}$ and Cannon $^{32}$ pointed out and enumerated physiological mechanisms which help to maintain homeostasis, or a steady state. These self-selection experiments have shown that behavior mechanisms, that is, responses of the total organism, are used to maintain a constant internal environment $\left(\right.$ Richter $\left.^{33}\right)$.

\section{REFERENCES}

1. Evvard, 1. M.: Proc. Iowa Acad. Scis. 22:375. 1915 .

2. Evrard. J. M.: Iowa Agricult. Exper. Statn. Bull. no. 118 , 1929.

3. Pearl, R., and Fairchild, T. E.: Amer. Jl. Hyg. 1:253. 1921.

4. Dove, W. F.: Amer. Naturlst. 69:469, 1935.

5. Lewis, S. L.: Amer. Pigeon Jl. 16:211, 1927.

6. Stearns, G. I.. and Hollander, W'. F.: Amer. Pigeon J1. 28:35.5, 1939.

7. Godden. W: J1. Agric. Sci, 16:-8, 1926.

8. Orr, J. B.: Minerals in Pastures (London: 1929).

9. Theiler, 1.: Green. H. H., and Viljoen. P. R.: Repts. Director Veterin. Resich., Inion South Africa $3 / 4: 9.1915$.

10. Osborn, T. B., and Mendel, L. B.: J1. Biol. Chem. 20:351, 1915.

11. Mitchell, H. S., and Mendel, L. B.: Amer. Jl. Physiol. 58:211, 1921. 
12. Davis, C. M.: Amer. Jl. Diseases Childr. 36:651, 1928.

13. Davis, C. M.: Amer. Jl. Diseases Childr. 46:743, 1933 .

1.4. Sweet, C.: Jl. Amer. Med. Assn. 107:765, 1936.

15. Richter, C. P., and Hawkes, C. D.: Amer. Jl. Physiol. 131:639, 1941.

16. Richter, C. P.; Holt, L. E., Jr.; Barelare, B., Jr., and Hawkes, C. D.: Amer. JI. Physiol. $124: 596,193^{8}$.

17. Richter, C. P'; Holt, L. E., Jr., and Barelare, B., Jr.: Amer. Jl. Physiol. 122:734, $193^{8}$.

18. Richter, C. P., and Barelare, B., Jr.: Endocrinology 23:15, 1938.

19. Richter, C. P., and Eckert, J. F.: Amer. Jl. Med. Scis. 198:9, 1939.

20. Richter, C. P., and Schmidt, E. C. H., Jr.: Endocrinology 28:179, 1941.

21. Mannering, G. J.; Lipton, M. A., and Elvehjem, C. A.: Proc. Soc. Exper. Biol. \& Med. 46: $100,19.1$.

22. Richter, C. P., and Birmingham, J. R.: Endocrinology 29:655, 1941 .

23. Richter, C. P.: Quart. Jl. Studies Alcoh. 1:65o, 1941.

24. Richter, C. P., and Campbell, K. H.: Jl. Nutrit. 20:31, 1940.

25. Richter, C. P., and MacLean, A.: Amer. Jl. Physiol. 126:1, 1939.

26. Richter, C. P., and Clisby, K. H.: Amer. Jl. Physiol. 134:157, 1941.

27. Salmon, T. N., and Blakeslee, A. F.: Proc. Natn. Acad. Scis. $21: 78,1935$.

28. Blakeslee, A. F.: Proc. Natn. Acad. Scis. 18:120, 1932.

29. Blakeslee, A. F., and Fox, A. L.: Jl. Hered. 23:97, 1932.

3o. Snyder, L. H.: Ohio JI. Sci. 32:436, 1932.

31. Bernard, C.: Leçons sur les Propriétés Physiologiques et les Altérations Pathologiques des Liquides de l'Organisme (Paris: $18_{59}$ ).

32. Cannon, W. B.: The Wisdom of the Body (New York: 1932).

33. Richter, C. P.: Psychosom. Med. 3:105, 1941. 
THE RELATIONSHIP OF THE ANTERIOR PITUITARY TO THE THYROID AND THE ADRENAL CORTEX IN THE GONTROL OF CARBOHYDRATE METABOLISM

$$
\text { By }
$$

JANE A. RUSSELL

$$
\text { 称 }
$$

From the

DEPARTMENT OF PHYSIOLOGICAL CHEMISTRY

YALE UNIVERSITY SCHOOL OF MEDICINE NEW HAVEN, CONNECTICUT 



\section{THE RELATIONSHIP OF THE ANTERIOR PITUITARY TO THE THYROID AND THE ADRENAL CORTEX IN THE CONTROL OF CARBOHYDRATE METABOLISM}

$\mathrm{I}^{\mathrm{N}}$

THE PAST several years, the anterior pituitary gland has been shown to have important functions in the control of the intermediary metabolism of carbohydrate and of protein, and directly or indirectly in that of fat. The determination of the precise role of any hormone in metabolism is difficult, but in the case of the anterior pituitary it is the more so because of the manifold activities of this gland. Particularly, complications arise from the trophic control by the anterior pituitary of two other endocrine organs which are known to affect certain phases of metabolism-the thyroid and the adrenal cortex. Thus, the removal of the hypophysis brings about extensive atrophy of these glands, and extracts of the anterior pituitary contain factors which affect the activity of these glands and which are to be separated, chemically or physiologically, from those other factors which may exert direct effects on metabolic activities. Much of the work of recent years which has sought to define the nature of hormonal control of metabolism has of necessity been devoted to the interrelationships between the hormones of the anterior pituitary, thyroid, and adrenal cortex. Since most of these studies have been in the field of carbohydrate metabolism, this discussion will be confmed to that subject. It must be remembered, however, that whenever changes occur in the metabolism of carbohydrate inevitably changes also are to be expected in fat and often also in protein metabolism. These may be very important, or they may eren be primary to alterations in carbohydrate metabolism; it is only because of a scantiness of data bearing on the interrelations of the homones in these fields that they are mentioned here but briefly, as they seem related directly to the topic in hand.

The chief effects of the removal of the anterior pituitary gland or of treat ment with anterior pituitary extracts on metabolism are now familiar phenomena and many phases of these subjects have been reviewed. ${ }^{1-4}$ The outstanding facts may be again outlined here, before they are analyzed with respect to the various hormonal factors affecting them. The first strong indication of a relationship of the anterior pituitary to carbohydrate metabolism was the observation by Houssay, in 1924. of the remarkable hypersensitivity to insulin of hypophysectomized animals. This discovery was followed by that which is now called the Houssay effect-the amelioration of pancreatic diabetes by hypophysectomy. Then the diabetogenic effects of anterior pituitary extracts were demonstrated-the induction of states simulating pancreatic dia- 
betes by the administration of APE* to so-called "Houssay" animals and later to normal animals of many species. Permanent diabetes, lasting long after the cessation of APE injections, was first observed by Evans and collaborators and later extensively studied by Young, ${ }^{3}$ Campbell and Best, ${ }^{5}$ Dohan, Fish and Lukens, ${ }^{B}$ and others. This permanent diabetes, observed so far only in dogs, has now been ascribed to damage to the pancreatic islets induced by unknown mechanisms during the prolonged administration of APE. The temporary diabetes first observed, however, continues to be considered of direct pituitary origin. All these observations have been many times confirmed, and many other metabolic effects of APE have also been demonstrated-the glycotrophic or anti-insulin effect (in which all trace of insulin action may be prevented by suitable preparatory administration of APE to the experimental animals), the pancreotrophic effect, the power of increasing the content of liver fat by transference of fat from peripheral depots, the ketogenic factor, and the glycostatic effects-among them.

In recent years, in work on small animals such as the rat and rabbit, it has been possible to investigate the role of the anterior pituitary in metabolism with more precision than is usually possible in larger animals, such as the cat and $\mathrm{dog}$, in which most of the earlier work was done; and most of the work defining the interrelationships of the hormones has been carried out on the smaller animals. In the rat, rather complete studies have been made of the effects of hypophysectomy upon the metabolism of carbohydrate. Hypophysectomized rats, like other species of such animals, exhibit atrophy of the thyroid, adrenals, and gonads, and fail to grow, but as long as they are well fed, they do not show any great abnormalities in their metabolism of carbohydrate except an extreme hypersensitivity to insulin. However, when these animals are fasted, differences from the normal are at once apparent. In as short a time as eight hours after the removal of food, glycogen is found to have disappeared almost entirely from the liver, and the blood sugar has begun to fall rapidly. At about this time the muscle glycogen content begins to fall, and by the time the animal has been fasting 16 to 18 hours, the muscle glycogen may be only half its normal value, whereas of course in normal animals the muscle glycogen is ordinarily quite stable for long periods of fasting. ${ }^{7}$ During this period of carbohydrate depletion, the $\mathrm{RQ}$ of the hypophysectomized rats is higher than that of the normal, and sufficiently so to indicate that the rapid rate of glycogen loss could have been due to more rapid oxidation of carbohydrate. ${ }^{8}$ Similar studies have not as yet been completed in other species than the rat; but the loss of liver glycogen and rapid decline of the blood sugar has been observed frequently. Cope ${ }^{9}$ and others have shown clearly in hypophysectomized rabbits that a rapid loss of liver glycogen and subsequent decline in the blood sugar sets in during fasting and something like this situation also is found in hy-

* APE refers to anterior pituitary extracts, without distinguishing between any of the various types of cxtract. In most cases a crude, or at least not highly purified, extract was used, which contained many of the several anterior pituitary factors. 
pophysectomized cats, ${ }^{10}$ but in these cases the changes occur more slowly than in rats. In the fasted hypophysectomized rat the abnormal loss of muscle glycogen can be prevented entirely by APE administration and the RQ is depressed to normal at the same time. . 11, $12^{2}$ This action-the maintenance of fasting muscle-glycogen levels in hypophysectomized animals-has been defined as the glycostatic effect, and it can be used to assay APE. The term is also sometimes applied to the effects of APE on liver-and blood-carbohydrate levels, in normal as well as in hypophysectomized animals, but, as will be evident later, these data do not always afford trustworthy evidence of glycostatic activity.

Two possible explanations exist for the apparent rapid rate of disappearance of carbohydrate in the absence of the pituitary and its prevention by APE. One is, of course, that the rate of oxidation of carbohydrate is increased. The other is that, since ordinarily the carbohydrate levels are maintained during fasting by ghuconeogenesis, interruption in this process occurs in hypophysectomized animals and a normal rate of peripheral oxidation permits the apparently more rapid disappearance of carbohydrate. However, there is not a sufficient fall in the rate of excretion of nitrogen after hypophysectomy in the rat to make a critical difference in gluconeogenesis probable. In addition, data obtained from experiments on rats fed glucose and on eviscerated animals indicate that an accelerated rate of peripheral oxidation of carbohydrate exists in the hypophysectomized animal.

One of the first, but still most convincing, of these experiments was one in which hypophysectomized and normal rats, after being fasted, were fed meals of carbohydrate (starch) and the glycogen and blood-sugar values followed for $3^{6}$ hours thereafter. It was found that the hypophysectomized rats conld be fed twice as much carbohydrate as the normal rats and at the end of the experimental periods still have much lower levels of liver and muscle glycogen than the control animals. That is, despite metabolic rates one-third below normal, the liypophysectomized rats must have disposed of twice as much carbohydrate as the normal animals in the given time. ${ }^{7}$ Further demonstration of the increased rate at which hypophysectomized animals dispose of carbohydrate is seen, together with an indication of its fate, in balance studies of the Cori type (table 1). ${ }^{13}$ In this case, a much smaller proportion of the absorbed glucose was recovered 4 hours after its feeding in the hypophysectomized rat than in the normal, and respiratory data obtained during the absorption period indicated that the carbohydrate which clisappeared could have been oxidized. Now if one is to explain the difference between the findings in the normal and the hypophysectomized rats on the basis only of a decrease in gluconeogenesis in the latter case, lhen one would have to assume that massive gluconeogenesis had taken place in the nommal animals under these conditions-in an amount equal to about half of the carbohychate deposited-in the presence of a plethora of carbohydrate. 
Anterior pituitary extract, administered to normal or to hypophysectomized rats, in experiments of exactly similar type to those described above, reverses the direction of the clunges. In the hypophysectomized animal, the restoration to normal by APE is not quite complete, but in normal animals the changes are striking. There is a marked fall in the $R Q$ and increased deposition of muscle glycogen, but not of liver glycogen. This fall in the $\mathrm{RQ}$ in glucose-fed animals has been used as the basis of assay of APE for metabolic effects. ${ }^{13,14}$

TABLE 1

Disposition of Fed Glucose in Rats

(4 hours after feeding)

\begin{tabular}{|c|c|c|c|c|c|c|}
\hline & \multirow{2}{*}{$\begin{array}{c}\text { No. of } \\
\text { obser- } \\
\text { vations }\end{array}$} & \multicolumn{4}{|c|}{$\begin{array}{c}\text { Carbohydrate recovered (per cent of } \\
\text { absorbed glucose) as }\end{array}$} & \multirow{2}{*}{$\begin{array}{l}\text { Carbohydrate } \\
\text { oxidized } \\
\text { (calculated from } \\
\text { respiratory data) } \\
\text { per cent of } \\
\text { absorbed glucose }\end{array}$} \\
\hline & & $\begin{array}{c}\text { Tissure } \\
\text { glucose }\end{array}$ & $\begin{array}{c}\text { Muscle } \\
\text { glycogen }\end{array}$ & $\begin{array}{c}\text { Liver } \\
\text { glycogen }\end{array}$ & Total & \\
\hline Normal rats. & 19 & 3 & $16 \pm I^{*}$ & $16.5 \pm 0.7$ & $35 \cdot 5$ & $+9 \cdot 5 \pm 1 \cdot 3$ \\
\hline $\begin{array}{l}\text { Hypophysectomized rats. } \\
\text { Difference from normal. }\end{array}$ & $\begin{array}{l}13 \\
\cdots\end{array}$ & 2 & $\begin{array}{l}9 \pm 2 \\
\cdots\end{array}$ & $\begin{array}{l}6.5 \pm 0.7 \\
\ldots \ldots \ldots\end{array}$ & $\begin{aligned} & 17 \cdot 5 \\
- & 18\end{aligned}$ & $\begin{aligned} & 68.5+2.0 \\
+ & 19\end{aligned}$ \\
\hline $\begin{array}{l}\text { Normal rats given APE } \dagger . \\
\text { Difference from normal. }\end{array}$ & $\begin{array}{l}7 \\
\cdots\end{array}$ & 5 & $\begin{array}{l}27 \pm 4 \\
\cdots\end{array}$ & $\begin{array}{l}17.2 \pm 2.4 \\
\ldots \ldots \ldots\end{array}$ & $\begin{aligned} &+9 \cdot 2 \\
&+1+\end{aligned}$ & $\begin{aligned} & 28.8 \pm 2.4 \\
- & 21\end{aligned}$ \\
\hline
\end{tabular}

* Standard error.

$\uparrow$ Saline anterior pituitary extract, $1 \mathrm{ml}$. given intraperitoneally 1 to 2 hours before glucose feeding.

Additional evidence that the anterior pituitary affects peripheral oxidation of carbohydrate has been obtained in eviscerated or hepatectomized animals. The first positive indication that APE had a peripheral action was obtained by Marks, ${ }^{15}$ who found that it prevented the deposition of muscle glycogen following insulin administration in eviscerated cats. Himsworth and Scott ${ }^{16}$ continued this work by determining the relative effects of APE and insulin on the survival time of functionally hepatectomized rabbits. The data in table 2, taken from their paper, where the time between hepatectomy and the occurrence of hypoglycemic convulsions measures inversely the rate of fall of the blood sugar, shows that the APE prevented the hypoglycemic effects of insulin in the absence of the liver.

More recently, the metabolism of the hypophysectomized eviscerated preparation has been studied. Greeley ${ }^{17}$ first determined that hypophysectomized rabbits, in which the blood sugar falls very rapidly when they are fasted, require the administration of glucose at the rate of about $5^{\circ o} \mathrm{mg}$. per kilogram per hour to maintain normal blood-sugar levels. Of course, the normal rabbit requires no extra glucose beyond that which it makes itself. Now this large glucose requirement has been found to persist unchanged in the absence of the liver or of the abdominal viscera, and it is several times the amount needed by the normal eviscerated rabbit $\left(\right.$ Drury ${ }^{18}$ ). This abnormally great 
peripheral use of glucose after hypophysectomy has been found now also in the eviscerated rat, and in addition it has been shown not to be due to increased deposition of muscle glycogen or to lactic acid formation (Russell ${ }^{19}$ ). In fact, in the absence of added glucose, a loss of muscle glycogen occurs in

TABLE 2

Anterior Pitutitary Extract and Insulun in Hepatectomized Rabitis.

(From Himsworth and Scott)

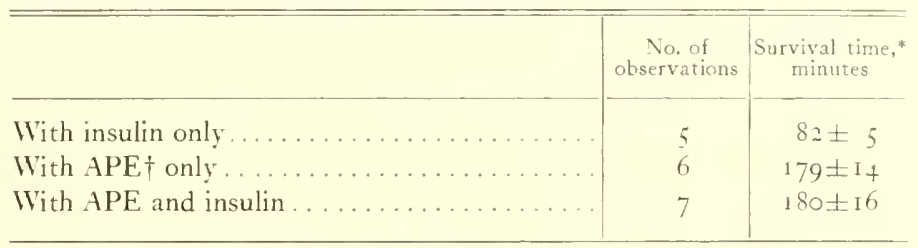

* Time after hepatectomy until convulsions occurred.

† Young's glycotrophic extract.

the hypophysectomized eviscerated rat (but not in the normal animal), which can be prevented by pretreatment of the animal with APE, just as in the intact fasted rat. The rate of fall of the blood sugar after evisceration in the rat is also increased by hypophysectomy and diminished by APE (table 3).

TABLE 3

Carbohydrate Metabolism in Eviscerated Rats

\begin{tabular}{|c|c|c|c|}
\hline & $\begin{array}{l}\text { Rate of fall in } \\
\text { blood sugar, } \\
\text { mg. per cent } \\
\text { per hour }\end{array}$ & $\begin{array}{l}\text { Rate of change in } \\
\text { muscle glycogen. } \\
\text { mg. per cent } \\
\text { per hour }\end{array}$ & $\begin{array}{l}\text { Glucose required } \\
\text { to maintain } \\
\text { normal blood } \\
\text { sugar level, } \\
\text { mg. per roo gm. } \\
\text { per hour }\end{array}$ \\
\hline $\begin{array}{l}\text { Normal rats (adrenal-demedullated) } \\
\text { Hypophysectomized rats.......... } \\
\text { Hypophysectomized rats given APE } \\
\text { Adrenalectomized rats (salt treated) }\end{array}$ & $\begin{array}{l}37 \pm 3.0 \\
72 \pm 5.8 \\
+7 \pm 3.6 \\
58 \pm 6.7\end{array}$ & $\begin{array}{l}+\quad 2 \pm I I \\
-108 \pm 16 \\
+\quad 1 \pm I 3 \\
-\quad I \pm 7\end{array}$ & $\begin{array}{l}13.5-1+0 \\
26-.30 \\
\ldots \ldots\end{array}$ \\
\hline
\end{tabular}

Thus, since the rapid rate of disappearance of carbohydrate noted after hypophysectomy persists in the absence of the liver, which is the prime site of gluconeogenesis, it can be assumed that there exists an accelerated rate of peripheral oxidation of carbohydrate in the absence of the pituitary.

Many other changes in metabolism observed after hypophysectomy can be associated with a high rate of oxidation of carbohydrate in conditions where ordinarily carbohydrate oxidation is reduced to a minimum-among them the failuxe to recover from insulin hypoglycemia, the fatal hypoglycemia and relative failure of fat and protein metabolism which is found in phlorizinized hypophysectomized animals, and the apparent resmmption of carbohydrate metabolism in the absence of the pancreas. Yet, in none of the latter cases is 
it possible to say whether increased peripheral oxidation is the sole explanation of these changes. Evidence is available that a diminution of gluconeogenesis occurs in the diabetic states after hypophysectomy, and increased gluconcogenesis is associated with the adrenotrophic and with the anti-insulin activities of certain APE. Thus it is possible that the anterior pituitary pro-

TABLE 4

Carbohydrate Levels in Thyroidectomized-Parathyroidectomized Rats

\begin{tabular}{|c|c|c|c|c|c|c|c|}
\hline & $\begin{array}{c}\text { No. of } \\
\text { observa- } \\
\text { tions }\end{array}$ & $\begin{array}{c}\text { Glucose } \\
\text { absorp- } \\
\text { tion, mg. } \\
\text { per 100 } \\
\text { gm. } \\
\text { per hour }\end{array}$ & $\begin{array}{c}\text { Blood } \\
\text { glucose, } \\
\text { mg. } \\
\text { per cent }\end{array}$ & $\begin{array}{l}\text { Liver } \\
\text { glycogen, } \\
\text { per cent }\end{array}$ & $\begin{array}{l}\text { Muscle } \\
\text { glycogen, } \\
\text { mg. } \\
\text { per cent }\end{array}$ & $\begin{array}{l}\text { Oxygen } \\
\text { consump- } \\
\text { tion, } \\
\text { ml. per } \\
\text { 10o gm. } \\
\text { per hour }\end{array}$ & $\begin{array}{c}\mathrm{RQ} \\
\text { (uncorrected) }\end{array}$ \\
\hline $\begin{array}{l}\text { A. Not fasted } \\
\text { Normal rats...... } \\
\text { Thyroidectomized } \\
\text { rats.......... }\end{array}$ & $\begin{array}{l}13 \\
5\end{array}$ & . & $\begin{array}{l}125 \\
92\end{array}$ & $\begin{array}{l}1.7 \\
3.7\end{array}$ & $\begin{array}{l}530 \\
527\end{array}$ & & \\
\hline $\begin{array}{l}\text { B. Fasted } 2_{4} \text { hours } \\
\text { Normal rats ..... } \\
\text { Thyroidectomized } \\
\text { rats ......... }\end{array}$ & $\begin{array}{c}15 \\
12-19\end{array}$ & . & 82 & $\begin{array}{l}0.1 \\
0.1\end{array}$ & $\begin{array}{l}524 \pm 10 \\
+65 \pm 12\end{array}$ & $\begin{array}{l}154 \pm 2 \\
100 \pm 2\end{array}$ & $\begin{array}{l}.725 \pm .005 \\
.719 \pm .003\end{array}$ \\
\hline $\begin{array}{l}\text { C. Fed glucose after } \\
2+\text {-hour fast } \\
\text { hours after feed- } \\
\text { ing) } \\
\text { Normal rats..... }\end{array}$ & 19 & I 85 & 127 & $2.9^{8}$ & $7+8 \pm 18$ & $145 \pm 2$ & $887+.005$ \\
\hline $\begin{array}{l}\text { Thyroidectomized } \\
\text { rats ........... } \\
\text { Thyroidectomized } \\
\text { rats given } \mathrm{APE} .\end{array}$ & 8 & $9^{6}$ & 120 & I. 26 & $\begin{array}{l}58+ \pm 10 \\
667 \pm 12\end{array}$ & $\begin{array}{l}97 \pm 3 \\
111 \pm 5\end{array}$ & $\begin{array}{l}.826 \pm .005 \\
.778 \pm .005\end{array}$ \\
\hline
\end{tabular}

duces some part also of its effects on carbohydrate metabolism by affecting gluconeogenesis. Since the adrenal cortical hormone is now known to promote gluconeogenesis and since thyroid activity may also limit the rates of this and other intermediary metabolic reactions, the roles of the thyroid and adrenal hormones in metabolism must next be examined.

The Thyrotrophic Relationship: One of the first trophic effects of the anterior pituitary to be established was that on the thyroid. In view of the wellknown effects of the thyroid on the metabolic rate of tissues, and therefore presumably upon the rates of many metabolic reactions, it would be reasonable to suppose that some of the effects of the anterior pituitary might be mediated through this gland. However, few comprehensive studies seem to have been made on the metabolism of thyroidectomized animals or on animals made only moderately hyperthyroid with thyroid hormone, so that it is 
difficult to compare in a general manner the cffects of the thyroid to those of the anterior pituitary on carbohydrate metabolism. Of the experimental observations which have been made in this field, most fall into the following classes: (a) loss of glycogen (and fat) reserves in animals given large amounts of thyroxin, due in ail probability to rapid utilization in the lypermetabolic state; (b) abnomalities in glucose tolerance curves, the "diabetic" type being

TABLE 5

Disposition of Fed Glecose in Thyoldectomized Rats Four Hours after Feeding (Calculated from table 4 )

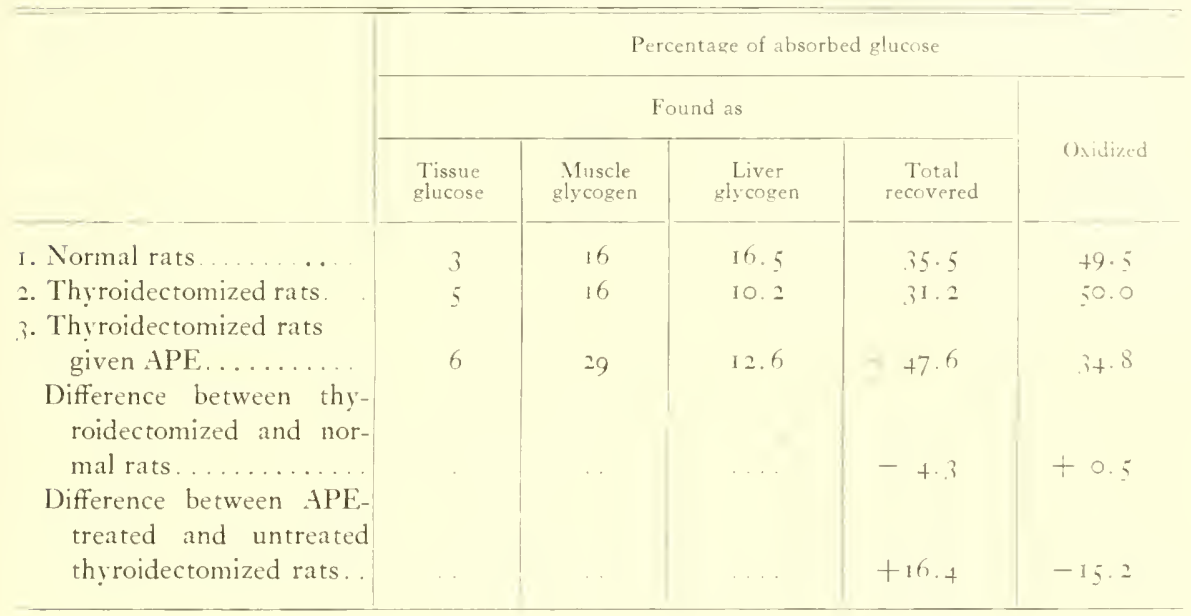

associated with hyperthyroidism; and $(c)$ high absorption rates from the gastrointestinal tract of glucose and of other metabolites in hyperthyoidism and low" absorption rates in hypothyroidism, which, according to Althausen and Stockholm, ${ }^{2 n}$ explain the altered glucose tolerance curves. The latter effect is of interest as demonstrating one specific effect of the thyroid hormone, but its mechanism is still controversial.

Recently, specific attempts have been made to determine whether there is any parallelism between the effects of thyroidectomy and hypophysectomy in carbohydrate metabolism under a number of different circumstances. In thyroidectomized-parathyroidectomized rats (maintained with calcium lactate in their drinking water) the nonfasted carbohydrate levels lie within the normal range (table 4 ). The levels after 2.4 hours of fasting also are practically normal; only the muscle glycogen is slightly low, and this is probably the result of muscular tremors due to the concomitant state of hypoparathyroidism. The RQ is normal; but the oxygen consumption is of course quite low. In thyroidectomized rats fed glucose the expected abnormalities-a low metabolic rate and a low rate of absorption of glucose-are found. However, the distribution of the absorbed carbohydrate is fairly normal, especially as compared 
with that observed in hypophysectomized rats (table 5). Thus, the metabolic rate and absorption rate which are similarly low in hypophysectomized rats would appear to be the result of thyroid atrophy in this condition, but the effects of hypophysectomy on carbohydrate oxidation would seem to be independent of thyroid function.

The effects of thyroidectomy on pancreatic and phlorizin diabetes are of interest, because of the marked diminution of gluconeogenesis found after

TABLE 6

Insulin-Sensitivity Tests in Rats

\begin{tabular}{|c|c|c|c|c|c|}
\hline & $\begin{array}{l}\text { Days post- } \\
\text { operative }\end{array}$ & $\begin{array}{l}\text { Insulin given, } \\
\text { units per kg. }\end{array}$ & $\begin{array}{l}\text { No. of } \\
\text { tests }\end{array}$ & $\begin{array}{l}\text { No. } \\
\text { reacting* }\end{array}$ & $\begin{array}{l}\text { Percentage } \\
\text { reacting }\end{array}$ \\
\hline \multirow[t]{2}{*}{ I. Normal rats. } & $\ldots \ldots$ & $3 \cdot 0$ & 15 & 3 & 20 \\
\hline & & +.0 & 24 & 19 & 79 \\
\hline \multirow[t]{4}{*}{ 2. Hypophysectomized rats.. } & $I-6$ & 0.25 & 3 & 3 & 100 \\
\hline & $\mathrm{I}-6$ & 0.5 & 21 & I 5 & 72 \\
\hline & more than 6 & 0.5 & 40 & 39 & $9^{8}$ \\
\hline & more than 6 & 1.0 & 12 & $1 \mathrm{I}$ & $9^{2}$ \\
\hline \multirow{2}{*}{$\begin{array}{l}\text { 3. Partially hypophysecto- } \\
\text { mized (more than } 1 / 2 \text { an- } \\
\text { terior lobe remaining)... }\end{array}$} & & & & & \\
\hline & more than 8 & 1.0 & 17 & 6 & 35 \\
\hline \multirow[t]{4}{*}{ +. Thyroidectomized rats.... } & $9^{-12}$ & $0.25-2.0$ & $\mathrm{I}_{4}$ & 0 & 0 \\
\hline & more than 18 & $0.25-0.5$ & 5 & 2 & 40 \\
\hline & more than 18 & 1.0 & $1+$ & 8 & 57 \\
\hline & more than 18 & $2.0-3.0$ & 9 & 7 & 78 \\
\hline \multirow{2}{*}{$\begin{array}{l}\text { 5. Thyroidectomized-gonad- } \\
\text { ectomized rats ........ } \\
\text { 6. Thyroidectomized-hy- } \\
\text { pophysectomized rats... }\end{array}$} & $12-18$ & $1.0-3.0$ & 10 & 5 & 50 \\
\hline & more than 18 & 0.25 & 6 & 6 & 100 \\
\hline
\end{tabular}

* Convulsions or deep coma without spontaneous recovery.

hypophysectomy in these conditions. Thyroidectomized-depancreatized animals have been examined many times, with somewhat variable results. Dohan and Lukens ${ }^{21}$ have recently reinvestigated this problem carefully and shown that in cats thyroidectomy reduces glycosuria and nitrogen excretion only slightly-less even than might be expected due to the decrease in metabolic rate. Similarly, phlorizin diabetes was early reported by Houssay ${ }^{22}$ and others to be but little affected by thyroidectomy. Wells and Kendall ${ }^{23}$ recently compared the effects of various procedures on the phlorizin diabetes of rats, and reported that thyroidectomy produced but a barely significant decrease in glucose and nitrogen elimination in this condition, the average excretion rates being 15 per cent low, whereas they were 75 per cent below normal in hypophysectomized rats. From these data, it appears that the failure of gluconeogenesis after hypophysectomy in pancreatic or phlorizin diabetes can be the result of thyroid atrophy in small part only. However, it may be true, as 
suggested by Wells and Kendall, that the activity of the thyoid places always a limit upon such manifestations as gluconcogenesis, and this factor may be of importance when replacement therapy is at tempted.

Hypersensitivity to insulin has often been reported to be present after thyroidectomy. However, when thyroidectomized and hypophysectomized rats are compared in this respect under comparable conditions, it appears that the hypersensitivity after thyroidectomy is much more slowly developed after the operation than is that after hypophysectomy (table 6). Thyroid atrophy therefore probably is not the cause of the sensitivity in the latter condition In addition, the hypersensitivity seems not to be so extreme after thyroidectomy as after hypophysectomy (Goldblatt ${ }^{2 *}$ and table 6). Gonadectomy does not add to the sensitivity of the thyroidectomized animal, so the gonadal atrophy after hypophysectomy cannot contribute to the hypersensitivity. The cause of the hypersensitivity to insulin after thyroidectomy is not known; quite possibly it is the result of hypofunction of the anterior lobe consequent to thyroidectomy, for even very slight damage to the hypophysis may noticeably affect the response to insulin and it is well known that cytological changes of a degenerative nature occur there after thyroidectomy. In any case, the abnormal response to insulin of hypophysectomized animals is probably due only in part, if at all, to thyroid atrophy.

If the thyroid were an important intermediary in the action of the pituitary on carbohydrate metabolism, it would be expected that APE would have less than its usual activity in the absence of the thyroid. However, practically all of the known metabolic effects of these extracts have been observed in thyroidectomized animals. Growth occurs, as shown by Erans and others; nitrogen retention was observed by Gaebler ${ }^{25}$ and ketogenic effects were shown to occur normally when APE was given to thyroidectomized rats by Fry. The contrainsulin effect has been found in rabbits by Himsworth and Scott. ${ }^{16}$ Houssay. Gaebler, and others have reported diabetogenic effects of APE in the absence of the thyroid, and phlorizin diabetes is restored to normal in thyroidectomized-phlorizinized animals. Lastly, in some experiments on glucose-fed rats, APE reduced the RQ and increased muscle-glycogen deposition in thyroidectomized rats just as in normal animals (tables 4 and 5 ).

Finally, replacement of the pituitary by thyroid hormone has been attempted. Thyroid hormone is not diabetogenic in hypophysectomized-depancreatized animals. It has been stated ${ }^{2 \pi}$ to raise the blood sugar of fasted hypophysectomized dogs; this fact may or may not have physiological significance, for a very large amount of the hormone was given, and no record was made of its effect on the metabolic rate to determine whether there may have been overdosage (hypophysectomized animals are very sensitive to thyroxin, and glycogenolysis commonly accompanies overdosage of thyroid hormone). In hypophysectomized rats thyroid hormone, given in amounts sufficient just to raise the metabolic rate to the normal range, did not affect fasting glycogen 
or blood-sugar levels, or the relative disposition of fed carbohydrate. It did restore the glucose absorption rate to normal, the only method by which this has been accomplished so far, and since the metabolic rate was increased, the amount of carbohydrate which was oxidized in the hypophysectomized rats given thyroid hormone was still much greater tban in the normal. ${ }^{28}$ The administration of $\mathrm{APE}$ and thyroxin at the same time to hypophysectomized rats permitted very nearly normal metabolic rates, absorption rates, and peripheral deposition of carbohydrate (table 7 ). Only the liver-glycogen deposition was still quite low.

TABLE 7

Carbohydrate Levels in Hypophysectomized Rats Fed Glucose

(Four hours after feeding)

\begin{tabular}{|c|c|c|c|c|c|c|c|}
\hline Treatment & $\begin{array}{l}\text { No. of } \\
\text { observa- } \\
\text { tions }\end{array}$ & $\begin{array}{c}\text { Glucose } \\
\text { absorbed, } \\
\text { mg. per } \\
100 \text { gm. } \\
\text { per hour }\end{array}$ & $\begin{array}{l}\text { Blood } \\
\text { sugar, } \\
\text { mg. } \\
\text { per cent }\end{array}$ & $\begin{array}{l}\text { Liver } \\
\text { glycogen } \\
\text { per cent }\end{array}$ & $\begin{array}{l}\text { Muscle } \\
\text { glycogen, } \\
\text { mg. } \\
\text { per cent }\end{array}$ & $\begin{array}{c}\text { Oxygen } \\
\text { consump- } \\
\text { tion, } \\
\text { ml. per } \\
\text { 100 gm. } \\
\text { per hour }\end{array}$ & $\begin{array}{c}\mathrm{RQ} \\
\text { (uncorrected) }\end{array}$ \\
\hline $\begin{array}{l}\text { None . . . . . . . . . . . } \\
\text { APE (during previous }\end{array}$ & 10 & I 22 & 71 & 0.70 & $521 \pm 1+$ & 107 & $.908 \pm .010$ \\
\hline $\begin{array}{l}\text { fasting period) ......... } \\
\text { Thyroxin (during ro days }\end{array}$ & 9 & 125 & 163 & 1.21 & $704 \pm 17$ & 110 & $.788 \pm .009$ \\
\hline $\begin{array}{l}\text { previous to experiment) } \\
\text { APE plus thrroxin as }\end{array}$ & 9 & $18 I$ & 109 & 1. 24 & $559 \pm 33$ & 1,30 & $.9^{11} \pm .008$ \\
\hline above. . . . . . . . & 7 & 163 & 152 & 0.97 & $690 \pm 43$ & $1+5$ & $.79^{6} \pm .007$ \\
\hline
\end{tabular}

In summary, it can be said that the thyroid hormone affects the general metabolic rate, and thereby may limit the over-all rates of such processes as gluconeogenesis or carbohydrate oxidation. It also controls the rate of intestinal absorption of sugars, but it does not appear to affect specifically any other processes of intermediary metabolism. Certainly, it does not critically affect the relationship of the anterior pituitary to carbohydrate metabolism in any demonstrable way.

The Adrenocorticotrophic Relationship: Another important trophic relationship of the anterior pituitary which may be concerned in the role of this gland in metabolism is its effect upon the adrenal cortex. The present position of the adrenal cortex in metabolism has been reviewed by Long and collaborators, ${ }^{20}$ G. Evans, ${ }^{30}$ and Russell. ${ }^{31}$ In summary, it appears that the adrenal cortex has as its role in carbohydrate metabolism chiefly the making available of protein as a source of carbohydrate. The exact point at which cortical hormone is effective in this process is unknown. It affects the deamination of amino acids to some extent, ${ }^{32}$ and the formation of carbohydrate from certain keto acids derived from amino acids, ${ }^{33}$ and it may also affect protein mobilization directly, since under some circumstances gluconeogenesis from body pro- 
tein only and not that lrom fed protein seems affected by adrenalectomy.: The cortical hormone is also defmitely a factor in liver-glyeogen deposition, and it may possibly affect oxiclation of carbohydrate, although whether the latter is a direct or secondary effect is not now known.

When it was furst realized that the adrenal cortex might be a factor in carbohydrate metabolism, it was thought by many workers that most or all of the effects of the anterior pituitary might be mediated through the adrenal cortex. Particularly, the work of Long on the ameliorating effects of adrenalcetomy on pancreatic diabetes pointed to this interpretation, for it exactly duplicated the effects of hypophysectomy in this regard. ${ }^{35}$ Most of the effects of hypophysectomy which were known at that time, in fact, appeared explicable on the basis of a decrease in gluconeogenesis in this condition. Some experimental results obtained more recently do not agree with this interpretation; but the fact remains that to a certain extent the functions of the hypophysis and adrenal cortex in metabolism do overlap. To what extent the hypophysis acts through the adrenal cortex and to what extent it may have independent functions has been the subject of much recent work.

Similarities between the effects of hypophysectomy and of adrenalectomy in metabolism are erident on any inspection of data obtained in these states. The most important of these similarities are the following: (a) The carbolyydrate levels of adrenalectomized animals are normal when the animals are in the unfasted state (that is, when they are given adequate amounts of salt and their appetites are well maintained); but, as in hypophysectomized animals. there is a rapid loss of liver glycogen and lowering of the blood sugar when the animals are fasted for even very short periods of time. In adrenalectomized animals not well maintained, where anorexia is a prominent symptom, all the carbohydrate stores may be low. The nitrogen excretion of adrenalectomized animals is low during fasting; that of hypophysectomized animals has also been reported to be low, but it is not always found so. An explanation for this will be discussed shortly. (b) The amelioration of both pancreatic and phlorizin diabetes by both adrenalectomy and by hypophysectomy is well known. Both operations reduce glycosuria and ketonuria, and permit survival for relatively long periods of time after pancreatectomy. (c) The gluconeogenesis which occurs in rats exposed to low oxygen tensions is prevented b! both operations. ${ }^{36}(d)$ Insulin hypersensitivity is of roughly comparable sererity in the two conditions, although it is not certain that it is identical in extent or in origin. ${ }^{37,35}$ Removal of the adrenal medulla without damage to the cortex does not produce similar results, nor does removal of the posterior lobe of the pituitary without damage to the anterior lobe. Animals both adrenalectomized and hypophysectomized are extremely sensitive to insulin, suggesting that there has been an additive effect of the two operations. These similarities between the effects of adrenalectomy and of hypophysectomy would suggest that the anterior pituitary acts through the atrenal cortex. It should be noted 
that in all these cases, however, failure of gluconcogenesis could explain the findings in both types of animal.

Additional support to the idea that the anterior pituitary acts through its adrenocorticotrophic relationship is given by the failure of certain effects of APE to be evident in adrenalectomized animals. The diminution of the diabetogenic effects of APE is quite striking, although the effect may not be altogether absent and the maintenance of high blood-sugar levels by APE after adrenalectomy has been reported in some species. The ketogenic effect of APE has also becn considered to be absent after adrenalectomy. However, it has been shown recently that ketonemia is in fact produced, although not always to the same cxtent as in normal animals, and that ketonuria is not found because the renal threshold for acetone bodies is not usually excecled. ${ }^{39,40}$ Also, fat accumulation in the liver after APE does not occur in adrenalectomized animals. ${ }^{28,41}$

There are also similarities between the effects of certain APE, particularly those rich in adrenocorticotrophic factor, and of adrenal cortical preparations. The diabetogenic effects of cortical hormones have been demonstrated in partially pancreatectomized normal, adrenalectomized, and hypophysectomized animals. Glycosuria and nitrogen excretion are much increased, roughly in proportion to the amount of cortin given, and ketonuria is also increased. In phlorizinized adrenalectomized or hypophysectomized rats, cortical compounds also effectively restore glucose and nitrogen excretion to normal ${ }^{34}$ as APE does also in hypophysectomized animals. In most of these experiments with cortical hormone there is evidence of increased gluconeogenesis only, and not of any depression in carbohydrate oxidation.

Contrainsulin effects of cortical extracts and of adrenotrophic APE were demonstrated by Jensen and Grattan ${ }^{42,43}$ and others. ${ }^{44}$ In all cases, increased supplies of carbohydrate and elevation of liver glycogen, as a result of gluconcogencsis following administration of the cortical hormone, satisfactorily explained the anti-insulin effects of these substances.

Finally, cortical hormones administered in quantity to fasted normal, hypophysectomized, or adrenalectomized animals increase the liver glycogen, the blood sugar, and often the muscle glycogen, evidently by increasing ghconeogenesis, and these extracts may also appear to diminish carbohydrate oxidation in glucose-fed rats. ${ }^{29}$ The effects are similar in a general way to those of APE, and particularly to the effects of adrenocorticotrophic extracts, but, as will be discussed shortly, there also exist certain differences between the effects of the hormones of the two glands.

All of these points, then, indicate that some, at least, of the actions of the anterior pituitary on carbohydrate metabolism are mediated through the adrenal cortex. However, increasing evidence is accumulating that the pituitary may have actions on metabolism not so mediated, but instead carried out directly, or perhaps in some instances through some sort of synergism between 
the two hormones. The basis of this statement I shonld like to discuss in some detail.

First, a major stumbling block in the interpretation of the adrenal-pituitary relationship as a strictly trophic one, mainly centered on glnconeogenesis, has been the different effects of the two glands on nitrogen metabolism. It is true that a diminution in protein breakdown is one of the effects of adrenalectomy and that cortical extracts greatly increase nitrogen excretion at the same time that they increase glycogen production. These effects, however, are not at all similar to those related to the anterior pituitary. Lee ${ }^{45}$ and others have shown clearly that in hypophysectomized animals, a short time after operation, there is a greater loss of nitrogen and a smaller loss of fat than in normal rats on the same food intake. That is, the protein stores seem drawn upon more readil rather than less readily in hypophysectomized animals. The relationship of the length of time after operation at which such observations are made, to the nitrogen excretion rates found, has not always been recognized. Evidently, at a time sufficiently long after hypophysectomy, adrenal cortical atrophy may reduce the rate of nitrogen excretion to normal or subnormal values, such as have also been reported in hypophysectomized animals.

In comparing APE and cortical hormones, in their effects on nitrogen metabolism, a like difference is encomntered. That is, APE in normal or hypophysectomized animals always has an anabolic rather than a catabolic effect. decreasing nitrogen excretion and the free nitrogen of the body, and increasing protein deposition. Even in adrenalectomized rats, APE diminishes nitrogen excretion, as Harrison and Long ${ }^{* 6}$ showed. The effects of APE on nitrogen excretion are also evident in phlorizinized dogs, where gluconeogenesis is proceeding at a high rate and where one would expect nitrogen excretion to be increased rather than decreased, if the APE acted similarly to cortical hormone. ${ }^{\star 7}$ Thus, the adrenal cortical and pituitary hormones seem to have different and opposite effects on nitrogen metabolism as such. Only under certain special conditions, as after pancreatectomy, is there in hypophysectomized animals a marked diminution in nitrogen excretion which can be attributed to a decline in ghuconeogenesis as a result of the adrenal insufficiency.

Another difference has been observed between the effects of adrenal and pituitary extracts which may or may not still be evident when further work has been done: APE, easily and in almost erety instance attempted, can be shown to increase liver fat deposition and ketone production in normal animals, but cortical hormones have not been observed to have these effects even when massive doses were given. In these circumstances, it would be extraordinary if the action of $\mathrm{APE}$ in these respects were purely a result of adrenocorticotrophic activity.

Turning again to carbohydrate metabolism, differences also between the effects of hypophysectomy and adrenalectomy become apparent on close inspection of the data available. The loss of muscle glycogen in fasting is much 
less in adrenalectomized than in hypophysectomised rats, in spite even of the lower metabolic rates of the latter. The adrenalectomized rats do not show the high fasting RQ's of the hypophysectomized animals. ${ }^{31}$ After evisceration. the rate of fall of the blood sugar is not so fast as in hypophysectomized rats, and the muscle glycogen does not fall at all. ${ }^{15}$ Thus, the peripheral utilization of glycogen does not secm to be increased in the absence of the adrenals as it is after hypophysectomy. This difference is emphasized by the fact that the amount of cortical hormone necessary to maintain normal carbohydrate levels in adrenalectomized rats (without salt treatment) is very much less than the amount of extract needed to affect hypophysectomized rats; the amount of cortical extract sufficient for the maintenance of normal carbohydrate levels in adrenalectomized animals is without effect in the absence of the hypophysis. ${ }^{?, 50}$

When adrenalectomized rats are fed glucose, there is relatively normal distribution of the absorbed carbohydrate, although some changes may be observed. The liver-glycogen deposition is usually low, but not always quite so low as in hypophysectomized rats. Muscle glycogen, as a fraction of the absorbed carbohydrate, is nearly normal. There may be some increase in carbohydrate disappearance over the normal, but it is certainly not of the magnitude observed in hypophysectomized rats. (These remarks refer to animals given salt and kept in good condition by this means. Little deposition of glycogen of any kind may be found in animals in acute insufficiency.) The glucose tolerance may be normal. The rate of glucose absorption may be normal or moderately subnormal, depending upon the particular experimental conditions employed.* When this rate has been below normal, it has not been restored, in the author's experience, by either APE or cortical hormone therapy, indicating that it may have had a nonspecific origin. When the rate has been normal, quite normal disposition of the absorbed carbohydrate has been reported..$^{30,31,32,51}$

From a close examination of the data described above, obtained in operated animals, there is an indication of a possible difference in the roles of the anterior pituitary and the adrenal-that the adrenal cortex hormone affects the liver glycogen and thence the blood-sugar levels, as suggested by the similarity between the effects of adrenalectomy and of hypophysectomy on these substances, but that the anterior pituitary has specific effects on peripheral glycogen storage. This hypothesis fits quite wcll a corollary thesis, that the adrenal hormone produces its effects by acting on the gluconeogenetic process in some stage, and that the anterior pituitary affects peripheral carbohydrate utilization directly, as indicated by its effects not only on muscle glycogen but also on the RQ. This hypothesis, of course quite tentatively based on the observations above, has been supported by study of the actions of the extractsby a demonstration of two different types of action of the hormones.

* Marrazi ${ }^{52}$ has presented evidence that the low glucose absorption rates of adrenaleciomized rats are due to inanilion. 
First, the following observations made in fasted rats are relevant to this view. Simple saline or alkaline APE maintain muscle-glycogen levels in fasted hypophysectomized rats. In short fasts, liver glycogen and blood sugar may be also maintained, but in fasts as long as 24 hours, no effect is obscrved on these levels even though perfect maintenance of muscle glycogen is obtained. There is no evidence of new formation of glucose, but only of maintenance of already formed glycogen stores. These extracts also act on muscle glycogen in adrenalectomized or adrenalectomized-hypophysectomized rats. ${ }^{7}{ }^{12}$ In contrast to the effects of simple APE, however, adrenocorticotrophic extracts (containing up to ten times the potency of adrenocorticotroplic factor as the simple APE) given over sufficient time for adrenal hypertrophy to take place in hypophysectomized rats, increase liver-glycogen and blood-sugar levels even above normal values. This type of activity is not evident in adrenalectomized animals. ${ }^{53}$ These effects of the corticotrophic extracts are remarkably similar to those obtained by Long and collaborators with cortical extracts in hypophysectomized and nomal fasted rats. In all cases, there is produced a large increase in liver glycogen and blood sugar; but the effects on muscle glycogen are much smaller and more slowly obtained than those on liver glycogen, and they appear to be the result of an orerflow of the glycogen formed in the liver. Acural new formation of carbohydrate is clearly seen, in conditions in which it is not demonstrable with simple APE; as mentioned before, maintenance of preformed carbohydrate only results when APE is given. When cortical hormone alone is given to fasted hypophysectomized rats, less carbohydrate is found, compared to the increase in nitrogen excretion, than is the case in normal animals treated similarly. That is, the usual greater disappearance of carbohydrate after hypophysectomy seems to persist even when massive amounts of cortical hormone have been administered. Finally, summation of the different effects of adrenal hormone and APE is evident when both are given to lasted hypophysectomized rats. ${ }^{\text {jt }}$

Further support for the view that more than one active hormone is found in $\triangle \mathrm{PE}$ lies in comparisons of the "adrenocorticotrophic" and of the "glycostatic" potencies of these extracts. There appears from the results of Bennett ${ }^{53}$ to be a discrepancy some sixtyfold in magnitude, when the morphologic effects of different APE on the adrenals are compared with their ability to maintain muscle-glycogen levels. There is, however, a close correlation between the amount of cortical repair and the blood-sugar levels obtained in hypophysectomized rats treated with adrenocorticotrophic preparations. This work has been repeated recently by Bennett with even more potent adrenocorticotrophic extracts, with the same results as before (personal communication). Again, there has been a separation of the effects of these homones on blood sugar and liver glycogen from those on muscle glycogen.

Sensitivity to insulin as a similarity between hypophysectomized and adrenalectomized animals has been mentioned, as has the eviclence for the 
view that the adrenocorticotrophic factor is the glycostatic substance. It is not surprising that adrenocorticotrophic and cortical hormones should commeract the action of insulin, for their gluconeogenetic action might be compared ahmost to that of the administration of glucose in preventing insulin convulsions. It is important, however, that complete parallelism between adrenocorticotrophic and anti-insulin activities has not yet been demonstrated in all APE. That is, there may still be other anti-insulin factors in APE than adrenocorticotrophic hormone, and this may be expected from the frequent observations of glycotrophic activity in the crudest of APE, which ordinarily contain little adrenocorticotrophic homone. There is also evidence that an anti-insulin factor in APE acts in the absence of the adrenals, for Himsworth and Scott ${ }^{16}$ report the full glycostatic activity of APE in adrenalectomized rabbits. While the activity of the adrenal cortex must be very important in determining an animal's response to insulin, it is not certain that the hypersensitivity to insulin after hypophysectomy and the glycotrophic action of APE are in fact solely the result of their relationship to the adrenal cortex.

Turning from the fasted animal to that fed carbohydrate, we find further evidence that the hypophysis and the adrenal cortex have different functions. Now both cortin and APE (the former given in quite large amounts, however) depress the oxidation and increase storage of the fed carbohydrate. ${ }^{29,31}$ One difference between these actions is apparent, however: APE promotes the deposition in muscle exclusively, whereas cortin causes deposition principally in the liver and to a smaller extent in the muscles of normal animals. In adrenalectomized rats, this difference was more clearly seen: cortical hormone did not increase deposition in the periphery at all, but only in the liver. In addition, there is another curious feature of these relationships: in adrenalectomized rats the APE alone failed to have any effect on oxidation and only a small effect on muscle-glycogen deposition at the expense of liver glycogen. When, however, cortin was given along with APE, there occurred the usual unique effect of APE on muscle-glycogen deposition at the expense of oxidation. This effect of cortin occurs even when the amount of cortin given is too small to have any effect by itself. ${ }^{31}$ There is apparently a sort of synergism here between the APE and the cortical hormone; the relationship is not exclusively trophic, for the presence of acting cortical tissue is not necessary for the action of the APE, nor is the presence of cortical hormone in any large amount-only enough is required to "grease the wheels," so to speak. This phenomenon has also been observed elsewhere in hypophysectomized rats. and it was observed by Long in adrenalectomized-depancreatized rats, in which, when cortin was given, APE, without effect by itself, was now able to produce a further increase in the glycosuria. ${ }^{29}$

Whether the cortical and anterior pituitary hormones repress carbohydrate oxidation by the same mechanisms or not is unknown. Since quite large amounts of cortical hormone are required to produce these effects, in con- 
trast to the small amounts of pituitary substance necessary; since in fasted hypophysectomized rats treated with cortical extract there is still seen a rapid rate of carbohydrate disappearance despite intense glyconeogenesis; and since cortical extracts always cause liver-glycogen deposition rather than peripherat storage of carbohydrate; it seems likely that different processes are affected by the two hormones. It is possible that the cortical hormone affects glycogen storage in the liver directly, and hence, when it is causing such deposition,

TABLE 8

Comparison of the Effects of Cortical and Anterior Pituitary Hormones on the Disposition of Fed Glucose in Hypophysectomized Rats

(Four hours after feeding)

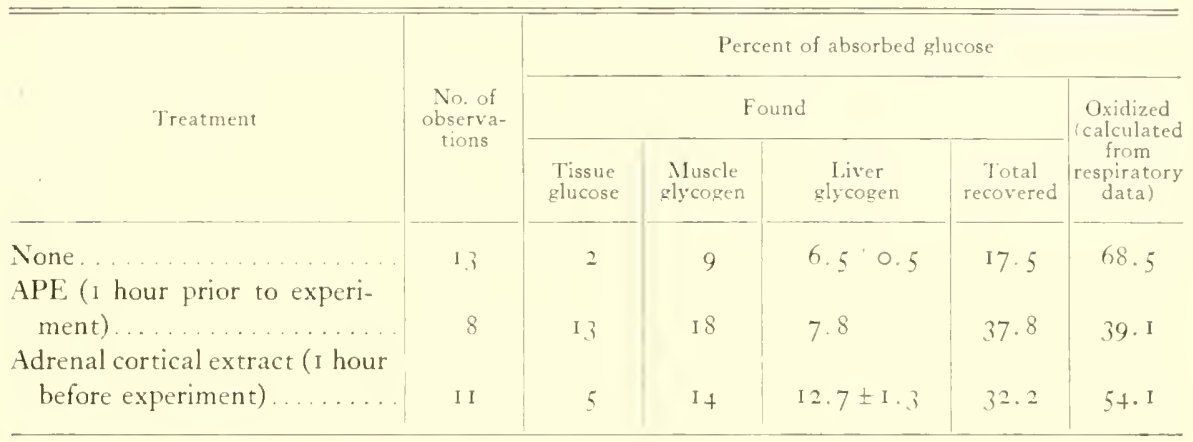

prevents other forms of utilization. In agreement with this suggestion is the lact that liver slices of adrenalectomized rabbits fail to form glycogen from glucose at a normal rate. ${ }^{55}$ The anterior pituitary may then more directly affect peripheral oxidation of carbohydrate.

It has already been seen that in fasted hypophysectomized animals, the effects of cortical hormone and of APE are different, that they are additive, and that by combining the two types of therapy we are able to reproduce normal conditions in the carbohydrate metabolism of these animals. If our analysis of the factors affecting the metabolism of fed carbohydrate is correct, we ought to be able to do the same thing in fed hypophysectomized rats. Here the difference between the actions of APE and of cortical hormone is also clear, the APE affecting muscle-glycogen deposition and the adrenal hom mone the liver glycogen (table 8). The experiment has not been carried out, but if the two substances were given together, there ought to be obtained a fair approach to the normal in the distribution of the fed carbohydrate. Since thyroxin does not affect this distribution but does restore to normal the oxygen-consumption and glucose-absorption rates, and since APE act as usual in the presence of thyroxin in these animals, if all three types of therapy were given at the same time, it should be possible to reconstitute the hypophysectomized rat in regard to its metabolism of fed carbohydrate. 


\section{REFERENGES}

1. Houssay, 13. A.: New England Jl. Med. $214: 971,193^{6}$.

2. Russell, J. A.: Physiol. Revs. 18:1, $193^{8}$.

3. Young, F. G.: Endocrinology 26:345, 19.10.

1. Thomson, D. L.: Jl. Amer. Med. Assn. 115:2169, $194^{\circ}$

5. Campbell, J., and Best, C. H.: Amer. Jl. Physiol. 123:P3o, 1938.

6. Dohan, F. C.; Fisl, C. A., and Lukcns, F. D. W.: Endocrinology 28:341, 566, 1941.

7. Russell, J. A., and Beunett, I. L.: Amer. Jl. Physiol. 118:196, 1937.

8. Fisher, R. E.; Russell, J. A., and Cori, C. F.: Jl. Biol. Chem. $115: 627,1936$.

9. Cope, O.: J1. Physiol. 88:401, 1937.

10. Dye, J. A.: Amer. Jl. Physiol. $119: 299,1937$.

11. Russcll, J. A., and Bennett, L. L.: Proc. Soc. Exper. Biol. \& Med. 34:406, $193^{6}$.

12. Russcll, J. A.: Endocrinology 22:80, $193^{8 .}$

13. Russell, J. A.: Amer. Jl. Physiol. 121:755, 1938.

1 1. Greaves, J. D.; Freiberg, I. K., and Johns, H. E.: Jl. Biol. Chem. 133:243, 1940.

15. Marks, H. P.: J1. Physiol. 87:15 P, 1936.

16. Himsworth, H. P., and Scott, D. P. M.: Jl. Physiol. 92:183, $193^{8}$.

17. Greeley, P. O.: Endocrinology 27:317, 1910.

18. Drury, D. R.: Amer. Jl. Physiol. 111:289, 1935.

19. Russell, J. A.: Amel. J1. Physiol. 136:95, 1942.

20. Althausen, T. L., and Stockholm, M.: Amer. Jl. Physiol. 123:577, $193^{8 .}$

21. Dohan, F. C., and Lukens, F. D. W.: Amer. J1. Physiol. 122:367, $193^{8 .}$

22. Houssay, B. A.: New England Jl. Med. 214:961, 1936.

23. Wells, B. B., and Kendall, E. C.: Proc. Staff Meetgs. Mayo Clin. $15: 493,1940$.

24. Goldblatt, M. W.: Iroc, Roy. Soc. Med. 29:668, 1936.

25. Gaebler, O. H.: Amer. Jl. Physiol. $110: 5^{8}$, 1934.

26. Fry, E. G.: Endocrinology 21:283, 1937.

27. Soskin, S.; Levine, R., and Heller, R. E.: Amer. Jl. Physiol. 125:220, 1939.

28. Russell, J. A.: Amcr. Jl. Physiol. 122:517, $193^{8}$.

29. Long, C. N. H.; Katzin, B., and Fry, E. G.: Endocrinology 26:309, 1910.

30. Evans, G.: Endocrinology 29:731, 1911.

31. Russell, J. A.: Amer. J1. Physiol. 128:552, $194^{\circ}$.

32. Russell, J. A., and Wilhelmi, A. E.: J1. Biol. Chem. 137:713, 1941.

33. Russell, J. A., and Wilhelmi, A. E.: Jl. Biol. Chem. 1 fo:747, 1941.

34. Wells, B. B., and Kendall, E. C.: P'roc. Staff Meetgs. Mayo Clin. 15:565, 1940.

35. Long, C. N. H., and Lukens, F. D. W.: Jl. Exper. Med. 63:465, 1936.

36. Evans, G.: Amer. Jl. Physiol. $114: 297,193^{6 .}$

37. Zucker, T. F., and Berg, B. N.: Amer. Jl. Physiol. 119:539, 1937.

38. Grattan, J. F.; Jensen, H., and Ingle, D. J.: Amer. Jl. Physiol. 13 1:8, 1941.

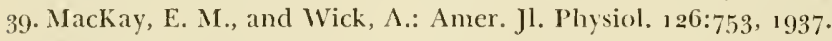

to. Mirsky, I. A.: Science (n.s.) 88:332, 1938.

f1. Mackay, E. M., and Barnes, R. H.: Aner. Jl. Physiol. 118:525, 1937.

12. Jensen, H., and Grattan, J. F.: Amer. Jl. Physiol. 128:270, 19 4o.

13. Jensen, H., and Grattan, J. F.: J1. Biol. Chem. 135:511, $194 \%$.

4. Hartman, F. A.; Brownell, K. A.; Walther, R., and Edelmann, A.: Endocrinology 27:6.12, $194^{\circ}$.

45. Lee, M. O.: Proc. Assn. Resrch. Nerv. \& Ment. Disease 17:193, 1936.

46. Harrison, H. E., and Long, C. N. H.: Aner. Jl. Physiol. 126:526, 1939.

47. Gacbler, O. H.: Amer. Jl. Physiol. 128:111, 1940.

18. Russell, J. A.: Amer, Jl. Phṛsiol. 133:P434, 1941; and unpublished data. 
19. Grollman, A.: Amer. J1. Physiol. 122:.160, 1938.

50. Bennett, L. L.: Endocrinology 22:193, 1938.

51. Denel, H. J., Jr.; Hellman, L. F.; Murray, S., and Samuels, L. 1.: J1. Biol. Chem. 119:601937.

52. Marrazi, R.: Amer. Jl. Physiol. 131:36, 19.10.

53. Bennett, L. L.: Proc. Soc. Exper. Biol. \& Med. 37:50, 1937.

54. Russell, J. A., and Craig, J. M.: Proc. Soc. Exper. Biol. \& Med. 39:59, 1938.

55. Holmes, E., and Lehmann, H.: B1it. Jl. Exper. Pathol. 21:196, 1910. 



\title{
VESALIUS AND DON GARLOS
}

A Historical Footnote

\author{
By \\ John B. deC. M. Saunders, \\ M.B., CH.B., F.R.C.S.(ED.)
}

\section{独}

From the

DIVISION OF ANATOMY

UNIVERSITY OF CALIFORNIA MEDICAL SCHOOL

SAN FRANCISCO, CALIFORNIA 



\section{VESALIUS AND DON CARLOS}

\section{A Historical Footnote}

"I

N YEARs that bring the philosophic mind," no year is quite so golden as that which saw the great conjunction of scientific utterance on the Macrocosm and on the little world of man. As though the mere conjuncture were not enough to signalize for all time in the history of science the year 1513 , the year itself is measured against its contemporary and universal beliefs, when the vasty circuits of the Macrocosm faced inwards to the Microcosm, fashioned in His own image, the concentrated epitome of the Universe. Such is the year which saw the press unfold the De Revolutionibus Orbium Coclestimm of Nicolaus Copernicus (1473-1543) and the De Humani Corporis Fabrica of Andreas Vesalius $\left(15^{1} 4^{-1} 5^{64}\right)$.

As the heady Falernian wine, "solo vinorum flamma accenditur," is quenched, says Horace, by the lighter Sorrentine, so with the passing of the year the swelling ferment of the Renaissance settled somewhat, for Copernicus was dead and Vesalius had passed into obscurity, lost to science, swallowed by the court of the Emperor Charles $V$. What induced Vesalius to relinquish his professorship at Padua we do not know. In view of his downright and forceful character it seems unlikely that he sought, as suggested by some, ${ }^{2}$ protection at the court of this powerful monarch from the persecution of his enemiesenemies for whom he had little but contempt. Indeed, Vesalius was bold enough to indulge at times in the dangerous pastime of baiting the clergy and sufficiently unafraid to turn on occasion to the still more hazardous occupation of rational Biblical exegesis. In fact, the protection of the Duke Cosino de' Medici and those "very learned Italians who are so friendly towards me"s would perhaps by its very liberality have proved more adequate than did that of bigoted and heresy-hunting Spain. Nerertheless his actions in destroying his manuscripts and his works demonstrate that he was deeply upset over the calumnies of his enemies and particularly by the vicious attacks of his old friend and teacher Sylvius. "I am at present," he says, "in such a state of mind that no matter how great my desire or how great the urge of self-love, I can bring myself neither to attempt any new work, nor to contemplate any publication.".

A sensitive and volatile man, fully aware of the significance of his own work, it is not surprising that he should divorce himself from academic pursuits and the clangor of the Italian schools and seek seclusion, far removed, at a court where he had such excellent ancestral comnections. Vesalius was genuinely interested in the practice of medicine, and perhaps the opportunity of applying his new-won knowledge and method to fresh and wider fields of endeavor was sufficient incentive to the change.

Our picture of Vesalius' character and outlook rould be very incomplete 
and false were we to consider him solely from the point of view of his anatomical achievement. It was his ambition to master the whole of medical science. His preface to the Fabrica ${ }^{5}$ is an eloquent plea for an eclecticism in the medical art. He is pungent in his criticism of the sectarian disunity which characterized the practice of his day. "The Art of Healing," he says, "cannot and should not be disunited but belongs together so that all parts of medicine, resting upon an equal footing, can be brought to bear with the cumulative force of all." Anatomy is but the essential preliminary. Medical practice, especially therapeutics, was close to his heart. It was the subject of his first work, a recension of the treatise of Rhazes to the King Almansor, De Singularum Corporis Partium Affectuum Curatione, ${ }^{\circ}$ and his further interest is again evident in his discussion of the China Root and in those works which he destroyed.*

There is strong evidence to suggest that preoccupation with problems of practical therapeutics had provided the incentive which led to the production of his master work. There was no more burning question in the whole realm of therapeutics in the sixteenth century than the exact mode and place of bloodletting in the treatment of disease. The literature of the contemporary period is shot through with blast and counterblast. The humanistic movement had to some extent cleared away the rubbish of Arabian compilations and scholastic commentary which concealed the remnants of the classic culture and had exposed how far opinion had deviated from the precepts of the Father of Medicine. But even those who defended and expounded the purified classics against the onslaughts of the Arabists were necessarily conditioned by precedent scholasticism, whose bonds they could not break. Lacking the touchstone of factual appeal, their learning, their width of reading, their textual criticisms prove as barren as the disputations of their forbears. Every argument of their therapeutic doctrine rested on the unshakable foundation of Galen's pronouncements concerning the arrangement of the venous system. It was from this salient, the most vulnerable of the Galenical anatomy, that Vesalius lodged his attack. Already in 1536 he had observed in Guinter of Andernach's Institutiones Anatomicae ${ }^{8}$ that his findings on the vena azygos would in no wise jibe with those of Galen. By $153^{8}$ with the publication of the Tabulae Sex, although still as yet held in thrall by Galenical authority as evidenced by his illustrations of the five-lobed liver and his opinion on the constitution of the sternum, sacrum and coccyx, he has begun to doubt. In his second figure of the venous system he says signifying the vena azygos: "Hanc sine pari venam, quae octo inferiores costas nutriere dicitur, numquam sub dextra cordis auricula propagatam vidimus, imo ut in canibus et simiis paulo supra auriculam. Quare dolore laterali ad inferiora vergente, magis quoque venae sectione,

* These works included his annotations, a complete paraphrase on the ten books of Rhazes to the Caliph Almansor, and his notes for a book on medical formulae. "Quod vero attinet ad Annotationes, quae in ingens volumen excrenerant, illae cum integra in decem libras Rhazes ad Almansorem regem paraphrasi, multo diligentius quam illa quae in nonum librum prostat a me conscripta, \& libri cuiusdam de medicamentorum formulis apparatu (in cuius nateriam multa meo judicio non inutilia congesseram) una die mihi interierunt . . ." 
quam purgante medicamento utendum erit, et propter Hippocratis sententian, Galenum in secundo libro de victus ratione in morbis acutis olsscure de hac vena locutum opinior ..."

In the following year, 1539 , he had developed this theme in the letter on blood-letting in the treatment of pleurisy. Here he is ready to challenge Galen's infallibility. How important a role the subject of blood-letting played in the emancipation of Vesalius can still further be judged by the attention he devotes to the subject in the Fabrica ${ }^{11}$ and again in the China Root. ${ }^{12}$ As has so often happened in the history of science, the doctrine which incited the appeal to the facts had paradoxically, in its sterility brought forth a bountiful harvest.

Of Vesalius' life at court so little is known that, as Singer ${ }^{13}$ has remarked, "without the book [the Fabrica] he would be but a ghost." Roth, ${ }^{14}$ in his admirable biography of Vesalius, has discussed his merits and progressive development in the practice of medicine although not always without bias, for like so many biographers of the last century, he can hear no ill of his hero. There is available, however, the detailed records of the most famous clinical case with which Vesalius was associated. This case, although it puts Vesalius in a somewhat unfavorable light, is nonetheless of great interest in revealing a rivid picture of the manner and conduct of an important consultation and the difficulties which had to be contended with and overcome by a court physician.

The drama, romance and legend have told in many tongues the story of that tragic and pitiful figure, the Infante Don Carlos $\left(1554^{-1} 5^{68}\right)$. Beginning with Saint-Réal ${ }^{15}$ (1639-1692) and Thomas Otway ${ }^{16}(1652-1685)$, historians ${ }^{17,15}$ and the literati alike (Schiller, Alfieri, de Campriston, Russell) have woven and embroidered the fable of the unlawful attachment of the slighted youth to his promised bride, Elizabeth of Valois, who soon became his stepmother, and of how, inflamed by the machinations of Ruy Gomez and his wife, the Duchess of Eboli, the boy's jealous father, Philip II, exacted his terrible vengeance. Although no decisive rerdict can be given, modern historical opinion is kinder to Philip II and ascribes the boy's death to natural causes. In 1562 Don Carlos met with an accident followed by a severe illness, and after his recorery he showed more obvious signs of progressive mental deterioration. His conduct both in public and in private became extremely vicious and disorderly. He developed an intense dishike to the Duke of Alva and a morbid hatred of his father whose life he contemplated. At length, in ${ }_{5} 56$, following an attempted flight from Spain, he was seized and confined by order of his father. Commissioners were appointed to try the Prince and he may have been put to death for treason in accordance with their verdict. However, always of wretched physique and health, his outrageous behavior may well have undermined his feeble constitution.

The story of the accident and illness which marked the beginning of the end for Don Carlos and with which the name of Vesalius has been associated 
has likewise been so garbled that no accurate account exists in the most anthoritative histories of today. Cardanus ${ }^{17}$ wrote that Vesalius snatched the Prince from the very jaws of cleath, “. . . servato illi sua arte a morte evidenti Carolo unico eius filio, ita ut e faucibus orci vere rectus dici posset . . .," but this is scarcely true and others have credited Vesalius with an operation which he never performed. The account in the famous work of Llorente ${ }^{18}$ is full of crrors. Roth admits that the matter is confused. He relied for the most part on secondary sources and had not seen the reports on which the following account is based. These reports, mutually confirmatory of this important historical episode, are those of the Licentiate Daça Chacon $\left(1503-157^{6} \text { ? }\right)^{1 \mathrm{~s}}$ and Dr. Santiago Diego Olivares $\left(15^{10-1573)^{20}}\right.$ two of the Prince's attendants, and appear among the unedited documents of Spain. Daça's version* also appears in his work on the theory and practice of surgery. ${ }^{21}$ The name of this gifted man is an unfamiliar one to students of the history of medicine. Born at Valladolid circa 1503 , he occupied a prominent position as a surgeon at the courts as well as in the camps and fleets of his country. He was attached to the immediate person of Emperor Charles $\mathrm{V}$ and later served with distinction his children, Philip of Spain and the Princess Juana of Portugal. He, like Cervantes, was present with Don John of Austria in his Mediterranean campaign which was to terminate in the dreadful slaughter at Lepanto (Oct. 7,1571 ). He was a colleague and friend of the immortal Vesalius whom he held in the highest regard as "the greatest anatomist of the times" and with whom he both consulted and operated. He held in more than one campaign that position in the Spanish army which was simultaneously held by Ambroise Paré (1510-1590) in the opposing forces of France. His work is probably the furst of its kind written in the Spanish vernacular and is characterized by its scholarship, its sagacity, its sound common sense, and its freedom from superstition. Resting on personal experience rather than on tradition, but with nonetheless a wide erudition, he demonstrated his true kinship to the Renaissance. His work is worthy of ranking with that of Ambroise Paré.

In 1562 , Philip of Spain, in order to complete the education of his son Don Carlos, then in his seventeenth year, sent him, together with Don John of Austria and Alexander Farnese, to Alcalà where they were placed under the tutorship of the Archbishop. On Sunday, April $19^{\text {th }}$ of that year, a month or so after the termination of a quartan fever for which he had been treated, the young prince, having had his midday meal, fell down a dark staircase "missing five steps" and was thrown against a door at its foot. The boy remained for some time unconscious. His personal physicians, Drs. Olivares and Vega, and later

\footnotetext{
* Roth ${ }^{14}$ (p. 268, note 2) obliquely challenges the report of Daça and supposes it to have been filched from Olivares. He was evidently unaware of the existence of two reports, one by Olivares and the other by Daç. He confesses, however, that he obtained his information from sccondary sources. Roth unjustly regards Daça as unreliable apparently because of certain derogatory remarks he made of Vesalius's surgical ability. Had he consulted the original work he would have found that, on the contrary, Daça always speaks of Vesalius in the highest terms.
} 
Daça, were sent for by Don Garcia de Toledo, Governor and First Majordonno to the Prince. They found a small contused wound on the left side of his head in the region of the lambda. The wound apparently penetrated to the bone. The physicians of the household promptly dressed the injured youth. As the Prince was in great pain, Luis Quijada, Master of the Horse, fearing that the physicians in deference to the patient's rank would exhibit too great a forbearance, commanded them to treat him as an ordinary person. The physcians replied that "such was the custom." 'The P'rince was immediately put to bed and as promptly bled. A gentleman-in-waiting, one Don Diego de Acuna by name, was dispatched to inform Philip of the accident. The King gave orders to his physician, Juan Gutierrez, to leave without delay for Alcalà and to bring with him a Portuguese doctor and Pedro de Torres, Surgeon to His Majesty. All seemed to be going well, "laudable pus" had made its appearance, but the glands in the patient's neck were swollen and painful and there was some fever. Little attention was paid to these symptoms, as the fever was ascribed to the Prince's quartan and the swollen glands to the fact that His Highness was suffering from a cold at the time of his fall. As is so typical of crysipelas, the dreadful red scourge of the early surgeons, on the tenth day the Prince developed a chill and by the next day his condition was regarded as grave. The medical attendants, now numbering six, were shocked into action. They decided to incise the scalp immediately, but were unable to determine whether the skull was injured or not, because of hemorrhage. A messenger was sent in haste to His Majesty, who rode through the night accompanied by Indreas Vesalius and arrived in time to witness the dressing of the wound. At this time an opportunity was afforded of minutely examining the bone, but, except for a small area of redness, neither fracture nor crack could be discovered. The wound was dressed with one of the usual elaborate dressings so characteristic of the times. On this occasion a mixture of powdered iris and the common birthwort (Aristolochia) was applied to the bone, no doubt to promote exfoliation. Then came an unguent of turpentine and egg yolk to the edges of the wound, the purpose of which was to assist suppuration. On top of these was placed honey of roses as a cleansing agent and finally, the old tandby, a plaster of betony over all.

The unhappy prince made no progress. The erysipelas continued to spread and the "aposteme" now covered the whole face and extended clown the neck to the chest and arms. The patient was cupped, purged and dosed with potions "that thou wouldst tremble to receive thyself" * and became delirious.

At daybreak on May $4^{\text {th, }}$ sixteen days after the fall, opinions among the attendants became divided. Vesalius and the Portuguese doctor urgently proposed trephining the skull, for they felt that the lesion was within. In this they were bitterly opposed by the other physicians, although Daça admits that

\footnotetext{
* Shakespeare: Pericles, Prince of Tyre, I, 2, 67:
}

Thou speak'st like a physician, Hericanus,

That minister'st a potion unto me

That thou wouldst tremble to receive thyself. 
"Vesalius had plenty of good reasons to support his view. . . ." Finally a compromise was reached, says Olivares, and it was decided to ruginate and, as the bone bled under the raspatory, the more serious procedure was avoided, although Vesalius persisted in his view.

Things were going so badly that the attendants were induced to try the nostrum of a quack, one Pinterete, a Moor from the Kingdom of Valencia. "Most of us were opposed," says Daça, "being ignorant of its composition and not judging it reasonable that an individual remedy could be fitted "for all seasons, ages and complexions.", "However," he continues, "public opinion was against us for not using them." The nostrum burnt the wound and it was getting worse and worse so that the Moor was discharged and "went to Madrid to take care of Hernando de Vega whom he sent to Heaven with the help of his ointment."

By May $9^{\text {th, }}$ three weeks after the accident, little hope was left. In the afternoon, a procession of townsfolk came to the palace bearing the corpse of San Diego,* a friar celebrated for his life and miracles. The body was brought into the chamber of the Prince and placed as close to his person as possible. But His Highness was "so beside himself" that he could scarcely be conscious of the saintly form of intercession so characteristic of the credulity and superstition of the times. The Prince was now moribund, and that evening Dr. Mena informed the King that the worst was to be expected. "We had confidence only in God's mercy and in His Highness' age, which was only seventeen." The frantic Philip seized his horse and set off in the darkness of the night, during a terrible storm, for the sanctuary of San Jerome in Madrid and left the distressed physicians who were in "great danger" because of the sentiments of the public against them.

Vesalius, Daça, and their colleagues remained steadfast to their duty and responsibilities. They cupped, fomented and applied restoratives, and on the next day there was a marked improvement. The Duke of Alva clispatched the alguazil Malaguilla, with the good tidings to Madrid. They were received as Philip, his Queen and the Princess Dona Juana were taking part in a procession to Our Lady of Atocha.

The improvement continued although it was found necessary to incise and drain both of the Prince's orbits. This was done by Pedro de Torres, surgeon to His Majesty, on the advice of Vesalius. Thereafter his convalescence was slow and, after discharging a sequestrum from the skull, by July $5^{\text {th }}$ he was sufficiently well to pay his respects to the corpse of the Blessed Diego and attend a bullfight all in the same day. At the end of his illness, Don Carlos weighed, fully clothed, seventy-six pounds.

\footnotetext{
* St. Diego d'Alcalà was canonized in 1588. under the pontificate of Sixtus V. twenty-six years after this incident.

+ Gachard,,$^{22}$ p. 89 , quotes a letter from Charles de Tisnacq to the Duchess of Parma, in which we are informed that drainage of the eyelids was carried out on the advice of Vesalius but much against the opinion of several of the attendants.
} 
Throughout the illness, Philip II exhibited the most fatherly solicitude, making repeated journeys to be at his son's bedsicle, attending the archous consultations and watching the chessings. The Duke of Alva was ever present and spent his nights all dressed, in a chair beside the boy. Don Garcia of Toledo presided over all, called the meetings of surgeons and physicians and scarcely went to bed. Luis Quijada, the Prince's riding master, contracted the erysipelas which endangered his life. Even the Prince's invalid preceptor and spiritual adviser, Honorato Joan, never failed to be present at the dressings and consultations. Daça's report introduces us very vividly to one of these consultations. More than fifty were held, of which fourteen were in the presence of His Majesty, the latter being the longest. Some lasted for at least two and others more than four hours.

His Majesty was seated on a chair with the grandees and noblemen behind him. The Duke of Alva and Don Garcia of Toledo were at his sicle. The physicians and surgeons were seated in a semicircle in front of the King. Don Garcia called upon each in turn to state his opinion with the reasons and authorities on which they were founded, and His Majesty would ask each consultant to explain such technical terms as he did not understand. On one occasion, no doubt during an unusual wordy session, Don García, in calling upon Daça to speak, said, "Speak, Licentiate Daça, and do not quote so many texts, according to His Majesty's wishes." "This," observes Daça with unction, "was a rare distinction," "I am quoting this," he says, "because there was no way that we could prepare ourselves by study, so that it was thus easy to see what each knew by heart.'

The purpose of these consultations, apparently, was not only to determine what was to be done with regard to the immediate treatment of the Prince, but also to discuss possible complications so that adequate preparations could be made to treat these, should they arise. A very necessary procedure, as messengers would have to be dispatched to obtain the rare drugs and herbs which the therapeutics of the day demanded.

Such was the last important consultation in which Vesalius participated. The records paint a motley picture with a disfigured prince, a tender father. the austere Duke of Alva transfigured into a patient sick nurse, a Moorish quack, processions and watchings, the grisly relic of a dead friar, ceremonious consultations and a threatening populace.

Vesalius' longing to return to the cloistered quiet of Padua can best be expressed in his own words. In his letter to Fallopius (1523-1562). penned within a few months of this inciclent, he writes, "I sincerely hope that you may long maintain this purpose in that sweet leisure of letters which is yours and in that throng of learned men, whose studies are dear to their hearts, and with whom you can daily compare the concepts of your mind. For I feel that the ornaments of our art originate in that arena from which as a young man, I was diverted to the mechanical practice of medicine, to numerous wars and to continuous travels ... therefore continue to embellish our common school, whose memory 
is always most dear to me, with the fruits of your talent and industry. And if you are willing, weigh one by one these words of mine with those in the open book of your observations." ${ }^{23}$

1. Horace: Satires II, 4 .

\section{REFERENCES}

2. Nordenskiöld, E.: The History of Biology (New York: 1936).

3. Andreae Vesalii Bruxellensis, medici caesarei epistola, rationem modumque propinandi radicis Chynae decocti, quo muper invictissimus Carolvs V. Imperator usus est, pertractans: et praeter alia quaedam, epistolae cuiusdam ad Jacobum Syluium sententiam recensens, veritatis ac potissimum humanae fabricae studiosis per utilem: quum qui hactenus in illa nimium Galeno creditum sit, facile commonstret . . . Basileae. ([Colophon:] Basileae, ex officina Ioannis Oporini, Anno salutis humanae MDXLVI. Mense octobri.), $46\left(\mathrm{~F}_{3} \mathrm{v}\right)$.

4. Vesalius: Epis: Chy: (as cited), $40\left(\mathrm{E}_{4}^{\mathrm{v}}\right)$.

5. Andreae Vesalii Bruxellensis, scholae medicorum Patavinae professoris, de humani corporis fabrica libri septem . . . Basileae. ([Colophon:] Basileae, ex officina Joannis Oporini, Anno salutis reparatae MDXLIII mense Iunio.), preface, $2^{\vee}$.

6. Paraphrasis in nonum librum Rhazae medici Arabis clariss. ad Regem Alnansorem, de singularum corporis partium affectuum curatione, autore Andrea W'esalio Bruxellensi medicinae candidato. (Lovanii ex officina Rutgeri Rescii, mense Februar. 1537.)

7. Vesalius: Epis: Chy: (as cited), 196 (for 195) $\left(\mathrm{Bb}^{\mathrm{r}}\right)$.

8. Guinterius [Andernacensis], Joannes: Institutionum anatomicarum secundum Galeni sententiam ad candidatos medicinae libri quatuor... (Basileae, Balthasar Lasius et Thomas Platterus, MDXXXV1.)

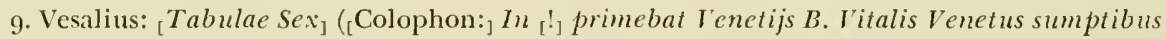
Ioannis Stephani Calcarensis Prostr $\left[!_{3}\right.$ ant verò in officina D. Bernardi A 1538.); see Des Andreas Vesalius Sechs Anatomische Tafeln vom Jahre 1538 in Lichtdruck, ed. by M. Holl and K. Sudhoff (Leipzig: 1920).

10. Andreae VVesalii Bruxellensis, scholae medicorum Patavinae professoris publici, epistola, docens uenam axillarem dextri cubiti in dolore laterali secandam: et melancholicum succum ex uenae portae ramis ad sedem pertinentibus, purgari. Basileae. ([Colophon:] Basileae, in officina Robcrti Winter, mense aprili. Anno MDXXXIX.)

11. Vesalius: Fabrica (as cited), $278\left(i 3^{\mathrm{v}}\right)$ : "Venae cavae, eirs partis quae supraiecur consistit, distributionis series" (Liber III, Caput VII).

12. Vesalius: Epis: Chy: (as cited), $71\left(\mathrm{I}_{4}^{\mathrm{r}}\right)$.

13. Singer, C.: The Evolution of Anatomy (New York: 1926), 115.

14. Roth, M.: Andreas Vesalius Bruxellensis (Berlin: 1892).

15. Saint-Réal, C. V. de: Oeuvres Complètes (Paris: 1745). His romantic novel, Don Carlos, was published in 1672 .

16. Otway, T.: "Don Carlos, Prince of Spain" in The Complete Works, ed. by M. Summers (Bloomsbury, [London]: MCMXXVI).

17. Cardanus, Hieronymus: "Anathomiae Mvndini cum expositione ..." in his Opera Omnia, X (Lvgduni: M. DC. LXIII), 129-67; see p. 153 .

18. Llorente, J. A.: Histoire Critique de l'Inquisition (Paris: 1817).

19. Daça Chacon, D.: "Documentos Inéditos para la Historia de España" XVIII (Madrid: $1851)$.

20. Olivares, S. D.: "Documentos Inéditos para la Historia de España" XV (Madrid: 1849).

21. Daça Chacon, D.: Practica y Teorica de Cirugia en Romance, y cn Latin. (En Madrid en la Imprenta de Reyno, por Lucas Antonio de Bedman y Valdivia, en la Calle de los Preciados. $A \tilde{n} o{ }_{16} 6$. $)$, segunda parte, $190\left(\mathrm{Ri}^{\mathrm{v}}\right)$.

22. Gachard, L. P.: Don Carlos et Phillipe II (Bruxelles: 1863).

23. "Andreae Vesalii anatomicarum Gabrielis Fallopii observationum examen" in Vesalius's Opera Omnia, ed. by H. Boerhaave and B. S. Albinus, II (Lugduni Batavorum: MDCCXXV), $7^{61}$ (Ii ii i $3^{\mathrm{r}}$. 


\section{IMPOTENGE AS A RESULT OF}

\section{WITCHCRAFT}

$$
\text { B)' }
$$

HENRY E. SIGERIST

\section{綿}

From the

INSTITUTE OF THE HISIORY OF MEDICINE

THE JOHNS HOPKINS UNIVERSITY

BALTIMORE, MARYLAND 



\section{IMPOTENCE AS A RESULT OF WITCHCRAFT}

TN THE MAJORITY of all cases impotence is due to nervous causes. It is a phobia. 1 The fear of being impotent prevents individuals from having nomal erections. ${ }^{1}$ It is not astonishing that in the Middle Ages such a condition was frequently attributed to witchcraft. The question was important because it had legal consequences. Inability to consummate marriage was a reason for declaring it inull and roid $a b$ initio.

The first who brought up the question of witchcraft in this connection was Hincmar, archbishop of Rheims, who lived in the ninth century. In discussing a definite case he came to the following conclusion: ${ }^{2}$ if a marriage has been annulled on account of the impotence of the husband, he cannot marry again if his impotence was due to natural (physical) causes. If his condition, however, was the result of witchcraft and the marriage had been declared void after the customary treatments had failed, he was permitted to marry again.

Gratian, who in the twelf th century codified canon law, accepted Hincmar's view and so did Peter the Lombard in the same century in his Liber Sententianm where he has a special chapter: "De his qui maleficiis impediti coire non possunt." Peter's book was commented upon by the leading scholastic theologians."

Since impotence resulting from witchcraft was to be treated, not only was the Church interested in the question but the physicians also. In the eleventh century Constantine of Africa devoted a chapter of his Pantechne to it, "De his qui coire non possunt." The same text with additions was wrongly attributed to Arnald of Villanova and was published in his Opera Omnia. ${ }^{6}$ Constantine's text with or without additions is frequently found in medical manuscripts as an independent anonymous treatise. It has been published and discussed by Gerda Hoffmann in an excellent dissertation. ${ }^{7}$

In my studies on the medieval medical manuscripts of Montpellier ${ }^{8}$ I found in the fifteenth century nanuscript $\mathrm{H}_{27} 7$, , fol. $60^{\circ}$, a version that is mentioned but was not used by Gerda Hoffmann. This may justify its publication here, although it follows rather closely the text of other manuscripts. I am adding an English translation and a few remarks on its content in relation to the Malleus Maleficarum.

\section{TexT}

Incipit libellus de hiis qui maleficis impediti cum uxoribus suis cohire non possunt.

Sunt quidam qui maleficiis diabolicis impediti, cum uxoribus suis cohire non possunt, de quorum sufragio nolumus nostrum librum enudare, quod medicamentum ni fallor est sanctissimum.

Igitur si hoc alicui contigerit, speret in domino et ipse dabit benignitatem. Sed quia maleficia sunt multimoda, oportet ut de hiis disputemus. Maleficiorum enin quedam de animatis funt, ut testiculi galli si sint suppositi lecto cum ipsius sanguine, efficiunt ne concumbant in lecto iacentes. Quedam kar- 
acteribus scriptis ex sanguine vespertilionis. Quedam vero de inanimatis, ut sicut si nux vel glans separentur, quarum medietas ex una parte vie, altera ex altera, unde sponsus et sponsa pergere debent.

Sunt et alia que de granis fabarum conficiuntur, que neque aqua calida molifficantur nec igne coquuntur, quod maleficium pessimum est si quattuor illarum vel in tecto vel in via vel super hostium vel infra ponantur.

Sunt et alia que sunt metalica sicut que funt ex ferro vel plumbo, ex ferro sicut que fiunt ex acu cum qua mortui suuntur vel mortue. Sed quia hec sunt diabolica, et maxime sunt in mulieribus, aliquando divinis auxiliis aliquando humanis curantur.

Igitur si sponsus et sponsa supradictis maleficiis conturbentur, sanctius est de hiis diserere quam silere, quia si non succurantur, separantur et sic degenerantur, et hoc malum exercentes, non solum in proximis sed etiam in spiritu sancto peccare videntur.

Si enim maleficium recte extirpare volumus, videndum est, si supradictum maleficium subsit lecto, auferatur. Sed si actor istius maleficii in die auferat et in nocte ponat vel converso, aliam domum acquirant sponsus et sponsa, ibique iaceant.

Si karacteribus hoc maleficium fiat, quod cognoscitur quia sponsus et sponsa non diligant se adinvicem, queratur supra limen hostii vel infra, et si quid inveniatur, defferatur ad episcopum vel ad sacerdotem, sed si non, fiant ea que inferius ponuntur.

Si nux vel glans sint causa huius maleficii, accipiat mulier quandan nucem vel glandem separetque eam, et cum una medietate pergat vir ex una parte alicuius vie et ibi ponat, mulier vero ex altera parte vie ponat alteram partem nucis, deinde sponsus et sponsa accipiant ambas partes nucis testa non extracta et postea sic tota nux reintegretur et servetur per vii dies, hoc facto coheant.

$\mathrm{Si}$ autem sit propter fabas, magis divinis quam humanis curari potest. Si sit propter acus mortuorum, querantur maleficia vel in fulon ${ }^{2}$ vel in pulvinari. Si non inveniantur, in altera domo concumbant.

Canis fel masculi domum purgat et efficit ut nullum malum medicamentum domui inferatur.

Canino sanguine domus parietes asperge et ab omni maleficio liberabitur.

Fel alicuis pissis et maxime zangarini [id est lucii] si sponsus et sponsa secum habeant in pisside iuniperi et cum eunt dormitum ponatur super carbones vivos et inde fumigentur, omnia supradicta maleficia evanescunt.

Similiter si argentum vivum accipiatur et in calamo canne mittatur, calamo cum cera et plumbo cohoperto, nescientibus sponso et sponsa, in loco nullum maleficium eis nocebit.

Sed si pecatis imminentibus supradicta minime profuerunt, accedant ad sacerdotem vel episcopum, et si episcopus hoc concesserit et nullum remedium invenitur, facta confessione ab episcopo vel a religioso sacerdote, in die sancte resurectionis seu ascensionis vel pentecostem communicentur. Corpore et sanguine domini accepto, sponsus et sponsa dent inter se osculum pacis et 
accepta benedictione ab episcopo vel a sacerdote, det sibi episcopus vel sacerdos hunc versum profeticum scriptum in carta: Vox domini super aquas, dominus magnus super aquas multas. ${ }^{10}$ Deinde veniant donum et a copulacione per tres dies et noctes se custodiant, postea rem agant et sic omnis diabolica virtus destruitur.

Expletus est libellus de maleficiis. Deo gracias amen.

\section{TRANSLATION}

A short treatise about the people who, impeded by spells, are unable to have intercourse with their wives.

There are people who, impeded by diabolical spells, are unable to have intercourse with their wives. We do not want to deprive our book of their applause, for the remedy, if I am not wrong, is most sacred.

Now, if this should happen to somebody, he must set his hope in the Lord and He will be merciful. Since, howerer, there are many kinds of spells, it is necessary that we discuss them. Some spells are made of animated substances such as the testicles of a cock. If they are put under the bed with blood of the cock, they bring it about that the people lying on the bed cannot have intercourse. Some are made of letters written with the blood of a bat. Some are made of inanimate substances, for instance if a nut or an acorn is divided in two, and one half is put on one side, the other on the other side, of the road along which the bride and bridegroom must proceed.

There are others also which are made from beans which are not softened with hot water nor cooked on the fire. This spell is very bad if four such beans are placed on the roof or on the road or over or under the door.

There are others also which are of metal, such as those that are of iron or lead, for instance, the iron ones made of the needle with which the dead men or women have been sewn. And because these spells are devilish and are particularly in women, they are sometimes cured by divine, sometimes by human measures.

If therefore bridegroom and bride are disturbed by the above-mentioned spells, it is better to talk about them than to keep silent, for if the victims are not succored they are separated and thus disgraced, and doing this evil they seem to sin not only against their relatives but also against the Holy Ghost.

If we wish to extirpate the spell properly, we must look out: if the abovementioned spell is under the bed, it must be removed. But if the author of this spell removes it in daytime and puts it back at night or vice versa, then bridegroom and bride must acquire another house and lie down there.

If the spell is made of letters, which is recognized by the fact that bridegroom and bride do not love each other, one must search above and under the threshold of the door, and if something is found it must be taken to the bishop or priest. If not, one must do what is indicated below.

If a nut or an acorn are the cause of this spelt, the woman shall take a nut or an acom and divide it in two. And with one half the man shall proceed on 
one side of the road and deposit it there; the woman however shall put the other half on the other side of the road. Thereupon bridegroom and bride shall take both parts of the nut without having removed the shell. And then the nut shall thus be made whole again and shall be kept for seven days. Having done this they shall have intercourse.

If, however, it happens on account of beans, it can be cured with divine rather than human means. If it is on account of the needles for the dead, the spells must be sought either in the pillow or in the mattress. If they are not found, the victims shall lie together in another house.

Bile of a male dog purifies the house and brings it about that no evil remedy be brought to the house.

Sprinkle the walls of the house with dog's blood and it will be liberated from every spell.

If briclegroom and bride carry bile of a fish and particularly of zangarinus (that is lucius) along in a box made of juniper, and if when they go to sleep they pour some on burning coals and are fumigated therefrom, all spells mentioned above vanish.

Similarly, if quicksilver is taken and put into a reed pen and the pen is sealed with wax and lead while the bridegroom and bride know nothing about it, no spell will harm them at the place.

If, however, on account of impending sins the above-mentioned measures did not help at all, they shall go to a priest or the bishop. And if the bishop has permitted it and no remedy is found, after having confessed to the bishop or an ordained priest they shall take Holy Communion on the day of the Holy Resurrection or Ascension in Whitsuntide. Having received the body and blood of the Lord, bridegroom and bride shall give each other the kiss of peace.

And after they have received the benediction of the bishop or priest, the bishop or priest shall give this verse of the prophet written on paper: The voice of the Lord is upon the waters, the great Lord is upon many waters. Thereafter they shall go home and shall abstain from intercourse for three days and three nights. Then they shall perform it and thus all diabolical power is destroyed.

The little treatise on spells has come to an end. Thanks be to God. Amen.

Impotence as a result of witchcraft was discussed by many scholastic physicians whose writings have been reviewed very carefully by Gerda Hoffmann.

Since witches were considered the chief authors of such evil spells the Witches Hammer, the Malleus Maleficarum, of 1489 devotes many passages to the question. ${ }^{11}$ Following the Dominican scholar Peter of Palude who died in 1342 , it distinguishes five methods by which the devil causes impotence: ${ }^{12}$

And as to this, Peter of Paluck (III, 3t) notes five methods. For he says that the devil, being a spirit, has power over a corporeal creature to cause or prevent a local motion. Therefore he can prevent bodies from approaching each other, either directly or indirectly, by interposing himself in some bodily shape. In this way it happened to the young man who was betrothed to an idol and nevertheless married a young maiden, and was consequently unable 
to copulate with her. Secondly, he can excite a man to that act, or freeze his desire for it, by the virtue of secret things of which he best knows the power. Thirdly, he (an so disturl) a man's perception and imagination as to make the woman appear loathsome to him: since he can, as has been said, influence the imagination. Fouthly, he can directly prevent the erection of that member which is adapted to fructification, just as he can prevent a local motion. Fifthly, he can prevent the flow of the vital essence to the members in which lies the motive powers; by closing as it were the seminary ducts, so that it does not descend to the generative channels, or falls back from them, or does not project from them, or in any of many ways fails in its function.

More specifically witches were supposed to "impede and prevent the power of procreation" in the following way: ${ }^{13}$

Extrinsically they cause it at times by means of images, or by the eating of herbs; sometimes by other external means, such as cocks testicles. But it must not be thought that it is by the virtue of these things that a man is made impotent, but by the occult power of devils' illusions witches by this means procure such impotence, namely, that they cause a man to be unable to copulate, or a woman to conceive.

The Malleus Maleficarum states that "God allows the devil to afflict sinners more than the just," ${ }_{14}$ and in the case of impotence "the infirmity we are considering can only be due to the sin of incontinence. For, as we have said, God allows the devil more power over that act than over other human acts, because of its natural nastiness, and because by it the first sin was handed down to posterity."

The victim of a spell was therefore frequently branded as a sinner. The remedies were fuve: ${ }^{15}$

In conclusion we may say that there are five remedies which may lawfully be applied to those who are beritched in this way: namely, a pilgrimage to some holy and venerable shrine; wue confession of their sins with contrition; the plentiful use of the sign of the Cross and devout prayer; lawful exorcism by solemn words, the nature of which will be explained later; and lastly, a remedy can be effected by pruclently approaching the witch ...

Johann Weyer who in his De Praestigiis Daemonum, published in $15^{6} 3$, so courageously opposed witch-hunting, discussed also the question of impotence. ${ }^{16}$ He pointed out that such a condition could result from various natural causes and that it could also be produced incidentally by drugs. One should therefore not think of sorcery whenever such a case occurs, nor accuse innocent people. Weyer did not deny that the devil could disturb a man's generative function, but he was most violent in affirming that the clevil would certainly not need the intermediary of some filthy old wench. He discarded as lies various stories told about impotence caused or cured by magical means. In the case of a gentleman who was cured by anointing himself with bile of a raven and some kind of an oil after a recipe of the book of Cleopatra, ${ }^{17}$ W' conclusion was that erroneous beliefs can harm an individual but can also relieve him.

Impotence is no longer a mystery, and we can understand the condition without taking recourse to the devil. Impotence, however, like other nervous disorders and particularly sexual neuroses is still a playground for superstitions and quackery. 


\section{REFERENCES}

1. See Marcuse, Max: in Handwörterbuch der Medizinischen Psychologie (Leipzig: 1930).

2. Migne: Patrologia Latina 126:15o.

3. Lib. IV, dist. 34, in Migne: Patrologia Latina 192:927.

4. See Hansen, Joseph: Zauberwalın, Inquisition und Hexenprozess im Mittelalter (München

\& Leipzig: 1900; "Historische Bibliothek" XII), 152.

5. Omnia Opera Ysaac (Lugduni: 1515 ), fol. $117^{\mathrm{r}}$.

6. Arnaldi de Villa Nova Remedia contra Maieficia (Basileae: 1585), 129.

7. "Beiträge zur Lehre von der durch Zauber verursachten Krankheit und ihrer Behandlung in der Medizin des Mittelaiters" Janus 37:129, 179, 211, 1933.

8. See Sigerist, H. E.: "Early mediaeval medical texts in manuscripts of Montpellier" Bull. Histor. Med. 10:27, $191^{1}$.

9. Other MSS have culcitra.

10. Psalm 28:3 in the Vulgate; 29:3 in the King James version.

11. Malleus Maleficarum, tr. by the Rev. Montague Summers (London: 1928).

12. Part i, Question 8; p. 55 .

13. Part ii, Question 1, ch. 6; p. 118.

14. Part ii, Question 2, ch. 2; p. 168.

15. Part ii, Question 2, ch. 3; p. 17 o.

16. Book iv, ch. xx.

17. Various books on the subject of gynecology and cosmetics were transmitted under the name of Cleopatra and some of them were printed in the Renaissance. 


\section{THE COAGULATION OF BLOOD:}

\section{QUANTITATIVE VIEWPOINTS}

$$
\text { By }
$$

H. P. SMITH, M.D.

\section{3}

From the

DEPARTMENT OF PATHOLOGY, STATE UNIVERSITY OF IOWA IOWA CITY, IOWA 



\section{THE COAGULATION OF BLOOD QUANTITATIVE VIEWPOINTS*}

$I^{\prime}$ IS ONLY in recent years that quantitative viewpoints have gained a prominent place in the literature of blood coagulation. Methods for the assay of fibrinogen and fibrin are well established, ${ }^{1}$ and quite recently methods have been devised for the assay of prothrombin and thrombin. ${ }^{2-8}$ The thrombin unit has been defined ${ }^{2-4}$ as the amount of activity which will cause coagulation of 1 cc. of standard fibrinogen solution in 15 seconds. One unit of prothrombin is the amount which, on maximal conversion, is capable of forming one unit of thrombin.

In normal clotting, the rate at which thrombin forms depends upon the amounts of prothrombin and thromboplastin present in the clotting mixture. Inhibitors likewise affect conversion rate. Recent work ${ }^{-11}$ indicates that the rate may also be determined by a "convertibility factor" of unknown nature. To add to the complexity, it is known that the thrombin, once formed, is rapidly destroyed by antithrombin. This complex interplay of variables is indeed bewildering, for our concepts are purely at the qualitative level. To comprehend the process as a whole, it is now quite evident that the quantitative concept must be developed. Only then can we truly understand the interplay of variables and the significance of clotting time and the reasons for variations in the latter.

Assay methods for thromboplastin, inhibitors, and the "convertibility factor" are still incompletely developed, and a complete quantitative analysis of the clotting problem is not at present possible. It is proposed, nevertheless, to make a beginning by presenting certain quantitative data regarding prothrombin and thrombin titers. These data will help to outline the problem and to indicate the nature of the problems which still await solution.

The Period of Induction in Blood Clotting. This expression was introduced by Mills $s^{12}$ to designate the period which must elapse before thrombin can be formed in sufficient amounts to cause clotting-a period which is normally $4^{-8}$ minutes. Mills believed that almost the entire period is consumed in reactions preparatory to thrombin formation, and that thrombin does not make its first appearance until a few seconds before the clot forms. From a theoretical standpoint it is, nevertheless, possible that traces of thrombin do appear earlier, but are kept minimal through action of antithrombin. This possibility must be kept in mind in comnection with the oft-reported statement that the carly stages of clotting, taken as a whole, are autocatalytic in nature (see $\left.\operatorname{Astrup}^{13}\right)$. The writer has employed the new assay techniques in an effort to determine whether small amounts of prothrombin do disappear during the

\footnotetext{
* Aided by a grant from the John and Mary R. Markle Foundation.
} 
“induction period." Certain technical difficulties were encountered, and further work is needed.

The Titer of Prothrombin and of Thrombin During and After Clot Formation: the "Thrombin Tide." At the conclusion of the "induction period" prothrombin is consumed and thrombin makes its appearance at a rather rapid rate, and very little difficulty is experienced in recording the changing titer of each substance. The experiments, summarized in table 1 , are typical. Tube 1, a sample of freshly drawn human blood, was placed at once in the centrifuge. On removal from the machine ten minutes later, the cells were

TABLE 1

Prothrombin and Thrombin Titers in Whole Blood Which Was

Centrifugalized at Varying Intervals After Being Drawn

\begin{tabular}{|c|c|c|c|}
\hline Tube number & $\begin{array}{l}\text { Time elapsing } \\
\text { after drawing } \\
\text { blood, } \\
\text { minutes* }\end{array}$ & $\begin{array}{l}\text { Protrombin } \\
\text { titer, } \\
\text { units }\end{array}$ & $\begin{array}{l}\text { Thrombin } \\
\text { titer, } \\
\text { units }\end{array}$ \\
\hline I. & IO & 330 & 0 \\
\hline 2. & 15 & 266 & I. 5 \\
\hline $3 \ldots \ldots$ & 25 & 250 & 2.0 \\
\hline$+\ldots \ldots$ & 60 & 55 & I. 8 \\
\hline $5 \ldots \ldots \ldots$ & I 35 & 6 & 0.1 \\
\hline
\end{tabular}

* Time includes a ro-minute period of centrifugalization.

found to be thoroughly packed and the blood to be unclotted. This tube may thus be considered a control, taken near the end of the induction period. The supernatant plasma was found to contain $33^{\circ}$ units of prothrombin per cubic centimeter-a level identical with that found in freshly oxalated plasma from this same individual.

Tube 2 represents freshly drawn untreated blood which was allowed to stand for five minutes, and was then centrifugalized for ten minutes. On removal from the centrifuge, the plasma was found to be clotted, and the prothrombin titer of the plasma had fallen to the 266-unit level.

Tubes 4 and 5 were allowed to stand for still longer periods before being centrifugalized. From the table, it is seen that the prothrombin titer of the serum fell to the 55 -unit level in 1 hour, and to the 6 -unit level in $21 / 4$ hours.

During the period of study 324 units of prothrombin were converted into 324 units of thrombin, yet from table 1 it is seen that the thrombin titer ("thrombin tide") did not rise at any time above the 2-unit level. It is evident that the antithrombic activity of serum is so great that thrombin is destroyed almost as rapidly as it is formed. Simple calculation shows that during the latter two-thirds of the first hour thrombin was being formed in each cubic centimeter at the average rate of 5 units, or $5 \mathrm{~N}$ molecules of thrombin per minute. The thrombin was destroyed at approximately the same rate, and the 
2N molecules continuously present represent the average thrombin "population." Since a stable population is the product of life span by number of births, it follows that the average life span of each thrombin molecule is approximately $2 / 5$ minutes, or 24 seconds, if one assumes the "birth" and the "death" of each molecule to be instantaneous. It is during this brief 24 -second period that the thrombin molecule is available for reaction with any fibrinogen which may be present. It is the astonishing activity of antithrombin which makes necessary the enormous excess of prothrombin which is required to build up a "thrombin tide" quickly and to adequate levels for clot formation.

TABLE 2

Prothrombin and Thrombin Titers in Serum Allowed to "Age" after Removal of the Blood Cells by Centrifugalization

\begin{tabular}{|c|c|c|c|}
\hline Tube number & Age of serum* & $\begin{array}{c}\text { Prothrombin titer, } \\
\text { units }\end{array}$ & $\begin{array}{c}\text { Thrombin titer, } \\
\text { units }\end{array}$ \\
\hline I . & $20 \mathrm{~min}$. & 225 & 1. 5 \\
\hline 2. & $30 \mathrm{~min}$. & 200 & 0.8 \\
\hline 3. & $+5 \mathrm{~min}$. & 170 & 0.5 \\
\hline 4. & I hr. & 150 & 0.4 \\
\hline 5 & $2 \mathrm{hr}$. & 9.3 & 0.2 \\
\hline 6. & thr. & 60 & $0.0+$ \\
\hline 7. & $7 \mathrm{hr}$. & 32 & $0.0+$ \\
\hline
\end{tabular}

* Whole blood placed in test tube, allowed to stand ten minutes at room temperature, then centrifugalized for ten minutes at $5^{\circ} \mathrm{C}$. The serum was removed and its "age" dated from the time the blood was drawn.

By the same token, it is the obvious role of the antithrombin to protect the circulation against the baneful effects of the enormous excess of thrombin which might spread from areas of thrombosis to endanger the fluidity of the entire mass of circulating blood.

The Effect of Cellular Elements on the "Thrombin Tide." The thromboplastin which is needed for clotting is derived from margins of wounds, from injury of fixed tissues, and from disintegration of blood cells and platelets. In the experiments reported in table 1, it is almost certain that most of the thromboplastin came from blood cells and platelets; it is unlikely that much came from the margins of the venipuncture wound. It will be noted that in these experiments the cells and platelets were continuously present throughout the entire period of the experiment. The continued disintegration of these cells and platelets may provide more and more thromboplastin as long as the blood is allowed to stand. If this were so one would expect that prothrombin would be converted to thrombin more slowly if the cells were removed by centrifugalization soon after the blood was drawn. To test this point, whole blood was allowed to stand for ten minutes only, after which it was centrifugalized for ten minutes, during which time it clotted. The serum was carefully removed and was allowed to stand at room temperature. The initial assays on this 
serum, table 2, showed that 225 units of prothrombin and 1.5 units of thrombin were present. From this point on, prothrombin was converted into thrombin very slowly, approximately one-fourth as rapidly as in those previous experiments where cells were present. It is quite evident that when cells and platelets are present they do continue for some time to supply thromboplastin, and the latter, in turn, causes a marked increase in the rate of prothrombin conversion. When conversion is rapid (table 1), the "thrombin tide" is high but brief; when conversion is slow (table 2), antithrombic activity predominates more strikingly, and the "tide" is low but more protracted.

\section{Discussion}

This attempt to view the entire process of clotting from a quantitative point of view is necessarily incomplete. It is now becoming apparent that there is great need for assay methods which are specific for the inhibitors and for thromboplastin. In addition to assay methods, it is important that every effort be made to isolate the various clotting factors in pure form. Already, gratifying progress has been made in the case of prothrombin and thrombin, and with these substances in a purified state it has been possible to work with simplified systems, and thus to establish important quantitative interrelationships. ${ }^{14,15}$ As other factors are purified and studied in simplified systems, it is, perhaps, not too much to hope that one will be able to plot all of the variables which enter into the clotting sequence.

\section{REFERENGES}

1. Cullen, G. E., and Van Slyke, D. D.: Proc. Soc. Exper. Biol. \& Med. 13:197, 1916.

2. Warner, E. D.; Brinkhous, K.M., and Smith, H. P.: Archs. Pathol. 18:587, 1934.

3. Warner, E. D.; Brinkhous, K. M., and Smith, H. P.: Amer. J1. Physiol. $1_{4} 4: 667,1936$.

4. Smith, H. P.; Warner, E. D., and Brinkhous, K. M.: Jl. Exper. Med. 66:801, 1937.

5. Quick, A. J.: Jl. Biol. Chem. 109:1xxiii, 1935.

6. Quick, A. J.; Stanley-Brown, M., and Bancroft, F. W.: Amer. Jl. Med. Scis. 190-501, 1935.

7. Quick, A. J.: Amer. Jl. Physiol. 114:282, 1936.

8. Ziffren, S. E.; Owen, C. A.; Hoffman, G. R., and Smith, H. P.: Amer. Jl. Clin. Pathol., tech. supp. $4: 13,1940$.

9. Warner, E. D.; Brinkhous, K. M., and Smith, H. P.: Proc. Soc. Exper. Biol. \& Med. $4^{0: 197}$, 1939.

10. Ziffren, S. E.; Owen, C. A.; Holfman, G. R., and Smith, H. P.: Proc. Soc. Exper. Biol. \& Med. 40:595, 1939 .

11. Owen, C. A.; Hoffman, G. R.; Ziffren, S. E., and Smith, H. P.: Proc. Soc. Exper. Biol. \&. Med. $41: 181,1939$.

12. Mills, C A.: Chin. Jl. Physiol. 1:123, 1927.

13. Astrup, T.: Enzymologia 9:337, 1941.

14. Mertz, E. T.; Seegers, W. H., and Smith, H. P.: Proc. Soc. Exper. Biol. \& Med. $41: 657$, 1939. 15. Mertz, E. T.; Seegers, W. H., and Smith, H. P.: Proc. Soc. Exper. Biol. \&. Med. 42:604, 1939. 


\title{
AN EXPERIMENTAL ANATOMIGAL
}

\section{STUDY OF SENSORY MASKING}

\author{
By \\ I. MACLAREN THOMPSON \\ B.SC., M.B., CH.B.(EDIN.)
}

\section{蕬}

From the

DEPARTMENT OF ANATOMY, UNIVERSITY OF MANITOBA WINNIPEG, MANITOBA, CANADA 



\title{
AN EXPERIMENTAL ANATOMICAL STUDY OF SENSORY MASKING*
}

\author{
INTRODUCTION
}

$\mathrm{T}$

THE TEMPORARY local "benumbing” effects of stimulating nerves with certain electric currents have been known for a long time-certainly since 1858 , when Robert ${ }^{1}$ suggested that this diminished perception results not from anesthesia in the ordinary sense, but from diversion of attention, or confusion of consciousness, by the sensation springing from the electrical stimulus. This type of diminished sensibility, the mechanism of which he attributed to the central nervous system (though the electric current was applied peripherally), Robert designated "anesthésie de diversion," or "masking." Detailed reference to the numerous subsequent observations of this phenomenon (for example by Peterson, Leduc, and others) seems unnecessary; an experimental study was published by 'Thompson, Banks, Barron, Fratis and Mattison in 1934. Thinking, with Robert, that the diminished sensibility was central in nature, I proposed $^{3}$ in 1933, upon the basis of purely subjective experience, to follow him in calling it "masking." In 1934 my assistants (L. W. Denny and J. C. Luce) and I performed a series of experiments upon ourselves, designed to prove or disprove Robert's suggestion that this type of diminished perception is a central phenomenon. I gave a preliminary account ${ }^{4}$ of these experiments before the Association for Research in Nervous and Mental Disease on December 27 , 1934. In 1935 Davis and Derbyshire ${ }^{3}$ advanced evidence that auditory masking is a peripheral phenomenon, dependent upon the refractory period of nerve fibers. Thereupon, in a note to Science, ${ }^{6}$ I gave another preliminary (illustrated) account of our experiments; concluded that they confirmed Robert's suggestion that this type of electrical masking is a central phenomenon, and suggested that the term "masking" be restricted to Robert's original usage. Stevens and Henry ${ }^{s}$ objected to this suggestion, mainly on the ground that in the literature of audition the term "masking" has been employed in a purely phenomenological way, without reference to suggested underlying mechanisms; they urged the continuance of this practice. Though not convinced that it is wholly justified, I prefer adopting their contention to arguing about it .

\section{Observations and Discussion}

This contribution is mainly a detailed account of the experiments referred to above, now published for the first time. Many of these experiments involved

\footnotetext{
* From the Departments of Anatomy of the Universities of California and Manitoba. This investigation was aided by grants lrom the Board of Research ol the University of California, and from the University of California Chapter of the Society of Sigma Xi, to whom appreciative acknowledgments are tendered. The procaine used was kindly donated by Ely Lilly and Compans. All the injections (save one) were skillfully performed by Dr. A. A. Konelf.
}

$$
[.5,5]
$$


blocking nerves with procaine. The results of certain experiments, mostly early ones, before our technique was reliably developed, were rejected, either because the block was imperfect, or because it began to pass off before the required observations were finished. Our criterion of a complete block was anesthesia to all types of sensation in the cutaneous area supplied by the nerve. The successful blocks were induced with 1 cc. of 2 per cent procaine containing $0.04 \mathrm{mg}$. of adrenalin.

For this study the sense of pressure was chosen, because its threshold is readily raised and easily measured (as described by Thompson and coworkers ${ }^{2}$ ). In each experiment the question to be answered was: Under these conditions, is the pressure threshold significantly raised or not? For this purpose experience led us to define a significant rise as one of four increments or greater (see Thompson and co-workers ${ }^{2}$ ). Hence the following rises are considered significant: a rise of $4 \mathrm{gm}$. or more above an initial threshold of less than $10 \mathrm{gm}$.; a rise of $8 \mathrm{gm}$. or more above an initial threshold of 10 to $50 \mathrm{gm}$.; and a rise of $20 \mathrm{gm}$. or more above an initial threshold higher than $50 \mathrm{gm}$. This may seem a severe criterion of significance, but it is not unnecessarily so in view of the strong stimulating currents employed. These were alternating currents that just failed to cause distress; they were generated and applied as described by Thompson and co-workers. ${ }^{2}$

(1) The radial nerve being blocked with procaine in the lower part of the forearm, the skin supplied by that nerve was quite anesthetic; hence superficial pressure was abolished; but upon pressing through this insensible skin the sensation of pressure in the deep structures (especially the first dorsal interosseous muscle) could be aroused, the impulses evoking the sensation ascending along the ulnar nerve; the threshold of this deep pressure was measured.

(2) The radial nerve being strongly stimulated distal to the block, the deeppressure threshold was again measured at the same spot as before. This was done twenty-eight times (three subjects): a significant rise in the deep-pressure threshold occurred three times, a drop twice, and no significant change took place on the remaining twenty-three occasions. Clearly, stimulation of this cutaneous nerve distal to a procaine block produced no consistent effect upon the deep-pressure threshold beneath the anesthetized skin.

(3) Under similar circumstances, the same (radial) nerve was stimulated proximal to a complete block forty-three times (four subjects): five times there was no significant change in the deep-pressure threshold; but on the remaining thirty-eight occasions that threshold was significantly elevated.

(4) The dorsal branch of the ulnar nerve was stimulated proximal to a procaine block eighteen times (two subjects): every time, there was a significant rise in the pressure threshold in the fourth dorsal interosseous muscle and other structures lying beneath the anesthetized skin and supplied by the deep branch of the ulnar nerve.

Thus stimulation of the radial nerve and of the dorsal branch of the ulnar, 


\section{Maclaren Thompson}

proximal to a procaine block, raised the pressure threshold in structures supplied by the deep branch of the unar nerve.

(5) The radial nerve being blocked, the median nerve was stimulated at the wrist twenty times (three subjects): the deep-pressure threshold beneath the anesthetized skin was unaltered once, and was significantly raised nineteen times.

(6) The radial nerve being blocked, the dorsal branch of the uInar was stimulated four times (one subject): each tine the deep-pressure threshold beneath the anesthetized skin was significantly raised.

(7) The radial nerve being blocked, the medial cutaneous nerve of the forearm was stimulated twenty times (three subjects): the deep-pressure threshold beneath the anesthetized skin was unchanged four times, but was significantly raised sixteen times.

Similar experiments were performed with the dorsal branch of the ulnar nerve blocked.

(8) The median was stimulated at the wrist twenty-five times (three subjects): six times there was no change in the deep-pressure threshold beneath the anesthetized skin, twice there was a fall in the threshold, and seventeen times a significant rise.

(9) The radial was stimulated eleven times (three subjects): four times there was no change in the deep-pressure threshold, seven times there was a significant rise.

(10) The medial cutaneous was stimulated eleven times (three subjects): three times there was no change in the deep-pressure threshold, eight times there was a significant rise.

Elevation of thresholds was never produced by a current too weak to evoke a tingling sensation; only when the throbbing reached a certain degree of intensity did elevation of thresholds occur; and the rise in threshold varied directly as the intensity of the tingling. Moreover, stimulation of a cutaneous nerve proximal to a procaine block evoked tingling in the anesthetized skin and raised the deep-pressure threshold beneath it, whereas stimulation distal to the block evoked no sensation and did not elevate the deep-pressure threshold. Evidently masking depends upon the sensation of tingling.

This leads us to inquire concerning the throbbing or tingling felt in the cutaneous area supplied by a nerve under electrical stimulation. That this sensation, though felt in the skin, is not caused by retrograde stimulation of end-organs therein (with or without the liberation of chemicals) is shown by our observations just mentioned, that (a) stimulation proximal to a procaine block elicited the sensation exactly as with an unblocked nerve (though the block isolated the end-organs from the stimulus), whereas (b) stimulation distal to the block elicited no sensation. In 1936 Lewis $^{9}$ published a description of similar experiments yielding sensory results identical with those listed as $(a)$ and $(b)$ above, but without mentioning our work, the preliminary accounts 
of which were published in 1935. Although both sets of experiments were essentially similar (with respect to the points under discussion), we were interested in the concomitant tingling sensation, Lewis in the subsequent hyperalgesia. We did not observe such hyperalgesia, perhaps because of the kind of electric stimulus that we used, but more probably because we were not looking for it. Lewis ascribes this hyperalgesia to liberation of a chemical in the skin supplied by the nerve stimulated, supporting this by an appeal to a statement of Foerster's that stimulation of the distal segment of a divided cutaneous nerve produced pain, relieved by section of overlapping nerves. So far as I know, this statement of Foerster's awaits confirmation. It would lead one to expect sensation upon stimulation distal to a block, but neither in our experiments nor in Lewis's was this observed, with the following trivial exceptions. (1) Lewis observed a little sense of burning accompanying the post-stimulatory hyperalgesia described by hinı. (2) We sometimes found that when the stimulus applied distal to a procaine block was very strong, tingling was felt everywhere distally except in the area supplied exclusively by the blocked nerve under stimulation. We call this a "negative picture" of tingling; but, since this tingling was widespread, it may be ascribed simply to spread of the strong current to the other nerve trunks. In my opinion, Foerster's statement should be ignored in this connection, at least for the present. Whatever may be true of the subsequent hyperalgesia, it seems clear that the tingling sensation accompanying electrical stimulation of cutaneous nerves does not depend upon the peripheral liberation of a chenuical, since it occurred upon stimulation proximal to a complete block. Experiments under the condition of partial block were interesting. If cutaneous tests showed that only the (small) temperature and pain fibers were blocked, distal stimulation evoked tingling indistinguishable from that accompanying stimulation of normal nerve; hence the sensation may be attributed principally to stimulation of the unanesthetized (large) touch and pressure fibers. The idea that the tingling upon electric stimulation of nerve fibers cloes not depend upon end-organs is further supported by observations made in 1934 by two other assistants of mine (R. C. Combs and H. S. Kimball): they found that normal throbbing could be felt in a cutaneous area completely anesthetized by freezing with an ether spray (radial area, once in each of five subjects).

It seems clear that the tingling sensation accompanying stimulation of a cutaneous nerve depends upon bombardment of the sensorium by impulses ascending from the electrode, the sensation being "projected" by the brain into the cutaneous distribution of the nerve stimulated; in other words, this form of tingling is a central phenomenon, resulting from impingement of nerve impulses upon the sensorium. To some this may seem so obvious as scarcely to require proof; but in view of our finding that the type of masking under consideration is invariably associated with tingling, it has seemed desirable thus to prove to the hilt that this sensation depends upon a mechanism 


\section{Maclaren Thompson}

extending from the electrode, along the nerve stimulated and its central pathways, to the sensorium (but not upon anything distal to the electrode, even in an unblocked nerve).

\section{Concilasion}

Notwithstanding the shight inconsistencies common in work of this kind, these various experiments, taken as a whole, show that the threshold for decp-pressure in muscles, etc., supplied by the deep branch of the ulnar nerve may be elevated by suitable electrical stimulation of any other nerve in the forcarn and hand. This proves that the phenomenon is not one of peripheral block. (If it were, only stimulation of the deep branch of the ulnar nerve could raise the threshold in structures supplied by it.) Nor does it depend upon retrograde stimulation of end-organs. (If it did, elevation of pressure threshold in muscles supplied by one nerve could not be produced by stimulating another cutaneous nerve.) It may be concluded that this type of masking depends upon a mechanism within the central nervous system. This is supported by the invariable association of masking with a tingling or throbbing sensation.

\section{REFERENCES}

1. Robert: Union méd. $12: 487,18,38$.

2. Thompson, I. M.; Banks, G. F.; Barron, A.; Fratis, A. M., Jr., and Mattison, B. F.: Univ. California Publns. Anat. 1:167, 1934.

3. Thompson, I. M.: Science (n.s.) 78:268, 1933 .

4. Thompson, I. M.: Proc. Assn. Resrch. Nerv. \& Ment. Disease 15:98, 1935.

5. Davis, H., and Derbyshire, A. J.: Amer. Jl. Physiol. 113:34, 1935.

6. Thompson, I. M.: Science (n.s.) 82:221, 1935 -

7. Stevens, S. S.: Science (n.s.) 82:390, 1935.

8. Henry, F.: Science (n.s.) 83:231, 1936.

9. Lewis, T.: Clin. Sci. 2:373, 1936. 



\section{THE EFFEGT OF PROGESTERONE}

\section{AND LAGTOGENIG HORMONE UPON \\ PROLONGATION OF PREGNANGY \\ IN THE LACTATING MOUSE}

$$
\text { By }
$$

KAISA TURPEINEN

\section{䟢}

From the

DEPARTMENT OF EMBRYOLOGY, CARNEGIE INSTITUTION OF WASHINGTON, BALTIMORE, AND THE WOMEN'S CLINIC UNIVERSITX' OF HELSINKI, HELSINKI, FINLAND 



\title{
THE EFFECT OF PROGESTERONE AND LACTOGENIC HORMONE UPON PROLONGATION OF PREGNANCY IN THE LACTATING MOUSE
}

\begin{abstract}
A EARLY as fifty years ago Lataste ${ }^{1}$ made the interesting observation that in some rodents (three species of gerbil, the brown rat, and the house mouse) the period of gestation was prolonged if the mother simultaneously lactated young from the previous litter. In studying the phenomenon more closely in the mouse, he observed that the delay of parturition was correlated with the number of young lactated, each young prolonging the gestation by approximately one day. From his experiments Lataste concluded that after the ova had reached the uterus there followed during lactation an arrest in their derelopment, which equaled in length the prolongation of pregnancy. After this rest period, the gestation proceeded in a normal way, and the young born showed a normal stage of development.

Curiously enough, this pioneer work of Lataste seems to have passed largely unnoticed. Of recent investigators Brambell ${ }^{2}$ is the only one who makes any reference to it. Later workers (Daniel ${ }^{3}$; King Kirkham $^{5,6}$; Long and Evans; Mirskaia and Crew; Enzmann. Saphir and Pincus'; Hain ${ }^{11}$; and Brambellº) have generally confirmed Lataste's findings, although in certain points their results differ to some extent.
\end{abstract}

As to the mechanism of the prolongation of pregnancy it was already indicated by Lataste's early observations that the prolongation of pregnancy during lactation was due to a delay in the implantation process. This view was given more support by Kirkham s experiments, and it was conclusively proven by Enzmann, Saphir and Pincus in their careful study. By flushing the uterine horns with Ringer's solution, these investigators rere able to recover free blastocysts at any time until the eighteenth day and to show that in the lactating females implantation occurred betreen the sixth and sixteenth days, thus being delayed by one to eleren days.

The hormonal factors controlling this delayed implantation have so far received but little attention. Teel ${ }^{11}$ was able to produce delayed implantation in nonlactating rats by injecting anterior hypophysial extract early in the pregnancy. Tislocki and Goodmann attempted to carry out similar experiments in the rabbit, but without success. Hamlett, ${ }^{13}$ on the other hand, tried to shorten the naturally very long free blastocyst stage in the Texas armadillo (Tatusia novemcincta), but his results were likewise negative. Pincus ${ }^{24}$ injected estrone-free corpus luteum hormone into lactating mice and observed that parturition in the treated animals occurred even later than would be expected 
by assuming that each suckling young would prolong gestation by one day. From this he concluded that the delay in implantation was due to an excessive corpus luteum secretion during lactation.

The present study is an attempt to elucidate further the hormonal mechanism of delayed implantation in the lactating mouse. Since the data of earlier workers on the effect of the number of young on the prolonged pregnancy during lactation were in certain respects somewhat conflicting, it was deemed necessary to study first this phenomenon as such.

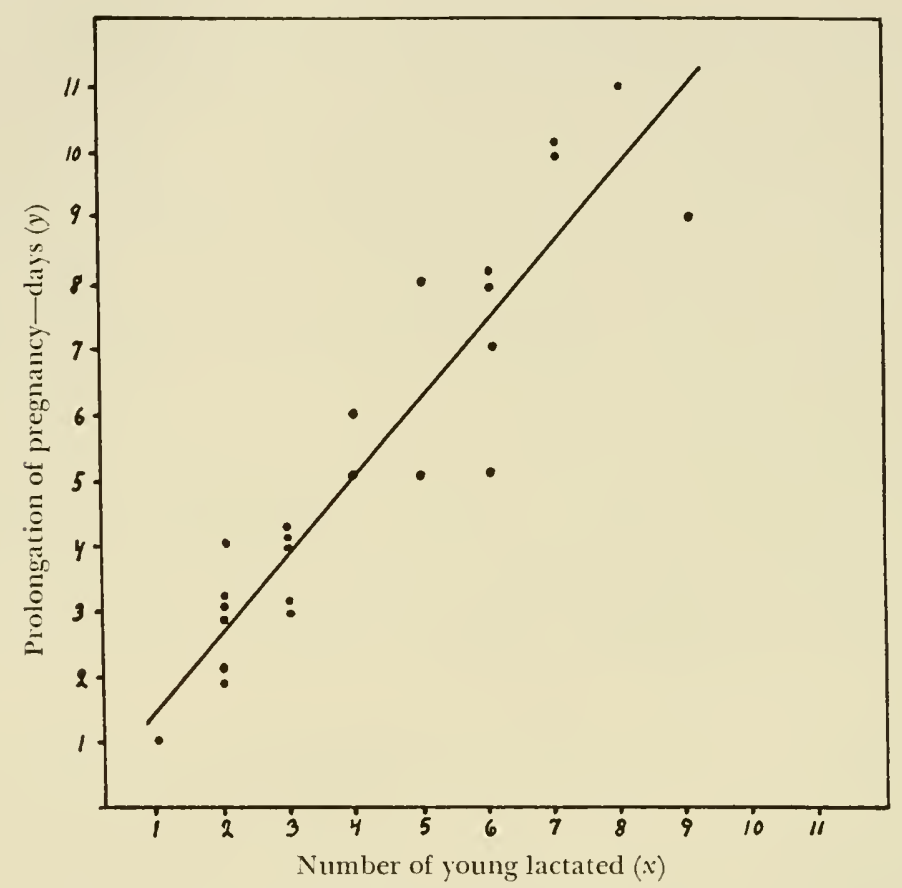

Fig. 1. Dot diagram showing the relationship between prolongation of pregnancy and number of young lactated.

$y=1.20 x+0.30$

Methods. Albino mice, from two to four months old, were used. They were kept in glass jars and given a milk-cereal diet and water ad libitum. Near term the pregnant female was isolated with a male into a separate jar. When the litter was found at the daily inspection, the date of the birth and the number of young were recorded. The vaginal content was then examined for positive mating on the two following days. When sperm were found the male was removed and the female was left to lactate her litter and observed for the second litter. The length of gestation was regarded as the time interval between the date of the positive copulation (the finding of plug or sperm) and the date when the following litter was found. The normal length of pregnancy in the non- 
lactating females of this strain of mice was, as numerous carcful obscrvations showed, nineteen days. The prolongation of pregnancy was found by subtracting this value from the observed length of pregnancy.

In the experiments with hormones, they were injected subcutaneously, and the injections were timed so that they took place before the calculated implantation time, either normal or delayed. Injections were, however, not given too soon after delivery in order not to influence the passage of eggs through the Fallopian tubes, and they were not continued too long so that the lactation

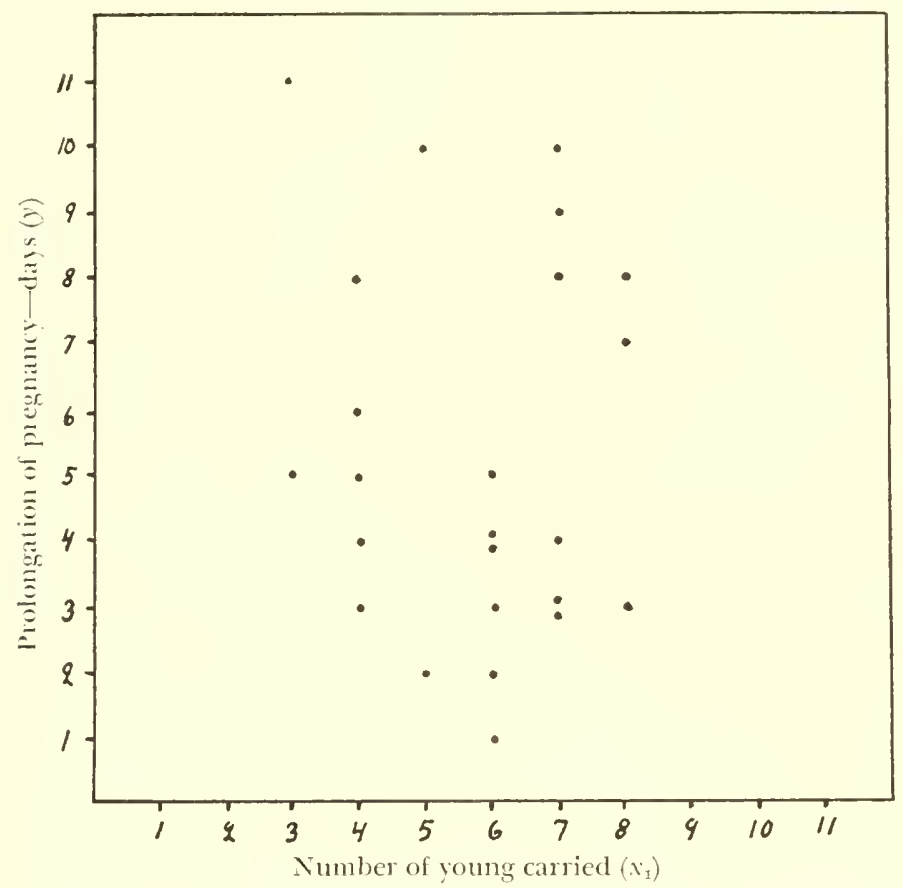

Fig. .. Dot diagram showing the relationship between prolongation of pregnancy in days and number of young carried.

process itself was not too greatly affected. The observed prolongation of pregnancy was compared with the expected prolongation which lactation alone would have caused and which was calculated from the equation:

$$
y=1: 20 x+0.30 \text { (see below). }
$$

Prolongation of Pregnancy During Lactation. In twenty-four cases of pregnancy during lactation, the length of gestation varied from twenty to thirty days. As the normal length was nineteen days, pregnancy was thus prolonged in every instance, the delays in parturition ranging from one to eleven days.

These data make possible a study of the relationships between the prolongation of pregnancy and the number of young lactated or young carried. The relationships are represented in the form of two dot diagrams (figs. 1 and 2). 
Figure 1 shows the prolongation of pregnancy plotted against the number of young lactated. It can be seen by inspection that the relationship between these two variables is linear and that there is an unmistakable positive correlation between them. The correlation coefficient was calculated and found to be:

$$
r_{x y}=+0.928
$$

This indicates a high degree of positive correlation. It is also statistically highly significant, for a $t$-test shows: $t=11.68, n=22, P=$ far smaller than 0.01 (Fisher, ${ }^{15}$ p. 198 and 177 ).

Consequently, there is a practically perfect positive correlation between the prolongation of pregnancy and the number of young lactated. The calculation was now carried further by computing the line expressing the relation between the delay and the number of young lactated (line of regression). The equation of this line of regression was found to be:

$$
y=1: 20 x+0.3^{0}
$$

in which $y$ is the prolongation of pregnancy in days and $x$ is the number of young lactated. This equation shows that the delay of pregnancy per young in this strain of mice is on the average 1.2 days. In the latter experiments with hormones, the expected delays were always calculated by means of this equation. The line of regression is also marked on the dot diagram (fig. 1).

Figure 2 shows the relationship between the prolongation of pregnancy $(y)$ and the number of young carried $\left(x_{1}\right)$. Even a superficial inspection of this figure reveals that there could be little if any significant correlation between these variables. The calculation of the correlation coefficient fully confirms this view:

$$
r_{x_{1} y}=-0.067
$$

This value has no statistical significance ( $t=0.318, n=22$, and $P=0.75$ ). This "total" correlation coefficient may, however, be somewhat unsatisfactory. Since the delay is greatly influenced by the number of young lactated $\left(x_{2}\right)$, as has just been shown, it is possible that this influence may entirely overshadow any effect which the number of young carried might have had on the prolongation. Therefore, a better index of the correlation between the prolongation and the number of young carried is the "partial" correlation coefficient, from which the influence of the number of young lactated is eliminated. This was found to be:

$$
r_{x_{1} x_{2}}=-0.128
$$

Under these conditions the correlation is somewhat increased, but even this latter value is fairly low and statistically not significant $\left(t=0.59^{\circ}, n=21\right.$, and $\left.P=0.5^{6}\right)$. Consequently, no correlation could be shown to exist between the prolongation of pregnancy during lactation and the number of young carried.

The Effect of Progesterone upon Prolongation of Pregnancy During Lactation. Since during lactation there is a persistence of functional corpora lutea, 
it seemed interesting to test whether progesterone, the hormonal product of corpora lutea, has any effect on the length of pregnancy during lactation. Mirskaia and Crews have postulated that the activity of the corpus luteum might be insufficient to meet the requirements of both lactation and pregnancy at the same time and that this might be the cause of the prolongation. There is, howerer, some experimental evidence to the contrary. Thus, Teel ${ }^{11}$ in his experiments was able to produce delayed implantation in pregnant rats with

T.ABLE 1

Effect of Progesterone in Prolongation of Pregnanci During Lactation

\begin{tabular}{|c|c|c|c|c|c|c|c|}
\hline & \multirow{2}{*}{ Mouse No. } & \multirow{2}{*}{$\begin{array}{c}\text { Dose } \\
\text { injected, } \\
\text { mg. }\end{array}$} & \multirow{2}{*}{$\begin{array}{l}\text { Day of } \\
\text { injection }\end{array}$} & \multirow{2}{*}{$\begin{array}{l}\text { Number } \\
\text { of suckling } \\
\text { young }\end{array}$} & \multicolumn{3}{|c|}{ Prolongation of fregnancy } \\
\hline & & & & & $\begin{array}{c}\text { Expected. } \\
\text { days }\end{array}$ & $\begin{array}{c}\text { Observed, } \\
\text { days }\end{array}$ & $\begin{array}{c}\text { Diterence, } \\
\text { days }\end{array}$ \\
\hline 20 & & 0.25 & 氵th & 3 & 3.9 & 10 & +6.1 \\
\hline $2 I$ & & $0 .: 5$ & gth & $\vdots$ & 6.3 & 9 & +2. \\
\hline 27 & & $0.2:$ & $6 \mathrm{th}$ & $\vdots$ & 6.3 & 10 & +3. \\
\hline 46 & & 0.25 & $-\mathrm{ch}$ & 6 & -5 & I 1 & +3.5 \\
\hline 38 & & $0 . \vdots$ & ird & + & $\vdots .1$ & 9 & $+\therefore .9$ \\
\hline 17 & & 0.5 & th & $\vdots$ & 6.3 & 9 & +2.7 \\
\hline+2 & & 0.5 & th & 6 & $i \vdots$ & 9 & +15 \\
\hline 24 & & $0 . \vdots$ & sth & 6 & $7 \vdots$ & $\mathrm{I}+$ & +6.5 \\
\hline 26 & & 0.5 & 氵th & $\vdots$ & 6.3 & 6 & +0.3 \\
\hline \multirow[t]{2}{*}{46.} & & $0 .:$ & 氵th & $\vdots$ & 6.3 & - & +0.7 \\
\hline & & & & & & Average & +3.1 \\
\hline
\end{tabular}

anterior-pituitary extracts which caused luteinization of the oraries. Pincus, ${ }^{2 *}$ also reported a prolongation of pregnancy in lactating mice by injections of estrone-free corpus luteum hormone during the five to eight days after the first parturition. He concluded that the excessive corpus luteum secretion caused the delayed implantation during lactation.

The source of corpus luteum hormone used in the present work was "Lutren." a preparation of synthetic progesterone in oil. manufactured by Bayer I. G. Farbenindustrie (Leverkusen, Germany). The results are represented in table 1.

From this table it appears that when progesterone was given during lactation, before the expected implantation, from the third to the seventh day after the first delivery, a prolongation of pregnancy ensued, which in all cases except one (mouse no. 26) was longer than anticipated if only lactation had caused the delar.

The Effect of Hypophysial Lactogenic Hormone upon Prolongation of Pregnancy During Lactation. Originally, anterior pituitary lactogenic hormone was connected with the process of lactation. Later several new properties were arcribed to this same hormone. Dresel" observed a distinct suppression 
of estrous cycles in mice when lactogenic hormone was injected. Lahr and Riddle $^{17}$ were able to demonstrate the same thing in rats. They inclined to the view that the amenorrhea in mammals and human beings during pregnancy and lactation is due to the presence of lactogenic hormone. Nathanson, Fevold and Jennison ${ }^{18,18}$ believed that the experimental suppression of the estrous cycle in mammals is due to the presence of luteinizing hormone in the commercial preparations of lactogenic hormone. Evans, Simpson, Lyons and

TABLE 2

Effect of Lactogenic Hormone on Prolongation of Pregnancy During Lactation

\begin{tabular}{|c|c|c|c|c|c|c|}
\hline \multirow[b]{2}{*}{ Mouse No. } & \multirow{2}{*}{$\begin{array}{l}\text { Dose } \\
\text { injected, } \\
\text { B.U. }\end{array}$} & \multirow{2}{*}{$\begin{array}{c}\text { Day of } \\
\text { injection }\end{array}$} & \multirow{2}{*}{$\begin{array}{c}\text { Number } \\
\text { of suckling } \\
\text { young }\end{array}$} & \multicolumn{3}{|c|}{ Prolongation of pregnancy } \\
\hline & & & & $\begin{array}{l}\text { Expected, } \\
\text { days }\end{array}$ & $\begin{array}{c}\text { Observed, } \\
\text { days }\end{array}$ & $\begin{array}{l}\text { Difference, } \\
\text { days }\end{array}$ \\
\hline $7+\ldots \ldots \ldots$ & 5 & $3 \mathrm{~d}$ & 5 & 6.3 & 7 & +0.7 \\
\hline $95 \ldots \ldots \ldots \ldots$ & 5 & $3 \mathrm{~d}$ & 7 & 8.7 & I I & +2.3 \\
\hline $21 \ldots \ldots \ldots \ldots$ & 5 & th & + & $5 \cdot 1$ & II & +5.9 \\
\hline $1,34 \ldots \ldots \ldots \ldots$ & 5 & 4th & 8 & $9 \cdot 9$ & no litter & $\ldots \ldots$ \\
\hline $6+\ldots \ldots$ & 5 & 6 th & 6 & $7 \cdot 5$ & 17 & +9.5 \\
\hline $26 \ldots \ldots$ & 5 & 7 th & + & 5. 1 & 8 & +2.9 \\
\hline${ }^{1} 35 \ldots \ldots \ldots \ldots$ & 10 & +th & 3 & $3 \cdot 9$ & no litter & $\ldots \ldots$ \\
\hline $121 \ldots$ & 10 & 6 th & 6 & $7 \cdot 5$ & no litter & $\ldots$ \\
\hline $35 b \ldots$ & $10^{*}$ & $2 \mathrm{~d}-8$ th & 5 & 6.3 & 10 & +3.7 \\
\hline $2 b \ldots$ & $10^{*}$ & $2 \mathrm{~d}-8 \mathrm{th}$ & 6 & $7 \cdot 5$ & no litter & $\ldots$ \\
\hline \multirow[t]{2}{*}{$3 \mathrm{I} b \ldots$} & $20^{*}$ & $2 \mathrm{~d}-8 \mathrm{th}$ & 5 & 6.3 & no litter & $\ldots \ldots$ \\
\hline & & & & & Average & +4.2 \\
\hline
\end{tabular}

* Divided in two daily doses.

Turpeinen ${ }^{20,21}$ were able to produce deciduomata in hypophysectomized rats with injections of pituitary lactogenic hormone. They were of the opinion that lactogenic hormone increases the production of corpus luteum hormone thus sensitizing the uterine mucosa for the deciduoma reaction. This and the existence of functional corpora lutea during lactation, as well as the release of hypophysial lactogenic hormone at delivery, made it worth while to study the question whether lactogenic hormone injections during lactation had the same effect on the delay of implantation as the corpus luteum hormone.

In these experiments lactogenic hormone of the anterior hypophysis was used in the form of "Prolactin" manufactured by Eli Lilly \& Company (Indianapolis, Ind.). This preparation is a yellowish powder, which is standardized in pigeons (B.U.) according to the method described by Bates, Riddle and Lahr. ${ }^{22}$ For these experiments it was dissolved in distilled water. The results appear in table 2.

The results show conclusively that injections of lactogenic hormone into 
lactating and pregnant mice prolong the span of gestation still more than lactation alone, and given in large doses may entirely prevent pregnancy, presumably because of too excessive delay of implantation.

\section{Discussion}

There seems to be a reciprocal effect in the relationship between lactation and the implantation process. From the work of Frank $l^{23}$ we know that transplantation of placentas into pregnant animals near term inhibits lactation. On the other hand, lactation has an inhibiting effect on implantation by delaying it. The action of lactogenic hormone and corpus luteum hormone prevails during lactation. These facts and the results of my work support the view that the excessive production of lactogenic hormone and corpus luteum hormone during lactation would be the cause of delayed implantation.

\section{SUMMARY}

The prolongation of pregnancy, which occurs in some species of lactating rodents and which is due to the delay of implantation, has been studicd. Particular attention has been given to the effect on the prolongation of pregnancy of progesterone and hypophysial lactogenic hormone administered during the first part of the pregnancy, that is during the implantation time. Albino mice were used as experimental animals. The hormones were injected subcutaneously, and their effect on the prolongation was noted. Before starting the experiments with hormones, the effect of the number of young on prolongation of pregnancy during lactation was studied.

The following conclusions were reached:

1. In accordance with the majority of earlier workers, it was found that the length of pregnancy in lactating mice is dependent on the number of young the mother is suckling. There is an almost perfect positive correlation between these two variables $(r=+0.928)$. Each of the young lactated prolongs the pregnancy on the average by 1.2 days.

2. There is no demonstrable correlation between the delay and the number of young carried.

3. The synthetic corpus luteum lormone (progesterone) causes a further prolongation of pregnancy, that is, the length of pregnancy is prolonged beyond what lactation alone would cause.

4. The injection of the hypophysial lactogenic hormone causes further prolongation of gestation duxing lactation. Given in larger doses it may entirely prevent littering.

I wish to express my gratitude to Dr. Carl G. Hartman for suggesting this problem and for his aid during the early part of the work.

Since Dr. Turpeinen's return to her fatherland, it has been found by two experimenters, Dr. Segar-Jones at the Johns Hopkins Medical School, working with the mouse and rat, and 
by Dr. C. K. Weichert working with the rat (for the latter see Anat. Recrd. 8 r [supp.]:28, 1941). that estrogens favor the attachment of the vesicle at normal time and shorten the gestation period of the lactating female to normal.

\section{REFERENCES}

1. Lataste, F.: Cpts. rd. Soc. de biol., méms. 43:21, 1891 .

2. Brambell, F. W. R.: Amer. Jl. Obstet. \& Gynecol. 33:942, 1937.

3. Daniel, F. J.: Jl. Exper. Zool. 9:865, 1910.

4. King, H. D.: Biol. Bull. 24:377, 1913 .

5. Kirkham, W. B.: Anat. Recrd. 11:31,1916.

6. Kirkham, W. B.: Jl. Exper. Zool. 27:49, 1918.

7. Long, J. A., and Evans, H. M.: Anat. Recrd. 18:2ł1, 1920.

8. Mirskaia, L., and Crew, F. A. E.: Proc. Roy. Soc. Edinburgh 51:1, 1930-31.

9. Enzmann, E. N.; Saphir, N. R., and Pincus, G.: Anat. Recrd. 54:325, 1932.

10. Hain, A. M.: Quart. JI. Exper. Physiol. 24:101, 1934.

11. Teel, H. M.: Amer. Jl. Physiol. 79:170, 1926.

12. Wislocki, G. B., and Goodman, L.: Anat. Recrd. 59:375, 1934.

13. Hamlett, G. W. D.: Quart. Rev. Biol. 10:432, 1935 .

14. Pincus, G.: The Eggs of Mammals (New York: 1936).

15. Fisher, R. A.: Statistical Methods for Research Workers (7th ed.; Edinburgh, London: 1938 ).

16. Dresel, I.: Science (n.s.) 82:173, 1935.

17. Lahr, E. L., and Riddle, O.: Proc. Soc. Exper. Biol. \& Med. $34: 880,1936$.

18. Nathanson, I. T.; Fevold, H. L., and Jennison, D. B.: Proc. Soc. Exper. Biol. \& Med. 36 : $4^{81,1937 .}$

19. Nathanson, I. T., and Fevold, H. L.: Endocrinology 22:86, 1938.

20. Evans, H. M.; Simpson, M. E., and Turpeinen, K.: Anat. Recrd. 7o (supp. 3):26, 1938.

21. Evans, H. M.; Simpson, M. E.; Lyons, W. R., and Turpeinen, K.: Endocrinology 28:933, 1941.

22. Bates, R. W.; Riddle, O., and Lahr, E. L.: Amer. Naturlst. 69:55, 1935.

23. Frankl, O.: Amer. Jl. Obstet. \& Gynecol. 6:399, 1923. 


\title{
IS INCREASED CAPILLARY \\ FRAGILITY A SIGN OF ASCORBIG ACID SUBNUTRITION?
}

\author{
B) \\ OSMO TURPEINEN
}

\section{紹}

From the

INSTITUTE OF PHYSIOLOGY, UNIVERSITY OF HELSINKI HELSINKI, FINLAND 



\section{IS INCREASED CAPILLARY FRAGILITY A SIGN OF ASCORBIC ACID SUBNUTRITION?}

$\mathrm{I}^{1}$ Is WELL KNown that the tendency to bleed is one of the main symptoms of scurvy. In manifest scurvy the hemorrhages either occur spontaneously or are caused by trivial traumas. This symptom is not based on any pathologic changes in the composition of the blood, for both the bleeding time and the coagulation time are normal, but on decreased capillary resistance, which apparently is due to defective formation of intercellular substances.

This symptom of increased capillary fragility, which usually is the first morbid expression of scurvy, has also been utilized for diagnosis of milder deficiency states, so-called subclinical scurvy. In this condition the hemorrhagic tendency is not severe enough to lead to manifest symptoms. It can, however, be demonstrated by subjecting the capillaries to extra strain. This may be done by using the well-known Rumpel-Leede test, which in manifest scurvy is, as a rule, strongly positive.* In an attempt to refine the Rumpel-Leede test and to bring it to a more quantitative basis, Göthlin ${ }^{5}$ some years ago developed a capillary-fragility test which he thought could be utilized for diagnosis of subclinical scurvy. This method consists of increasing the intracapillary pressure in the arm by means of a Riva-Rocci cuff and counting the petechial hemorrhages which appear in a specified skin area under standard conditions. The original procedure has since been modified. ${ }^{6}$ Besides this "overpressure" method, another form of the capillary-fragility test has also been in use. This is the "suction" or "underpressure" test, originated by Hecht ${ }^{7}$ and later used and modified by several workers (see Jersiłd and Elmby ${ }^{8}$ ). The two methods do not necessarily give concordant results. According to Göthlin ${ }^{6}$ the overpressure method is preferable for its basis is "clear and unassailable," which "can by no means be said of the suction procedure."

After the chief role of ascorbic acid in the etiology of scurvy had been demonstrated, it was generally assumed that the increased capillary fragility as shown by the above-mentioned tests would, in otherwise healthy persons, be indicative of ascorbic acid subnutrition. Accordingly, these methods have gained a wide use in assessing the nutritional status in regard to ascorbic acid.

It is not, however, quite clear how reliable a sign the increased capillary fragility is in showing ascorbic acid deficiency. There is evidence both pro and con. Göthlin and his collaborators, who are the chief proponents of the test, have furnished most of the evidence in favor of the test. ${ }^{5,6-13}$ Some confirmative evidence has also come from other quarters; thus Dalldorf, ${ }^{14}$ Molitch, ${ }^{15}$ and Cianci ${ }^{18}$ considered the test satisfactory. Also Sloan ${ }^{17}$ found the capillary-

* However, cases of scurry have been repored which, even in spite of the presence of spontaneous hemorthages, give negative results in capillary-fragility tests. ${ }^{1-4}$ 
fragility test useful though less sensitive than chemical methods in indicating ascorbic acid subnutrition.

On the other hand, there are many dissenting opinions. Several investigators $^{18-23}$ have for various reasons questioned the reliability of the test. Weld ${ }^{4}$ found that vitamin $\mathrm{D}$ was even more effective than ascorbic acid in increasing capillary resistance.

Thus the opinions about the capillary-fragility test are rather contradictory. In view of the frequent use of this test in nutritional surveys, it would, however, seem desirable to have at hand some more definite evidence in regard to its reliability as a means of detecting ascorbic acid subnutrition. The present paper is a further attempt to evaluate the capillary-fragility test.

Correlation of Capillary Fragility with the Ascorbic Acid Content of the Diet. If ascorbic acid deficiency were a cause of increased capillary fragility, a correlation should exist between the ascorbic acid content of the diet and the capillary resistance. This question has not to my knowledge been studied previously on any considerable scale. Gedda ${ }^{10}$ and Nordenmark, ${ }^{13}$ it is true, demonstrated the existence of a seasonal difference in capillary fragility, which apparently paralleled a corresponding difference in ascorbic acid intake. The same fact is also evident from my data, which indicate a very definite scasonal difference between the capillary resistance values in the spring and those in the late autumn and an equally definite, parallel difference in the amounts of dietary ascorbic acid. Such evidence, however, is of limited value, for it is clear that a multitude of dietary and other environmental factors undergo seasonal variations. Thus there is not enough justification for the conclusion that the seasonal changes observed in capillary resistance were due to changes in ascorbic acid intake. On the other hand, it would constitute decidedly more valuable evidence in favor of the test, if it were possible to demonstrate a fair correlation between these two variables in a sufficiently large body of material. An extensive mass of data collected by the Finnish National Nutrition Committee some time ago offered an opportunity for studying this question.

In the years 1936-1937 the diet of a number of families of the lower income classes in Finland was examined. All food consumed by the families during a 1o-day period was carefully weighed, and its contents of the chief nutrients, ascorbic acid among them, were calculated. The amounts of the nutrients found in the diet were compared with the estimated requirements of the family. The requirements for ascorbic acid were taken as $50 \mathrm{mg}$. per day for persons over ten years of age and $25 \mathrm{mg}$. per day for children less than ten years old. Capillary-fragility tests were carried out by Göthlin's method ${ }^{5}$ on the members of the families ( 616 persons in all), the results being expressed as the number of petechiae developing under $50 \mathrm{~mm}$. $(\mathrm{Hg})$ pressure.

Table 1 shows the distribution of the 616 persons examined in regard to their ascorbic acid intake and the capillary status. This table reveals that the 
correlation between these two variables camnot be a very close one, for the values seem to be rather irregularly distributed. Among families with very low intakes of ascorbic acid, cases of normal capillary resistance are often found, and, on the other hand, a relatively high ascorbic acicl intake does

TABLE 1

Distribltion of 616 Persons in Regard to the Ascorbic Acid Content of the Diet and Capillary Fragility

\begin{tabular}{|c|c|c|c|c|c|c|c|c|c|c|c|c|c|c|}
\hline \multirow{2}{*}{$\begin{array}{c}\text { Number } \\
\text { of } \\
\text { petechiae* }\end{array}$} & \multicolumn{12}{|c|}{ Dietary ascorbic acid-percent of the estimated requirement } & \multirow{2}{*}{ Totals } & \multirow{2}{*}{$\begin{array}{l}\text { Array } \\
\text { means, } \\
\text { per } \\
\text { cent } \\
\text { ascor- } \\
\text { bic } \\
\text { acid }\end{array}$} \\
\hline & $\begin{array}{r}20- \\
40\end{array}$ & $\begin{array}{c}40- \\
60\end{array}$ & $\begin{array}{l}60- \\
80\end{array}$ & $\begin{array}{l}80- \\
100\end{array}$ & $\begin{array}{l}100- \\
120\end{array}$ & $\begin{array}{l}120- \\
140\end{array}$ & $\begin{array}{c}140- \\
160\end{array}$ & $\begin{array}{l}160- \\
180\end{array}$ & $\begin{array}{l}180- \\
200\end{array}$ & $\begin{array}{l}200- \\
220\end{array}$ & $\begin{array}{l}220- \\
240\end{array}$ & $\begin{array}{l}240- \\
260\end{array}$ & & \\
\hline $0 \ldots$. & 3 & 10 & $2 I$ & 28 & 32 & 50 & 16 & 20 & 6 & 6 & I 2 & 2 & 206 & 127 \\
\hline $1, \ldots$ & 2 & 8 & I3 & 10 & I 6 & 20 & 9 & 9 & 7 & + & 10 & I & $1 \circ 9$ & I3I \\
\hline $2 \ldots \ldots$ & I & 7 & I5 & 8 & $\mathrm{I}_{4}$ & 2.3 & . . & 8 & 5 & I & + & . & 86 & 119 \\
\hline $3 \ldots$ & 5 & + & 7 & + & 9 & I7 & 2 & I & 5 & . & 2 & . & $5^{6}$ & I I 2 \\
\hline$+\ldots$ & . & 3 & 8 & 2 & 8 & 6 & I & 5 & 2 & I & 5 & $\ldots$ & $t^{1}$ & 129 \\
\hline $5 \ldots$ & I & I & 6 & . & 6 & 5 & I & 2 & 2 & . & 4 & . & 28 & I 29 \\
\hline 6. & 3 & . & + & . & 2 & 3 & . & I & I & $\ldots$ & 2 & . & 16 & $\mathrm{II}_{3}$ \\
\hline $7 \ldots$ & . & I & 6 & . & 3 & + & . . & . & . & $\ldots$ & I & . & I 5 & 103 \\
\hline $8 \ldots$ & 2 & . & 5 & . & 2 & 3 & I & . & I & . & $\ldots$ & . & $I_{t}$ & 97 \\
\hline $9 \ldots$ & . & . & 6 & . & . & 3 & . & I & . & . & . & . & 10 & $9^{8}$ \\
\hline $10 \ldots$ & . & . & . & I & I & 3 & I & I & . & . & I & . & 8 & $\mathrm{I}_{4} 2$ \\
\hline II $\ldots$ & . & $I$ & . & . & I & I & . & $\ldots$ & . & . & . & . & 3 & 97 \\
\hline $12 \ldots$ & . & I & .. & . & I & . & . & . & . & . & .. & . & 2 & 80 \\
\hline $13 \ldots \ldots$ & 3 & . & I & . & 2 & . & . & . & . & . & . & . & 6 & 6.3 \\
\hline Over 13 & . & . & 7 & 3 & 3 & 3 & . & . & . & . & . & . & 16 & 92 \\
\hline Totals & 20 & 36 & 99 & 56 & 100 & $I+I$ & $3 I$ & $4^{8}$ & 29 & 12 & $t^{I}$ & 3 & 616 & \\
\hline $\begin{array}{l}\text { Array } \\
\text { means, } \\
\text { pete- } \\
\text { chiae. }\end{array}$ & +.9 & 2.3 & $5 \cdot 2$ & 2.9 & 3.0 & 2.6 & $1 \cdot+$ & I. 7 & 2.2 & 0.8 & 2.3 & 0.3 & & \\
\hline
\end{tabular}

* The number of petechiae indicates: $0-4$, normal capillary resistance; $5^{-8}$, borderline cases; and over 8 , increased fragility (Göthlin).

not seen to exclude increased capillary fragility. Only when the ascorbic acid intake reaches the level of nearly twice the estimated requirement do cases of increased capillary fragility clisappear. However, if the array means shown in table 1 are exanined, it may be seen that, though there is much irregular fluctuation, the capillary-fragility values tend to decrease slightly when ascorbic acid intake is increased, and, on the other liand, the average intake of ascorbic acid generally becones somewhat lower in persons with higher capillary fragility. Thus there seems to be at least some kind of correlation between these two variables. 
To define the degree of this correlation more accurately, a correlation coefficient was computed from the data given in table 1. This was found to be:

$$
r=-0.155 \pm 0.040 \text { (S.E.). }
$$

As this coefficient is nearly four times its standard error, it is certainly statistically significant. Therefore, a negative correlation undoubtedly exists between the ascorbic acid intake and the number of petechiae in Göthlin's test. This correlation is, however, of fairly low degree. If compared with some known correlations $\left(\mathrm{Pearl}^{24}\right)$, it is, for example, seen to be no better than the correlation between the brain weight and the body weight and only slightly better than that between intelligence and the horizontal head circumference.

There are, however, factors which may have unduly lowered this coefficient. First, the regression of the number of petechiae on the ascorbic acid content of the diet need not necessarily be rectilinear; some other function might give a better fit and, consequently, a higher correlation.* In view of the irregular course of the array means (table 1), it seems very doubtful, however, whether any simple function could be found which would give an essentially better fit with the data. In any case, the maximum influence of this factor may be estimated by computing the correlation ratio, a value which provides an upper limit such that no regression function giving a higher correlation can be found. This was found to be: $\eta=0.225$. This is higher than the correlation coefficient but still a relatively low value. Furthermore, the ascorbic acid values may be somewhat inaccurate because inclividual differences may have existed in the ascorbic acid intake among the different members of the families, differences which have been disregarded by using the familial averages of the ascorbic acid intake values for the individuals. These two factors may have exerted a somewhat depressing action on the value of the correlation coefficient. Their influence, however, can hardly have been great enough to alter significantly the fact that the correlation between the ascorbic acid content of the diet and the capillary resistance is low.

Effect of Treatment with Ascorbic Acid on Capillary Fragility. The significance of ascorbic acid as a capillary controlling factor should also manifest itself in the capacity to raise an abnormally low capillary resistance, and to prevent a normal resistance from falling. The earlier experiments on this point have yielded cliscordant results., 5, 9, 12, 13, 16, 19, 22, 25 Besides, many of these experiments have been inadequately controlled and on a relatively small scale. The problem was further studied on the basis of the data next presented. $\dagger$

In March, 1941, the capillary resistance of a number of elementary school children was measured by Göthlin's improved method, ${ }^{6}$ the double-sided petechial index being determined. From these children two equal groups

\footnotetext{
* See Ahlborg and Brante, ${ }^{0}$ who found that the relationship between the plasma ascorbic acid and the capillary fragility expressed as the "petechial index" could best be represented by a hyperbola.

+ This part of the work was aided by a grant from the foundation "Suomen Kultturirahasto."
} 
were formed. One of these received $100 \mathrm{mg}$. of synthetic ascorbic acid daily for fifty days, the other group being held as the control. During this period the children lived at their homes and continued on their usual diets. After fifty days (in May, 1941), the capillary resistance of all of these children was measured again. Originally, there were sixty children in each group, but some of them had to be cliscarcted because of intercurrent infections (mostly chicken-

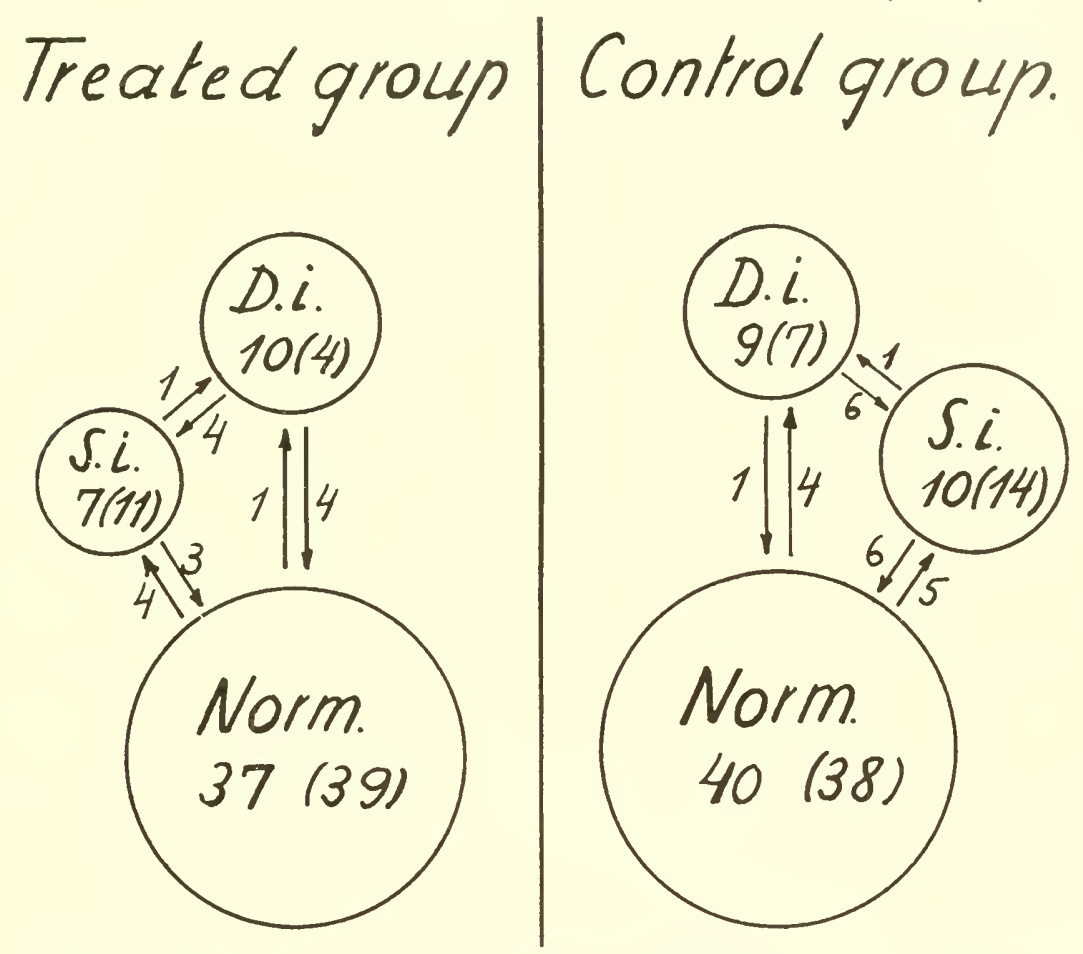

Fig. 1. Effect of ascorbic acid on capillary fragilits. The circles represent the capillary-fragility classes: Norm. $=$ normal, $S . i .=$ slightly increased fragility, and $D . i$. = definitely increased fragility. The figures show the number of children in each class in the beginning and (in parentheses) at the end of the experiment. The changes are indicated by arrows.

pox) which might have affected their capillary status, so that finally only fiftyfour children in the treated group and fifty-nine in the control group remained. The distribution of these children among the capillary-fragility classes and the changes observed during the experiment are shown in figure 1.

From the figure it appears that there were numerous changes in both directions. In the treated group the capillary resistance rose in eleven children and fell in six; in the control group the figures were thirteen and ten, respectively. The sum total of these changes seems to be a slight improvement in the capillary resistance of the treated children, whereas that of the control children remained essentially the same. 
For further treatment of the data, the capillary fragility was expressed in numerical values as follows: normal $=0$, slightly increased fragility $=1$, and definitely increased fragility $=2$; definitely decreased fragility $=-2$. The changes during the experiment were, accordingly, expressed by values ranging from -2 to +2 . The observed changes are shown in table 2. There is a small improvement in the group given ascorbic acid, but the change is too small to have statistical significance.

TABLE 2

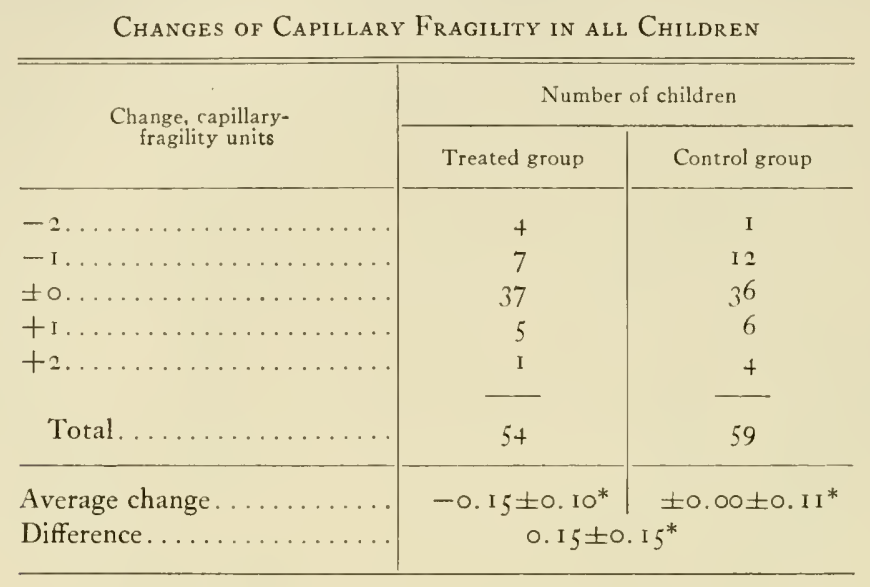

* Standard error.

Now, one might be inclined to assume that the circumstance that the groups consisted of a large proportion of children having normal capillary resistances may have overshadowed any possible effects of the treatment on the "deficient" children. Therefore it seemed worth while to examine the results after exclusion of the normal children. When the changes taking place in the capillary status of the originally "deficient" children were segregated from the data presented in figure $I$ and the data treated in a way similar to that shown in table 2 , the following values were obtained: the average changes were $-0.82 \pm$ 0.21 (S.E.) fragility units in the treated group and $-0.68 \pm 0.15$ units in the control group. Thus there was a substantial improvement in both groups. It seemed to be greater in the group treated with ascorbic acid, but the difference between the groups (0.14 \pm 0.26 units) was again too small to be statistically significant.

Consequently, the results of this experiment do not permit the conclusion that treatment with ascorbic acid had materially improved the capillary resistance.

\section{Discussion and Conclusions}

It is clear from the foregoing that there exists a correlation between the ascorbic acid content of the diet and capillary fragility. The latter may be considered to be some kind of a measure of the former. The correlation is, however, 


\section{Osmo Turpeinen}

so low that the capillary-fragility test can hardly be regarded as a good method for assessing the nutritional status with regard to ascorbic acid. When large groups are examined, it may lead to fairly satisfactory results, but in smaller groups, to say nothing about individuals, the results obtained must often be grossly erroneous. In keeping with this low correlation is the observation that treatment with ascorbic acid often fails to return the increased capillary fragility to normal and to prevent the normal resistance from falling.

It is thus evident that ascorbic acid cannot be the sole factor-and hardly even the primary factor-controlling capillary resistance in apparently healthy human beings. What the other factors are cannot, of course, be said on the basis of the evidence presented here. In this connection it seems, however, proper to refer to the recent investigations on vitamin $\mathrm{P}$. Whatever the much disputed role of this factor is in the experimental scurvy of the guinea pig, it cannot be denied that in human beings vitamin $\mathrm{P}$ has frequently been found efficacious in returning increased capillary fragility to normal and in checking a tendency to bleed., 26,27, 28 The view ${ }^{3}$ that human scurvy often should be regarded as due to a combined lack of both ascorbic acid and vitamin $P$, of which the latter would be the chief factor controlling capillary fragility, may prove correct. In view of the existence of such capillary controlling factors other than ascorbic acid, which possibly play a significant role in the etiology of scurvy, the capillary-fragility test may still remain a useful means of detecting subclinical scurvy, although it undoubtedly is a poor index of ascorbic acid subutrition.

\section{SUMMIARY}

The correlation between capillary fragility and the ascorbic acid content of the diet was studied in 616 apparently healthy persons. The correlation coefficient was found to be: $r=-0.155 \pm 0.040$ (S.E.). Although of a low degree, the correlation thus was certainly statistically significant.

In an experiment with a group of fifty-four elementary school children, treatment with $100 \mathrm{mg}$. of ascorbic acid daily for fifty days seemed to improve capillary resistance. This improvement, however, was so irregular that no statistically significant difference in the capillary status could be found between the treated group and the control group at the end of the experimental period.

It was concluded that, in general, increased capillary fragility is not a dependable sign of ascorbic acid subnutrition. It is evident that ascorbic acid cannot be the sole-and hardly even the primary-factor controlling capillary resistance in apparently healthy human beings.

\section{REFERENCES}

1. Crandon, J. H.; Lund, C. C., and Dill, D. B.: New England J1. Med. 229:353, 1940.

2. Goettsch, E.: Amer. Jl. Diseases Childr. 49:1441, 1935 .

3. Scarborough, H.: Lancet 239:641, 1940. 
4. Weld, C. B.: Jl. Pediat. 9:226, 1936.

5. Göthlin, G. F.: Skandinav. Arch. f. Physiol. 61:225, 1931.

6. Göthlin, G. F.: Lancet 233:703, 1937.

7. Hecht, A. F.: Jrbh. f. Kinderheilk., Ergzgshft. no. 113, 1907.

8. Jersild, T., and Elmby, A.: Klin. Wchnschr. 17:1359, 1938.

9. Ahlborg, N. G., and Brante, G.: Act. med. Scandinav. 104:527, 1940.

10. Gedda, K. O.: Skandinav. Arch. f. Physiol. 63:306, 1932.

11. Göthlin, G. F.: Act. paediat. 20:71, $193^{8}$.

12. Göthlin, G. F.; Frisell, E., and Rundqvist, N.: Act. med. Scandinav. 92:1, 1937.

13. Nordenmark, W.: Skandinav. Arch. f. Physiol. 70:186, 1934.

14. Dalldorf, G.: Amer. J1. Diseases Childr. 46:794, 1933.

15. Molitch, M.: J1. Laborat. \& Clin. Med. 21:43, 1935.

16. Cianci, V.: Quadrni. nutriz. 6:527, 1940.

17. Sloan, R. A.: Jl. Laborat. \& Clin. Med. 23:1015, 1938.

18. Abt, A. F.; Farmer, C. J., and Epstein, I. M.: Jl. Pediat. 8:1, 1936.

19. Anderson, G. K.; Hawley, E. E., and Stephens, D. J.: Proc. Soc. Exper. Biol. \& Med. 34:778, 1936.

20. Difs, H.: Act. med. Scandinav., supp. no. $110,1940$.

21. Liebmann, J.; Wortis, H., and Wortis, E.: Amer. Jl. Med. Scis. 196:388, $193^{8}$.

22. O'Hara, P. H., and Hauck, H. M.: Jl. Nutrit. 12:413, 1936.

23. Rapaport, H. G.; Miller, S. H., and Sicular, A.: Jl. Pediat. 16:624, 1940.

24. P'earl, R.: Introduction to Medical Biometry and Statistics (3d ed.; Philadelphia and London: 1940).

25. Dalldorf, G., and Russell, H.: Jl. Amer. Med. Assn. 104:1701, 1935.

26. Armentano, L.; Bentsáht, A.; Béres, T.; Rusznyák, S., and Szent-Györgi, A.: Deutsch. med. Wchnschr. 62:1325, 1936 .

27. Kugelmass, I. N.: Jl. Amer. Med. Assn. 115:519, $194^{\circ}$.

28. Scarborough, H.: Biochem. Jl. 33:1 40o, 1939. 


\section{THE EXPERIMENTAL PRODUCTION OF PSEUDOHERMAPHRODITISM IN THE MONKEY}

By
G. VAN WAGENEN AND JAMES B. HAMILTON

\section{然}

From the

DEPARTMENT OF OBSTETRICS AND GYNECOLOGY AND THE DEPARTMENT OF ANATOMY YALE UNIVERSITY SCHOOL OF MEDICINE NEW HAVEN, CONNECTICUT 



\section{THE EXPERIMENTAL PRODUCTION OF PSEUDOHERMAPHRODITISM IN THE MONKEY*}

$\mathrm{M}$ ODIFICATIONS of the urogenital tract in the genetically determined female have long been observed and described as occurring in man and domestic animals. Differentiation of accessory sex organs in a genetic female so that they resemble those of a male is termed female pseudohermaphroditism. Obviously, such profound changes in structure must have been initiated in early intra-uterine life. The masculinization of female offspring in mammals has been accomplished experimentally by Dantchak off, ${ }^{1}$ who used sex homones to develop embryonic heterosexual genital ducts in the guinea pig, and by Greene and Ivy, who produced similar changes in the rat.

In the experiments to be described in the present paper, masculinization of the female monkey fetus resulted in a striking resemblance to human infants who at birth have all the appearance of a male (cryptorchid), but whose subsequent developmental history is such that the question of sex does arise and in whom upon examination a uterus and ovaries are found.

\section{MATERIAL AND METHODS}

Testosterone propionate was the androgen used. Crystals dissolved in sesame oil in a concentration of $20 \mathrm{mg}$. per cc. rere injected intramuscularly six times a week. The wish to spare the animal an abdominal section at the very beginning of the experiment led us to avoid the direct method of Dantchakoff, who introduced pellets of hormone into the amniotic cavity of guinea pig embryos. There were no previous data to indicate dosage in the monkey, so three graded dosages were arbitrarily chosen, 5, 10, and $20 \mathrm{mg}$. per day. Monkey 05 receired $5 \mathrm{mg}$. per dose; monkeys 99 and $77,10 \mathrm{mg}$; and monkeys $9^{6,59}$ and $3^{6}$ the largest amount, $20 \mathrm{mg}$. Table i summarizes for each individual the daily and total amounts of testosterone propionate administered and the time of the initiation and duration of the treatment.

The rhesus monkey (Macaca mulatta) provides us with a primate laboratory animal in which anatomical and physiological characteristics of the reproductive organs are similar to those of man. For the purpose of properly timing the period for injection of the pregnant animal it was necessary in our study to have definite information concerning the beginning of pregnancy. The

* This work was supported chiefly by grants to the Department of Obstetrics and Gynecology, from The John and Mary R. Markle Foundation and the Flud Research Fund of Vale University School of Medicine and also aided by a grant from the International Cancer Research Foundation to the Department of Anatomy.

$$
[589]
$$


menstrual cycle of the rhesus monkey is normally about twenty-eight days long and the duration of gestation six lunar months (168 days). In our laboratory the female animal is placed with the male for only forty-eight hours in a given cycle, so that the day of conception can be reckoned without great error. However, the early detection of pregnancy in the monkey presents greater difficulty than in the human because there is neither a "missed menstruation" to suggest that conception has taken place, nor a pregnancy test to confirm it. A menstrual cycle slightly longer than usual and a more prolonged bleeding

TABLE 1

Hormone Administration to Mother Monkeys and Description of Fetuses

\begin{tabular}{|c|c|c|c|c|c|c|c|}
\hline \multirow{2}{*}{$\begin{array}{c}\text { Fetus } \\
\text { No. }\end{array}$} & \multicolumn{2}{|c|}{$\begin{array}{c}\text { Testosterone } \\
\text { propionate given to } \\
\text { mother }\end{array}$} & \multirow{2}{*}{$\begin{array}{l}\text { Span of iniec- } \\
\text { tion during } \\
\text { fetal life, } \\
\text { days }\end{array}$} & \multicolumn{3}{|c|}{ Fetus } & \multirow{2}{*}{ Description of Fetuses } \\
\hline & $\begin{array}{c}\text { Daily, } \\
\text { mg. }\end{array}$ & $\begin{array}{c}\text { Total, } \\
\text { mg. }\end{array}$ & & $\begin{array}{l}\text { Age, } \\
\text { days }\end{array}$ & $\begin{array}{c}\text { Weight, } \\
\text { gm. }\end{array}$ & $\begin{array}{l}\text { Length, } \\
\mathrm{cm} .\end{array}$ & \\
\hline 967 & 20 & 1000 & 41 to 99 & 100 & $1+2$ & $1.3 \cdot 3$ & Female pseudohermaphrodite \\
\hline 우 80 & 20 & 930 & +3 to $9^{8}$ & 99 & I 56 & $13 \cdot+$ & Female pseudohermaphrodite \\
\hline None & 20 & 690 & $4^{1}$ to 82 & 84 & fibrou & s mass & \\
\hline$\sigma^{7} 68$ & 10 & 270 & 58 to 108 & 109 & 200 & I 5.6 & Male apparently unaffected \\
\hline None & 10 & 220 & 60 to 99 & 100 & macer & ated & \\
\hline 963 & 5 & 152 & 69 to 99 & 100 & $\mathrm{I}_{7} \mathrm{O}$ & $13 \cdot 3$ & Modified female \\
\hline$\$ 60$ & $\ldots$ & & & 102 & 117 & I2. 5 & Control \\
\hline $8^{7} 66$ & . & $\ldots$ & $\ldots \ldots$ & $7+$ & 50 & $9 \cdot 9$ & Control \\
\hline $0^{7} 86$ & . & $\cdots$ & $\ldots \ldots$ & $9^{6}$ & I 38 & $13 \cdot 3$ & Control \\
\hline
\end{tabular}

at the time of the expected menstruation (placental sign) are two bits of evidence, neither one invariably present, which may indicate pregnancy. If rectal palpation then discloses that the uterus is gradually changing in consistency and shape, the diagnosis of pregnancy becomes possible sometime between the twenty-fifth and thirty-fifth day after conception.

Experimental. Nine monkeys as they became pregnant were selected from the breeding colony. Most of these were parous animals which had delivered living young the preceding year. Six of these received a series of hormone injections beginning at various times after conception; the pregnancies of the other three were allowed to continue without treatment.

Because of the relatively great length of pregnancy in the monkey, it was possible to save both time and the hormone by removing all fetuses as nearly as possible on the one hundredth clay of gestation. As control material, a normal female fetus was removed from monkey 72 on the one hundred second day, and a normal male fetus from monkey 94 on the ninety-sixth day. For a comparative study, a younger stage in normal male development was sought and a seventy-foụr-day fetus removed from monkey 29 completed the control series. 
At the outset it was feared that an early injection of large amounts of hormone might cause abortion, and for this reason the animals first injected were given the smaller doses, beginning around the sixtieth day. When it was found that the homone so given was well tolerated, higher doses were aclministered beginning about the fortieth day. Thus, the animals receiving the largest amounts of hormone were also those placed on carliest treatment. By analogy with human development, the genital organs at the forticth day would still be in an indifferent stage with both male and female ducts present and the sex of the gonad unidentifiable by histological examination.

Results. From the six androgen-treated animals, four living and developing fetuses were removed. In the other two monkeys the contents of the uterus were found to be degenerated. Fortunately, three of the four living fetuses were genetic females and only one a male. Two were female complete pseudohermaphrodites.

Pseudohemaphrodites are classified according to the sex of the gonad and the sexual type of the accessory sex organs. The first adjective applied to the pseudohermaphrodite is "male" if the gonads are testes, "female" if they are wraries. The second adjective "external," "internal," or "complete" denotes whether it is the external, internal, or both external and internal genitalia which are at variance with the sex of the gonads. Thus, an individual with testes, whose extemal genitalia are female in type, is a male extemal pseudohermaphrodite.

Monkeys $9^{6}$ and 59, which received $20 \mathrm{mg}$. of testosterone propionate daily begimning on the forty-first and forty-third days, yielded female fetuses which

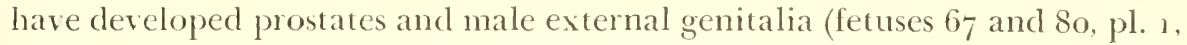
figs. 1, 5, and 6). The largest dosage of hormone (20 mg.) so completely changed the appearance of the fetuses removed from monkeys 96 and 59 that, as they were lifted from the uterus, the operator believed them to be normal males. The presence of hypospadias and the absence of palpable testes were the first hints that the fetuses might be, in reality, pseudohermaphrodites.

The third female, fetus 69 , came from monkey $0_{5}$, which received a total dose of $152 \mathrm{mg}$. of testosterone propionate between the sixty-ninth and ninetyninth days. Following this minimal amount and late treatment, the masculinizing influence of the homone was found in the enlarged clitoris and modified vestibule (pl. I, fig. 4).

Fetus 68 (pl. 1, fig. 2) was a genetic male from a pregnant animal injected with 270 mg. of homone. No external changes were apparent unless possibly in the scrotal size.

In monkey 36 vaginal bleeding and a dilated cervix led us to believe she was about to abort, in which case there was a danger that she might destroy the uterine contents. Monkeys usually eat only the placenta when a baby is born alive and vigorous, but may devour all the products of an abontion or an early parturition. In this monkey. hysterotomy was performed on the eighty-fourth 
day of pregnancy and the fetus was found to have degenerated to a fibrous mass. Since pregnancy during the previous year had terminated with the birth of a normal baby, this deleterious result may have been the effect of the administered hormone.

Monkey 77, which had not been pregnant previously, received $220 \mathrm{mg}$. of testosterone propionate between the sixtieth and the one hundredth day, a quantity less than that tolerated by monkeys $9^{6}$ and 59 . On the one hundredth day, the uterus was opened and found to contain a macerated fetus and placenta.

\section{Protocols}

Sinus hairs were present on the supraorbital areas and also circumorally in the fetuses of both treated and untreated animals. The remainder of the hairy coat, except that on the head, had not appeared in any fetus. Teeth do not appear until after term birth.

Fetus 86 , Untreated Control Male. The external genitalia were well formed. The anterior border of the scrotum, lying $2.6 \mathrm{~cm}$. ventrocephalad to the ischial callosities, appeared as a turgid, partially bilobed swelling with a prominent median raphe, which was especially marked on the cephalic border of the scrotum from whence it extended to the under surface of the penis. The meatus was present as a sagittally placed slit. The prepuce was not distinct from the glans. The external appearance of this animal was similar to fetus 68 as shown in plate $\mathbf{1}$, figure 2.

Sections of the testis with epididymis and selected regions of the reproductive tract are shown in plate 2, figures 7 to 10 , for comparison with androgentreated male and female fetuses.

The freely branching seminal vesicles were compressed to bluntly pyramidal structures. The lumen of each branch was circular in cross section, lined with cuboidal epithelium and occupied about one-third of the diameter. The lumen was somewhat narrow toward the ends of the branches and enlarged as it passed backward to the stalk of the gland. The stalk lay in the connective-tissue mass with the vas deferens of the same side.

Tissue of the cephalic lobe of the prostate was present dorsal to the ejaculatory ducts and also ventrally between ducts and the urethra. This lobe of the prostate was loosely arranged, and isolated blunt ends of rudimentary glands protruded into the mass of connective tissue. The fibromuscular stroma of the cephalic lobe contained solid epithelial cores in which an occasional lumen had formed. Plate 2, figure 8, shows this part of the prostate. The utriculus masculinus can be seen between the relatively larger ejaculatory ducts.

The caudal lobe of the prostate was the more compact and was situated on the dorsal wall of the urethra and for the most part below the entrance of the ejaculatory ducts into the urethra (pl. 2, fig. 9). The caudal lobe consisted chiefly of solid branching cords of epithelial cells with no lumen except in the ducts of the gland near their entrance to the urethra. 
The bulbo-urethral glands were grossly twice the size of the homologous glands of the normal female fetus (compare pl. 2, fig. 10, and pl. 3, fig. 12). The epithelium lining the ducts was irregular and lumens were formed throughout. The excretory ducts of these glands coursed dorsal to the penile urethra and accompanied it for some distance into the spongy portion before opening in to the dorsal wall.

Plate 2, figure 7 , presents the structure of the testis and epiclidymis.

Fetus 6o, Untreated Female Control. The gross appearance of the external genitalia of the animal is shown in plate 1 , figure 3 . The clitoris was a small non-protuberant mass, without a distinct glans, that overlay the anterior end of the vestibular orifice. The vestibule opened to the exterior between the anterior portions of the ischial callosities. The region over the symphysis pubis corresponding to the scrotum presented no swellings.

The gonad was recognizable as an ovary with stroma and sex cords. Its character and that of the Fallopian tube and ampulla are shown in plate 3 , figure 11. There was a cavum uteri which in longitudinal section could be seen to dip into the uterine wall as irregular crypts, some of which were subdivided (pl. 3, fig. 19). The epithelial lining of the uterus was composed of pseudostratified columnar cells, with their nuclei bordering upon the lumen, and the deeper parts of the cells appeared as a clear zone beneath the layer of crowded nuclei. The cells lining the crypts were cuboidal. The stroma, well developed and without edema, was composed of compact muscular tissue.

The vagina lay dorsal to the urethra (pl. 3, fig. 12) to which in the distal portion it was bound by an outer common fibromuscular coat. At a site proximal to that in plate 3 , figure 13 , the cross section of the conjoint structures was egg-shaped, with the vagina in the broad portion and the urethra in the narrow. The vagina was a solid cord of cells for the greater part of its length, but patent at the uterine end and also as it entered the vestibule. The vagina, whether a solid or an open structure, was compressed dorsoventrally throughout the greater part of its length, but just before opening to the surface, the vestibular part was compressed laterally (compare pl. 5, fig. 22, of animal 63 with pl. 3, fig. 14). Plate 3, figure 12, shows the urethra entering the vestibule on the summit of a papilla, while on the opposite wall of the restibule there open ducts from the laterally located vulvovaginal glands. Essentially, then, the conformation of the vagina, urethra, and restibule was that found postnatally in the normal female monkey.

The clitoris was composed of two corpora cavernosa which in the peripheral part of this organ fused to form a single body. Nothing comparable to the corpus cavernosum urethrae was seen, but the tissue immediately surrounding the sagittal spike of cells attaching the frenulum to the glans was as loosely packed as that in the prepuce. Cavernous tissue was prominent only in the glans (pl. 3, fig. 15), although large veins were found within more proximal portions of the cavernous bodies. The clitoris had a core of non-ossified, 
fibrous connective tissue in a position analogous to the structure forming the os penis. The prepuce remained attached to the glans, both circumferentially and as a deep sagittal penetration on the under surface of the clitoris.

There was no modification of the skin and underlying tissue in the region over the pubic bones.

Fetus 68, Treated Genelic Male. The mother of this fetus received daily injections of $10 \mathrm{mg}$. of testosterone propionate from the fifty-eighth to the one hundred eighth day of gestation, a total dosage of $270 \mathrm{mg}$. The external genitalia of the fetus (pl. 1, fig. 2) are well developed, normal in appearance, and not appreciably enlarged.

Plate 4, figures 16 to 20, are of histological sections comparable to those of the untreated control male, fetus 86 , shown in plate 2 , figures 7 to 10 . The two lobes of the prostate gland and the bulbo-urethral glands of the treated nale fetus were larger than those of the untreated male. The fibromuscular structure throughout the whole genital tract appeared better developed. In the injected fetus the pattern of the urethral lumen at the various levels and the contour of the surrounding parts were characteristic of the infant or young monkey. However, some of this increase in size and development must be discounted when it is noted that the control male fetus ( $9^{6}$ days and $13^{8} \mathrm{mg}$.) was younger and smaller than the injected fetus (109 days and $200 \mathrm{mg}$.). Histologically, the bulbo-urethral glands of the injected male apparently reflected androgenic stimulation. Changes in the prostate and seminal vesicles were less distinct.

In the medullary portion of the testis of fetus 68 there is a longitudinal core of irregular, communicating spaces lined with a single layer of low cuboidal cells (pl. 4, fig. 16). The longitudinal section in plate 4 , figure 16 , can be compared with plate 2 , figure 7 , a cross section of the test is of the untreated male, fetus 86 .

The epididymal tube was lined with a single layer of cuboidal cells with large nuclei and comparatively little cytoplasm. The histological character of the epithelium was similar to that in the epididymis of the untreated fetus.

Felus 63, Partially Modified Female (pl. 1, fig. 4). The treatment of the mother of this animal was deferred until the sixty-ninth day of pregnancy and then continued through the ninety-ninth day. Also, the amount of testosterone propionate employed was relatively small, $5 \mathrm{mg}$. per day with a total closage of $152 \mathrm{mg}$. The vestibular orifice lay between the ischial callosities in the normal location for the female, and was surmounted by a clitoris, also in the normal position. However, the edges of the lateral walls of the vestibular orifice were irregular, clearly indicating a defect in their formation. The clitoris protruded for a distance of several millimeters and possessed a distinct glans covered only partly by the frenulum. Bilobed "scrotal swellings" were developed over the symphysis pubis. 
The gonads were ovaries and contained no testicular tissues. The uterus resembled that of the control animal (compare pl. 5, fig. 21, and pl. 3, fig. 13).

The ragina (pl. 5 , figs. 22 and 23 ) was imperfectly formed. It consisted of two distinct dorsoventrally flattened tubes that from respective openings in the cervix and restibule approached one another to overlap and end blindly. The overlapping extended for $1.6 \mathrm{~mm}$. at the level of the neck of the bladder and in this region the two vaginal canals intercommunicated (pl. 5, fig. 23). Each part of the vagina possessed a separate muscular coat except in this region. The portion of the vagina opening to the exterior was the more ventrally placed, lying between the uterine portion of the vagina and the urethra. The two parts considered as a single raginal canal resembled the ragina of the control animal in that a lumen was present only in the inner and outer thirds of its length. The hmen was lined with pseudostratified columnar epithelium for the most part, but the type of epithelium was variable with occasional patches of cuboidal cells. The nuclei were oval in shape and in the taller cells tended to lie in the middle third.

Seminal vesicles and prostatic tissue were not observed. The bulbo-urethral glands lay ventral to the urethra as in the male, thereby differing from the position of the glands ventral to the vagina in the normal female.

Tissues sumounding the vestibule had cavernous spaces, which in the parts lateral and rentral to the vestibule were especially noticeable (pl. 5 , fig. 24). The clitoris, including cavernous tissues, was well developed. The homologue of the os penis was present in the form of an elongated column of fibrous tissue (pl. 5 , fig. 25).

There was a distinct modification of the skin and underlying tissues composing the sex swellings. The epidermis was thin, with the stratum intermedium lacking or reduced to a single layer. In this region the subepidermal lissue formed bilateral mounds of loosely arranged tissue of the same character as that in the scrotum of the nomal male fetus. The transition between the compact tissue of the corium of the normal skin and the scattered cells of the scrotal swellings was definite but not abrupt.

Fetus 67, Female Complete Psendohermaphrodite. The mother of this genetic female received daily injections of $20 \mathrm{mg}$. of testosterone propionate from the forty-first to the ninety-ninth day of pregnancy. Structures, apparently a scrotum and penis, were developed at the location where normally these organs are found in males and quite removed from the usual position of the clitoris in females (pl. 1, fig. 5). The scrotum, like that of the control male, was large and bilobed with the phallus lying partially embedded between the lobes. There was no vestibular orifice in the perineum but there was instead a prominent raphe in the midline extending from the anus to the urethral meatus. The phallus was hypospadiac, no gonadal mass was palpable in the scrotum or inguen.

Internally the uterus and adnexa were similar to those shown in plate 7 , fig- 
ure $3 \mathbf{1}$, for the other pseudohermaphrodite, fetus 8o. The ovaries, Fallopian tubes, and uterus of the two pseudohermaphrodites were the same size and occupied the same position as that found in the normal fetus. The vagina was short and passed ventrally, surrounded by prostatic tissue, to enter through the dorsal wall of the urethra below the neck of the bladder. The urethral end of the vagina was a flattened cord of cells, $U$-shaped in cross section. As it approached the urogenital sinus it was reduced in size and greatly resembled the prostatic utricle of the male. A lumen was present at the cervical and urethral extremities of the vagina. Plate 6 , figure 27 , shows a section in this region which, except for the absence of the ejaculatory ducts, could be mistaken for that of a normal male. At a slightly higher level, part of the vagina on the left side was detached as an expanded vesicle.

Prostatic tissue resembled in amount and degree of development that of the normal male of this age (compare pl. 6, fig. 27, and pl. 2, fig. 9). Glandular tissue was present as solid epithelial cords, very few of which had lumens. Open ducts passed from this tissue to enter the urethra both cranially and caudally to the level of entrance of the vagina.

Seminal vesicles and ejaculatory ducts were absent.

The bulbo-urethral glands (pl. 6, fig. 26) were about half again as large as in the normal female fetus with the proportion of epthelial tissue approximately twice as great and the stroma recluced in amount. The gland was similar to that of the normal male (compare pl. 6, fig. 26, and pl. 2, fig. 1o) but smaller than that of the treated male (pl. 4, fig. 19).

The urethra at the level of the bulbo-urethral glands had abundant cavernous tissue (pl. 6, fig. 26). More distally in the penile portion of the urethra there were well-developed corpora cavernosa which lay above the roof of the urethra. Sections through the clitoris internal to the hypospadiac portion demonstrated a large amount of cavernous tissue and the presence of an os clitoris in which some bone had ahready been formed (see pl. 6, fig. 28). The prepuce was not separated from the glans.

Fetus 8o, Female Complete Pseudohermaphrodite (pl. 1, figs. 1 and 6, pl. 7 , figs. $3^{0}$ to 35 ). The mother received $20 \mathrm{mg}$. of testosterone propionate daily from the forty-third to the ninety-eighth day of pregnancy. Presumably this fetus and the preceding one were subjected to comparable treatment. The daily amount of hormone, the span of injection, and the weight of the mothers were very nearly the same. The two pseudohermaphroditic fetuses were similar except for the configuration of the scrotum and phallus, the external genitalia of this animal, fetus $8 \mathrm{o}$, being more like that of the male. The phallus had reached a position anterior to the scrotum, the two parts of which were united. In the other pseudohermaphrodite the phallus was short and occupied a position between the two lobes of the scrotum and the distinct raphe suggested fused lips of the labia (compare pl. 1, figs. 5 and 6). In fetus 80 the male appearance was attained save for the hypospadias and cryptorchidism. 
In both fetuses the scrotum was turgid and translucent. In fous so the end of the penis projected slightly beyond the cephalic edge of the scrotum. The prepuce had not separated from the glans.

The microscopical appearance of the ovaries, Fallopian tubes, and uterus was in all essential respects like that of the female control, whercas the ragina in terminating at the urogenital simus was like that of the other pscudohermaphrodite. Plate 7 , figure 33 , presents the most distal part of the vagina as it enters the urethra, and at this level through the caudal lobe of the prostate the arrangement of all the tissues is typically that of the male. The tissue of the colliculus seminalis is shown at a greater magnification in plate 7 , figure 34 .

The scrotum was histologically identical with that of the normal male (pl. 7 , fig. 35).

\section{Discussion}

The type of masculinization produced experimentally in these female monkeys strongly resembled female external pseudohermaphroditism in humans, such as is observed in the adreno-genital syndrome. Sex reversal did not occur. Organs derived from the Müllerian ducts differ little in structure and position from those of the control female fetus. Structures derived from the Wolffian ducts, such as the vas deferens, ejaculatory ducts, and seminal vesicles, were not developed as a result of the treatment employed in these experiments. However, the hormone was not administered in any instance until the end of the sixth week, when the gonads may have been differentiated into ovaries. This is probable since, in humans with their longer period of gestation, the sexual character of the gonads is already morphologically idlentifiable at this time.

In the human female, glands corresponding to the prostate are found in the fetus lying above the Müllerian tubercle and may remain as rudimentary structures in the normal adult (Johnson'3). Such structures have not been observed in normal adult female monkeys and were not present in the control female fetus of this series. Following androgenic stimulation the prostate glands of the female monkey fetuses developed to fully the size of those in the male fetuses. But in the human female pseudohermaphrodite the stimulated prostatic tissue is said to consist only of outgrowh from that portion of the urethra lying above the homologue of the vagina masculina or utricle in the male (Young $\mathrm{Y}^{4}$. This is in sharp contrast to the growth of prostatic glands in the masculinized monkey which arise both cranial and caudal to the Miillerian tubercle.

The nipple of the mammary gland was present in experimental as well as control animals. In species such as mice and rats, in which the males do not have nipples, females subjected to androgenic stimulation fail to develop nipples (Hamilton and Gardner ${ }^{5}$ ). This suppression did not occur in the androgen-treated female monkey fetus. 


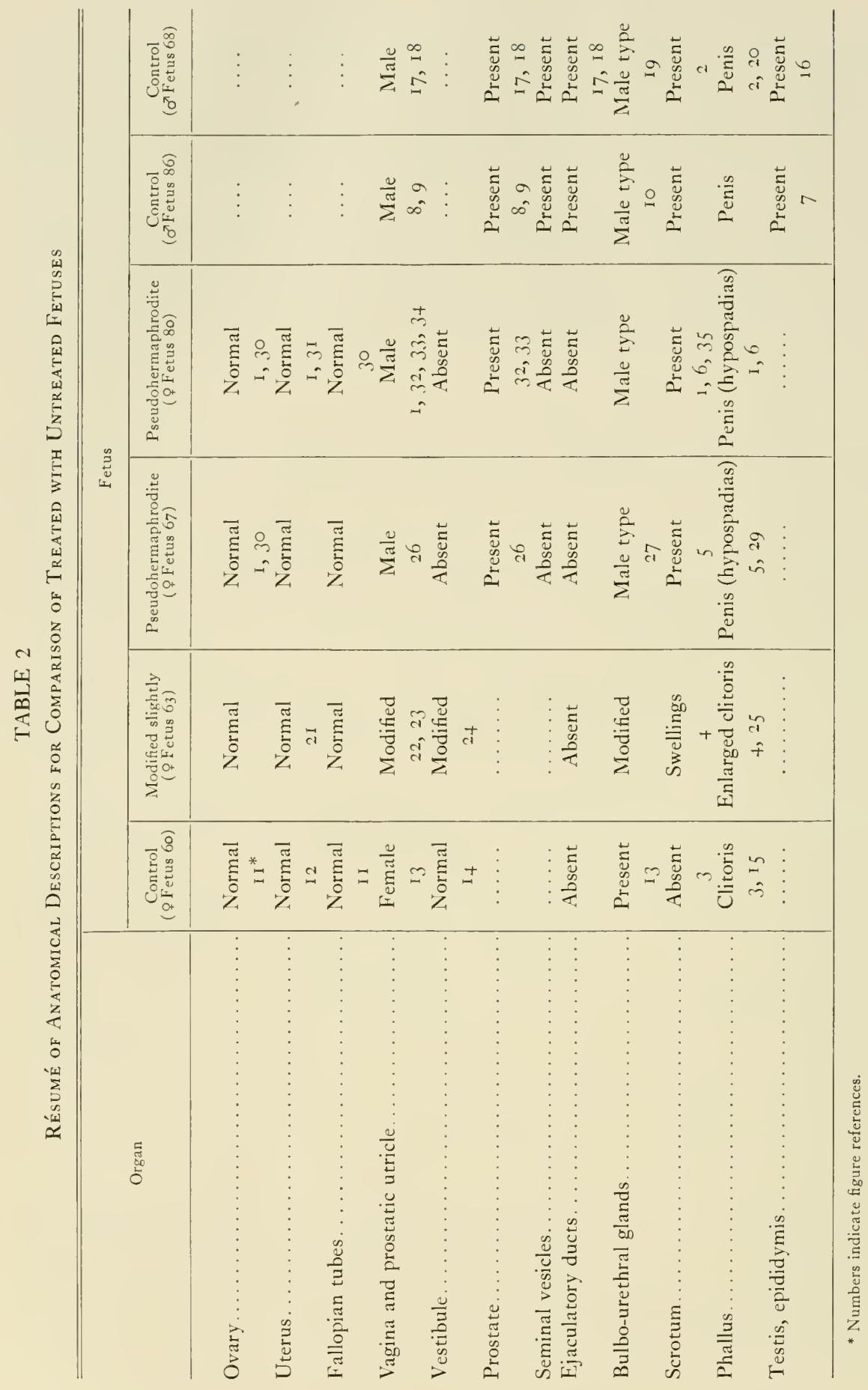




\section{SUMMIARY}

Genetic female monkey fetuses, the mothers of which had been treated with androgenic hormone, developed as pseudohermaphrodites and exhibited anomalies which closely resemble those observed in human female pseudohermaphroditism (table 2 ).

Six pregnant monkeys received daily injections of 5 to $20 \mathrm{mg}$. of testosterone propionate beginning upon the forty-first to fifty-ninth days of gestation and ending about the one hundredth day. Fetuses were removed from these animals at the end of the period of treatment. Two males and one female fetus, removed from untreated mothers at a similar time in gestation, were studied as control specimens.

The series of fetuses from mothers which had received hormone included three genetic lemales, two of which were pseudohermaphrodites and one which was less extensively modified by the treatment. One fetus was a genetic male which showed relatively little stimulation.

The female pseudohermaphrodites had external genitalia that were male in appearance with a penis-like phallus containing the urethra lying cephalad to a well-formed scrotum. Internally, the uterus, uterine tubes, and upper portion of the ragina were normal in structure and position. The vagina ended in the dorsal wall of the prostatic urethra and bore a striking resemblance to a prostatic utricle. Prostatic glands were present and as large as those of the control male; they surrounded the vagina and had developed as outgrowths of the urogenital sinus, both above and below the Muillerian tubercle.

\section{Conclusion}

An exogenous androgen can pass through the placenta to induce pseudohermaphroditism in the female young of the monkey.

Grateful acknowledgment is made to Miss Natalie MacCarthy, Mr. Frank Caruso, and Mr. Joseph Negri who assist in the research of the Department of Obstetrics and Gynecology.

Testosterone propionate was furnished under the trade name Perandren by Ciba Pharmaceutical Products, Inc., and Oreton by the Shering Corporation.

\section{REFERENGES}

1. Dantchakoff, V.: Cpts. rd. Soc. de biol. 123:\$73, 1936.

э. Greene, R. R., and Iry, A. C.: Science (n.s.) 86:200, 1937.

3. Johnson, F. l'.: Jl. Urol. 8:13, 1922.

4. Young, H. H.: Genital Abnormalities, Hermaphroditism and Related Adrenal Disernes (Baltimore: 1937).

5. Hamilton, J. B., and Gardner, W. I.: Proc. Soc, Exper. Biol. \& Med. $37: 570,1937$. 


\section{EXPLANATION OF PLATES}

\section{PLATE 1}

Fig.1. Monkey fetus 8o: dissection to show anatomy of the urogenital tract and both internal and external changes present in the female complete pseudohermaphrodite; ovaries and utenus in position normal for the female; vagina entering clorsal wall of urethra well below bladder through prostatic tissue; the extended urethra of the male and scrotum of size and development character. istic of the male monkey fetus of this age except for the slight hypospadias.

Fig. 2. Fetus 68: testosterone propionate-treated male, logth day of gestation. Normal male appearance.

Fig. 3. Fetus 6o: control female, 102d day of gestation.

Fig. 4. Fetus 63: modified female, 96 th day of gestation. Mother received daily $5 \mathrm{mg}$. of testosterone propionate (total, $152 \mathrm{mg}$.). Note length of clitoris and defective vaginal lips.

Fig. 5. Fetus 67: female complete pseudohermaphrodite, rooth day of gestation. Mother received daily $20 \mathrm{mg}$. of testosterone propionate (total, i, ooo $\mathrm{mg}$.). Phallus does not lie in true male position in relation to the scrotum.

Fig. 6. Fet us 8o: female complete pseudohermaphrodite, 99th day of gestation. Nother received daily $20 \mathrm{mg}$. of testosterone propionate (total, $930 \mathrm{mg}$.). Compare with genetic male in figure 2 . 

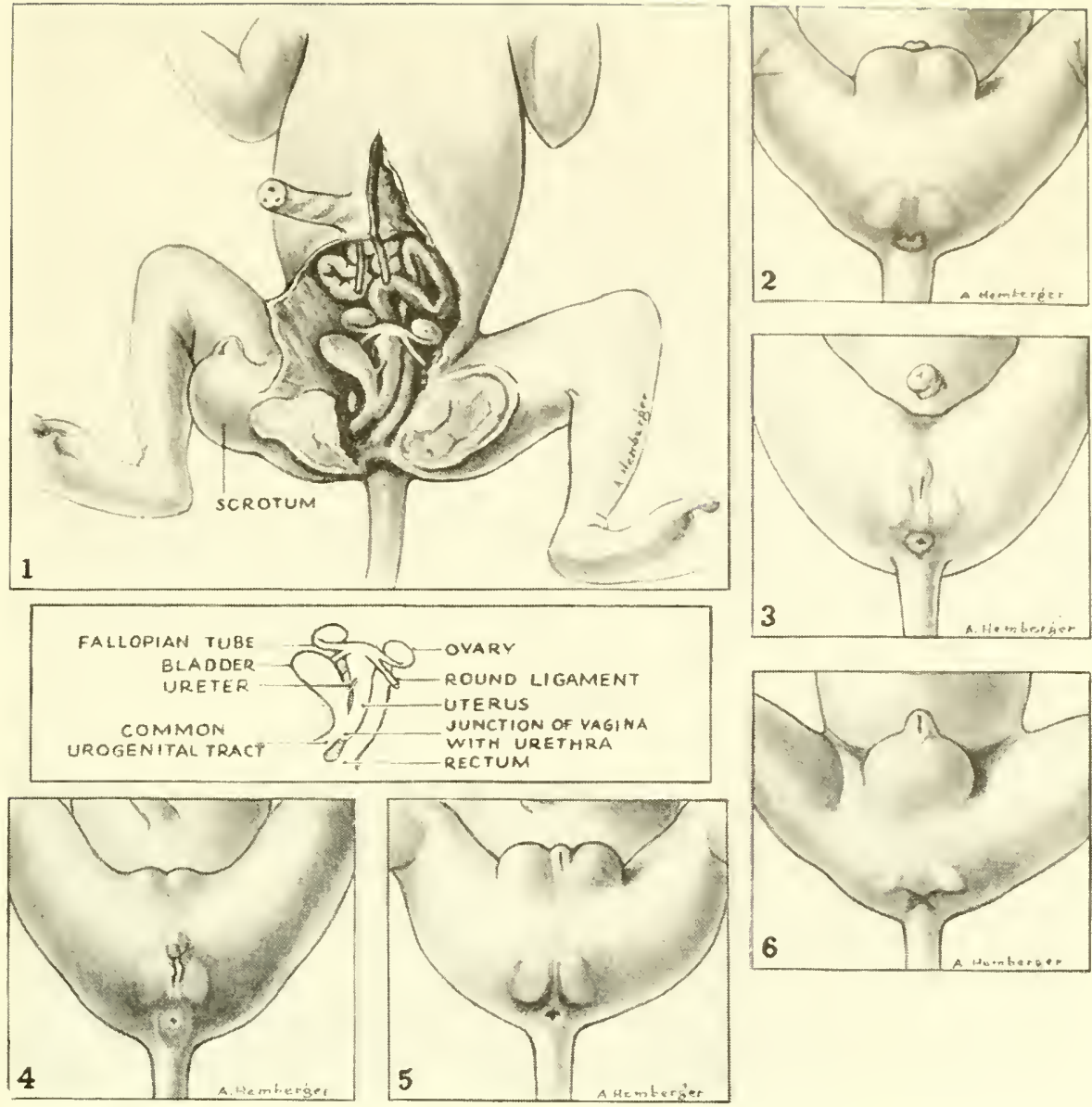

-OVARY

ROUND LIGAMENT

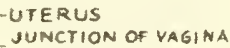
WITH URETHRA RECTUM
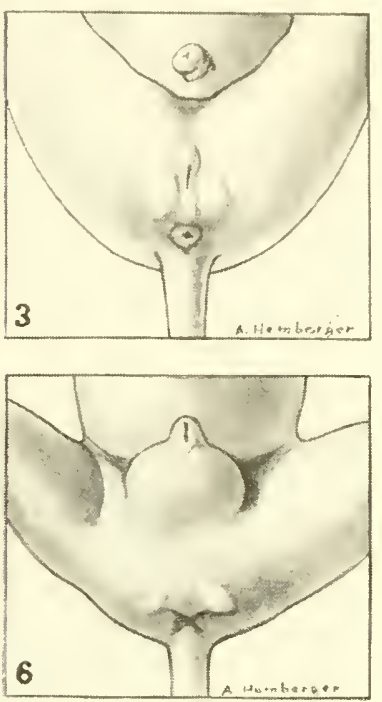

Plate 1 


\section{PLATE 2}

All magnifications of photomicrographs are $\times 25$, except figure 34 which is $\times 170$. Fig. 7. Fetus 86: (normal male, figs. $7^{-10}$ ), testis and epididymis.

Fig. 8. Fet us 86: urethra and paired ejaculatory ducts, the capsule of the latter including the prostatic utricle. Partially developed prostatic glands are present.

Fig. 9. Fetus 86: uretlira with seminal colliculus on the summit of which opens the prostatic utricle and laterally the open ejaculatory ducts. Many prostatic glands and ducts of the caudal lobe are also present.

Fig. 10. Fetus 86: urethra with bulbo-urethral glands. 


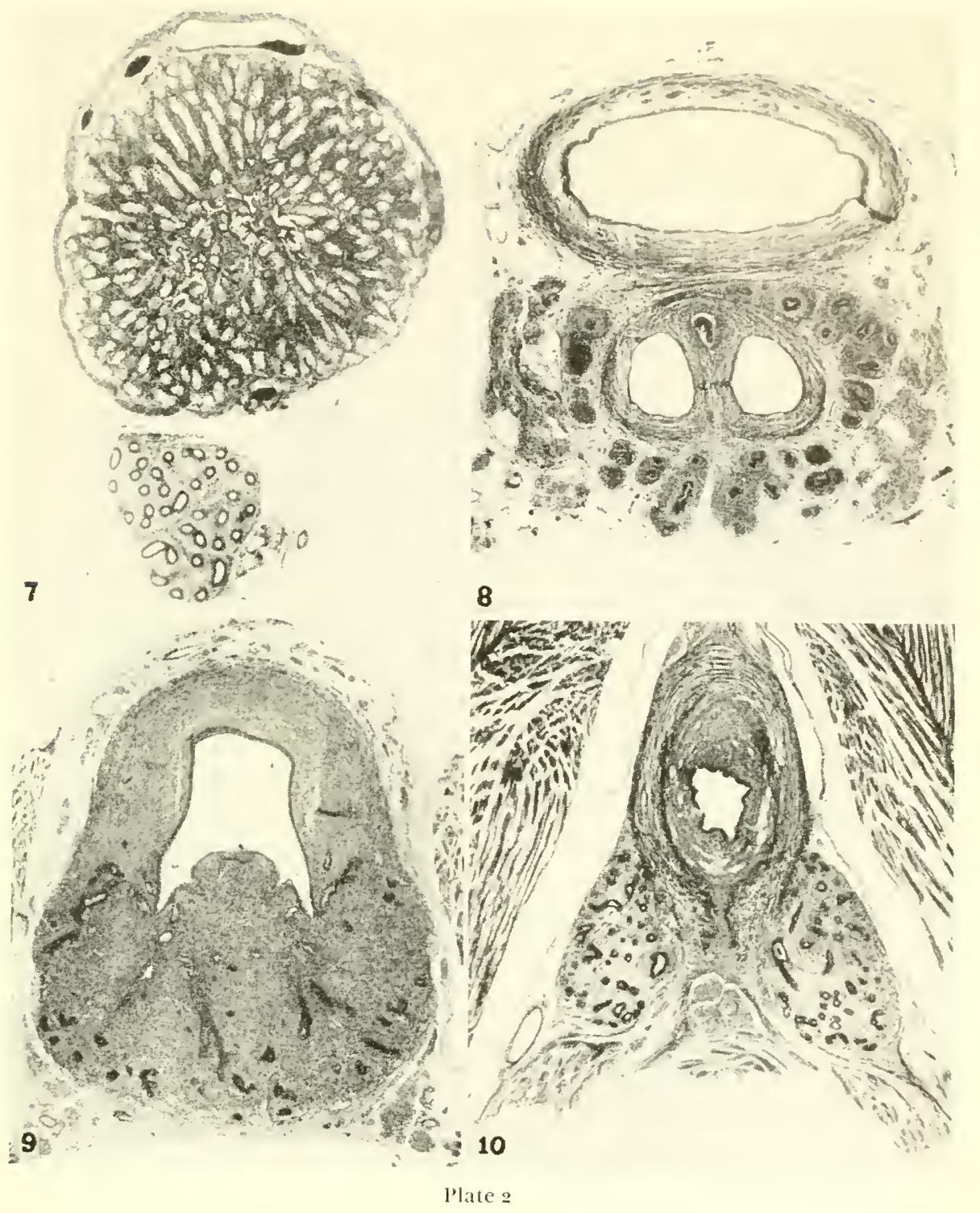


PLATE 3

Iig. 11. Fetus 6o: (untreated female, figs. 11-15), ovary and adnexa.

Fig. 12. Fetus 6o: urethra and vagina. Bulbo-urethral glands lie laterally.

Fig. 13. Fetus 6o: longitudinal section of the uterus.

Fig. 14. Fetus 6o: peripheral portion of vestibule.

Fig. 15. Fetus 6o: glans clitoris and frenulım. 


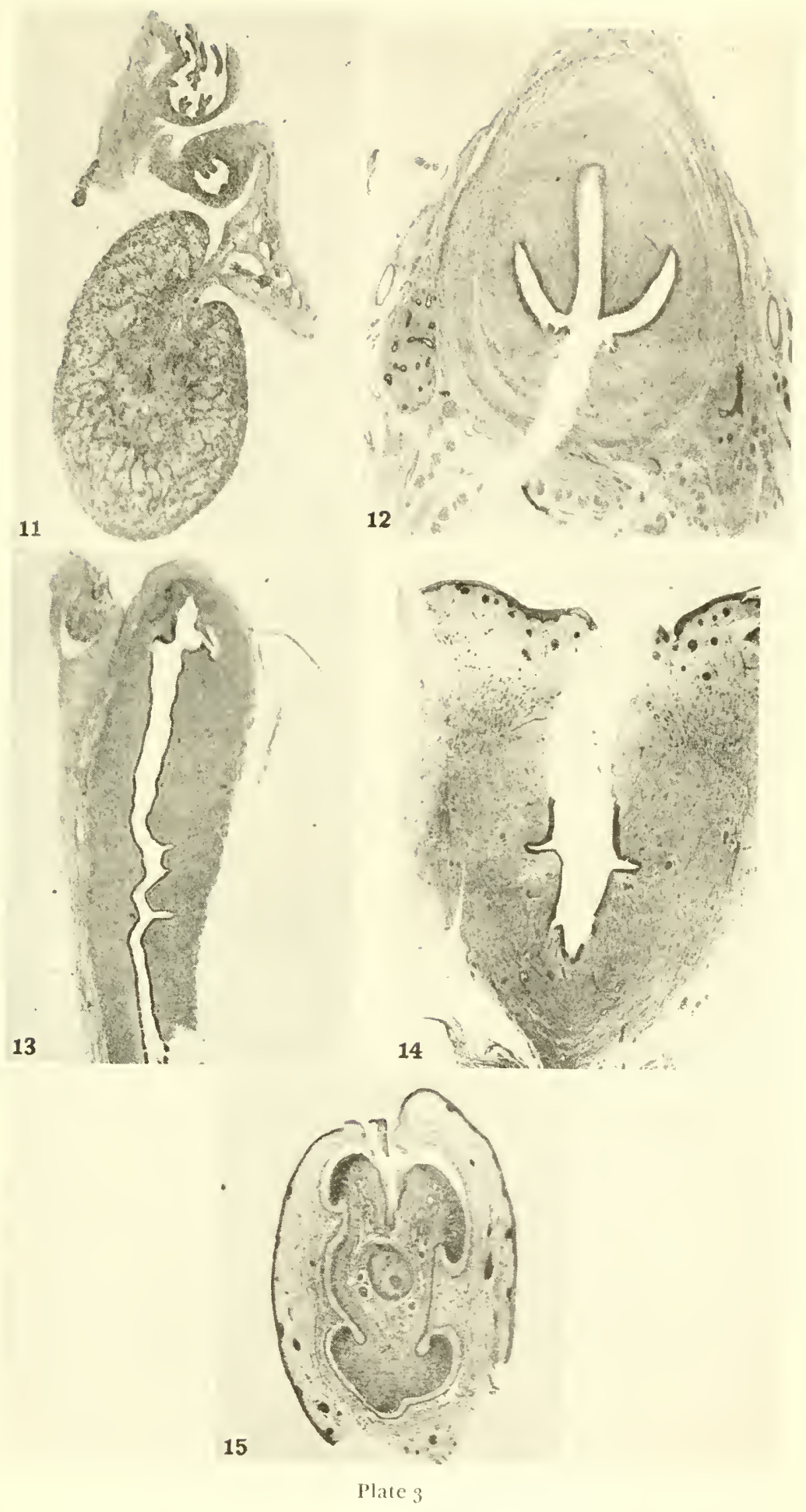




\section{PLATE 4}

Fig. 16. Fetus 68: (treated male, figs. 16-2o), longitudinal section through test is and head of epididymis.

Fig. 17. Fetus 68: urethra and paired ejaculatory ducts, the capsule of the latter including the prostatic utricle. Partially developed prostatic glands are present.

Fig. 18. Fetus 68: urethra with seminal colliculus on the summit of which opens the prostatic utricle and laterally open the ejaculatory ducts. Many prostatic glands and ducts of the caudal lobe are present.

Fig. 19. Fetus 68: urethra with bulbo-urethral glands.

Fig. 20. Fetus 68: glans penis illustrating lack of hypospadias. 

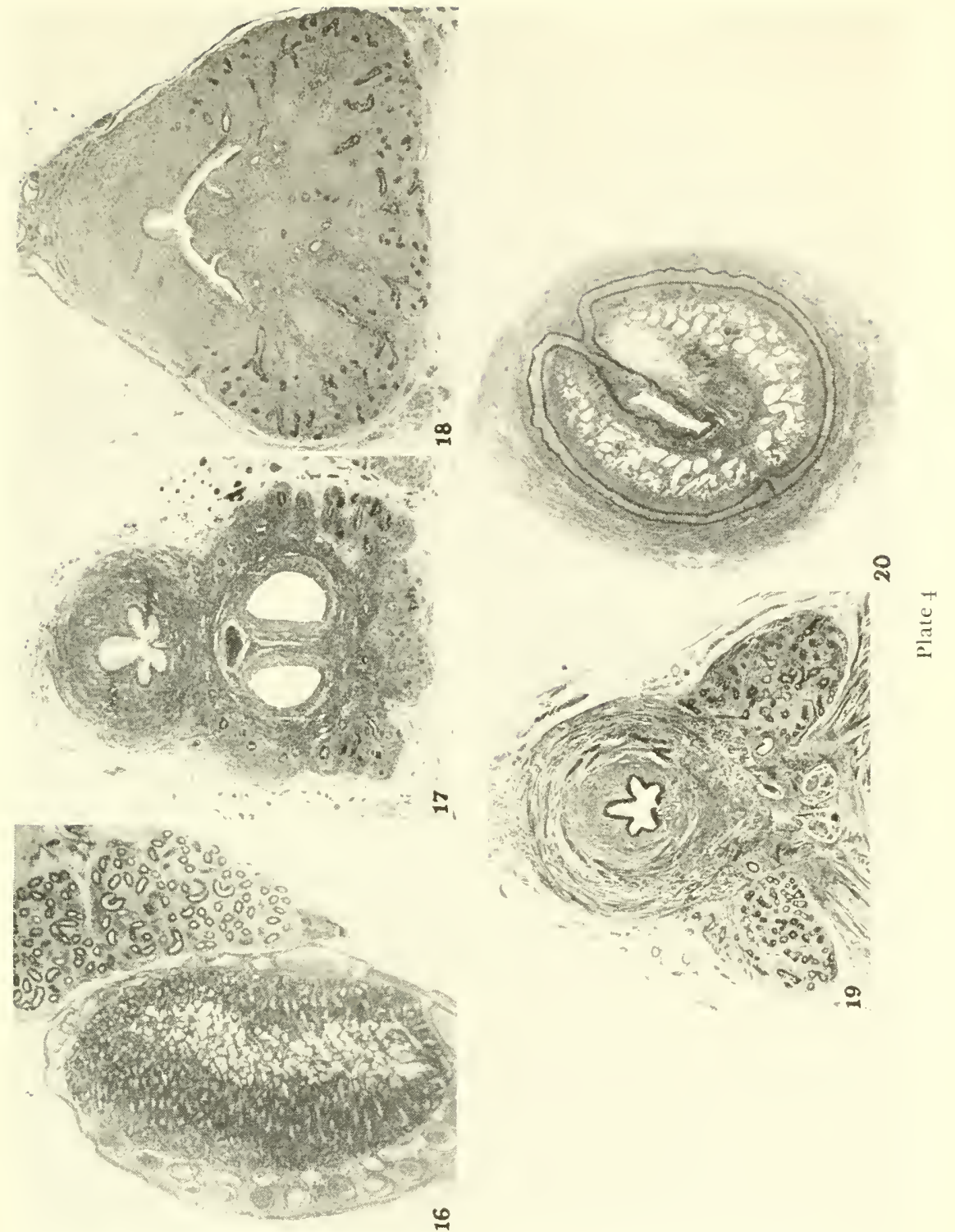
I'LATE 5

Fig. 21. Fetus 63: (androgen-treated slightly modified female, figs. 21-24) longitudinal section of uterus.

Fig. 22. Fetus 63: urethra and two raginal canals.

Fig. 23. Fetus 63: intercommunication between two vaginal canals.

Fig. 24. Fetus 63: peripheral portion of vestibule.

Fig. 25. Fetus 63: glans clitoris and frenulum. 


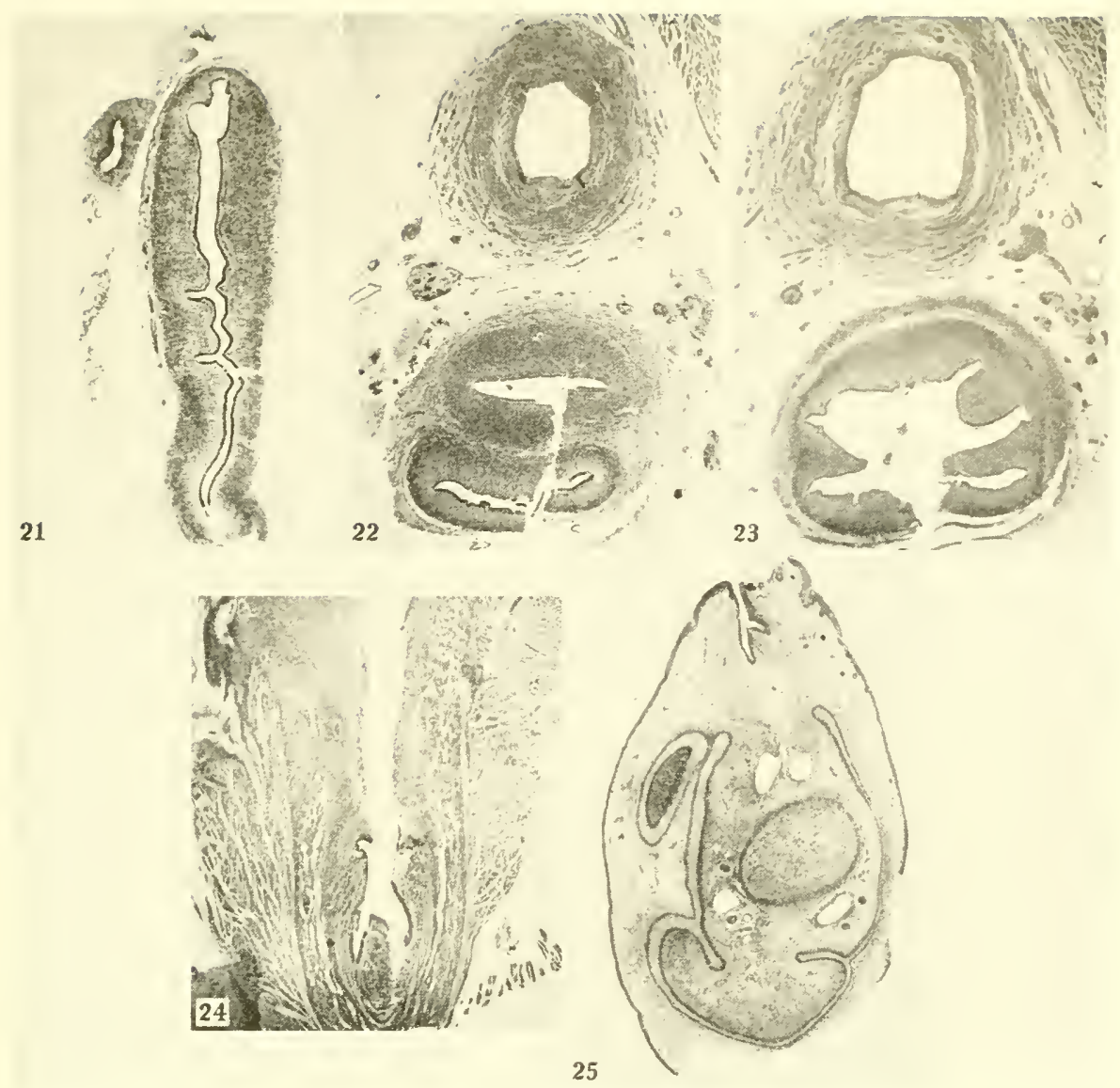

Plate 5 


\section{PLATE 6}

Fig. 26. Fetus 67: (androgen-treated female complete pseudohermaphrodite, figs. 26-29), urethra with bulbo-urethral gland.

Fig. 27. Fetus 67: section through prostatic gland showing vagina (prostatic utricle below urethra).

Fig. 28. Fetus 67: glans clitoris proximal to hypospadiac portion.

Fig. 29. Fetus 67: glans clitoris showing hypospadias. 

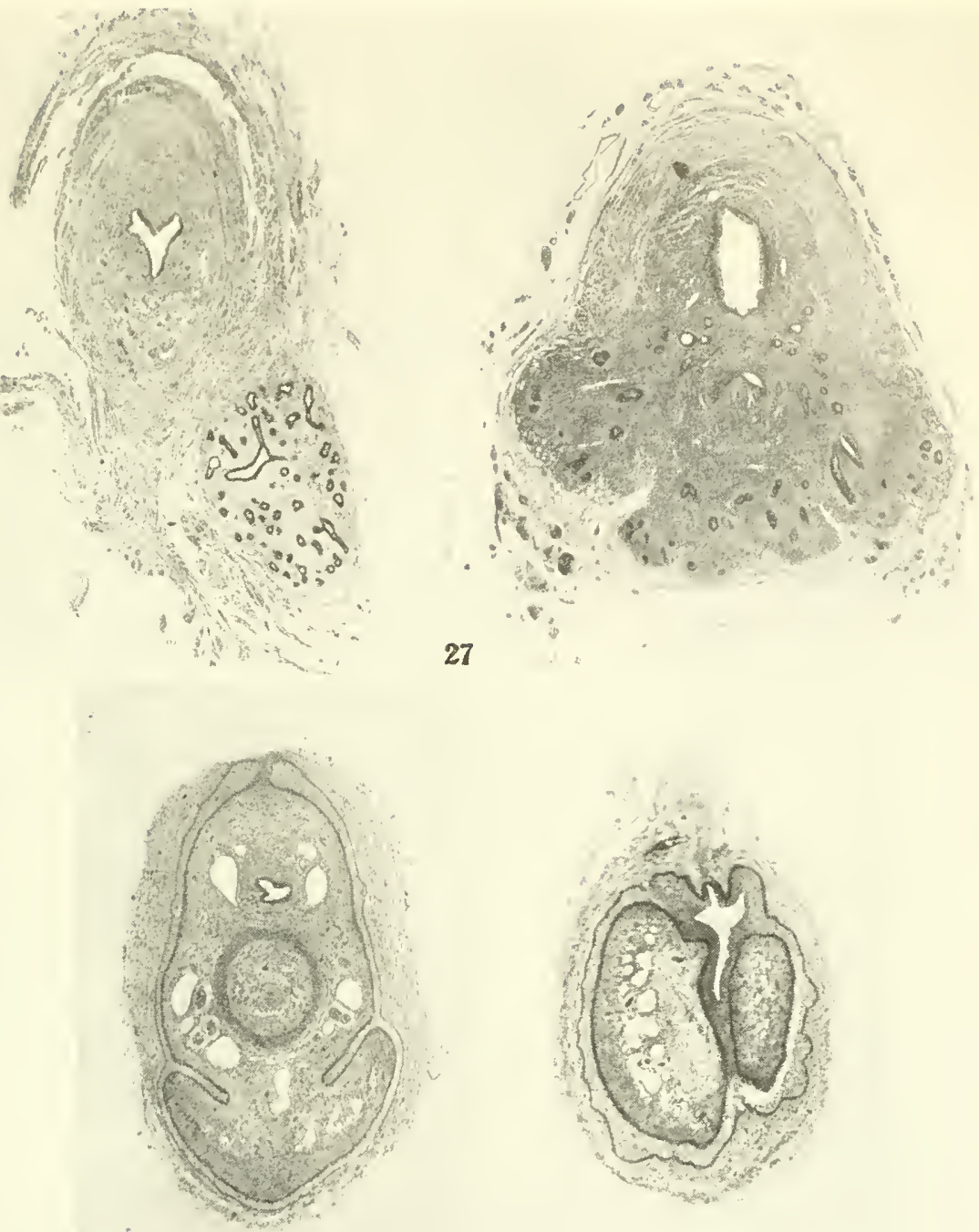

28

Plate 6 


\section{PLATE 7}

Fig. 30. Fetus 80: (androgen-treated female complete pseudohermaphrodite. figs. $30-35)$, ovary and adnexa.

Fig. 31. Fetus 80: longitudinal section of uterus.

Fig. 32. Fetus 8o: urethra and vagina, the latter surrounded by prostatic tissue.

Fig. 33. Fetus 8o: urethra with structure similar to seminal colliculus on the summit of which opens the terminal portion of the Miillerian ducts (vagina, prostatic utricle).

Fig. 34. Fetus 80: higher magnification of colliculus from area shown in fig. 33 .

Fig. 35. Fetus 8o: scrotal swellings with median raphe. 

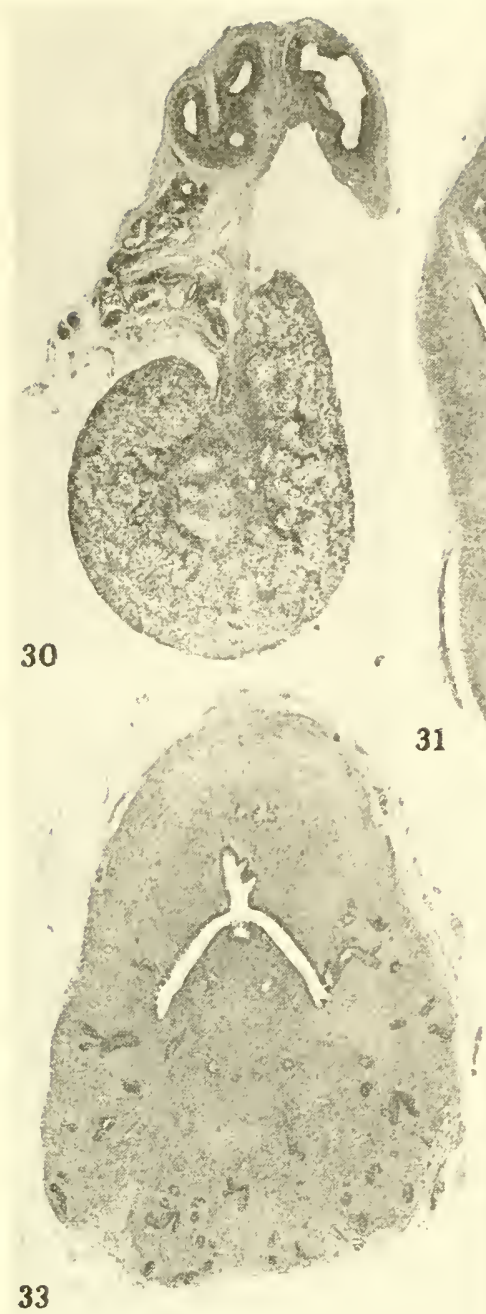

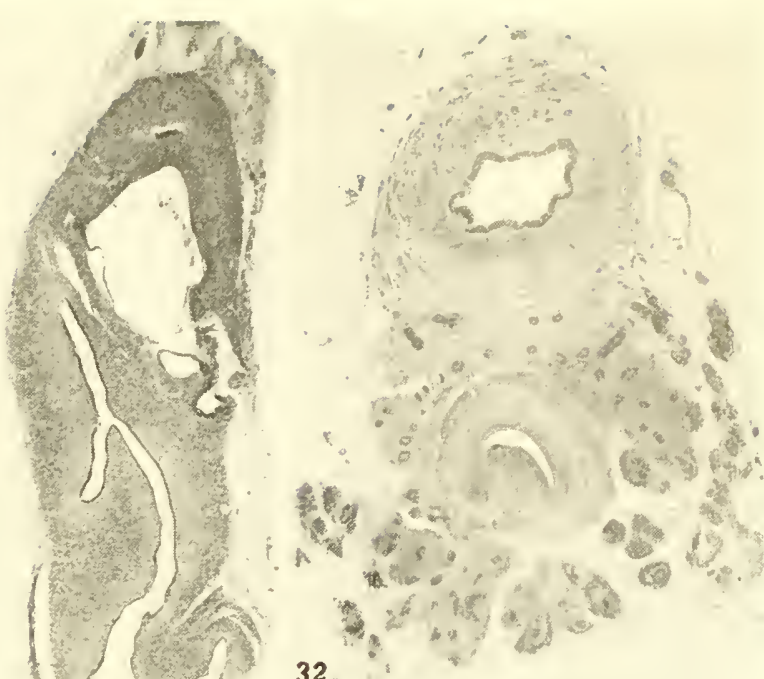

32.
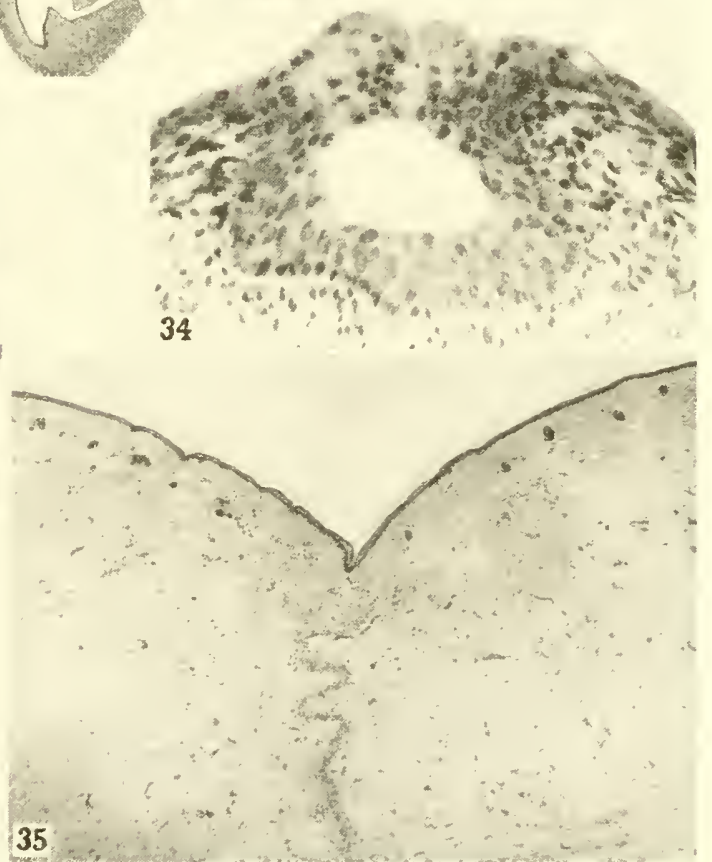

Plate - 



\section{THE HEART IN MYXEDEMA}

$$
\text { By }
$$

JAMES J. WARING, M.D.

$$
\text { 點 }
$$

From the

UNIVERSITY OF COLORADO

SCHOOL OF MEDICINE AND HOSPITALS

DENVER, COL ORADO 



\section{THE HEART IN MYXEDEMA}

$\mathrm{T}$ HE ASTONishing number and variety of the signs and symptons of myxedema (table 1), their intriguing nature, the possibilities of accurate diagnosis of a malady that frequently masquerades as pernicious ancmia or cardiorenal disorder, the remarkable mental, spiritual, and physical rejuvenation wrought by thyroid therapy have all contrived to make myxedema a disease fascinating to the clinician. This paper is a review of previously published observations on the changes in the heart in myxedema and a repont of a case with enormous pericardial effusion.

Experimental work on thyroidectomized animals as well as many clinical observations on myxedema in human beings all indicate the early development of cardiovascular disease of degenerative nature in the absence of the normal secretion of the thyroid gland. Evidences of cardiovascular discase consist in the main of arteriosclerosis, interstitial edema of the myocardium. swollen or vacuolated heart-muscle cells, and pericardial effusions.

Around H. Zondek's paper of $191 \mathrm{~S}^{1}$ on "Myxödemlierz," giving details of four cases of heart failure due to thyroid deficiency and cured by thyroid medication, has arisen a lively discussion on the heart in myxedema. Zondek said all chambers of the heart were dilated, the heart action under the fluoroscope was indolent, the pulse slow, and the blood pressure normal. In the electrocardiogram he noted marked diminution in the $P$ and $T$ waves. After treatment with thyroid he observed striking reduction in size of the heart, more vigorous action of the heart under the fluoroscope, a more rapid pulse without change in the blood pressure. In the electrocardiogram he observert a gradual return of the $P$ and $T$ waves to normal. In 1919 Zondek $^{2}$ said the aorta was dilated as well as both sides of the heart. In the electrocardiogram, $\mathrm{P}$ and $\mathrm{T}$ waves were greatly diminished or absent from normal cardiac cycles but were present in association with extrasystolic complexes. Under treatment the heart returned to normal size but the aorta still remained dilated. If in the course of treatment with thyroid the waves of the electrocardiogram become abnormally high ("Basedowkardiogram"), treatment should be reduced or stopped altogether. Finally in certain forms of myxedema, the cardiovascularsystem complex may suggest the correct diagnosis.

Although Assmann, ${ }^{3}$ Meissner, ${ }^{4}$ and Zins and Rösler ${ }^{5}$ in Germany and Fahr ${ }^{6}$ in the United States published cases in substantial agreement with Zondek, others doubted if a cardiac abnormality existed sufficiently characteristic of myxedema to justify the term "myxedema heart." Fahr believes that heart failure is a prominent feature of an outspoken case of myxedema and furthermore that a mild degree of heart failure with very slight dilation of the heart is not at all infrequent in women patients past forty-five years exhibiting slight but definite evidence of hypothyroidism. Objective as well as subjective signs of heart failure, which do not respond to digitalis but are

$$
[6,1]
$$


cured by thyroid therapy, may be present for many years. Fahr describes the "myxedema heart" as follows: All chambers of the heart are dilated, sometimes enormously; the $\mathbf{T}$ wave in lead $\mathbf{I}$ is absent or negative; all cases show negative Q-R-S complexes in lead III during the stage of marked cardiac dilatation; during thyroid medication, the dilatation of the heart disappears rapidly and the $T$ wave becomes positive. During the transition from a negative to a positive $\mathrm{T}$ wave, the $\mathrm{T}$ wave may be temporarily diphasic. $\mathrm{A}$ few cases

\section{TABLE ] *}

MYXEDEMA: SYMPTOMS AND SIGNS

\section{General}

1. Fatigue

2. Weakness

3 . Intolerance to cold

4. Subnormal temperature

5. Defective temperature regulation

6. Increase in weight

7. Increase in water content of the body

8. Serous effusions

9. Local "tumefactions"

10. SIow speech

11. Deep, monotonous voice

12. Joint pains and muscle stiffness

13. Intolerance to morphine and digitalis

II. Skin
1. Pale, cold, dry, scaly
2. Inelastic
3. Absence of sweating
4. Hair, thin, coarse
5. Brittle nails

III. Edema

1. Eyelids

2. Face and cheeks

3. Ankles

4. Turgescence, infiltration of mucous membranes

IV. Hematologic

1. Increased cholesterol

2. Anemia

3. Hyperproteinemia

4. Decline in blood iodine
V. Circulatory

1. Shortness of breath

2. Slow pulse

3. Low puIse pressure

4. Decreased minute volume, cardiac output

5. Decreased blood volume

6. Increase in heart size

7 . Poor quality heart sounds

8. EKG changes

9. Feeble heart sounds

10. Feeble heart movements

VI. Neurological

1. Drowsiness, excitability

2. Mental disorders

3. Slowness of thought and movement

4. Numbness and tingling

5. Impairment of memory

6. Deafness

7. Prolongation of tendon reflexes

8. Electroencephalogram

9. Diminution of tone in autonomic system

10. Increased protein in spinal fluid

VII. Gastro-intestinal

1. Poor appetite

2. Achlorhydria

3. Indigestion

4. Constipation

5. Hemorrhoids

VIII. Bladder atony

IX. Amenorrhea, menorrhagia, metrorrhagia

X. Low BMR

XI. Apparent absence of thyroid

XII. Improvement with thyroid therapy

* Modified from a similar table of Means. 
show the split and prolonged Q-R-S complex of delayed intraventricular conduction, which also appears under thyroid medication.

Since the negative Q-R-S group in lead III, thought by many to be characteristic of left ventricular hypertrophy, becomes positive in these cases after thyroid medication, Fahr concluded that a negative Q-R-S group in lead III is not due to a preponderance of musculature of the left ventricle.

In $1927, \mathrm{Fahr}^{7}$ reiterated his conviction that heart failure, as evidenced by dilatation of the heart, dyspnea on exertion, anasarca of the dependent portion of the body, passive congestion of the liver, and edema of the hungs, is not very infrequent in myxedema. If relief of these symptoms by thyroid extract in amount sufficient to bring the basal metabolism up to normal and to cause the myxedema to disappear is evidence that both the myxedema and the heart failure have the same cause, namely thyroid deficiency, then the term "myxedema heart" is justified.

Christian $^{8}$ in his earliest paper (1925) did not note the changes so clearly described by Zondek. In $1928^{\circ}$ he said that digitalis was without effect in a few patients with enlarged heart and signs of congestive faihure due to myxectema but that thyroid medication resulted in marked improvement. In $1935^{10}$ he thought pericardial effusions were probably present in those instances in which great apparent enlargement of the heart markedly and rapidly decreased under thyroid therapy. In other instances atony as well as edema of the heart muscle played a part in producing enlargement.

Of 162 cases of severe myxedema studied with special reference to the cardiovascular system by Willius and Haines, ${ }^{11} 148$ or 90 per cent showed no subjective symptoms or objective evidence of organic cardiovascular disease. Eleven or 7 per cent showed definite signs of organic cardiovascular disease which was, in only one instance, appreciably influenced by the disappearance of myxedematous symptoms under thyroid treatment. Analysis of $\mathrm{X}$ rays of the hearts in this series was not given. Willius and Haines conclude that their observations do not justify the establishment of a cardiac syndrome characteristic of myxedema.

Christian ${ }^{8}$ warned against the possibility of circulatory failure from the incautious use of thyroid medication in myxedema. Although some cardiocirculatory disturbance may be due to hypothyroidism and correctable in the earlier stages, the later stages of circulatory disturbance will not be changed because of their permanent organic nature. In intermediate stages a properly balanced treatment with digitalis and thyroid substance is indicated and may produce good results, provided the thyroid dosage does not overburden the heart.

In forty-eight myxedematous patients seen at the thyroid clinic of the Massachusetts General Hospital in the preceding twelve years, Means, White and Krant $\mathrm{Z}^{12}$ found only one in which there was a definite cardiac enlargement which subsided under thyroid. They concluded that "myxedema heart" in the sense of Zondek and Fahr, is far from common. On the other hand they 
were not prepared to say that it does not exist. When symptoms and signs of heart failure are present, a coexisting hypertension and arteriosclerosis will be found.

In 1933, Lerman, Clark and Means ${ }^{13}$ summarized their subsequent observations as follows: "Myxedema heart" in the sense of cardiac enlargement which undergoes shrinkage on thyroid medication is common. In the sense of Zondek and Fahr, that is, a cardiac enlargement in association with congestive failure, it is rare. The heart changes are part of the picture of myxedema and not a separate cardiac entity. Patients with cardiac failure usually have hypertension and arteriosclerosis. The change in the heart size with thyroid treatment is probably due to increased muscle tone and loss of interstitial edema, occasionally to loss of an accumulation of pericardial fluid.

In 1933, Means ${ }^{14}$ suggested that the cardiac enlargement found in some cases of myxedema may be due either to hypertrophy, dilatation, or edema of the heart muscle. Pericardial effusion may be possible but the X-ray appearance is against it.

In further studies on the heart in myxedema, Lerman, Clark and Means ${ }^{1.5}$ state that all of eighteen patients showed enlargement of the heart which decreased in size after thyroid medication. None showed congestive failure. All had abnormal electrocardiographic changes.

Subsequently, Means ${ }^{16}$ described the state of the heart in myxedema in brief, as due to dilatation and low tonus, but without true insufficiency, since along with the reduction in the heart's capacity for work there goes a parallel reduction in the amount of work it is called upon to perform. "The condition of the heart in myxedema is not a complication, it is part of the disease, myxedema of the heart in fact, and whether it is to be looked at as in a sta te of failure is, to a certain extent, a matter of terminology." As to digitalis, he says, myxedematous patients tolerate digitalis badly just as they do morphine.

In 1932, Fahr ${ }^{17}$ summarized his observations on the heart in seventeen cases of severe and moderately severe myxedema. In thirteen instances or 75 per cent he found signs and symptoms of heart failure, all of which disappeared after giving thyroid. If coronary disease is present he warns that the blood supply to the heart in proportion to the work done may be much less after than before giving thyroid. Provided the heart shows better function and provided no angina pectoris is induced, thyroid may be given. If the coronaries can dilate, anginal attacks may disappear after thyroid treatment is started in myxedema.

Sturgis and Whiting ${ }^{18}$ reported the sudden death of a myxedematous patient shortly after treatment with thyroid was started. They urge caution in thyroid therapy, especially in myxedematous patients with anemia and recommend preliminary treatment with small transfusions and digitalis.

Ohler and Abramson ${ }^{10}$ report the sudden death of a young myxedematous patient given enormous doses of desiccated thyroid. Less serious unfortunate effects of thyroid therapy, auricular fibrillation $\left(\operatorname{Swan}^{20}\right)$ and Stokes-Adams 
attacks (Thompson ${ }^{\text {s1) }}$, in both instances disappearing when thyroid medication was temporarily withdrawn, have been reported. On the other hand, the pain of angina in myxedema may disappear during thyloid therapy, as in the case reported by Ziskin. ${ }^{22}$ The blood pressure in myxedema may be low, normal, or moderately elevated. Under treatment the general tendency is for the pressure to move toward a normal range (Ohler and Ullian ${ }^{23}$ ).

In a valuable study of thirty-five cases of myxedema seen at the Boston City Hospital in the preceding seven years Ohler and Abramson ${ }^{10}$ found characteristic changes in the electrocardiograms in thirteen, namely decrease in voltage in all the complexes and frequently an inversion of the $T$ waves in all leads. The $T$ waves in lead I were abnormal in every one of these thirteen. Also the P curves were low in all but one case. Prolonged A-V time was occasionally seen and convex S-T intervals in three cases. With few exceptions these changes were observed when the basal metabolic rate dropped to a level of -25 or lower. In some cases under treatment it was noticed that the electrocardiographic changes returned to normal before the basal metabolic rate had risen to normal. Enlargement of the heart occurred in seven of the thirteen cases showing electrocardiographic changes. With one exception, perhaps due to the brief period of treatment, the increased size of the heart was reduced as a result of thyroid therapy. In several instances, therefore, the heart was not enlarged and yet the electrocardiogram was characteristic. Distant heart sounds and "mild congestive failure" were frequently found. They conclude: "The changes noted in this series are characteristic of the disease and warrant the use of the term, 'myxedema heart.',

Ohler and Abramson suggest that the presence of a myxedematous infiltration of the heart, a mucinous tissue involving the muscular fibers and interfibrillar spaces and nervous elements of the heart, which disappears with thyroid therapy, may in small quantity produce only changes in the electrocardiogram without increase in size of the heart, but in larger quantities will cause dilatation. They do not believe that resistance of the skin can cause inversion of the $T$ waves nor prolongation of the conduction time. Coelho ${ }^{24}$ does not think cutaneous resistance important, since the use of needle electrodes gave the same results as ordinary electrodes. Paul White also by the use of needle electrodes showed that the altered conductivity of the myxedematous skin had no influence on the graphic records.

Bellet and McMillan ${ }^{25}$ ascribe the electrocardiographic changes to alteration in the myocardium. The low voltage may be explained by easier dissipation of the heart current through the myxedematous tissue. They do not mention S-T displacements among the characteristic changes.

Ohler and Abramson ${ }^{19}$ call attention to the close resemblance between the variations in the electrocardiogram in certain cases of myxedema and the picture not infrequently seen in coronary sclerosis as originally described by Pardee. The low voltage, the inverted $T$ waves, and the upward convexity of the S-T interval are common to both diseases. However, in their cases of 
myxedema the amplitude was constantly low, while in coronary sclerosis the Q-R-S complexes though frequently low may be high. In the one condition the electrocardiogram returns to normal with thyroid therapy, in the other it remains unaffected. In only one of the thirty-five cases of myxedema was there a suspicion of pericardial effusion on fluoroscopic and roentgenographic examination. The fact that in general the cardiac pulsations returned to normal under thyroid therapy with very little change in the size of the heart makes the presence of pericardial effusion in those cases at least unlikely.

Pardee $^{26}$ also says the S-T segment may show an upward convexity suggesting the coronary $T$ wave but in contrast to the usual appearance of the coronary $T$ the voltage of $T$ in myxedema is small. The $A-V$ time is frequently prolonged. These changes, he thinks, are due to physiological variations in the muscle metabolism and not to pathological changes, because the administration of thyroid brings about their reversal.

$\mathrm{Katz}^{27}$ thinks the electrocardiographic changes in myxedema are due to changes in the water and protein content of the heart and surrounding tissues brought about by removal of the normal action of thyroid secretion. The changes comprise (1) sinus bradycardia, (2) low Q-R-S complexes in the limb leads, (3) small or inverted $T$ waves, and (4) S-T depressions. Gross changes in the heart include dilatation, sluggish pulsations, pericardial effusions. Coronary insufficiency may develop in either hyperthyroidism or hypothyroidism. In the latter case it is probably due to the combined effect of the frequently present anemia and interference with oxgen by the myxedematous cardiac muscle.

As for large pericardial effusions in myxedema, Freeman, ${ }^{28}$ and Gordon ${ }^{10}$ have reported such cases. In each instance the patient made satisfactory recovery with thyroid therapy. Suspicion naturally arises that the slight and the moderate "cardiac" enlargements seen so frequently in myxedema might be due to small pericardial effusions and not, as at first thought, to dilatation of the heart. Pericardial effusions are frequent in thyroidectomized animals, but in human myxedema their presence or absence can be settled only through many post-mortem examinations or through the hazardous aspiration of the "moderately enlarged hearts." Pathologists rarely have the opportunity to examine a person dead of untreated myxedema. Furthermore, myxedema is by no means a very common malady. In the following report of a case of enormous pericardial effusion in myxedema, the later changes in the size of the heart shadow were quite probably due to recurrences of the effusion.

\section{Case Report}

D. C., male, farmer; age 54 years; myxedema; lues; enormous pericardial effusion; ascites; pleural effusion; atony bladder; complete disappearance of pericardial effusion after $3 \mathrm{cc}$. Salyrgan intravenously; typical electrocardiographic changes; recovery with thyroid therapy.

This man entered the Colorado General Hospital on January 27, 1935, with 
the complaints of marked constipation, increasing shormess of breath, "pain in the stomach," enlargement of the belly, and swclling of the feet.

About six months previous to admission he first noted difficulty in getting his bowels to move. In spite of frequent cathartics, he was still troubled with constipation and some distress in the upper part of the belly, which had slowly but markedly increased in size for the previous five months. All this had been accompanied by shight swelling of the feet and ankles, shortness of breath, increasing weakness and lethargy. Past history was unimportant except for the fact that in 1916 he contracted syphilis for which he took rery liule treatment.

Physical Examination. On admission the patient was comatose, answered questions not at all or only after a notable pause and then in a deep, monotonous voice and without opening his eyes. He seemed in no respiratory distress while lying flat in bed. The skin was dry, brown, scaly, not cyanotic; the mucous membranes of the lips were a little cyanotic. The hair was thin, especially on the back of the neck and above the ears. The eyebrows were thin in the outer thirds. The eyelashes were thin on the upper eyelids and missing from the lower lids. Pubic and axillary distributions of hair were normal. The face was generally swollen, the eyes narrowed to slits by edematous upper and lower eyelids. The belly was much distended, with dullness in the flanks, and the feet and legs were slightly edematous. The hands were dry, cold, thick, the skin over the backs parchmentlike. There was some occupational dermatitis. The tongue was dry, coated, thick; the mouth edentulous; there was slight cervical adenopathy; the thyroid gland was not palpable. Both pupils reacted sluggishly to light and during accommodation.

Chest. The cardiac impulse was not visible nor could the movements of the heart be felt by palpation. On percussion the area of precordial dullness extended from right anterior axillary line to left anterior axillary line at the levels of the fourth and fifth ribs. The interspaces over this area were filled out. The mediastinal dulhness was about $1+\mathrm{cm}$. wide in the third interspace. The heart sounds were inaudible. The veins in the neck were somerhat prominent. The radial pulse was regular in rhythm, rate 60 , temperature $97^{\circ}$, respiration 28, blood pressure 150,95 . The lungs were resonant in the upper lateral portions of the chest and also in the upper portions posteriorly. The base of the left lung was dull. Signs of pulmonary edema were absent.

Abdomen. The abdomen was distended, tympanitic superiorly and dull in the flanks. A fluid wave was present. The liver was just palpable. The spleen was not felt.

Extremities. The lower extremities showed a slight edema. The knee jerk were present but sluggish, with a quick contraction and tardy recovery typical of myxedema (Chaney" ${ }^{2:}$.

Genitalia. Penile scar present: prostate moderately large and firm.

Laboratory Tests. Urine: specific gravity, r.ogo. No albumin, sugar, acetone, or casts, but a small number of pus cells. 


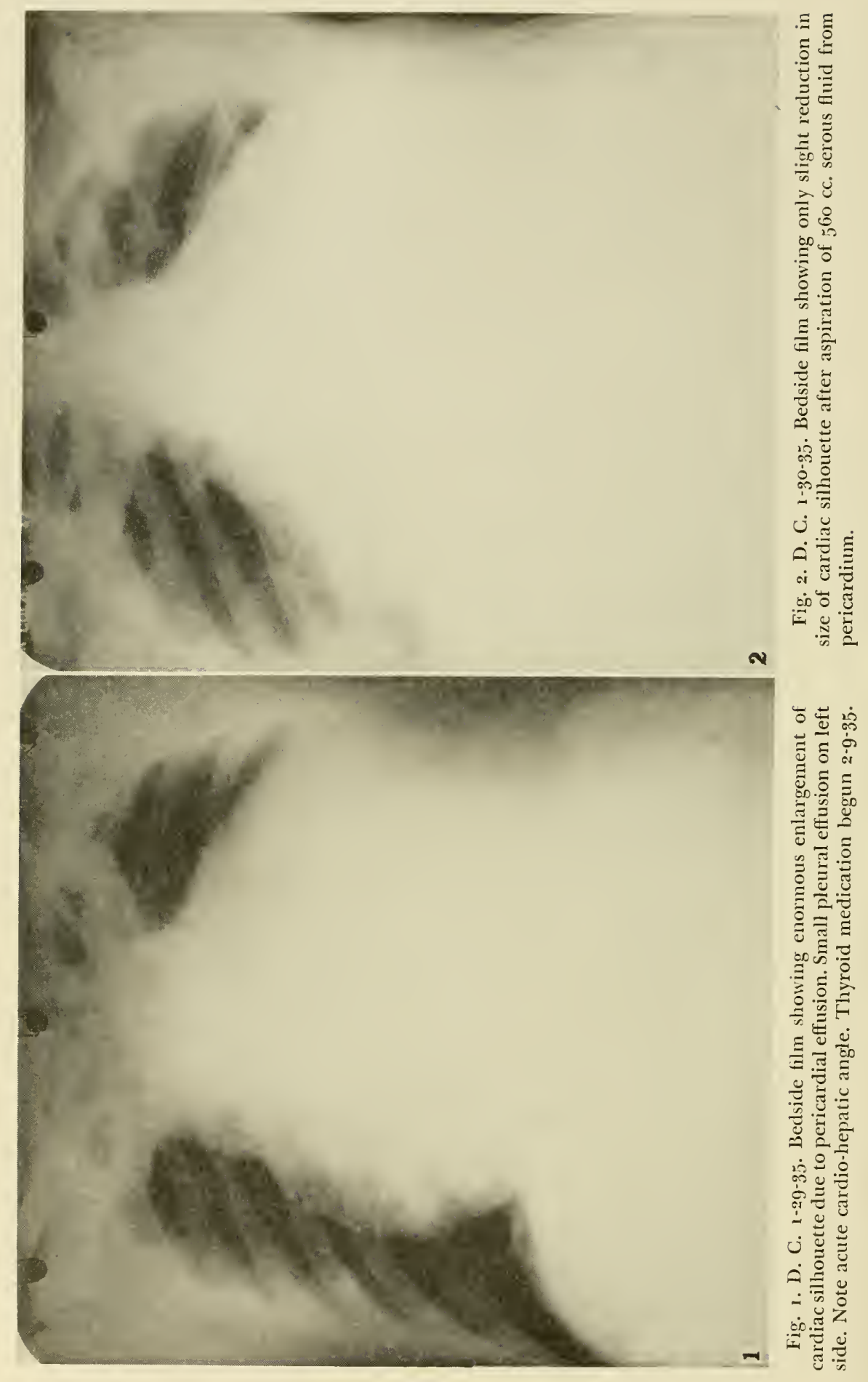


Blood. Hb. 11.2 gr.; red blood cells, 3,950,0oo; white blood cells, 9,85o. Differential count: neutrophiles 67 per cent, lymphocytes 25 per cent, endothelial cells 7 per cent, cosinophiles 1 per cent. Wassermann test +4 . Eagle flocculation test, positive. Blood sugar 80 , nomprotein nitrogen 14.

On 1-28-35 catheterization showed 150 cc. residual urine. Utotropin gr. X t.i.d and acid sodium phosphate gr. XX t.i.d. were given until $2-4-35$ when the urine became bloody. They were then discontinued. The urine resumed normal appearance on 2-11-35.

On 1-29-35 portable A-P X-ray film of chest showed immense enlargenent of the cardiac silhouette (fig. 1.)

On the morning of $1-30-35,560$ cc. of straw-colored serous fluid was aspirated from the pericardial sac. No attempt was made to withdraw all the fluid. The blood pressure before aspiration was 160/95, after aspiration 135/90. Heart sounds were now faintly audible. The area of cardiac dullness seemed but little affected by the removal of the lluid (fig. 2). The Wassermann test on the pericardial fluid was +4 . After aspiration, a portable A-P X-ray film of the chest showed very little reduction in size of the cardiac silhouette.

Microscopic examination of the fluid removed from the pericardium: The sediment after centrifugation was highly cellular. It was composed chiefly of monocytes, a few small lymphocytes, and only an occasional polymorphonuclear leucocyte. A few acinar structures lined with cuboidal epithclium containing hyperchromatic granular nuclei were present. No acid-fast organisms or other bacteria were found by smear or culture.

On 1-31-35 he was given $1 \mathrm{cc}$. Salyrgan intravenously and on 2-1-35 2 cc. Salyrgan intravenously. He was given also theobromin sodium salicylate gr. X t.i.d. every other day until 2-5-35. Meanwhile, the area of cardiac dullness rapidly diminished. A six-foot posteroanterior film (fig. 3) on 2-4-35 showed a cardiac silhouette of normal size, a cloudy left costophrenic angle, possibly due to a small amount of pleural effusion and a triangular area of platelike atelectasis or interlobar effusion in the right lung.

The first electrocardiogram on 2-4-35 (fig. 3) showed changes characteristic of myxedema. Notes on this and subsequent electrocardiograms are shown in table 2.

On 2-9-35 the BMR was -40 . Thyroid therapy was begun cautiously with small doses of desiccated thyroid, $1 / 4 \mathrm{gr}$. daily, increasing the dose until by 3-19-35 he was taking $1 / 2$ gr. four times daily. Antiluetic treatment consisted of daily inunctions with blue ointment, sodium iodide intravenously, and later potassium iodide by mouth.

On 2-12-35, when the BMR was - 4o, tests for hearing defects showed partial perceptive deafness, which later improved under thyroid therapy.

On 2-19-35 the total plasma proteins were 6.2, albumin 3.1. globulin 2.9, fibringogen 0.2. The albumin-globulin ratio was 1.07 .

On 2-22-35 a lumbar puncture showed the spinal fluid under normal pressure. The fluid was clear, contained rery lew cells, sugar $71 \mathrm{mg}$. and total 


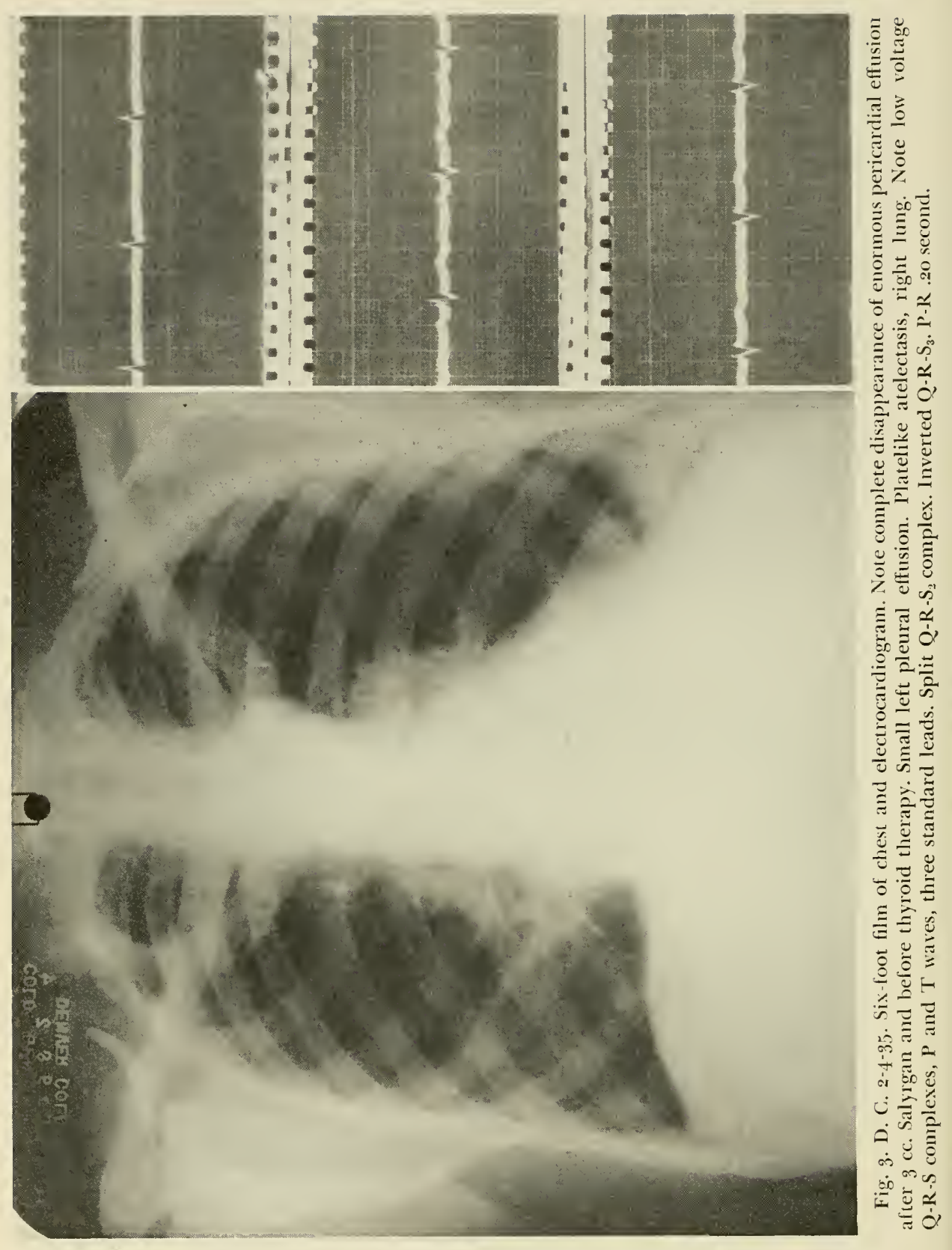


protein $25 \mathrm{mg}$. per $100 \mathrm{cc}$. The Wassermann test on the spinal fluid was negative and the colloidal gold curre normal. BMR -23 .

On $4-2-35$ spinal fluid protein was $20, B M R+2$.

The glucose-tolerance curve on 3-5-35 was flat after $1.75 \mathrm{gm}$. glucose per kilogram body weight. Fasting blood sugar was 62; at 1 hour, 84 ; at 2 hours, 6o; at 4 hours, $7^{\circ}$.

On $3-4-35$ the hemoglobin was $8.2 \mathrm{gm}$., the red cells $2,840,000$. The patient was given one transfusion of $5^{\text {oo }} \mathrm{cc}$. blood and thereafter continued to improve and left the hospital $3-31-35$ in good condition.

\section{TABLE 2}

\section{ELECTROCARDIOGRAIS}

2-4-35 Low voltage in 3 standard leads. T wave practically isoelectric in lead I. Q-R-S upright in lead I. Q-R-S split in lead II. T wave upright in lead II. Q-R-S inverted in lead III and T wave upright. Rate is 60 . P-R .20 second.

2-6-35 Low voltage. Q-R-S upright in lead I with a low upright $T$ wave. T wave low but upright in lead II. Q-R-S inverted in lead III. T wave upright. Rate is 66. In general the voltage of all Q-R-S complexes is less in this picture than in the preceding one. P-R . 6 second. BMR -40 .

2-22-35 Voltage is definitely improsed but still low. Slight left axis deviation. T waves in leads I and II more conspicnous than in previous leads. T wave isoelectric in lead III. Rate is 74 . B.IR - 23. P-R .24 second.

7-22-35 Voltage of Q-R-S complexes improved in all leads hut $\mathrm{P}$ and $\mathrm{T}$ waves are still very low in all leads. Rate is 46 . P- R .25 second. Q-R-S $S_{3}$ inverted. BMR -41 .

10-4-35 Great improvement in voltage in all three leads with conspicuous upright $\mathrm{T}$ waves in all leads. Occasional premature ventricular contraction. Rate is 66 . BMR -2 . P-R .20 second.

3-20-36 Good voltage Q-R-S and T wares. P-R . 20 second. T wave small but upright. Split $\mathrm{R}_{3}$. Small $\mathrm{Q}_{3}$. Rate is 74 .

6-12-36 No change except for improvement in voltage of $T$ wares.

1-15.37 Voltage is good in alt leads. Slight left axis cleviation. Upright and conspicnous T waves in all three leads. Slight elevation of S-T in lead II. Q-R-S in lead III is $\mathrm{W}$-shaped $\mathrm{P}^{\prime}-\mathrm{R}$. 20 second. Rate is $72 . \mathrm{BMR}+1$.

$5^{-10-37}$ Rate is 60 . Voltage good in all 3 leads. P'R .19 second. Split Q-R-S . T waves are upright, with good voltage. B.IR - 3 .

6-18-37 Voltage is definitely lower in all 3 learls. T wave is diphasic in lead 1. upright in lead II, and upright in lead III. Rate is 6o. BMR -19. Q-R - $S_{3}$ is split.

$7^{-16-37}$ Rate is 5. Voltage of Q-R-S in all 9 leads is lower. T wave is isoelectric in lead I, low in II, fairly upright in III. BMR -25.

8-13-37 Rate is 5o. Lower voltage of Q-R-S in all 3 leads. T wave practically isoelectric in lead I, slightly upright in II and in III. P-R now .24 second. BNIR -36 .

10-8-37 Marked improvement of voltage in all 3 leads. Q-R-S upright in all 3 leads. T wares of good voltage and upright in all 3 leads. Slight splitting of the descending limb of the R wave in lead III. Slight elevation of take-off of S-T in It. P-R .20 second. Rate is still 6o. BMR -11 .

1-10-39 Rate is 7. P P-R .19 second. Voltage good in all 3 leads. BMIR +2. 


\section{Comment and Subsequent History}

Although the enormous pericardial effusion disappeared before thyroid therapy was begun it seems clear that this effusion, as well as the pleural effusion, ascites, atony of bladder, and constipation ("lazy bowel of myxedema"), were all due to hypothyroidism. On two occasions after dismissal myxedematous signs and symptoms returned when this man voluntarily quit taking desiccated thyroid tablets and disappeared again when thyroid therapy was resumed. The changes in the electrocardiograms in relation to the changes in basal metabolic rate can be followed in table 2. Changes in heart size in relation to basal metabolic rate and other pertinent data can be followed in table 3 . Selected electrocardiograms are shown in figures 1 to 3 . Since the cardiothoracic ratio is quite unreliable, the observed width of the heart shadow is given and also the percentage deviation from the estimated average diameter of the heart as calculated from Ungerleider's table. Since table 3 carries no figures for hearts more than 25 per cent above estimated average size, plus signs have been added to indicate deviations greater than 25 per cent.

The rapidity of the disappearance of a very large pericardial effusion with the use of Salyrgan, the rapid adjustment of a much dilated pericardial sac to the diminution in bulk of its contents, and the small size of the heart as shown by the $\mathrm{X}$ ray on $2-4-35$ (fig. 3) are worthy of comment. On this date $(2-4-35)$, when the pericardial effusion had disappeared and the cardiac shadow was normal in size, the heart sounds were audible though quiet and there were no murmurs.

Although thyroid therapy was begun on 2-9-35, the width of the "cardiac" shadow increased steadily until 2-27-35, doubtless due to a return of the effusion and not to an increase in heart size.

The small amount of pitting edema of the face was partly due to increased pressure in the superior vena cava from the obstructive effect of the increased intrapericardial pressure. The dullness at the base of the left lung behind was due to a small pleural effusion and possibly also to compression of the left lung by the increased size of the pericardial contents (Ewart's sign). The acute cardiohepatic angle on the right in the $\mathrm{X}$ ray was due to the fixed attachment of the pericardium to the diaphragm inferiorly and the wider displacement of the side walls of the pericardium by the large amount of contained pericardial fluid ("water-bottle" heart shadow). The swelling of the feet was due to increased venous pressure in the inferior vena-caval system from the increased intrapericardial pressure and to downward displacement of liver and obstruction of the hepatic vein (Elias and Feller ${ }^{30,31}$ ). The underlying disturbance of water metabolism characteristic of myxedema was fundamentally responsible for water retention.

The absence of pulmonary edema was perhaps due to interference by the pericardial effusion with venous filling and the consequent small cardiac output. Unfortunately, renous pressure determinations were not made before 


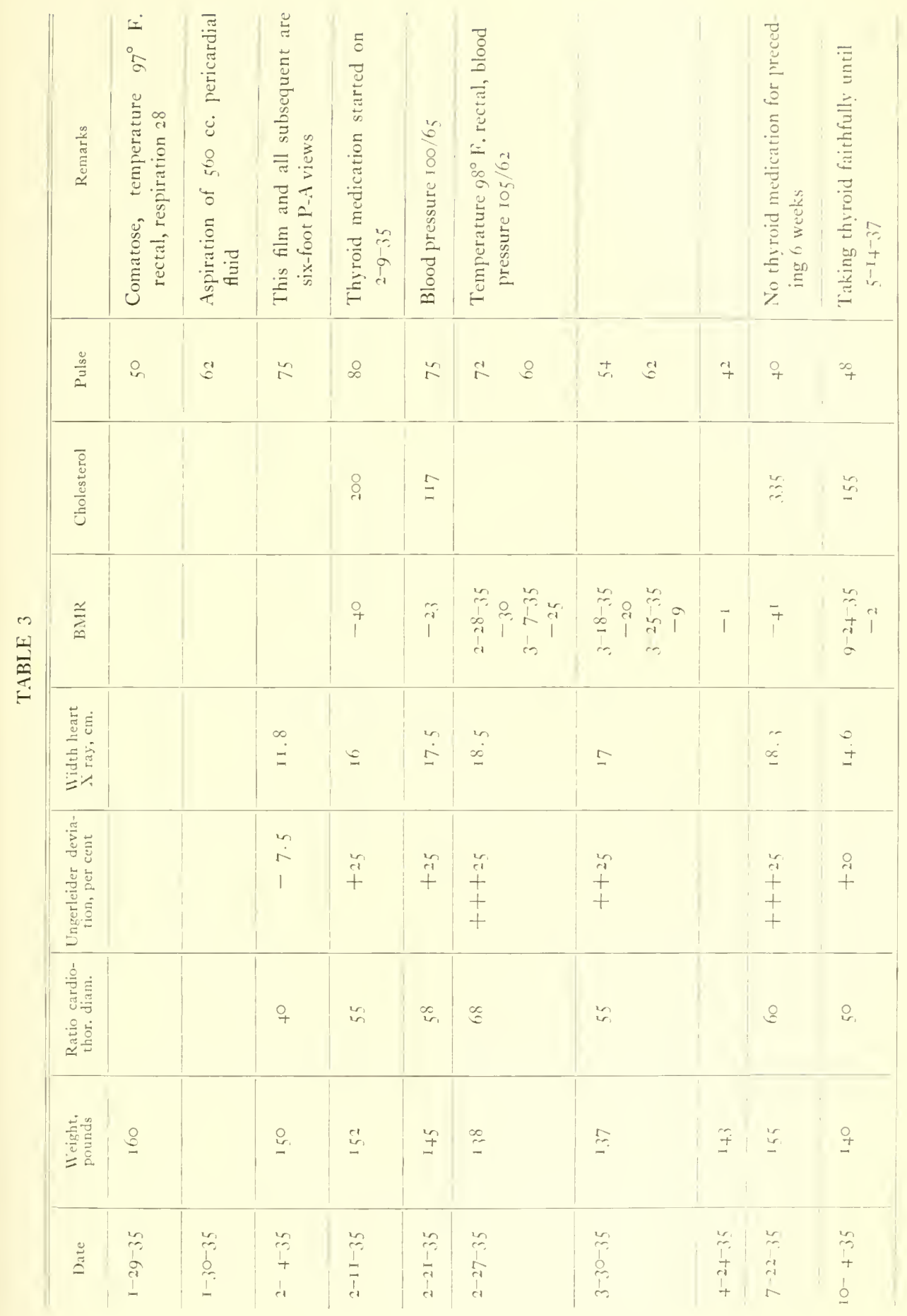




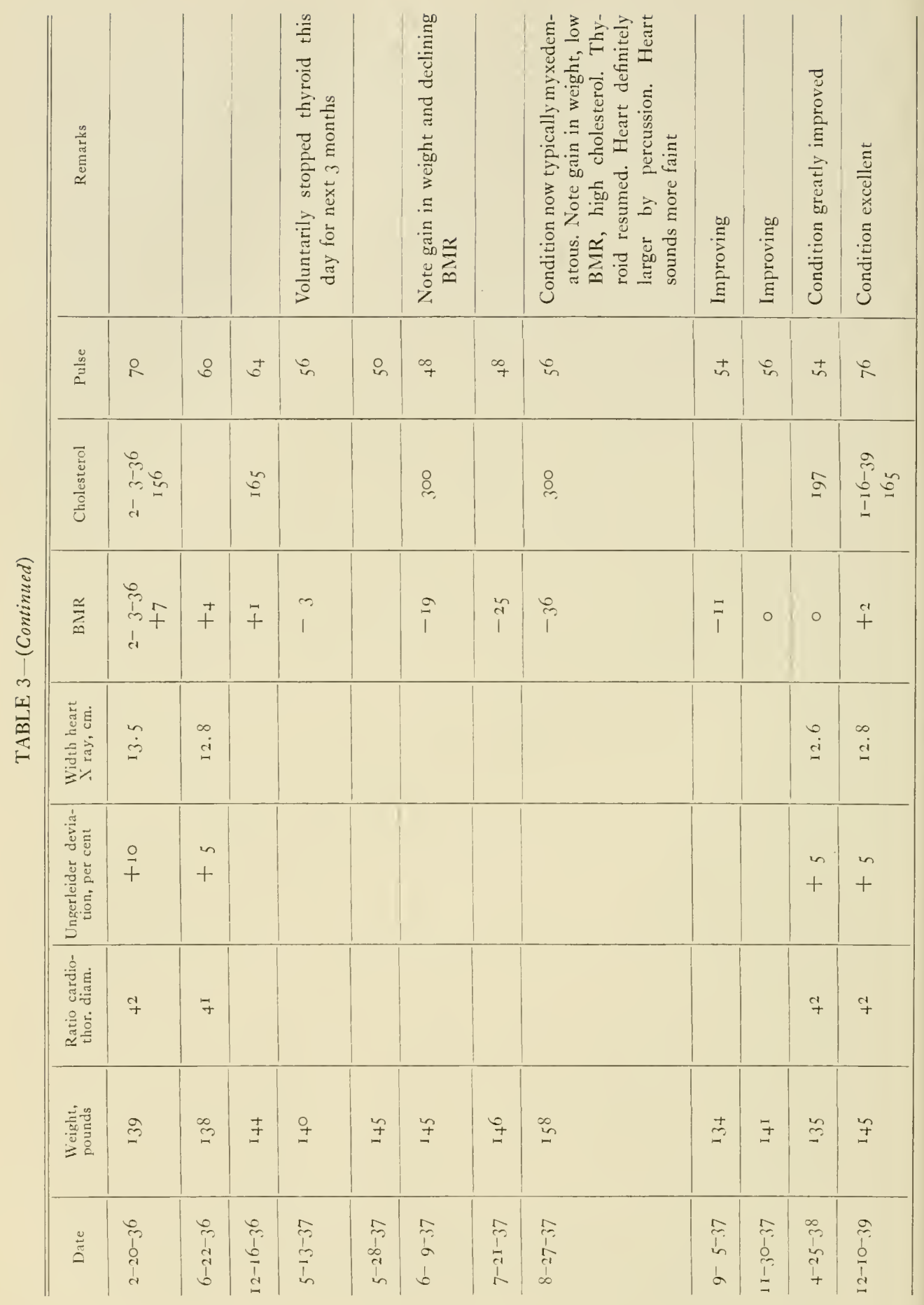


disappearance of the pericardial effusion. On 3-6-35 the venous pressure was $4 \mathrm{~cm}$. water, well within normal limits. At this time the BMR was -25 .

In spite of the large size of the pericardial effusion, the pulse pressure was good. Before aspiration of $560 \mathrm{cc}$. on 1-30-35, the blood pressure was $160 / 95$, after aspiration $135 / 90$. After complete disappearance of the effusion the blood pressure (2-3-35) was $100 / 55$. On 7-22-35, when the BMR was -41 clue to omission of thyroid medication, the blood pressure had risen to $132 / 84$, the pulse was 46 , the patient's condition again noticeably myxedematous. At this time significant electrocardiographic changes were: very low $\mathrm{P}$ and $\mathrm{T}$ waves in all leads, inverted Q-R-S, and P-R time .25 second. The area of cardiac dullness was larger to percussion, the heart sounds were fainter. Although at this time aspiration of pericardial fluid was not attempted, it was felt these signs indicated a reaccumulation of pericardial fluid. During the next two and a half months, thyroid therapy was pushed vigorously. The general condition improved greatly. The "heart" became reduced in size judged by physical examination and by measurement of the cardiac silhouette on the X-ray film. The heart sounds improved in quality. The pulse rate increased to 66 , the BMR increased to -2 , the voltage of Q-R-S complexes increased in all leads. The P-R interval diminished to .20 second.

During all of 1936 the patient reported regularly at the Out-patient Department and took from $1 \frac{1}{2}$ to $2 \mathrm{gr}$. desiccated thyroid daily. In the spring of 1937 , he wearied of well-doing, stopped his medication and slowly resumed the myxedematous state. On 8-13-37, his weight had increased from his 1936 average of 142 to $1581 / 2$ pounds. His whole appearance was again typically myxedematous. His BMR had fallen to $-3^{6}$, blood cholesterol was 300 , pulse rate $5^{\circ}$, the "heart" was increased in size by physical examination, the heart sounds were more faint. The voltages of Q-R-S complexes in all leads were diminished; P and $\mathrm{R}$ waves in all leads were very low or isoelectric; the P-R time had increased to .2.4 second.

During the next two months, thyroid therapy again restored this man's condition to normal. When last seen in the early part of 1939 his condition was good. The BMR was +2 . The pulse rate 74 . The voltage was good in all three leads, the P-R interval was about . 19 second.

In general, the cholesterol determination did not closely follow the basal metabolic rate. Body weight and pulse rate were useful indicators of metabolic level. In the electrocardiogram, improvement in $\mathrm{P}$ and $\mathrm{T}$ waves lagged behind improvement in Q-R-S complexes. The P-R time increased with increase in the myxedematous state. Reduction in cardiac size lagged behind the improrement in metabolism.

The somewhat elevated blood pressure and increased pulse pressure at the time the pericardial effusion was greatest declined with the disappearance of the effusion, decreased still more during thyroid therapy, and increased as the "cardiac" size increased with the return of the myxedematous state.

It is obvious that much of the controversy about "myxedema heart" has been 
clue to disagreement as to what constitutes "congestive failure." In the writer's opinion "congestive failure" as seen in myxedema is a very different thing from the congestive failure of chronic valvular disease of the heart. In congestive heart failure: (1) the general picture is dynamic-for example, restlessness, tachypnea, tachycardia, loud heart sounds, great cardiac activity; (2) shortness of breath occurs with orthopnea; (3) the heart is practically always enlarged; (4) blood volume is increased; (5) venous pressure is elevated; (6) pulmonary congestion is almost constant; $(7)$ an enlarged tender liver is frequent; (8) cyanosis is usual; (9) edema is dependent; (10) and finally, digitalis is helpful but thyroid is not.

In myxedema: (1) the general picture is hypodynamic-for example, lethargy, slow respiration, bradycardia, faint heart sounds, sluggish cardiac action; (2) shortness of breath occurs on exertion but there is no orthopnea; (3) the heart is not always enlarged; (4) blood volume is decreased; (5) venous pressure is usually not elevated; (6) pulmonary congestion is infrequent; (7) an enlarged tender liver is infrequent; (8) cyanosis is infrequent; (9) edema is widely distributed; (10) and finally, reversion to normal is complete with thyroid therapy.

Since the characteristic changes in the electrocardiogram may be present in myxedema with a heart of normal size or, of even greater importance, a heart of apparently normal size that does not become smaller with thyroid therapy. and since sluggish cardiac movement usually accompanies these electrocardiographic changes, it would seem that these two latter signs are of fundamental diagnostic importance and that they usually precede cardiac enlargement. Electrocardiographic changes are practically always found when the BMR falls below -25 . Under thyroid therapy the cardiac pulsations may become normal before the electrocardiogram returns to normal.

The division (Escamilla, Lisser and Shepardson") of "cardiac complications" in myxedema into three groups: (1) atony without decompensation, (2) atony with decompensation, (3) atony with decompensation and arteriosclerosis, has the advantage of simplicity and the virtue of indicating the progressive nature of the damage to the heart in myxedema of long duration, but it introduces the controversial words "decompensation" and "complications." It seems clear that heart changes are part of the picture of myxedema and not a separate cardiac entity or complication.

The following is a classification of myxedema based upon the changes in the heart:

1. Myxedema with normal heart size and normal electrocardiogram.

2. Myxedema with the heart normal in size but with sluggish pulsations and characteristic electrocarcliographic changes both of which return to normal with thyroid therapy. (Not infrequent.)

3. Myxedema with the heart enlarged but, rarely, the electrocardiogram normal. (The larger the heart and the lower the basal metabolic rate the more frequently the electrocardiogram is abnormal.) 
4. Myxedema with the heart enlarged, cardiac pulsations sluggish, and the electrocardiogram characteristic. Under thyroid therapy all retum to nomal. Zondek's "Myxödemherz." (Common.) Small pericardial effusion may explain the enlargement.

5. Myxedema with the heart enlarged and the electrocardiogram abnormal but return of neither to normal under thyroid therapy. Irreversible changes have taken place in the coronary vessels, either incidentally or as the result of long continued myxedema. Forced thyroid therapy is dangerous.

6. Myxedema with or without an enlarged heart, but with sluggish pulsations and electrocardiographic abnormalities, all of which return to normal with cautious treatment. Angina may or may not be present. Forcing thyroid therapy may cause death from acute coronary insufficiency. (Sturgis and Whiting; ${ }^{18}$ Fahr $;{ }^{6,7}$ Christian $;{ }^{8,9}$ Ohler and Abramson. ${ }^{19}$ )

7. Myxedema with greatly enlarged cardiac silhouette due to pericardial effusion, and characteristic electrocardiographic changes, all of which return to normal under thyroid therapy. (Gordon; ${ }^{10}$ Freeman. ${ }^{28}$ )

\section{SUMMARY}

Detailed report has been given of a case of myxedema with enormous pericardial effusion, ascites, and pleural effusion. Important publications on "myxedema heart" have been reviewed and a classification of the heart changes in myxedema offered.

All basal metabolic and cholesterol determinations and glucose-tolerance tests were done by members of the staff of the Department of Biochemistry under the supervision of Dr. Robert C. Lewis, Dr. Robert M. Hill, and Dr. Bernard B. Longwell.

\section{REFERENCES}

1. Zondek, H.: München. med. Wchnschr. 65:1180, 1918.

2. Zondek, H.: München. med. Wchnschr. 66:68ı, 1919 .

3. Assmann, H., and Leipzig, H.: Mïnchen. med. Wchnschr. 66:9. 1919.

4. Meissner, R.: München. med. Wchnschr. 67:1316, 1920.

5. Zins, B., and Rösler, H.: Wien. klin. Wchnschr. 39:1360, 1926.

6. Fahr, G.: Jl. Amer. Med. Assn. 8.1:345, 1925.

7. Fahr, G.: Amer. Heart Jl. 3:1 1 , 1927.

8. Christian, H. A.: Rhode Island Med. Jl. 8:109, 1925.

9. Christian, H. A.: Pennsylvania Med. Jl. 32:70, r 928.

10. Gordon, A. H.: Trns. Assn. Amer. Physns. 50:272, 1935; discussion by H. A. Christian.

11. Willius, F. A., and Haines, S. F.: Amer. Heart J1. 1:67, 1925 .

12. Means, J. H.; White, P. D., and Krantz, C. I.: Boston Med. \& Surg. J1. 195:455, 1926.

13. Lerman, J.; Clark, R. J., and Means, J. H.: Ann. Internal Med. 6:1251, 1933 .

1 4. Means, J. H.: New England J1. Med. 208:541, 1933.

15. Lerman, J.; Clark, R. J., and Means, J. H.: Ann. Internal Med. 8:82, 1931.

16. Means, J. H.: The Thyroid and Its Diseases (Philadelphia: 1937).

17. Fahr, G.: Amer. Heart J1. 8:91, 1932.

18. Sturgis, C. C., and Whiting, W. B.: J1. Amer. Med. Assn. 85:2013, 1925.

19. Ohler, W. R., and Abramson, J.: Archs. Internal Med. 53:165, 1934. 
20. Swan, J. M.: Ann. Clin. Merl. 3:311, 1924.

21. Thompson, W.: Jl. Clin. Investig. 2:477, 1926.

22. Ziskin, T.: U. S. Veterans' Bur. Med. Bull. 6:24, 1930.

23. Ohler, W. R., and Ullian, L. J.: Med. Clins. North America 8:1495, 1925.

24. Coelho, E.: Ann. de méd. 3o:272, 1931.

25. Bellet, S., and McMillan, T. M.: in Diagnosis and Treatment of Cardio-Vascular Disease, ed. by W. D. Stroud (Philadelphia: 1940), 679 .

26. Pardee, H. E. B.: Clinical Aspects of the Electrocardiogram (4th ed.; New York: 1941).

27. Katz, L. N.: Electrocardiography (Philadelphia: 1941), 278.

28. Freeman, E. B.: Ann. Internal Med. 7:1070, 1934.

29. Chaney, W. C.: J1. Amer. Med. Assn. 82:2013, 1924.

30. Elias, H., and Feller, A.: Wien. klin. Wchnschr. 38:725, 1925 .

31. Elias, H., and Feller, A., cited in Lichtwitz, L.: Functional Pathology (New York: 1941).

32. Escamilla, R. F.; Lisser, H., and Shepardson, H. C.: Ann. Internal Med. 9:297, 1935. 


\section{STUDIES ON GROWTH OF DEER}

\section{ANTLERS}

II. Seasonal changes in the male reproductive tract of the Virginia deer (Odocoileus virginianus borealis) with a discussion of the factors controlling the antler-gonad periodicity

$$
\text { By }
$$

GEORGE B. WISLOCKI

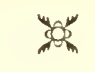

From the

DEPARTMENT OF ANATOMY, HARVARD MEDICAL SCHOOL

BOSTON, MASSACHUSETTS 



\title{
STUDIES ON GROWTH OF DEER ANTLERS
}

II. Seasonal changes in the male reproductive tract of the Virginia deer (Odocoileus virginianus borealis), with a discussion of the factors controlling the antler-gonad periodicity*

\begin{abstract}
$\mathrm{A}^{\mathrm{N}}$ NUMBER of authors mention briefly the observation that the testes of deer undergo seasonal enlargement and spermatogenesis, but little in the way of actual evidence has been submitted to give a concise picture of the seasonal changes. For the European roc deer (Capreolus capreolus) the frag. mentary observations of Ziegler, ${ }^{2}$ Bischoff, ${ }^{3}$ Keibel, ${ }^{1.5}$ Retzius, ${ }^{6,7}$ Strahl, ${ }^{8}$ Lenninger," and Stieve ${ }^{10}$ can be combined to establish the fact that the testes begin to swell in the spring, attaining their maximum size in June, July, and August, when breeding occurs. In the fall the testes undergo involution and by winter are reduced to one-third their former size. Spermatogenesis apparently commences in the spring (Stieve) and ceases, according to the somewhat conflicting statements of different observers, sometime in October or November. In midwinter (December and January) there are no traces of spermatozoa. For other species of deer little is known beyond the fact that the testes undergo periodic swelling, being largest at the time of the rutting season.

The present account deals with the seasonal changes in the testes and seminal vesicles of the Virginia or white-tailed deer (Odocoileus virginianus borealis). The material consists of the reproductive tracts of adult Virginia deer secured throughout the year at intervals of one or two months. The material was obtained by permission of the trustees of Naushon Island, Massachusetts, with the help and interest of Dr. Henry S. Forbes to whom especial thanks are due. The deer were taken from a herd of several hundred animals on free range on Naushon Isłand.

The weight of the testes, with epididymides attached, was recorded in each instance. The testes and male accessory glands were fixed in Bouin's fluid or 10 per cent formalin. The histological sections were stained with haematoxylin and cosin. No provision was made to reigh the entire animals, so that testesbody-weight ratios are lacking.
\end{abstract}

\section{Seasonal Ghanges in the Male Reproductive Tract}

Testes. The weights of the testes in thirteen adult deer are presented in table 1. It will be observed that the weight of the testes fluctuates seasonally, with the maximum weight in the fall at the period of rutting, and the minimum weight from late winter until early summer (graph s).

Examination of the histological sections (pl. 1, figs. 1 to 4) reveals the pres-

* A summary of the present investigation was given at the meeting of the American Association of Anatomists in Chicago in $1911^{1}$

$$
\left[63^{1}\right]
$$


ence of spermatozoa in the testes just beginning in July, maximal in October (pl. 1, figs. 3 and 4), and diminishing in December and January. In the specimens obtained in March, May, and June the seminiferous tubules are in a state of regression, without any discernible spermatids or spermatozoa. In the specimen obtained on June 9 tubular atrophy is most extreme, the tubules having been reduced to a single layer of cells (pl. 1, figs. 1 and 2). In the May specimen and in the testes of the June 27 specimen the atrophy is not quite so extreme. In the specimen of July 13 regeneration of the tubules is well under way, with the beginning production of spermatids and a few spermatozoa.

TABLE 1

Weights of the Testes and Epididymides of Adult Virginia Deer

\begin{tabular}{|c|c|c|c|}
\hline & $\mathrm{gm}$. & & $\mathrm{gm}$. \\
\hline 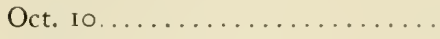 & 111 & Mar. $9 \ldots$ & 37 \\
\hline Oct. Io......... & 100 & May $5 \ldots$ & $3 I$ \\
\hline Oct. IO......... & 66 & June $9 \ldots \ldots \ldots$ & 25 \\
\hline Oct. I $2 \ldots \ldots \ldots \ldots \ldots$ & 105 & June $27 \ldots \ldots \ldots \ldots$ & 50 \\
\hline Dec. $10 \ldots \ldots \ldots \ldots \ldots \ldots$ & 72 & July $1.3 \ldots \ldots \ldots \ldots \ldots \ldots$ & 45 \\
\hline Dec. $17 \ldots \ldots \ldots \ldots \ldots$ & 92 & Aug. $20 \ldots \ldots \ldots \ldots \ldots$ & $67 \cdot 5$ \\
\hline Jan. $2 \mathrm{I} \ldots \ldots \ldots \ldots \ldots \ldots \ldots$ & 49 & & \\
\hline
\end{tabular}

Regarding the interstitial cells, the impression is gained that the cells are larger, with clearer nuclei and more cytoplasm in the October specimens (pl. 1, fig. 3) than in May or June (pl. 1, fig. 1), when the cells of the interstitial tissue appear to be small with dark-staining shrunken nuclei. No special cytological techniques have been adopted to establish these differences more clearly.

Male Accessories. The male accessories were dissected and studied histologically in five animals, one each in June, July, and August, and two in October (pls. 2 and 3 , figs. 5 to 10 ).

Striking changes were observed in the seminal vesicles, whereas in those glandular tissues surrounding the urethra, which we regard as representing the prostate and bulbo-urethral glands, no variations were apparent. Consequently we shall limit our presentation to the changes observed in the seminal vesicles. The latter appear to be represented by two tortuous, firm, glandular

Graph 1 , illustrating the periodicity of the antless, testes, seminal resicles, and breeding season of the Virginia deer. On the abscissa the months of the year are indicated, beginning with March. The curve for testes is derived from their monthly weights, their individual weights being designated by crosses. The curve for seminal vesicles is expressed in terms of microns $(\mu)$ representing the height of the glandular epithelium in successive months.

The periodicity of the antlers is schematically presented for 2-, $4^{-}$, and 8-year-old animals. (1) represents the time of onset of antler growth; (2) the completion of antler growth and the shedding of the velvet; while (3) shows the time of dropping of the antler.

At the top of the graph the results of castration are represented graphically. A, an animal in which castration was performed in Jume; B, in which castration took place in October. 


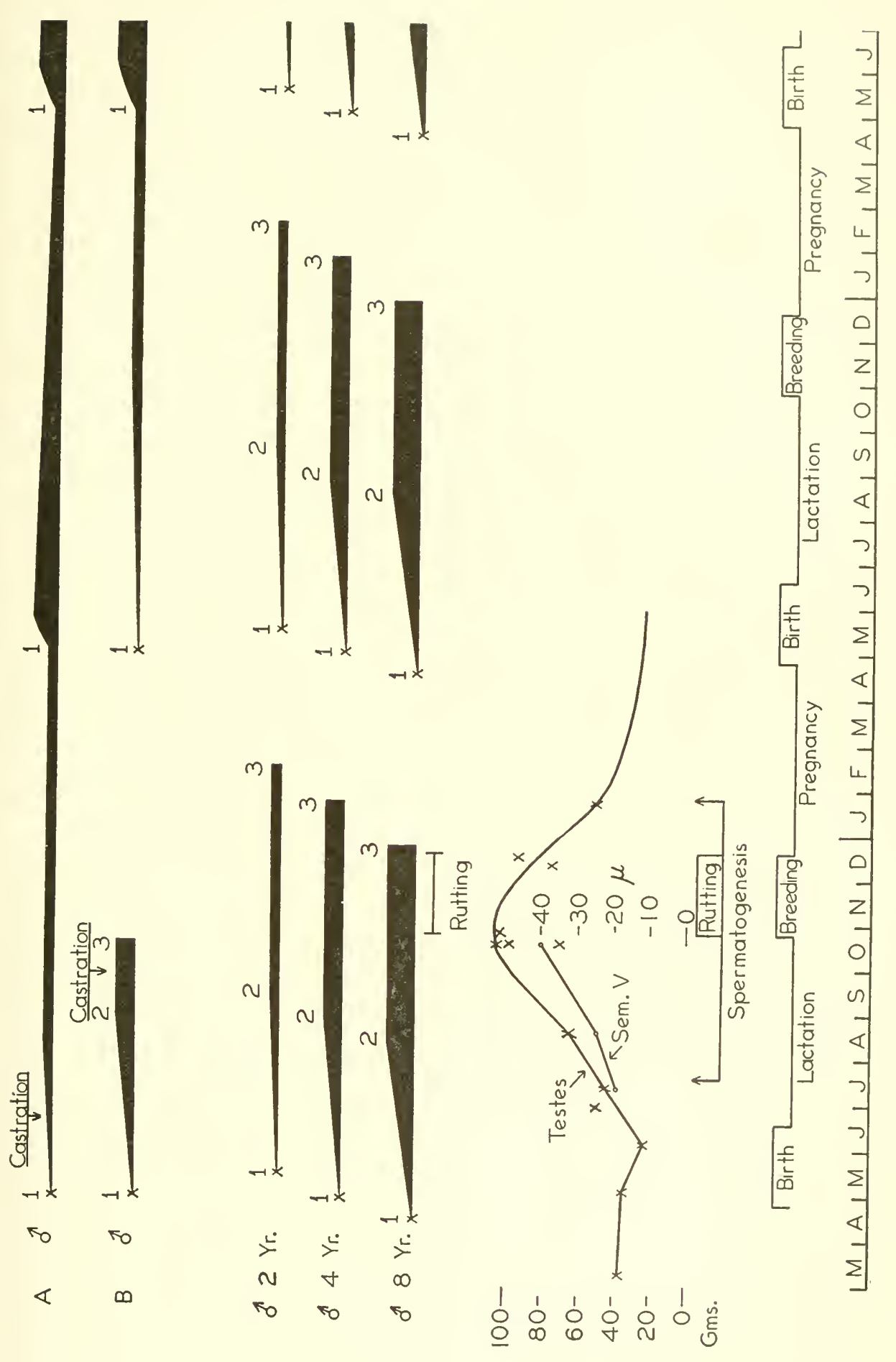


masses situated on either side of the base of the bladder, compactly ensheathed by connective tissue, and varying from 2 to $4 \mathrm{~cm}$. in length and about $1 \mathrm{~cm}$. in diameter, depending on their functional condition. In the June and July animals (pl. 2, figs. 5 and 6 ) the seminal vesicles are minimal in size; in the August animal (pl. 2, figs. 7 and 8) they are distinctly enlarged; while in the October specimens (pl. 3 , figs. 9 and 10 ) they are about twice the size of the June glands. The histology also undergoes a marked change. In the June and July specimens (pl. 2 , figs. 5 and 6 ) the gland presents numerous small cavities lined by relatively low, inactive cells. The connective-tissue partitions between the glanduIar spaces are relatively thick. Very characteristic of these months is the presence in the lumina of darkly pigmented, amorphous masses which give the impression of being inspissated secretion. In August (pl. 2, figs. 7 and 8) the lumina are distinctly enlarged and the epithelial cells lining the mucous membrane are considerably taller than in June and July and show signs of secretory activity. The black, amorphous masses of secretion have diminished. By October (pl. 3, figs. 9 and 1o) the gland is markedly changed, its cavities having become very much enlarged and filled with copious amounts of globular and granular secretion. Accompanying this enlargement, the partitions separating the numerous cavities have become stretched, transforming the mucous membranes into an intricate system of trabeculae or septa. The epithelial cells have become exceedingly tall and slender, with the nuclei pushed to the bases of the cells. From an average height of around 18 to $20 \mu$ in June and July the cells have attained a height of about $40 \mu$. None of the black, amorphous, inspissated masses of the preceding stages are present any longer.

From these observations it may be concluded that the seminal vesicles, as well as the testes, of the Virginia deer undergo pronounced seasonal variations. Both the testes and seminal vesicles which are in a state of regression in May and June become gradually activated, to reach a maximum state of activity in the fall, when rutting occurs. It is known that in other mammals the male accessories are maintained by the male sex hormone produced by the testes; consequently, it seems fully justifiable to relate the seasonal activation of the seminal vesicles, shown here in the Virginia deer, to a seasonal activity of the testes. One may deduce that the testes of the Virginia deer begin to become active late in June, and that they in turn begin to stimulate the male accessories in July until these reach their maximum activity, together with the gonads, during the fall rutting season.

The Effects of Gastration on the Growth and Periodicity of the Antlers. The periodicity of the gonads and seminal vesicles invites comparison with the antlers, a male secondary sex character which is also subject to seasonal changes. In a separate paper the writer ${ }^{11}$ has described the annual cycle of the deciduous antlers of the Virginia deer, based upon a study of the same animals utilized in the present report. Briefly stated, the antlers of the white-tailed deer commence to grow late in April or early in May; they attain their full 
growth, become hard, and shed the velvet in September, while in late December, or in January, the antlers are cast off.*

Examination of the schedule for gonads and antlers (graph 1) reveals that the antlers begin their annual renewal at a time when the testes and senimal vesicles are most inactive; they become hard and the velvet is shed when the testes and male accessories are rapidly enlarging, whereas the antlers are lost when the reproductive organs have begun to decline. These observations suggest that some nongonadal factor must be responsible for the initiation of antler growth. Fortunately for om knowledge of the antler-gonad relationship, numerons deer have been castrated at various times. Few records of these experiments, however, have been kept, beyond in some instances the antlers themselves, or pictures of them. The most extensive account of such experiments has been written by John Dean Caton, ${ }^{12}$ a judge in Illinois who studied the natural history of deer as a scientific avocation. He castrated numerous Virginia deer and elk. From his classical account of these experiments the following passages are excerpts. They illustrate with the utmost clarity how the antlers become typically deformed following castration.

"If a cleer be castrated at any time after the antlers are so far matured that their velvet may be removed without material injury, and while they still furmly occupy their seat, they will invariably drop off within thirty days thereafter, though it may be months before the time that they would have been shed in the course of nature. In this case, and also when the operation is performed after the antlers are dropped naturally, in the spring following when the new antlers on the perfect buck commence their growth, the same growth commences on the mutilated animal, and progresses to all external appearance the same as on the perfect animal till they have attained nearly the same size as those which were last cast off. If the buck be a young one with a spike antler, this will be a spike also of nearly the same length. If an old buck with five tines, these will be of nearly the same size as the former, with five tines also. These, however, never perfect their growth and never lose their velvet: but at the time the antlers on the perfect buck lose the velvet, those on the mutilated bucks stop their growth, but a moderate circulation is kept up in the velvet, which remains warm to the touch, and so they continne stationary till the severe weather of winter freezes the antlers through down to or very near the burr, when by the application of some accidental force they snap oft within half an inch or an inch of the burr, depending on the size of the antler. If we now examine the detached portion of an antler we shall see that

* With variations of a month or two, a similar calendar holds for the majority of deer in the temperate zone north of the equator, the only marked exception being the European roe deer (Capreolus capreolus). In this unusual species the antlers appear in January, and the breeding season occurs in August (Bischoff," Keibel, ${ }^{4}$ Stieve ${ }^{10}$ ). With this odd calendar the females combine the unique feature among deer of displaying delayed implantation, namely. a period of three to four months before implantation occurs during which the fertilized eggs lie dormant in the uterus. Implanted, as in other deer, at the usual time (November), the young are consequently also born at the usual time (May). 
its entire body is loose and spongy, more condensed at the circumference than within, but has nowhere attained the consistency of hard bone, so as to close up the blood-vessels leading into it from the periosteum.

"These stumps of the antlers are carried till the next spring, when a new antler shoots out from the old stump not so large as its predecessor, and grows on in the same way and at the same rate as on the perfect animal, till those so far mature as to shed their velvet, when as before that on the mutilated animal stops its growth. In the meantime the old stump has enlarged its diameter and put out large tubercles as if supplemental to the burr, which is also considerably enlarged. The new antler thus produced is not so large as the former, and if branched has less tines. And so this process goes on year after year, each succeeding antler being less in size and perfection than its predecessor, while the enlargement at the lower end becomes an exaggerated burr. This process of growth differs very considerably in different individuals of the same species. In some, in a few years, these stumps grow to an enormous size, covered all over with large tubercles, some of them amounting to shafts two or three inches long, which may be frozen and broken off in the winter, while neither may be so conspicuous as to be recognized as a beam. The whole of this irregular mass is ever covered with the fine, soft, glossy fur. These two large masses in the place of the antlers, covered all over with these rudimentary shafts, present a very curious and interesting appearance on the head of a deer."

Similar deformed antlers in various North American deer, following castration, are mentioned or pictured by sketches in the writings of Seton. ${ }^{13}$ Townsend and Smith ${ }^{14}$ show several photographs of two Virginia deer which had been castrated. The deformed antlers resulting from castration are sometimes referred to as "cactus-antlers" in the United States.

Similar observations for European deer of various species have been collected by Gaskoin, ${ }^{15}$ Fowler, ${ }^{16}$ Rörig, ${ }^{17,}{ }^{18}$ and Brelum. ${ }^{19}$ In the European roe deer a similar but more peculiar and striking deformity of the antlers occurs following castration. In these deer the antlers become converted into huge masses of rubbery, exuberant protuberances, which are permanently covered by fur, remain vascular, and are only moderately calcified. An outspoken example of this type of antler deformity, designated as "wig antlers," because of its resemblance to an old-fashioned wig, is shown in a photograph by Tandler and Grosz. ${ }^{20}$ A related, although somewhat different, response to castration has been observed in the reindeer (Tandler, ${ }^{20}$ Tandler and Grosz ${ }^{20}$ ). In reindeer oxen, according to Tandler, the antlers are much larger than in the bulls, and they never lose their velvet completely. Reindeer oxen, according to these observers, contrary to all other observed species of castrated deer, do, however, shed and renew their antlers annually, although the antlers are shed several months later in the oxen than in the bulls. However, Jacobi ${ }^{22}$ adds the observation that the antlers of castrate reindeer, due to a preponderance of soft, spongy bone, are not so hard as those of normal animals. Contrary to 
Tandler, Jacobi claims (p. 298), however, that totally castrated oxen drop their antlers at the same time as bulls. It should be remaked, however, that the data regarding castration in reindeer are not so trustworthy or complete as for other deer, because reindeer are frequently mutilated by the Lapps by crushing the testes, instead of by actual castration, and in the cases cited by Tandler and by Jacobi there is no evidence that the degree of castration was ever verified in any individual instance by post-mortem examination.

Tandler and Grosz also contribute brielly the statement that in a doe of the European roe deer, as well as in a second doe of undesignated species, both of them belonging to species in which normally the females do not possess antlers, removal of the ovaries did not induce formation of antlers. Similarly in a female reindeer, a species in which the female normally possesses antlers, the ammual growth and renewal of the antlers was not modificd by bilateral ovariectomy.

Various interpretations have been placed on the observations outlined above. Regarding his own experiments with deer, Caton ${ }^{12}$ remarked in 1877 . "We may admit that one physical body can only produce a physical effect upon another body by a physical medium, and so conclude that there must be a physical medium between the testes and the antlers, specially designed and qualified to produce the effect observed; but if so it is as yet not identified, and we can only hope that some more ingenious and careful observer may find it. The utmost we may safely say now is that in some way the testes enable or stimulate the proper blood vessels to carry into the antler a larger amount of earthy matter and there properly deposit it than they can do after the testes are removed, presuming at the same time that the absence of the generative organs deprives these vessels of, or weakens other important functions necessary to, the full maturity of the antler."

Tandler and Grosz $z^{20}$ summarize their observations on roe deer to the effect that castration at a time when the velvet is present leads directly to the formation of wig antlers, while castration after the velvet has been shed imposes prompt loss of the antlers and subsequent development of wig antlers. Concerning reindeer Tandler ${ }^{21}$ concludes that antler formation is independent of the presence of the gonads. A castrated reindeer, whether male or female, renews its antlers anmually, as do the individuals who are in possession of gonads. Consequently, according to Tandler, the antlers of reindeer represent a species character which is independent of the gonads.

A more recent contributor $\left(\mathrm{Olt},{ }^{23}\right)$, speculating on the gonad-antler relationship based on consideration of castrated roe deer, begins with the assumption that spermatogenesis is limited to the rutting season, whereas the testicular hormones are given off constantly throughout the year. Furthermore he postulates four testicular hormones: one, which induces antler growth; a second, which regulates growth; a third, which initiates resorption of the velvet by a marked local "eosinophilia"; and a fourth hormone, which atcts on the muscu- 
lature of the blood vessels of the antlers inducing a nutritional disturbance, so that the antlers die and are eventually cast off. In a second article $\mathrm{Olt}^{24}$ concludes further that there is a seasonal inhibition of antler growth by the testes, expressed by the withering of the velvet and subsequent death of the antlers. The present observations on the annual cycle of gonads and seminal vesicles indicate that the basic assumption of Olt is false; contrary to his belief, the present evidence supports the conclusion that the internal secretion of the testes, which is responsible for the changes in the male accessories, increases and declines annually in a time sequence coinciding with the rise and fall of spermatogenic activity.

The present writer would interpret the ammual sequence of events in the normal antler-gonad cycle, viewed in the light of the results obtained by castration, as demonstrating that nongonadal factors are responsible for the initiation of antler growth in adult deer, but that full maturation of the antlers in all species of deer depends to some degree on the presence of intact gonads. This conditioning by the testes is greater in the Virginia deer and roebuck, however, than in the reindeer. Nevertheless, in the latter, contrary to the conclusion reached by Tandler and Grosz, an appreciable testicular effect is actually present, judged by observations made following castration (increased size, failure to harden completely, longer retention of velvet). In female deer, on the contrary, judging from the fragmentary observations of Tandler and Grosz, whether the female possesses antlers (reindeer) or not, gonadectomy produces no apparent change in regard to antler formation, and hence in the female the antlers or their rudiments are possibly unconditioned.

From what has been observed in normal as well as castrate deer, it appears that the antler cycle must be regulated by both nongonadal and gonadal factors. In the normal cycle of the white-tailed cleer the nongonadal factor obviously initiates antler growth before the testes have revived from their involution of the previous winter, while in castrate deer this factor must be responsible for the continued formation of antler tissue. The gonadal factor, on the contrary, apparently does not begin to come into play until six to eight weeks after antler growth has been initiated. This factor evidently exercises normally a role in the internal reconstruction and hardening of the July and August antlers by the laying down of the compact or cortical bone which replaces much of the initial spongy bone. Contrariwise, upon removal of the gonadal influence by castration, the capacity to form compact bone is abolished and shedding of the velvet never occurs.

Whether the shedding of the velvet in the normal animal is directly controlled by testicular hormone is more difficult to answer. Olt ${ }^{23}$ regards the testicles as being directly responsible, basing his judgment upon the retention of the velvet after castration, as well as on the occurrence, cluring the normal shedding of the velvet, of a local "eosinophilia," the nature of which he does not further elicidate. Caton ${ }^{12}$ and Macewen, ${ }^{,-5}$ on the contrary, regard local 
factors as being responsible for the atrophy of the blood supply to the antlers; these explanations assume in one way or another that the internal or external ressels are gradually mechanically choked by bone which is deprosited around them. Macewen adopts the belief, current anongst natmalists and humers. that the external blood supply of the velvet is obliterated by compression of the large vessels of the velvet at the base of the antler by the gradual enlargement of the bony corona. Caton presents various reasons why these vessels are not compressed in that way, and offers, instead, the explanation that the internal and external sets of ressels are directly obliterated by gradual closure of the smaller radicals in the Haversian canals and manow spaces, due to the pressure of accumulating deposits of lime salts.

These theories involving local factors are based, howerer, more upon assumptions than upon any adequate histological proof. Vascular injections made by Rhumbler, ${ }^{2,5}$ as well as several which I have prepared, ${ }^{11}$ inclicate that the blood supply reaches the antler almost exclusively by the external vessels in the velvet, whereas the internal supply reaching the antler through its base is almost negligible. Thus the characteristic, dense calcification of the interion of the antler base is probably not responsible for the occlusion of any important larger blood ressels. Although Caton's and Macewen's concepts are poorly substantiated, it does not necessarily follow, as postulated by Olt, that atrophy of the relvet must be hormonally controlled; it is still conceivable that, in some as yet undisclosed way, local factors may be directly responsible for interruption of the circulation. Nevertheless, the idea of hormonal control is inviting. In favor of it one might cite the slender parallels that the testes are known to exert effects upon certain rascular beds. for example, upon the ressels of the cock's comb (Hardest $y^{-2 \pi}$ ), as well as upon the human skin (Edwards and co-workers $\left.{ }^{26}\right)$.

The erentual loosening and shedding of the dead antler, on the contrary, appear more definitely to be hormonally determined. At this period the pedicle becomes exceedingly hyperemic and the bone undergoes manked resorption, especially at the line of junction of the antler with the apex of the pedicte (ron korff, Macewen, Wislocki ${ }^{11}$ ). This event occurs nomally during the period of gonadal involution. Moreover, in deer castrated after the antlers are dead, the homs are shed prematurely within one to four weeks following removal of the gonads. Hence, the casting off of the antlers appears to be clue to withdrawal of testicular hormone, resulting in a local hyperemia and decalcification of the apices of the pedicles of the frontal bones.

It has been pointed out that in all castrate deer, excepting the reindeer, the antlers assume variable forms, reaching their most extreme expression in roe deer in which bizarre masses of poorly calcified antler tissue arise. If castration occurs soon after antler growth has commenced, the horns develop normally up to the time when the influence of the testes ordiuarily begins to express itself. Only from then on do the horns begin to show the effects of gomadal 
loss. At intervals in subsequent months and years additional abortive antler growth takes place from the antler pedicle. Apparently, since individual antlers can no longer be matured and shed, the nongonadal hormone which is responsible for initiating antler growth, and for stimulating the pedicle, succeeds only in producing an irregular succession of undersized, poorly calcified, abortive antlers which are not shed and which crowd one another. These become fused, forming eventually an irregular mass attached to an enlarged pedicle. Study of castrate antlers, besides observations on other types of deformed antlers (Schumacher ${ }^{30}$ ), indicates that the abnormal growth is initiated recurrently from the skin and periosteum covering the distal portion of the pedicle. Consequently the tissue covering the bony pedicle must be regarded as being peculiarly sensitive to some hormonal stimulus which is released periodically and which is not gonadal in origin.

On the Factors Controlling the Periodicity of Antler Growth and Breeding Season. In several recent articles F. H. A. Marshall ${ }^{31,32,33}$ has assembled data to prove that the hypophysis is a regulator of gonadal rhythm. He concludes that, especially in female mammals, "the phases within the sexual cycle as well as sexual periodicity itself are brought in relation with the changes in the environment and more obviously with the seasonal environment by other factors, and there is now much general and experimental evidence to show that these factors are mainly or largely exteroceptive ones acting through the intermediation of the nervous system upon the anterior pituitary." He states further that in a large number of animals the incidence of daylight is almost certainly an important factor in controlling the cycle. He cites in this connection data demonstrating the change over in the estrous cycle and breeding season in animals after transference across the equator. Especially illustrative of this are observations on ruminants, particularly sheep and deer.

Regarding deer, numerous observations have been made by Donne ${ }^{34}$ upon various species of the northern hemisphere which have been transferred to New Zealand. The changes are well illustrated by the specific example of a group of red deer, as reported by Marshall, ${ }^{32}$ which were transferred from New Zealand to England: “Eight red deerhinds were brought from New Zealand where the deer rut in April to Warnham Court Park, Sussex, England, arriving in March. They at first maintained their original gonadal rhythm and came on heat in April (at the New Zealand time). Their next sexual season, however, was in December-January and their third sexual season in England was in October or at the normal time for British deer. It is thus seen that the changed environment had an effect upon the periodicity of estrus, and in view of the evidence derived from other animals there is a presumption that the regulating influence was the anterior pituitary, this organ receiving stimuli from the environment and bringing the estrous cycle into suitable relation with seasonal change." 
Marshall concludes, however, that ruminants, including deer, are exceptional, since, if they react to light at all, it must be to diminution rather than to increase, because their breeding season, both north and south of the equator, falls in the period of diminishing daylight. If one be permitted to carry this interesting analysis and speculation somewhat further, what apparently puzzles Marshall about the ruminants can perhaps be harmonized to some extent with the behavior of other mammals. Marshall ${ }^{32,33}$ does not consider the periodicity of the antlers of deer, but it is clear from the observations of Donne ${ }^{34}$ that, in the transference of deer across the equator, not only does the breeding season shift but the whole antler-gonadal cycle is also shifted to accord with the new climatic or seasonal environment.

If we consider now the antler-gonadal sequence as related phenomena and as a whole, it appears justifiable to assume from the sequence observed in Virginia deer that the initiation of antler growth and the activation of the gonads occur in succession in the climatic spring or early summer. And if we assume on the basis of the accumulated evidence that seasonal periodicity is related to exteroceptive stimuli, we may postulate with some validity from examination of various species of deer that the seasonal growth of the antlers and of the gonads is initiated sometime in the spring or early summer by the influence of light acting through the hypophysis.* Furthermore, it seems reasonable to assume from the clata on the growth of antlers and testes that the hypophysis first releases an antler-stimulating hormone which is followed one to two months later by the release of gonadotrophic hormones. The former stimulates periosteal hypertrophy in the antler pedicles and initiates the process of ossification. The latter activate the interstitial tissue of the testes and initiate spermatogenesis. The androgenic hormones, so stimulated in the testes, in turn subsequently influence and regulate the full maturation of the antlers. Finally, the casting off of the antlers occurs when the testes are declining, but is precipitated immediately if castration is resorted to in the fall; consequently dropping of the antlers must be due to a decline or removal of gonadal hormone.

Regarding the relationship of initiation of antler growth to activation of the testes, it is apparent that in the European roe deert a similar situation prevails to that here observed in the Virginia deer. From perusal of data for this deer one finds that the antlers make their appearance from December to February $\left(\right.$ Brehm $\left.^{19}\right)$, whereas, according to Stieve, ${ }^{10}$ spermatogenesis does not commence until April. Thus it scems justifiable to conclude that, as in the

* The pituitaries of the present series of deer have not been studied histologically. The adrenals, howerer, have heen examined histologically by Dr. H. Stanler Bennett of this department. He reports that no apparent seasonal variations are present in the specimens with regard to cortical zoning or staining of the cells, as revealed by Mastons technique. The thyroids of the same deer have also been the subject of study by Dr. A. L. Graflim, who reports that he has been unable to demonstrate seasonal variations in the material from that gland.

t hee footnote on page $63 . \%$ 
Virginia deer, hypophysial stimulation of the antlers precedes gonadal stimulation by several months.

Thus pituitary and gonadal hormones interplay in a definite way and sequence in regulating antler growth. The gonadal hormone probably exercises a direct control in the internal reconstruction and maturation of the bony parts of the antler. As explained in a previous passage, it remains to be demonstrated whether it is also directly responsible for the vascular changes which lead to shedding of the velvet. The gonads appear also gradually to inhibit pituitary function, resulting in the eventual cessation of the hypophysialgonadal cycle by mid- or late winter, with no further manifestation of hypophysial activity until the onset of the next cycle which begins, depending on the species of cleer, several weeks or months after the previous antlers have been cast off. This inhibition of the pituitary is also illustrated by the fact that, upon castration of most species of deer after the velvet is shed, the antlers are cast within a month and new antlers are not formed until the following spring at the usual time $\left(\right.$ Caton $\left.^{12}\right)$. In similarly castrated roe deer, the antlers are likewise immediately shed, but, contrariwise, growth of the permanent castrate or wig antlers begins at once $\left(\right.$ Rörig $\left.{ }^{18}\right)$, indicating that in this species the pituitary has not been fully inhibited. The tremendously rapid and exuberant growth of wig antlers in the roe deer, as compared with the lesser growth of castrate antlers in other deer, also suggests that the pituitary in this species is either relatively more potent in its antler-growth-promoting action or is less inhibited by the testes.

In connection with the possibility of light stimulating the hypophysis of deer, the data of Schumacher ${ }^{30}$ are interesting. From the observation of roe deer, over many years in the Austrian Alps, he ascertained that their antlers were larger and better developed in those years in which the incidence of sunlight was greater. He concludes that sunlight should be regarded as the most important, although not the only, factor responsible for good development of the antlers. He believes that sunlight, activating vitamin $D$, is responsible for the vigorous growth of the antlers in good years. He overlooks, however, the additional possibility of the direct response through neural centers of the hypophysis to light. Other factors, including the abundance or scarcity of food, are also said to exert an influence on the size of the antlers (Caton, ${ }^{12}$ Seton, ${ }^{13}$ Jacobi, ${ }^{22}$ Anthony ${ }^{37}$ ).

Other aspects of the periodicity of antler growth and of the reproductive cycle fit into the concept of the role of the hypophysis and testes proposed above. There is a law governing antler growth, based upon the experience of numerous observers (Caton, ${ }^{12}$ Murie, ${ }^{38}$ Jacobi, ${ }^{22}$ Seton, ${ }^{13}$ Brehm, ${ }^{18}$ Rörig, ${ }^{18,18}$ ) to the effect that the more sexually mature and vigorous the animal, the earlier in a given season the antlers begin to grow (graph 1). Thus the antlers of a six- or eight-year-old healthy buck put in their appearance some weeks earlier than those of the two- or three-year-olds. Similarly the velvet is shed sooner 
and the antlers are cast earlier in mature bucks than in younger animals. It seems reasonable to interpret these observations in the sense that the nore mature the animal the earlier in the season the hypophysis is activated and hence the sooner the hypophysis in turn actirates the antler pedicles and the testes. In senescent animals (Seton, ${ }^{13}$ Brehm, ${ }^{1.9}$ Anthony"in), conversely, the antlers diminish in size, appear later in the season, and the velvet is retained longer. In addition, in the senile roebuck the antlers are reported as never being shed $\left(\right.$ Schumacher $\left.^{30}\right)$. These age changes inclicate a lessening of the potency of the hypophrsial-testicular mechanism. Finally, it is known that deer of a given species give birth to their young earlier in the southern than in the northern parts of the United States (Audubon and Bachman ${ }^{20}$ ), and similar findings have been recorded for Europe (Brehm, ${ }^{1.4}$ Jacobi"w), observations which again point to seasonal influences in the control of reproduction. Moreover, many species of tropical and subtropical deer tend to have extended sexual seasons and may breed at any time of the year (Marshall ${ }^{32}$ ), besides having no definite period for the appearance of the antlers (Brehm ${ }^{19}$ ). observations which indicate that. in latitudes in which climatic changes are relatively slight, sexual periodicity and antler growth are not sharply regulated. Many of these various observations indicate the probable role of exteroceptive stimuli in regulating the periodicity of antlers and gonads and these leads should be more carefully followed up.

We return at this point to the thesis of Marshall, to the effect that. whereas many mammals have their sexual seasons in spring or summer under the exteroceptive influence of light, the ungulates have their period of rut or estrus in the fall. when. if exteroceptive stimuli are involved, the animals must be reacting to a diminution of light or possibly to temperature. From the observations reported in the present studs, it appears very likely that in deer, as in many other seasonal animals, the hypophysial-gonadal cycle is alon initiated by the exteroceptive stimulus of light. In ordinary seasonal mammals we are accumstomed to a short cluration of these crcles, consisting of stimulation of the pituitary gland followed immediately, in days or weeks, by the sexual season. In the white-tailed deer it is erident that the anmual hypophysial-gonadal cycle is initiated in early summer, the major difference betreen deer and other mammals being that in the former the entire cycle requires five or six month, for its completion. whereas in the latter the cycle is usually very much shorter. Thus it is apparent that in deer the pituitarygonadal cycle is initiated, as in other seasonal mammals, in the spring or summer, under conditions of maximal light, whereas only the terminal phenomena of rut occur in the fall at a time of diminishing light. That withdrawal of light may be an active factor in precipitating the terminal phase of the ungulate cycle is suggested by recent observations by Bissomnette to the effect that the onset of the sexual season in goats, which normally occurs in the fall. may be hastened by subjecting them to diminished light. If this be the ase in 
ungulates in general, initial stimulation by light, followed by its subsequent withdrawal, may control the hypophysis and determine the sequence of the reproductive events. The present observations on deer draw attention merely to the fact that the annual hypophysial cycle has its onset much earlier than has been suspected from the sexual behavior and that, as in other mammals, light, acting in spring or summer, probably serves as the initial exteroceptive stimulus. It is suggested that similar conditions may prevail in other ungulates which exhibit sexual behavior in the fall.

In conclusion, a few remarks seem appropriate regarding the question of secondary sex characters. We are accustomed to thinking of the anterior lobe of the hypophysis as acting upon the gonads, but as having no direct influence, in the adult animal at least, upon the Wolffian- or Müllerian-duct derivatives. These latter it is believed are activated by androgens and estrogens, and not directly by the anterior pituitary. Similarly it is generally assumed that the secondary sex characters are also under direct control of the gonads. Thus Riddle ${ }^{41}$ states: "The secondary sex characters (in vertebrates at least) represent or reflect specific responses of developing parts, areas or tissues to a specific hormone of the gonad." Allen"2 remarks: "Perhaps the time in evolution when the gonads assumed control of the secondary sex characters will never be known." Whereas Lillie ${ }^{43}$ believes that "all sex primordia or rudiments and, possibly, all sex tendencies, assumed to be common to the life history of both male and female individuals of a species, may be divided in two classes, those that respond positively to the female hormone, and those responsive to the male hormone, each class being uninfluenced by the opposite hormone."

Nevertheless, in the case of certain sccondary sex characters, for example, the antlers, it seems likely that the initiation of their growth in the adult male deer is under the control of the hypophysis. The subsequent maturation and involution of the antlers, however, appear to be subject to additional regulation exerted by the testes. Hence, it seems probable that this particular secondary sex character is under the joint control of both anterior hypophysis and gonads in the manner outlined, with the pituitary providing the initial stimulus. In lower vertebrates most secondary expressions of sex appear to be under complete control of the gonads, yet occasionally in birds, as exemplified in the plumage of one of the African weaver finches (Witschit ${ }^{4 t}$ ), the pituitary evidently plays a determining role. In mammals, in the case of the mammary glands (Turner ${ }^{45}$ ), the hypophysis may also exert a regulating influence. One interesting difference exists between the case of the African weaver finch and the control of antler growth. Witschi's observations indicate that both gonads and plumage are controlled by gonadotrophic hormones. In the case of the Virginia deer, in which antler growth precedes gonadal growth by some six weeks to two months, it seems likely that two separate pituitary factors are operative, the first a form of growth hormone acting on 
the skeletal tissues which give rise to the antlers, while the second consists of gonadotrophic hormone activating the testes.

The hypophysial and gonadal influences, here described as initiating and regulating antler growth, may not differ fundamentally from the hormonal control of growth of ordinary skeletal parts, for recent investigations demonstrate that androgens and estrogens, as the case may be, supplement hypophysial factors in the normal process of ossification and maturation of the growing skeleton (Silberberg and Silberberg ${ }^{48,47,45}$ ).

\section{Sumimary and Conclusions}

1. The Virginia deer exhibits seasonal changes in the size and histological picture of the testes and seminal vesicles. Examination of the testes reveals the presence of spermatozoa beginning in July, being maximal in October, and diminishing in December and January. The seminal vesicles, inactive in Jume and July, commence to grow in August, and reach a high degree of activity by October.

2. The antlers begin their annual renewal at a time when the testes and seminal vesicles are most inactive; they become hard and the velvet is shed when the testes and seminal vesicles are rapidly enlarging, while the antlers are lost when the reproductive organs have begun to decline.

3. Following castration, as reported in the literature, the antlers of most species of deer are retained permanently, continue to grow irregularly, and never lose the velvet.

4. Consideration of the normal seasonal cycle of antlers and gonads in the Virginia deer, and the results of castration of adult deer, indicate that the initiation of antler growth is independent of the testes. For various reasons presented in the text the assumption is made that the hypophysis, activated by light in the spring and early summer, is responsible for stimulating the growth of the antlers (May), and for the subsequent activation of the testes (July). Subsequently the testicular hormone, either alone or more probably interacting with the hypophysial antler-growth-stimulating factor, induces the internal reconstruction of the antlers (August). The shedding of the velvet occurs after the antlers have hardened (September), but the evidence available at present is inconclusive as to whether the atrophy of the blood supply, responsible for this event, is directly under hormonal control. Normal withdrawal of testicular hormone after the rutting season, or abnormally (following castration), produces hyperemia and decalcification of the pedicles, resulting in casting off of the antlers (January). The concept proposed here assumes that antler growth is primarily initiated and controlled by the hypophysis, although the subsequent internal reconstruction and hardening of the antlers, as well as their ultimate shedding, are regulated by the testes, either alone or in conjunction with the pituitary.

5. The gonads and male accessories, under the influence of the pituitary, 
begin to grow in the early summer during a period of maximal light, whereas growth is completed and rut ensues in the fall under conditions of climinishing light. It is pointed out that the annual hypophysial-gonadal cycle, compared with those of other mammals, is extremely protracted, and that rut represents a relatively brief terminal phase. It is postulated that, as in other seasonal mammals, the cycle is initiated by light, although the terminal phase of reproductive activity, including rut, may be influenced by withdrawal of light, as suggested by experiments on goats carried out by Bissonnette.

6. The growth of the antlers in adult male deer does not appear to be initiated by the gonads, but by some other hormonal factor, probably hypophysial. Hence, unlike many other seconclary sex characters, antler growth is not primarily dependent upon the gonads. Only after the antlers have reached a certain size do the testes begin to exert a regulating influence.

\section{REFERENCES}

1. Wislocki, G. B.: Anat. Recrd. 79(supp.):6.4, 1941.

2. Ziegler, L.: Beobachtungen über die Brunst und den Embryo des Rehes (Hamover: 18.13).

3. Bischoff, T. L. W.: Entwicklungsgeschichte des Rehes (Giessen: 1854).

4. Keilsel, F.: Anat. Anzgr, 16(Ergzgshft.):6.4, 1899.

5. Keibel, F.: Anat. Anzgr. 19(Ergzgshft.): 18 , 1901.

6. Retzius, G.: Anat. Anzgr. 16(Ergzgshft.):65, 1899 .

7. Retzius, G.: Biologische Untersuchungen (n.F.) IX (Stockholm, Jena: 19oo), 109.

8. Strahl, H.: Anat. Anzgr. 16(Ergzgshft.):66, 1899 .

9. Lemninger, W.: Zischr. f. Anat. 68:230, 1923.

10. Stieve, H.: Ztschr. f. mikroskop.-anat. Forsch, 13:159, 1928.

11. Wislocki, G. B.: Amer. Jl. Anat. 71:371, 1942.

12. Caton, J. D.: The Antelope and Deer of North America (New York: 1877).

13. Seton, E. T.: Life-Histories of Northern Animals, I (New York City: 1909).

1.4. Townsend, M. T., and Smith, M. W.: Rooserelt Wild Life Bull. 6:161, 1933.

15. Gaskoin, J. S.: Proc. Zool. Soc. London 24:151, 1856.

16. Fowler, G. H.: Proc. Zool. Soc. London 1894:485.

17. Rörig, A.: Arch. f. Entwcklgsmech. d. Organsmn. 8:382, 1899 .

18. Rörig, A.: Arch. f. Entwcklgsmech. d. Organsmn. 23:1, 1907.

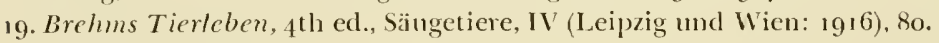

20. Tandler, J., and Grosz, S.: Die Biologischen Grundlagen der Sekundären Geschlechtscharaktere (Berlin: 1913).

21. Tandler, J.: Anzgr. Kais. Akad. d. Wissnschftn. (Wien), mathem.-naturwissnschft. Kls. $47: 252,1910$.

22. Jacobi, A.: Zool. Anzgr. 96 (Ergzgsbd.), 1931.

23. Olt, A.: Brcht. Oberhess. Gschft. f. Natu- u. Heilk. zu Giessen (n.F.: naturwissuschft. Abtl.) $11: 3,1927$.

24. Olt, A.: Natur u. Mus. (Brcht. Senchenberg. naturforsch. Gschft.) 58:376, 1928. 25. Nacewen, W.: The Growth and Shedding of the Antler of the Deer (Glasgow: 1920). 26. Rhumbler, L.: Wilhelm Rous' Arch. f. Entwcklgsmech. d. Organsmn. 119:111, 1929.

27. Hardesty, M.: Amer. J1. Anat. 47:277, 1931.

28. Edwards, E. A.; Hamilton, J. B.; Duntley, S. Q., and Hubert, G.: Endocrinology $28: 119$. $19+1$. 


\section{George B. Wislocki}

29. von Korff, K.: Anat. Hfte. $5^{1: 691,19^{1} \text {. }}$.

3o. Schmmacher, S.: Österreichs Weiclwerk 2:1, 1937.

31. Marshall, F. H. A.: Philos. Trns. Roy, Soc. London, s. B3 226:.123. $193^{6}$.

32. Marshall, F. H. A.: Proc. Roy. Soc. London, s.B 122:113, 1937.

33. Marshall. F. H. A.: in Les Hormones Sexnelles, ed. b! L. Brouha (1'ar is: 19g, , 215.

31. Honne, T. E.: The Game Inimals of New Zealand (London: 1924).

3.5. Graftlin, A. L.: J1. Morphol. $70: 21,1912$.

36. Schumacher, S.: Deutsch. Jäger $45: 1,1937$.

37. Anthony. H. L.: Bull. New York Zoöl. Soc. 32:3, 1929.

3s. Murie, O. J.: North Amer. Famn. no. 51. 193.5.

39. Audubon, J. J., and Bachman, J.: The Quadrupeds of North America, II (New York: 1851) 220; III (New lork: 1851), 168 .

fo. Bissonnette, T. H.: Pluysiol. Zö̈l, 1.7:379, 19.11.

11. Riddle, O.: in Sex and Intermal Secretions, ed. by E. Allen (1st ed.; Baltimore: 1932), 269. 12. Allen, E.: in Sex and Internal Secretions, ed. by E. Allen (st ed.; Baltimore: 1932), f60. 13. Lillie, F. R.: in Sex and Internal Secretions, ed. by E. Allen (1st ed.; Baltimore: 1932). 9. 14. Witschi, E.: Scientia 6o:265, 1936.

45. Turner, C. Wr: in Sex and Imernal Secretions, ed. by E. Allen (2d ed.; Biltimore: 1939). 740.

46. Silberberg. M., and silberberg. R.: Archs. Pathol. 32:85, $19+1$.

17. Silberberg, M., and Silberberg, R.: Anat. Recrd. 80:347, 1941.

f. Silberberg, MI., and silberberg, R.: Amer. Jl. Anat. 69:295, 1941. 


\section{EXPLANATION OF PLATES}

\section{PLATE 1}

Fig. 1. A section of the testes of a Jume deer. $x 110$.

Fig. 2. A section of the epididymis of the same deer, showing the absence of sperm in the tubules. $\times 110$.

Fig. 3. A section of the testes of an October deer. $\times 16_{5}$.

Fig. 4. A section of the epididymis of the same deer, showing abundant sperm in the tubules. $\times 110$. 

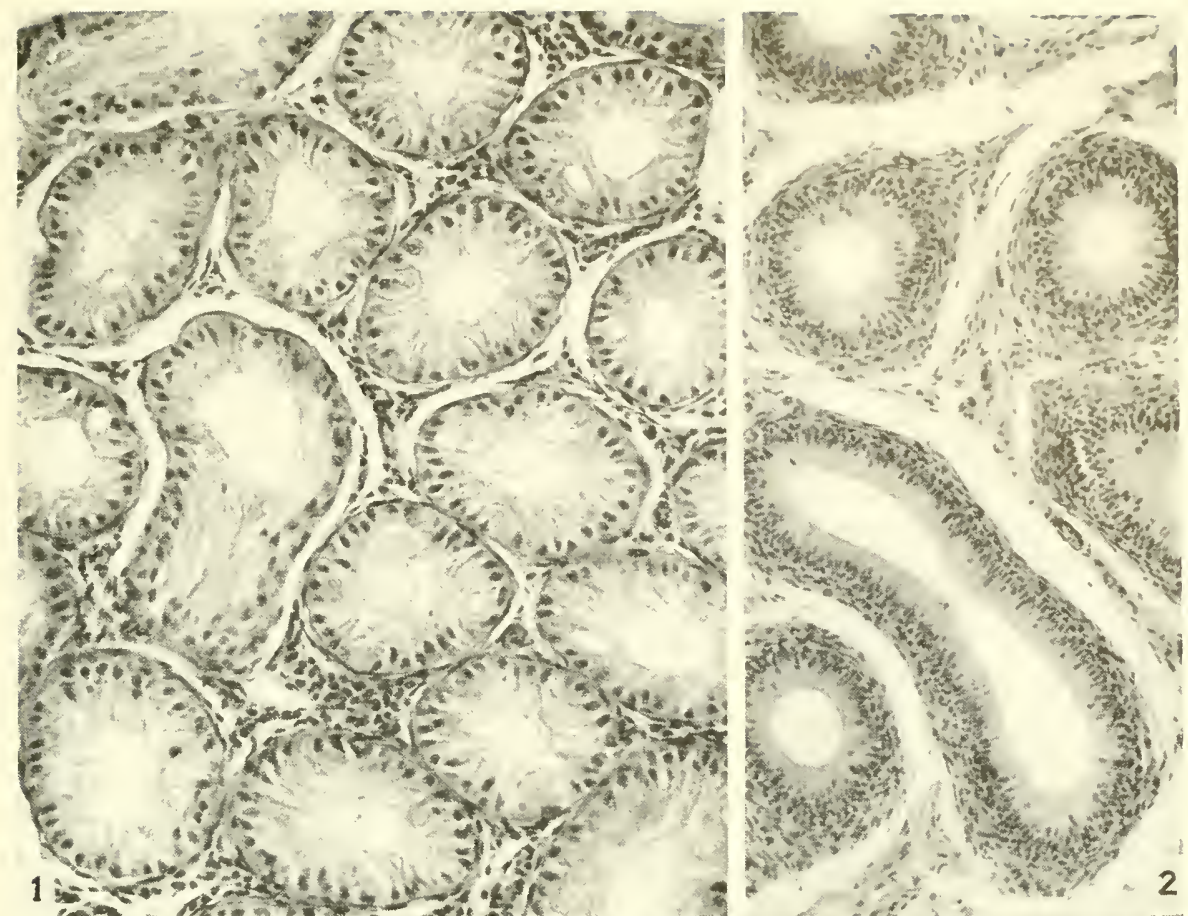

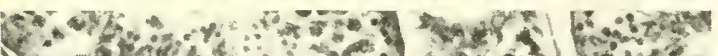

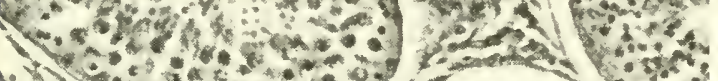

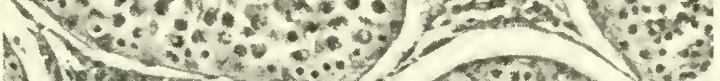
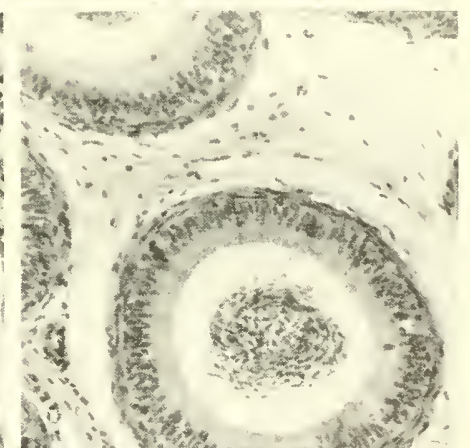

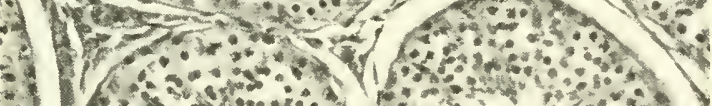

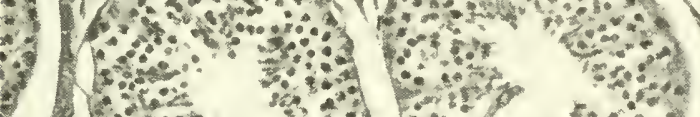

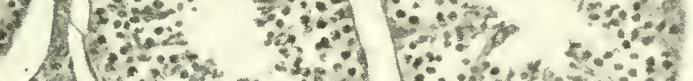

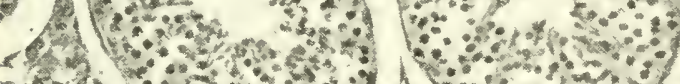

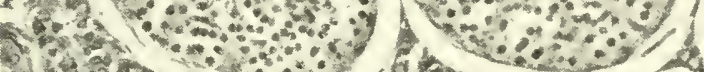

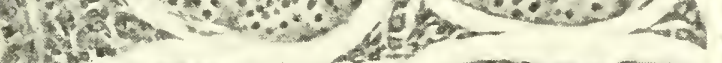

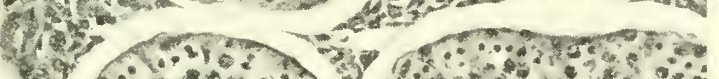

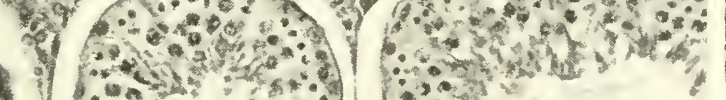

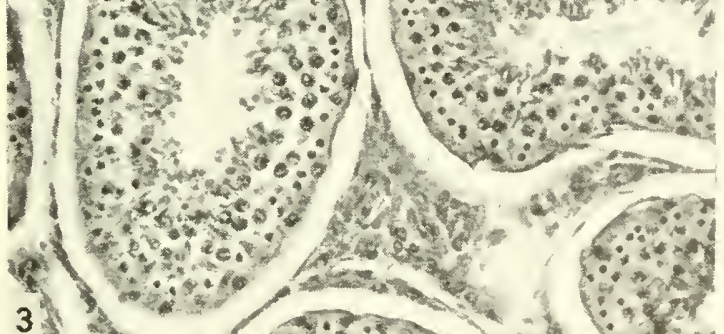

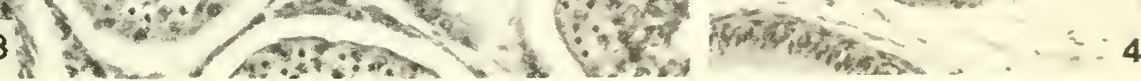

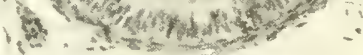




\section{PLATE 2}

Fig. 5. A section of the seminal vesicles of a July deer. $\times 7+$.

Fig. 6 . The same enlarged. $\times 200$.

Fig. 7 . The seminal vesicles of an August deer. $\times 74$.

Fig. 8. The same enlarged. $\times 200$. 


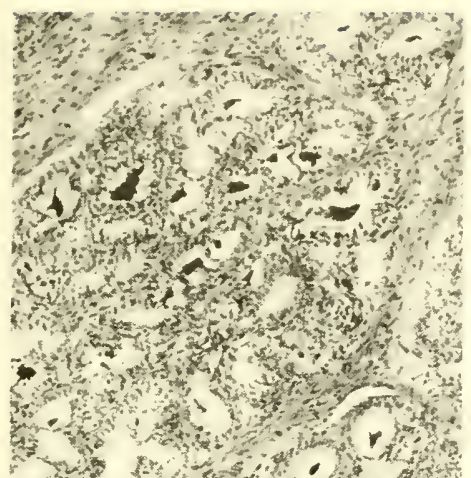

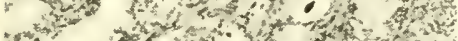
stom ditis on

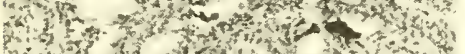

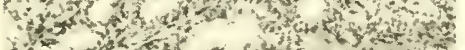
Ho Q. 16.

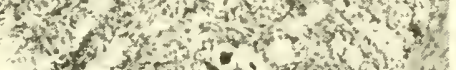
5 stow

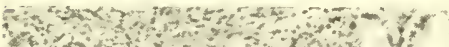
24 w and of

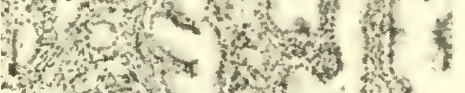

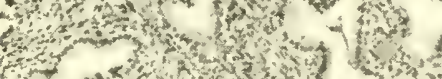

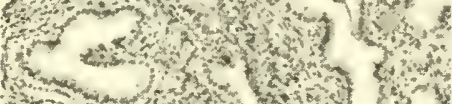
की (1)

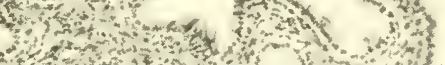

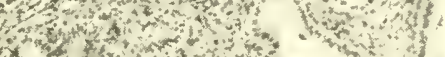

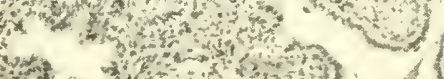

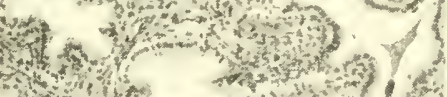
and

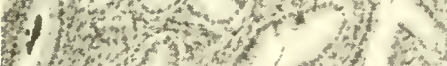

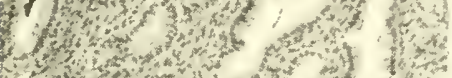

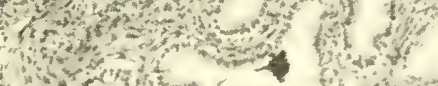
7 ing

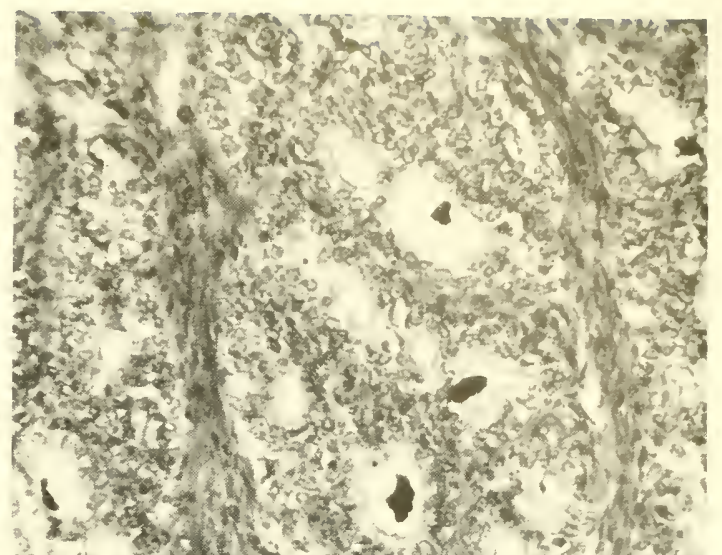

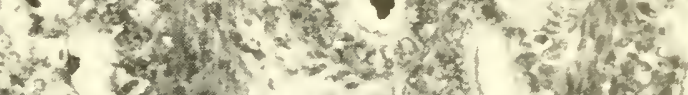

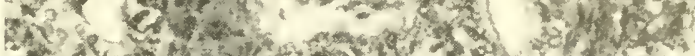

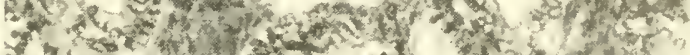

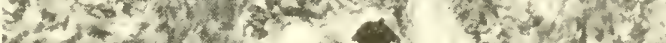

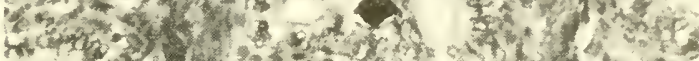
p)

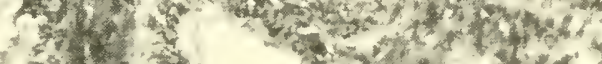
1.

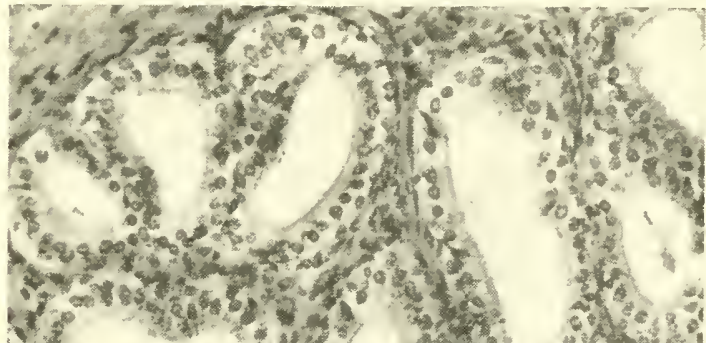

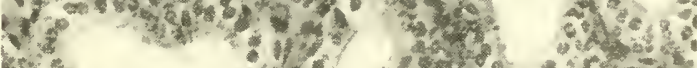
2. $81^{\circ}$.

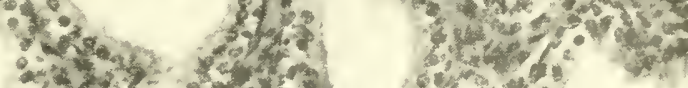

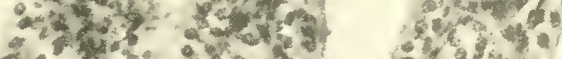

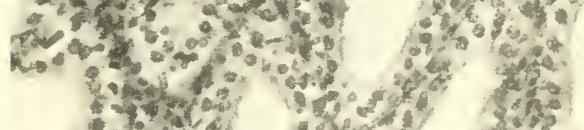

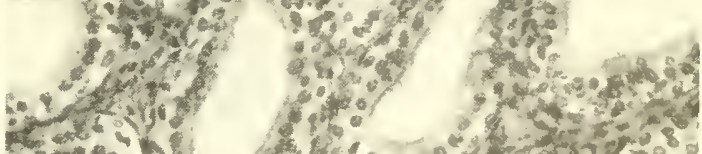

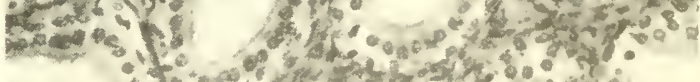
1.5 00 ond

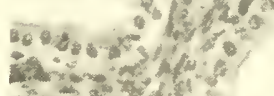

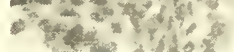

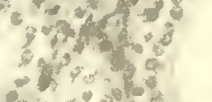
- जिए है $1=00$

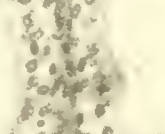


PLATE 3

Fig. 9. The seminal vesicles of an October deer. $\times 90$.

Fig. 10. The same enlarged. $\times 25^{\circ}$.

$\left[65^{2}\right]$ 


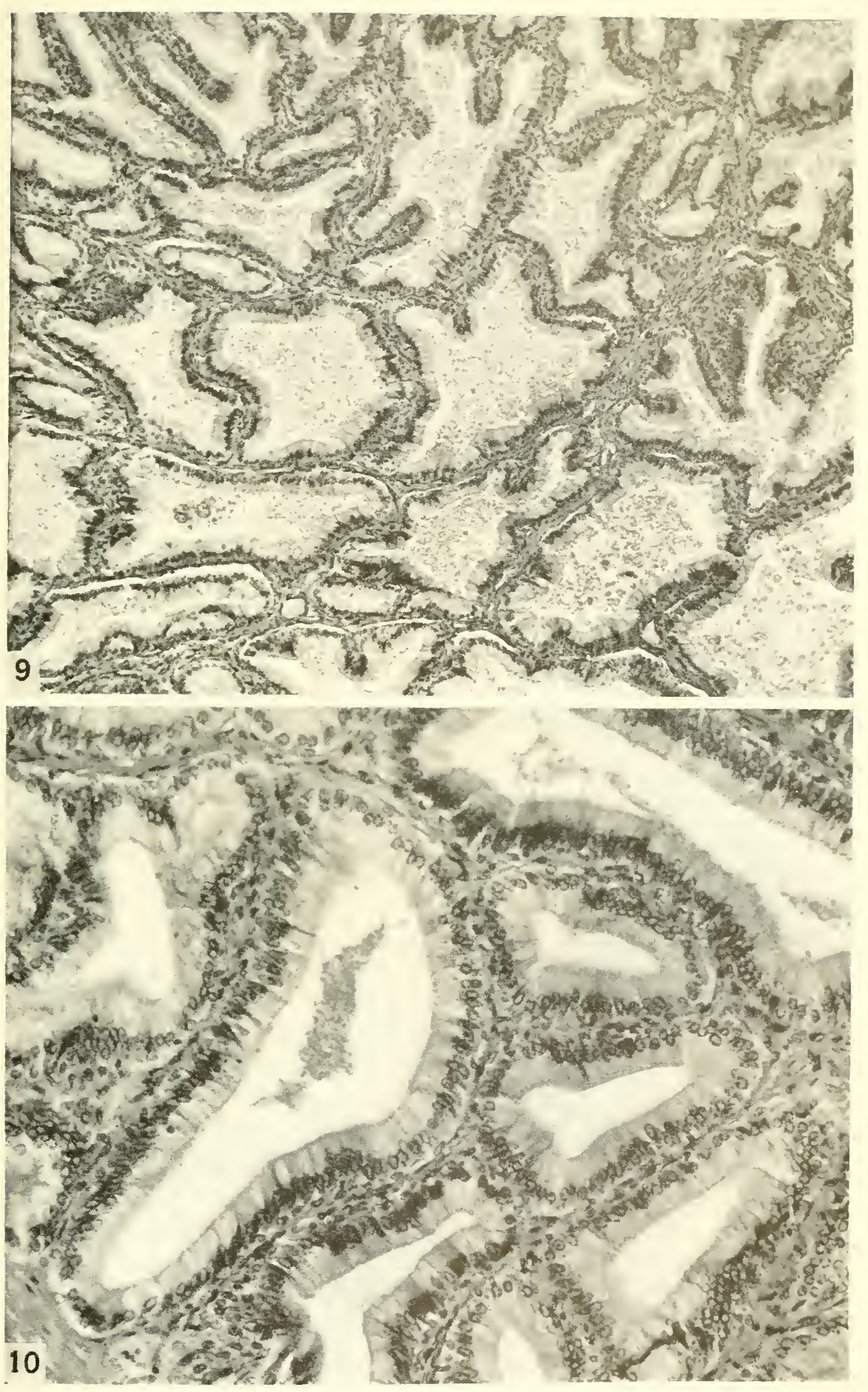

Plate 3 



\section{SEX DIFFERENTIATION IN}

\section{HETEROGENOUS PARABIOTIC TWINS}

$$
\text { (Ambystoma } \times \text { Triturus) }
$$

$$
\text { B) }
$$

EMIL WITSCHI AND HARRIET M. M. MCCURDY

$$
\text { 纆 }
$$

\section{From the}

DEPARTMENT OF ZOÖLOGY, STATE LNIVERSITY OF IOWA IOWA CITY, IOW'A 



\section{SEX DIFFERENTIATION IN HETEROGENOUS PARABIOTIC TWINS (Ambystoma $\times$ Triturus)*}

W $\mathbf{W}^{\mathrm{ITH}}$ growing information on sex development in parabiotic twins, definite indications of taxonomic specificity of the sex-differentiating substances are increasingly demanding our interest. It has been found ( $\mathrm{Witschi} \mathrm{i}^{1,2}$ ) that in some species these substances, corticin and medullarin, are spread by the blood stream like hormones, while in others they diffuse more slowly and with falling concentrations through the tissues. In at least one amphibian species, their presence was noticeable even before the initiation of morphological sex differentiation (Witschi and McCurdy ${ }^{3}$ ). On the contrary, in afl other well-analyzed cases, the antagonism between the sexes appears only at later developmental stages (Witschi, ${ }^{4,5}$ comprehensive review ${ }^{6}$ ).

This variety of conditions immediately suggests further investigations by the method of heterogenous parabiosis. It would seem interesting indeed to know what effects might be obtained from inductive substances of salamanders, poured into the blood streams of frogs. Unfortunately, the possibilities of such testing are limited by the factors of compatibility in heteroplastic grafting. In our laboratory, salamander-frog and newt-frog twins lived for several weeks, but they died invariably before the stage of initial sex differentiation. More successful were the experiments with salamander-newt twins. The fact that grafting between taxonomic orders (Caudata and Salientia) and families (Salamandridae and Ambystomidae) yields twin combinations which may last for weeks and even years is in itself remarkable, and deserves further study; the present paper will, however, be restricted to the analysis of the interactions observed in the sex development of the heterogenous twins.

\section{Controls}

In these experiments, three species of salamander, Ambystoma maculatum, A. jeffersonianum, and A. tigrinum, were used in combination with the Californian newt, Triturus torosus. The latter is smaller than Ambystoma tigrinum, but slightly larger than $A$. maculatum. This is true particularly for the late larval and metamorphosing stages, while adult newts and spotted salamanders are nearly of same size. A. jeffersonianum in Iowa is represented by a series of size variations. A dwarf form from Cedar Falls has been clescribed in $1937 .^{5}$ The typical form is larger than T. torosus and A. maculatum, but

* The first experiments of this series were tarted in 1927 while, as a fellow of the Rockefeller Foundation, the senior author spent three months in the Anatomy Department of the Lniversity of California. In spice of the length of the interval, the authors are desirous of expressing their gratitude for the cordial hospitality extended to them by Dr. Herbert M. Evans and for the stimulating interest and the generous help with which he furthered their work. During several years the continuation of the expeniments was made possible by grants from the National Research Council, Committee for Research in l'roblems of sex. 
not quite of the size of $A$. ligrinum. It appears only once as a mate of a parabiotic pair (jef- $\mathrm{T}_{1}$; fig. 7). All other jeffersonian salamanders of the series (table 3) belong to a medium-sized variety, the eggs of which were collected in the vicinity of Iowa City. Few observations on sex development in jef-

\section{TABLE 1}

Parabiotic Twins, Series mac-T (Ambystoma maculatum $\times$ Triturus torosus). $\mathrm{F}$, normal ovaries; $\mathrm{f}$, inhibited ovaries; $\mathrm{M}$, normal testes; $\mathrm{m}$, inhibited testes; i, indifferent gonads.

The maculatum members are of the semi-differentiated Ozark race except those of pairs 12 and 16, which are from Massachusetts and Tennessee.

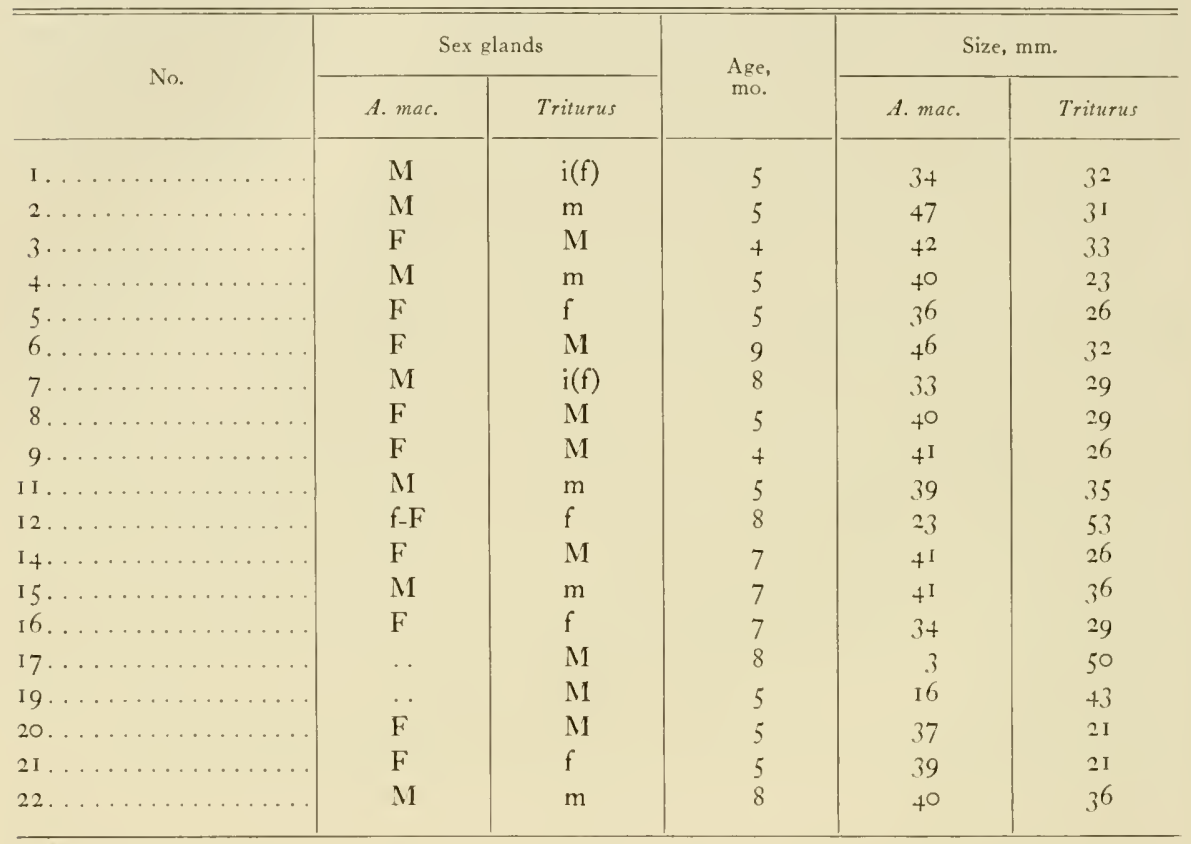

fersonianum controls are available. They indicate a slight hermaphrodite tendency, at least in some of the varieties.

Single newts and salamanders metamorphose at the age of from four to six months, and sex differentiation starts during the second month, when the larvae are from 22 to $30 \mathrm{~mm}$. long. Tiger salamanders progress somewhat faster than $A$. maculatum, $A$. jeffersonianum, and $T$. torosus, though time differences are not sufficiently large to enter as an important factor into the consideration of the experiments reported in this paper.

At the metamorphosis stage, the gonads are largest in $A$. Iigrinum and jeffersonianum, smallest in $T$. torosus (compare the cross sections shown in fig. $8 m, 9 T$, and $12 t$ ). Triturus torosus differs from the salamanders in being strictly gonochoristic. No trace of hermaphrodism has yet been found in any controls of this species $(\mathrm{McCurdy})$. On the other hand, in the salamanders, 
hermaphrodite features are observed with striking regularity (Gilbert"), most frequently in the Ozark race of $A$. marulatum, which in represented in serenteen of the nineteen maculatum-Triturus pairs (table 1).

Besides the single nomals, the homogenous parabiotic paits of the various species must also be considered as controls of the experimental heterogenous twins. In Triturus torosus, the sex glands of female-temale and male-male twins develop normally, like those of single controls. In female-male combinations, one observes a severe antagonism from which, at the beginning, both sexes suffer almost equally. It becomes evident even before morphological sex differentiation, and interferes with the formation of the indifferent gonad primordia. Later, the male rccovers normalcy while the female becomes nearly or completely sterile (Witschi and McCurdy preparation). In heterosexual pairs of salamanders, the antagonism is lese pronounced, and only ovarial development suffers appreciably. The Ozask race of $A$. muculatum is especially notable for a very low degree of interference between members of heterosexual pairs (Witschi, ${ }^{\star 6}$ the latter contains references to the important papers of Burns and Humphrey).

\section{EXPERIMENTAL SFRIES}

The Californian newt, Triturus torosus (family Salamandridae), was joined with each of the three mentioned species of the genus Ambystoma (family Ambystomidae). The three combinations will be designated by the symbols mac-T, tig-T and jef-T. Embryos of the tailbud stage were grafted together by the previously described routine technique (fig. 4). In early experiments. one embryo was joined with its right side to the left of another (figs. 5 and 7 ): later it was found to be of some advantage to use the right side in both embryos for grafting (figs. 4 and 6 ). At first, no unusual difficulties appear to exist. Healing and recovery from the operation are as easy as in homogenous twins. Later on, however, the salamander remains immotile for two or three weeks, due to a poisonous substance contained in the newt (Twitty"). This paralysis of the salamander during the critical period when feeding habits normatly become established, is probably the main reason for the excessive mortality in this experimental group. Of about eight hundred pairs of embryos which were successfully joined, only thirty-nine survived until the time of metamorphosis or longer. Anastomoses between large blood ressels become established very early (fig. 5), and even at the metamorphosis stage, blood is still freely exchanged. The largest pair was preserved at an age of thirteen and one-hall months; it had passed through metamorphosis when six months old. Since the change from the aquatic to the terrestrial life proved to be a great hataird, most pairs were preserved toward the end of the metamorphic period. As a rule. the newt is the one of the pair which accepts food first. Later, after recovery from the effect of the poison, the salamander also begins to eat and sometimes cren assumes the leading role both in swimming and catting. Like normal salitmanders and newts, most twin pairs metamorphose at an age of from fou to 
six months (room temperature); though poor feeders may be delayed, some as much as two or three months.

In only one of the thirty-nine pairs were both mates of approximately normal size at the time of metamorphosis (jef-T ${ }_{1}$; fig. 7). Quite obviously, there exists an imbalance in these twin systems, tending toward dwarfing or even elimination of one of the partners. Surprisingly enough, Triturus is the loser in this struggle when combined with $A$. maculatum (fig. 1), but the winner here in competition with the normally larger $A$. jeffersonianum and $A$. tigrinum (figs. 2, 3). In considering the measurements given in tables 1-3, one must take into account the fact that the normal size of tiger salamanders at the meta-
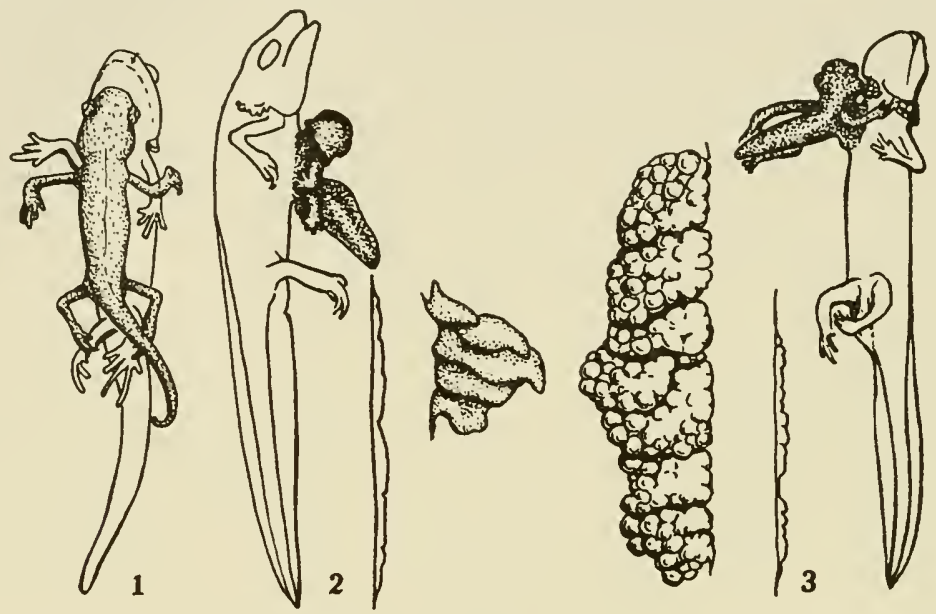

Fig. 1. Heterogenous parabiotic pair, Ambystoma maculatum $\times$ Triturus torosus, at the end of the metamorphosis stage. The salamander (white) is larger and the newt (stippled) smaller than normal size. Four-sevenths actual life-size.

Fig. 2. Heterogenous pair jef- $\mathbf{T}_{12}$, at a late metamorphosis stage. The salamander is of pigmy size, but its testes are of about normal dimensions (the folded organ shown at the right side). The newt is rather larger than normal, but its gonads are reduced to narrow vestiges (center figure). Twins are four-sevenths life-size, sex glands $\times 6$.

Fig. 3. Heterogenous pair tig- $T_{7}$, at a late metamorphosis stage. The dwarfed salamander (stippled) has ovaries of normal size and structure (left figure). The newt has undifferentiated gonads of rudimentary size (center figure). Twins are four-sevenths life-size, sex glands $\times 6$.

morphosis stage is from about 140 to $180 \mathrm{~mm}$. Even the case tig- $\mathbf{T}_{9}$ (table 3 ) is, therefore, no exception from our generalization, for the newt of $50 \mathrm{~mm}$. is above the average size of controls, while the salamander of $90 \mathrm{~mm}$. is undersized. The reasons for this peculiar growth phenomenon are not clear, but it is significant that the developmental rates of the sex glands do not follow the same trends as the soma.

The excessive mortality rate seems to influence the initial sex ratio but very slightly. Adding up all surviving salamanders, we find twenty-two females and fourteen males. The moderate prevalence of females is in line with previous similar observations on somewhat greater vitality of this sex in parabiotic 
TABLE 2

Parabiotic Twins, Series jef-T (Ambystoma jeffersonianum $\times$ Triturus torusus). $\mathrm{F}$, normal ovaries; $f$, inhibited ovaries; $\mathrm{M}$, normal testes; $\mathrm{m}$, inhibited testes; $i$, indiffcrent gonads.

The $A$. jeffersonianum was of the typical Iowa form in pair 1 and of a slightly dwarfed variety in all other pairs.

\begin{tabular}{|c|c|c|c|c|c|}
\hline \multirow{2}{*}{ No. } & \multicolumn{2}{|c|}{ Sex: glands } & \multirow{2}{*}{$\begin{array}{l}\text { Age, } \\
\text { mo. }\end{array}$} & \multicolumn{2}{|c|}{ Size, mm. } \\
\hline & 1. jef. & Triturus & & A. jef. & Triturus \\
\hline I. . & $\mathrm{F}$ & $M$ & 13 & $9^{8}$ & +1 \\
\hline.+ & $\mathrm{F}$ & $f$ & 9 & 15 & +5 \\
\hline 5 . & $M$ & $\mathrm{i}(\mathrm{m})$ & 9 & 12 & +8 \\
\hline $6 \ldots \ldots \ldots$ & $\mathrm{F}$ & $\mathrm{m}$ & 7 & 19 & to \\
\hline $7 \ldots \ldots \ldots$ & $\mathrm{F}$ & $\mathrm{i}(\mathrm{m})$ & 10 & II & 32 \\
\hline $8 \ldots \ldots \ldots$ & M & $i(f)$ & + & 24 & +4 \\
\hline $9 \ldots \ldots \ldots$ & M & $i(f)$ & 5 & $2 I$ & 40 \\
\hline 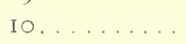 & $\mathrm{F}$ & $\mathrm{i}(\mathrm{m})$ & 3 & 17 & 35 \\
\hline I I $\ldots$. & & $\mathrm{F}$ & + & 6.5 & +5 \\
\hline I $2 \ldots$ & M & $i(f)$ & $\vdots$ & 18 & 55 \\
\hline $13 \ldots$ & $\mathrm{F}$ & $i(f)$ & 5 & 15 & 51 \\
\hline
\end{tabular}

TABLE 3

Parabiotic Twins, Series tig-T (Ambystoma tigrinum $\times$ Triturus torosus).

$\mathrm{F}$, normal ovaries; $f$, inhibited ovaries; $\mathrm{M}$, normal testes; $\mathrm{m}$, inhibited testes; $\mathrm{i}$, indifferent gonads.

The A. tigrinum member of pairs $\mathrm{I}-8$ is of the mexicanum variety, the one of pair 9 is of the typical Iowa form.

\begin{tabular}{|c|c|c|c|c|c|}
\hline \multirow{2}{*}{ No. } & \multicolumn{2}{|c|}{ Sex glands } & \multirow{2}{*}{$\begin{array}{l}\text { Are. } \\
\text { mo. }\end{array}$} & \multicolumn{2}{|c|}{ Size, mm. } \\
\hline & A.tiv. & Triturus & & t. $i$ is. & Triturus \\
\hline I . & $\mathrm{F}$ & $i(f)$ & 7 & 36 & 30 \\
\hline 2. & $\mathrm{~F}$ & $j(m)$ & 7 & 25 & 19 \\
\hline 3. & $M$ & $\mathrm{i}(\mathrm{m})$ & 9 & 8 & +9 \\
\hline+ & $\mathrm{F}$ & i & 8 & $2 \mathrm{I}$ & 16 \\
\hline 5. & $\mathrm{M}$ & $i(f)$ & 12 & $2+$ & 5.3 \\
\hline 6. & $\mathrm{~F}$ & $\mathrm{i}(\mathrm{m})$ & 9 & 19 & 22 \\
\hline 7. & $\mathrm{~F}$ & $i(m)$ & 16 & 15 & 50 \\
\hline 8. & $\mathrm{~F}$ & $i(f)$ & 16 & .30 & so \\
\hline $9 \ldots$ & $M$ & $i(f)$ & 6 & 90 & 50 \\
\hline
\end{tabular}

pairs (Witschi ${ }^{5}$ ). The sex of Triturus cannot always be ascertained, though the definite identification of eight females and fifteen males proves that also in the newt there occurs no pronounced selective elimination.

If, on the basis of the observations on controls, one might be tempted to predict a leading role for the newt members, the actual results prove markedly different from such expectations. As a matter of fact, a survey of the entire material which is contained in condensed form in tables 1 to 3 shows 
that neither ovaries nor testes of the salananders become much modified, while the gonads of the newts suffer severely in all but one of the twin combinations.

The maculatum-Triturus series (table 1) is of particular interest because here the antagonism is moderate enough to permit identification of the genetic sex of the newt in every case. In combinations of female salamanders with

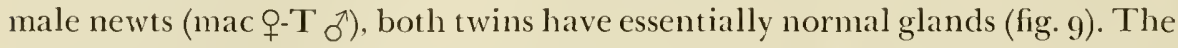
newt testes are not smaller than in single controls of corresponding developmental age. The salamander ovaries are entirely normal in five of the six cases of this group (see table 1). They contain numerous large ovocytes and spacious ovarial sacs. In the sixth pair ( $\left.\operatorname{mac}_{-} \mathrm{T}_{6}\right)$, the left ovary is likewise normal, while the right one has no open ovarial sacs. Instead, its medullary cords are compact (fig. $10 m_{1}$ ), and in a few places, they contain even a few primary gonia (fig. $10 m_{2}$ ). However, at the same time, this ovary contains large and healthy ovocytes, so that one hesitates to ascribe the deviation to the proximity of the newt testes. Yet it may be significant that we deal here with the oldest pair of this series (table 1). A delayed suppressive action of the Triturus testes is, therefore, not excluded. In fact, it gains support from another case, the first of the jeffersonianum-Triturus twins (jef- $\mathrm{T}_{1}$ ). This differs markedly from the other pairs of the second series (table 2) but resembles closely the mac-T pairs. Probably the salamander in this instance belongs to a racial strain of marked hermaphrodite tendency, while all others are of more gonochoristic type. At any rate, in this jef- $T_{1}$ pair we find also newt testes of normal size and salamander ovaries with some effects of inhibition (fig. 11). As in mac- $T_{n}$, the ovary which is located nearer the newt testes shows more degenerative changes in the cortex and has more medullary gonia than the other one. These two cases, each the oldest pair in its series, present the only, and certainly very meager, indication of a possible inductive influence coming from the newt and affecting the salamander sex glands.

In female-female pairs mac $9-\mathrm{T}$ Q), the ovaries of the newts are small, retarded, and of reduced fertility. In male-male twins (mac $\delta^{\lambda-T} \delta^{\top}$ ), the Trimrus testes are considerably inhibited and, therefore, much smaller than in the mac - $T$ o combination. Lastly, in the mac $\delta^{-T} q$ combinations, the salamander males completely suppress ovarial development in newt females (fig. 8). The gonads of the latter are nearly sterile primitive folds in which the female character is barely recognizable. In short, of the reciprocal heterosexual combinations, one (maco-T $\sigma^{\top}$ ) shows the minimal, the other (mac ${ }^{7}-$ $\mathrm{T} q)$ the maximal degree of interference and inhibition. In the unisexual combinations, the gonads of the Triturus member are partially inhibited.

In two instances (nos. 17 and 19 ), the maculatum members, which had been partly resorbed, were without gonads; their Triturus co-twins were males with normal testes.

The jeffersonianum-Tritumus and tigrinnm-Tritums series are summarized in tables 2 and 3 . The sex glands of the newt are much more severely damaged 
in the combinations with jeffersonianmm or tigrimum salamanders. As a rule, they consist only of long, narrow, and threadlike lolds (figs. 2 and 3) which, on sectioning, prove to contain but few primordial gonia (lig. 12T) and to be sexually undifferentiated. In the tables, the symbol $i$ (indifferent) is followed by $f$ or $m$ if a majority of the germ cells are found in either the cortical (as in fig. ST), or the medullary (fig. 12T) position. This relationship is not sufficient, howerer, to establish with certainty the basic sex; for in normal newts, at the indifferent stage, the gonia are also scattered throughout the gonad primordia.

In jef- $T_{4}$, the newt glands are definitely on the way to ovarial differentiation, a few germ cells having become translormed into synaptic ovocytes. Similarly, in jef- $T_{i,}$, a number of gonia are clearly located in nedullary cords and some segments of the glands have a distinctly testicular appearance. In one pair, the newt gonads are nearly nomally developed. This is the previously described case of jef- $T_{1}$ (figs. 7,11 ), in which the salamander has lairly large ovaries and the newt good-sized testes. These three cases form an important link between the first and the two other series, for in the seven remaining jef- $T$ and in all tig- $T$ pairs the newt gonads are reduced to diminutive primordial rudiments, while the salamander gonads are of the impressive size (figs. 2, 3 and 12), which is characteristic lor normal specimens of these two species.

\section{Discussion}

The present series of heterogenous twins dillers markedly from the many previously described groups of homogenous twins or combinations of various races or species of salamander, especially in the following two leatures.

1. Triturus does not interfere with normal gonad development of $\mathrm{Am}$ bystoma co-twins, in any of the four possible sex combinations.

2. Ambystomas of the three species inhibit the development of co-twin gonads not only if the newt is of opposite sex, but also if it is of same sex.

The fust result is very surprising in view of earlier work which had given prool that the newt is a distinctly gonochoristic species and that its gonads emit morphogenic substances of the corticin and medullarin type (Witschi and McCurd $y^{3}$ ). As stated before, in heterosexual pairs of newts (T $0-T_{0}^{7}$ ), the severe mutual antagonism becomes manifest even before morphological sex differentiation, that is, at so early a stage, that the failure of the same species to produce effects when in parabiosis with salamanders camnot be attributed to a time lactor. The lack of eflectiveness of the newt substances is drastically demonstrated by the five maculatum -Triturus ${ }^{\lambda}$ pairs (fig. 9). in which large testes of Triturus cocxist with large and absolutely nomal Ambystoma ovaries. In Triturus 0 -Triturus $\sigma^{\lambda}$ pairs, testes of equal size and normalcy reduce the female gonads to near sterile, and often cntirely undifferentiated, rudiments. It must, therefore, be concluded that the inductive sex substances of Triturus torosus are of a specific nature which prevents then from becoming effective in the salamander co-twins. Since blood is exchanged 
through large anastomoses (fig. 5), it seems improbable that the substances become removed before they reach the gonads of the co-twin. It appears more likely that the salamander gonad is not an adequate receptor and therefore remains unresponsive to the Triturus substances.

The fact that in two of the oldest pairs (mac- $T_{6}$ and jef- $T_{1}$ ) the ovaries of the salamander show some deficiencies may possibly indicate a change of conditions governing sex interference on approach of the stage of maturity. However, the observed effects are too slight and the material too meager to permit a definite statement in this respect. Attempts to solve this particular problem by transplanting gonads between larvae of salamanders and newts were unsuccessful, because the implants failed to develop properly.

The second result is more complex in its aspects and implications. The fact that the newt gonads in most jeffersonianum and in all tigrinum combinations, even the unisexual ones, are extremely reduced could seem to indicate that one deals with a general effect of parabiosis between species of different taxonomic families, rather than with specific sex antagonism. It is easy to show that such an assumption would be untenable. For one thing, in the maculatum combinations, where the antagonism is more moderate, we have a gradation of inhibition types, which definitely depends on sex combinations. Inhibition becomes more and more severe in the following sequence: $(a)$

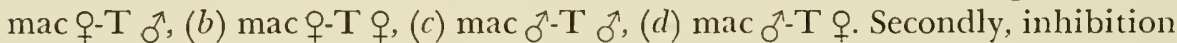
effects happen to be more pronounced in newts combined with salamanders of large gonad and small body size (jeff. and tig.) than in those joined with salamanders of large bodies and relatively small gonads (mac.). Hence, the extent of the reaction in the newts is not correlated with body size of the salamanders. Thirdly, in three pairs in which the salamander member was without gonads (due to early destruction of the gonad-forming body region), the newts had normal and full-sized gonads. The pair jef- $T_{11}$ is the most convincing case in this regard. Its Triturus member is the only female newt with entirely normal ovaries in the whole set of thirty-nine twins. It is significant that the jeffersonianum member is deficient mainly in the lower body region while its upper parts, the head, and especially also the hypophysis gland, are as well developed as in most other jef- $T$ pairs. The importance of this case gains relief by comparison with pairs like jef- $T_{5}$ where the upper body region of the salamander is deficient, the hypophysis absent, and the testes well developed; in this pair the Triturus gonads are as rudimentary as in all other combinations with male salamanders. The conclusion that the salamander gonads alone are responsible for the inhibitions is unavoidable. The interesting suggestion made by $\mathrm{C}$. $\mathrm{R}$. Noore, ${ }^{10}$ in connection with his work on the opossum, namely that substances issuing from the entire somatic complex rather than from the gonads only may be the humoral agents responsible for free-martin effects, is therefore ruled out as far as the present experiments and materials are concerned. Likewise, the mentioned observations show that the hypophysis gland is not in any specific way involved. In fact, some other 
unpublished experiments prove that even loss of the hypophyses by both twins does not change the larval sex antagonism.

Having therefore made sure that we deal actually with gonadal antagonism, it becomes immediately evident that not only do the sex glands of Triturus respond to the gonadal substances of the Ambystomas, but that ther serve as extremely sensitive indicators. This is in keeping with the previously established rule that heterosexual parabiosis produces more extensive reartions in the gonochoristic species and races than in those with hermaphrodite tendencies (Witschi ${ }^{4}$. Sensitivity grows from A. maculatum to A. jeffersonianum, $A$. tigrinum, and $T$. torosus. It fits well with this rule that maculatum males and females reduce the gonads of Triturus more than those of twins of their own kind; or that the female of A. tigrinum, which manifests a dominance over male salamanders only under special conditions of time and size (Witschi $\mathrm{i}^{5}$ ), is able to completely suppress testicular differentiation in Triturus males.

Yet there still remains the problem of unisexual antagonism which is apparent in the suppression of Triturus ovaries by Ambystoma ovaries and of Tritums testes by Ambystoma testes.* Of course, it is quite probable that every larval gonad releases simultaneously corticin as well as medullarin. albeit in different proportions. At least for all forms which, like the salamanders, are strongly inclined toward hermaphrodism, it is safe to make this surmise. All differentiating gonads consist morphologically of double primordia: cortex and medulla. Sex differentiation consists, in morphological terms, in the further development of one and the relative reduction and suppression of the other. It can, therefore, be taken for granted that in female pairs a small amount of medullarin, released by the Ambystoma ovary, is retarding ovary formation in Triturus, and likewise in male pairs, that corticin given off by the salamander testes holds back the development of male gonads in a newt co-twin. In view of the previously established high responsiveness of Triturus gonads, this new aspect of the ambisexual nature of vertebrate sex glands certainly must be given consideration as a factor in the interpretation of unisexual gonadal antagonism. Yet it cannot in itself serve as a complete and satisfactory explanation, since there still remains the odd fact that in the maculatum-Triturus combinations, the Triturus testes are more inhibited by salamander testes than by salamander ovaries (table 1 ). It certainly seems unlikely that male salamanders produce more corticin than females of the same species. Therefore, as in an earlier discussion of conditions observed in heterogenous frog twins (Witschi ${ }^{2}$ ), we feel again impelled to assume that the growth of certain organs, and especially the sex glands, is controlled by special growth substances which are available only in limited quantity. They are possibly responsible for compensatory hypertrophy after partial castration, as well as for the often-experienced difficulty of establishing suc-

* According to a recent paper by Humpher ${ }^{11}$ imilar conditions occur in A. maculalum hosts carring large gonads derived from implanted 1. tigrinum preprimordia. 
cessful grafts of gonads in normal animals as compared with the relative ease of getting implants in castrates. In many heterogenous parabiotic twins, the ovaries (or testes) of one twin seem to be able to monopolize the whole supply, thus depriving the co-twin more or less completely of this substance and,

TABLE 4

Type of Reactions Produced in the Sex Glands of Male and Female Newts (Triturus torosus) ву Parabiotic Twins

$\mathrm{F}, \mathrm{M}$, normal sex glands (no reaction); $\mathrm{f}, \mathrm{m}$, inhibited yet clearly differentiated sex glands (moderate reaction); i, rudimentary and sexually undifferentiated glands (maximal reaction).

The sex types of the producers of inductive substances are indicated by ss (distinct hermaphrodite tendency), $s$ (slight hermaphrodite tendency), d (prevailingly gonochoristic) and dd (fully gonochoristic).

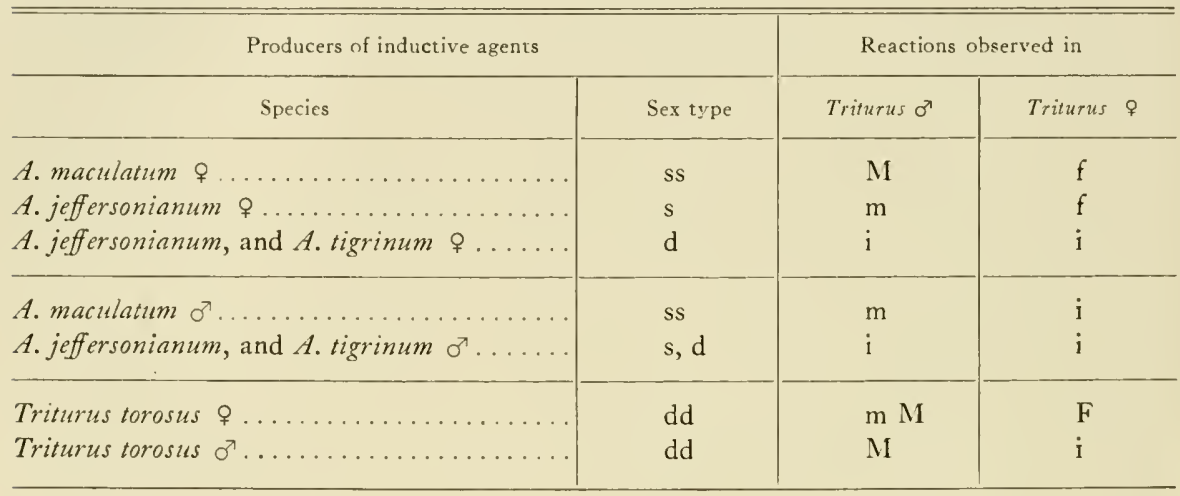

therefore, of the possibility of growing normal gonads. These hypothetical substances are not hypophysial hormones, since sex glands of larval newts grow normally even in the complete absence of the hypophysis gland (Woronzowa and Blacher, ${ }^{12}$ Witsch $\left.\mathrm{i}^{13}\right)$. Nor can they be sex hormones, for the characteristic reactions which these produce in salamanders $\left(\right.$ Foote $^{14}$ ) are entirely different from anything observed in the present experimental series (Witschis ${ }^{15}$. Since they serve to control the size and the total amount of gonadal tissue in single individuals, as well as in conjoined twins, they may be designated, provisionally, as ovarial and testicular growth substances.

The reactions produced in Triturus testes and ovaries are represented in a summary way in table 4 . Their correlation with sex $\left(q, \delta^{\top}\right)$ and sex type (ss, $\mathrm{s}$, d, dd) of the parabiotic twins is quite obvious. Comparing the reactions in heterogenous pairs with those obtained in homogenous Triturus twins (two bottom columns), it becomes evident that in the latter the effects are produced only by a mutual cortex-medulla antagonism; whereas in the former the mechanism is complicated by the following factors:

1. Salamanders do not respond to inductive agents of the newt and, therefore, continue with the unimpeded output of substances which interfere with gonadal development in the newt. 
2. Both sexes of the salamander produce corticin as well als medullarinthough at different ratios-and suppress thereby ovarial as well at testicular development of newt co-twins.

3. In order to understand the reactions in unisexual pairs, one is loreet to assume that gonad size is limited by special orarial and testicular growh substances. These substances seem to be utilized and used up more quickly by the salamanders than by the newts.

The unequal growth of the gonads in heterogenous twins is not a unique phenomenon. In the above-mentioned frog twins $(R$. syluaticn $\times R$. temporaria), it was found that the spleen of the syluatica member is always greatly enlarged, while in the temporaria it is reduced to a mere vestige. In the present experimental series, we find that in general body growth, Ambystoma maculatum surpasses Tritums, while the other two salamander species lag behind their newt co-twins, especially during the late larval stages. Of great interest is the development of the kidneys. In the mac-T combinations, the kidneys are somewhat larger and better differentiated in the maculatmm than the Tritums nember. In all jef-T and tig-T pairs, however, the Tritum kidneys alone are normally developed, while the salamander kidncys are inhibited, of small size and histologically incompletely differentiated. There is no correlation between size of the kidney and size of the sex glands. Kidney development and body size rum somewhat parallel, though in jel- $T_{1}$. the salamander is of normal size while its kidneys are greatly inhibited.

\section{SUMMARY}

1. Of about eight hundred pairs of salamander-newt twins which were united in parabiosis at the tailbud stage, only thirty-nine lived to the metamorphosis or later stages.

2. In heterogenous pairs, growth of the twins is usually uneven; so that one nember is of normal size, or even larger, while the other member is drarfed.

3. Similarly, the kidneys of the two species develop differently.

4. It is suggested that the growth of various organs is controlled by specific growth substances, which are produced in limited amounts. In heterogenous parabiosis, one twin may use up more than its share of such substances.

5 . With respect to sex, the three species of salamanders used in this experiment are of markedly different type. Ambystoma maculatum shows distinct hermaphrodite tendencies (ss). A. jeffersonimum is of slightly hermaphrodite (s) or prevailingly gonochoristic (d) type. A. tigrinum is prevailingly gonochoristic (d). The newt. Triturns torosus, with which these salamanders were combined, is of distinctly gonochoristic type (dd).

6. Sex development in salamanders is not modified by parabiosis with newts. It is concluded that the sex-dillerentiating substances, corticin and nnedullarin, have a certain taxonomic specificity and that salanander gonats do not respond to the substances emitted by the newts. 
7. Sex development in the newt is greatly affected by parabiosis with salamanders. The detailed analysis leads to the conclusions:

a. That botl sexes of salamanders release corticin as well as medullarin, though in different proportions and

$b$. That the growth of ovaries and testes is controlled by gonadal growth substances.

\section{REFERENCES}

1. Witschi, E.: J1. Fxper. Kool. 5s:113. 1931.

2. Witschi, E.: in sex and Internal fecretions, ed. bs L. Allen (1st ed.; Baltimore: 1932), 160.

3. Witschi, E., and McCurdy, H. M.: P'roc. Soc. Exper. Biol. \& Med. 26:655, 1929.

4. Witschi, E.: Anat. Recrel. 66:483, 1936.

5. Witschi, E.: Jl. Exper. Zool. 75:313, 1937.

6. Witschi, E.: in Sex and Internal Secretions, ed. by E. Allen (2d ed.; Baltimore: 1939), 145.

7. McCurdy, H. M. M.: Amer. Jl. Anat. 47:367, 1931.

8. Gilbert, W. M.: Proc. Iowa Acad. Scis. 47:307, $194 \%$.

9. Twitty, V. C.: Jl. Exper. Zool. $76: 67,1937$.

10. Moore, C. R.: Physiol. Zoöl. 1.1:1, 1941.

11. Humphrey, R. R.: Amer. Jl. Anat. 70:345, 1942.

12. Woronzowa, M. A., and Blacher, L. J.: Wilhelm Roux' Arch. f. Entwcklgsmech. d. Organsmn. 121:327, 1930.

13. Witschi, E.: Proc. Soc. Exper. Biol. \& Med. 27:763, 1930.

14. Foote, C. L.: Jl. Exper. Zool. 86:29 1, 1911.

15. Witschi, E.: Cold Spring Harbor Sympsa. Quantit. Biol, ro: $145,1942$. 
EXPLANATION OF PLATES 
PLATE 1

Figs. 4-7. Heterogenous parabiotic pairs.

Fig. 4. Ambystoma maculatum $\times$ white axolotl, one day after grafting operation; showing the stage at which union is established. $\times 8$.

Fig. 5. Two pairs (Ambystoma maculatum $\times$ Triturus torosus) showing the reduction of the yolk sacs and formation of anastomoses between the abdominal veins. The (longer) salamanders are paralyzed. $\times 5$.

Fig. 6. Another pair of the same combination at the time when feeding becomes established. The salamander (longer member) is coming out of the paralyzed condition. $\times 4$.

7. Ambystoma jeffersonianum $\times$ Triturus torosus, shortly after metamorphosis $(6$ months old). $\times 1$. 

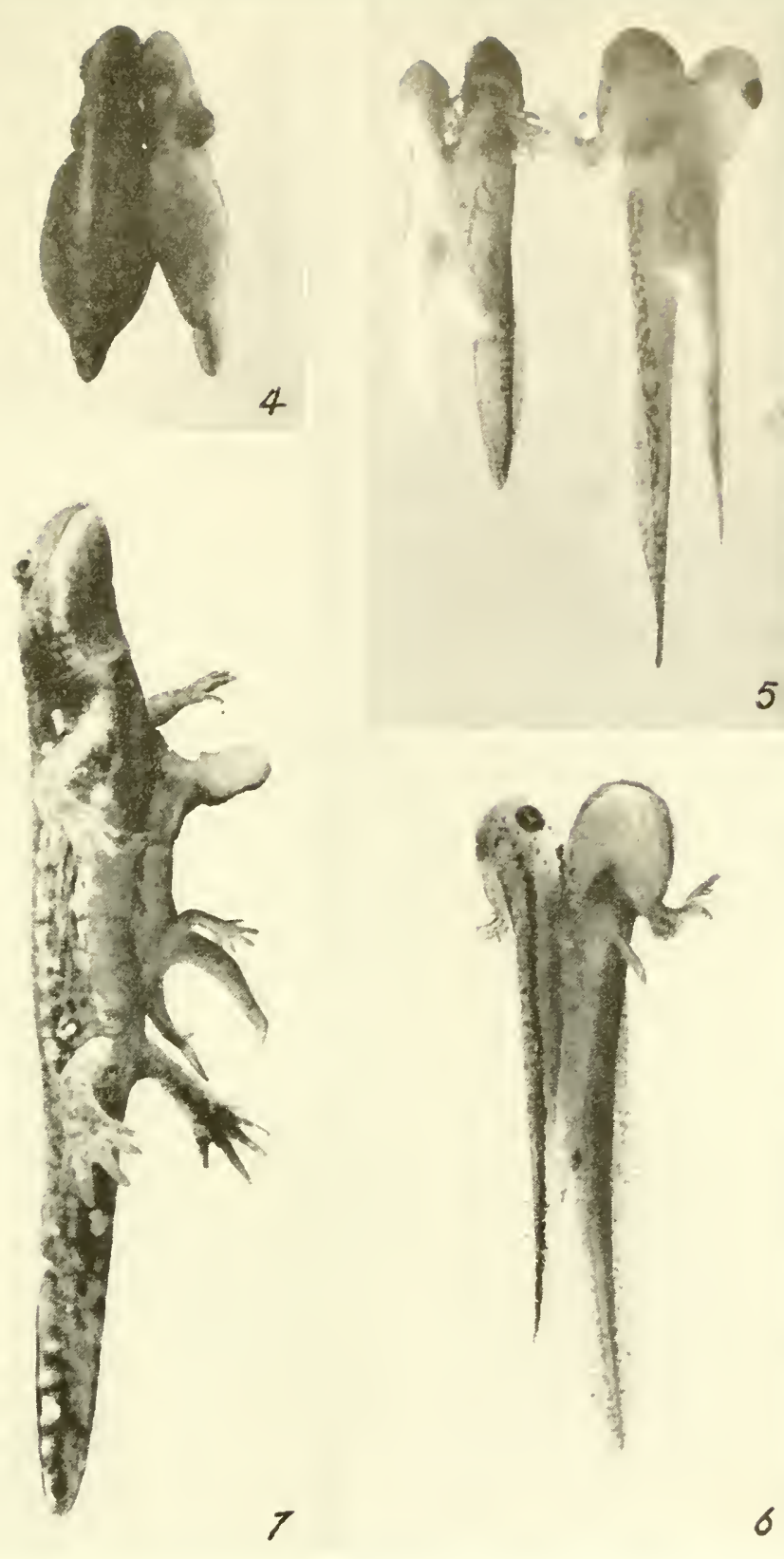

6

[671] 
PLATE 2

Figs. 8-10. Sex glands of three pairs of the combination Ambystoma maculatum $\times$ Triturus torosus. m, gonads of $A$. maculatum; T, Triturus gonads. Att $\times 188$. Fig. 8. Case mac- $T_{1}$ : normal testis of salamander, rudimentary gonad of newt. Fig. 9. Case mac- $T_{9}$ : normal ovary of salamander, normal test is of newt.

Fig. 10. Case mac- $T_{6}$ : Slightly reduced ovary of salamander, normal testis of newt. 


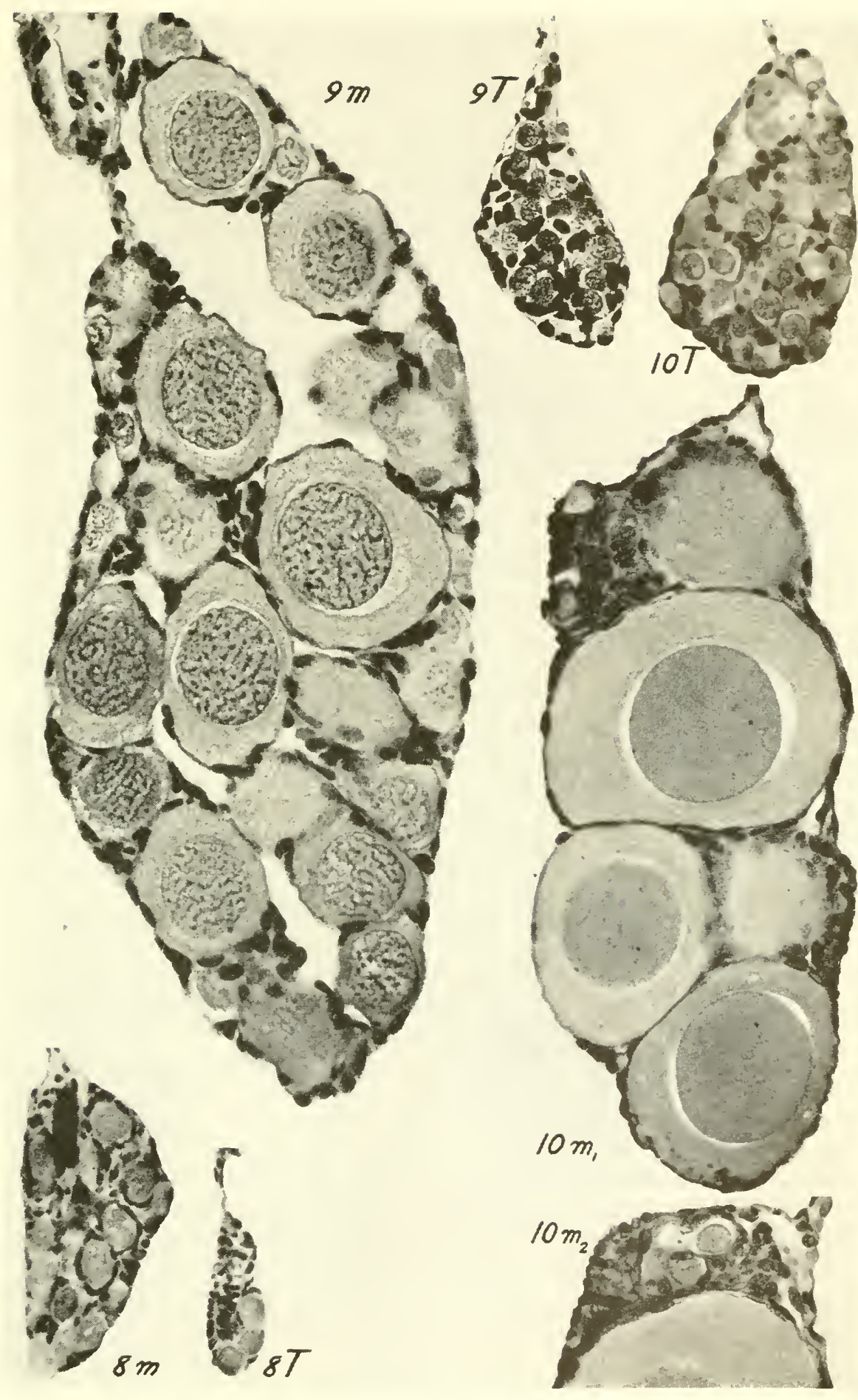

Plate 2 


\section{PLATE 3}

Fig. 11. Ambystoma jeffersonianum $q \times$ Triturus torosus of (jef- $\left.\mathrm{T}_{1}\right)$; cross section through gonads at the age of 13 months. $\times 94$.

Fig. 12. Ambystoma tigrinum $\sigma^{2} \times$ Tritums torosus, undifferentiated (tig- $\mathrm{T}_{3}$ ); cross section through gonads. $\times 188$. 


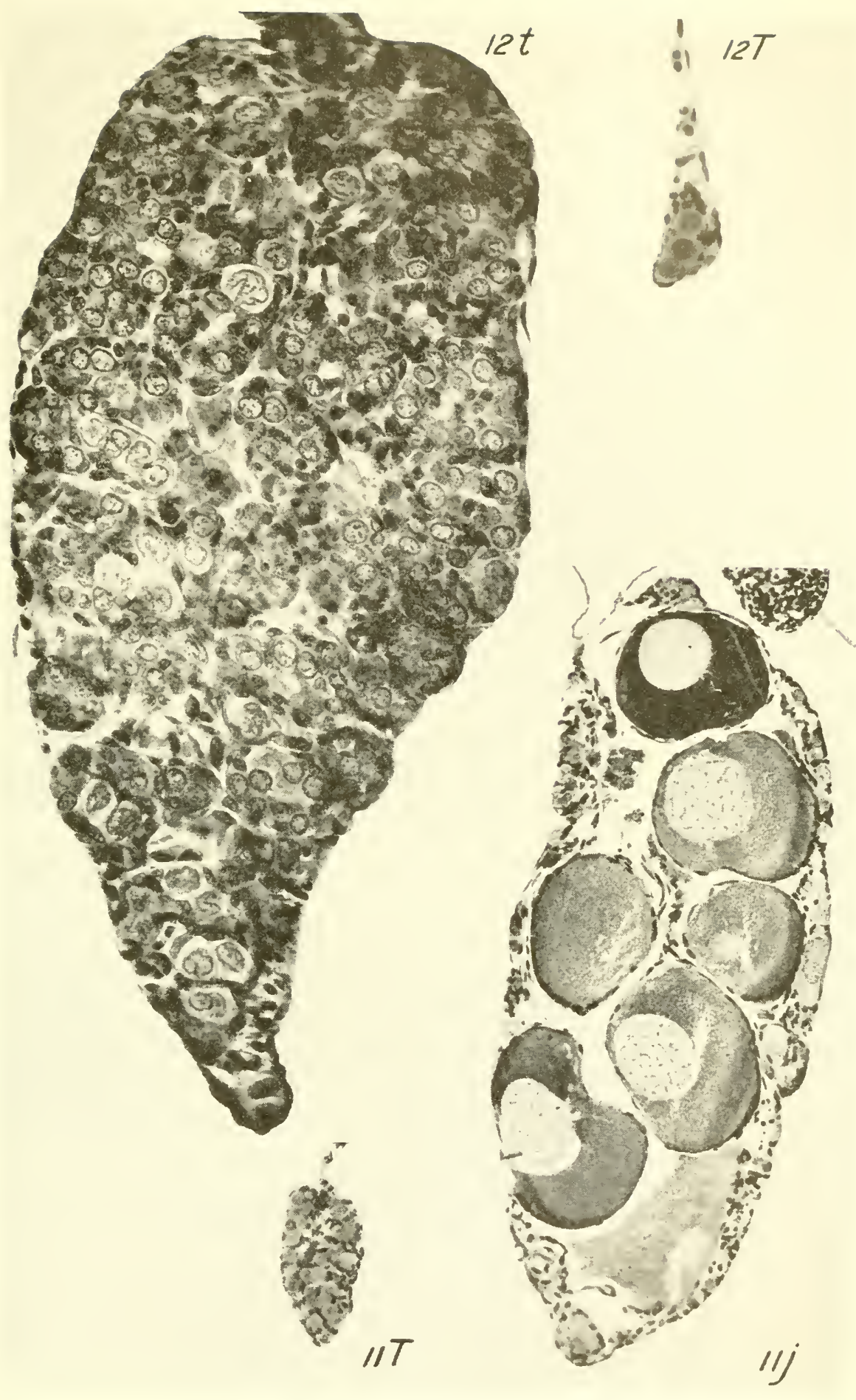

Plate 3 



\section{OVUM, GYGLE, AND MENSTRUATION}

By

BERNHARD ZONDEK

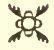

From the

GYNECOLOGICAL-OBSTETRICAL DEPARTMENT

OF THE ROTHSCHILD-HADASSAH UNIVERSITY HOSPITAL, AND THE HORMONE RESEARCH LABORATORY OF THE HEBREW UNIVERSITY,

JERUSALEM, PALESTINE 



\section{OVUM, GYCLE, AND MENSTRUATION}

$\mathrm{O}$ NE I UNDAMENTAL difference between the sexual mechanism in the male and female organisms is of particular importance. While in the male its function is continuous, it is subject to cyclic variation in the fentale. What are the factors governing these cyclic phenomena? For a long time the theory of the prime importance of the orum ("Primat der Eizelle"), adranced particularly by $R$. Meyer on the grounds of anatomical studies, was gencrally accepted. This theory implied that the ovary is under the control of the orum and that the entire generative process receives its stimulus from it; that as soon as fertilization takes place the cycle is discontinued; if, howerer, the orum dies without fertilization, the now useless, progestationally dereloped mucous membrane breaks down and its discharge from the uterus is accompanied by bleeding (=menstruation).

This theory, in our opinion, was rather unsatisfactory for the following reasons: (1) It is based on the fact that the death of the ovim, a destructive process, is the event initiating the onset of the new cycle, the menstrual cycle thus being considered a pathological process which takes place only if the orum does not fulfill its physiological purpose, fertilization. (2) It is difficult to understand how the orum, dying on its way through one of the tubes, should be able to set in motion the generative mechanism when one considers that it has no contact with the maternal circulation.

After it had been discovered ${ }^{1-4}$ that a gonadotrophic substance is elaborated in the anterior pituitary lobe and that it is possible to reproduce, experimentally, the entire generative process with this factor, the role which the orum plays within this complex was again open to discussion. It is with great pleasure that I am giving an accomnt of these investigations in the Anniversary Volume published in honor of Herbert M. Evans to whom we owe most important progress in endocrinology, including the problems dealt with in the following lines.

When attempting to analyze the relationship between the ovum and the hormones involved in the cyclic phenomena, the experimental procedure was to create an opportunity of studying the functions of the orum independently of hormonal factors and vice versa.

1. What happens if the function of the ovmm is eliminated? Orular function can be destroyed by Roentgen rays. Investigations on this subject (carried out by Parkes ${ }^{5}$ and at the same time in our laboratory by $r$. Schubert ${ }^{6}$ ) yielded the following results: Eren the application of doses ten times as high as the castration dose (up to $500 \mathrm{r}$.) does not interfere with the raginal estrous cycle in the sexually mature mouse, in fact the cycle may continue for weeks or even months. If such animals are sacrificed in mid-estrus, serial sections show very marked changes in the ovary, but-and this is the decisive factor-not one single follicle with a large follicular carity. One fincls only remnants of de-

$$
[679]
$$


generated ova, but none appear to have survived. The cycle as well as the estrous development of the mucous membrane, therefore, takes place in the absence of functioning ova. Similar results were obtained by giving an irritation dose to the infantile ovary (ref. 7, p. 6o, 317). Small Roentgen doses $(10-25$ r.) are able to stimulate follicular growth so that the follicle may be developed to the size of a Graafian follicle just before rupturing. No estrogenic hormone is, however, elaborated in these follicles in which growth but no function has been induced. Morphologically, the ova present in these follicles are not to be distinguished from those of normal mature animals. Thus, although the follicle is large and contains ripening ova, no estrogenic hormone is produced there and the ripening follicle with its ovum is obviously unable to initiate the production of hormone.

2. Does estrogenic hormone stimulate follicular maturation? This question has to be answered in the negative. Estrus can be produced in infantile animals with estrogenic hormone, but no follicular maturation takes place. The gonadotrophic hormone-as is well known-initiates both the production of estrogenic hormone and the ripening process in the follicle. The production of estrogenic hormone is, however, already accomplished (in the twenty-seventh hour) before the growth and maturation of the follicle has even started., $8,0,10$

3. Does the ovum stimulate corpus luteum formation? Does it produce substances likely to initiate the second generative phase? That this is not the case is clearly shown by the following experiments: (a) In hibernating animals ovarian function slumbers too. It was, however, possible to achieve follicular rupture in hibernating bats in winter (ref. 11 ; also ref. 7, p. 267); in one case pregnancy was obtained in December. (In the bat, as is generally known, copulation takes place previous to hibernation, the living spermatozoa remaining in the uterus all the time.) If large doses of prolan are injected into such animals, the formation of several corpora lutea is thus initiated (4-6 in one ovary). (This never occurs under physiological conditions since the bat usually has one young, at the most two.) Large doses may give rise to the formation of corpora lutea atretica in which the ovum is completely pushed aside and, seemingly crushed. No signs of ripening are recognizable in these ova. Notwithstanding the death of these ova, normally functioning corpora lutea appear, as is seen from the effect on the uterine mucous membrane. The ovum cannot, therefore, be held responsible for corpus luteum formation. $(b)$ It could be imagined that the ovum, although dead at this stage, might previously liave produced a hormone active in bringing about corpus luteum formation. That neither is the case could be demonstrated by Westmann's and later by our experiments ${ }^{12,13}$ conducted on the follicles of rabbits from which the ova had been removed. In our experiments the procedure was to extirpate one entire ovary in sexually mature rabbits, while in the other the ovarian tissue was cut down to such an extent that only a small portion remained, containing just a single follicle on the point of rupturing. This follicle was then punctured and the orum aspirated. By microscopical examination of 
the aspirated fluid it was possible to make sure that the ovum had actually been entirely removed. After intravenous injection of prolan this follicle, which contained no ovum, developed into a typical corpus luteun. When, after aspiration of the ovum, the topmost portion of the follicle was also cut ofl with scissors, even this torso grew into a corpus luteum. These expcriments give very clear evidence that a follicle which certainly contains no orum may be transformed into a corpus luteum in precisely the sanle manner as is normally the case. From the foregoing evidence the ovum may thus be assumed to have no importance for corpus luteum formation.

4. What happens if the gonadotrophic function is inhibited? By giving thallium ${ }^{14}$ to sexually mature mice the cycle is interrupted. In contradistinction to functional interruption, the ovary shows in this case no morphological changes. Large follicles are to be found containing the cumulus oöphorus and ova in mitosis. Thallium, no doubt, effects partial inhibition of the gonadotrophic secretion of the anterior pituitary lobe so that, although sufficient amounts of hormone are elaborated to maintain the intactness of the ripening follicle anatomically, the hormone production does not suffice to initiate the elaboration of estrogenic hormone in the theca cells. If now gonadotrophic hormone is injected into the thallium-treated animals they instantly go into estrus. It is, therefore, apparent that, although the cycle has been discontinued and the production of gonadotrophic hormone to some extent inhibited, the ovary nevertheless contains ripe follicles with fully developed ova.

That even the complete elimination of hypophysial function has no bearing on the ripening of the ovum is shown by experiments on hypophysectomized animals. H. M. Evans and O. Swezy ${ }^{15}$ found, in hypophysectomized but sexually mature rats, the new formation of germinative cells, increased oögenesis, and, in the atresic follicles, the nuclei in the stage of mitotic division with pola bodies. We have examined the ovaries of infantile rats in which the hypophysis had been removed on the twenty-seventh day of their life and which had then been sacrificed twenty days later. In these ovaries, too, ripening ova with mitoses were found to be present. There can, therefore, be no doubt that the process of maturation may take place in ova which, for a considerable length of time, have not been under the influence of the gonadotrophic hormone of the anterior pituitary.

Summarizing, it may thus be said that the orum does not stimulate the production of estrogenic hormone, that estrogenic hormone has no influence whatsoever on follicular maturation or on the growth of the orum itself. The ovum has no influence on corpus luteum formation or the production of its hormone. Neither is there a dependency of the ovum on the anterior pituitary and its gonadotrophic hormones. It thus appears that the ovum leads its own life, its development does not depend in any way on either the follicle with its hormone or the anterior pituitary lobe. The ovary is the host of the ortum but at the same time its servant, since with its hormones it assists in preparing the uterine mucous membrane anatomically and functionally for the recep- 
tion of the ovum after fertilization. Nevertheless, the anterior pituitary is the superior factor in this process. Without the anterior lobe, without gonadotrophic hormone, no follicular rupture would be possible, and the ovum could not migrate through the tube to fulfill its natural function, fertilization. The ovum itself, therefore, is of no significance for the process of hormonal production in the ovary nor for the growth and breakdown of the uterine mucosa. It has no bearing on cyclic changes.

\section{Segmentation of Ovun}

Although this problem is not directly related to the menstrual cycle, we are taking the opportunity of referring briefly to our experiments concerning the segmentation of the ovum. The subject usually employed for the study of this phenomenon is the pregnant animal, since in its ovary follicular atresia is particularly marked, and segmented ova are preponderantly met with in atresic follicles. Spuler ${ }^{16}$ holds the view that, in the degenerated granulosa cells, substances may be formed which induce segmentation in the ovum. L. Loeb ${ }^{17,18}$ holds changed chemical and mechanical conditions in the atresic follicle responsible for this event, while Häggström ${ }^{10}$ takes changed osmotic pressure or difficult supply of nutritional factors to the follicle into consideration. Is segmentation actually nothing but the consequence of follicular atresia? In order to study this question (ref. 7, p. 329) it was necessary to produce artificial follicular maturation in the rat by means of prolan injections, in order to find out whether in these ripening follicles segmentation might also be discovered. A total of eighteen infantile rats were treated with prolan, and serial sections of their ovaries were examined microscopically. In thirteen of the animals segmented ova were in fact encountered. It seems to me noteworthy that these segmented ova were present not only in atresic follicles but also in the ripening ones as well as in those that had already reached the stage of vascularization and, in part, luteinization. In one rat which had been treated with prolan a segmented ovum was found on its way through one of the tubes after follicular rupture (pl. 1, fig. 1). This tubal ovum consisted of five segments of different size containing altogether ten chromatic bodies. Some granulosa cells were still adhering to the ovum. It may thus be assumed that segmentation is not a consequence of atresia.

Is the segmentation of the ovum to be considered a regressive process? We do not think that this is the case. Two separate processes have to be taken into account: (a) Since the ovum shows signs of maturation, and, moreover, segments of equal size with perfect nuclei and mitoses are present, a mitotic division of the ovum must be assumed; $(b)$ even more frequently than this division another picture presents itself which, in our opinion, is due to the chromosomes being drawn apart and secondarily enveloped in plasma so that segments with irregularly distributed chromatic bodies are formed.

That segmentation of the ovum does not depend on the anterior hypophysis is shown by the fact that a similar occurrence is also met with in infantile 
hypophysectomized rats. Plate 1 , figure 2 , shows an ovum consisting of five segments in a follicle of a rat (forty-seven days old, hypophysectomized twenty days earlier). Cell no. 1 contains a nucleus, cell no. 2 a nuclear spindle; in cell no. 3 only a suggestion of the small nucleus is recognizable in the photograph; cell no. 4 contains no nucleus; cell no. 5 shows cytolysis. Plate 1 , figure 3 , show's three segments of the ovum in a follicle of medimu size of an infantile hypophysectomized rat. Two of the segments contain nuclear spindles, the third a polyaster. This may possibly indicate that subdivision has taken place. In the segments, vacuoles are clearly seen, as a sign of the early stages of degcneration.

Ovular segmentation is, therefore, not a consequence of follicular atresia since it occurs in the ripening as well as in the rupturing follicle. We are inclined to assume that this phenomenon must be considered a degeneration on parthenogenetic lines. The ovum which very early (even in the infantile ovary) displays its ripening tendency may continue its development even without fertilization. This parthogenetic impulse ends in an abortive effect, since very soon degeneration sets in and the ovum dies with signs of cytolysis. The constructive process is, therefore, very soon replaced by a degenerative one.

\section{Theory of Cyclic Menstruntion}

In the foregoing we have seen that the orum leads its own life in the ovary and is of no significance to the cyclic process and the initiation of menstruation. In the following lines a brief account will be given of how the cycle and the appearance of menstruation can be imagined to be brought about: $:^{20}$ Menstruation is a complex process initiated by the functional, harmonious coöperation of the anterior lobe of the pituitary gland on the one hand, and ovarian hormones and uterine mucosa on the other. The regulating factor of the entire cycle is the estrogenic hormone-the estrogenic hormone level operating similarly to the mercury level in the regulator of the thermostat.

The cycle can be imagined to run as follows: In the theca cells, constantly increasing amounts of estrogenic hormone are elaborated, the peak production being in the middle of the cycle. The high estrone level cuts off prolan A and this initiates the activity of prolan $\mathrm{B}$. This hormone brings about follicular rupture, corpus luteum formation, and progesterone production. Since now. however, prolan $\mathrm{A}$ is no longer active, the estrone level is lowered, and this lowering starts again the activity of prolan A, so that estrogenic hormone is again produced. At the peak of production, that is, when the corpus luteum is fully developed, the very high estrone level cuts off both gonadotrophic factors (A and B) in the anterior pituitary. The gonadotrophic hormone can no longer enter the blood stream, and in this way both progesterone and esterone levels are lowered. Some days later the bleeding sets in. With the lowering of the estrone level, prolan A automatically comes again into activity. previous to and during the hemors hage, and the cycle of follicular maturation is again begun. In brief: (1) lowering of the estrogenic hormone level brings prolan A into activity, (2) high estrogenic hormone level cuts off prolan $\mathrm{A}$. 
and (3) very high estrogenic hormone level cuts off both prolan A and B and later initiates menstruation.

We do not know what happens in the interval between the exclusion of prolan $\mathrm{A}$ and $\mathrm{B}$ and the resulting lowering of the estrone and progesterone levels, on the one hand, and the bleeding, on the other,-that is, the actual initiator of the bleeding is as yet unknown. The experimental induction of uterine bleeding through esterone and/or progesterone suggests the existence of a chain reaction initiating the activity of a special bleeding factor which may be produced in the organism by the hormones themselves. Further experiments will have to prove whether this hypothesis can be confirmed.

\section{REFERENCES}

1. Zondek, B.: Deutsch. med. Wchnschr. 52:343, 1926.

2. Zondek, B.: Ztschr. f. Geburtsh. u. Gynäkol. 90:378, 1926.

3. Zondek, B., and Aschheim, S.: Arch. f. Gynïikol. 130:1, 1927.

4. Smith, P. E.: Proc. Soc. Exper. Biol. \& Med. 2f:131, 1926.

5. Parkes, A. S.: Proc. Roy. Soc. London, s.B 101:71, 121, 1927; 102:51, 1927.

6. v. Schubert, E.: (Habilitationsschrift, Univ. of Berlin, July 1926).

7. Zondek, B.: Hornone des Ovariums und des Hypophysenvorderlappens (2d ed.; Wien: 1935).

8. Zondek, B.: J1. Endocrinol. 2:12, 19.4\%.

9. Zondek, B., and Sklow, J.: Jl. Endocrinol. (in press).

10. Zondek, B.; Sulman, F., and Sklow, J.: Jl. Endocrinol. (in press).

11. Zondek, B.: Lancet 231:1256, 1933 .

12. Westman, A.: Arch. f. Gynäkol. $156: 55^{\circ}, 1934$.

13. Zondek, B.: Jl. Physiol. 81:4, 1934.

14. Buschke, A.; Zondek, B., and Bermann, L.: Klin. Wchnschr. 6:683, 1927.

15. Evans, H. M., and Swezy, O.: Mems. Univ. California 9:119, 1931.

16. Spuler, A.: Anat. Hfte., 1. Abtl. 16:85, 1901.

17. Loeb, L.: Arch. f. mikroskop. Anat. 65:728, 1905.

18. Loeb, L.: Ztschr. f. Krebsforsch. 2:259, 1912.

19. Häggström, P.: Act. obstet. et gynecol. Scandinav. 1:137, 1922.

20. Zondek, B.: Clinical and Experimental Investigations on the Genital Functions and their Hormonal Regulation (Baltimore: 1941), 243. 


\section{EXPLANATION OF PLATE}




\section{PLATE 1}

Fig. 1. Microphotograph $\times 213$. Tubal ovum of an infantile rat treated with prolan. Five segments of the ovum with granulosa cells adhering to them.

Fig. 2. Microphotograph $\times 473$. Five segments of an ovum in the follicle of an infantile hypophysectomized rat. Cell no. 1 contains a nucleus, cell no. 2 has a nuclear spindle, cell no. 3 has the shadow of a nucleus, cell no. 4 is without nucleus, cell no. 5 is cytolytic.

Fig. 3. Drawing $\times 790$. Three segments of an ovum in the follicle of an infantile hypophysectomized rat. Two of the segments contain nuclear spindles, the third a polyaster. 

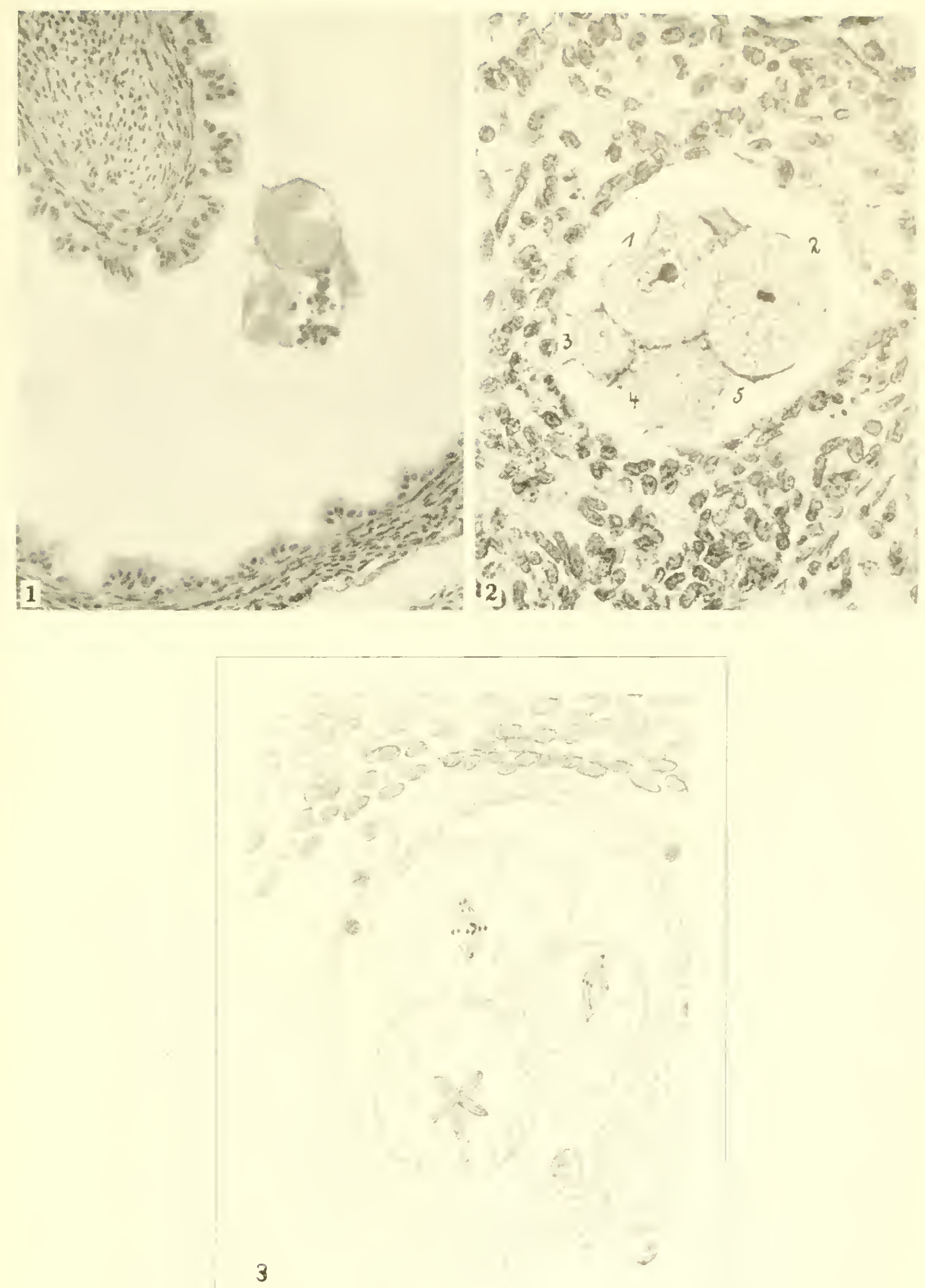















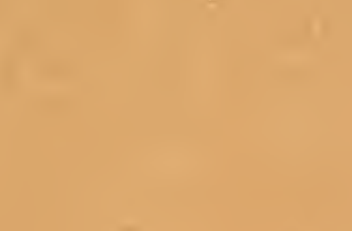

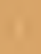

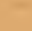

1 


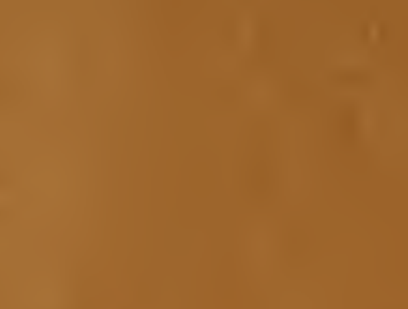

AP

ut

c.

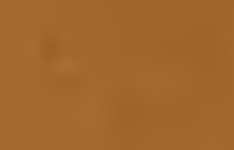

I

$=$

$\div$

in.

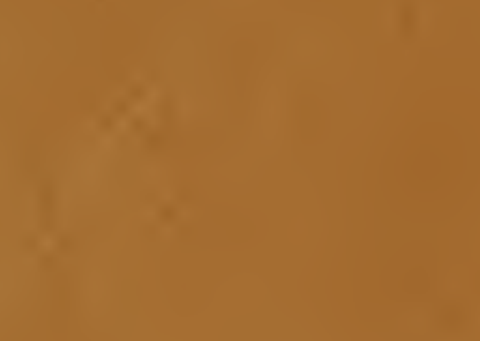


I 
